USAARL Report No. 2016-02

\title{
Invited Lectures from a Spatial Orientation Symposium in Honor of Frederick Guedry, Day 2
}

By Ben D. Lawson ${ }^{1}$, Angus H. Rupert ${ }^{1}$, Anil K. Raj ${ }^{2}$ Jillian N. Parker ${ }^{1,3}$, Linda B. Thompson ${ }^{1,4}$, John Golding

${ }^{1}$ U.S. Army Aeromedical Research Laboratory ${ }^{2}$ Institute for Human and Machine Cognition ${ }^{3}$ General Dynamics Information Technology ${ }^{4}$ Oak Ridge Institute for Science and Education ${ }^{5}$ University of Westminster

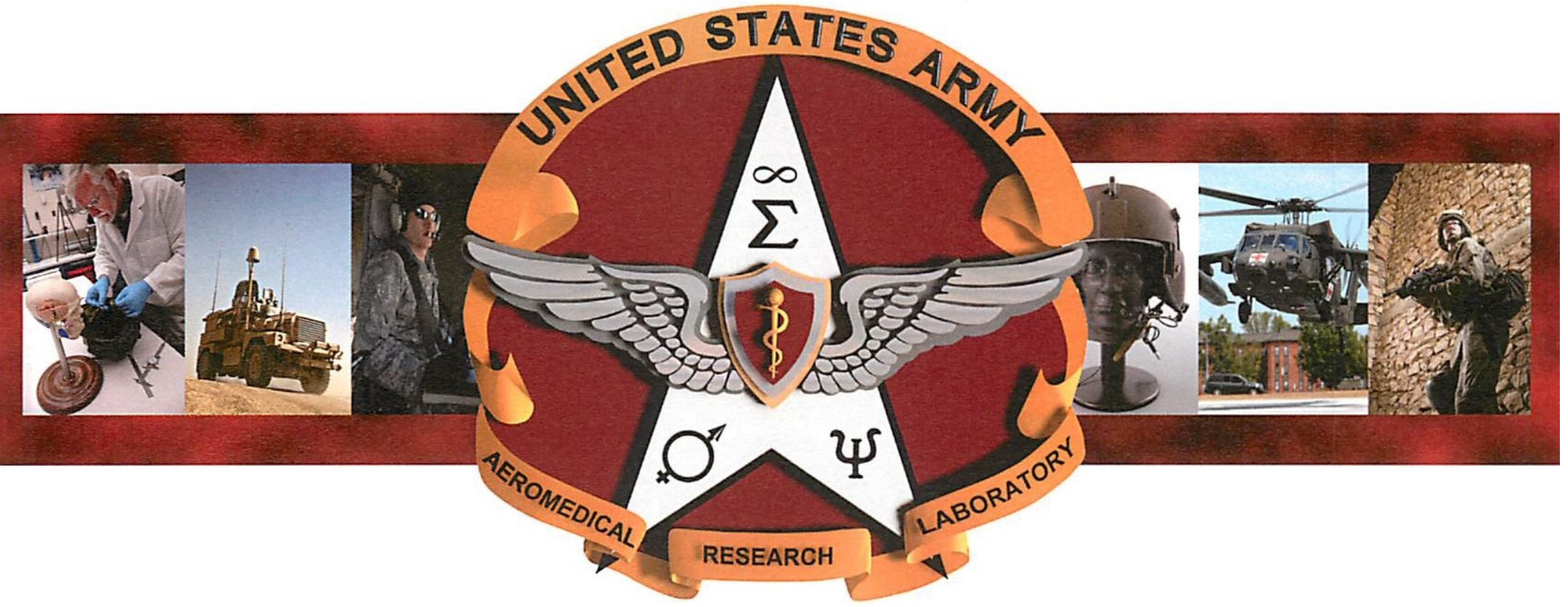

\section{United States Army Aeromedical Research Laboratory}

Aircrew Health and Performance Division

November 2015 


\section{Notice}

\section{Qualified Requesters}

Qualified requesters may obtain copies from the Defense Technical Information Center (DTIC), Cameron Station, Alexandria, Virginia 22314. Orders will be expedited if placed through the librarian or other person designated to request documents from DTIC.

\section{Change of Address}

Organizations receiving reports from the U.S. Army Aeromedical Research Laboratory on automatic mailing lists should confirm correct address when corresponding about laboratory reports.

\section{Disposition}

Destroy this document when it is no longer needed. Do not return it to the originator.

\section{Disclaimer}

The views, opinions, and/or findings contained in this report are those of the author(s) and should not be construed as an official Department of the Army position, policy, or decision, unless so designated by other official documentation. Citation of trade names in this report does not constitute an official Department of the Army endorsement or approval of the use of such commercial items. 


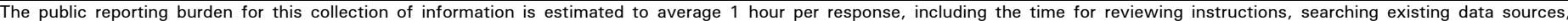

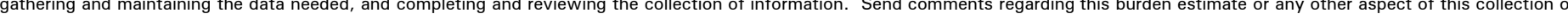

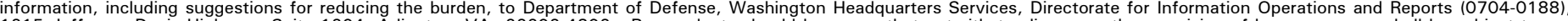

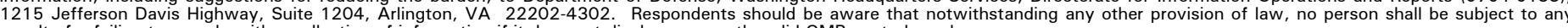
penalty for failing to comply with a collection of information if it does not display a currently valid OMB control number.

PLEASE DO NOT RETURN YOUR FORM TO THE ABOVE ADDRESS.
1. REPORT DATE $(D D-M M-Y Y Y Y)$ 2. REPORT TYPE
3. DATES COVERED (From - To)

10-11-2015

Final

\section{TITLE AND SUBTITLE}

(

Invited Lectures from a Spatial Orientation Symposium in Honor of Frederick

Guedry, Day 2

\section{(1)}

5b. GRANT NUMBER

5c. PROGRAM ELEMENT NUMBER

\section{AUTHOR(S)}

Lawson, Ben D.

Rupert, Angus H.

Raj, Anil K.

Parker, Jillian N.

Thompson, Linda B.

Golding, John

\section{PERFORMING ORGANIZATION NAME(S) AND ADDRESS(ES)}

U.S. Army Aeromedical Research Laboratory

P.O. Box 620577

Fort Rucker, AL 36362

\section{SPONSORING/MONITORING AGENCY NAME(S) AND ADDRESS(ES)}

Coalition Warfare Program

Office of the Under Secretary of Defense for Acquisition, Technology and Logistics

International Cooperation

4600 Mark Center Drive

Alexandria, VA 22350

\section{DISTRIBUTION/AVAILABILITY STATEMENT}

Approved for public release; distribution unlimited.

\section{5d. PROJECT NUMBER}

5e. TASK NUMBER

\section{5f. WORK UNIT NUMBER}

8. PERFORMING ORGANIZATION REPORT NUMBER

USAARL 2016-02

10. SPONSOR/MONITOR'S ACRONYM(S)

11. SPONSOR/MONITOR'S REPORT NUMBER(S)

\section{SUPPLEMENTARY NOTES}

\section{ABSTRACT}

This report contains the invited lectures from day 2 of a Spatial Orientation Symposium in honor of the late Dr. Frederick Guedry, held at the Institute of Human and Machine Cognition (IHMC) in Pensacola, Florida in November of 2010. The conference was sponsored by the Coalition Warfare Program of the Office of the Under Secretary of Defense for Acquisition, Technology, and Logistics. It was organized by Drs. Angus Rupert and Ben Lawson (USAARL) and hosted by Drs. Anil Raj and Ken Ford (IHMC). The lectures from day 1 are in Lawson et al., 2014. Day 2 includes lectures by Drs. Scott, Ben Lawson, Angus Rupert, Owen Black, Karen Atkins, Kim Gottshall, Anil Raj, and Måns Magnusson. The lectures focus on the structure, function and reflexes of the vestibular system, orientation perceptions, motion sickness, adaptation, and rehabilitation. This report also features banquet talks given by Drs. Lawson and Rupert, in which they honor Dr. Fred Guedry. Also featured is an interview with Dr. Guedry, conducted by a Navy historian, in which the reader can catch a glimpse into Dr. Guedry's wartime experiences and early days as a researcher.

\section{SUBJECT TERMS}

vestibular, tactile, balance, falling, spatial orientation, spatial disorientation, motion sickness, rehabilitation

\begin{tabular}{|c|c|c|}
\hline \multicolumn{3}{|c|}{ 16. SECURITY CLASSIFICATION OF: } \\
\hline a. REPORT & b. ABSTRACT & c. THIS PAGE \\
UNCLAS & UNCLAS & UNCLAS \\
\hline
\end{tabular}

\begin{tabular}{|c|c|}
$\begin{array}{c}\text { 17. LIMITATION OF } \\
\text { ABSTRACT }\end{array}$ & $\begin{array}{c}\text { 18. NUMBER } \\
\text { OF } \\
\text { PAGES } \\
\text { SAR }\end{array}$ \\
& 281 \\
\hline
\end{tabular}

19a. NAME OF RESPONSIBLE PERSON

\begin{tabular}{l} 
Loraine St. Onge, PhD \\
\hline 19b. TELEPHONE NUMBER (Inc/ude area code) \\
334-255-6906
\end{tabular}


This page is intentionally left blank. 


\section{Acknowledgements}

Support for this conference was provided by the Coalition Warfare Program (CWP), International Cooperation, Office of the Under Secretary of Defense for Acquisition, Technology, and Logistics.

The authors thank:

- John Noulis (contractor, Navy/U.S. Marine Corps liaison, CWP), Kathleen Hithe (COL, USAF, Deputy Director, CWP), and Steve Austin (Director, CWP) for their support and advice.

- Melinda Vasbinder, Deahndra Grigley, Shauna Legan, and Dennis Bergstrazer for their assistance in the preparation of this manuscript.

- Jim Chiaramonte and Stanslaus Simiyu for final proofreading of certain sections of this report.

- Edna Rath for assistance with the appendices.

- Ken Ford and the Institute of Human and Machine Cognition (IHMC) for hosting a very successful meeting.

- Elizabeth Stokes and Casey Harris for assisting with technical, logistical, and administrative aspects of this conference.

This research effort was supported in part by a person appointed to the Research Participation Program at the U.S. Army Aeromedical Research Laboratory (USAARL) administered by the Oak Ridge Institute for Science and Education (ORISE) through an interagency agreement between the U.S. Department of Energy and the U.S. Army Medical Research and Materiel Command (USAMRMC). 
This page is intentionally left blank. 


\section{$\underline{\text { Table of contents }}$}

$\underline{\text { Page }}$

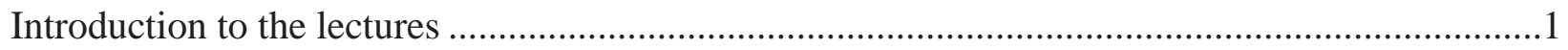

SRR and spaceflight: Similarities in time course of adaptation and readaptation - Scott Wood ...9

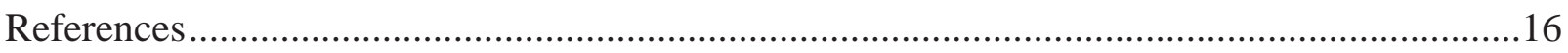

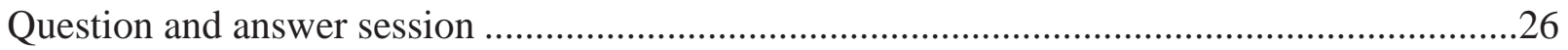

The understanding of Coriolis cross-coupling - Ben Lawson .................................................30

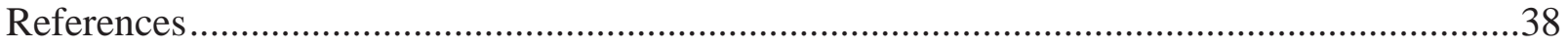

Motion sickness aetiology: Alternative to Treisman’s evolutionary theory - Angus Rupert........66

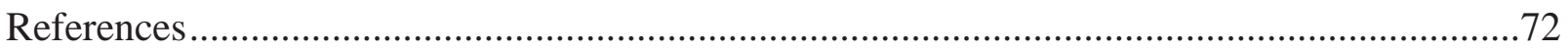

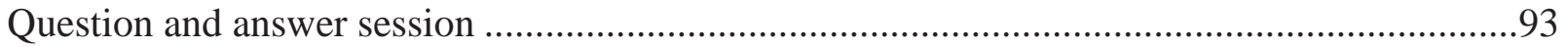

Vestibular injury and treatments: Clinical applications - Owen Black..................................103

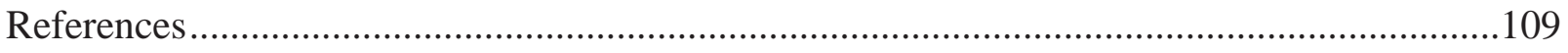

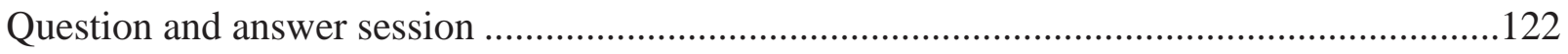

Vibrotactile postural control in patients with sit-to-stand balance deficits and falls - Karen

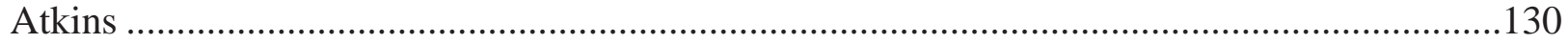

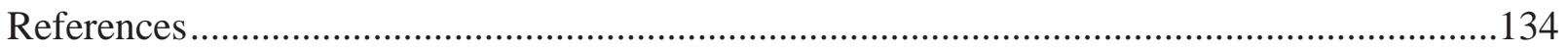

Vestibular physical therapy - Kim Gottshall......................................................................143

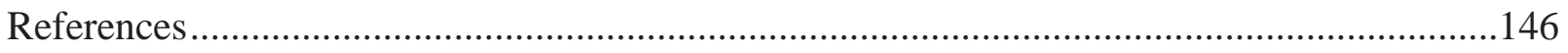

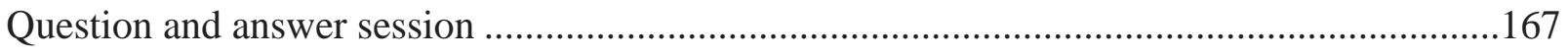

Anthrocentric multisensory interfaces - Anil Raj .........................................................169

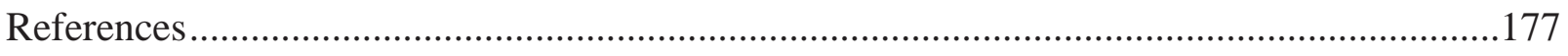

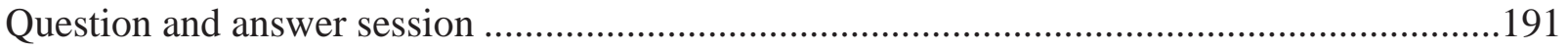




\section{$\underline{\text { Table of contents (continued) }}$}

$\underline{\text { Page }}$

Experimental acute bilateral vestibular loss - Måns Magnusson .............................................193

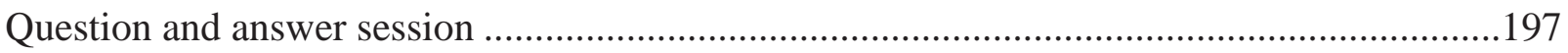

Dr. Angus Rupert's banquet toast to Guedry..................................................................199

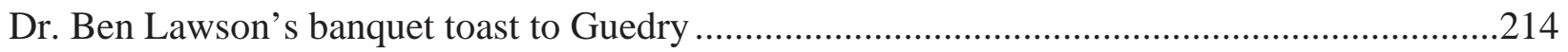

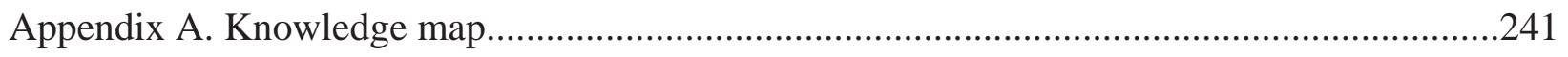

Appendix B. Bucket list survey and answers...............................................................246

Appendix C. Frederick Guedry obituary and funeral oration .............................................254

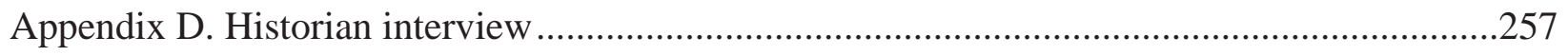

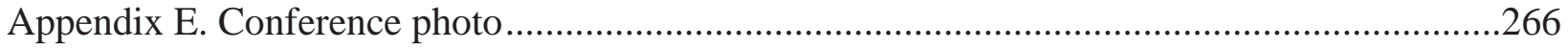

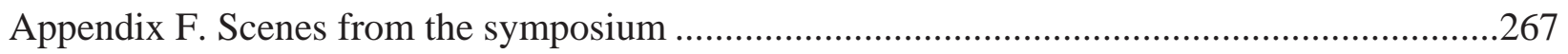




\section{$\underline{\text { Introduction to the lectures }}$}

This report contains invited lectures from the second day of a 2-day ${ }^{*}$ spatial orientation symposium in honor of the noted vestibular researcher Frederick Guedry, Jr., Ph.D. The symposium was held 19-20 November 2010 at the Institute of Human and Machine Cognition (IHMC) in Pensacola, Florida. The conference was sponsored by the Coalition Warfare Program of the Office of the Under Secretary for Acquisition, Technology, and Logistics and organized by Drs. Angus Rupert and Ben Lawson of the U.S. Army Aeromedical Research Laboratory (USAARL) and Drs. Anil Raj and Ken Ford of IHMC. The attendees included Dr. Guedry and many of his esteemed colleagues from around the world, including Drs. Alan Benson, Owen Black, Robert Cheung, Manning Correia, Jay Goldberg, Ken Money, and others (a full list of conference attendees is provided in table 1 on page 2).

This report features transcribed lectures presented by multiple researchers in the field of vestibular science. The speakers included: Drs. Scott Wood (Universities Space Research Center), ${ }^{* *}$ Ben Lawson (USAARL), Angus Rupert (USAARL), the late Owen Black (Legacy Research Institute), the late Karen Atkins (BalanceSense, Limited Liability Company), Kim Gottshall (Naval Medical Center San Diego), Anil Raj (Institute for Human and Machine Cognition), and Måns Magnusson (Lund University). The lectures focus on the structure, function and reflexes of the vestibular system, orientation perceptions, motion sickness, adaptation, and rehabilitation. The transcribed lectures are followed by museum toasts honoring Fred Guedry and presented by Angus Rupert and Ben Lawson. The full conference agenda for both days is shown in table 2 (page 4).

In addition to these lectures, this report provides a knowledge map ${ }^{* * *}$ summarizing the issues discussed at this symposium (found in appendix A on page 241). Appendix B summarizes the opinions of several participants concerning the most important recent developments in vestibular science and recommended future research (found on page 246).

Some words of explanation are necessary for the reader to fully appreciate certain important features of this report. First, it should be noted that the transcribed lectures and the audience discussion following them are preserved close to their original form rather than being rewritten as polished prose proceedings papers and lacking any record of spontaneous audience questions and comments. This has been done to faithfully preserve the spirit and immediacy of the presentations, and to capture the valuable verbal exchanges which occurred during and after many of the lectures. When the reader considers the people in attendance (table 1 on page 2 and picture on page 8), he/she will readily understand that much interest can be derived from reading the audience exchange that occurred outside the context of the planned lectures, per se. In fact, it could be said that many advances in the young field of vestibular science start as in-person discussions among researchers.

\footnotetext{
*The events of the first day are in: Lawson, Rupert, Raj, Parker, and Greskovich. 2014. Invited Lectures from a Spatial Orientation Symposium in Honor of Frederick Guedry, Day 1. Fort Rucker, AL: U.S Army Aeromedical Research Laboratory. USAARL Report No. 2014-10.

**Currently affiliated with Azusa University, Department of Psychology.

***For further review of the knowledge map and video recordings of all of the lectures presented at this symposium, visit www.ihmc.us/GuedrySymposium
} 
Table 1.

Conference attendees.

\begin{tabular}{|c|c|}
\hline Attendee & Affiliation (at the time of the symposium) \\
\hline James Atkins, M.D. & Director, Florida Ear and Balance Center \\
\hline Karen Atkins, Ph.D., P.T. & Director, BalanceSense, Limited Liability Company \\
\hline Kara Beaton, M.S. & Johns Hopkins University \\
\hline Alan Benson, Ph.D. & Royal Air Force Medical Institute, retired \\
\hline Jamie Bishop, M.S. & Research Scientist, Environmental Tectonics Corporation \\
\hline Owen Black, M.D. & $\begin{array}{l}\text { Senior Scientist, Director of Neurotology Research, Legacy Research } \\
\text { Institute }\end{array}$ \\
\hline Kristin Blackwell, B.A. & $\begin{array}{l}\text { Senior Consultant, Ventera Corporation, Former Primary Research } \\
\text { Assistant to Dr. Guedry (accompanied by her spouse, David } \\
\text { Blackwell, Delta Airlines pilot) }\end{array}$ \\
\hline Robert Cheung, Ph.D. & $\begin{array}{l}\text { Senior Defence Scientist, Defence Research and Development } \\
\text { Canada, Toronto }\end{array}$ \\
\hline Manning Correia, Ph.D. & $\begin{array}{l}\text { Department of Otolaryngology, University of Texas Medical Branch } \\
\text { Galveston, retired }\end{array}$ \\
\hline Ian Curthoys, Ph.D. & Professor, University of Sydney \\
\hline Linda Elliot, Ph.D. & $\begin{array}{l}\text { Research Scientist, Army Research Laboratory/Human } \\
\text { Research and Engineering Directorate }\end{array}$ \\
\hline Jay Goldberg, Ph.D. & Professor, University of Chicago \\
\hline Mark Goto, M.D. & Director of Ear, Nose \& Throat Dept. Naval Hospital Pensacola \\
\hline Kim Gottshall, Ph.D., P.T. & $\begin{array}{l}\text { Director, Vestibular Assessment and Rehabilitation, Naval Medical } \\
\text { Center San Diego }\end{array}$ \\
\hline Wallace Grant, Ph.D. & $\begin{array}{l}\text { Engineering Science and Mechanics Director, Virginia Technical } \\
\text { Institute }\end{array}$ \\
\hline James Grisset, Ph.D. & $\begin{array}{l}\text { Chief Scientist (retired), Naval Aerospace Medical Research } \\
\text { Laboratory }\end{array}$ \\
\hline Frederick Guedry, Ph.D. & $\begin{array}{l}\text { Professor Emeritus, University of West Florida and former Chief } \\
\text { Scientist, Naval Aerospace Medical Research Laboratory }\end{array}$ \\
\hline
\end{tabular}




\section{Table 1 (continued).}

\begin{tabular}{|c|c|}
\hline Attendee & Affiliation (at the time of the symposium) \\
\hline Casey Harris & $\begin{array}{l}\text { Research Technician, U.S. Army Aeromedical Research } \\
\text { Laboratory }\end{array}$ \\
\hline Jan Holly, Ph.D. & Associate Professor, Colby College \\
\hline Robert Hoyt, M.D. & $\begin{array}{l}\text { Faculty Associate, School of Allied Health and Life Sciences, } \\
\text { University of West Florida }\end{array}$ \\
\hline Anthony Hughes, M.D. & Otolaryngologist, Nemours Children's Clinic \\
\hline Ben Lawson, Ph.D. & Research Scientist, U.S. Army Aeromedical Research Laboratory \\
\hline Måns Magnusson, M.D. & $\begin{array}{l}\text { Professor and Head, Department of Otolaryngology, Lund } \\
\text { University, Sweden }\end{array}$ \\
\hline Albert Mateczun, M.D. & $\begin{array}{l}\text { Former Commanding Officer, Naval Aerospace Medical Research } \\
\text { Laboratory }\end{array}$ \\
\hline Braden McGrath, Ph.D. & $\begin{array}{l}\text { Chief Technology Officer, QinetiQ (at time of this meeting); } \\
\text { Currently Professor at University of Canberra, Australia. }\end{array}$ \\
\hline Kenneth Money, Ph.D. & $\begin{array}{l}\text { Senior Defence Scientist (retired), Defence Research and } \\
\text { Development Canada, Toronto }\end{array}$ \\
\hline Bruce Mortimer, Ph.D. & Director of Research and Development, Engineering Acoustics, Inc. \\
\hline Michael Newman, S.M. & $\begin{array}{l}\text { Research Scientist, National Aerospace Training and Research, } \\
\text { Environmental Tectonics Corporation }\end{array}$ \\
\hline Charles Oman, Sc.D. & $\begin{array}{l}\text { Director, Man-Vehicle Laboratory, Massachusetts Institute of } \\
\text { Technology }\end{array}$ \\
\hline Henry Porter, M.D. & Head of Neurology, Naval Operational Medicine Institute \\
\hline Anil Raj, M.D. & Research Scientist, Institute for Human and Machine Cognition \\
\hline Angus Rupert, M.D., Ph.D & Research Scientist, U.S. Army Aeromedical Research Laboratory \\
\hline Mark Shelhamer, Sc.D. & $\begin{array}{l}\text { Associate Professor, Otolaryngology, Johns Hopkins University } \\
\text { School of Medicine }\end{array}$ \\
\hline Daniel Thomas, M.D., M.P.H. & President, Snell Memorial Foundation \\
\hline Scott Wood, Ph.D. & Senior Scientist, Universities Space Research Association \\
\hline Laurence Young, Sc.D. & Professor, Massachusetts Institute of Technology \\
\hline
\end{tabular}


Table 2.

Agenda.

A Spatial Orientation Symposium Held in Honor of Frederick Guedry, Jr. 19-20 November 2010

Site Host: Institute of Human and Machine Cognition, Pensacola, Florida

Sponsoring Hosts: U.S. Army Aeromedical Research Laboratory, sponsored by Coalition Warfare Program, Office of the Under Secretary of Defense for Acquisition, Technology and Logistics

Vestibular topics include modeling, psychophysics, plasticity, adaptation, motion sickness, clinical problems and tests, balance and vestibular rehabilitation.

Day 1: 19 Nov $^{*}$

Meet and Greet

Modeling and Orientation

- Angus Rupert: Welcome to the Fred Fest, in Honor of Fred Guedry, a National Treasure

- Larry Young : Mathematical Models of the Vestibular System

- Ken Ford: Welcome from Institute of Human and Machine Cognition Director

- Charles Oman: Models for Coriolis and Psuedo-Coriolis Response

- Jan Holly: The Shape of Self-Motion Perception

- Braden McGrath: Visualization of Spatial Disorientation Mishaps in the U.S. Navy: Case Study

Group Photo (page 8)

Anil Raj: Institute of Human and Machine Cognition Luncheon and Tour

Annual Update

- Wallace Grant: Experimental Measurement of Otolith Dynamic Displacement

- Wallace Grant: Computational Fluid Dynamics Model of Endolymph Flow around Hair Cell Bundle

- Ian Curthoys: Update from Sydney

Tactile Rehabilitation Brief and Demonstration Session 1

- Karen Atkins and Bruce Mortimer

- Bruce Mortimer

*The events of day 1 are outlined in: Lawson, Rupert, Raj, Parker, and Greskovich. 2014. 
Table 2 (continued).

Day 2: 20 Nov

Adaptation and Maladaptation

- Scott Wood: Slow Rotation Room and Spaceflight: Similarities in Time Course of Adaptation and Readaptation

- Ben Lawson: The Understanding of Coriolis Cross-Coupling

- Angus Rupert: Motion Sickness Aeitology: Alternative to Treisman's Evolutionary Theory

Vestibular Injury and Treatment

- Owen Black: Vestibular Injury and Treatments: Clinical Applications

- Karen Atkins: Vibrotactile Postural Control in Patients with Sit-to-Stand Balance Deficits and Falls

- Kim Gottshall: Vestibular Physical Therapy

- Anil Raj: Anthrocentric Multisensory Interfaces

- Måns Magnusson: Experimental Acute and Bilateral Vestibular Loss

Tactile Rehabilitation Brief and Demonstration Session 2

- Karen Atkins: Multimodal Biofeedback Demo

- Bruce Mortimer: Multimodal Biofeedback Demo

Banquet on the Deck of World War II Aircraft Carrier United States Ship Cabot (inside Naval Aviation Museum, photo in Appendix E, page 266)

- Angus Rupert: Fred Guedry: A National Treasure (Toast)

- Ben Lawson: Meetings with a Remarkable Man (Toast) 
This symposium was held late in 2010, slightly more than 2 months before the falling-related death of Dr. Guedry occurred. It took considerable time to make these lectures available in print, because the original plan for automated software speech-to-text conversion of the recorded speeches did not produce a usable result. Therefore, it was necessary for a team of people to transcribe and edit hundreds of pages of the speeches and discussions manually, based only on the video records. We hope that the discussions among vestibular experts will prove as interesting to vestibular specialists as the audience discussions that were preserved following the lectures from the classic first four symposia held on the Role of the Vestibular Organs in Space Exploration from 1965 to 1968 (these proceedings are available in the Journal of Vestibular Research repository at www.jvr-web.org/Links.html) ${ }^{*}$. These earlier symposia serve as an important historical example of the usefulness of preserving free-flowing scholarly discussion. It is in the spirit of those fascinating early discussions among vestibular researchers that we have attempted to capture the spontaneous dialogue of the esteemed participants at our 2010 meeting. Our goal was to strike a balance between a literal transcription (which can be very difficult to read) and a volume of conference proceedings papers (which, alone, would not faithfully represent the actual lectures and discussions).

While reading this document, the reader should keep in mind two writing conventions that have been employed to aid understanding concerning missing sections of the transcript and insertions made by the authors:

a. The majority of the speakers did not utilize the individual microphones that were available during the rapidly-shifting question-and-answer sessions; therefore, some of the comments were not intelligible. Wherever this occurs in the transcript, it is noted with the word "unintelligible" inserted at the appropriate place. Brief, fragmentary unintelligible comments or trivial sidecomments were usually excluded from this report; however, any important discussions were included, even if they were partially unintelligible.

b. The goal of editing was to preserve the integrity of the content of the original lecture while removing the most distracting word repetitions, half-finished thoughts, speech fillers (such as "um"), malapropisms, or grammatical errors that are common in spoken but not written expression. Therefore, square brackets -- "[ ]" -- are included in this report to denote our insertion of any significant words that were not spoken by the lecturers but were inserted by us to help the reader's understanding. Examples of this include the insertion of the last names of people the lecturer mentioned by first name only, insertions of the name of any person speaking during the question-and-answer session, or insertions of information that was implied during the speech (by tone of voice and body language) but difficult to convey in text (e.g., jokes that may not be immediately obvious to readers are denoted by following them with "[laughter]" to indicate the audience response or recognition of the speaker's intention at that point in the speech).

Some of the speakers chose to present videos to accompany their talks. The authors of this report have captured still frames of key points in the videos, which are included at the appropriate place in the slides shown at the end of each speaker's lecture.

*Highlights from which appear in Lawson, B. D. 2012. How I learned to stop worrying about space and start loving the vestibular organs. Journal of Vestibular Research Online Repository, www.jvr-web.org/Links.html. 
For those who may require an introduction to the honoree Fred Guedry, a few biographical comments are offered: Fred Guedry (November 1921 to February 2011) was a native of New Orleans, Lousiana. After military service in combat during WWII, Dr. Guedry earned his master's and doctorate degrees from Tulane University in 1948 and 1954, respectively. He joined the Army Medical Research Laboratory at Fort Knox, Kentucky in 1954 and served as Director of the Psychology Department starting in 1958. He moved to Pensacola, Florida in 1961 to work at the School of Aviation Medicine, later renamed the Naval Aerospace Medical Research Laboratory (NAMRL). At NAMRL, he served as Chief of the Perception and Behavioral Sciences Department, Head of the Sensory Sciences Department, and finally, the Chief Scientist of the laboratory.

Dr. Guedry retired from NAMRL in 1990, but continued his research under the shared auspices of NAMRL and the University of West Florida, consulting and carrying out research from his home until the time of his death in 2011. Dr. Guedry's obituary and a transcription of Dr. Ben Lawson's brief eulogy given at Dr. Guedry's funeral are provided in appendix C on page 254. Dr. Guedry was a pioneer in the field of vestibular science and authored hundreds of research articles, including studies now considered classics in the fields of spatial orientation, visual-vestibular integration, gaze control, sensorimotor coordination, and motion sickness. His work is the foundation for much of today's vestibular research. 


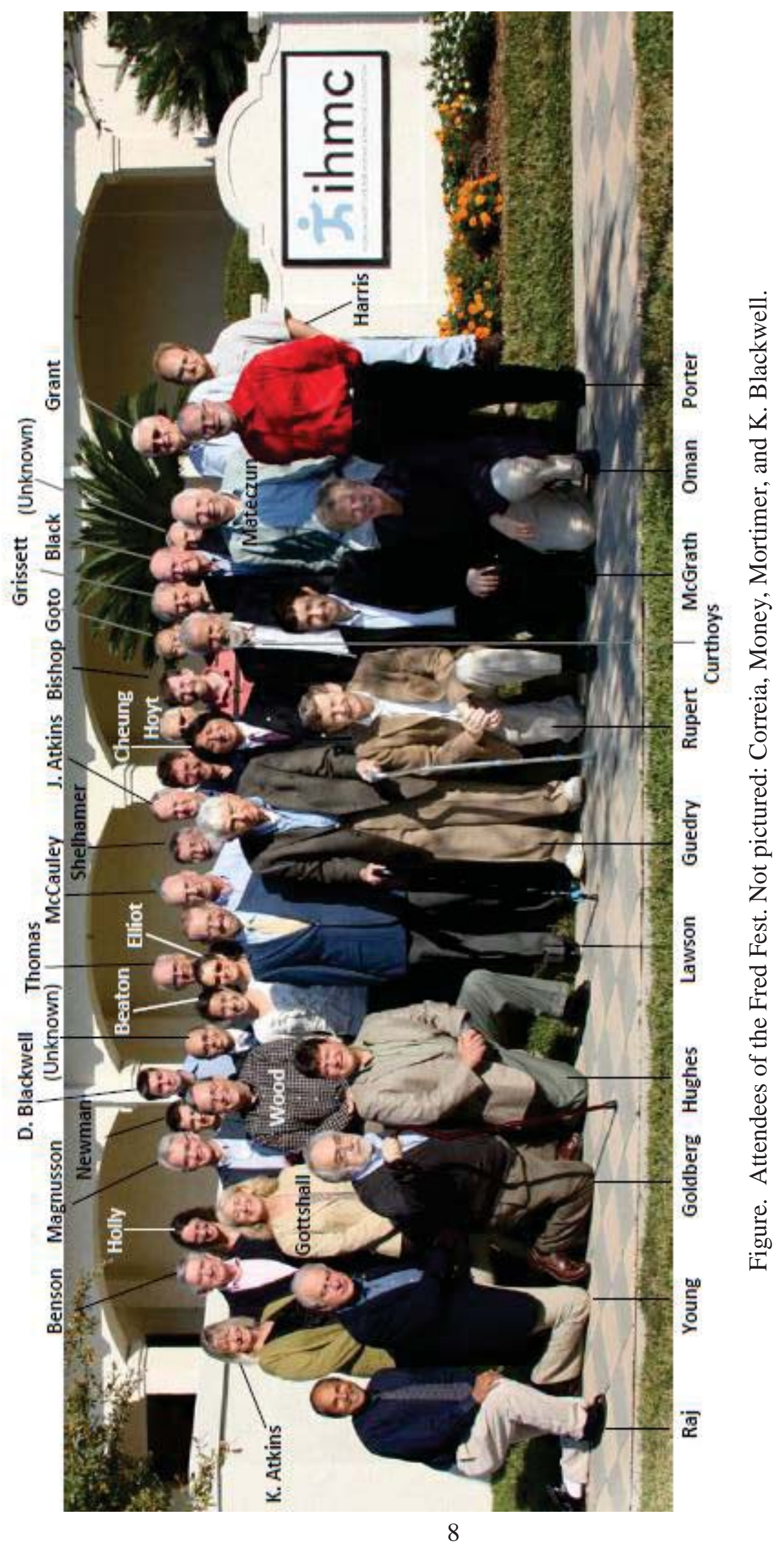


$\underline{\text { SRR and spaceflight: Similarities in time course of adaptation and readaptation - Scott Wood }}$

I have to thank Angus [Rupert] for inviting me to talk a little bit about some of Fred [Guedry's] work on the Slow Rotation Room, because it spurred me to pull up his [Guedry's] wonderfully written chapter from 1965 in the Handbook of Sensory Physiology where he reviewed that [work]. Actually, I was going to draw from that chapter today in hopes that I might engage him a little bit in reminiscing on some of these experiments [slide 1, page 17].

Originally, when I heard that Dr. Melvill Jones was coming I said, 'Oh, well I know a good topic. My title will be why slow rotation rooms are better than optical distortion paradigms,' just as a joke. I thought I better avoid that topic because he's not here to help me out. I know a lot of you know a lot about space and have been involved in that, so you could help me stay out of trouble. This is a little more appropriate because I came to know Fred as pictured here [slide 1] as we were preparing and implementing space lab experiments several years ago, under the direction of Mil Reschke at JSC [Johnson Space Center]. It was a time that I got to know many of you here in the room, and it was a really wonderful experience for me, and I thoroughly enjoyed it. I have to thank Angus [Rupert] again, who afforded me the opportunity to come back and live here in Pensacola for a few years. The incentive was that I could spend more time with Fred [Guedry] and sit with him and work with him a little bit. It certainly was one of the highlights of my time here, the gatherings we had over lunch and so forth. Fred, thank you so much for everything and, hopefully, I will do a little bit of justice to this.

One of the observations Fred has made on numerous occasions-and several other people have made - is the remarkable similarities between the time course of the adaptation to the Slow Rotation Room, as well as space flight. So clearly, there is some different [unique] etiology at play here. I thought I would talk about Fred's work and others' work on the [Pensacola] Slow Rotation Room and then move onto some of our flight data and draw the parallels there. Actually, to set the stage, there was Fred's other excellent chapter in '74 about some of the mechanisms of habituation that he talked [about] [slide 2]. I just thought I would bring this to our attention. As he wrote, this is not meant to be [a] mutually exclusive or exhaustive list, but certainly these mechanisms work together [Guedry, 1974]. One he called attention to was a suppressive mechanism. This is when you have a sustained change in the sensory input; for example, a prolonged acceleration with mechanisms to counter and reduce that response [which was referred to as] adaptation in some of the modeling work yesterday. So your sense of rotation will decay to zero before you finish the acceleration. There are switching mechanisms - Fred likened it to some of the work with attention habituation, where you have a repeated stimulus that over time becomes familiar. So maybe the central nervous system doesn't have to attend to it as much, but there could be a context cue. As an example, I am going to show you something that arouses the subject and reinstates that reflex. Sensory motor rearrangement occurs in these kind of unique and complex situations (like slow rotating rooms) where there are different patterns of sensory input and you have to come up with new motor strategies and motor responses to achieve efficient control. Fred has always definitely emphasized the importance of active and voluntary control. One of his speculations was that some of the shorter term mechanisms might serve to prevent maladaptation, so you could reduce the response to deal with the conflict without actually engaging in a motor learning response. That would be beneficial from an evolutionary perspective [Guedry, 1974]. 
So here is a quick example of a switching type of mechanism [slide 3]. Most of you may be aware of [findings concerning] repeated exposures to a rotation over a period of several days. In this case of five sessions, you start off with a pretty nice response. Here [slide 3], the arrows indicate a rotation response, and then the postrotatory and the nystagmus [response]. In several trials, a light came on to suppress the response; and the thing to call your attention to here [middle of slide 3], on the fifth and final session (in the middle here), there was something said by the operator to the subject that engaged the subject. Interestingly, the response on the next trial was strong, if not stronger than, the initial trial [Guedry, Collins, \& Sheffey, 1961]. So Fred has always called attention to these cognitive aspects. We talked a lot yesterday about some of the Coriolis and cross-coupling effects of slow rotating rooms or rotation environments, so I'm not going to belabor that point. Obviously, artificial gravity was the driver here [slide 4], along with living in an orbiting spacecraft; and there are some interesting trade-offs between how big the spacecraft would need to be versus how fast you spin it. So we know these effects just from the equations themselves. There is a strong effect of rotation rates so that as you're spinning faster, the same head tilt - in this case a roll head tilt — will induce a stronger pitch tilt sensation [than would occur at a slower rotation rate]. That same effect is also true in the nystagmus responses that Fred and others recorded. The Slow Rotation Room is actually arranged over this range of velocities from 3 RPM [revolutions per minute] to 10 or so. At 3 RPM there was no measureable nystagmus response [Guedry, 1964, 1965]. So just a real quick summary of these results [slide 5]: even at low RPM, their movement provoked sickness. When people were free to move, they naturally limited their movement to manage that. Control of limb and ambulatory movement were compromised because of the Coriolis effect. There were some subjects that developed an up-beating nystagmus, and within 3 to 5 days I think most people had adapted.

We were talking about LDs [labyrinthine deficient] [earlier]. LDs didn't have the same issues with adaptation. I thought it was interesting; as I was reading Fred's chapter, he mentioned that there were a few that, after their sickness had [dissipated], something happened that triggered sickness again. And then when [the experimenters] had the chance, they measured with electrodes and were able to establish the nystagmus had returned. So there is this kind of flashback, or switching, that happened on occasion during the rotating room [studies]. I'm not sure how frequent that was. On return to nonrotation, again, you have this strange feeling with limited head movement, compromised controls, and sickness returning. It's really these postrotation responses that led Fred to coin [identify] this in terms of conditioning of opposing responses.

So I will just walk you through this nice illustration [slide 5] from his [Guedry's] '74 chapter. Before you rotate, in panel A here, and make a roll head tilt, you have both the roll canal stimulus and response. During rotation, of course, that becomes a pitch canal stimulus which is in conflict with neck, proprioception, vision, otolith, and efference copy, and you have a pitch response. Over a course of adaptation, you continue to have this pitch stimulus during the roll head tilt, but now the response is reduced to nothing. After stopping rotation, if you make that same roll head movement, you have, of course, a roll canal stimulus. This response in the pitch plane reoccurs but in the opposite direction. Therefore, the notion that you are conditioning an opposing response is part of what is going on to deal with the conflict during the adaptation [Guedry, 1964, 1965]. 
So these [slide 6] are just a few of the studies reviewed by Fred in '65, not meant to be an exhaustive list, but again, [these studies involved] speeds ranging from 3 to 10 RPM, from a few hours (4 to 8 hours) over several weeks. Some of the factors that he noticed are: there were huge individual differences, such that some people enjoy cross-coupling just like they enjoy GVS [galvanic vestibular stimulation], and some people didn't really care for it. Fred mentioned that the compensatory nystagmus seen during the readaptation phase was only present when subjects were free to ambulate about the room. Magnitude was affected. Apparently 3 RPM wasn't enough to elicit a cross-couple vestibular nystagmus during the rotation. There was, of course, no compensatory nystagmus afterwards but 5.4 RPM was enough [to elicit nystagmus], and in these runs, subjects were in the room for 64 hours, and that was sufficient too. I thought it was interesting that the intensity of nystagmus was no greater when people spent 64 hours at 5.4 RPM as opposed to 12 days at 10 RPM. That's what I understand anyway.

Another thing that Fred has talked about is visual tasking. There was a series of runs in which he was looking at transfer of adaptation, when people are making roll head movements in one plane, and whether that [adaptation] would transfer over to movements in another coordinate. In this [slide 7] study, he actually did an interesting thing; he split the population into two groups. One group he gave visual tasking, which consisted of some cognitive tests that were projected on the screen; he had some interesting pictures that were presented on occasion to get their attention up. The other group was given no tasking instructions; they were just making head movements in the dark. You can see here by this graph [slide 7] that with those who had the visual tasking, there was a marked decrease and a decline in the nystagmus, whereas [in] the unoccupied group - the untasked group - the adaptation wasn't as great. The other interesting thing in this study is that those who had the visual tasking actually had less of a problem with motion sickness. So only three of ten had brief nausea where the unoccupied group had more severe motion sickness. But this was actually a little bit counterintuitive, since there was a visual stimulus presented; but, as Fred pointed out, that is consistent with other observations that people have made on slow rotating rooms, where people pay attention to some tasking that suppresses motion sickness [Guedry, 1964].

[Young] Was there a transfer across axes of motion?

[Wood] Oh, thank you! There was not. You can see that this is the practice quadrant and that this is the unpracticed [slide 7].

So that's what we were just talking about there [slide 8]. There are some other transfer tests that he did; one was just spinning people passively after the 12 day runs. No change in their passive yaw VOR [vestibulo-ocular reflex]. Those who did the 5.4 RPM were also tested at 10 RPM after the runs, so the magnitude produced not as great of a decrease-only 33 percent to 66 percent - relative to the speed that they adapted in [Guedry, 1965]. Of course, [there is] the well-known [adaptation transfer] effect that everyone here is familiar with. Chuck [Oman] was talking about this last night. [He said] that he is very well adapted to rotation in one direction. [Similarly], everyone knows Bob Kennedy spent a lot of time on the room*. That [adaptation] did not carry over when the room was going in the opposite direction. If I understood him

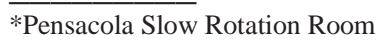


correctly, he was saying that at the time they were transitioning from the Slow Rotation Room to the CAP [Coriolis Acceleration Platform], the initial runs on the CAP were going in the opposite direction, and they had some people coming back who had experienced counterclockwise [rotation] in the Slow Rotation Room only to [then experience] clockwise rotation and [encounter] some issues with the CAP. And certainly he [Bob] experienced that.

This [slide 9] is showing just a way to look at the time course of the recovery. These are our data from subjects spun for 12 days in a counterclockwise direction, so they were practiced at tilting to the left. Actually, they are ambulating freely, but in this case, when they tilt to the left, there's an upward nystagmus. So here he [Guedry] is comparing data before or after the adaptation. If you also rotate in the opposite direction and tilt right, you will elicit an upward nystagmus. As you can see, when they rotated in the counterclockwise direction, the response was suppressed after the experiment - after the adaptation-whereas, rotation in the opposite direction clearly was not [Guedry, 1964]. That response stayed suppressed for up to 3 weeks after, and there is kind of an equilibrating to a new set point. They were suppressing both directions after a few weeks.

So how does that compare to space motion sickness? I think some of you are envisioning Bill Thornton's [Thornton, Moore, Pool, \& Vanderploeg, 1987] somewhat qualitative description of the time course. I think it captures it pretty well - the variability and motion sickness when people are adapting to space. This [slide 10] is actually the crew from the IML [International Microgravity Laboratory] mission that Fred spent some time working with. The incidence is highest on days 1 and 2; declining on days 3 and 5. One thing that's been my observation when talking with crew members that have gone on repeated flights (I would be curious if you guys have any case where you have talked to other people where this wasn't the case) is that on subsequent flights, they always seem to do better; certainly in terms of movement control, but [also] I don't know of anybody that actually had a harder time with motion sickness on a subsequent flight.

[Oman] The statistics have been looked at; it's clearly a lower symptomatology.

[Young] It doesn't say they are less sensitive. I agree with you; I think they have become a lot wiser about reducing head movement.

[Wood] That may be the case.

The incidence of that [sickness] overall is somewhat smaller, closer to 30 percent, after shuttle flights; incidence is greater after longer durations of flights, actually quite a bit greater. One thing that I have observed when talking with crew members is that some people do have a lot more difficulty on the return than they do adapting to space. And something that kind of surprised me was that we have had several people where that was the case. And the other thing is that the return on repeat flyers hasn't always gotten better, meaning that they have had more difficulty in subsequent flights; in fact, I will show that in a little bit. 
So [concerning] this readaptation syndrome: for those who aren't familiar with what it looks like, we will show some data, some movies, in just a bit [slide 11]. [Some complications associated with the syndrome are:] loss of stability when rounding corners (deviation from a straight trajectory) especially with eyes closed, and a wide stance gait to increase base of support. Many in the room have looked at visual dependence and have shown that there was more visual dependence and reduced visual acuity during walking — some of Jacob Bloomberg's work [shows this]. Several of us have looked at self and surround illusions. There is just overall more effort required to maintain balance. Now, thanks to the efforts of people like Owen Black and Bill Paloski, we have quite a lot of data on computerized posturography systems.

So we have over 100 shuttle flights and over 50 long duration flights. It's quite an impressive dataset. We've been able to kind of characterize the recovery curve for posture control using that system. One condition that is especially sensitive is subjects with their eyes closed, and we have the sway referenced or unstable support. We were disrupting some of the somatosensory input, so they have to rely more on vestibular input, and these are scored where zero is a fall and a higher number is greater stability. You can see the typical recovery trajectory here [slide 12]. And even though it is fairly sensitive, we have observed this same thing (and I think it was observed in Pensacola first, actually), that sometimes these scores are not reflecting the amount of performance decrement, and actually thanks to Brad [McGrath] and Angus [Rupert] and Fred and others here, we are starting to realize that if you ask people to make head movements, it really brings out some of that decremented performance. This is not at all typical, this is the extreme case here [slide 12], but I thought it was an interesting case; we had somebody that had been on a recent station flight and you can see where their eyes closed in this unstable surface [slide 12]. There didn't appear to be a great decrement in performance here, but when we asked this person to start making head movements, typically the performance was slower, and they had much difficulty within the first few days and took more than a week to get back to preflight performance.

So I am going to show a little bit of that data. This [slide 13] is scatter plots of the different data plots that we have from Owen [Black], Bill [Polaski], and others. This is a recovery curve for short and long duration, and this is the top part of the head erects [top half of slide 13]: in all cases, eyes [are] closed and [there is a] stable support surface. This is when we are asking for crew members to make pitch head movements [bottom half of slide 13]. One thing I would call your attention to is there is a lot of variability among people. In fact, we've had some shuttle flights where we've had some people returning from the space station. It was really hard to figure out whether this person was a shuttle person or not. But there is clearly an effect of flight duration. You can see the overall decrements are greater (even more pronounced) when making the head movement.

[Grant] Can you describe the bars; what are the two gray bars [slide 13]?

[Wood] Okay, this is from a 25 to 75 percentile range [labelled on slide 13]. This is a median right here, and these are 95 percent confidence level [labelled on slide 13]. So this is taken from all these individual responses, doing some curve fitting, and then trying to project the disruptions at different days post flight. 
Again, the postflight recovery time is on the order of days. There has been this observation that we were just talking about (in-flight adaptation). People who are repeat flyers tend to perform better after the flight than rookies. I think that is generally true. We have had a couple of occasions where that wasn't the case with individuals, and since we have a lot of posture data, we did look at this [slide 14]. We tried to look at people that we had tested on two different missions and the blue here is just indicating that their performance went down on a subsequent flight. The red indicates that their performance improved. So, it does look like overall there might be an improvement between the rookie flight and less so after other flights. We have several people that are not doing better on their subsequent flights, and I want an explanation for this. One important point is what they are doing during re-entry because the amount of head movements they make during re-entry is very critical to the readaptation process. So one individual, in particular, I can recall, was having a very difficult time on his second flight and I asked him about his strategy and he said, 'well, [during] my first flight I overdid it on the head movements a little bit, I made myself sick. So the second flight I purposed to keep my head perfectly still and not make any head movements.' And that was probably an incorrect strategy. In fact, we have had some recent crews where the Commander actually guided their whole crew. They had all the crew in synchrony with head movements, and we thought, what is it with this crew? - they are all looking very good. [Probably, that was because] they were all making these head movements. So, it's [head movement] just anecdotal data but it is definitely very critical to the postflight recovery [Graybiel et al., 1965].

Unfortunately, we didn't have computerized posturography back in the Slow Rotation Room days, but I was looking for some metric where we had some common measures. There was, as we were referring to earlier, a tandem walk, eyes-closed, and a rails test. I'm looking at the tandem walk, eyes closed on the 12 days study here [slide 15]. There have been some recent measurements that were made by my colleagues Mil Reschke and Jacob Bloomberg, using the similar protocol, so I thought I would show that data today.

So this is data from the 12 day study. The protocol had subjects standing at the wall and doing five tandem steps toward the center. [The graph on slide 15 shows] best two of three trials total for a maximum score of 10 . You can see all of the subjects were achieving the maximum score before the rotation. As the rotation started there was this individual response, taking several days for everyone to get to that prerotation performance level. And then, after the stopping, here they are doing that same test [slide 15]. There was a rail test (some postural test) done on this study, that showed decrements as late as the third day after rotation.

Here's [slide 16] the protocol that Mil and Jacob are using. They're using 10 steps, and they do three trials. What you will see here is somebody doing this before they fly. We're not getting 100 percent performance; you can see the gaps in some of the steps. They're not aligning their feet like we asked them to. Some of these are classified as incorrect steps. This is the same individual on landing day [slide 16]. This is not that atypical, really [speaker shows movie of ataxic subject]. This has been surprising for a lot of the crew members who, with their eyes open and standing, don't really look that bad. This [slide 16] is an individual after a shuttle flight. This is less than 2 weeks of shuttle flight. He's having a real difficult time knowing where to put his feet [Reschke et al., 2011]. 
[Young] Is the thinness in his leg muscle loss as well as fluid?

[Wood] Do you see a big difference between pre- and post- there? This same battery of test is looking at muscle performance and not seeing a huge change after this short duration flight, so I don't really think that is it. What's interesting is that this is not only a challenging test, but it's a provocative test for some. They said this is something that they really don't feel comfortable doing, and then several people have commented that it provokes motion sickness.

So again, they're scoring this a little bit differently [slide 17]. It's a slightly different protocol, and we're not getting a hundred percent performance before they fly, as was the case on the Slow Rotation Room. They see about three out of every four steps correctly, then there is a smart decrease in performance after the flight [Reschke et al., 2011].

So I'll just close with a few discussion points [slide 18]. I think it's interesting that there is an intra-vestibular conflict in both of these, where the otoliths on the Slow Rotation Room or canals in space is congruent with vision efference. Ambulatory movement is compromised by Coriolis effects in the Slow Rotation Room and unloading in space. Both the ambulation and head movements provoke sickness and are necessary for adaptation or readaptation, as well. There is a larger inter-subject variability. Again, the time course is three to five days. The readaptation occurs fairly quickly, but there could be some residual effects, and this occurs depending on what you are using for your metric and how you're challenging them. The repeat exposure does seem to lessen symptom severity. Chuck [Oman] was mentioning how he thinks he is pretty resistant to rotation in that one direction. Bob Kennedy said he's pretty sure he is too; he hasn't tested it recently, but he knows that one direction - counterclockwise - he can handle pretty well; but not always during readaptation. I was asking Bob, 'Do we have enough repeat Slow Rotation Rooms subjects to know if they were having any difference in their readaptation?' The answer is that he didn't know of any. That's one thing that the shuttle program has afforded for us, some repeat flyers.

So I close with this picture [slide 19]. Can you find Fred in the picture? This is a group of people from the IML flight. Again, just a delightful experience. That's it, thank you very much. 


\section{References}

Graybiel, A., Kennedy, R. S., Knoblock, E. C., Guedry, F. E., Mertz, W., McLeod, M. E., Colehour, J. K., Miller, E. F., and Fregly, A. R. 1965. Effects of exposure to a rotating environment $(10 \mathrm{rpm})$ on four aviators for a period of twelve days. Aerospace Medicine. 36: 733-54.

Guedry, F. E. 1964. Visual control of a habituation to complex vestibular stimulation in man. Acta Oto-laryngologica. 58(1-6): 377-389.

Guedry, F. E. 1965. Orientation of the rotation-axis relative to gravity: it's influence on nystagmus and the sensation of rotation. Acta Oto-laryngologica. 60(1-6): 30-48.

Guedry, F. E. 1974. Psychophysics of vestibular sensation. In: Handbook of sensory physiology: Vestibular system part 2: psychophysics, applied aspects and general interpretations. $6^{\text {th }}$ ed. 3-154. Berlin, Germany: Springer-Verlag Berlin Heidelberg.

Guedry, F. E., Collins, W. E., and Sheffey, P. L. 1961. Perceptual and oculomotor reactions to interacting visual and vestibular stimulation. Perceptual and Motor Skills. 12(3): 307-24.

Reschke, M. F., Fisher, E. A., Kofman, I. S., Cerisano, J. M., Harm, D. L., Peters, B. T., and Bloomberg, J. J. 2011. Walk on floor eyes closed test as a measure of postflight ataxia [Abstract]. Eighth symposium on vestibular research.

Thornton, W. E., Moore, T. P., Pool, S. L., and Vanderploeg, J. 1987. Clinical characterization and etiology of space motion sickness. Aviation, Space, and Environmental Medicine. 58. 2): A1-8. 


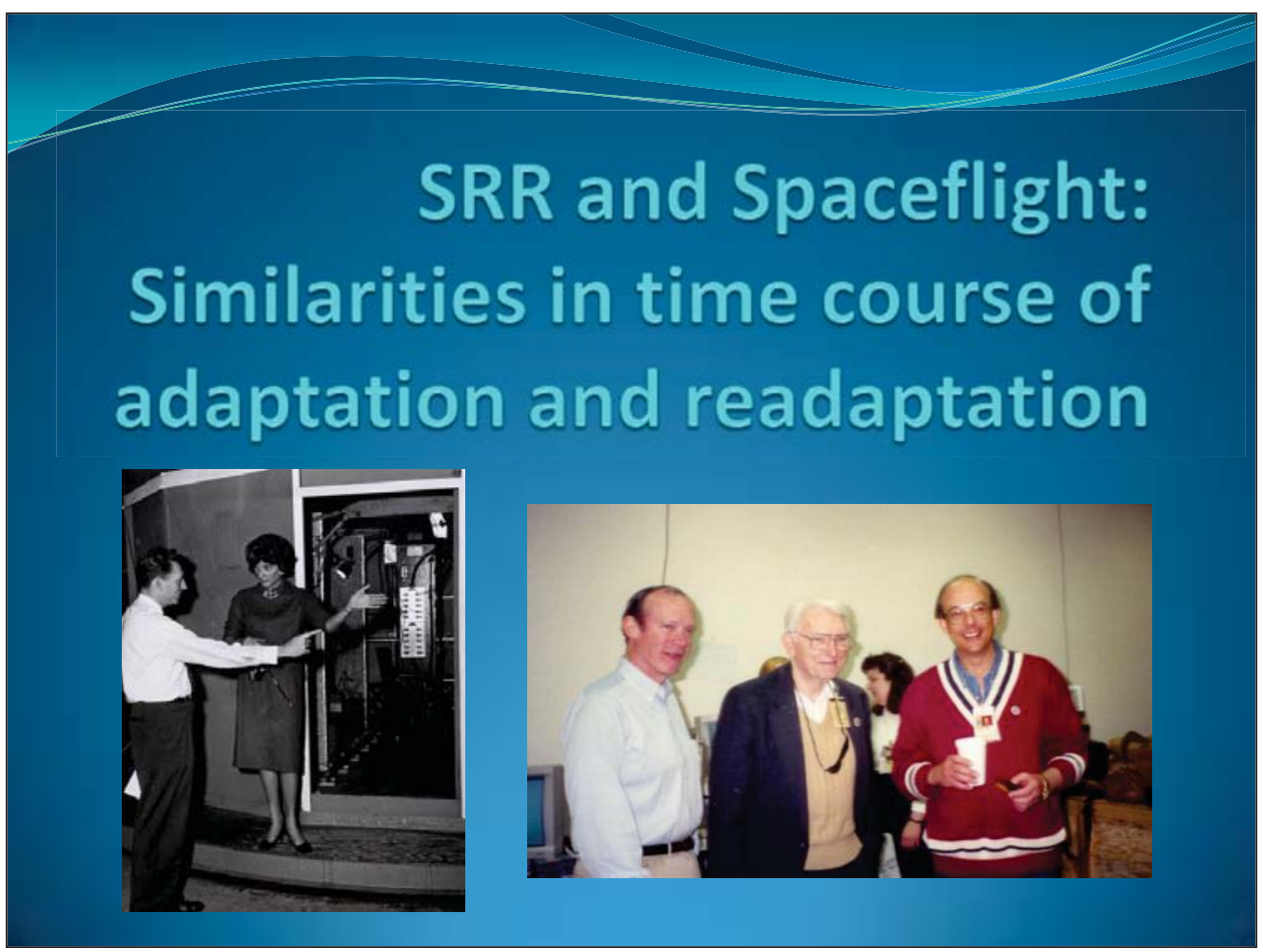

Slide 1

\section{Mechanisms of response alteration}

-1) Suppression - sustained change in sensory input is countered to reduce response output

-2) Switching (attention habituation) - repeated stimuli classified as familiar, heightened mental arousal can reinstate reflex output

-3) Sensory-motor rearrangement - change in pairing of sensory input and motor response to achieve efficient control, especially voluntary control

- Short-term reduction mechanisms (1 \& 2) can serve to prevent 3 - prevent maladaptation

Slide 2 


\section{Switching example: mental arousal}

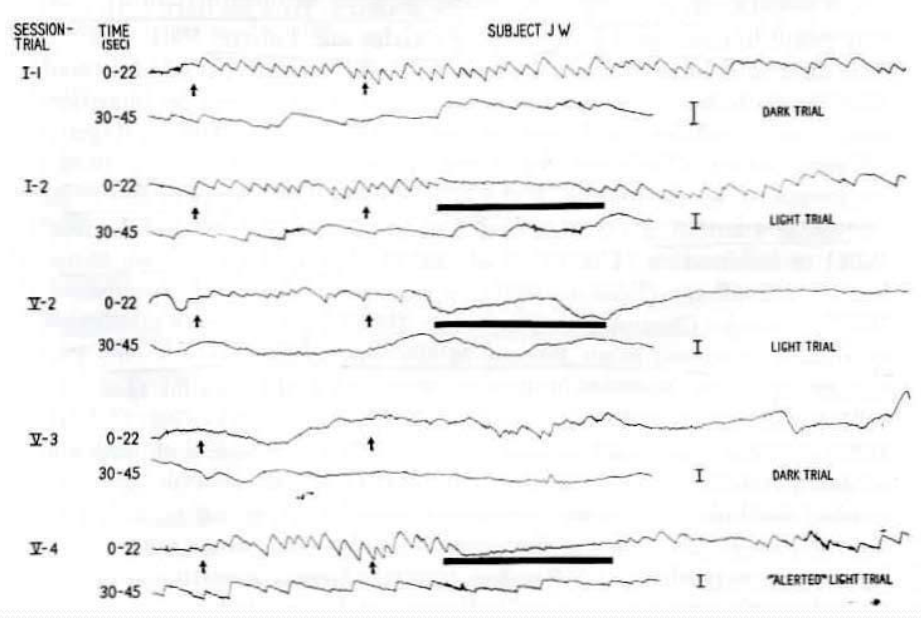

(Guedry et al., Percept Mot Skills, 1961)

Slide 3

\section{SRR paradigm}

- 1) Coriolis arthrokinetic effects

- At $10 \mathrm{rpm}: 5 \mathrm{ft} / \mathrm{s}$ results in Coriolis accel $\sim 0.3 \mathrm{~g}$

- 2) Coriolis Cross-Coupled vestibular effects

- $\omega_{\mathrm{h}} \omega_{\mathrm{r}} \cos \theta$
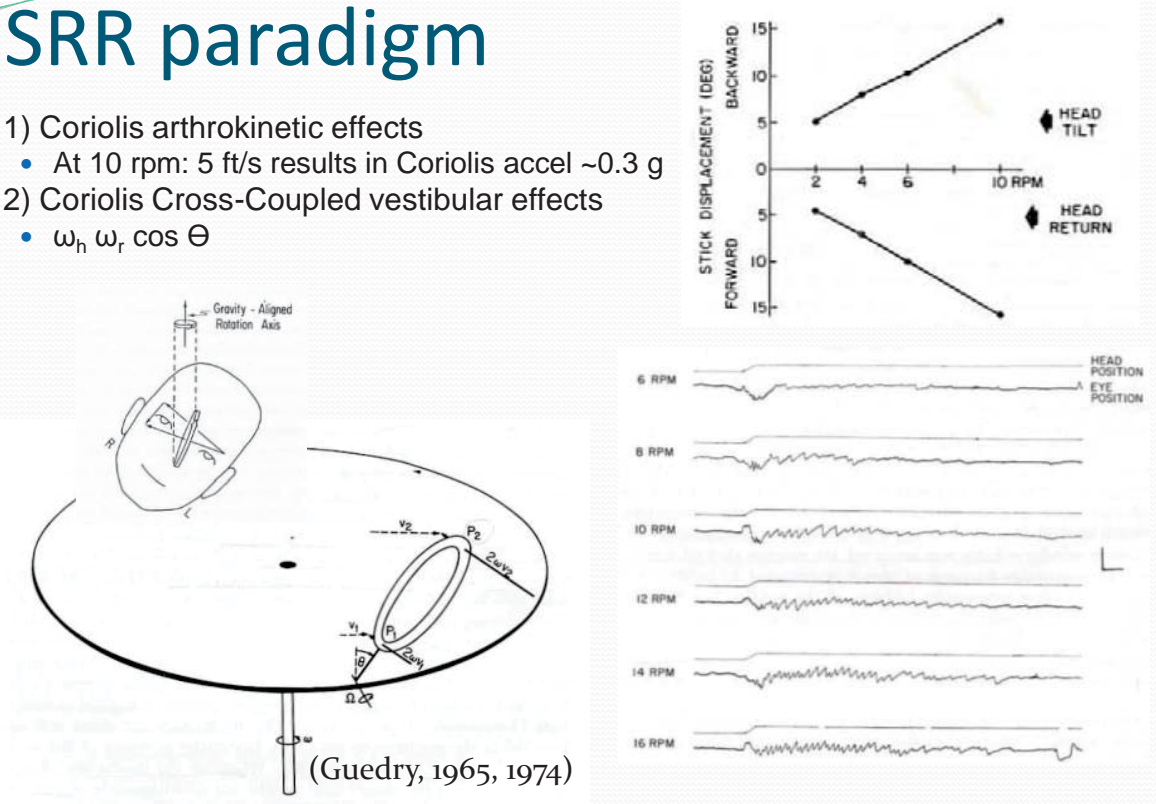

$16 \mathrm{RPM}=2$ vom

Slide 4 


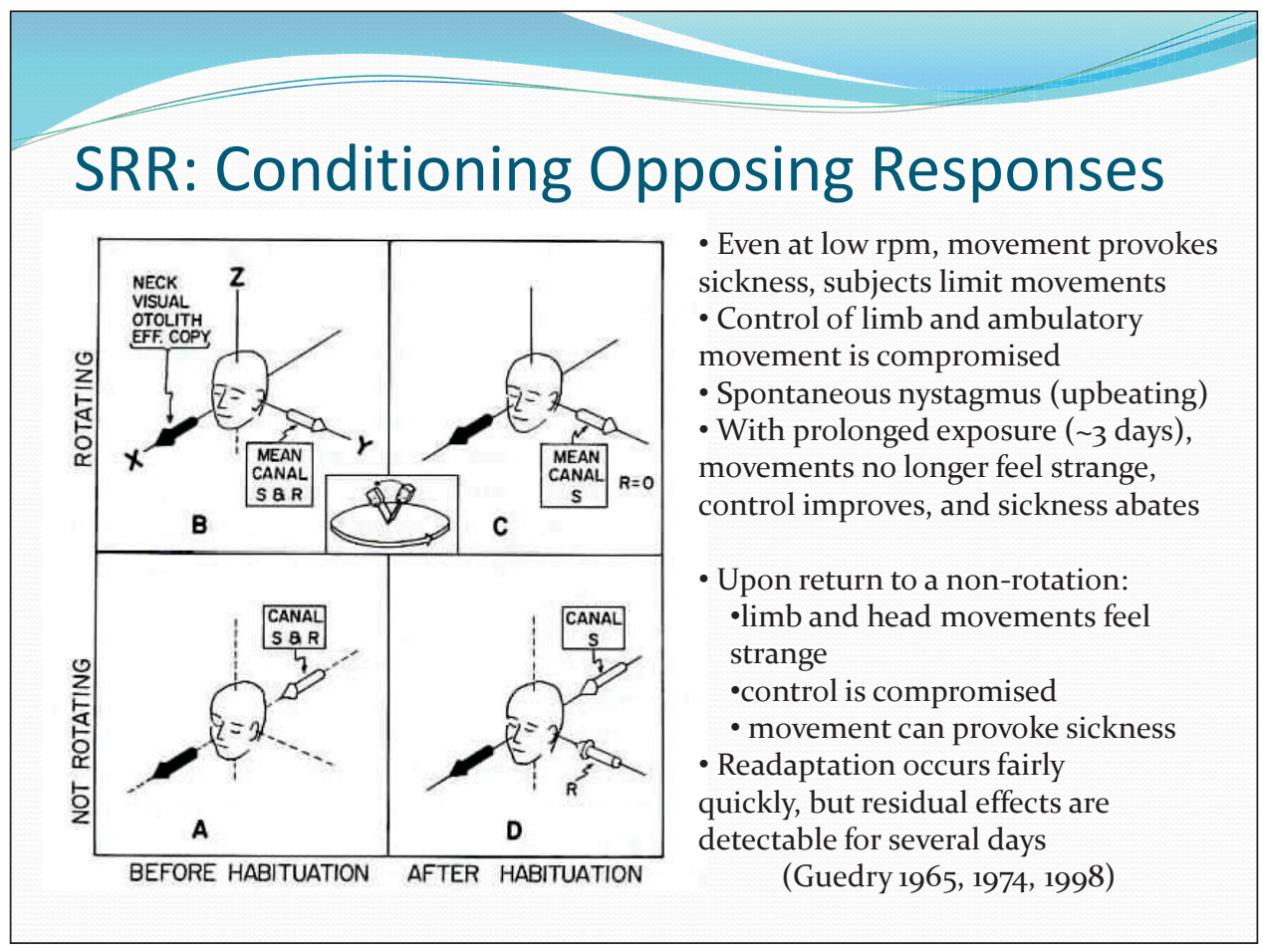

Slide 5

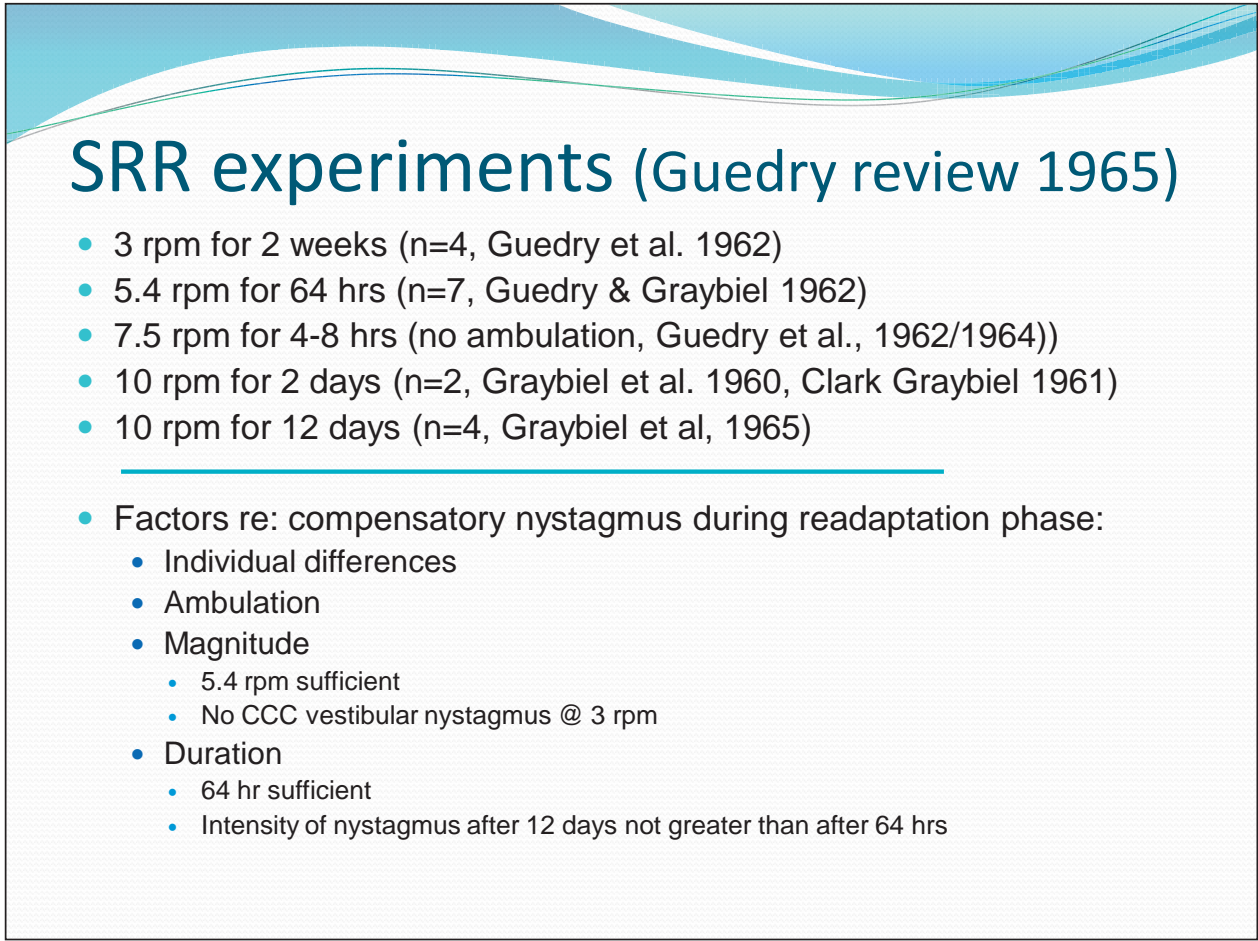

Slide 6 


\section{Factors (cont): Tasking}

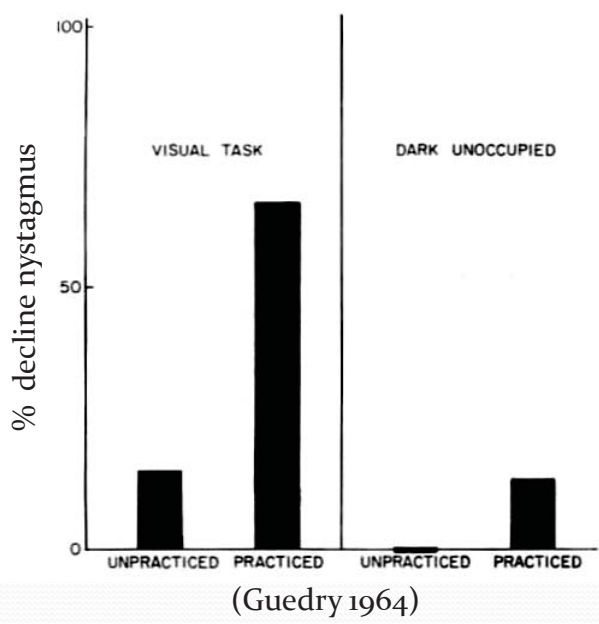

$7 \cdot 5 \mathrm{rpm}, 100$ cycles of roll HMs

Group A:

-Tests of mechanical

comprehension \& spatial relations projected on screen - Competitive attitude

$\cdot 3$ of 10 brief nausea

-Group B

-Eye closed, semidarkness

- 6 of 12 severe motion sickness

-Consistent with other SRR

observations that attention to tasks seem to suppress motion sickness

Slide 7

\section{Transfer}

- Same direction, different quadrant: Decreases in unpracticed quadrant only slight compared to practiced quadrant

- Plane: Following 12 days @ 10 rpm passive yaw VOR showed little or no decline

- Magnitude: Following 64 hrs @ 5.4 rpm decrease in nystagmus was $33 \%$ for $10 \mathrm{rpm}$ and $66 \%$ for $5.4 \mathrm{rpm}$

- When rotating in the opposite direction: head movements produced strong subjective and nystagmus reactions

(Guedry 1965)

Slide 8 


\section{Readaptation}

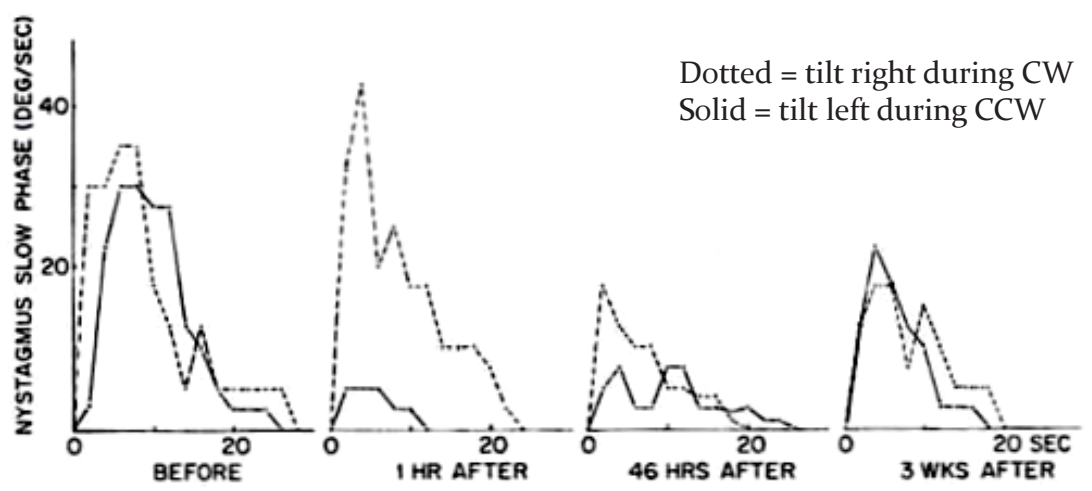

(Guedry 1964)

Slide 9

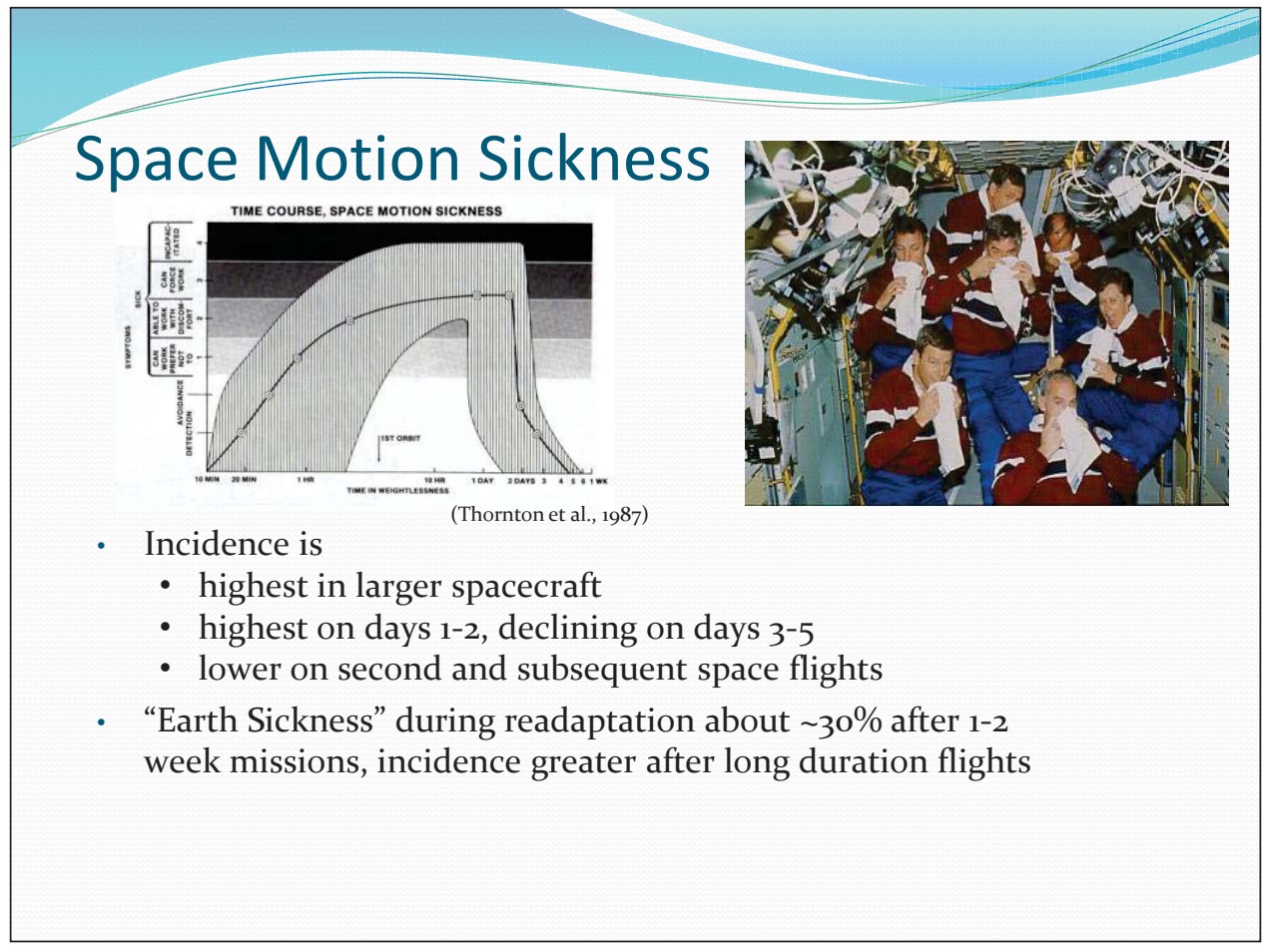

Slide 10 


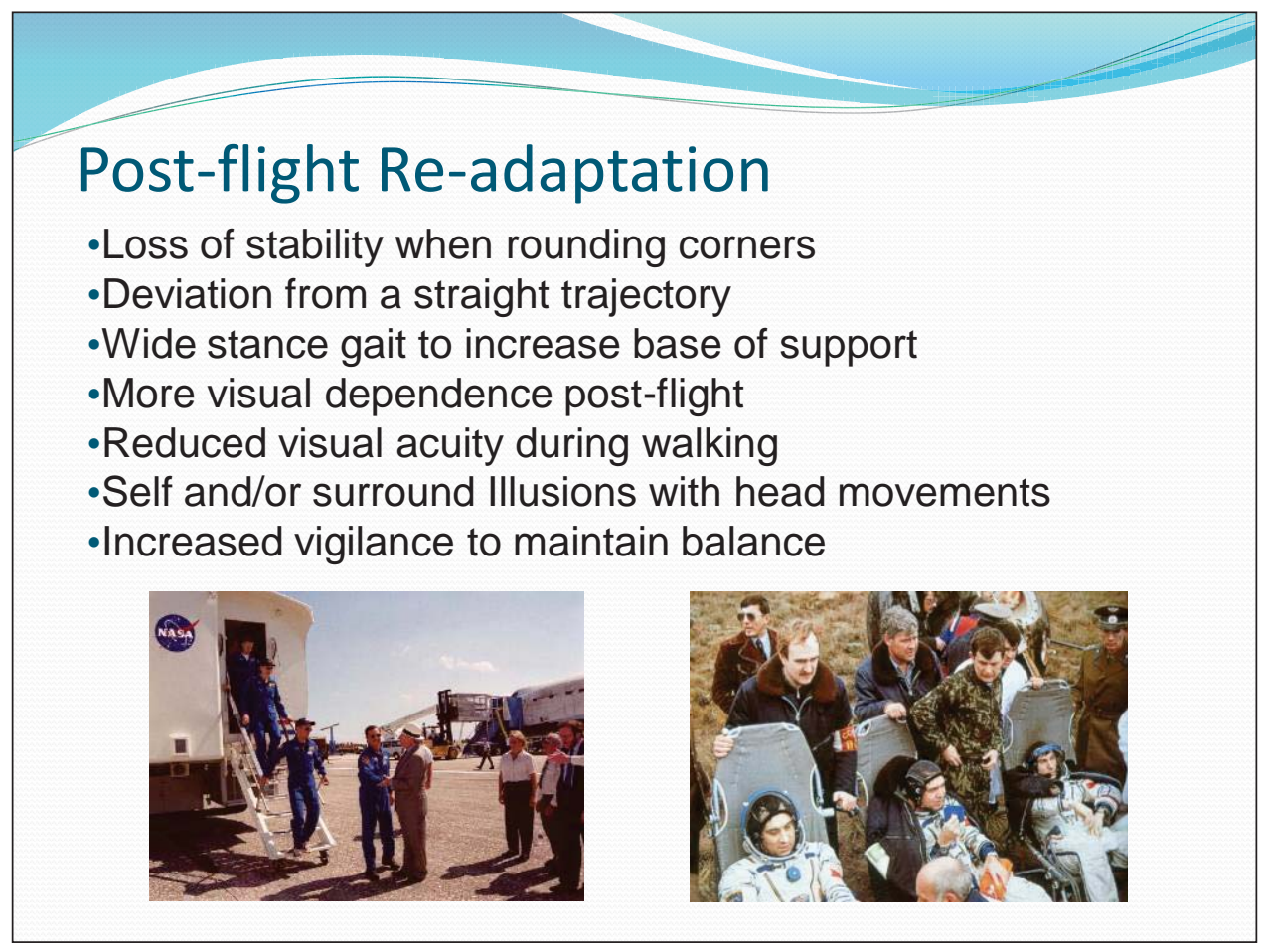

Slide 11

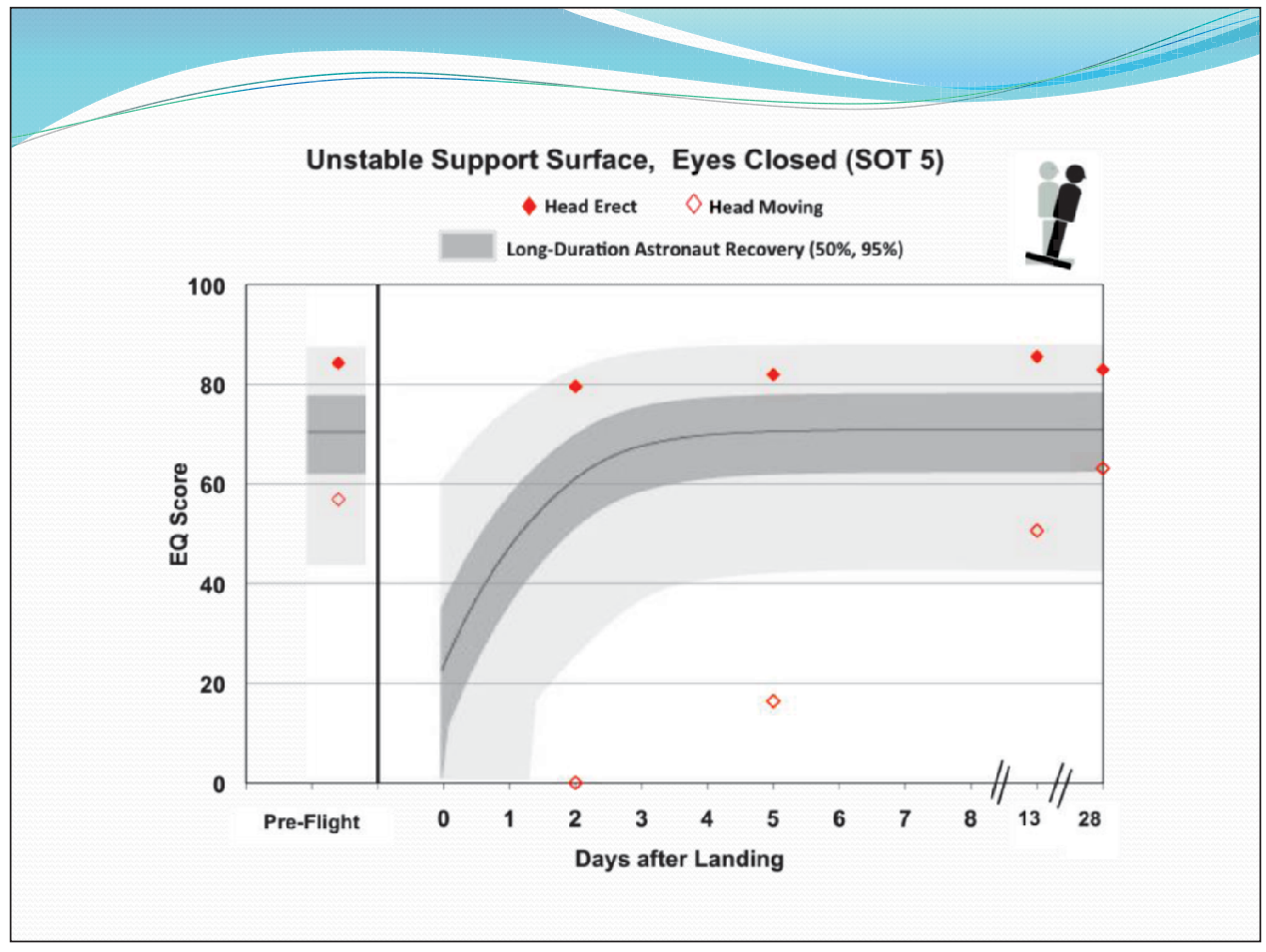

Slide 12 


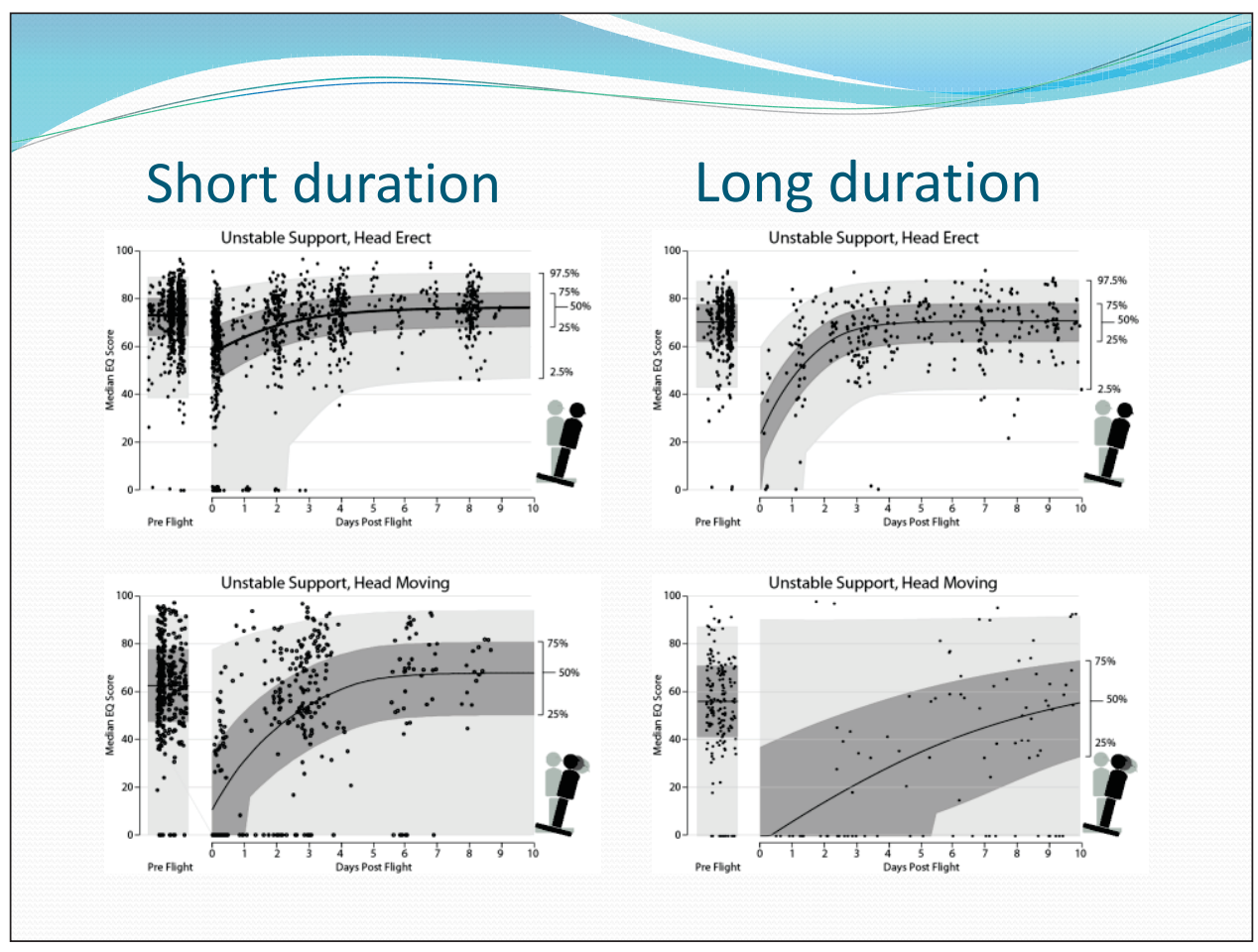

Slide 13

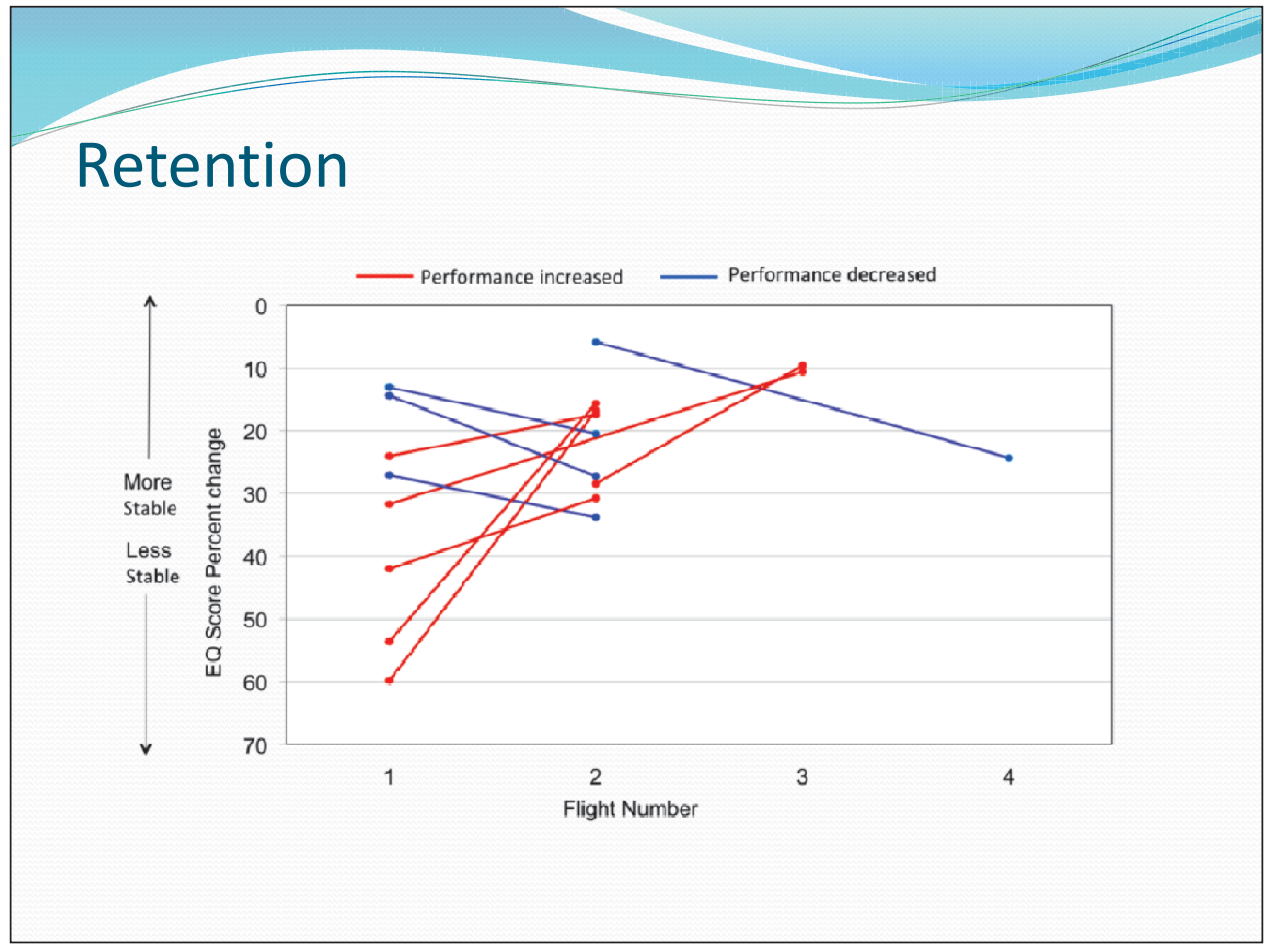

Slide 14 


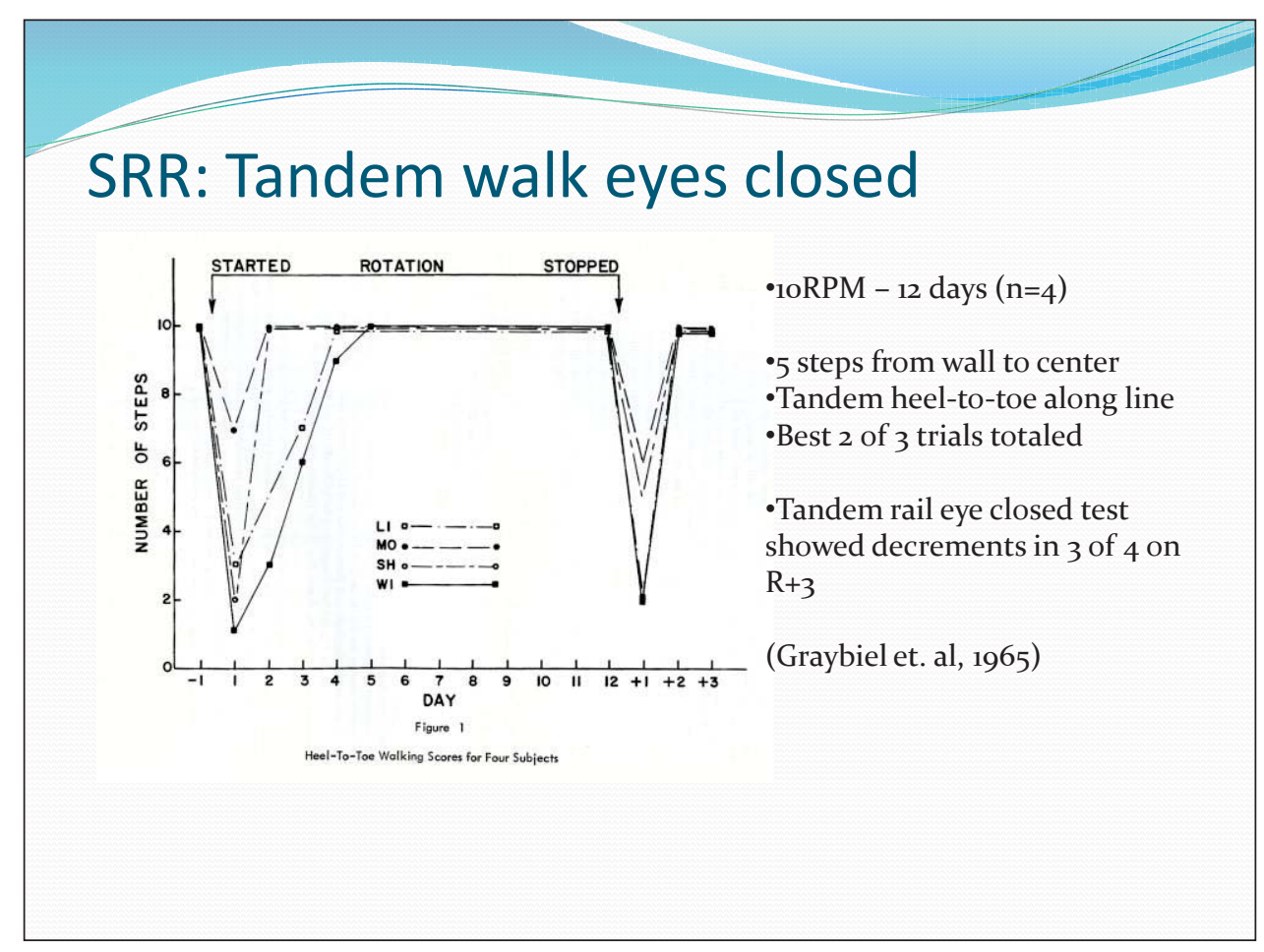

Slide 15

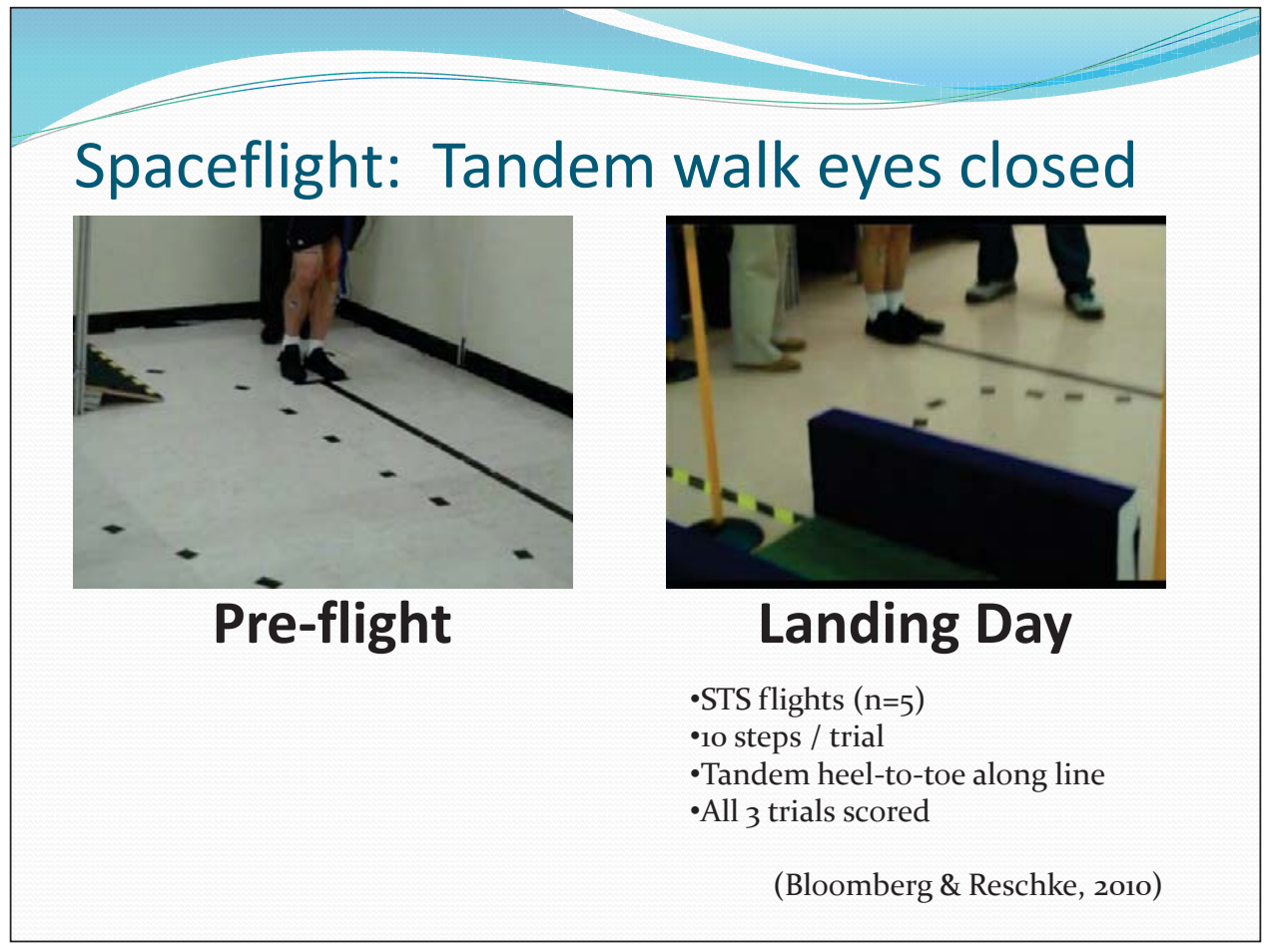

Slide 16 


\section{Spaceflight: Tandem walk eyes closed}

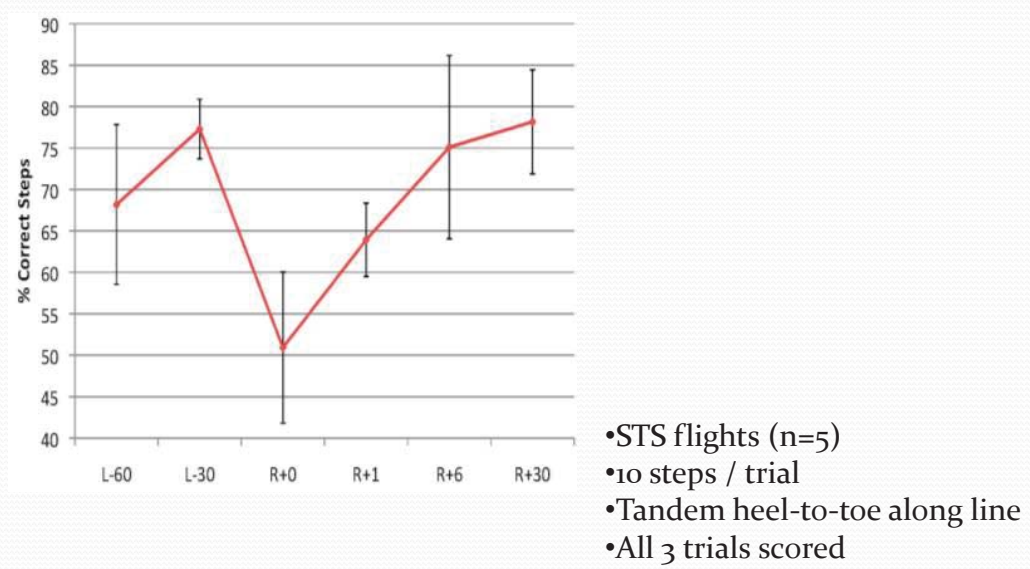

(Bloomberg \& Reschke, 2010)

Slide 17

\section{Discussion points...}

- Intra-vestibular conflict where otoliths (SRR) or canals (space) congruent with vision, efference

- Ambulatory movement compromised by Coriolis (SRR) and unloading (space)

- Ambulation and head movements both provoke sickness and promote adaptation/readaptation

- Large inter-subject variability

- Time course of adaptation is 3-5 days

- Readaptation occurs fairly quickly, but residual effects are detectable for several days to weeks

- Repeat exposures lessen symptom severity during adaptation, but not always during readaptation 


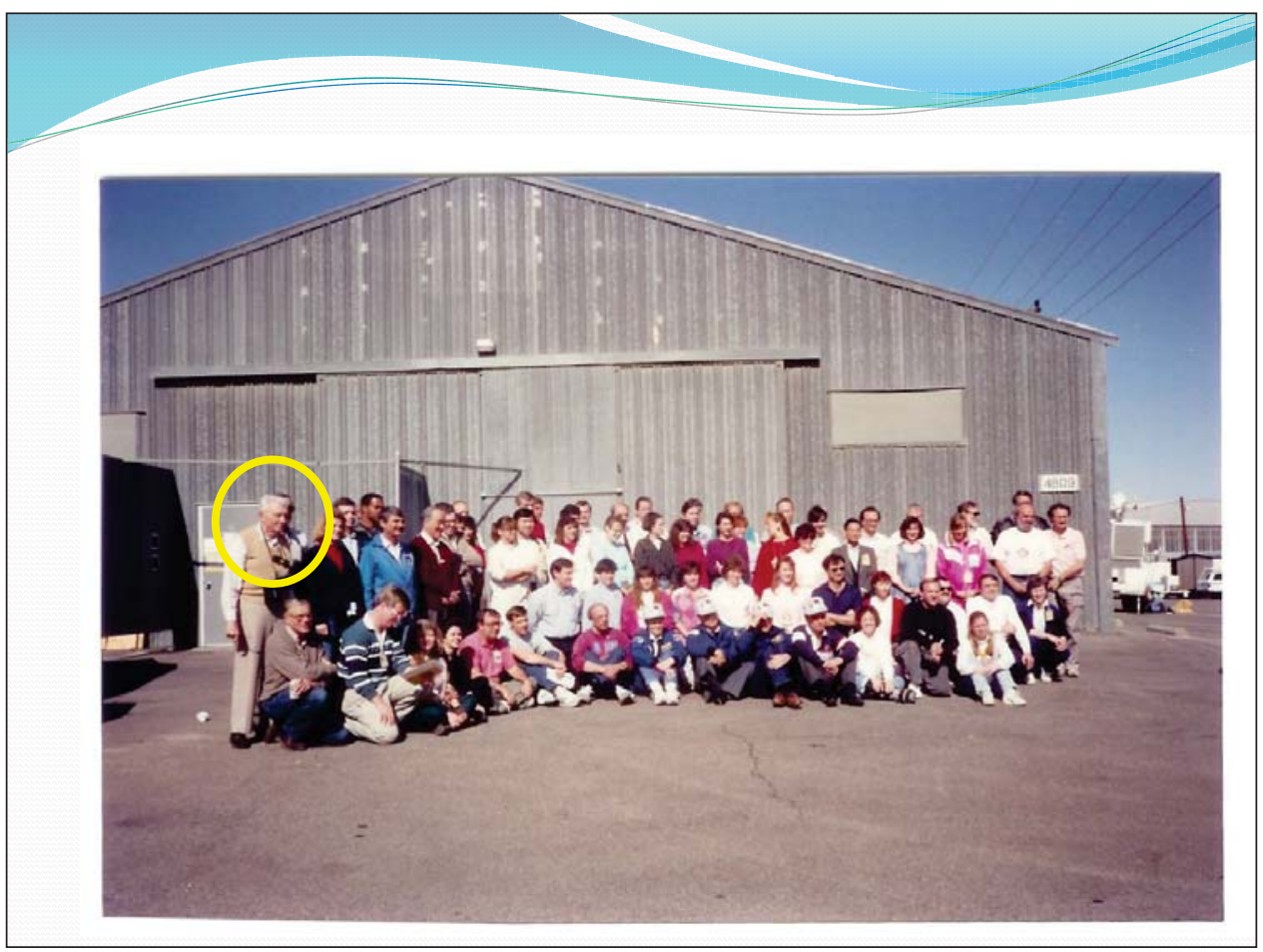

Slide 19

Question and answer session

[Oman] I was provoked by Jim Atkins's comment about MDD [mal de débarquement] and wanted to ask if you'd say a little something about other flashbacks after spaceflight, and what do you think causes them. Are they anything like the aftereffects the cruise ship passengers experience?

[Wood] Well, John Clark has a flight surgeon catalog with a few of these. There are some that I know of, but it's just really a handful. It's really anecdotal of people back in Houston [giving accounts] of riding around the traffic loop and feeling like they had to pull over because they were sliding right off the road. I've heard of some people in elevators having mild flashbacks. In our experiment on IML-1 [First International Microgravity Mission], one of our crewmembers, after getting off the rotator on day 5 (this is someone who was pretty severely impacted by space, maybe quite the outlier) and after apparent postural recovery, got off and said, 'that rotation did something to me.' So the answer is we know very little about that. There does seem to be a case for it. I don't really know.

[Oman] Certainly, there are also post parabolic flight aftereffects I think many of us have experienced.

[Wood] I thought it was interesting that even on the Slow Rotation Room, apparently, there have been some cases of that, which Fred was talking about, too. I was reading through his account of 
people having apparently adapted and all of a sudden switched back. This is what made me think of the "G" flashbacks actually.

[Rupert] Since I'm Bob Kennedy today [laughter], I have the most experience in the room on flashbacks. Actually, Bob has made multiple comments over the years because he collected data for probably 20 years from the Navy motion simulators on simulator sickness. And he has, probably, close to fifty anecdotal reports of people with these flashbacks. After they leave simulators, driving down the road, they feel the road sliding off underneath them and pull off the road inadvertently, hit the brake, and save themselves. But Bob has a huge collection of those [reports]. I've talked to one or two people who've had those [flashbacks], and I really wish Bob could have been here to answer that because that's the same question you were asking yesterday about the leans, for example. What is it that suddenly lets us...

[Oman] I don't know that the leans is an adaptation phenomenon ...

[Benson] Like mal de débarquement [MDD] ...

[Oman] One issue that I wanted to ask about was whether there is any relationship between these aftereffects and flight experience. Certainly, in parabolic flight, I remember the first couple of times that I flew in the mornings. I would have the aftereffects of parabolic flight, which Jim Lackner has written about. You know, I think that everyone who has flown has experienced it. But after ten campaigns in parabolic flight, I don't get them anymore, and what I'm wondering is do you have to be a relative virgin? I've experienced the simulator aftereffects myself. Bob Kellogg gave me a good case of aftereffects, making me sick. I am wondering, does it have to be provocative in order to elicit symptoms? Do you have to have symptoms in order to get flashbacks? Is there any causality or just correlation? And what about MDD? MDD goes on for weeks or years, right?

[Wood] Months, yes.

[Oman] And it's disabling?

[Wood] Completely disabling.

[Oman] Have you ever tried to measure leg EMG [electromyogram] in these people or something [similar], and do you see anything?

[Atkins, James] We don't see anything abnormal. We have posturography with EMG and you don't really see anything. They actually do well on posturography.

[Oman] They don't sway?

[Atkins, James] They don't sway.

[Oman] So it's an illusory sway? 
[Atkins, James] Correct. It all seems to be central somehow because they will tell you, 'I'm still rocking. I'm still on the boat. I can't get that perception gone.' But all of their objective testing is normal.

[Oman] But certainly, anecdotally, the drunken sailor stories make you think... I mean I have seen it myself many times after getting out of the Gulf Stream, walking down the dock.

[Atkins, James] Absolutely. And you know, you think the larger cruise ships have all the stabilizers and it doesn't seem to matter. They have the largest cruise ship in the world going out of Port Canaveral, the Oasis, which is a floating island, and I've had two people come back off that and complain of MDD.

[Lawson] Well, the ocean is a little bigger [than the boat], so... [Laughter.]

[Oman] Well, twice as many people, if the prevalence is small, still get more...

[Black] The ultimate MDD is the post[flight] astronaut mal de débarquement, which occurs in most of the subjects. But I think we should probably sit down, Jim [Atkins], and talk about this because the most common abnormal condition we see in patients with mal de débarquementcoming off a ship - is patients who have either a subclinical or unrecognized BPPN [benign paroxysmal positional nystagmus]. And they apparently - and I stress this is apparent-entrain to the motion of the ship. Then, when they get off, they can't readjust or get rid of their maladaptation. So first step, then, is to deal with their BPPN, which they often don't recognize that they have.

[Atkins, James] You know, I talked to John Epley about that, and John was using the Omniax ${ }^{\circledR}$. He felt there was some sort of a mismatch between gravity... where we sense gravity, and what [information] the vestibular center, or some sort of central center, was sending. We actually tried that on several patients, and I really didn't have much success with it, but he said he was actually having people hold a cylinder with a ball in the cylinder. He would cant them, and their task was to keep the ball always centered on gravity. So if he tipped them 30 degrees, he wanted them to rotate it. We tried that a little, but I can't honestly say we did a lot with that. But it didn't seem to help in the couple of people we tried.

[Black] Well, the other is that the BPPN won't get rid of the mal de débarquement, and so what we've done - and Larry [Young] and Chuck [Oman], I would be interested in hearing some things about this - what seems to happen is they then "lock in" to the peripheral vision, both angular and linear vection. So if you can get the subject to look off in the distance [and focus] on a firm, flat surface, and then start moving around, they'll get rid of that stretch reflex feedback and that helps some of them. The other thing is that a lot of the patients that I have with chronic vestibular disturbances will complain that they entrain to a vehicle, a car, or a bus, or whatever. So one of the things that seems to be helpful is to have them stop frequently, get out, and move, and that avoids the long-term mal de débarquement they get after riding for long periods of time. But to my mind - and this is what I wanted to discuss with you - I think there is both a peripheral and vestibular central component to it, and what those components are I'm not sure of, but I don't think mal de débarquement is an entity unto itself. I agree with the publications that 
this is a maladaptation, but it is important to determine what component is peripheral and what component is central. And I've never seen a true LD subject, a bilateral LD subject, with mal de débarquement.

[Oman] Motion aftereffects are normal. Most people get them, and it's just that whatever mechanism is responsible for readapting to land is not there.

[Atkins, James] Sure. I mean, [for] you or I, it's 24 hours or 48, and you're back [to normal].

[Young] As far as mal de débarquement post spaceflight, Owen [Black], we did not study it but we observed it in a number of cases. The worst cases were always going suddenly into a dark room on landing day. We were doing a rod-and-frame test, and I'd turn off the lights and that was the trigger.

[Magnusson] At least in some of the cases, having problems for a really long time-and we're not talking about astronauts, but talking about general people going on cruise ships and things like that - some of them seem to be very much like what Marianne Dieterich and others and Thomas Brandt call the postural phobic vertigos, which is more or less that they don't trust their own senses anymore. They start to experience their own movements as caused by something outside the body. So if you treat them as you treat those [phobic vertigo] patients... at least I had some success in those long-standing courses, and that means vestibular rehab. and then sometimes SSRIs [selective serotonin reuptake inhibitors] as well.

[Atkins, James] And I think that's what John Epley was working on, was to try and give a different sensory perception. So ignore what your brain is telling you and start over, building from the ground up on sensory perception. 


\section{The understanding of Coriolis cross-coupling - Ben Lawson}

Alan Benson described the phenomenon of motion sickness as being a maladaptation response, which I think is the best description. Alan Benson also described Fred Guedry as the "doyen" researcher in this field. I thought that sounded pretty good for a talk opener, but I had to Google it to see what it meant. So I entered doyen into Google and it asked, 'Did you mean older than Alan Benson?' [Laughter.]

I'm going to talk about Fred Guedry's contributions [slide 1, page 41]. Obviously, that would keep us here past midnight, so I'm going to be focusing on a very narrow topic, and that is Coriolis cross-coupling. First, I'm going to focus on that because it gave me the privilege of meeting him. So I actually consider it not a horrible thing. I consider it one of the best things that ever happened to me. Also, he revolutionized thinking about this phenomenon in both the laboratory setting and in centrifuge and training simulators. His provocative papers changed our thinking about its relevance to disorientation in flight. Consequently, this talk could be called The understanding of Coriolis cross-coupling: F.E. Guedry's Contributions: 'Orienting and Provocative or Not?' [slide 2].

First some semantics, some of the most common questions that you get are: 'What is Coriolis cross-coupling?' 'Why do they call it that?' [slide 3]. So [for] the cross-coupling part, one of the best descriptions I saw was in a Lackner and Dizio paper [2005]. They said that if you put angular rate sensors on a head, regardless of whether it had any vestibular organs, then you do a pitch forward head movement up and back while you're stationary, you'll get that trace [slide 3]. So you can see the nice pitch head movement; not much going on in yaw and roll. Then, if you do an angular rotation while you are rotating, you do the same thing [same head movement], you get the trace there, and you notice you have a lot of roll in that trace which is the cross-coupling part, and also some yaw [slide 3]. And, of course, that will affect your canals also as they move from one plane to the next. So that's a simplification of cross-coupling.

What about the Coriolis piece? We have to go back and give a little historical background. Coriolis effect is mostly known in terms of winds and waters [slide 4]. If you type "Coriolis Effect" in [to a search engine], [you will find that,] contrary to a recent spatial disorientation book, it wasn't first applied to vestibular phenomena. It was talking about the winds and waters. So, basically, for any object that's rotating, if things move along it perpendicular to the rotation, then they'll be deflected. That allows Scott Carpenter, here [slide 4] in the rotating room, to throw nearly as good a curve ball as young Fred Guedry. That's the way [to throw a perfect curve], if you ever want to do that.

Now this was first correctly described by Gasparde-Gustave Coriolis and he wasn't talking about winds and waters [Coriolis, 1835][slide 5]. He was talking about water wheel mechanisms. I thought that was pretty interesting because we know how much aligned this field [vestibular science] has always been with engineering, and we have engineers in the room. Fred Guedry has repeatedly emphasized the importance of math and engineering to it [vestibular science]. In fact, that was part of the [purpose of the] original Role of the Vestibular Organs in Space [Proceedings] — to say we need to bring those worlds together. So he's [i.e., Coriolis] one of the founders of engineering mechanics, which is the practical use of engineering. I'd like to 
note that this was during a time when that wasn't really all that common. In fact, the water wheel is the most commonly cited solution for the perpetual motion problem. As you can see [slide 5], the water [is] flowing down there, coming back around, [and] being pumped back in by the pump. So he's way ahead of his time.

A little Coriolis trivia for the cocktail party tonight [slide 6]: a) It's fictitious. Don't let anybody ever tell you it's real; b) It was not first observed by Coriolis [Gasparde-Gustave]. It was long before that in reference to balloons floating and the Earth moving, then motion of cannon balls, and so on. But it was first correctly described by him; c) It's not a factor in your bathroom sink, so any engineers in the audience who were taught by this textbook [slide 7] can ignore that. And it's also not a factor in spirality of cats in sinks [slide 6]! In fact, the original [image] caption was the wrong direction.

A little "poetic justice": Coriolis effect was first correctly calculated by a Parisian and it protected Paris during WWI [slide 7-8]. The Germans created one of the biggest cannons ever invented, and got about 75 miles from Paris and began shelling. That is quite an undertaking because this was such a powerful cannon (such huge charges and huge shells in it) that even if you shot [only] six or seven shells, you would have to rebore the cannon to keep going. [The Germans asked themselves] "Why are we not hitting Paris?" The reason was because Paris was moving as the shells were traveling. Like most French defensive measures, though, it only worked temporarily. [Laughter.] So in about the time you can say, "Lackner and Dizio's arm movement," they sort of had the ah-hah [moment] and recalibrated the direction of shelling.

What does all that have to do with the vestibular system? Well, if you just think about it, while you have a linear Coriolis going on it seems like that would affect your otolith, since that's a linear accelerometer. And also your head mass is attached to your neck, so you're going to get kinesthetic signals from that. So it logically makes sense that making a head movement out of the rotation axis might be a stimulus. But the thing is, in all the early literature it's referring to a canal function [slides 9-10]. So if you look a little bit into that you find some early examplesactually, very close examples - that I was alerted to from Benson's review [2003]. I knew I couldn't trust what he said [speaker is joking], so I went and got the original [papers] and read those. An early researcher, Van Wulfften Palthe, got very close [while considering] the pseudo Purkinje effect in flight, which I'll mention a little bit later [Van Wulfften Palthe, 1922]. The best you see is Schubert early on, with some brief recognition that the Coriolis formula may apply to flight maneuvers and reactions [Schubert, 1931]. In fact, it seems like it is kind of recognized there a little earlier than in the lab-for Coriolis at least, not for Purkinje. I tried to find the French citation that Dr. Benson mentioned and my professional librarian said it doesn't exist! So I had to go with the German one, and I was pretty stuck because I don't read German. Fortunately, there's a new exchange scientist in our lab [Sandra Born] and she's about this tall [motions above head] and she's a German lady with blonde hair, she looks like a Valkyrie. She turns out to be from the same institute as Schubert was and she said, 'I'll be glad to help you.' So, I pretty much cross-examined her. Here's what it seemed like was being said in the Schubert reference. He mentions that he clearly recognizes Coriolis effect and he describes the math of it related to flying. So that insight was clearly in there. He also believes it can affect your perception during banking. He thinks it's especially been recognized by him recently because the old aircraft turned more slowly — it took them longer than 2 seconds [of turning in order to 
bank], and the new advanced ones — is this ringing any modern bells? ? $^{*}$-were turning more quickly. He said, also, that it probably explained some mishaps because they seemed to be correcting in the wrong direction. There was no logic to the correction, but it did make sense in terms of the expected cross-coupling. And he said it does affect your vestibular system [Schubert, 1931]. So we got all the pieces together, except we could not find one piece in there (and I grilled her extensively) and that was the recognition of a specific effect on the vestibular system as meaningfully transducing the signal. Rather, it seemed like what Schubert was talking about were general effects on circulation or pressure in the labyrinth and so forth. So if anybody knows more about that, I'd be glad to find out. Incidentally, Johnson [Johnson, Stubbs, Kelk, \& Franks, 1951] mentioned [an aviation medicine text edited by] Voyachek '43, and then Voyachek - being presumably a Russian researcher - of course said he had discovered all this in 1908 [Popov, 1943]. Most sources don't mention this, though.

So, that's the history of it in flight, but most sources, starting with Fernandez [Fernandez \& Lindsay, 1964], cite Guedry and Montague [1961]. That's because that was the most complete explanation and it really put the quantitative modeling of Coriolis cross-coupling on the map. What they said there was, "The term Coriolis is appropriate because the inertial forces resulting from different magnitude Coriolis accelerations at different points in a given canal are the principal source of stimulation of the canal system..." that is, "during head movements..." after prolonged velocity (constant velocity) [Guedry \& Montague, 1961, page 1] [slide 11]. But more importantly, they showed that you can do quantitative measurement and modeling of complex stimuli like Coriolis cross-coupling [slide 12]. These were back in the days when we were just at the point of the torsion pendulum [model], and they're showing that you can deal with these kinds of [complex] stimuli. And they noted what later would be variously called velocity without displacement, or posi-motion, or paradoxical sensations - the feeling that there is velocity without actual displacement, and they noted very early on the relevance to centrifuge training.

They also noticed that earlier piece (the linear Coriolis that logically ought to affect the otolith) was often negligible in the laboratory: "Coriolis accelerations from the head movements... are small in magnitude... hence, the otoliths would respond... more or less as usual" [Guedry \& Montague, 1961, page 12] [slide 13]. That is further corroborated by Dr. Oman, who mentioned the paper, I believe from '87, talking about the effect of the linear Coriolis in the canal [Oman, Marcus, \& Curthoys, 1987]. Then there were a couple of experimental studies by Isu and Woodman and Griffin where they tried to vary the extent of the otolith versus the canal effect and found the canal effect seemed to predominate [Isu, Yanagihara, Yoneda, Hattori, \& Koo, 1996; Woodman \& Griffin, 1997]. Now that doesn't mean it [linear Coriolis] won't be very important for the naturalistic motions we've heard of here at about 3,000 degrees per second and so forth. So when Ken Money played badminton or Dr. Guedry played tennis, certainly you could get into highly significant linear effects there. Pigeon and Lackner and Dizio have followed up with Fred's naturalistic motion research and looked at that [Pigeon, Bortolami, Dizio, \& Lackner, 1999].

\footnotetext{
*Speaker is referring to modern highly maneuverable, agile, or vectored-thrust aircraft.
} 
Now, turning from where the linear Coriolis may not be the key factor in the laboratory. They [Guedry and Benson] found that while it may be negligible in the laboratory, gravitational linear acceleration was not [slide 14]. And this is one of the great teams [Guedry \& Benson], you know, [like] Laurel and Hardy. This is one of the great teams in our field. They compared the axis of cross-coupled effect - that is the angular impulse vector - to the linear gravity vector, and tried to see whether one was aligned with the other. They found a significant effect for that. So the linear acceleration becomes very important there, and in the classic paper, Coriolis crossCoupling Effects: Disorienting \& Nauseogenic or Not?, they found a head movement at the same chair velocity leads to different effects [Guedry \& Benson, 1978]. So basically, you've got the same chair velocity at all points, the same cross-coupling, but dramatically different effects. And also, I'd like to point out that [paper] set a new standard for cool paper titles [slide 15]. You've got everything in there. You've got a colon and a question mark. [Laughter.] That's as erudite as it gets. So they also explained why that was occurring. It was depending on whether that resultant angular impulse vector aligns with the gravity vector or not. So on the left, you see the case where you're still accelerating [slide 16]; everything's cool because you've got the yaw acceleration which causes the angular impulse vector to align around the linear acceleration due to gravity. In the middle case, after prolonged constant velocity, there is no acceleration. You see that's died completely away. All you've got left is the cross-couple, and then in the worst case (the deceleration) it's highly aberrant and it really is not pleasant. They formed an inspiration for many later studies, not just this [slide 17], but other studies. Their general approach stimulated interest in further modeling and empirical studies of Coriolis cross-coupling and combined linear-angular motion. A lot more complex stuff started happening, and there's way too much of that to get into, but we have to pay a special nod to our MIT [Massachusetts Institute of Technology] colleagues [slide 18]. Chuck [Oman], I didn't know whether to put you in the "early" or "modern" [category] but I figured you're older than me so you're an early researcher. [Laughter.]

I'd like to turn next to how you would get rid of these effects, because the beauty of Guedry's research is you don't just stop with [questions such as], 'Hey, wouldn't it be nice if we did a basic study on this phenomenon?' Now it's, 'What are we going to do about it?' Guedry, in '78, recognized that a visual reference influences sickness and that can occur on ships, on swings, and most interestingly, during Coriolis cross-coupling adaptations [Guedry, 1978] [slide 19]. Reason and Diaz looked at different visual situations, [such as] internal visual reference, where you only have the little cabin that moves with you, and an external one, and a third [condition] [slide 20] (I think it was a constricted view through the portal) [Reason \& Diaz, 1973, pages 87-97].

Basically, the finding is that the internal visual reference was the one [where subjects] had the most trouble adapting. Now, the findings of the study are a lot more complicated than that and it turns out there are combinations of the two that best describe it. But that's the closest you come to this following study, which is Reason and Diaz '73 [Reason \& Diaz, 1973]. I'm sorry that Cameron [Diaz] couldn't be here today, but she did send her love to Dr. Guedry [slide 20]. [Laughter.]

They [Reason and Diaz] found that, essentially, like these other cases, it [a visual reference] should also help preceding head movement in dark. In other words, you do a prolonged constant velocity rotation in the light, you cut the light right at the moment the head movement begins, and you get a beneficial effect. So far [the reader is probably thinking] 'yea that's nice,' but they 
[Reason and Diaz] explain why and that's really what's great about this [paper]: you have a hypothetical vector being created by the horizontal plane of the whole field visual motion [slides 21-22]. And we knew from a whole bunch of studies, starting with goldfish and so on (Guedry cites Dichgans and Brandt, ' 72 , in particular), that tell you that whole field visual reference would, in fact, be a vestibular stimulus [Dichgans \& Brandt, 1972]. Then, they did some extensions. Dr. Guedry did an extension where he found that the Coriolis cross-coupling effect can be quantified and visually counteracted in additional axes [slide 23] and that was the subject of my postdoctoral research and the reason why I think cross-coupling is awesome [Lawson, Guedry, Rupert, \& Anderson 1994]. It was also an unusual experience for me because I realized what a major scientist Fred was. I knew that, but I had never interacted with him. So I would come to him with my latest findings, and he's always very excited about anybody's findings, even mine. He always had very probing questions, the kind of things that would just put you right back to the drawing board. I wondered if he just didn't like my [postdoctoral] experiment or I wasn't doing it right. So I'd run back and do another control study and I gave them letters (A, B, C...). I'd figured there'd be maybe "A," "B," and "C" you know. Well, I got to "K!" [Laughter.] So, I did 11 control studies, and then I think he finally found it to be believable. He was convinced of the findings. I think that's the case, I've never asked him! I think that's the case because he finally said, 'You know what, you do too many control experiments.' He said, 'We need to get some Lackner remover for you.' [Laughter.] He was just joking, of course. He very much respects Jim. Fred, I've never admitted this to anyone anywhere: Having done 11 control experiments did not directly reflect on Jim Lackner [e.g., his known rigorousness as a researcher]. It was my attempt to impress you.

There were some side effects of the study that I should note, though, some spotting on the part of the subject [slide 24]. No, actually that's Kristin's [Blackwell] dog, Jake. [Laughter.] No longer with us, I assume. And the research inspired some other more preliminary studies which I've summarized [Lawson, Rupert, Guedry, Grissett, \& Mead, 1997, pages 945-948]. It turned out that this counteraction could actually continue to be helpful under different gaze strategies and different fields of view [slide 25]. Now, granted, I'm not talking about [it helping for] a 5 degree field of view, you know, but something [more] like 60 versus 120 . But the thing is, it was robust under different fields of view, didn't depend on the gaze strategy, and it worked for somatosensory feedback also, which feeds into a lot of earlier research concerning perception and arthrokinetics, and so forth. So just to summarize, if you have your feet up and you're rotating and you do the cross-coupling, that's the most sickening and disturbing [slide 26]. If you then have your feet down and they're dragging on the floor, but not affecting the velocity, that's the second most disturbing and disorienting. Finally, if you walk in time with the chair (similar to Guedry and Benson '83, although they did it with the arms and legs, I believe), then you have the least disturbance of all [Guedry \& Benson, 1983]. Now of course, you don't have shoes on [slide 26 shows subject wearing shoes]. So they found very similarly, much earlier, that the Purkinje effect is less disturbing under those same circumstances.

So the critical thing for Dr. Guedry [slide 27] was how do you transition this to practical understanding? Well, that part's a little more complicated. If we look at some training literature for aviation, we see this sort of [erroneous] statement [about Coriolis cross-coupling]: [the] 'almost unbearable sensation that the aircraft is rolling, pitching, and yawing all at the same time can quickly make the pilot become disoriented and lose control of the aircraft [Antunano, 2004, 
section titled "The Coriolis Illusion"][slide 28]. There's no mention of G-excess there or in this particular document. I won't say from what source this [next] document came [speaker is joking] [slide 29]: "Regardless of the aircraft type, it is the most dangerous of all vestibular illusions and causes overwhelming disorientation" [Department of the Army, 2009, page 9-14]. I think they might have got away with, you know, 'Okay, it occurs on a helicopter.' I'm okay with that. But, that [quote is] "regardless of aircraft type." That throws you off, and there's also no mention of G-excess there. So I don't think the correct view has quite made it into the aviation literature. Now, in the case of the Naval flight surgeon manual, however, it's informative, it's accurate [slide 30]. It tells you what Coriolis cross-coupling is, what it does, what it doesn't do, its role relative to G-excess [Department of the Navy, 1991]. That very good manual is still used. And I'll give you one guess who wrote the chapter [Guedry].

Now, I mentioned G-excess. What did Guedry do in regards to G-excess? Particularly, what is the role of Coriolis cross-coupling versus G-excess? [slide 31]? A little historical background: before you can do somatogravic or G-excess, you have to be able to initiate off-center rotation [i.e., at a radius]. Erasmus Darwin was the first to propose a centrifuge [slide 32] [Darwin, 1801]. It had nothing to do with producing these illusions. It was another way of procuring sleep mechanically. And it was for sedating out-of-control (they called them) maniacs back then. I'm here to tell you, it works fairly well. Angus was pretty quiet for quite a while after being in the centrifuge. [Laughter.] The idea came from James Brindley, a canal engineer. And again, you see the engineering connection. This is the quote:

"...he told me that he had... seen the experiment of a man extending himself across the large stone of a corn mill, and that by gradually letting the stone whirl, the man fell asleep, before the stone gained its full velocity, and he supposed would have died without pain by the continuance of the motion" [Darwin, 1801, page 314].

So that's the original centrifuge to the left, well not the one, but an example of exactly how that would have looked at that time. And there's [slide 33] Darwin's drawing. It looks like a sailboat, but you can see how the guy would lie down on the right. So that's your first centrifuge. So once that 'got the wheel rolling' [slide 34], there was immediately this application to therapy. Initially, it was cautious and it was all on-center kind of applications. So you see also some nonprovocative comments like that one [referencing the comment on slide 35 concerning a non-sickening experience] [Hallaran, 1810, page 67]. Of course, we're more mature than that now. [Laughter, as a picture of modern people cavorting in parabolic flight appears.]

Then all of a sudden, it went off-center: things got "Harsch." And, that's the author of that report [Harsch, 2006] [slide 36]. Depending on which source you look into, it either occurred on one [or the other] of those dates, where the first centrifuge was built by Horn at the "Charity" Hospital. Horn said, "...the more uncomfortable and onerous the application, the more charitable the effects..." [as cited in Harsch, 2006, page 159]. So now you have, literally, the centrifuge as a mechanism of control over unruly persons.

Then came the first perceptual recognition by Purkinje [slide 37]. He felt tilted on a merrygo-round and he attributed it to the centrifugal force; however, he went on to build an on-center rotator [Wade \& Brozek, 2001]. Mach was the first to identify the perceptual effect with the off- 
center rotation and attribute it to the vestibular mechanism [Gibson \& Mowrer, 1938] [slide 38]. He first saw it on a turning railway car. Then, he built a small centrifuge and that was the landmark recognition, right there, of what we would call a somatogravic type of effect now. And it also pretty much determined the look I wanted to go with. [Laughter as image of Lawson appears next to image of Mach.] You know, the teeny glasses, big nose, big forehead, the beard - out of respect for Mach. So with Mach began the psychophysics of off-center vestibular sensation and that's something Fred has led the charge in, since then [slide 39]. So imagine a parallel universe, had there been no Mach or Guedry, this [slide 40] would be the main use of the centrifuge today [for patients].

Now, finishing with Guedry and the fall, or demise of Coriolis cross-coupling (so to speak), in fixed-wing flight [slide 41]. This is modern research leading into G-excess, the nonspace part (since the space applications have been mentioned). The precursors, of course, are somatogravic, the earliest [reported by Van Wulfften Palthe] being mentioned by Benson in his really fascinating report [Benson, 2003] [slide 42]. So Van Wulfften Palthe, in 1922, described all kinds of maneuvers, one of them being banked flight. Four people repeatedly did this, and not a single correct perception could be obtained [Van Wulfften Palthe, 1922]. A number of other people, including Collar (from Benson), saw that the take-off acceleration leads to a backward tilt perception [Collar, 1946]. But you can say, 'Well, wait a minute, in these cases there's still some angular acceleration going on.' But in Clark and Graybiel '49, they tried to keep that to an absolute minimum [Clark \& Graybiel, 1949]. So it's linear deceleration and acceleration in flight, and they still got that tilt effect. So that part can't be a canal thing so much. So then, Gilson et al. found that the disorienting head movement effects were occurring during a 2 G banked turn [Gilson, Guedry, Hixson, \& Niven, 1973][slide 43]. And as Angus [Rupert] has pointed out to me, one of the brilliant parts of that study was that you have a bunch of disparate findings that are hard to interpret and it takes a Fred Guedry to realize, 'yes but I know what it cannot be, because it's going in the wrong direction.' So it could not be Coriolis cross-coupling, and they coined G-excess as an alternate. Then they clarified that further, in relation to some findings Gillingham had where he was talking about G-excess but as more of a steady state response [Gillingham \& Previc, 1993]. And, they tried to clarify and distinguish how there's a rate versus magnitude aspect [Guedry \& Rupert, 1991]. Both of those things are affected by Gexcess in the vestibular system. There are some interesting parallels in the history of thisthings coming first full circle. Pancratz et al. pointed out that Coriolis cross-coupling and also Gexcess can occur without head movement [Pancratz, Bomar, \& Raddin, 1994]. It can still occur in a super agile aircraft [slide 44]. And to that I would say that is very similar to what Wulfften Palthe said in '22, although he was talking more about a Purkinje-ish effect [Van Wulfften Palthe, 1922].

So, in conclusion, because of Guedry we know that complex stimuli, like Coriolis crosscoupling, are quantifiable, predictable, and sometimes even controllable [slide 45]. And [we now know] that this has important applications to centrifuge-based flight simulation and regular training. We also know that it's not usually the key problem under normal fixed-wing flight, standard rate turns, and so forth. That has important applications for mishap modeling in flight training. So where do we go from there [slide 46]? Well, there's several more things that need to be known about Coriolis cross-coupling, and Angus [Rupert] is discussing that with colleagues from Drexel, and Jamie Bishop is here and his advisor, Dr. James Tangora, 
and they're going to be exploring some further studies that should be done on that ${ }^{*}$. We can talk about that in the break if you wish.

In general, in completing a revolution, I think for future research it's very instructive to look at how consistent Dr. Guedry has been and how his recommendations to us, if we're willing to read them, form the same lesson. What I mean by that is in 1960, Guedry and Graybiel recommended the following types of research [Guedry \& Graybiel, 1960] [slide 47]: a.) We should focus more on the end organs, learn more about that; b.) The transduction, the neural pathways and projections, that's very important; c.) We should look more at interactions with visual and somatosensory systems; d.) We should also not forget the voluntary movement and the ordinary movement conditions. Now watch this, 32 years later, he [Guedry] said that some progress has been made in the end organs, and the transducers, and the projections, and some progress, in the interactions, but we still know almost nothing about the perception during goaldirected voluntary movement and complex and dynamic stimuli [slide 47] [Guedry, 1993]. That's an amazing full circle, I think.

Trying to figure out the future means you have to draw lines from the past to the present and then project forward. So I ask you, where should we be? What should we be saying? What should that slide bullet say in the next 30 years [slides 48-49]? Thank you very much.

[Questions are deferred to the break following this talk.]

*Due to unexpected illness, this work was carried forward by Michael Newman of Environmental Techtonics Corporation, instead. 


\section{References}

Antunano, M. J. 2004. Spatial disorientation: Why you shouldn't fly by the seat of your pants. Medical facts for pilots publication AM-400-03/1. FAA Civil Aerospace Medical Institute. Oklahoma City, OK. Retrieved from:

http://www.atlasaviation.com/medical/spatial_disorientation_seat_of_pants.htm

Benson, A. J. 2003. Spatial disorientation: A perspective. Paper presented at the RTO HFM Symposium on Spatial Disorientation in Military Vehicles: Causes, Consequences and Cures, 15-17 April 2002, at La Coruña, Spain.

Clark, B., and Graybiel, A. 1949. Linear acceleration and deceleration as factors influencing non-visual orientation during flight. The Journal of aviation medicine. 20(2): 92-101.

Coriolis, G-G. 1835. Memorie sur les 'equations du movement relative des systëmes de corps (On the equations of relative motion of a system of bodies). Journal de l'Ecole Polytechnique. 15: $142-54$.

Collar, A. R. 1946. On an aspect of the accident history of aircraft taking off at night . Aeronautical Research Council (London) Reports and Memoranda No. 2277.

Darwin, E. 1801. Zoonomia; or, the laws of organic life. Volume 4. $3^{\text {rd }}$ ed. UK: Johnson, London.

Department of the Army. 2009. Aeromedical training for flight personnel. Training Circular. Washington, DC: 3-04.93 (FM 3-04.301).

Department of the Navy. U.S. Naval Flight Surgeon's Manual Third Edition. 1991. Washington, D. C: Naval Aerospace Medical Institute.

Dichgans, J., and Brandt, T. 1972. Visual-vestibular interaction and motion perception. Bibliotheca Opthalmologica. 82: 327-38.

Fernandez, C., and Lindsay, J. R. 1964. The vestibular Coriolis Reaction. Archives of Otolaryngology. 80(4): 469-72.

Gibson, J. J., and Mowrer, O. H. 1938. Determinants of the perceived vertical and horizontal. Psychological Review. 45(4): 300-23.

Gillingham, K. K., and Previc, F. H. 1993. Spatial orientation in flight. Air Force Materiel Command. Armstrong Laboratory. Brooks Air Force Base, Texas. Technical Report No. ALTR-1993-0022.

Gilson, R. D., Guedry, F. E., Hixson, W. C., and Niven, J. I. 1973. Observations on perceived changes in aircraft attitude attending head movements made in a 2-g bank and turn. Aerospace Medicine. 44: 90-91. 
Guedry, F. E. 1978. Visual counteraction on nauseogenic and disorienting effects of some whole-body motions: A proposed mechanism. Aviation, Space, and Environmental Medicine. 49(1): 36-41.

Guedry, F. E. 1993. Space vestibulo-neuroscience in the new century: Why proceed in semidarkness? Journal for oto-rhino-laryngology. 55: 167-72.

Guedry, F. E., and Benson, A. J. 1978. Coriolis cross-coupling effects: disorienting and nauseogenic or not? Aviation, Space, and Environmental Medicine. 49: 29-35.

Guedry F. E. and Benson, A. J. 1983. Modification of pre- and postrotational responses by voluntary motor activity of the limbs. Experimental Brain Research. 52: 190-98.

Guedry, F. E., and Graybiel, A. 1960. Rotation devices, other than centrifuges and motion simulators: the rationale for their special characteristics and use. Washington, DC: National Academy of Science - National Research Council. Publication No. 902.

Guedry, F. E., and Montague, E. K. 1961. Quantitative evaluation of the vestibular Coriolis reaction. Aerospace Medicine. 32: 387-500.

Guedry, F. E., and Rupert, A. H. 1991. Steady state and transient G-excess effects. Aviation, Space, and Environmental Medicine. 62(3): 252-53.

Hallaran, W. S. 1810. An enquiry into the causes producing the extraordinary addition to the number of insane, together with extended observations on the cure of insanity, with hints as to the better management of public asylums for insane persons. Cork, Ireland: Edwards and Savage.

Harsch, V. 2006. Centrifuge "therapy" for psychiatric patients in Germany in the early 1800s. Aviation, Space, and Environmental Medicine. 77(2): 157-60.

Isu, N., Yanagihara, M., Yoneda S., Hattori, K., and Koo, J. 1996. The severity of nauseogenic effects of cross-coupled rotation is proportional to gyroscopic angular acceleration. Aviation, Space, and Environmental Medicine. 67: 325-32.

Johnson, W. H., Stubbs, R. A., Kelk, G. F., and Franks, W. R. 1951. Stimulus required to produce motion sickness: I. Preliminary report dealing with importance of head movements. The Journal of Aviation Medicine. 22: 365-74.

Lackner, R., and Dizio, P. 2005. Vestibular, proprioceptive, and haptic contributions to spatial orientation. Annual Review of Psychology. 56: 115-47.

Lawson, B. D., Guedry, F. E., Rupert, A. H., and Anderson, A. M. 1994. Attenuating the disorienting effects of head movement during whole-body rotation using a visual reference: further tests of a predictive hypothesis. In: Advisory group for aerospace research and 
development [Conference proceedings No. 541]. Virtual interfaces: Research and applications. Neuilly-Sur Seine, France AGARD.

Lawson, B. D., Rupert, A. H., Guedry, F. E., Grissett, J. D., and Mead, A. M. 1997. The human-machine interface challenge of using virtual environment (VE) displays aboard centrifuge devices. In: Smith, M. J., Salvendy, G., and Koubek, R. J. (eds.), Design of computing systems: Social and ergonomic considerations. pp. 945-48. Amsterdam, the Netherlands: Elsevier Science Publishers.

Oman, C. M., Marcus, E. N., and Curthoys, I. S. 1987. The influence of semicircular canal morphology on endloymph flow dynamics. An anatomically descriptive mathematical model. Acta Otolaryngologica (Stockh). 103: 1-13.

Pancratz, D. J., Bomar, J. B. Jr., and Raddin, J. H. Jr. 1994. A new source for vestibular illusions in high agility aircraft. Aviation Space Environmental Medicine. 65(12): 1130-1133.

Pigeon, P., Bortolami, S. B., Dizio, P., and Lackner, J. R. 1999. Arm reaching movements during voluntary trunk rotation involve compensation for self-generated Coriolis forces. Society for Neuroscience Abstracts. 25: 1912

Popov, A. P. 1943. Special vestibular training. In: Fundamentals of Aviation Medicine, Voyachek W. E. (ed.) English translation by Steinman I. Toronto, Canada: University of Toronto Press, Chapter 19.

Reason, J. T., and Diaz, E. 1973. Effects of visual reference on adaptation to motion sickness and subjective responses evoked by graded cross-coupled angular accelerations. In: NASA, Washington fifth symposium on the role of the vestibular organs in space exploration; 87-97. Hampton, VA: Scientific and technical information office, national aeronautics and space administration.

Schubert, G. 1931. Les effets physiologiques des accelerations de Coriolis. (Physiological effects of Coriolis accelerations). Int. Cong. Securite. Aerien, Paris. 4: 151-55.

Van Wulfften Palthe, P. M. 1922. Function of the deeper sensibility and of the vestibular organs in flying. Acta Otolaryngologica. 4: 415-48.

Wade, N. J., and Brozek, J. 2001. Purkinje's vision: The dawning of neuroscience. Mahwah, NJ: Lawrence Erlbaum Associates, Inc.

Woodman, P. D., and Griffin, M. J. 1997. Effect of direction of head movement on motion sickness caused by Coriolis stimulation. Aviation, Space, and Environmental Medicine. 68(2): 93-8. 


\section{F.E. Guedry's Contributions}

- Too many to enumerate!

- Focus: quick highlights / narrow topic...

- Coriolis cross-coupling $(\mathrm{Ccc}), \mathrm{b} / \mathrm{c}$ :

1. Gave me the privilege of meeting him

2. He "revolution-ized" our thinking about Ccc in the lab and in centrifuge training/sims

3. His provocative papers changed thinking about it's relevance to disorientation in flight

\section{The Understanding of Coriolis cross-coupling (Ccc)

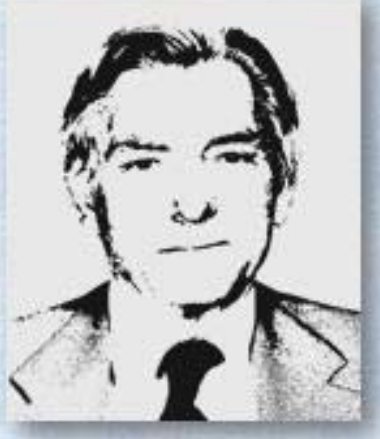 \\ F.E. Guedry's Contributions: \\ Orienting and Provocative or Not?}




\section{Semantics: "Cross-coupling?"}

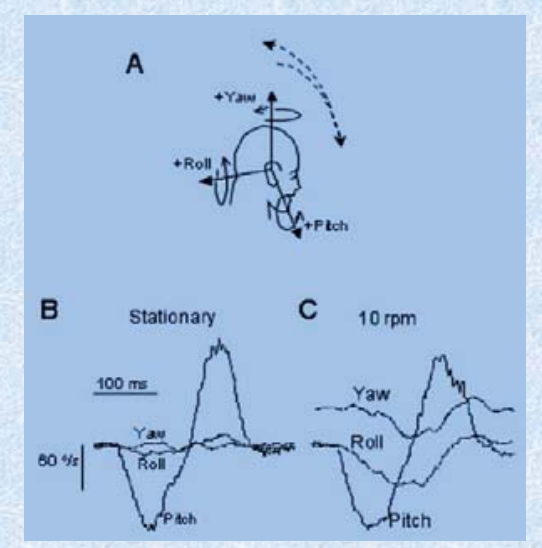

- Angular rate sensors on head during pitch forward-\&-back while stationary (B) and rotating $\mathrm{CCW}$ (C)

- Notice angular acceleration in roll (and yaw)

- Will affect canals also

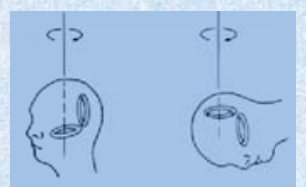

- What about "Coriolis?"...

Slide 3

\section{Historical Background} THECORIOLS EFEECY - "Coriolis Effect" (wind/water)

- Apparent deflection of objects moving in a rotating frame of reference
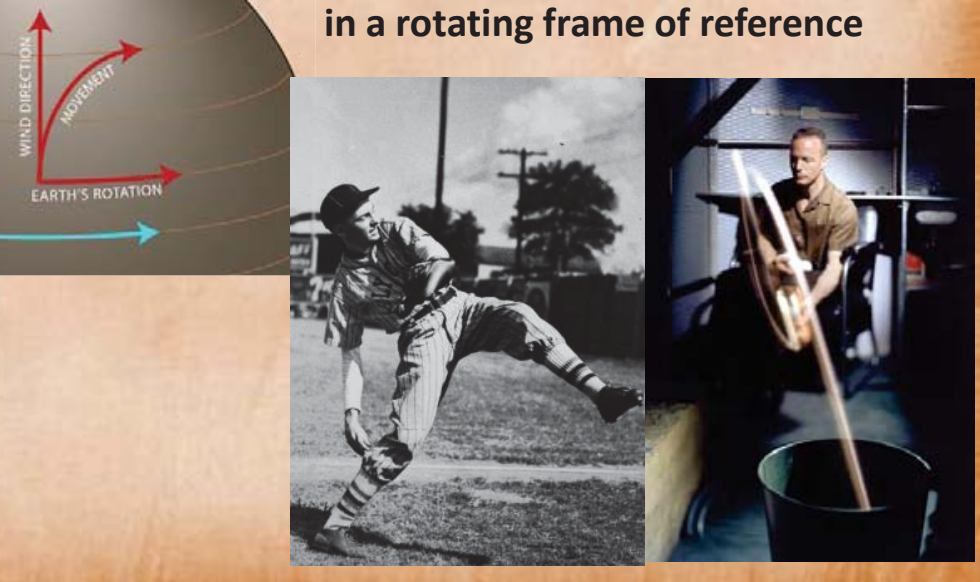

Slide 4 


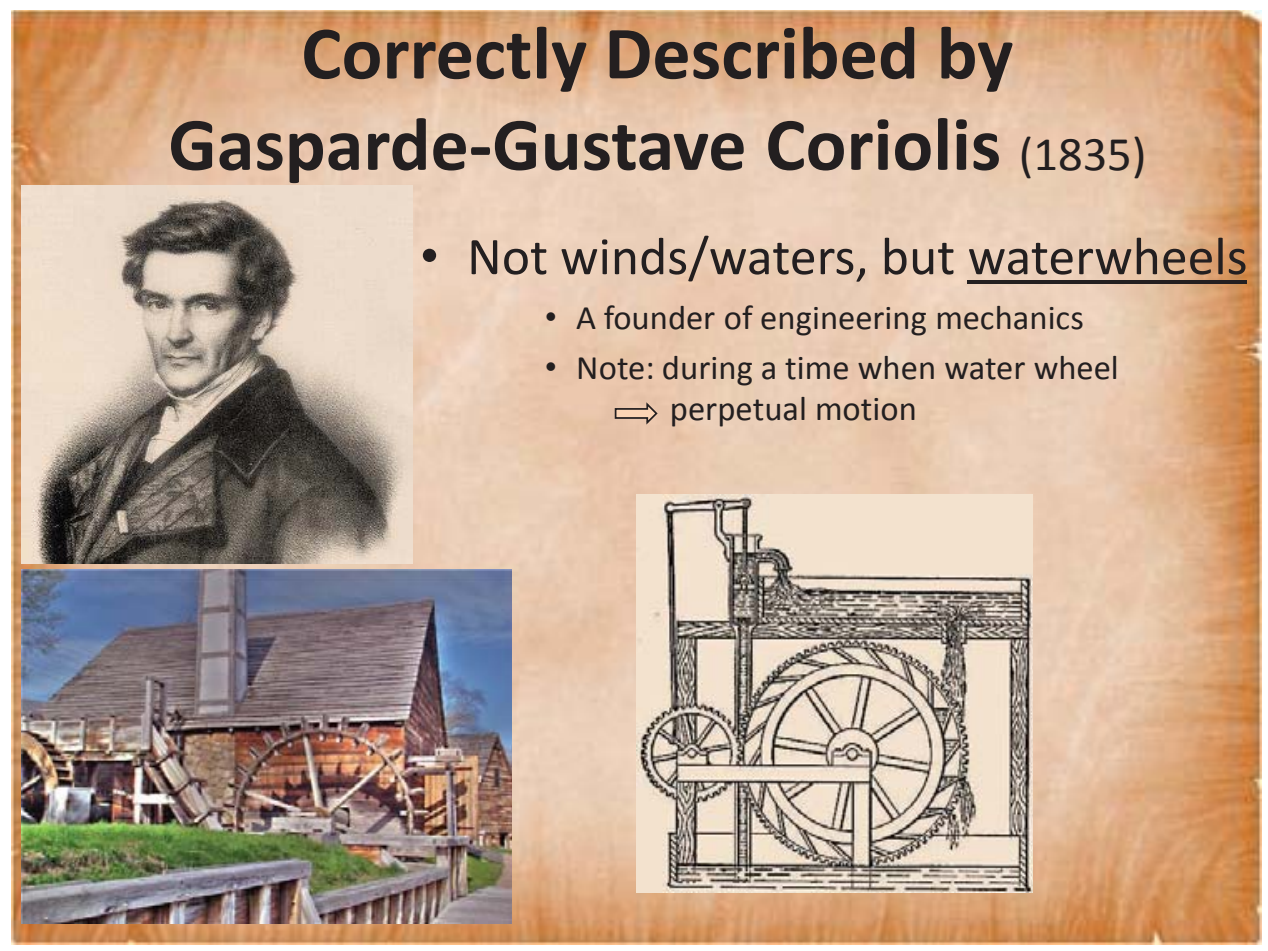

Slide 5

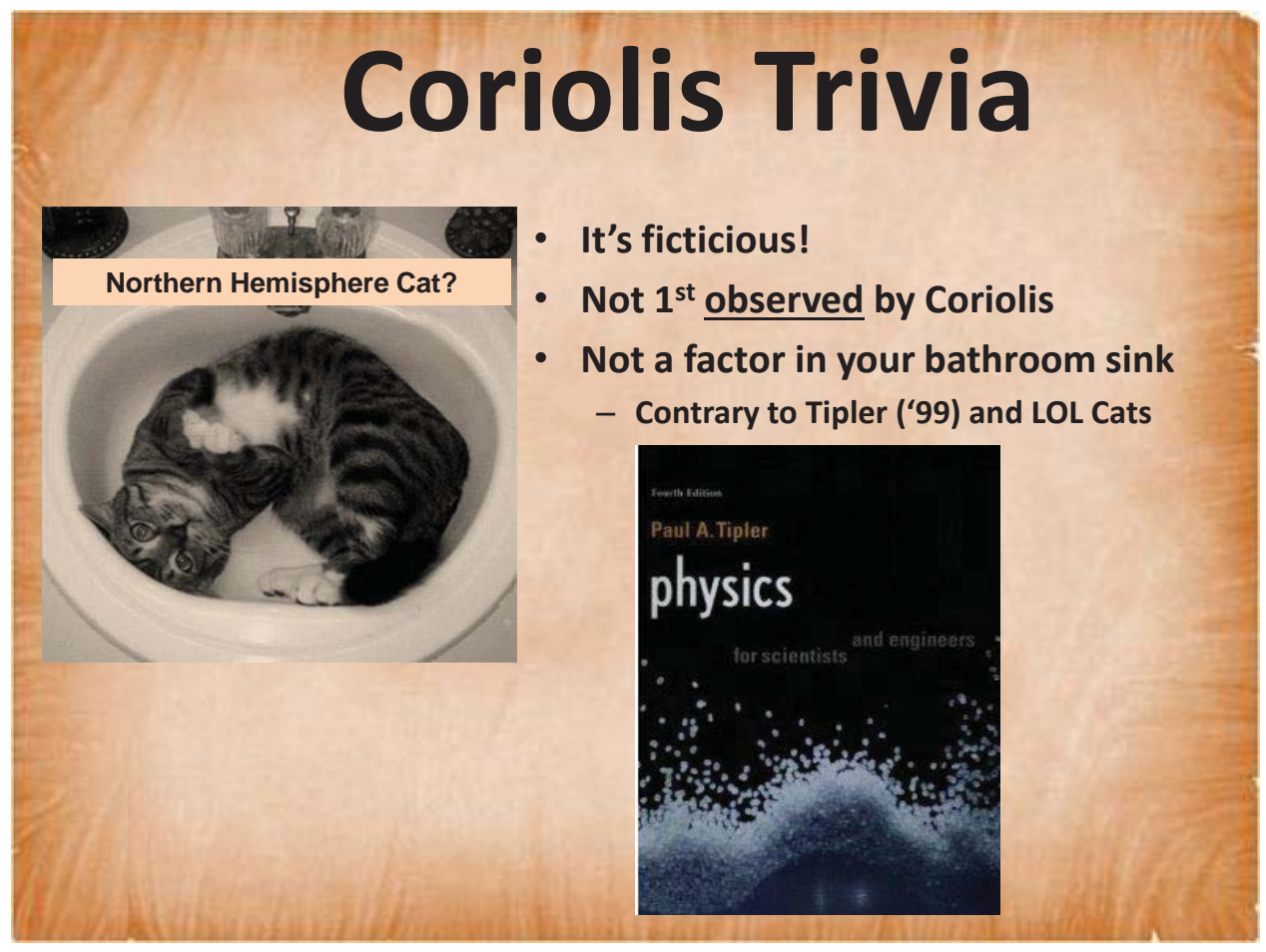

Slide 6 


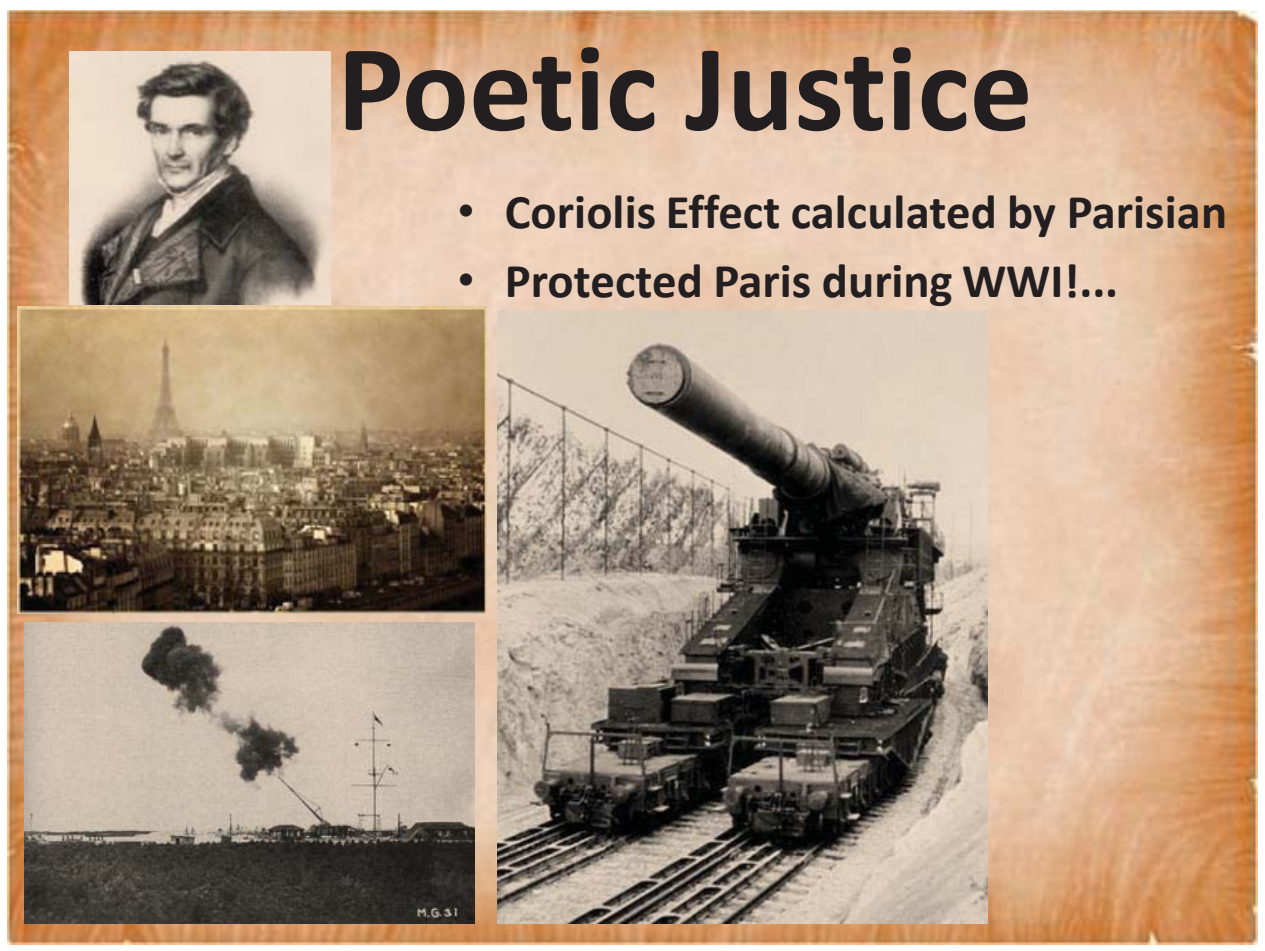

Slide 7

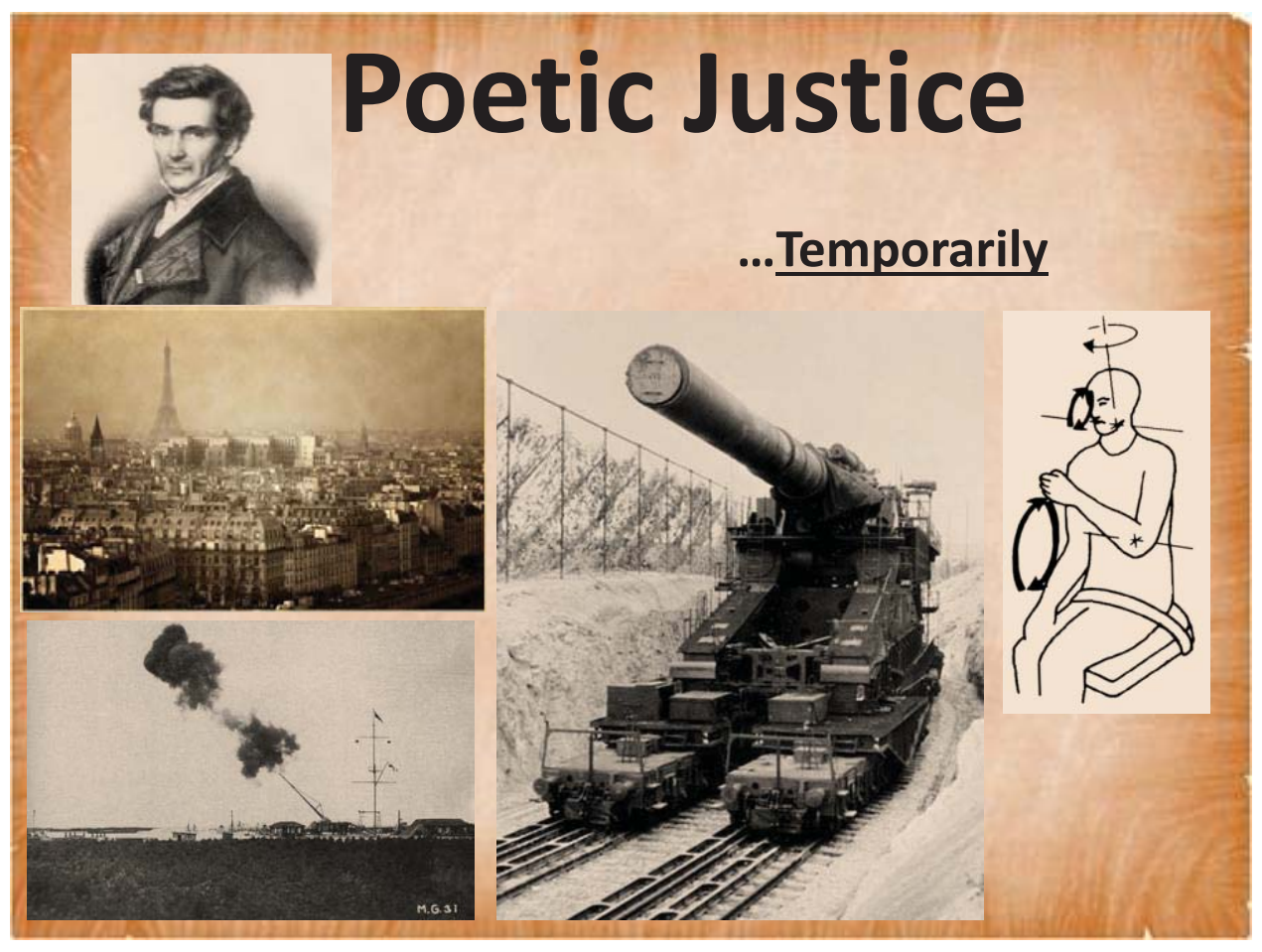

Slide 8 


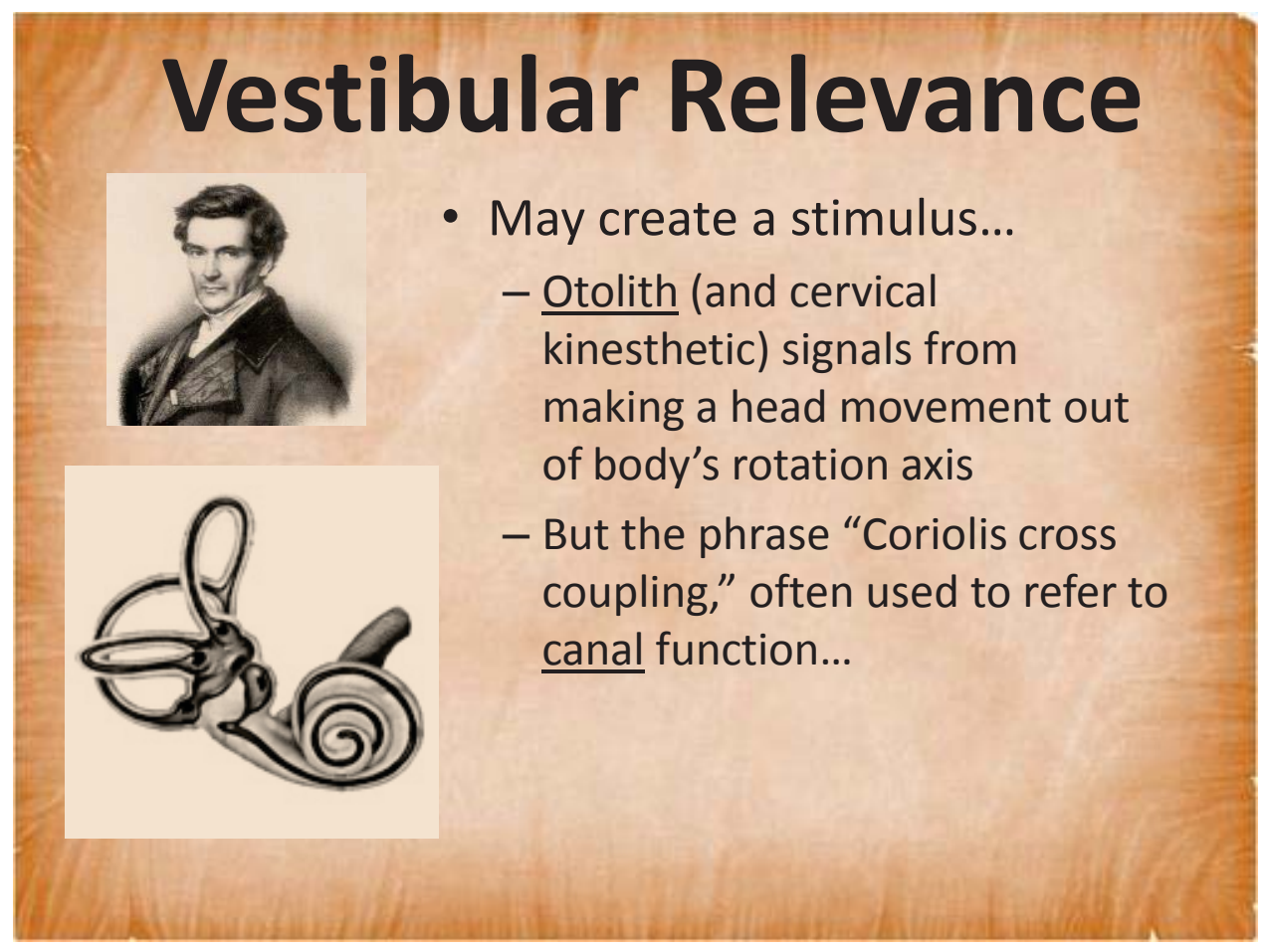

Slide 9

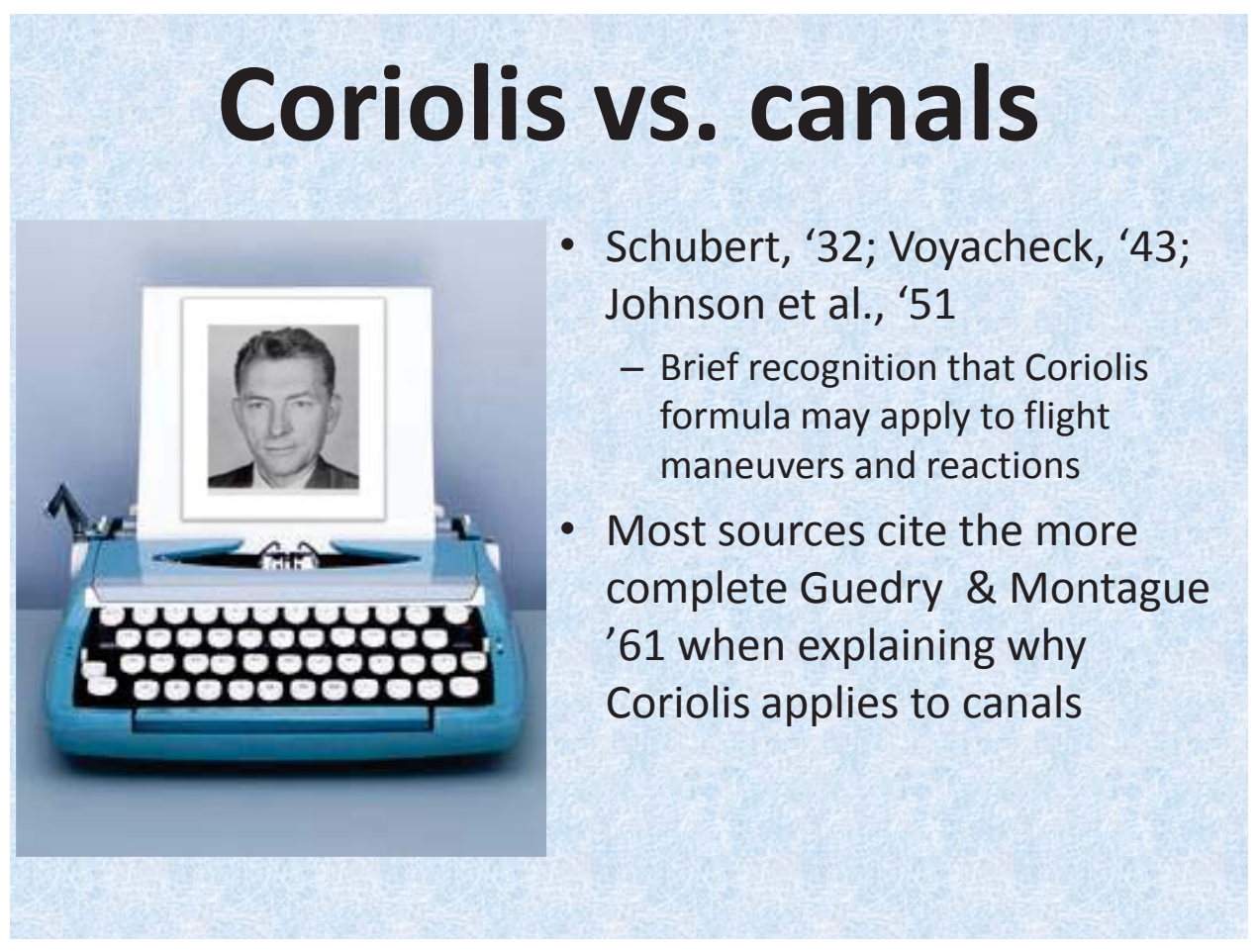

Slide 10 


\section{Coriolis vs. canals}

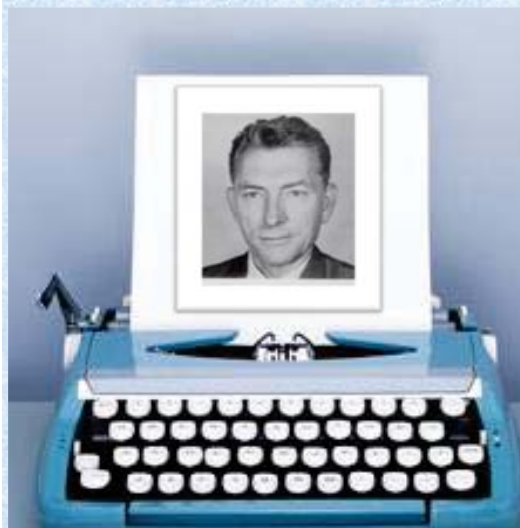

- Guedry \& Montague '61:

- "The term Coriolis is appropriate because inertial forces resulting from different magnitude Coriolis accelerations at different points in a given canal are the principal source of stimulation of the canal system"

(during head movement after prolonged constant velocity rotation)

Slide 11

\section{More Importantly...}

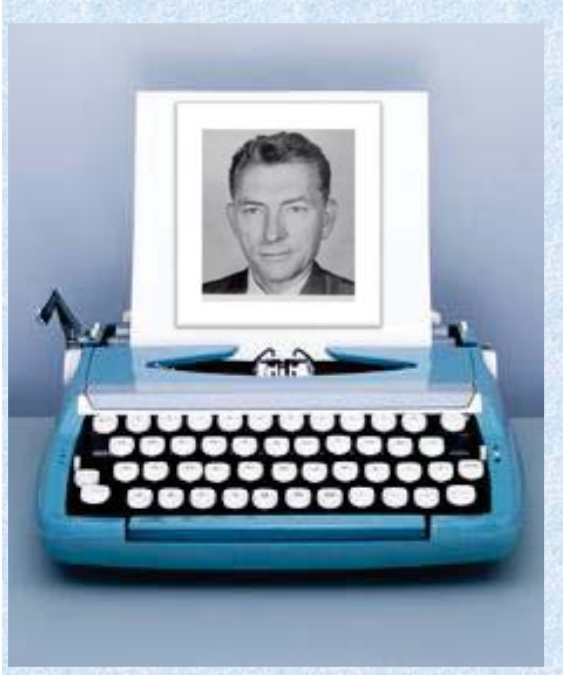

- Showed quantitative measurement/modeling of complex stim. like Ccc is possible.

- Noted what would later be called posimotion illusion

- Relevance to centrifuge training

Slide 12 


\section{More Importantly...}

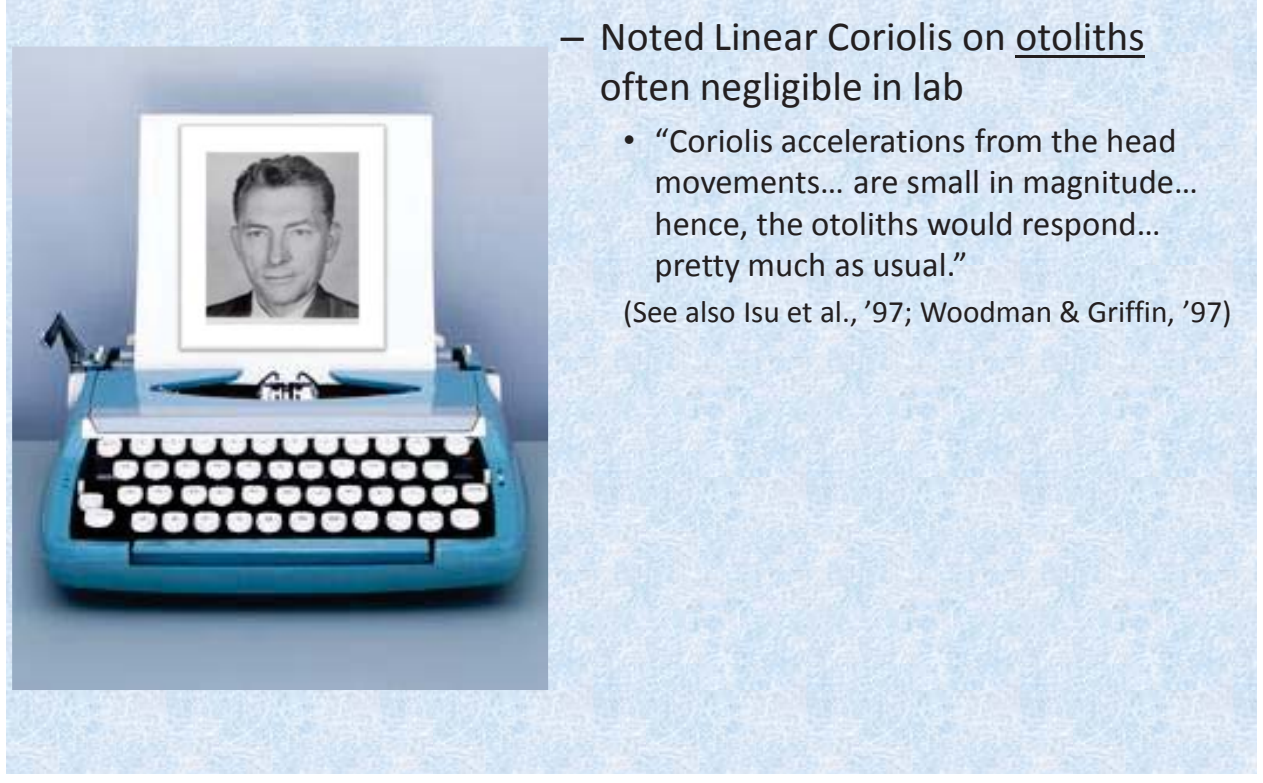

Slide 13

\section{Guedry: Role of Gravitational Linear Acceleration in Ccc}

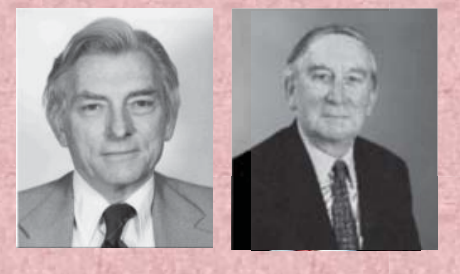

- Guedry \& Benson, '78

- Compared axis of cross-coupled effect (angular impluse vector) to linear gravity vector - significant effect there

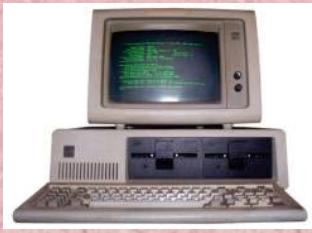

Slide 14 


\section{"Ccc: Disorientation \& Nauseogenic or Not?"}

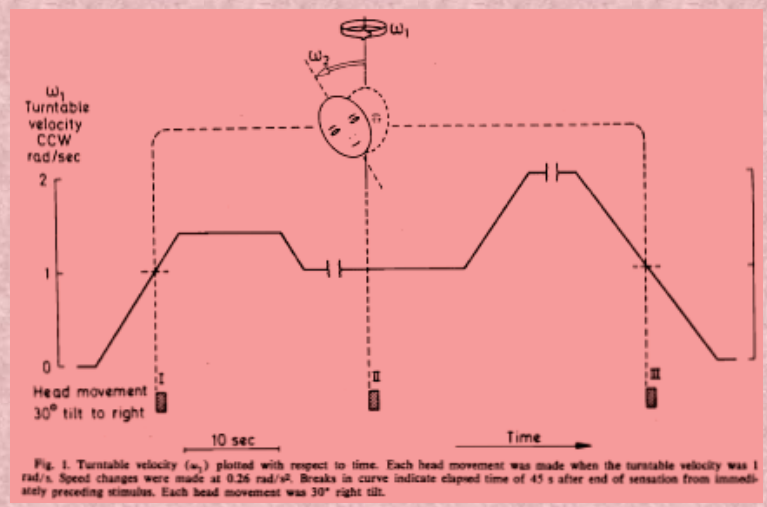

- Found head movement at same chair velocity leads to different effects...

Slide 15

\section{"Ccc: Disorientation \& Nauseogenic or Not?"}

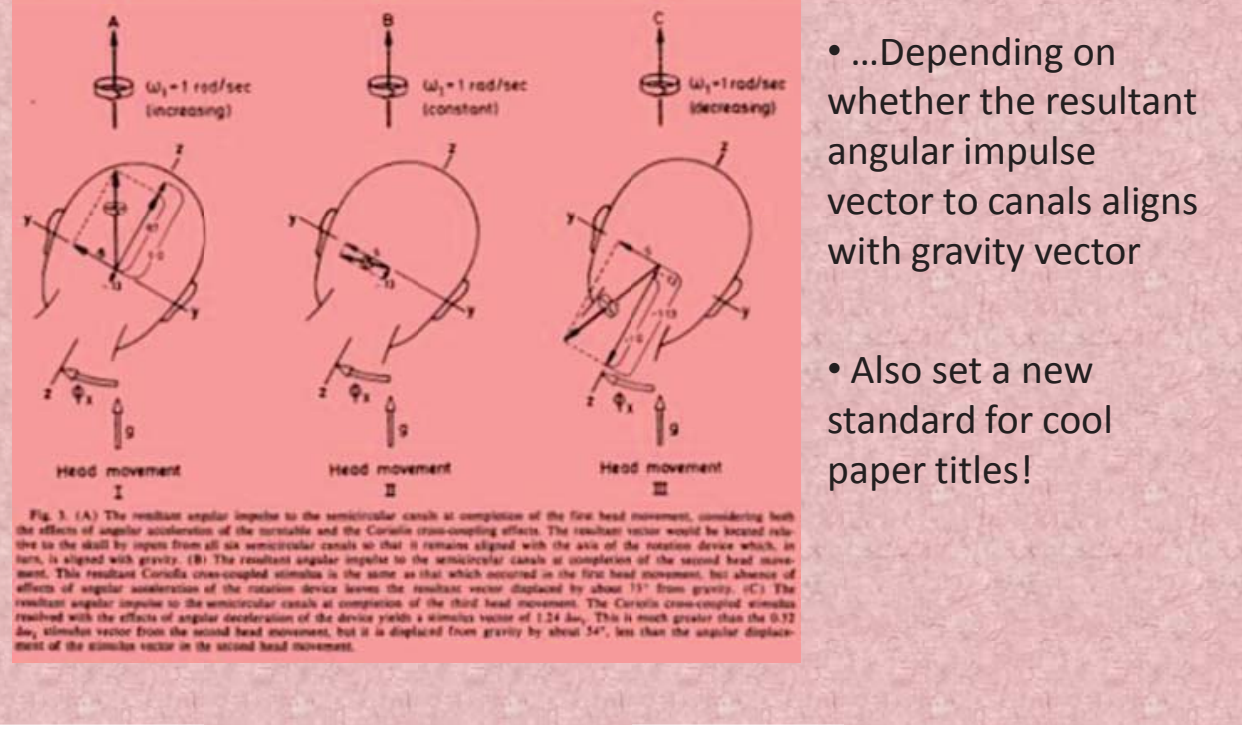

Slide 16 


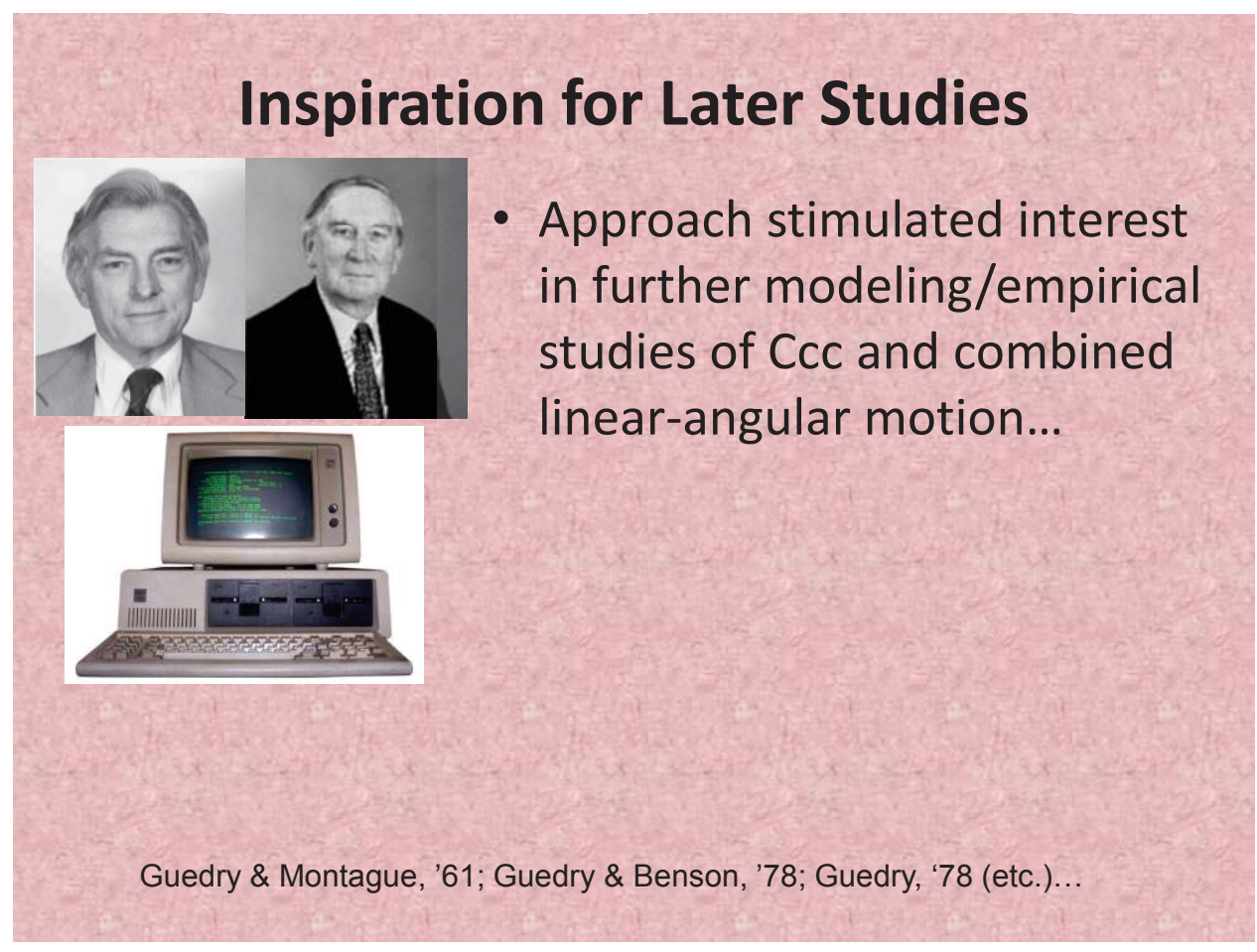

Slide 17

\section{Further Modeling/Empirical Studies}

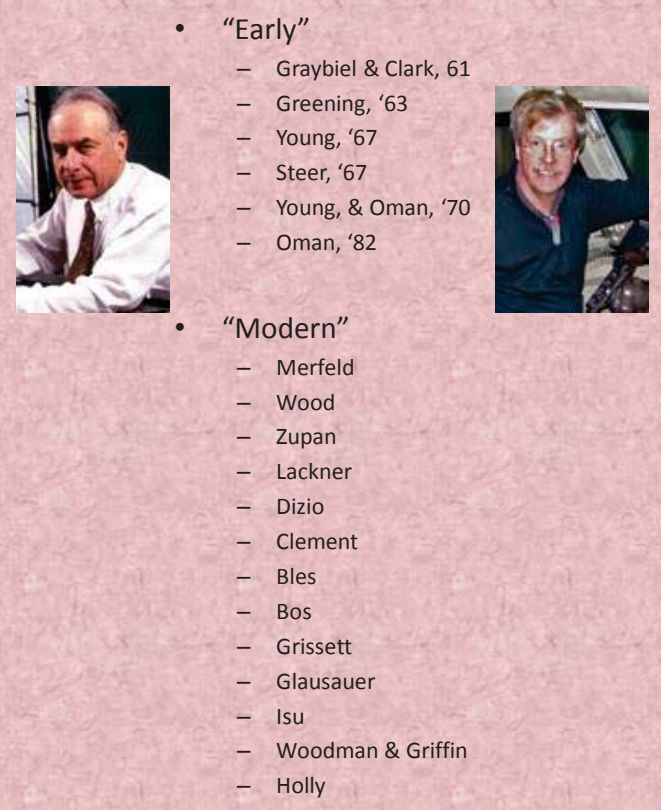

Slide 18 


\section{Guedry: Counteracting Unwanted Ccc Effects...}

Slide 19

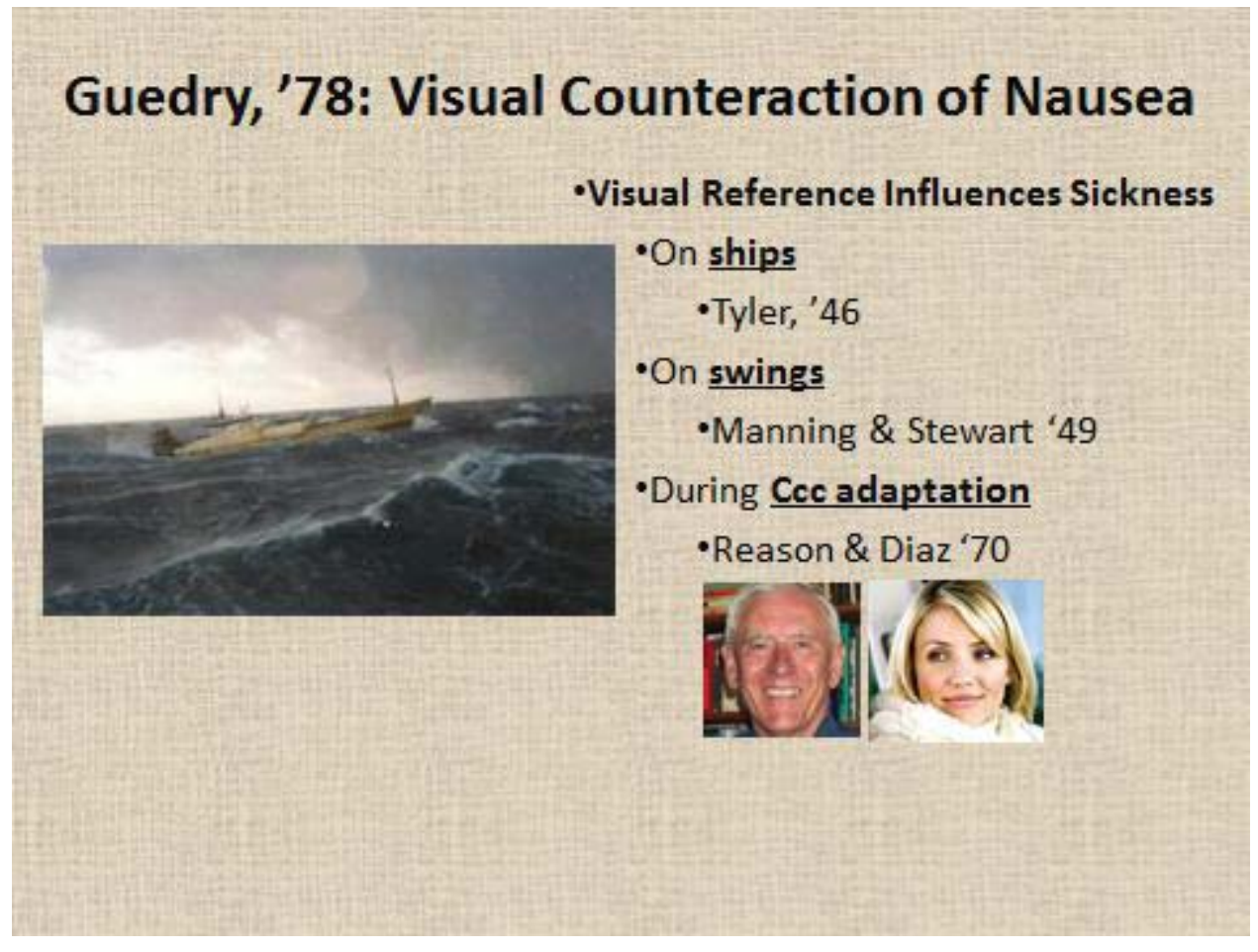

Slide 20 


\section{Guedry, '78: Visual Counteraction of Nausea}

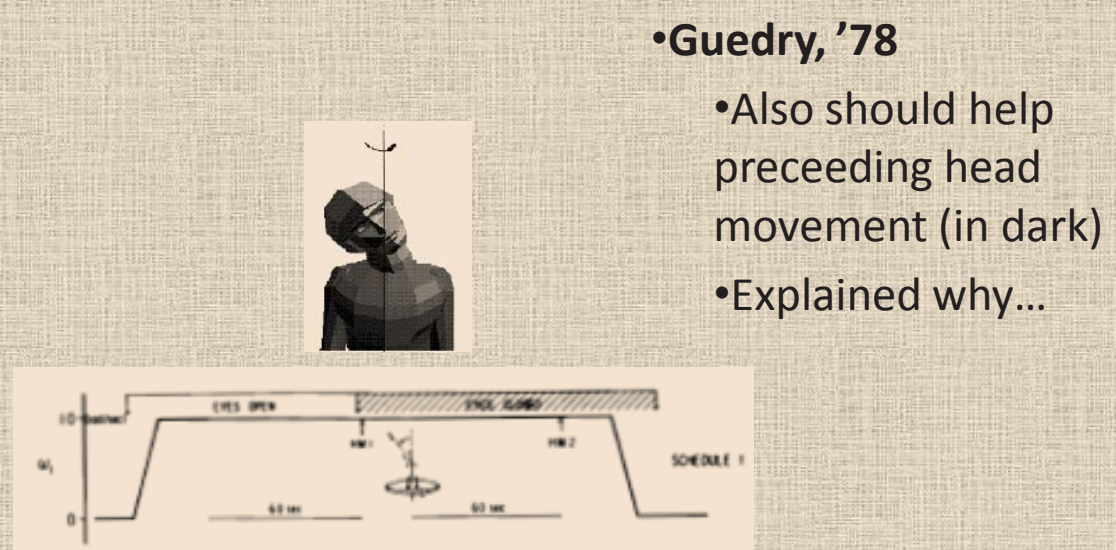

Slide 21

\section{Guedry, '78: Visual Counteraction of Nausea}

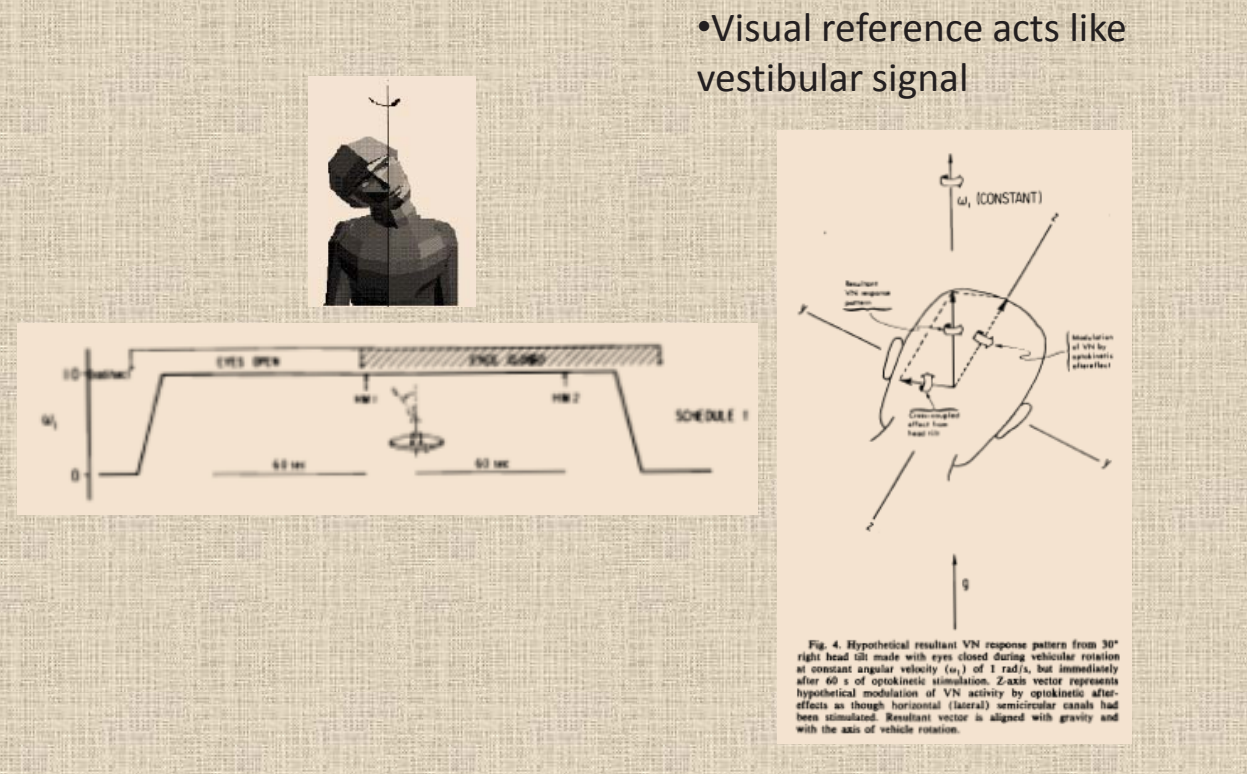

Slide 22 


\section{Extension by Guedry}

- Ccc effect can be quantified and visually counteracted in additional axes

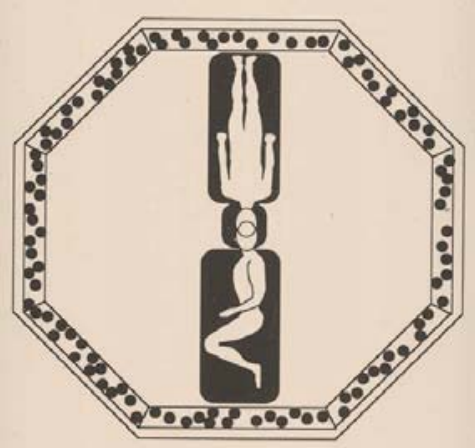

Lawson et al. '94

Slide 23

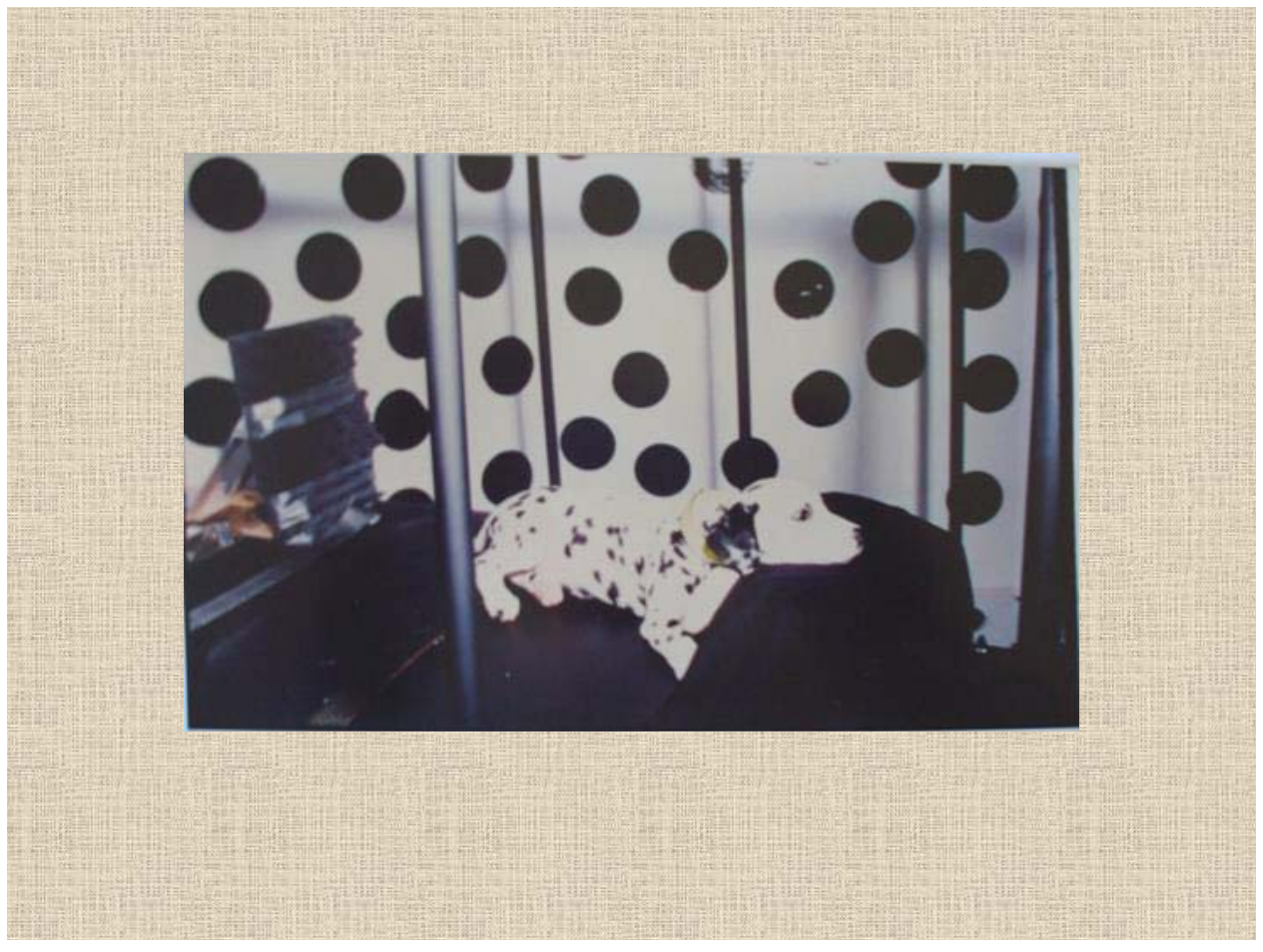

Slide 24 

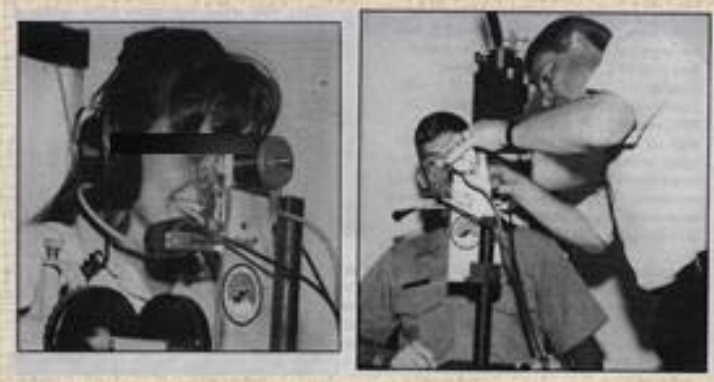

- Inspired other, more preliminary studies...

- Counteraction works with different:

- Gaze strategies and fields of view

- Modalities -somatosensory feedback...

(Summarized in Lawsonet al., '97)

Slide 25

\section{Somatosensory Counteraction of Ccc}

- Disorientation and symptoms:
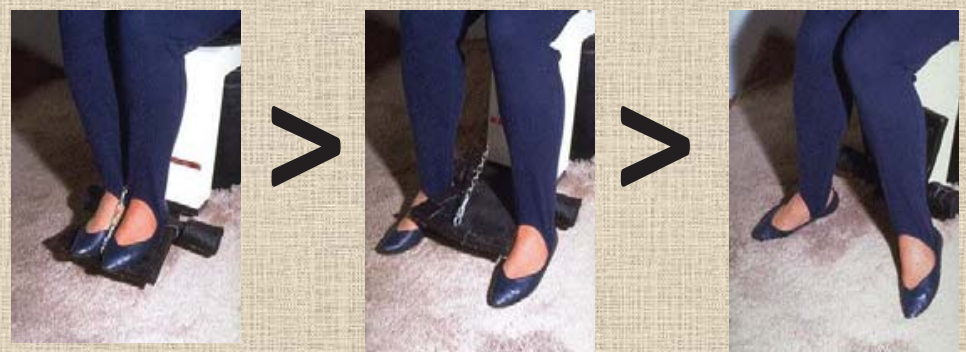

- Guedry \& Benson, '83,found Purkinje effect less disturbing following active turning/stopping

Slide 26 


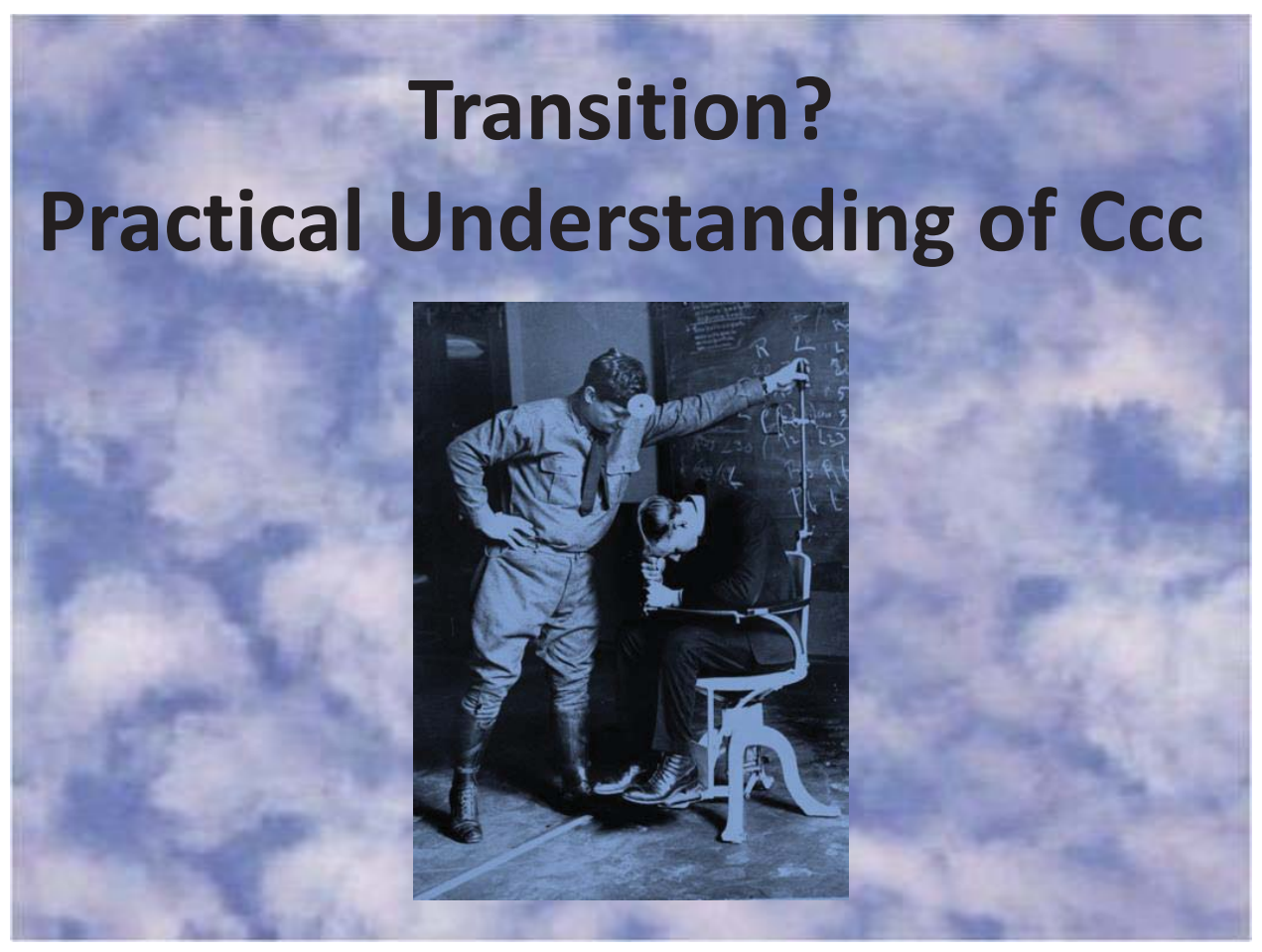

Slide 27

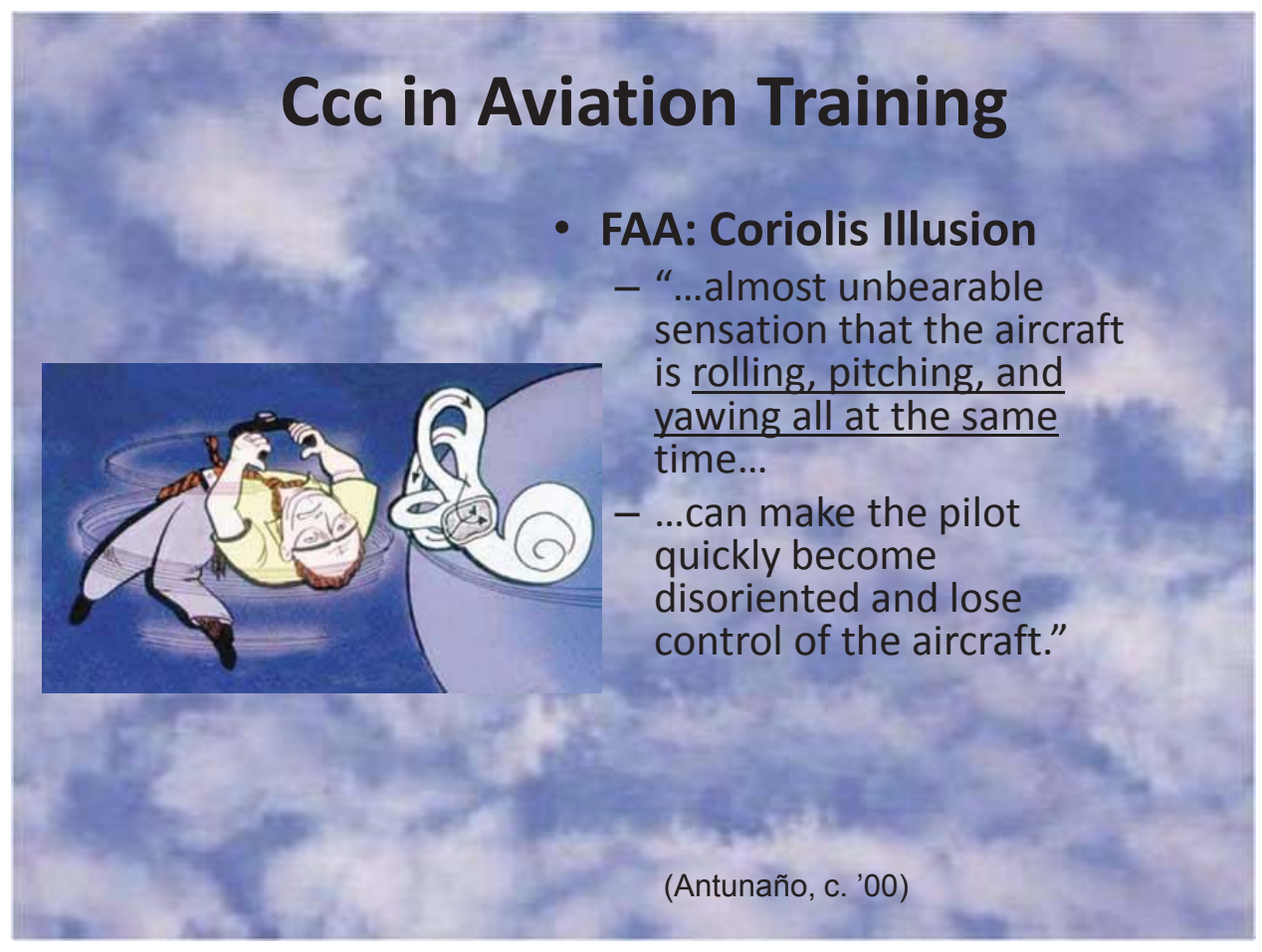

Slide 28 


\section{Ccc in Aviation Training Literature}

- "9-42. Regardless of aircraft type, Coriolis illusions are the most dangerous of all vestibular illusions and cause overwhelming disorientation"

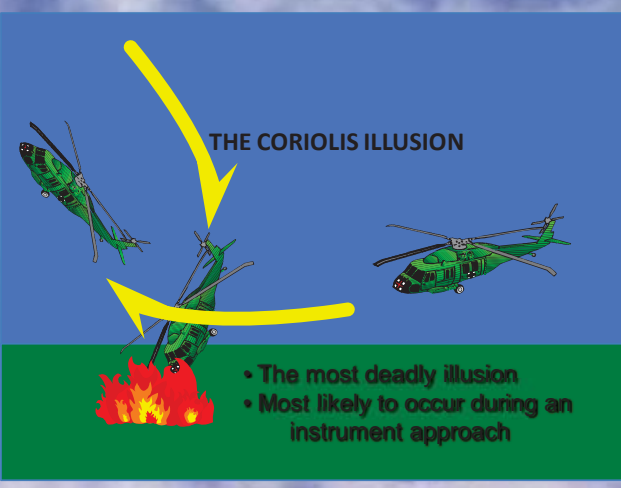

(FM 3-04.301 Aeromedical Training For Flight Personnel, '09)

Slide 29

\section{Ccc in Aviation Training Literature}

- Naval Flight Surgeon Manual, $3^{\text {rd }}$ edition, '91 is informative and accurate re. role of Coriolis cross -coupling and G-excess in flight

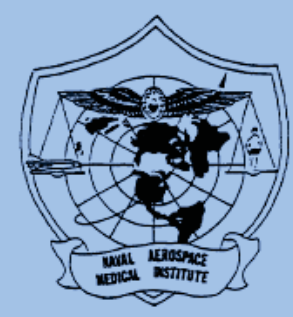

Slide 30 


\section{Guedry on Ccc vs. G-excess...}

Slide 31

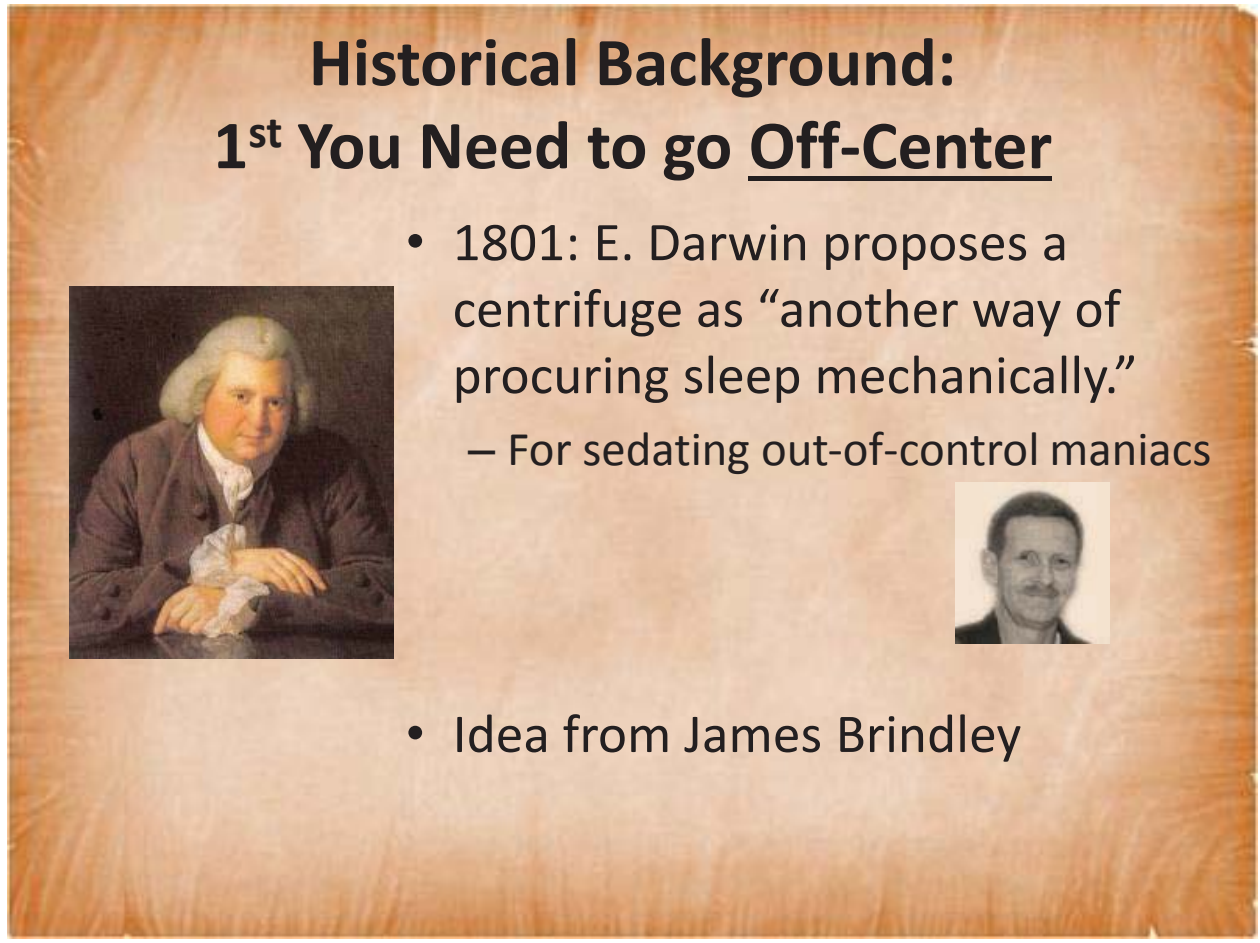

Slide 32 


\section{E. Darwin's 1801 Inspiration}

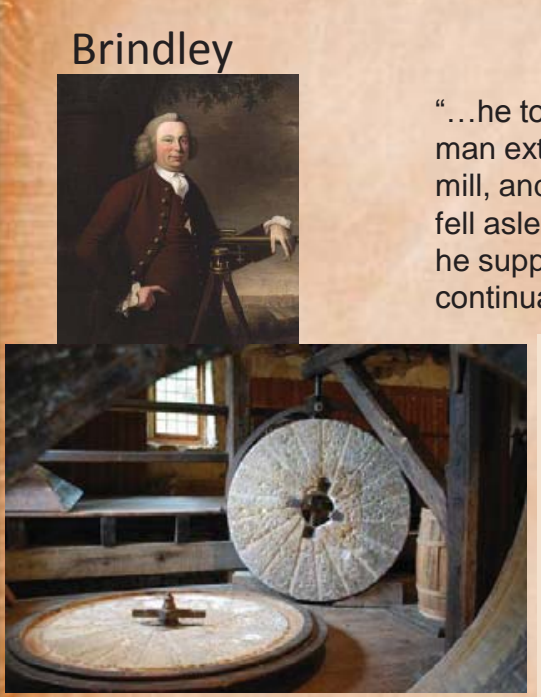

Darwin

“...he told me that he had... seen the experiment of a man extending himself across the large stone of a cornmill, and that by gradually letting the stone whirl, the man fell asleep, before the stone gained its full velocity, and he supposed would have died without pain by the continuance of the motion."

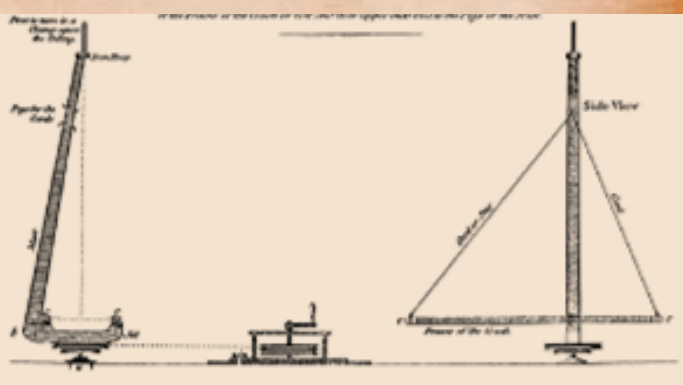

Slide 33

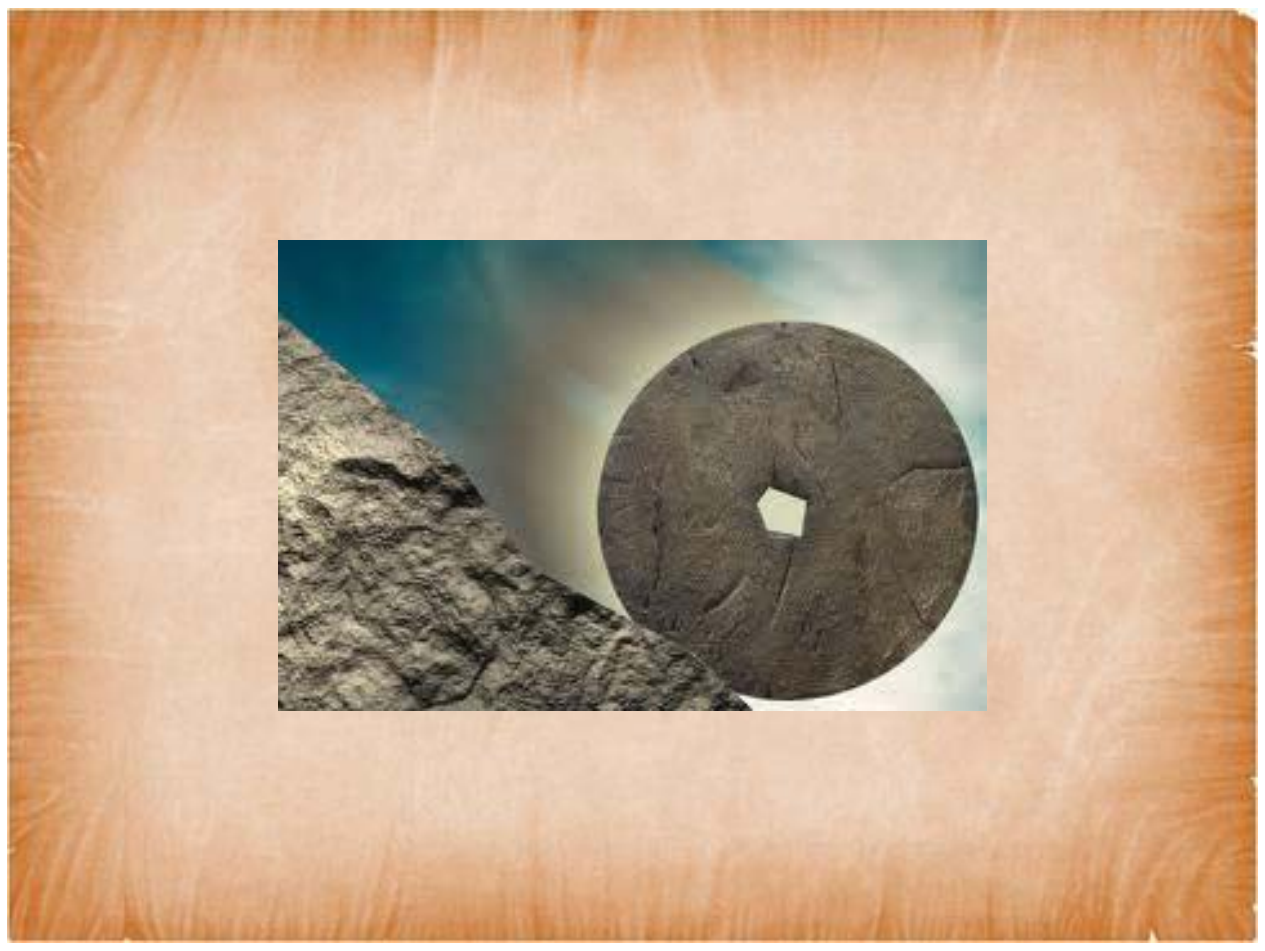

Slide 34 


\section{Initially Cautious Therapy with On-Center Devices}

- "The idiots belonging to the establishment have used it sometime when permitted, as a mode of amusement..."

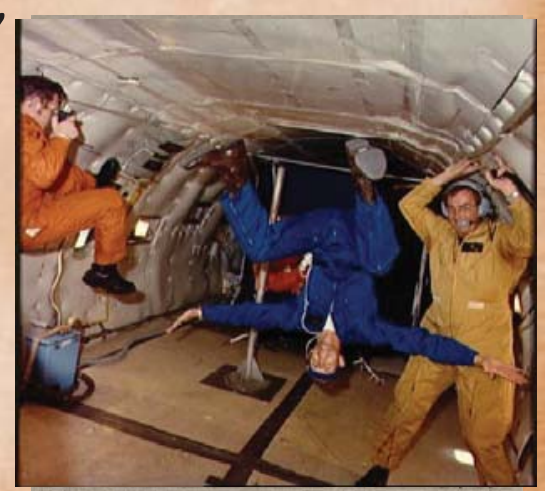

(Hallaran, 1810)

Slide 35

\section{Off-Center: Things Get "Harsch" (2006)}

- 1810/18: centrifuge built by Horn, Berlin "Charity" Hosp.

- 13 foot diameter, $4.5-\mathrm{Gz}$ to head

- "...the more uncomfortable and onerous the application, the more charitable the effects..."

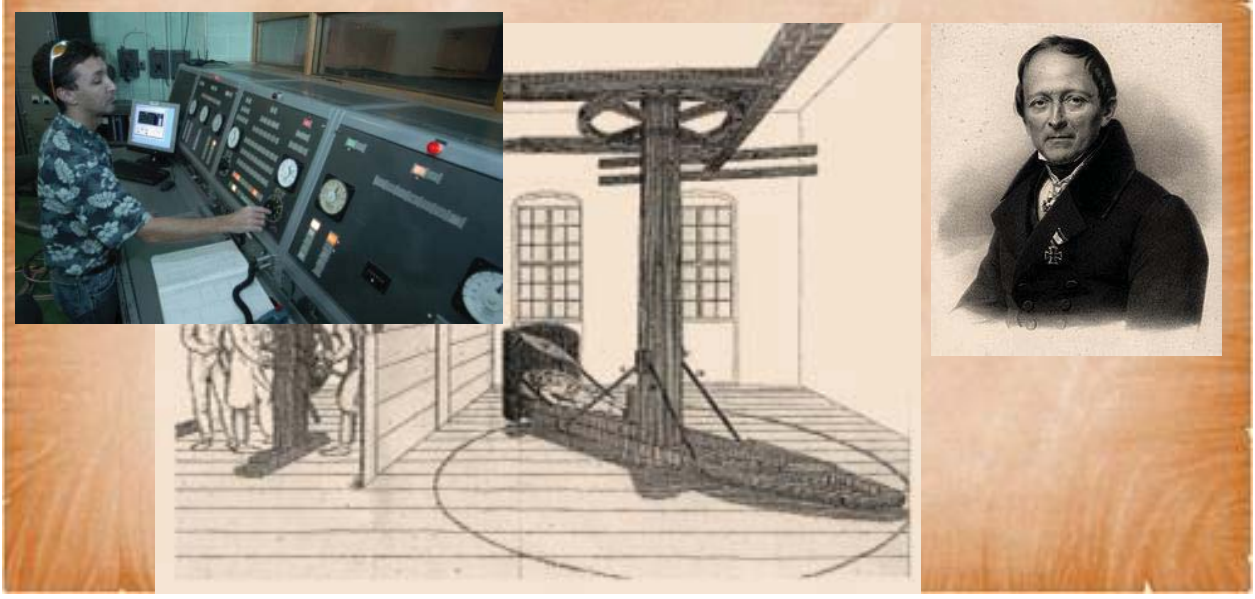

Slide 36 


\section{Perceptual Effect of Centrifugation}

- 1820: Purkinje felt tilted on a merry-go-round, attributed to centrifugal force

Slide 37

\section{Vestibular Effect of Centrifugation}

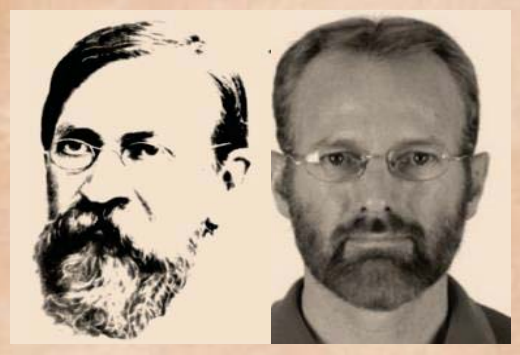

1873: Mach felt tilted

- On a turning railway car

- In a small centrifuge

- Related it to vestibular sensation

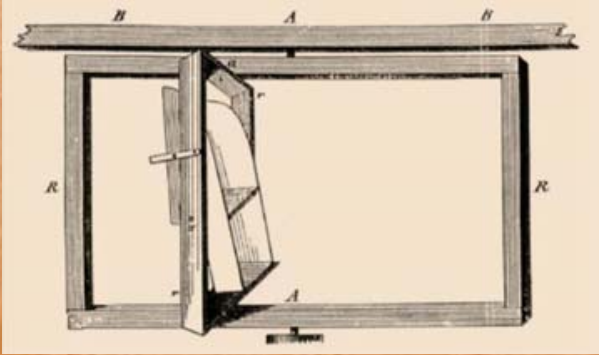

(From Gibson, 1938; Figs from Wade)

Slide 38 


\section{Vestibular Effect of Centrifugation}

- With Mach, began the psychophysics of off-center vestibular sensation!

- With Fred Guedry leading the charge in the $20^{\text {th }}$ century

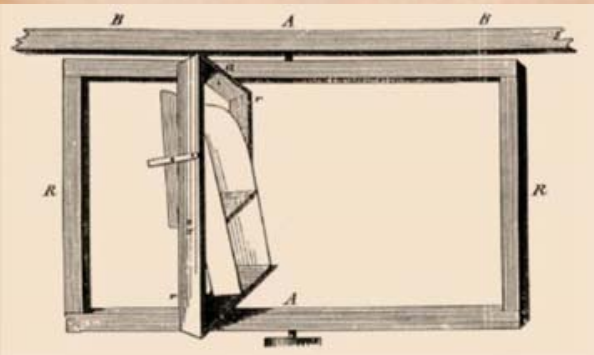

Slide 39

\section{Imagine a Parallel Universe...}

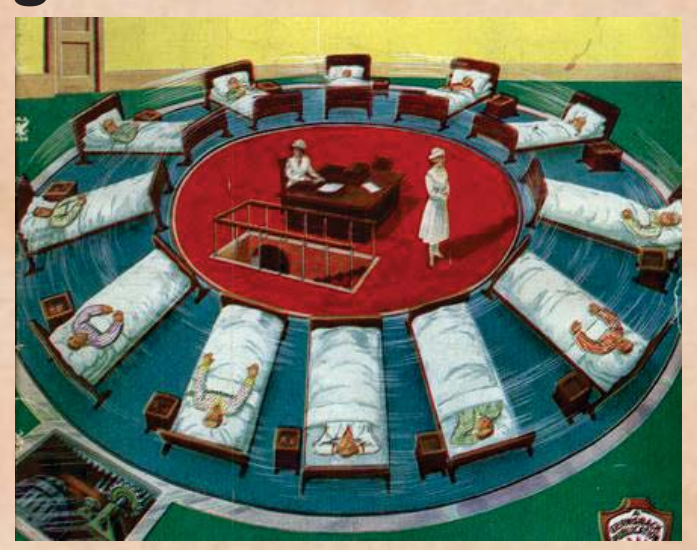

Had There Been No Mach or Guedry (The main use of the centrifuge today) 


\section{Guedry \& the "Fall" of Ccc in Fixed-Wing Flight}

\section{Modern (non-space) $R$ Research Leading}

to G-excess...

Slide 41

\section{G-excess Precursors (Somatogravic)}

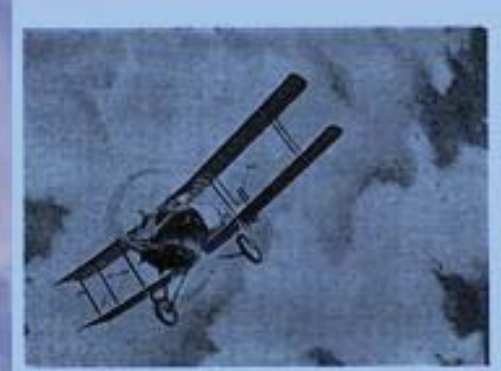

n.t. num

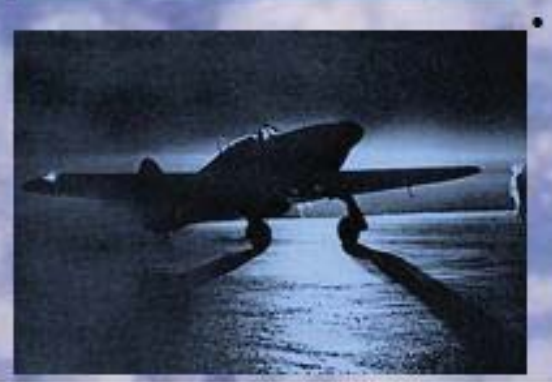

- Palthe, '22: banked flight

- "Not a single correct perception"

- Jones, et al. ('47); Vinacke ('47), MacCorquodale ('48)

- Collar, '46 (From Benson, ‘03)

- Take-off acceleration leads to illusion of backward tilt

Clarke \& Graybiel, ' 49

- Tilt sensation during nearly pure linear accel/decel in flight

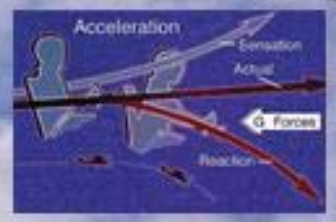

Slide 42 


\section{Guedry \& "Demise" of Ccc: G-excess}

- Gilson, Guedry, Hixson, Niven, '73

- Disorienting head movement effects during $2 \mathrm{G}$ banked turn

- Disparate findings, but realized what it must NOT be - Ccc!

- Guedy \& Rupert, '91

- Clarified steady state and transient effects vs. Gillingham's findings

- Distinguished magnitude versus rate of otolith sensation of tilt

- Role of Ccc in centrifuge

Slide 43

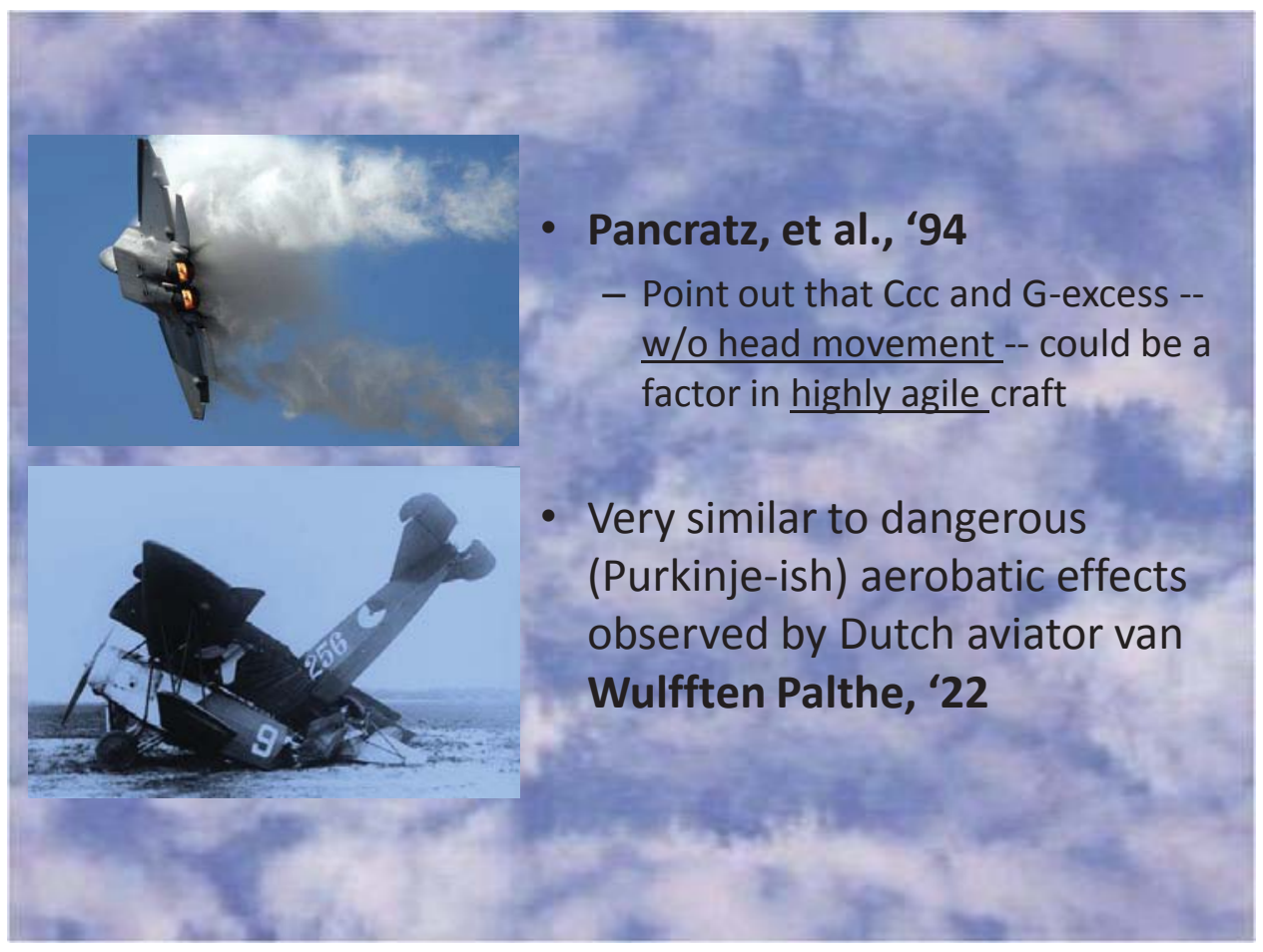

Slide 44 


\section{In CCCONCLUSION}

- B/C of Guedry et al., we know that:

- Complex stimuli like Ccc are quantifiable, predictable, sometimes even controllable

- Important applications of this include centrifuge-based training/simulators (and space)

- Ccc not usually the key problem in much "normal" fixed-wing flight

- Important applications include mishap modeling and flight training

Slide 45

\section{The Road Ahead...}

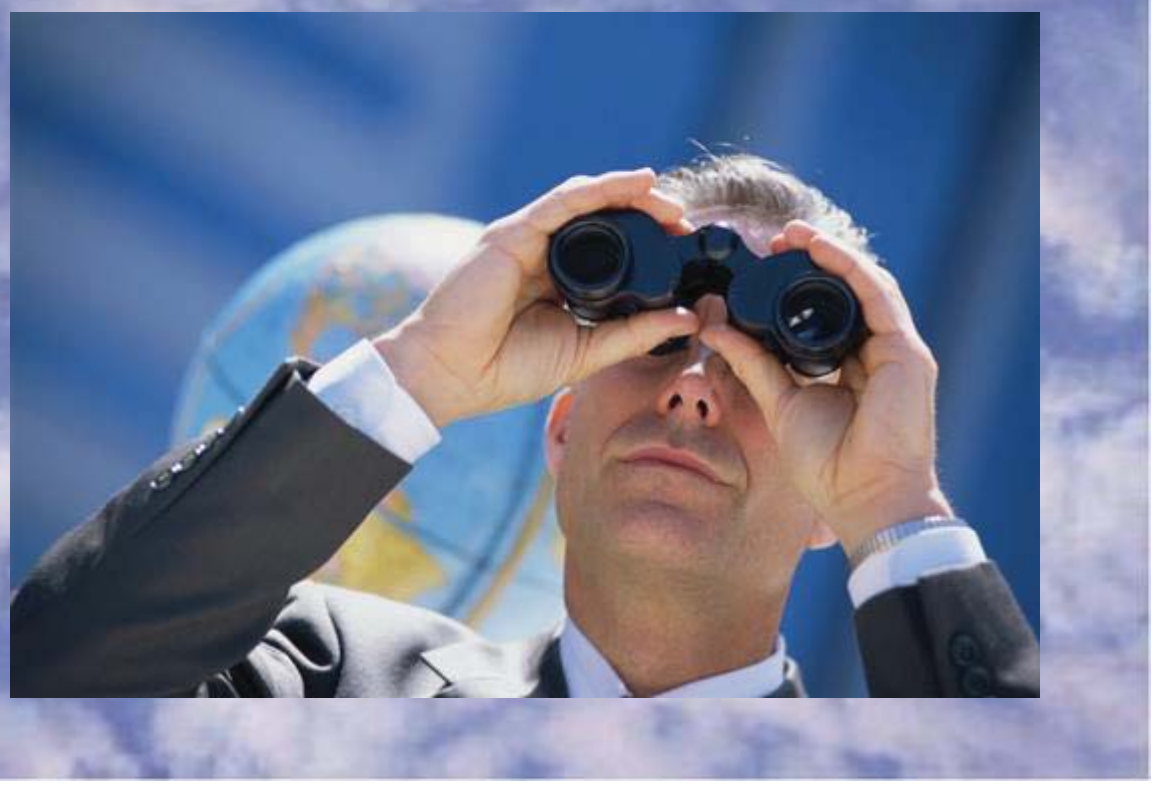

Slide 46 


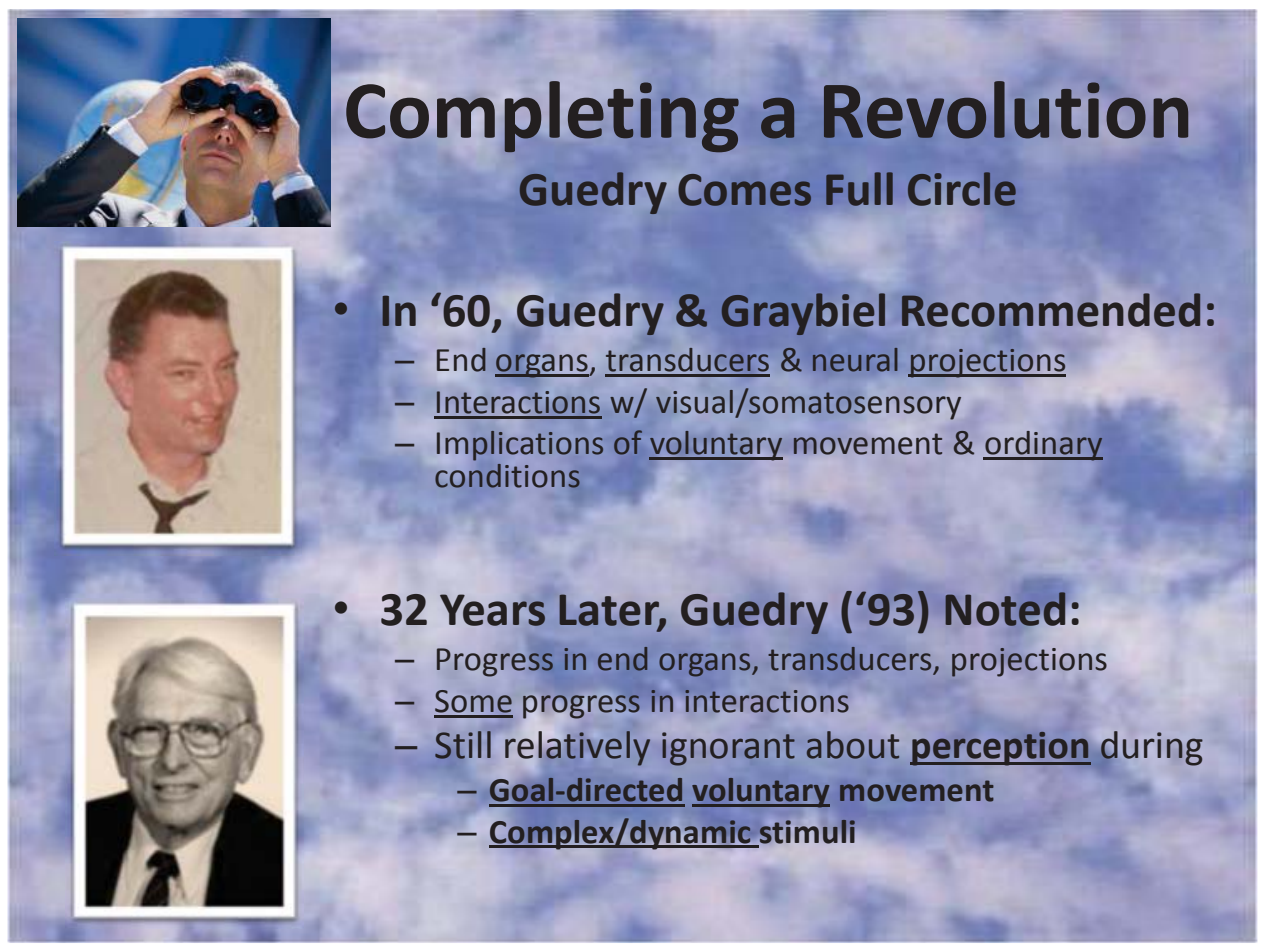

Slide 47

\section{Q: Where should we be in $\mathbf{3 0}$ years?}

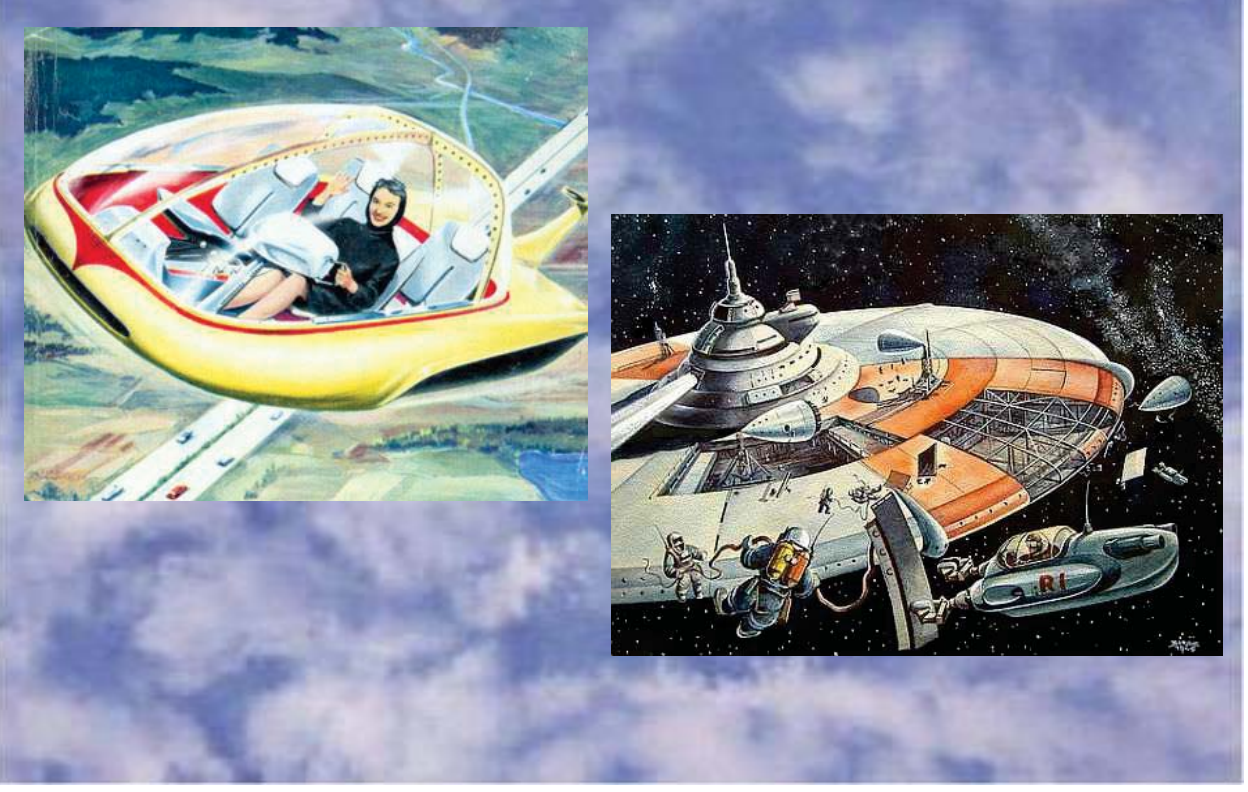

Slide 48 


\title{
Thanks to my Main Resources!
}

\author{
- Guedry
}

- Benson

- Wade

Slide 49 
Motion sickness aetiology: Alternative to Treisman's evolutionary theory - Angus Rupert

I will start by reading some messages for Fred Guedry that were sent by people who could not be here today [slides 1-2, page 73]. [Angus reads a letter from Alain Berthoz]: "When I was a young researcher, I visited [Fred] Guedry in Pensacola, [John] Brookhart in Portland, [Carlo] Terzuolo in Minneapolis, [Wolfgang] Precht who was with [Rodolfo] Llinás in Chicago, and Larry Young in MIT. I visited all of them. I was wonderfully received by all. In Pensacola, [Ashton] Graybiel invited me [to his] home, although I was just a young, completely ignorant researcher. This instilled in me a marvelous [appreciation] of how we should treat young people searching for their way. I visited the Pensacola facilities and saw the experiments of Fred Guedry and his colleagues. I still remember that they all showed me their large facilities, but they also took me to the small setups, built often in corners and beautifully imaginative. I learned there from Fred that what was important was to have a clear question and [to] build a small, even homemade setup rather than have a huge simulator. Over the years, I have followed the publications of Fred Guedry, and always, he was at the frontier of new questions and pioneering research on multisensory perception. A recent example that we have not yet fully exploited was his observations on the 3D percepts induced on the centrifuge during acceleration and deceleration. Most inspiring. I would also like to emphasize at a time when aggression, competitiveness, and ego are leading forces in science, that Fred has always been a model of modesty, generosity, and readiness to help, which are the qualities of all the best scientists. I would love to be with you for this event. But, also, because many of those who have been my companions in science are celebrating Fred. But even if my body and brain are not physically with you, I send you, Fred, my warmest feelings of admiration." So that was from Alain.

We also have a note from Geoffrey [Melvill Jones], for whom we had already bought the tickets, had everything lined up for him to come, and then he had a minor cardiovascular event. He had some atrial fib. This [slide 3] is him just a couple of weeks ago, sitting up on top of Kicking Horse Pass [Canadian Rockies]. That is at 8,000 feet. So we have to wonder whether or not the altitude may have helped contribute to that little bout of atrial fib, which is taking away from his other activities, which also include gliding. He's gotten back into gliding. So now he has to give up gliding for a period of time until things get back on track. But he did send me a couple of other pictures, one of which I thought was perfect for what Ian [Curthoys] was showing, namely how Hamish [MacDougall] has really come up with that lovely little system that you [Curthoys] have demonstrated. We can call it the $20^{\text {th }}$ generation after this one [slide 4] of Melvill Jones in 1959, before he went and got on a Meteor [Gloster Meteor aircraft] doing some spin work. But this [slide 5] is the picture I will leave up because this is the picture in the lab where Fred [Guedry] and Alan [Benson] had spent a bit of time within about this time frame doing some central nervous system work. This [letter] is from Melvill Jones: "I think our first encounter, Fred, must have been in January 1965 at the time of that very original symposium on the Role of the Vestibular Organs in Space [Exploration], conceived and implemented by the master mind of one astounding individual, Ashton Graybiel. It was an eye opener. A full slate of the world's vestibularly-oriented scientists collected together in one place at one time, Pensacola, Florida. At that time, my own work was focused on but one or two selected aspects of vestibular function. But here was the whole spectrum spread before us, ranging from microscopic ultrastructure of the end organs, through neuronal transduction of mechanical response, to implications for human behavior here on Earth and in space. I remember, particularly, a young 
man [Fred Guedry] who was actively exploring consequences of introducing artificial gravity into the space environment through the implementation of the (then exciting new) Slow Rotation Room. The whole concept seemed so imaginative, offering unending scope in exploratory fields such as the behavioral control of adaptive plasticity in sensory motor systems, functional interactions between the effects of linear and angular accelerations, and the mysterious implications of all this for the onset of motion sickness. This highly personable young man proved to be one of Ashton's greatest discoveries. And, for myself, he became and remains a cherished lifelong personal friend, and a hero in the challenging world of human spatial orientation."

"Perhaps the closest we came together was in the late 60s when Fred, Alan Benson, and I collaborated in my McGill labs during a series of animal studies on the interaction between linear and angular accelerative stimuli at the unit level in cat vestibular nuclei. For several weeks, we spent a wonderfully happy time eating, planning, and experimenting together day and night. Sometimes, we might find ourselves in need of some trivial item such as a teeny weenie little safety pin. What an excuse to emerge from the lab after a hard day's night, all three of us on this vital mission to prowl through the lively streets of Montreal, drop into a favorite coffee shop, settle the problems of our next experiment and, naturally, solve all of the teeming problems of the world at large, to boot. At last we would return to the lab, refreshed and ready to start again. But what the heck was it we set out to do in the first place? Ah yes, those darn safety pins wasn't it? Surely they weren't really necessary after all, were they?"

"Since those halcyon days we have, of course, had numerous brief encounters at various scientific meetings around the world. More significant were two memorable occasions when I was invited back to Pensacola as a guest. First, in 1989 to receive the cherished Ashton Graybiel lectureship award, and second, as a participant in the Neurological Tests in Spatial Awareness meeting of 1962. But now, dear Fred, I had so hoped to be with you again on this very special occasion of your own personal Fred Fest. Alas, this was not to be this time around. Still, you must surely know that I will be with you in the spirit of the occasion, wishing you joy and long continued new delights and insights in the home laboratory. With fondest personal regards, Geoffrey."

This is Lady Cat [slide 5]. Lady Cat supposedly was in the lab for many months, never left the lab, and they suddenly found out the cat was pregnant. They couldn't quite figure out how that happened. So, they weren't quite sure Lady Cat was the right name for her. [Laughter.]

We have a note here from Mil Reschke [slide 6]: "Dear Fred, as you celebrate your many contributions to our science, it is a source of great happiness to me that you will be surrounded by friends and colleagues who had a special place in your life. It also saddens me that I cannot be there to help you celebrate on this special day. Thank you Fred for all that you have done for me. You've been that special mentor that has guided me when I was confused or lost. I cannot think of a time in my career when you were not there for me, even before I was fortunate enough to meet you. Your words and thoughts have provided endless inspiration and confidence. I know that when you look upon the individuals gathered in your honor, each face will represent special memories, memories that help to stitch the fabric of your life and career. I regret that my face will not be among those present. But my greatest regret is that I will not see the joy and 
happiness that this celebration brings to you and to the ones that love you. Your student, Mil Reschke."

Ok, well this brings us to-I need some help from Manning Correia-who is that guy on the left [slide 7] [asked rhetorically]? Can you tell me who that is?

[Correia] His name is Ilte Niven [Jorma I. Niven].

[Benson] No.

[Rupert] Yes it is. It absolutely is. This is Dr. Niven.

[Benson] That's not what he looked like when I went canoeing with him. [Laughter.]

Well Manning [Correia], probably the most quoted paper that ever came out of Pensacola was obviously the Hixson, Niven, and Correia [1966] paper. It is probably the paper that has been the most quoted that has not been read by most of the people. [Laughter.] But you can't read what this [slide 7] says, so I'm going to read it for you... a piece of it. It's talking about Niven and says: "Above he uses an ear model to show LT J.G. Robert Kennedy, who is working on similar tests in the Slow Rotation Room, just where the problem of space sickness lies in the inner ear ." [Laughter.]

So it turns out that we have known that all these years. But Bob Kennedy is the one who knew it [slide 8]. Bob was supposed to be here today to talk about maladaptation and he was going to tell us the cause of motion sickness. Many of you know that Bob does court cases and litigation; they dumped upon him some 500 pages he has to digest over the weekend and then, Monday, put together for a deposition. So he's not going to be here [slide 9]. So I thought I'd throw something out as a cause of motion sickness because he had suggested that we not neglect to invite Mike McCauley who has done so much work on motion sickness with him over the years. I'm very disappointed that Ken [Money] hasn't shown up yet because this is a quote from Ken at the very first meeting in Pensacola, or the fourth symposium [on the Role of the Vestibular Organs in Space Exploration], I should say. He said, "the basic philosophical notion of motion sickness is something I have given some thought to and have come up with nothing" [Money, 1968, page 65] [slide 10]. [Laughter.] Actually, Ben [Lawson] had given me this slide and said, 'since Ken can't figure it out, what should the rest of us do?' I think most of us know that Ken wrote perhaps one of the best reviews on motion sickness and has studied motion sickness with various types of stimuli over the years [Money, 1970]. I remember when I first arrived here [Pensacola], Fred said, 'don't study motion sickness. It is too complex.'

So having said that, I'll just spend a few minutes to throw out to this audience an alternative to a [current] theory [slide 11]. I certainly think most of us can't really figure out how sickness and poisons relate to something that crosses all of the species. Fred had done more than

*The authors conjecture that this information was taken from a clipping from the Mobile Press-Register. It was found by Ben Lawson in a collection of old NAMRL news clippings, but the citation information was incomplete. 
one version of this picture [slide 12]. The one I was looking for and couldn't find last night has a stomach in here somewhere, with a special type of pump that pumps the fluid out of the stomach. I'll look for that one for you, Anil [Raj], because I know you were looking for a good one.

James Reason is another person who had worked here, of course, in Pensacola over the years and had been in the same building as Fred [slide 13]. In his summing-up chapter, he mentions that Benson had talked about how the vertical up-down motion does not pose a sensory conflict, yet, is one of most potent stimuli to generate motion sickness [Reason \& Brand, 1975]. So that was one of the failures in the neural conflict side. Any theory that's going to explain motion sickness should explain, hopefully, all of these points [slide 14]:

- Why does it cross all of the species, even fish, for example? If you take fish on a trip in a car, and they bounce up and down a lot, you will find the food at the bottom of the fish tank.

- It should explain the stimulus response curve. The person who developed that stimulus response curve is Mike McCauley, back in the second row, sitting there beside Fred.

- Why the vestibular end organ is absolutely necessary. Why we don't get sick if we don't have it.

- It should resolve that Sensory Conflict Theory issue.

- Why our stomach activity slows down at the beginning.

- Why we vomit. Why some people totally recover after they vomit.

- Why some continue vomiting.

- Why the supine position is less provocative than upright.

- Adaptation and the value of what is called the sopite syndrome, another term that was created and developed here in Pensacola.

Well, what I'm going to propose is that it's simply related to the digestive mixing process that occurs in the small intestine [slide 15]. Without digestion, we are not going to survive. It's every bit as important as respiration, cardiovascular, reproduction [systems], etc. In order for digestion to occur, we have to move our food through the small intestine in a very orderly way. This is usually done through peristalsis and segmental contraction. It would be expected that if you have certain types of contraction in a free moving environment, that they will be disturbed by similar motions in the external environment: that's going to help explain the McCauley curve, as we will see in another minute.

This [slide 16] is the curve that has been developed from thousands of data points over the years. The sickness is on the vertical axis, and then we have the frequency and amplitude. The point here is that the central nauseogenic frequency is 0.167 , and that's the frequency range from one side to the other. But it's most sensitive at this one point, right there [points to area on slide 16], that's at about every 6 seconds or so [O’Hanlon \& McCauley, 1974; McCauley et al., 1976]. So here's [slide 17] the motion in the small intestine; segmental contraction. At the bottom is a little diagram animation showing how it mixes the food back and forth. So it actually goes in both directions and then it moves it back and forth, back and forth. Because the frequency is greater at the upper end than the lower end, it keeps the food moving along. The key point here is that in the upper small intestine, as food leaves the stomach, the frequency is 12 times per minute [slide 18]. That's the pacemaker at the upper end. It's sort of like our heart; we have different pace-making frequencies as we transition [across] the heart. We have the same thing in 
the GI [gastrointestinal] tract. As you get to the lower small intestine, it's down to 9 per minute. So the frequency is varying from 0.2 to 0.15 in the intestine, for mixing our food - that one thing we have to do in order to have digestion. It just happens to perfectly bracket McCauley's central nauseogenic frequency, there [O'Hanlon \& McCauley, 1974]. So this [slide 19] is the central point all the way along here [points to area on slide 19]. That central line is the average frequency, if you will, in our small intestine, [used] for mixing up our food. Now, because the small intestine is not attached to our abdominal wall, it constantly is changing in orientation, and it is randomly oriented. For those reasons, it is not really possible for the stretch receptors (and they are very sensitive stretch receptors that we have in our GI tract) to detect those external stimuli [slide 20]. So if this [slide 21] is a fish in the water, and the central circle represents our abdominal cavity, the GI tract can be put in absolutely any orientation and is constantly moving around for digestion. So it's not capable of detecting that, say, up/down motion or a horizontal back and forth motion; it's not possible for it to detect those stimuli that are disrupting its behavior. So it requires accelerometers [slide 22]. That's why the role has been relegated to the vestibular end organ, to decide when we are in an environment that is not conducive to the digestion of food, by [not] allowing that segmental contraction to occur [slide 23]. The detectors and accelerometers can detect these disruptive events. So it's their responsibility to then come up with a coordinated response, just as the vestibular system coordinates so many things in our cardiovascular and other visceral [systems].

It was really only starting in the 1960s that people realized the importance of the vestibular system for all of the vegetative or visceral events. Because those accelerometers are coordinated and integrate information from all of the other senses - namely vision, auditory, and especially our other skin, muscle, and joint sensors [slide 24] —it [the vestibular system] can take that information and it ties in well with the vestibular conflict theory, because any time it cannot make sense of the motion, it's going to then carry out this visceral response. As we've seen, it's not an accident that average response in our segmental contraction in the small intestines just happens to match the McCauley curve. I think that it is the inconsistencies between the individual accelerometers, meaning between the angular and the linear accelerometers, that are the most nauseogenic for all of those people that have spent any time looking at cross-couple Coriolis because that's [the inconsistencies] impossible to interpret, the brain cannot make sense of that [slide 24]. That's probably why it's maybe the most particularly nauseogenic stimulus. It cannot make sense of that.

So going over some of those other things that a theory should explain: if the stimulus is mild or it is of short duration, we really don't want to lose the food in our stomach [slide 25]. So our body simply says, 'I'll just slow down the gastric emptying until either the stimulus dissipates, or I can get into another environment where I won't have to worry about it.' Then, it can once again start digestion, without having lost that food. So that makes sense. If the stimulus continues or if the intensity is particularly strong, then it needs to empty the stomach, and that is why we have vomiting. It is all done to protect that segmented contraction from becoming discoordinated [slide 26].

This also helps explain why, when you are lying supine, it's less provocative than when you are upright [slide 27]. In vertical motion while you are upright, there is more capability of the small intestine to move around in the abdominal cavity than when you are horizontal. After 
vomiting, there are some people who just go back to work as if there is no problem whatsoever. Well, if the stomach contents have been removed then there is no reason to experience any further problem, because you are not going to have anything going into the small intestine for this mixing and segmental contraction [slide 28].

Why do some people continue vomiting [slide 29]? Well, perhaps they are not aware of the empty stomach situation, or the stimulus is so strong the response cannot be stopped. But certainly, it is not good from a Darwinian perspective, because people who have chronic motion sickness will die as has been seen in the people in boats or small life rafts.

Adaptation: this one is a bit more difficult [slide 30]. Most people seem to adapt when the stimulus is mild and sustained. Some people don't. But, if they do not adapt, then they will die. So from a Darwinian perspective, they certainly need to adapt.

In the progression of symptoms, the sopite response is what really starts [the sequence]. Then finally, the GI tract slows down the gastric emptying, and then we have vomiting. I should also point out that the value of the sopite syndrome really is that the tiredness and fatigue that people have will encourage a low level activity, and people often will simply go to sleep and then, hopefully, they will wake up and they will be in a different environment and then, they will be able to start the digestive process again [slide 31].

There are some people, of course, who are totally immune. This [slide 32] is a picture of a lady in our HDD [human disorientation device]. She would be what we would today not call "labyrinth defective," we would have a more politically correct name [laughter] [for] a person without any vestibular function: totally immune. So the red herring in this, [the reason] I think we have never focused on the GI segmental contractions being the cause of motion sickness, is because of the fact that the vestibular end organ [has always been viewed as] absolutely necessary [slide 33]. So we have always been looking for more central nervous system reasons for why we get motion sickness. That's why people may have focused on the poison theory.

So the interruption of the digestion process, the interruption of our segmental contraction, helps explain why it's across all of our species, because we all have to digest food [slide 34]. It explains the shape of McCauley's curve, why we have to have the vestibular end organ, because it is the only organ that is capable of detecting these external motions and then coordinating what needs to be done at the GI tract [slide 35]. It explains the problem that we have in the sensory conflict theory. Then it explains the rest of the activity that we see: the slowing down, the vomiting, the recovery, etc. So I am throwing that out. This is the wrong audience, obviously, to throw such a thing out, but we will throw this out; we will blame it on Bob Kennedy who can't be here today [slide 36]. I'll mention my son [Yuri] because he pointed out that if something was randomly oriented in motion, and unattached, then the detectors in the GI tract really couldn't detect what was going on [slide 37]. So I'll come back to Ken [Money] who I was hoping would be sitting right there to ask him what he thinks. Is this a possibility for motion sickness etiology [slides 38-40]? 


\section{References}

Hixson, W. C., Niven, F. I., and Correia, M. J. 1966. Kinematics nomenclature for physiological accelerations: With special reference to vestibular applications. NASA Order R93, NASA-CR-81715, Naval Aerospace Medical Institute, Pensacola, FL.

McCauley, M. E., Michael, E., Royal, J. W., Wylie, C. D., O’Hanlon, J. F., and Mackie, R. R. 1976. Motion sickness incidence: Exploratory studies of habituation, pitch and roll, and the refinement of a mathematical model. Goleta, California: Department of the Navy Office of Naval Research. Technical Report No. 1733-2.

Money, K. E. 1968. The role of the vestibular organs in space exploration. Fourth Symposium. Pensacola, FL. September 24-26.

Money, K. E. 1970. Motion sickness. Psychological review. 50: 1-39.

O’Hanlon, J. F., and McCauley, M. E. 1974. Motion sickness incidence as a function of frequency and acceleration of vertical sinusoidal motion. Aerospace Medicine. 45: 369.

Reason, J. T., and Brand, J. J. 1975. Motion sickness. Academic press. Oxford, England. 


\section{Alain Berthoz}

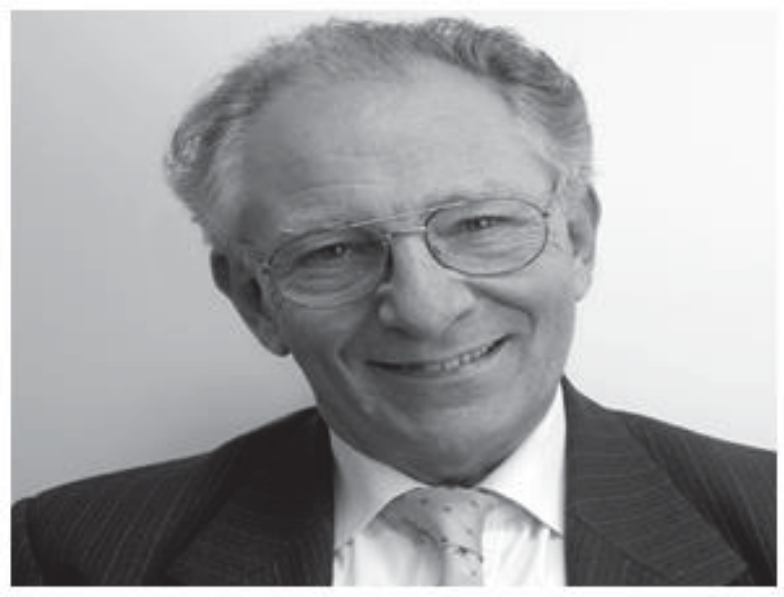

Slide 1

\section{Alain Berthoz}

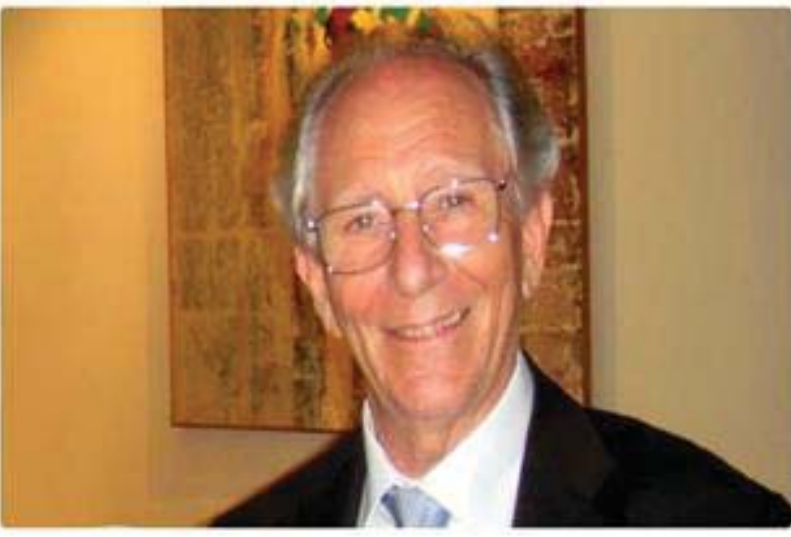

Slide 2 


\section{Geoffrey Melvill Jones}

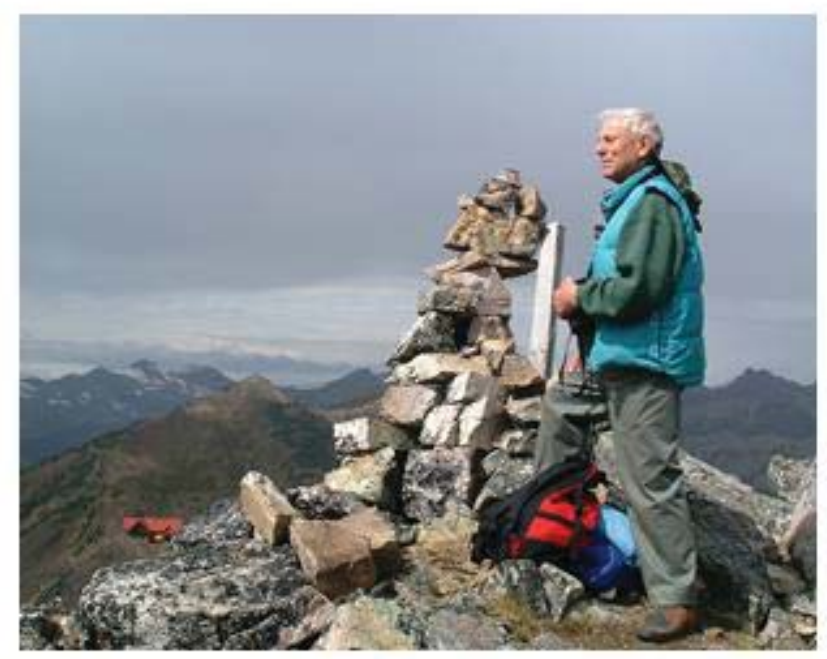

Slide 3

\section{Geoffrey Melvill Jones}

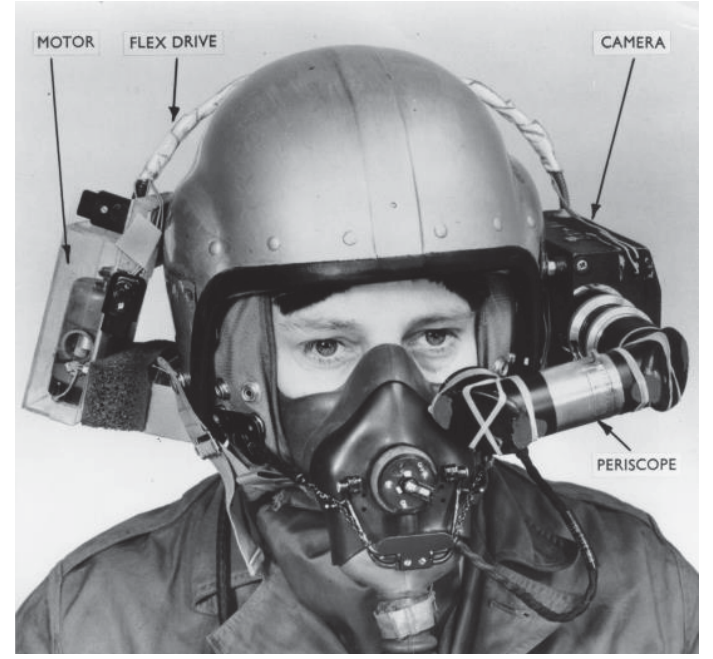

Slide 4 


\section{Geoffrey Melvill Jones}

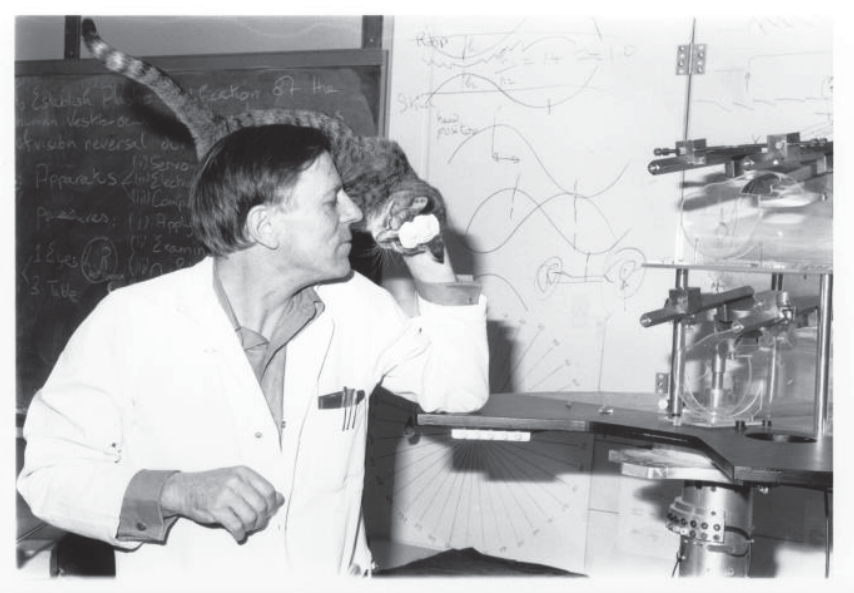

Slide 5

\section{Mil Reschke}

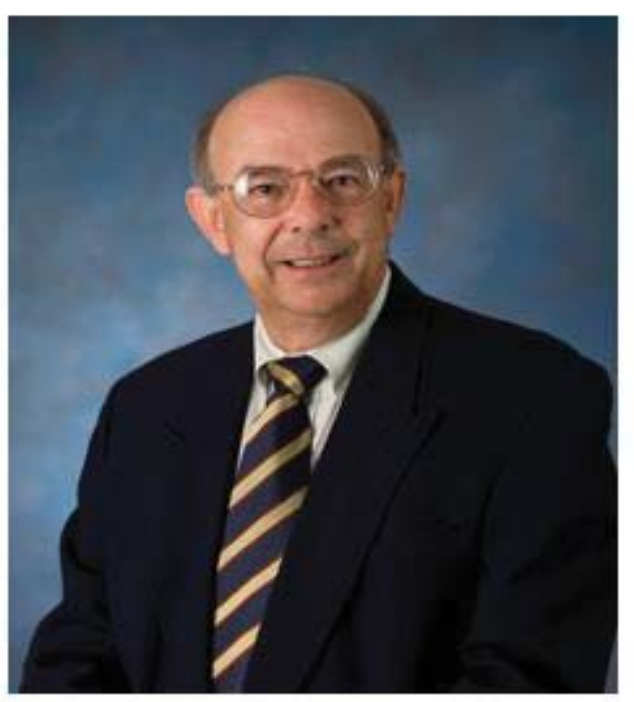

Slide 6 


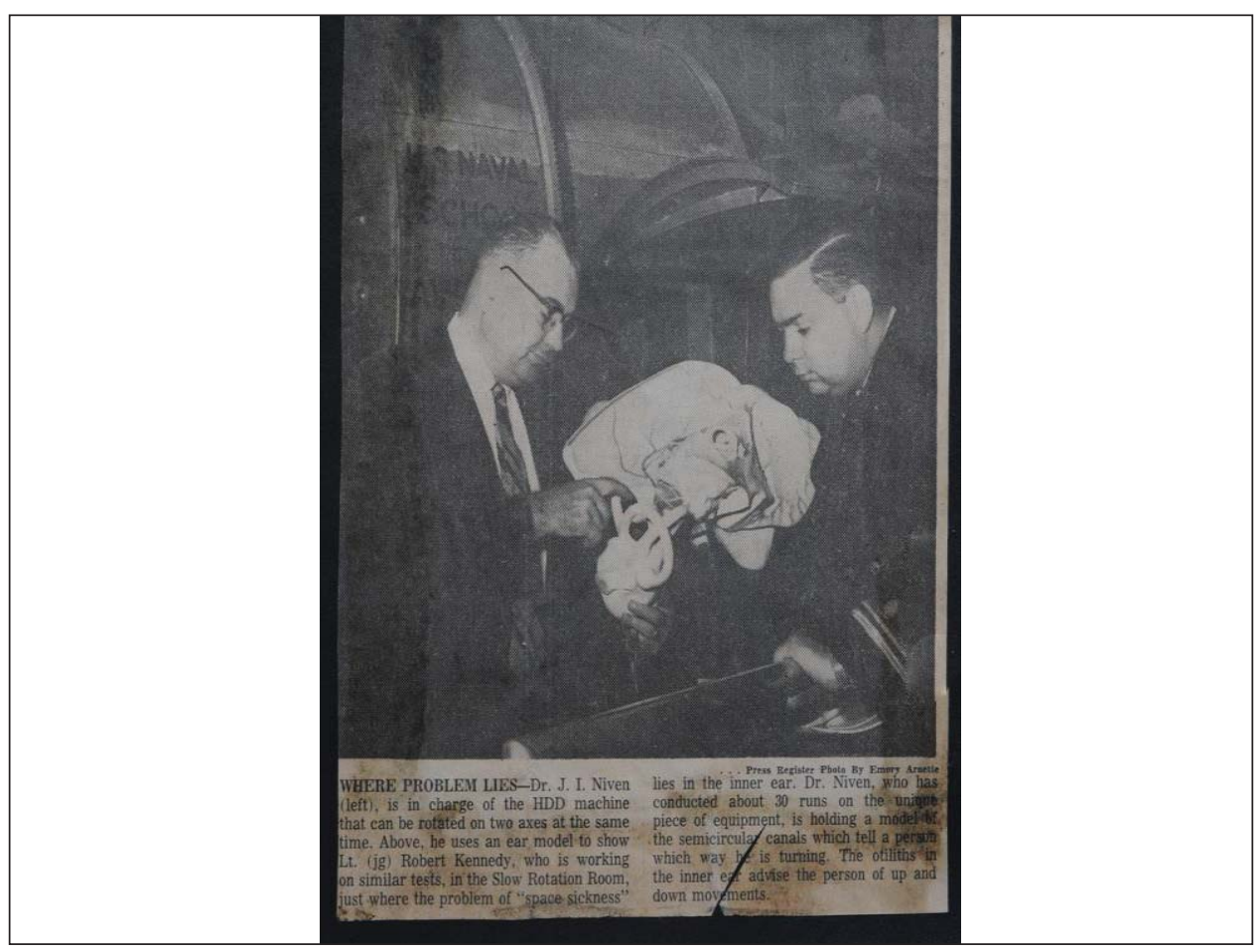

Slide 7

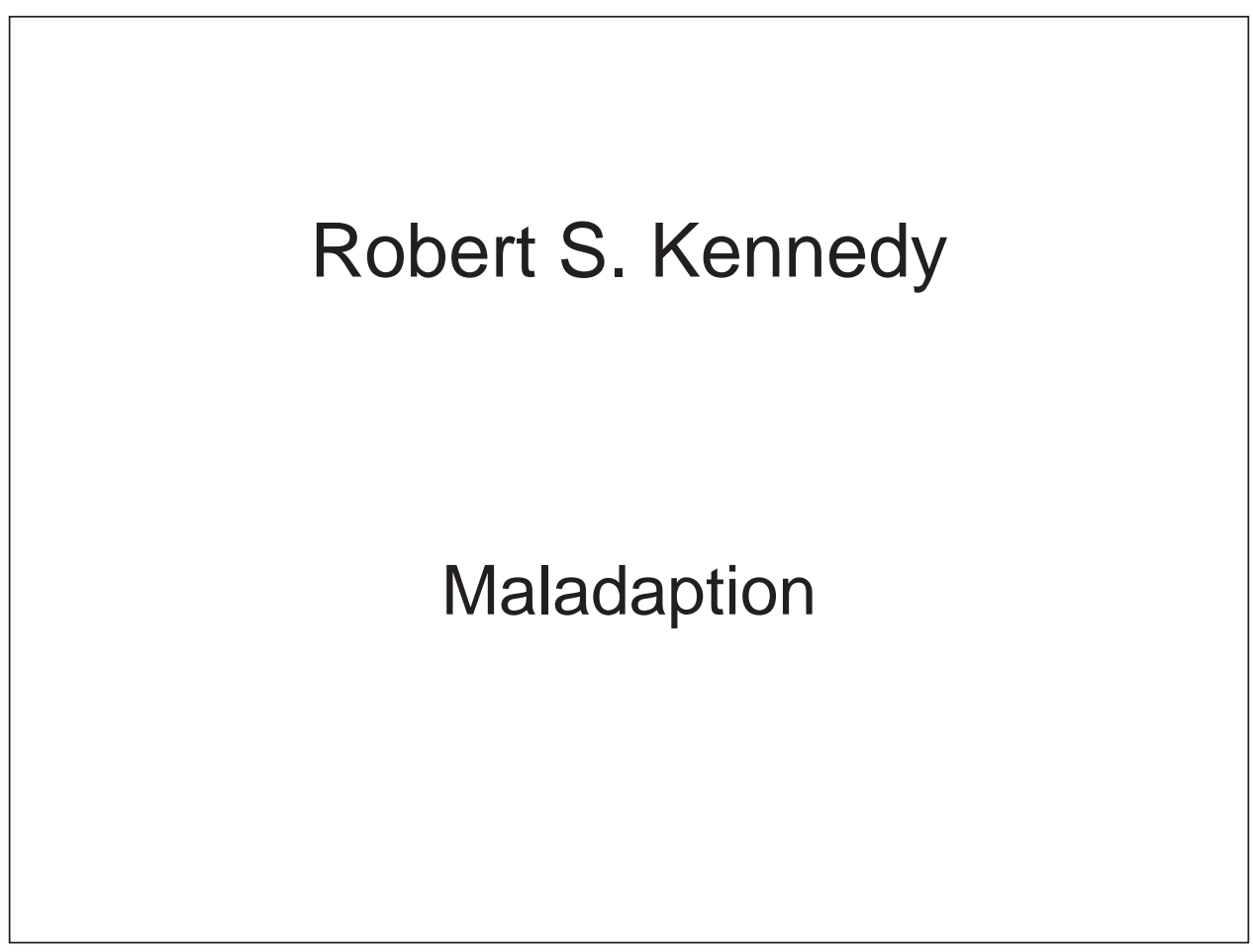

Slide 8 


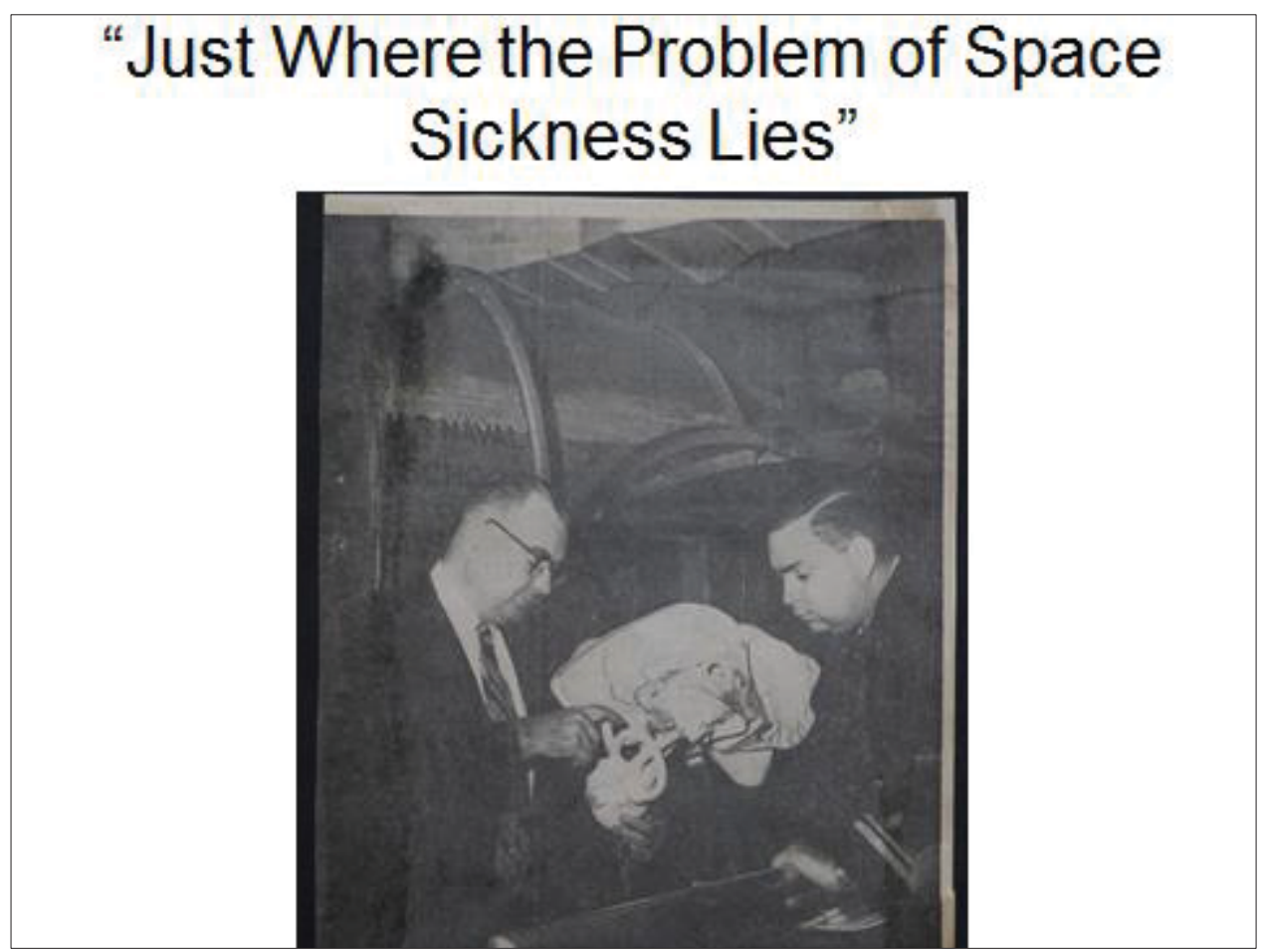

Slide 9

\section{Cause of Motion Sickness}

- MOTION SICKNESS

- "The basic philosophical notion of motion sickness is something I have given some thought to and have come up with nothing."

- Money, 1968, p65, $4^{\text {th }}$ Symposium, Role of Vestibular Organs in Space Exploration, Pensacola, being asked the purpose of motion sickness

- Since Ken can't figure it out, what should the rest of us do?

- Fred - "Don't study motion sickness. It is too complex" 


\title{
Motion Sickness Aetiology
}

\author{
An Alternative to Treisman's \\ Evolutionary Theory
}

Slide 11

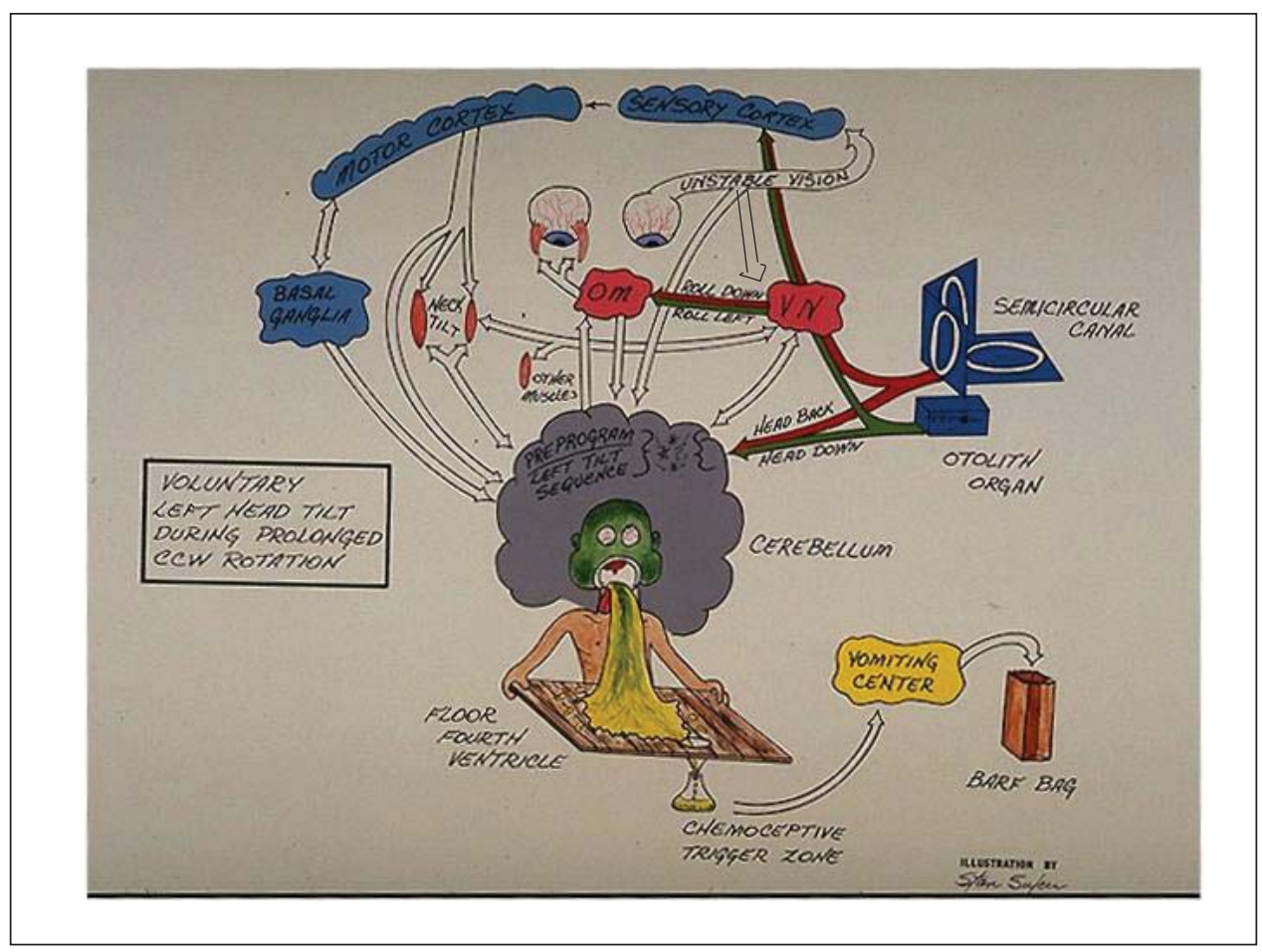

Slide 12 


\section{James Reason - Failure of Sensory Conflict}

- Vertical up-down motion does NOT pose a sensory conflict yet is one of most potent stimuli to generate MS

Slide 13

\section{Valid Theory should explain}

- "Universal" nature - should tie logically into basic need

- Shape of Stimulus Response Curve - freq amplitude

- Why Vestibular End Organ Necessary

- Resolve failure of Sensory Conflict Theory (e.g.vertical motion)

- Initial slowing down of Gastric activity

- Later frank vomiting

- Why some "recover" - symptoms dissipate after vomiting

- Why some continue vomiting

- Why supine less provocative than upright

- Why adaptation occurs to maintained stimulus

- Value of Sopite Syndrome

Slide 14 


\section{Digestive Process in Small Intestine}

- As critical for survival as Respiration, Circulation, Reproduction etc.

- Digestion is dependant upon orderly motion of food through alimentary canal or GI tract via the process of peristalsis \& segmental contraction.

- Expect the orderly movement disrupted by external acceleration and disruption greatest when at similar frequencies of normal GI peristalsis or segmental contraction frequencies.

- For a given frequency, expect the disruption to vary directly with amplitude above threshold. (these last two items explain shape of McCauley curve).

Slide 15

\section{HFR model (1974) McCauley}

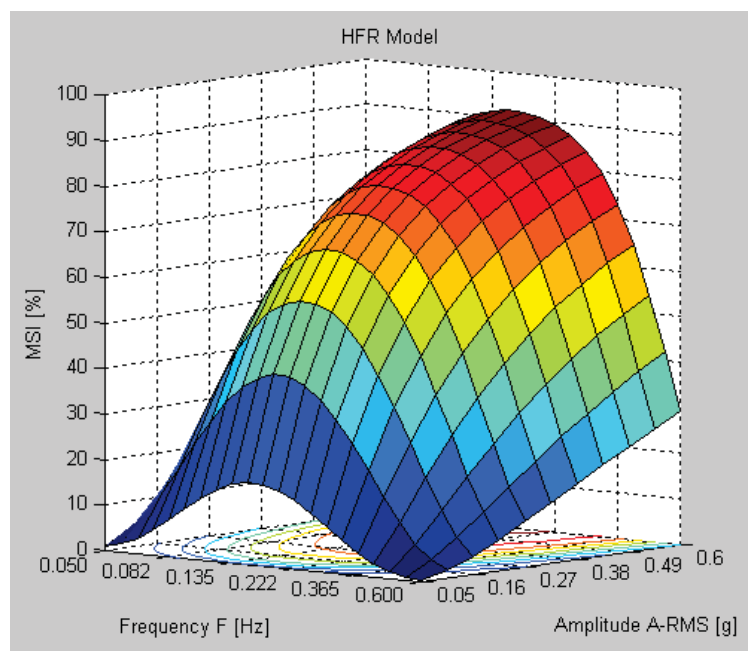

Model Characteristics

Vertical Acceleration

Only true motion

MSI: \% of people who vomit

Two-hour nauseogenic period

Nauseogenic frequency range

$0.05-0.6[\mathrm{~Hz}]$

Central nauseogenic frequency

$0.167[\mathrm{~Hz}]$

Slide 16 


\section{Motion in small intestine}

- Peristalsis and segmented contraction

- Very complex, primarily locally controlled, appearing random, with "overarching" hormonal and neural influences.

- Segmentation Contractions are the mixing motility actions seen in the small intestine - segmental rings of contraction chop and mix food.

Slide 17

\section{Segmental Contraction Frequencies along Small Intestine}

- Upper small intestine (duodenum) 12/min

- Lower small Intestine (term ileum) 9/min Fundamentals of Physiology, Sherwood P 494

- Frequency varies from 0.2 to 0.15 which perfectly brackets McCauley's central nauseogenic frequency 0.167 


\section{HFR model (1974) McCauley}

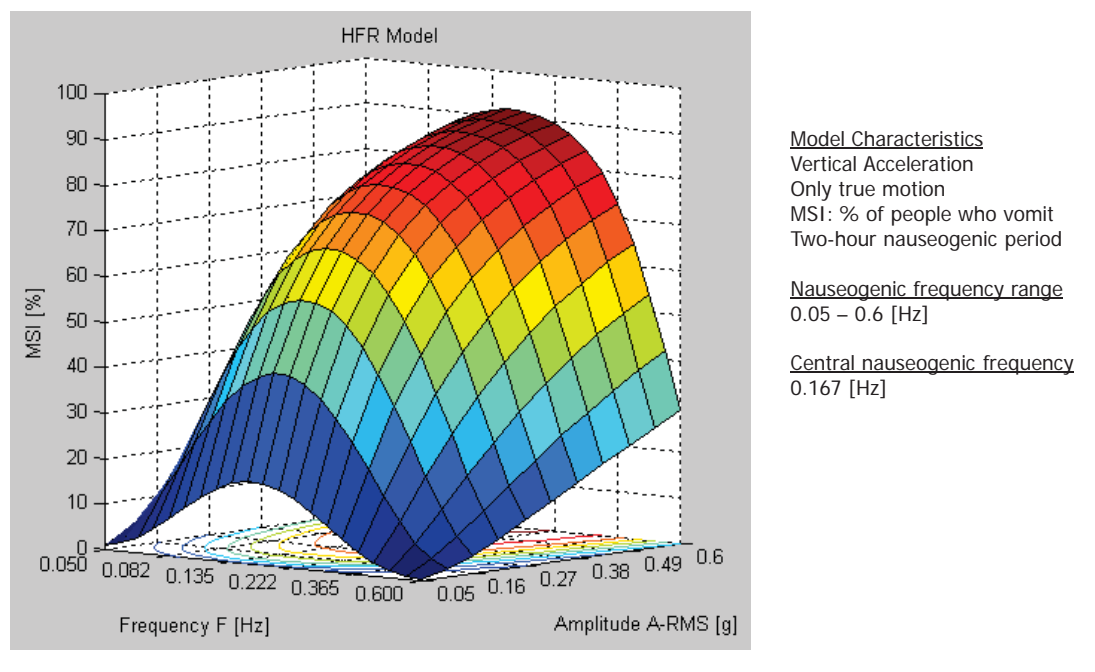

Slide 19

\section{Inability of Small Intestine to Detect Disruptive External Events}

- Small intestine is NOT attached to the abdominal cavity wall and has changing random orientation while it is busy mixing food with segmental contractions and moving food along the intestine with peristaltic contractions. For this reason it is very difficult if not impossible for the sensitive stretch receptors to detect the disruptive external acceleration forces especially when they are of a similar frequency and amplitude of normal GI activity.

Slide 20 


\section{Inability of Small Intestine to Detect}

Motion in Intrinsic Frequency Range

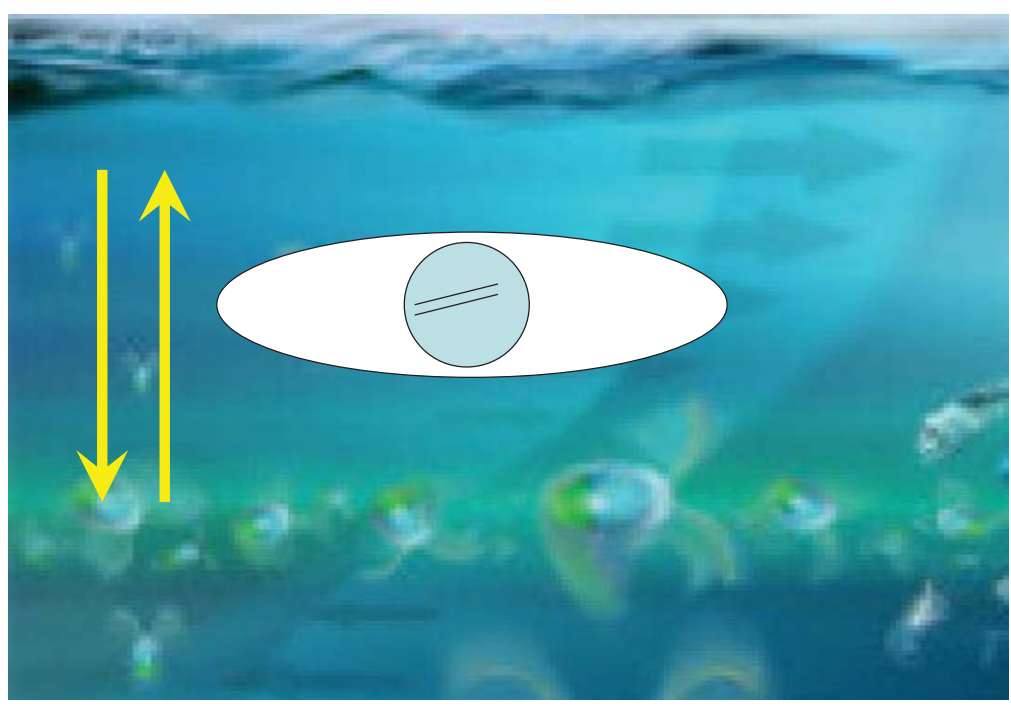

Slide 21

\section{Requires Accelerometers}

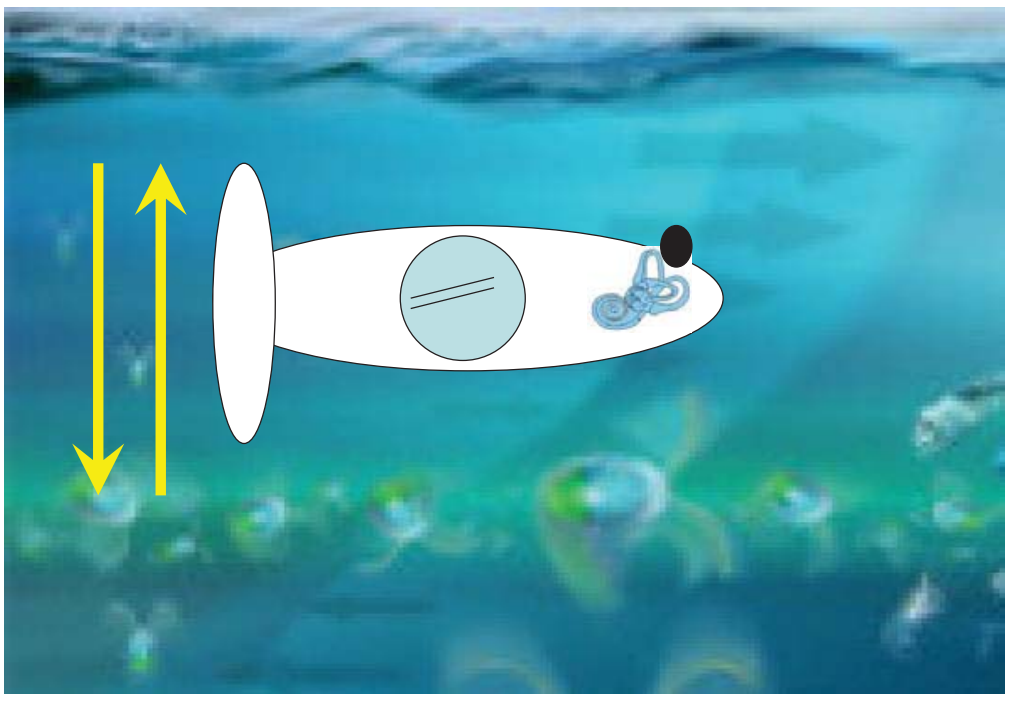

Slide 22 


\section{Why Vestibular System MUST Control Digestion via Motion Sickness}

- KEY POINT: The GI is NOT capable of identifying disrupting stimuli of close to same frequ and amplitude BUT the sensitive vestibular accelerometers CAN DETECT disruptive events.

- Vestibular system ONLY sensory system capable of accurately detecting acceleration motion. Nature has relegated role of assisting digestion via motion sickness to the ONLY system capable of accurately determining acceleration stimuli that are detrimental to normal process of digestion.

\section{Slide 23}

\section{Accelerometers}

- Linear and Angular accelerometers are integrated with other proprioceptive motion sensors, vision \& auditory motion sensors.

- Vestibular integrator detects any sensory anomaly inconsistent with accelerometer inputs from past experience and provides direction for visceral response.

- Frequency and amplitude combinations disruptive to segmental contraction and peristalsis create MS Sx.

- Inconsistencies between the individual accelerometers are particularly nauseogenic (e.g CCC and G-excess) since impossible to interpret and difficult to develop an adaptive response to "nonsensical" stimuli.

Slide 24 


\section{Vestibular Response to Mild or Short Duration Motion Stimulus}

- Food in the stomach (or gullet) is valuable and should not be wasted.

- The smart ecological response is to slow down gastric emptying until stimulus dissipates and the organism can reengage digestion without disruptive acceleration influence.

\section{Slide 25}

\section{Frank Vomiting}

- When disruption occurs it slows down the gastric emptying into small intestine but if disruption continues then it is necessary to empty stomach contents and start anew (feeding) when environment is more conducive to coordinated digestion.

- If the process of peristalsis and segmented contractions cannot continue optimally after prolonged stimulus then the stomach contents need to be emptied and frank vomiting occurs.

Slide 26 


\section{Resolve Failure of Sensory Conflict}

Theory (vertical motion). Also explains reduced Sx when supine

- The small intestine is not rigidly attached and is relatively free to move

- When vertical (standing or sitting in line with gravity) the SI will experience more movement in response to external generated motion and disruption of digestive motions than when laying down.

\section{Slide 27}

\section{Recovery after Vomiting}

- After stomach contents have been emptied there is no further need for vomiting. Many people experience cessation of symptoms and can engage in all activities after a bout of vomiting.

Slide 28 


\section{Why some continue vomiting}

- Perhaps not aware of empty stomach.

- Stimulus so strong response continues.

- Not a good survival reaction - chronic motion sickness can and has led to death in open seas.

\section{Slide 29}

\section{Adaptation}

- Most adapt to a mild maintained stimuli

- Strong stimuli may result in chronic motion sickness with dehydration.

- Without adaptation death will ensue.

- After sopite response, slowing down of gastric emptying, and then frank vomiting episodes it is necessary to accept new environment or cease to live.

Slide 30 


\section{Value of Sopite Syndrome}

- Fatigue and Tiredness encourage low level of activity including sleep until environment returns to normal and permits digestive process to occur unimpeded by external forces.

Slide 31

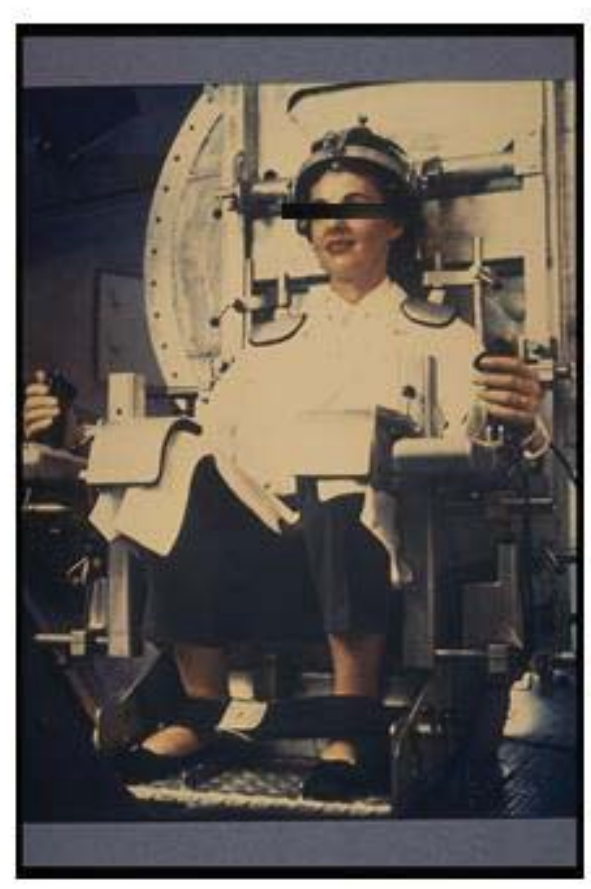

Slide 32 


\section{The Red Herring}
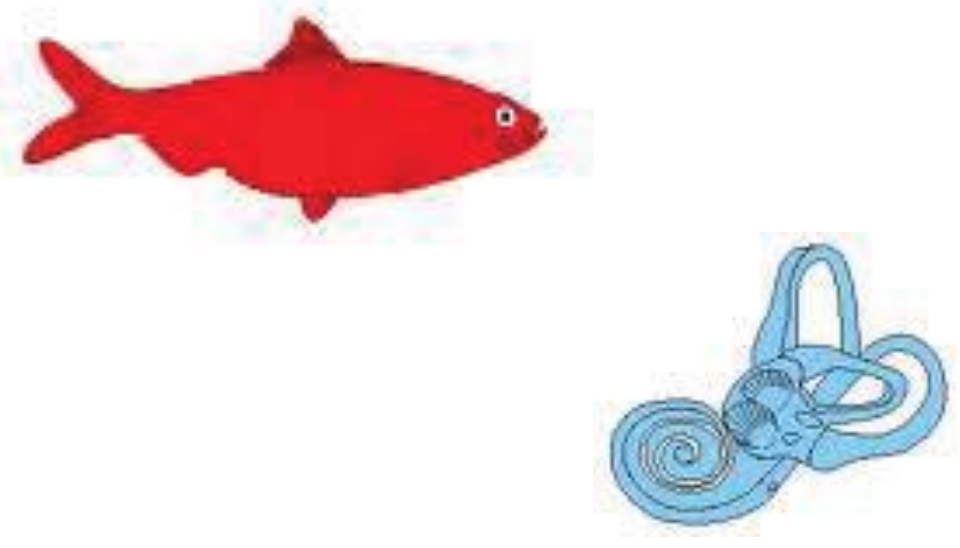

Slide 33

\section{Interruption of Digestion largely explains:}

- "Universal" nature - digestion necessary for survival

- Shape of Stimulus Response Curve - freq amplitude

- Why Vestibular End Organ Necessary

- Resolve failures of Sensory Conflict Theory (e.g.vertical motion)

- Initial slowing down of Gastric activity

- Later frank vomiting

- Why some "recover" - symptoms dissipate after vomiting

- Why some continue vomiting

- Why supine less provocative than upright

- Why ADAPTATION occurs to maintained stimulus

- Value of Sopite Syndrome

Slide 34 


\section{Implications of Aetiology}

- Vestibular system is system of systems with inputs from all major orientation sensors - touch (ext AND internal), vision, auditory and vest end organ - So there are multiple opportunities outside of pharmacology (or in addition to ) to ameliorate effects of stimuli - e.g prone, whole body affirmation of non movement (astronaut wedging), visual stimuli etc

- Directions for future research - "words of wisdom" from experts in MS.

Slide 35

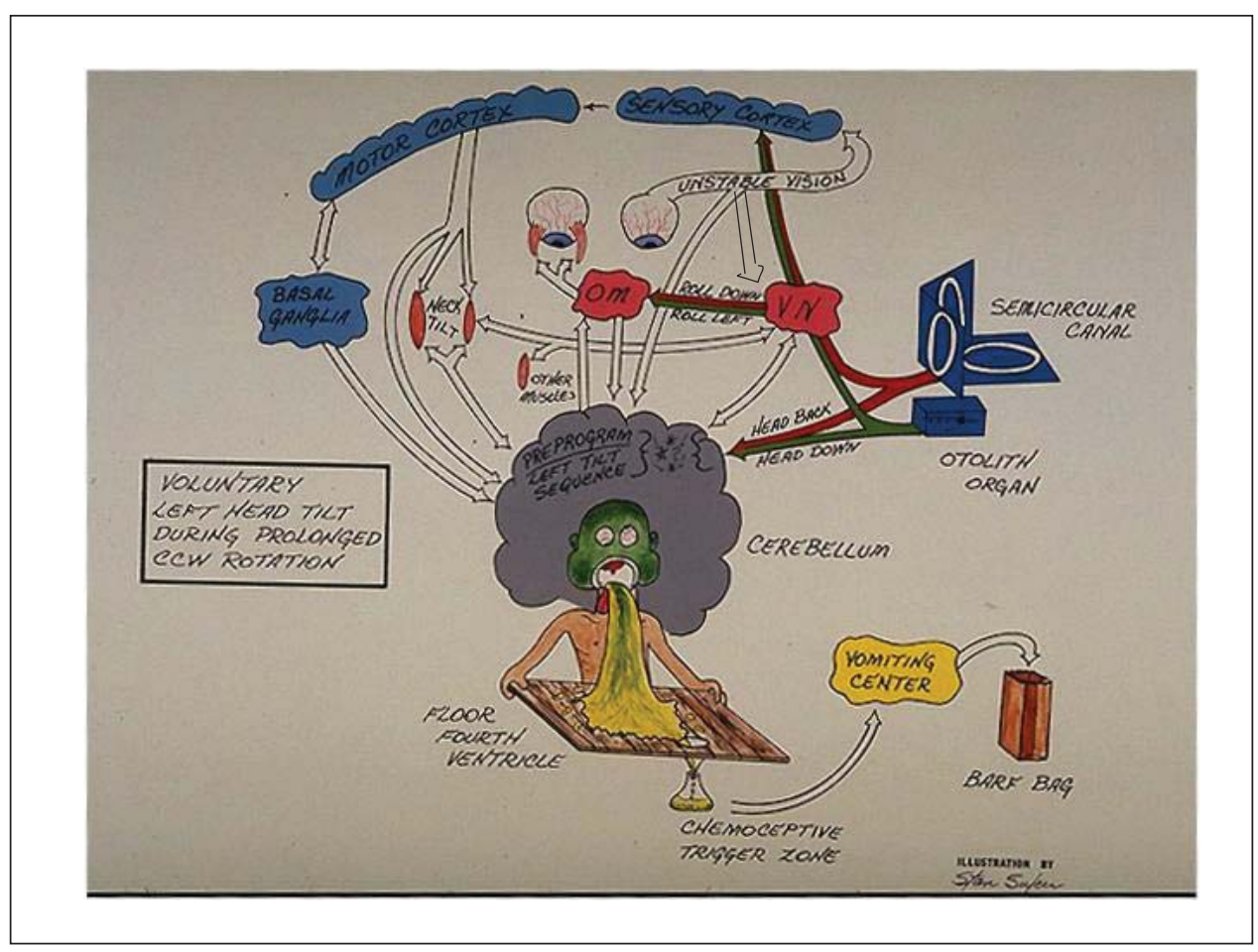

Slide 36 


\section{Thanks to Yuri for Controls Concept}

- Engineering student pointed out inability of random oriented, in-motion, unattached GI sensors to detect external motion of similar frequency and amplitude.

Slide 37

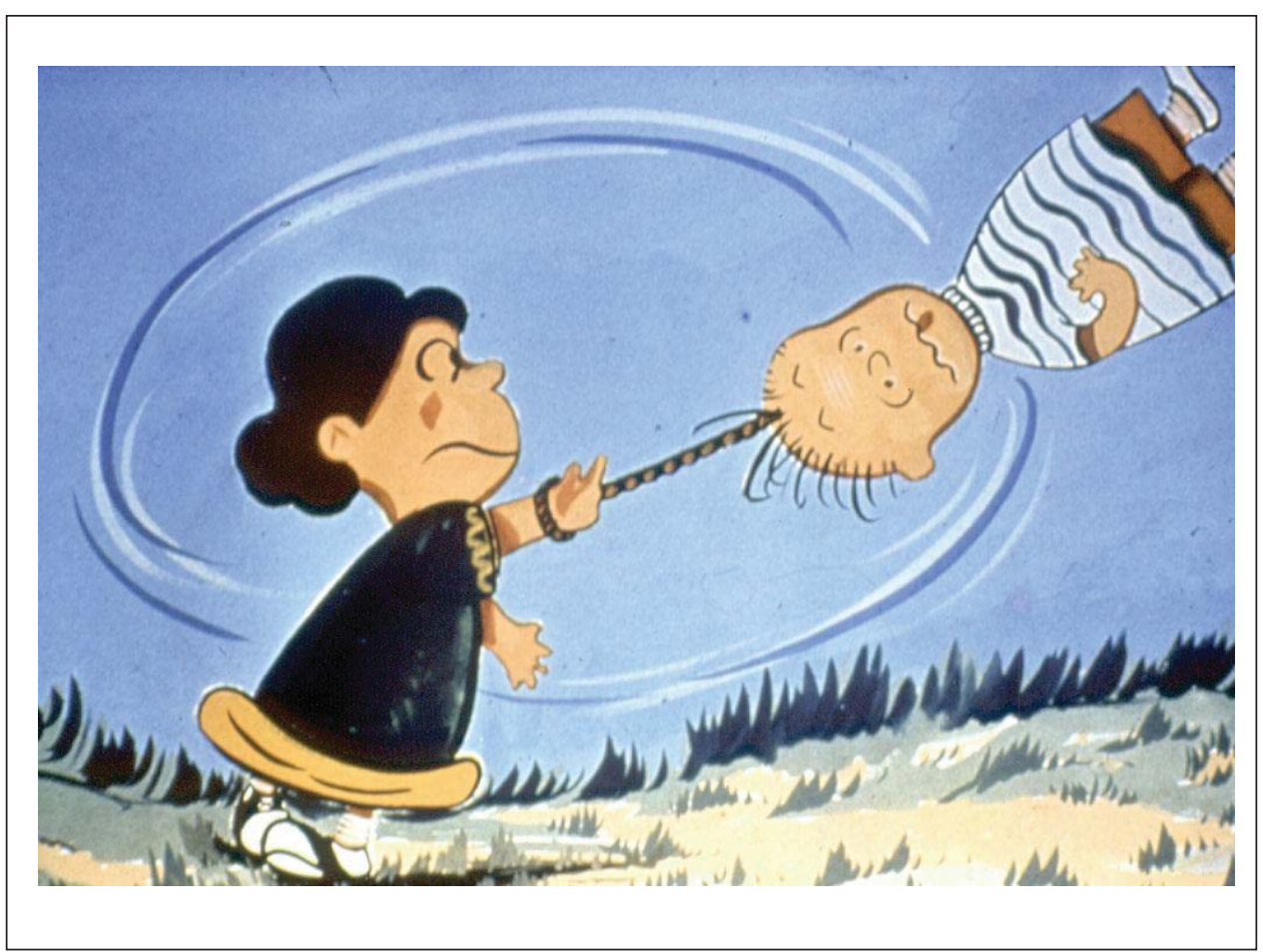

Slide 38 


\section{Discussion Starters}

- MOTION SICKNESS

- "The basic philosophical notion of motion sickness is something I have given some thought to and have come up with nothing."

- Money, 1968, p65, $4^{\text {th }}$ Symposium, Role of Vestibular Organs in Space Exploration, Pensacola, being asked the purpose of motion sickness

- Since Ken can't figure it out, what should the rest of us do?

Slide 39

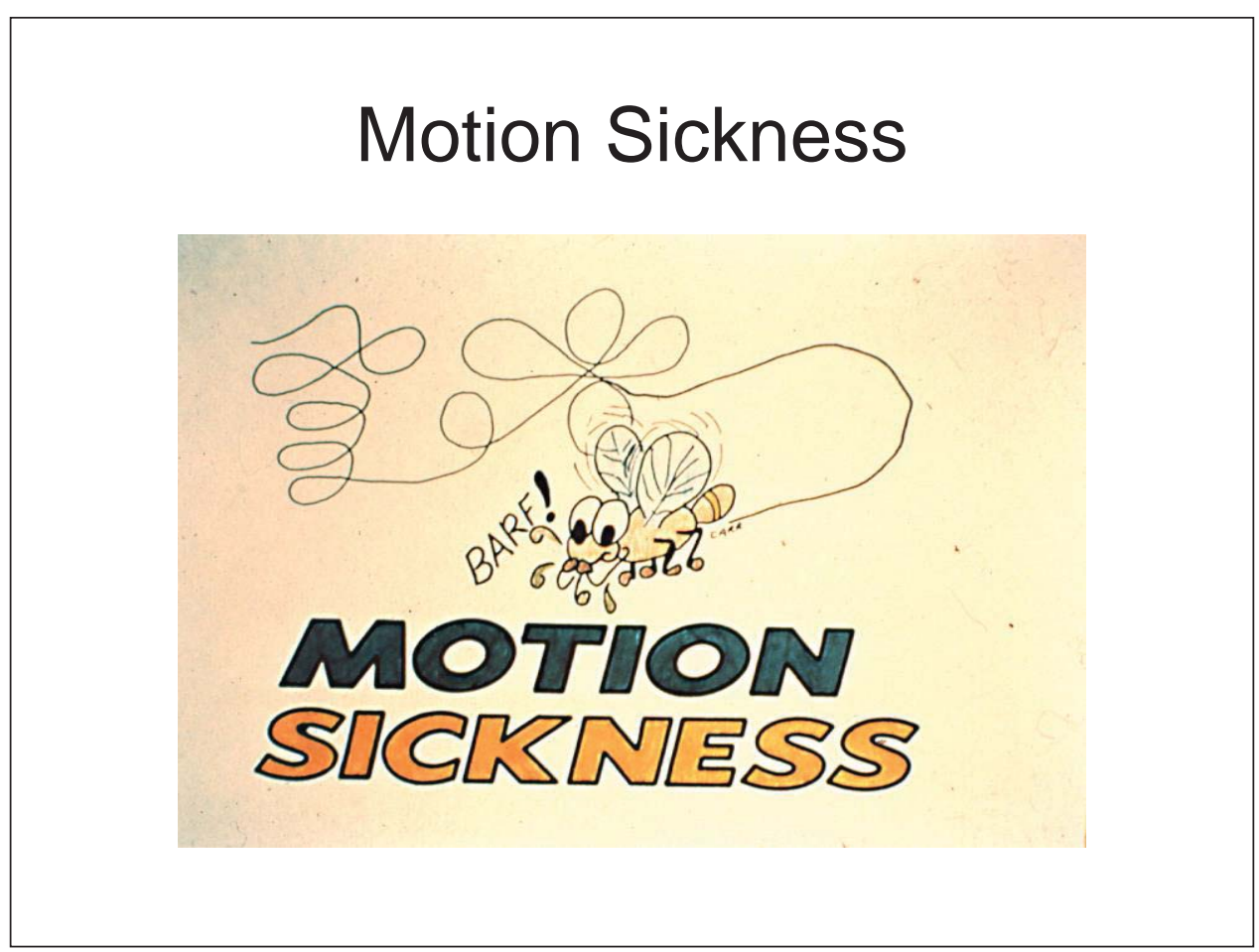

Slide 40 
Question and answer session

[Rupert] I was going to ask Ken [Money] what he thinks of this as a possibility for motion sickness etiology, but I guess [I will ask] Mike [McCauley] instead since Ken's not here.

[McCauley] I would never try to stand in for Ken Money.

[Correia] He [Ken Money] wrote a paper in "Nature," or in "Science," I can't remember which one, in which he postulated a role of motion sickness and what caused it. He put it within an evolutionary perspective, so I guess that would probably still be his answer.

[Oman] Ken developed the data, I think that's what you're referring to...

[Rupert] But, Triesman was the one who put that forward in the Nature article. It was Triesman who put forth the poison theory ${ }^{*}$.

[Lawson] Ken tested the theory.

[Oman] Can I make a comment? Two points: I think your quote about Jim Reason's concerns about vertical motion comes from his book, [Reason \& Brand, 1975; the full citation is provided in the reference list following Angus Rupert's lecture].

[Rupert] Right, it does.

[Oman] [That was] prior to his subsequent article, which I think we're all also remembering... I know I've talked with Jim [Reason] about this many times. He feels that there is a conflict with the conflict theory; in fact, vertical motion is provocative because it's not expected. It's externally imposed.

[Rupert] But even when you expect it and you're on board a ship, and you know it's there all the time, it's still the single most provocative stimulus.

[Oman] True enough.

[Rupert] As your boat experience tells you.

[Oman] Yeah, but Jim [Reason] would say it's exogenous motion. The other point just to finish with: I think the concern that we all should have when we evaluate these theories in the context of evolutionary biology (in recent years I've had a number of dialogues with people who are in this field) is that these kinds of arguments normally are adaptationist arguments (that's what they call them, and some of you may be familiar with the modern version), but this debate of whether you can take individual facts and argue from an evolutionary theory, and pull out anything beyond plausibility is an old issue in biology. It's called adaptationism, and actually, if you remember the story of why the tiger got its spots, we all thought that [as just] a childhood story.

${ }^{*}$ Treisman, M. 1997. Motion sickness: an evolutionary hypothesis. Science. 197(4302): 493-95 
[Goldberg] STRIPES! [Laughter.]

[Oman] Stripes, yeah. It was written by Rudyard Kipling, directly poking fun at the adaptationists, and the argument continues, but we all need to be aware that not every fact in physiology has a purpose that we define- let's put it that way.

[Goldberg] It seems to me, firstly, that in his classic review, Ken [Money] makes a very salient point that most of motion sickness has nothing to do with autonomic control but is, rather, somatic in origin. I don't have it in front of me, but I've read the article maybe 6 months ago and was struck by that. The second point is that it would be nice to have a rationale... what do you call it?

[Oman] Adaptationism.

[Goldberg] Right, okay, but you would have to get into the brain because that is the seat that expresses all of the symptoms, and even there I think there is, if not a dispute, then two contradictory theories. The only one I thought was reasonable, remarkably, was offered to me by Geoffrey [Melvill Jones]. [Has] anybody else heard this, the notion that the brain is poisoning itself? There was a paper, and I don't remember who did it, but basically, it was someone working in the visual cortex (I think the Colin Blakemore laboratory but I can't be certain of that), and he was trying to say that if you had just visual-visual conflict then out came things like catecholamines, and that it was a cardinal feature of adaptability. Okay, so Geoffrey's notion-I think there are two notions - one is connectivity. There's no question that the vestibular nuclei can be worked back to autonomic centers in the medulla, some directly, some quite indirectly. But his idea, basically, was [that] the brain is presented with-let's call it conflict, but it can be any number of things - and it tries to adapt its functioning in the same way as it does if you put on poisons, which I am sure is what inspired it, and it starts pouring out catecholamines and other neuromodulators. That, basically, is the brain poisoning itself. I would say at the level of the brain - and I'd like to hear feedback because I've never talked to anybody about this - is a kind of connectionist theory, which simply says we can go back to autonomic centers. Then [came] Geoffrey's idea which I thought was rather novel and clever (which isn't surprising given the source). I think the only study of that [idea] was done by George Crampton or maybe Nancy Daunton, but I didn't understand the rationale for the experiment. They attempted to plug the fourth ventricle or something like that. Can somebody suggest other mechanisms by which the brain would go into this state?

[Oman] George [Crampton] was trying to replicate the experiment done by Herman Chinn* which I think they called the cerebellar sweating theory. The idea was that there was some neuroactivation that went into the CSF [cerebrospinal fluid] and came down from the third to the fourth ventricle, and that, by blocking the transmission of this, you could render an animal immune to motion sickness. The first thing George did was try to put in a valve, essentially for blocking, and his ultimate experiment, which he never did, was to sort of transfuse CSF between

*The audio recording is unintelligible when Dr. Oman speaks this person's name. Based on the context of discussion, the authors conjecture that this is the name that is spoken. 
two dogs and make one dog sickly with CSF. I think he was doing it in cats actually. So that was the idea.

[Goldberg] But how many ideas are floating around as to neural mechanisms at the level of the brain?

[Oman] Well, there are a couple. The circumstantial evidence certainly suggests that there are both fast and slow mechanisms. You know, you can make one Coriolis head movement, particularly if you kind of soften it up, and it's an almost instant connection, which can sometimes be strong. Then, there's a slow process, which actually makes you more sensitive to that. That's why when we get sick on an amusement park ride, we can feel pretty well within a minute or two but we better not get back on for a half hour.

[Goldberg] Does anybody else have... if you just make this very global kind of... it's either just an accident or connections between vestibular nuclei and other things, or it's a framed thing we know about in terms of adaptability, brain learning.

[Lawson] Dr. Guedry had a developmental theory about motion sickness and I hesitate to try and sum that up.

[Goldberg] Oh come on. I jumped at something I know nothing about, so you can't use that as an excuse. [Laughter.]

[Lawson] Basically, he said that it was a developmental tool for allowing you to learn coordinated motion. So in a way, a kind of punishment system for learning to coordinate as you grow, and it's very important that you not fall over or fall off high places, and so on. So you need this steady feedback about any movements. Perhaps others can amplify.

[Oman] We were talking about John Laden's theory about reward, but there is no evidence.

[Lawson] Right, of reward and punishment. Can I just make a quick comment about the evolutionary thing? I thought a lot about that aspect, and to me, it's always functionalism versus structuralism. The most complete description of structuralism being Steven J. Gould's many examples of cases where something happens in the brain just because of the structure of the head, and it doesn't really have an evolutionary perspective [i.e., function]. Now, I think it's really more of a research approach one takes, rather than one [view] is right or one is wrong. But I will say one thing about functionalism. I think that when it comes to something that in just one trial will cause you to remember forever and is extremely aversive [namely, motion sickness], I'm leaning a little on the continuum towards functionalism. I think that's particularly true and I can challenge you in one respect. If we're going to sit and argue about how some tiny little [anatomical] curve in some part of the vestibular organ must be functionalist [referring to a previous talk], then I think we also should raise that same question in regards to something incredibly aversive, possibly deadly, and that only takes one trial.

[Oman] For any aversive reactions that we all have (not just emotion), not all are nausea. I mean nausea clearly has a protective evolutionary role, but there are so many flaws in human design, 
you know, that are the result of evolution-Stephen J. Gould called them spandrels. He said to look at the design of the lumbar spine, [in which] we all have a weakness, or [look at] the arrangement of the esophagus and the trachea that renders us so vulnerable to choking. Why are these the way they are? Well, you know, there are lots of genetic and evolutionary reasons for that.

[Lawson] A spandrel he referred to [likened to] as a section of an architectural feature. When you get done building a classic building, you have this little section left over, you know, with the arches, and you don't know what to do with it so you end up putting decorations in there.

[Rupert] Relating to Jay's [Goldberg] [earlier question regarding] all of the fluids and the internal hormonal rearrangements; it's that chemo-receptive trigger zone right here in the floor of the fourth ventricle [points to Fred's drawing, featured in slide 12 of Rupert's talk] that is supposedly able to detect those and then trigger the vomiting sequence.

[Oman] That's the cerebellar sweating theory that Fred drew right there in yellow.

[Rupert] [points to Fred's drawing, featured in slide 12 of Rupert's talk]: That's exactly what it is, and that's why I was pointing here, to the trigger zone, and back up to here. I'm only sorry the stomach is missing on this one, but go ahead, Larry [Young].

[Young] This is just a question, really, based upon experience many of us had. For years, when there was a motion sickness report in space, many of us would get letters from the public saying, 'Oh, why don't they try what my grandmother did? Why don't they eat ginger, Lebanese bologna, crackers, or something like that?' I reached the point where all the letters go to junk [laughter]; but in view of what you are proposing, Angus [Rupert], is it worth considering the relationship of any of this folk medicine to direct effects on the small intestines. Is that impossible?

[Atkins, James] That's what I was going to say. If we think about it, the thing that's most effective (and I think they came out with a lot of reports that were done in the '60s and the '70s) was scopolamine, which is a very good peristaltic halting mechanism. It slows peristalsis. I mean, for space sickness, it was [i.e., the protocol instructed] to give them the scopolamine, which is going to have peristaltic effect, and then you have to give them amphetamines because of the scopolamine. Now, when I see someone clinically who says, 'I am going on a cruise, doctor, what can you do for me so I don't barf the whole cruise and waste my 2,000 dollars?' I place this scopolamine patch on them which definitely has anti-peristaltic effects.

[Rupert] The person most experienced with those patches is... [gestures into audience towards McCauley].

[McCauley] Yeah, we did some studies on our motion machine, back in the '70s, for the transdermal scopolamine, [in an effort] to get it passed by the FDA, and it worked well. 
[Benson]: And you must have noticed that there is a form of scopolamine that doesn't pass the blood brain barrier, and it's not effective at treating motion sickness although it has a big effect on the gut.

[Atkins, James] And I think that's, of course, what you're saying [gestures towards Rupert].

[Rupert] Exactly. I see Dan Thomas in the back, who is also the other motion sickness person from out in California, together with McCauley [Mike] and Bob Kennedy, who isn't here today.

[Thomas] Has anybody discussed why marijuana works so well?

[Lawson] We said he's from California [speaker is joking].

[Thomas] Marijuana works beautifully.

[Five people talking over each other]

[McCauley, gesturing to Thomas] We were talking about that yesterday, you and I.

[Thomas] I mean, nothing keeps you absolutely from getting motion sick, unless you are a person born without any vestibular function. I think Kennedy knew that pretty well. The other thing was, I don't know if anybody without vestibular function has ever flown in space to decide if they also cannot get space motion sickness. These were the so-called-I shouldn't use this term, I guess - dummies ${ }^{*}$ that Ash Graybiel studied. They weren't dumb at all, it's just that they were usually used [for motion sickness testing] because they had no vestibular function. You could not make them motion sick no matter what you did.

[Oman] In the early Pensacola symposium, in a couple of papers, there was a discussion much like the one that we're having now, and Ash [Graybiel] actually put in print the suggestion that perhaps future astronauts should undergo a hemi-labyrinthectomy to reduce their susceptibility to space sickness. Jay [Goldberg] is the first to volunteer. [Laughter.]

[People start talking over each other. Young tries to give the microphone to Goldberg; he declines.]

[Thomas] It's one of the few absolutes that I'm aware of. The Navy got deeply involved with this. We did 48-hour simulations. Mike [McCauley] was there when we did those. We had 20 subjects. These were subjects that were tied to the Naval Biodynamics Laboratory. We had complete control of these subjects, because they were ours on permanent duty status. We basically loaned them to NAVSEA [Naval Sea Systems Command], and I ran the medical monitoring program out there at Goleta [California]. There were a couple observations about them. They all got sick except two people. We had 20 subjects; two didn't get sick. The other thing is, when they got sick they didn't get better. They were in there for 48 hours, so they stayed in the motion for 48 hours. There was no evidence of adaptation, whatsoever, despite the

\footnotetext{
*At one time, deaf people were called "dumb," as in silent. Also, a "dummy" sometimes referred to a placebo or control.
} 
fact that O'Hanlon [James] clearly indicated that you can do adaptation if you intermittently expose these people over a period of a couple weeks [O'Hanlon \& McCauley, 1974 - this source is cited in the reference list at the end of Angus Rupert's talk]. For the two that didn't get sick, I couldn't figure out why until I eventually realized and found out (and they admitted to me) that they had been using marijuana. The interesting thing was that they were not using marijuana during the experiments, which lasted for 48 hours. We knew they weren't because we had direct visual on them. So the marijuana that they were using must have been carrying over during that period of time, which is also a characteristic of marijuana - its effects last for a long, long time. Its metabolites can be found in the urine for quite a period of time, as separate from all the other drug screening programs. So this led to a lot of interesting things, and I wrote two reports to NAVSEA [Naval Sea Systems Command]. One was the big one, and the other one I wrote to Roger Ireland and told him I didn't think he should circulate it because we would have had an interesting problem - the entire fleet would be growing pot. [Laughter.] But I don't know if there are any controlled experiments with marijuana to indicate if its effects are fairly absolute. If you put somebody in heave motion at .16 hertz with displacements of about 6 to 8 feet, I will tell you, everybody would get sick! It's brutal, but you can adapt them and you can block it with marijuana. It's a hell of a lot better than scopolamine and I don't know where the experiments are, or if there are any experiments. This is not my field of my endeavor, I just got dragooned into that business.

[McCauley] I might add a little bit to that. Back when I was making all of the college students throw up, we had a preliminary screening device, the checklist kind of thing. [We asked questions such as:] 'What state are you in?' 'How much did you sleep?' 'What have you had to eat?' 'Are you on any medication?' 'Have you used any drugs?' And so on. They had to sign that. We ran hundreds of students through the vertical oscillator. We paid them 10 dollars, either to last two hours, or throw up. These days, I'm sure it would cost more. Anyway, some proportion of college students were probably, maybe, using marijuana, and while they would state that they were not, there were times that I believed that I could smell it. I don't know how I knew what that smell was, but it is my experience (I have never presented this or wrote it up or anything) that none of them ever got sick. It's a small sample size, I mean, half a dozen or eight, maybe, something like that.

[Oman] In the mid-80s, Randall Kohl had a motion sickness pharmacology symposium and I remember THC [tetrahydrocannabinol] came up at that meeting, and actually, that's the only time I met Andy Wile. In those days, before he went pot, he was a biology or botany professor, I think, at Harvard. This is the guy with the big black beard, you know, and he was advocating the use of cannabis against motion sickness. He produced some arguments. He gave a paper on it at that session.

[Young] He related it to high altitude workers in South America who did not get sick on their rides up to the mines on those winding mountain roads, and what they were eating or drinking.

[McCauley] One other [point] while I'm on an anecdotal roll here. I had a similar number of students who were into meditation. Some of them actually asked me, 'is it okay if I meditate?' I said, 'we have certain rules here, but whether or not you meditate, I can't control that, as long as you keep your eyes open.' Of those meditators, I never had any of those get sick either. I never 
had the chance to follow that up or know if anything was there, but it's sort of in that same bag with the marijuana.

[Rupert] So to speak, the bag... [Laughter.]

[Correia] At the risk of being historically inaccurate, I was there when we tested the LD subjects, and I think Fred [Guedry] will testify for [me] that I never heard the word dummies associated with Gallaudet students. They were incredibly intelligent, and they probably could sense rotation on the HDD [Human Disorientation Device] as well as any normal subject. I never heard Ash Graybiel say dummies either.

[Thomas] Oh I never did, I never did, but I'm just telling you, that's the way they were referred to.

[Correia] That may be legend, but that wasn't the case. They were very sophisticated and very helpful subjects.

[Thomas] These people were very intelligent, and, unfortunately, that word was used to describe people who, basically, can't hear. That's who they were referring to.

[Correia] They were a valuable part of the research effort in those days.

[Thomas] Were there any circumstances in which you could get these people sick, motion sick?

[Correia] I don't remember any circumstance under which they got sick, but the thing that was most remarkable to me was their ability to use proprioception in indicating end points of sinusoidal oscillation on the HDD, which is what we used to test them. But on the Slow Rotation Room, I don't remember any of them getting sick. Maybe Fred can remember that but I don't.

[Young] [This is] just a brief digression on this digression. [Laughter.] Dr. Graybiel [Ashton] and Al Fregly brought a number of these Gallaudet students up to MIT for part of the summer, and ran them through all of our tests (they weren't particularly motion sickness tests). None of them got motion sick. But, [I observed something] really consistent with what Manning [Correia] told you about the HDD. We were running linear acceleration threshold tests, and some of these guys had thresholds down at the 5 milli-G level, equivalent to the best of the normals. It was a little difficult to converse with them, but when I'd ask them what was going on, they would say, 'Oh, I can feel the shoulder belt against my collar bone, this is how I knew we were accelerating.' They were using all of these very, very subtle tactile/haptic cues. I remember one of them was a dancer, and he would just put in high frequency vibrations to modulate the haptic cues on his feet. They were incredible in their use of alternate cues.

[Atkin, James] Just another note: if anyone has any ideas on mal disembarkment syndrome for me, I'd love to spend hours talking about that because I have quite a number of patients. I'm in Orlando and everybody cruises right out of Cape Canaveral, so that's [mal disembarkment] a huge problem. 
[Curthoys] This relates to your model of motion sickness. I can speak from personal experience about a stimulus (which is very potent, purely vestibular, and really makes me very ill, as well as other people who are motion sick susceptible): pseudorandom galvanic stimulation between the mastoids. I've got the witness right here [gestures to Owen Black]. I was a subject on a posture platform in Owen's lab, and I think they've got the coffee cup that I barfed into in a glass case. [Laughter.] But, it's not just me. I happen to know another very motion-sick susceptible person, whom, with this galvanic stimulation (which a lot of people like - a lot of people think it's a buzz, but I find it very distressing), could take about 10 seconds of it before he just said, 'take it off.' [It's] not very powerful, but absolutely unpredictable and purely vestibular.

[Rupert] I will also confirm how nauseogenic that is. The Israeli AirForce, I think, were using that to disturb their pilots, perhaps in training mode. One of them who happened to be at WrightPatterson Air Force Base gave me a very brief stimulus of that. It was only very brief because I ripped it off. So, yeah...

[Thomas] On those subjects who did not have any vestibular function, were you able to get them to keep their eyes open, and did they indicate to you that they felt nauseogenic?

[Correia] We tested them mostly in the dark with regard to the HDD, of course, and with regard to the Slow Rotation Room, they had their eyes open.

[Thomas] I mean they never complained, 'I don't feel well,' and they never took the effort to close their eyes?

[Correia] Bob Kennedy knows that much better than I do. My remembrance is that they never complained about being...

[Thomas] So that leads you to the conclusion that regardless of the cause of motion sickness, you can't get it unless you have a functioning vestibular apparatus.

[Correia] I think that's a reasonable conclusion, and I think that's probably consistent with the literature.

[Thomas] And yet, most of the theories indicate that, probably, the nauseogenic business and everything is basically, somehow centrally mediated.

[Correia] Well, it's a central circuit.

[Thomas] It's a central circuit, but it has to have the vestibular input.

[Correia] That's right. That is correct.

[Oman] Well, the literature, I think, also points out that maybe the central conflict is vestibular, but visual inputs could lead to expected vestibular...

[Correia] Of course. Absolutely. 
[Thomas] Well, I don't know that you have to bring in a concept of conflict to even bring up any of this. I mean, it can just simply be that the vestibular system is a transducer, which operates at certain frequencies, and if you screw it up you get sick.

[Young] Well how else are you going to explain the nauseogenic properties associated with the visual input?

[Correia] Only visual.

[Thomas] Only visual, yeah.

[Young] In somebody who has a functioning vestibular system...

[Thomas] Well, because I don't know how well it's interconnected with the vestibular system; because without the vestibular system, the visual doesn't get you sick. That's why I asked the question to begin with. So it's something that has to do with the coincidental activity that must be mediated through a fairly peripheral part of the vestibular system to get you sick. Yet, the vestibular system alone doesn't explain it, because there's so much more to it.

[Correia] As you well know, there's so many interconnections in the central nervous system.

[Thomas] I don't know the systems at all, so I just look at it as a black box phenomenon.

[Oman] There's a small [amount of] literature on this issue, and there are two ideas that emerge. One idea is that there's a sort of expectancy signal coming in which could be vestibular, but could be just visual. The other's more of a gaining idea, that the vomiting center perceives a lot of inputs. You know, in surgery, you can jiggle all around in the gut and make somebody vomit within seconds. So there's a lot of convergence and maybe just, sort of, tonic vestibular convergence, and if you eliminate the labyrinth-you drop that out-you raise the motion sickness threshold. You know, it's sort of a gating version.

[Lawson] Also, I would just like to point out that Bob Kennedy talked about different kinds of motion sickness, not the old idea that there was a space kind or motion kind, but rather, that it has different factors and that one of those aspects is postural. And, we were discussing LDs. I just wanted to point out that the LDs did experience ataxia following the [Slow Rotation Room] stimulation. I also wanted to raise one point for discussion, which is, I don't think we can leave a theory concerning gut causation of motion sickness without at least mentioning or discussing the gravireceptors in the torso. Anybody have a comment about that part? And I'll also turn it over to...

[Black] Anybody want to respond to his [Lawson's statement]? I would like to ask Manny [Manning Correia] [a question] in preparation for a comment. Manny, how were the LD deaf subjects determined to be LD?

[Correia] There was no clear criterion in those days. They could have had some function. They were determined to be LDs because they had no hearing. They were recruited under that 
auspice... I don't remember any histopathology being done. I don't remember any radiation being done to confirm that.

[Young] The group that Dr. Graybiel brought up to MIT all had their records, which showed their ocular counter-rolling index.

[Correia] Oh, okay.

[Young] So I know that was measured.

[Black] Well, the reason I bring it up, and I'll touch on this in my talk, is that the determination of LD in deaf subjects is determined by the etiology. So many of the LD subjects have cochlear saccular degeneration and are totally deaf, but have intact canal otolith function. And in the LDs that have ototoxicity, often there is loss of canal function but preservation of otolith function. And so, I think many of these publications either weren't aware of it or didn't verify the LD status. And what you mean by LD, I think, should be specified by LD otolith, LD canal, or LD both.

[Lawson] I've seen the files from the early days, in the sense that I've had the privilege to go through those things that NAMRL [Naval Aerospace Medical Research Laboratory] deemed not worth keeping. I saw extensive vestibular tests on the rotating room subjects, including the LDs. Now that [limited testing] might have been the case in the earliest phase, but by the time I got records that I looked at from the '60's, they were getting every test you could imagine [of vestibular function, etc]. 


\section{Vestibular injury and treatments: Clinical applications - Owen Black}

Thanks to you Angus for a great visit and the invitation to be amongst the elite in the vestibular system. I don't know about the rest of you, but this has been one of the most enjoyable [conferences] that I've attended in recent years [slide 1, page 110]. This talk was supposed to be about vestibular injury and treatment, clinical applications, but after thinking about it, I took speaker's options and privileges and thought I'd just give you a list of the publications that we've done on vestibular injuries and treatment, including blast and blunt head trauma patients. The reason I decided not to talk about this aspect of what we've done in my facility and laboratory is that, at least in my opinion, it doesn't relate to the impact that Fred has had on my career. I'm a clinician and throughout my lifetime in the professional world, I've spent 50 percent [of my] time in the clinical world and 50 percent in research, thanks directly to Fred Guedry's impact on my career. While I was at the university of Florida, during my early academic career, I made contact with Fred for many, many reasons (which I won't go into right now). I used to call Fred up and chat with him and ask him questions, and in retrospect, I can hear him shaking his head about how incredibly stupid this guy was [Black is referring to himself] because I asked a lot of inane questions. Even at that time, when I was relatively young, I had a superficial introduction to Fred Guedry, but one thing I did know was that he had a lot of knowledge that I needed in order to deal with my patients. This is because when I take a history of patients, they describe perceptions that many times have absolutely nothing to do with pathology or the consequences of pathology, so, I'd like to concentrate on that aspect of my career [slide 2].

I'd like to focus on the comments and the critical knowledge gaps that, in my opinion, need to be addressed in vestibular research, and focus on the contributions that were made either directly or indirectly related to Fred [slide 3]. One of the things I experienced early in my career was that [when] I thought I had a bright idea, like all young people do, I would do a literature search and I would encounter "Guedry, F.E." (and I don't know about you, but I still do that), and there's not very many people, in my opinion, that we see such recurring references to in the literature. Now I'm going to talk about several aspects of what we did and I want to acknowledge, in addition to Fred (and these are in alphabetical order), some very important colleagues, and I am definitely privileged to work with every one of these very brilliant [individuals]. I'm often amazed at their willingness to collaborate. In addition to Jan Holly, who's here, and Dan Merfeld, whom you've heard referenced, [I would like to acknowledge] Bill Paloski, Sukyung Park, whom I think now is back in Korea, Claire Gianna-Poulin, who is a marvelous young bioengineer who worked in our laboratory with Dan and I, and of course Scott Wood, whom you know quite well [slide 4].

First, I'd like to just give a perspective on the prevalence of vestibular dysfunction in the United States in putatively normal subjects, aged 40 and over. This [slide 5] is [data] from the NIH [National Institute of Health] and the Aging Unit of the NIH from 2001 to 2004. Using a technique that's a derivative of the one developed by Lew [Lewis] Nashner and I, this [research] demonstrated that the prevalence of vestibular types with postural impairments is 35.4 percent, which corresponds to 69 million Americans [Agrawal, Carey, Della, Schubert, \& Minor, 2009]. To put this in perspective a little bit, the prevalence of vestibular disorders is considered to be 3 to 5 times more prevalent than hearing loss, yet, the funding for hearing loss is much greater. I'm not criticizing the funding for hearing loss, but in terms of need, from my perspective, the 
amount of funding for vestibular disorders lags way behind the research funding for hearing loss. Now, these findings are consistent with our experience in my laboratory because I've done a number of population studies, including prospective studies, and when we solicit normal subjects to act as controls, matched controls, at least 25 percent of those subjects are abnormal and we have to reject them. So my experience is very consistent with the publication [Agrawal, et al., 2009]. The project in which these statistics were drawn from used a compliant [standing] surface [for balance testing], so they probably overestimate the prevalence of vestibular disturbances, but even if they do, I think it's consistent with our experiences in NIH-sponsored studies. So an obvious, major potential source of variability in putatively normal subjects is raised by these findings. Therefore, one of the recommendations I'm going to make on this is that when studies are designed using putatively normal subjects, especially given the techniques that have been developed by colleagues such as Ian Curthoys, then there's absolutely no excuse in my mind for not documenting the normality of those subjects. This is because, in my opinion, much of the variability, or at least some of the variability, particularly the nuisance variables, is coming from abnormal subjects. So the focus of my talk, then, will be what we can do as clinicians to close the gap between what we know about the physics of motion and vestibular perception, or in the case of the clinician's approach, symptoms. And specifically, I'm going to focus on those inspired by Fred and his collaborators [slide 6].

First, just a couple of exemplary facts. First of all, vestibular stimulation may not produce perceptions, and a classic example is that there is a significant linear acceleration of gravity that most normal subjects don't perceive [slide 7]. That's obviously primarily to the otolith system, but even head turns and head movements, when they stimulate the canal systems, are rarely, if ever, perceived under normal circumstances. The next fact is that abnormal vestibular function may not produce perception [slide 8]. The classic example is slow bilateral loss of vestibular function. The slow loss of vestibular function doesn't produce symptoms until the loss of function is extensive enough or severe enough to prevent vestibulo-ocular interactions, for example, at which point you would start developing oscillopsia and movement of the visual surrounds when you move your head [Black, Pesznecker, \& Stallings, 2004]. I think that the presentation by Måns [Magnusson] is a great demonstration of the rapid loss of vestibular function [where strong symptoms occur].

Bárány [Robert], in some of his earlier publications, indicated that bilateral loss of vestibular function had no consequence. Unfortunately, that dictum still persists in some of the literature used to teach general medical physicians and other professionals and, unfortunately, is a detriment, I think, to detection of patients with bilateral loss of vestibular function, and it creates an enormous amount of [mis]information regarding the prevalence and treatment of vestibular disorders. Is Manny Correia still here? I don't know if you are still here or not, but I stole this figure [slide 9] or "wiring diagram" if you will [Correia \& Guedry, 1978 pages 311-351], because I find it extremely useful, both for teaching purposes and for thinking about the vestibular system. Since most of you here are familiar with this, I won't go through this in any detail, but obviously, the main distributions from the vestibular system are conjugate to the rostral systems to the eyes, but it's unilateral to the caudal systems to the legs, not to the cervical vestibular spinal systems, but to the legs. The studies of Zee and his colleagues have demonstrated that the transit time from the ocular muscles [to the vestibular system] is about 10 to 15 milliseconds [Leigh \& Zee, 1999; Black, Shupert, Horak, \& Nashner, 1988]. And by the 
way, I should back up and say one of the important things that Manny [Manning Correia] and Fred pointed out is that the distributions from the vestibular system eventually are distributed to all of the body musculature. The obvious, most important ones are distributed to the ocular muscles, as you know, and to the head, and to the muscles that control the center of gravity and the pelvis. The transit time from the ocular globe muscles is about 10 to 15 milliseconds; the transit time from the vestibular spinal system is about 50 to 100 milliseconds, dependent upon how you measure it and how tall the subject is and so on. Those transit times are too fast for the perception of what is happening. The average human requires about 300 milliseconds to accurately process any information. So the first principle here is that the normal and abnormal subjects cannot, from a cerebral or conscious level system [perspective], describe what is happening in these systems. What they describe is the effect of what's happening in those systems, and therein lies a large challenge for the clinician, to put it mildly, much less the researcher. Another set of problems here that is not demonstrated in this slide is that the information from the central retina goes to the cerebral cortex, the occipital cortex. And it's long been known that - I think, Larry [Young], you actually participated in these experiments - the peripheral retina input is coupled directly to the neurons in the brainstem that project from the semicircular canals. So it's a tightly coupled system there, and more recently it has been demonstrated that any linear movement that requires vergence obviously is driven from a sensory standpoint by the otolith system. So, these are very complicated interactions that I would say most other areas of science and medicine simply do not understand; our educational systems are not presenting this fundamental and basic information. So the missing link is the fact that the otolith contributes to vestibular information processing, which is what I'm going to focus on today [slide 10].

So, the question is how does the brain differentiate head tilts from head translations? This is a very important consideration in terms of approaching problems like fall risk, because unless the patient or the subject can differentiate tilt from translation, it really is difficult to, first of all, diagnose and determine who is at risk for falls; then second of all, to decide or develop methods to deal with falls. This applies both to putatively normal subjects, especially as they age, and then, of course, abnormal subjects. So I'd like to describe briefly - and obviously we can't go into detail here - all this data [slide 11], which are published in the journal of neurophysiology. I was privileged to work with Dan Merfeld, and based upon what Fred had discussed with me many, many years before, and upon reading Dan's gravito-inertial force resolution hypothesis, it occurred to me that this might be a way that we begin to sort out the problem of tilt translation, obviously [inspired] from his model [slide 11]. As you rotate on a centrifuge, the GIV [GravitoInertial Vector] [versus the usual vertical given by gravity] rotates, obviously. What are the components of that rotation? Well, Dan's [Merfeld] theory was that part of it had to do with the rotational component, and part of it had to do with the translational component contributing to the vector direction and magnitude [Merfeld, Zupan, \& Gifford, 2001; Merfeld, Park, GiannaPoulin, Black, \& Wood, 2005]. So here's the summary of the paradigm that we used [slide 12], and the question was: How does the brain differentiate tilt from translation? We used the tilt translation system that we developed in our laboratory, which allowed us to rotate the subject around the nasal occipital axis and move the head above and below the axis, and if we move the head below the axis we can cancel all linear accelerations including gravitational inputs, and get only canal results - canal inputs, rather. So we centrifuged the subject without rotation and then with rotation, and the responses that we studied were [those from] the vestibular ocular system, 
both ocular torsion and then the LVOR [linear vestibulo-ocular reflex]. The verbal reports included magnitude estimates of the motion and then somatosensory estimates of the GIV rotation relative to the body axis. So if one looks closely as we rotate the subject here [slide 13], the subject is being rotated, and the chair is moving back and forth for translation. We were recording the eye movements and the subject estimated her body axis position relative to the GIV, and then, of course, we question the subject for the verbal responses. This [slide 14] is just a demonstration of the fact that we can move the tilt system above and below the nasal occipital axis. This movie [slide 15] shows that we were basically making the same measurements I just described for centrifugation during rotation: eye movements, verbal reports, and the subject's estimation of the position relative to the GIV. So to briefly describe the results here [slide 16]: It was very clear from these experiments that there are qualitatively different mechanisms contributing to human perceptions, actions, and symptoms. It is also very clear from the data that the tilt perception primarily is from the canal clues and depends upon which system [is activated or assessed]; that is, the VOR [vestibulo-ocular reflex], verbal, cerebral, or somatosensory systems. Even in the normal subjects (by the way, these are all normal subjects), the order of magnitude of error, with respect to the physics, could be as much as a full order of magnitude off from the fundamental physics. Now, why is this important clinically? When somebody comes in and tells me that they feel off center, or somebody comes in and tells me that they're dizzy (they can't describe any of this), or when somebody comes in and tells me that when they move their head or tilt their head, the world tilts with them, what does that mean to me really? Well, unfortunately, not much, unless I have the ability, then, to test these systems. Now, working with Ian [Curthoys] and his group, and with Lew Nashner, we've been able to devise methods for assessing canal and otolith function and their interactions with vision, contact surface, and vestibular inputs. We still need to do a lot of work in abnormal subjects, using these methods, both for verification purposes and for understanding the full range of dynamics because, right now, all we have is our fundamental screening systems. But I think you can see how important it is, clinically, to have the ability to followup on what the patient is telling you and [to] search for what's actually wrong, what systems are working, and what systems aren't in order, [so that you may] interpret their symptoms, try to get to the pathology, and try, then, to develop a differential list for most probable to least probable (in other words a differential diagnosis list) in order to assess and develop treatments for these patients.

In summary, then, I think the abnormal vestibular mechanisms governing these systems are unknown, but they are critical for the identification and successful management of vestibular disorders. Additional conclusions [slide 17]: The qualitatively different mechanisms contribute to human perception, action, and symptoms, based on the fact that the linear accelerations forces measured by the otolith systems are ambiguous. This is Einstein's equivalence principle. Again, that's why our research areas need, at least in my opinion, the centrifugation and the type of approaches that we use, maybe not exactly, obviously, but similar approaches. And then we need to know, in abnormal subjects, how the brain resolves the tilt (that is, the canal) versus translation. We don't have a good way to do that clinically, [but] maybe something like these approaches will provide us with that information. I think some of these other conclusions are probably worth reading [in] the details of the publications. So to move on here, because I know we have a time constraint, there's a condition known as Tumarkin's otolithic crisis, and it's usually in patients with burned out vestibular disorders. The patient will describe a giant hand pushing them down. Now, it's not the same giant hand as the other giant hand syndrome that is 
known amongst researchers ${ }^{*}$. In observing these patients (and this is pure speculation at this point), what seems to happen is they have a sudden change in pressure in the sacculus, which causes them to feel as though, or perceive as though, they're tilted. So when they tilt, they move the center of gravity off the support base of the feet and then, of course, they are crashing to the ground. This is a very dramatic, very dangerous type of crisis. Fortunately, it's not very common, but it's common enough, especially with the aging population, that it's an area that we need to understand so we can prevent injury as a consequence of these disastrous falls in patients with late Meniere's disease. The first description of this by Tumarkin actually occurred in a subject who fell in the middle of the street and was run over by a carriage, killing him ${ }^{* *}$. So while it's not that dramatic these days, if we have a subject driving a car, it can be dramatic, and it does and has happened.

The second example is the exaggerated perception of tilt in patients with dehiscence of the superior semicircular canal, and then, of course, there are many other examples such as BPPN [benign paroxysmal positional nystagmus] and especially the BPPN and aging. So for demonstration purposes and because we can document it, I would like to... oh, before we go into the example here, in my opinion, the next steps would be to apply these techniques to the study subjects who are at fall risk, and one of the nice things about computerized dynamic posturography is the studies have shown that not only can you predict fall risk, you can predict the number of falls in a workplace, if using the proper paradigms [slide 18]. Also, [in reference to] roll tilt perception in patients with BPPN aging and dehiscence superior semicircular canal syndrome, in my opinion, we can reduce the morbidity and, of course, in extreme cases, the mortality from these vestibular injuries. Also, I should stress that sometimes there's not immediate mortality, but if the patient falls and they have to restrict their activity, then their life expectancy is reduced significantly. Two of the most significant developments have been the cVEMP and oVEMP [cervical vestibular evoked myogenic potential and the ocular vestibular evoked myogenic potential], which you've heard from about from Ian [Curthoys] [Curthoys, Manzari, Smulders, \& Burgess, 2009]. We have implemented [these developments] in our laboratory, [which] have brought about a significant improvement and significant positive impact on the way we are able to evaluate and manage patients. To give you an example of the extremes of perceptions in some patients, I saw a 45-year-old otolaryngologist with a Bachelor of Science degree in mechanical engineering, and he was from Canada, so he flew from wherever he lived in Canada to way out in north Canada to attend clinics, and he would say that he noted that when the plane would bank, especially to land, he felt as though he was upside down [slide 19]. Now, he had seen I don't know how many physicians before he showed up in our clinic, and he was told that this can't happen: this is physically impossible. I've heard this from BPPN patients before, so BPPN and vertigo were at the top of the list here. When we did the cVEMP, the threshold for his response was $60 \mathrm{~dB}$ [decibels] whereas, normally, it's about $90 \mathrm{~dB}$ [slide 20]. And he had a very high amplitude [but] I have forgotten what the amplitude was. So he had both of the components that Lloyd

\footnotetext{
*This other illusion is described in Weinstein, L.F, Previc, F. H., Simpson, C. G., Lyons, T. J., and Gillingham, K. K.. 1991. A test of thumb and index finger control in overcoming a visual analogue of the giant hand illusion. Aviation, Space, and Environmental Medicine. 62(4): 336-341.
}

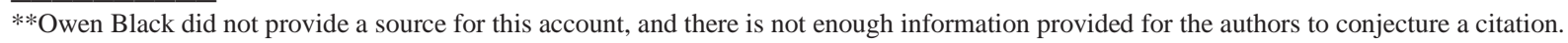


Minor [Minor, Solomon, Zinreich, \& Dee, 1998] described as characteristic of dehiscence of the superior canal. A CT [computerized tomography] scan, as you can see here [slide 21]: this is a scan coplanar with the vertical canal here [points to black section in the center of the scan], and you can see that there's no bone over that vertical canal. Now, who knows what the absolute mechanism of the patient's symptoms are? When you tilt [them] (and especially with a rapid tilt), the intracranial pressure will change, and as sensitive as the semicircular canals are, you can imagine that it's like putting a plunger into that canal and putting pressure against that cupula. And so, at least in my opinion, this and potentially other mechanisms explain his symptoms.

There are other symptoms. This is a figure from John Epley [slide 22] [Epley, 1980]. By the way, John Epley is a marvelous, marvelous person and a genius. He singlehandedly described the mechanisms of BPPN and benign paroxysmal positional vertigo [BPPV]. Although the diagnostic procedures have been explained, he also explained the physiology of the diagnostic procedures, and he postulated that the reason for BPPN is [the presence of] otilith particles in the endolymph - they're not supposed to be there. Endolymph and the cupula normally have zero buoyancy, that is, they have the same specific gravity. The difference, of course, between the cupula and the fluid in the canal is that the cupula is attached to the skull so that when one turns the head, there's a relative force against the cupula, producing stimulation of the outer lying hair cells. So normally, when the subject tilts their head, there's no stimulation of the canals if it's slow enough. But, if there are particles in the canal, particularly if they clump, then, as the semicircular canal is made range coplanar with gravity, the gravity will move the clump and produce the same effect as head rotations. And John [Epley] and I both have observed that sometimes drivers, particularly with rapid breaking, will have the sensation that they're tilting in the automobile, and in some cases this has led to automobile accidents. Now, the reason I'm bringing this up, or using this as an example, is that the way the patient describes this is not understood by most medical professionals. So, again, the patient will come in and say, 'Doc, as long as things are quiet in the car, I don't have any trouble, but every time I go around a clover leaf, or if I have to stop suddenly, I have the sensation that the car is moving when it's not.' This is one of the types of BPPN.

So Fred... everybody goes through this process of the wheels of life, we start out in a carriage and most of us leave in a carriage, and so don't lose heart because we're all headed in the same direction [slide 23]. I thank you for the trip of my life and my profession, in which I was privileged to know you and so many other wonderful people, and I must say, one of the attributes of this group that I think is probably the most admirable, is that you all are teachers. I have learned so much from all of you and especially Fred, who's the teacher of teachers, in my opinion. Thank you. 


\section{References}

Agrawal, Y., Carey, J. P., Della, S. C. C., Schubert, M. C., and Minor, L. B. 2009. Disorders of balance and vestibular function in U.S. adults. Archives of Internal Medicine. 169(10): 93844.

Black, F. O., Pesznecker S., and Stallings, V. 2004. Permanent gentamicin vestibulotoxicity. Otology and Neurotology. 25(4): 559-69.

Black, F. O., Shupert, C. L., Horak, F. B., and Nashner, L. M. 1988. Abnormal postural control associated with peripheral vestibular disorders. In: Pompeiano, O., and Allum, J. H. J. (eds.). Vol. 76. Vestibulo-spinal control of posture and movement: Progress in brain research. Amsterdam: Elsevier.

Correia, M. J., and Guedry, F. E. 1978. The vestibular system: Basic biophysical and physiological mechanisms. In: Masteron, R. B. (ed.). Handbook of Behavioral Neurobiology. Volume 1. Sensory Integration. New York: Plenum Press.

Curthoys, I. S., Manzari, L., Smulders, Y. E., and Burgess, A. M. 2009. A review of the scientific basis and practical application of a new test of utricular function - ocular vestibular evoked myogenic potentials to bone-conducted vibration. Acta Otorhinolaryngologica Italica. 29(4): 179-86.

Epley, J. M. 1980. New dimensions of benign paroxysmal positional vertigo. Otolaryngology and Head and Neck Surgery. 88(5): 599-605.

Leigh, R. S., and Zee, D. S. 1999. The neurology of eye movements. $3^{\text {rd }}$ ed. New York, NY: University Press, Inc.

Merfeld, D. M., Zupan, L. H., and Gifford, C. A. 2001. Neural processing of gravito-inertial cues in humans. II. Influence of the semicircular canals during eccentric rotation Journal of Neurophysiology. 85(4): 1648-1660.

Merfeld, D. M., Park, S., Gianna-Poulin, C., Black, F. O., and Wood, S. 2005. Vestibular perception and action employ qualitatively different mechanisms: I. Frequency response of VOR and perceptual responses during translation and tilt. Journal of Neurophysiology. 94(1): 186-98.

Minor, L. B., Solomon, D., Zinreich, J. S., and Zee, D. S. 1998. Sound and/or pressure-induced vertigo due to bone dehiscence of the superior semicircular canal. Archives of Otolaryngology - Head and Neck Surgery. 124(3): 249-58. 


\title{
Greetings from Portland, Oregon, USA!
}

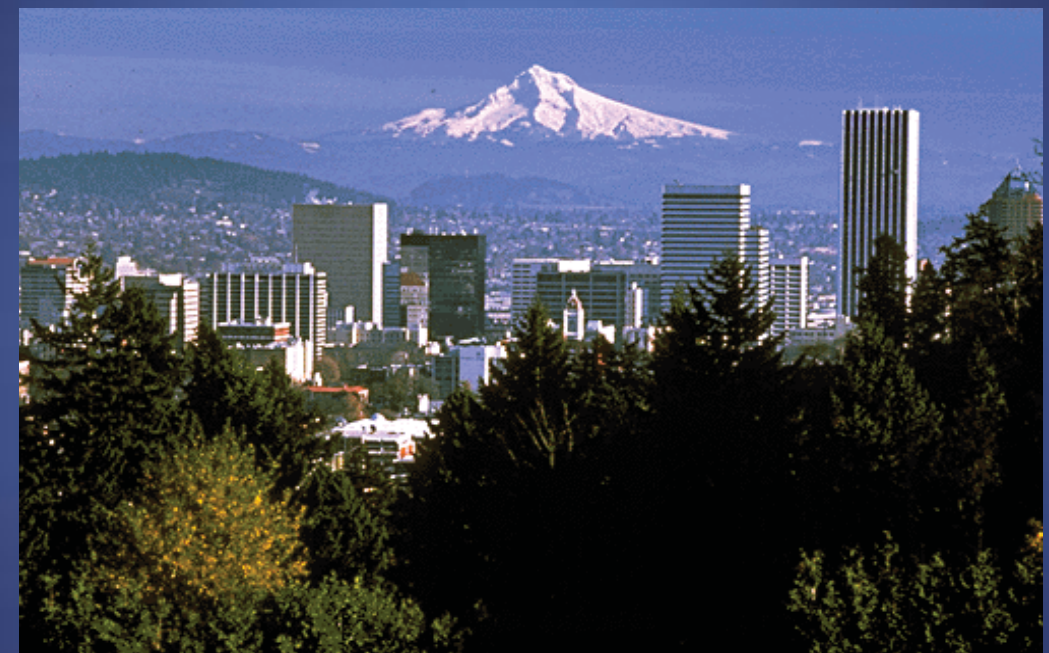

View from Rose Garden

Slide 1

\section{Vestibular Injury and treatment: Clinical Applications}

\author{
Selected References
}

Black, FO, et al.: Quantitative diagnostic test for perilymph fistula. Otol. H\&N Surg. $96: 125-134,1987$

Grimm, RJ et al: The Perilymph Fistula Syndrome Defined in Mild Head Trauma. Acta Otolaryngol. Suppl 464, 1989 (Retrospectivereview)

Black, FO et al:-Surgical management of perilymph fistulas. A new technique. Arch. Otol. H\&N Surg.: 117:641-688, 1991 (Outcomeanalysis)

Hanes, DA \& McColllum, G: Cognitive-vestibular interactions: A review of patient difficulties and possblemechanisms. JVR 16:75-91, 2006

Slide 2 


\section{Comments on critical knowledge gaps that need to be addressed in vestibular research}

\section{Contributions inspired by Fred Guedry}

F Owen Black MED,F.A.C.5.

Neurotology Research

Legacy Clinical Research

\& Technology Center

Portland, Oregon

Supported in part by NASANAGW-3799, NIDC DC-00205, LPH RAC

\section{Slide 3}

\section{Co-Investigators}

John M. Epley (Portland Otologic)

Fred E. Guedry (NAMRL)

Jan Holly (Colby College)

Dan Merfeld (MEEI)

William H. Paloski (NASA/JSC/ U Houston)

Sukyung Park (MEEI)

Claire Gianna-Poulin (RSD NSI)

Scott Wood (USRA)

Slide 4 


\section{Epidemiology}

Prevalence of vestibular dysfunction in the US population aged 40 years and older from 2001 through 2004 is $35.4 \%$, corresponding to 69 million Americans.

Agrawal, Y et al.: Disorders of Balance and Vestibular Function in US Adults. Arch Internal Med 2009; 169(10):938-944

1) Findings consistent with $\sim 25 \%$ abnormal vestibular function in candidates for participation as control subjects in NASA \& NIH funded studies.

2) Obviously a major potential source of variability in putatively normal subjects?

3) Recommend baseline vestibular function tests for inclusion in research projects. (NASA now considering baseline vestibular tests as part of annual crew physical exam)

Slide 5

Close gaps between what we know about the physics of motion and vestibular perceptions (symptoms)

Contributions inspired by Fred Guedry and collaborators

Slide 6 


\section{Fact:}

\section{Vestibular stimulation may not}

produce perceptions

1) Normal subjects.

Example: Linear acceleration of gravity constantly stimulates the otolith receptors producing no symptoms.

Slide 7

\section{Fact:}

Abnormal vestibular function may not produce perceptions (symptoms)

2) Example:

Bilateral loss of vestibular function, if symmetrical and incomplete does not produce symptoms unless loss occurs rapidly and/or if loss is severe.

Slide 8 

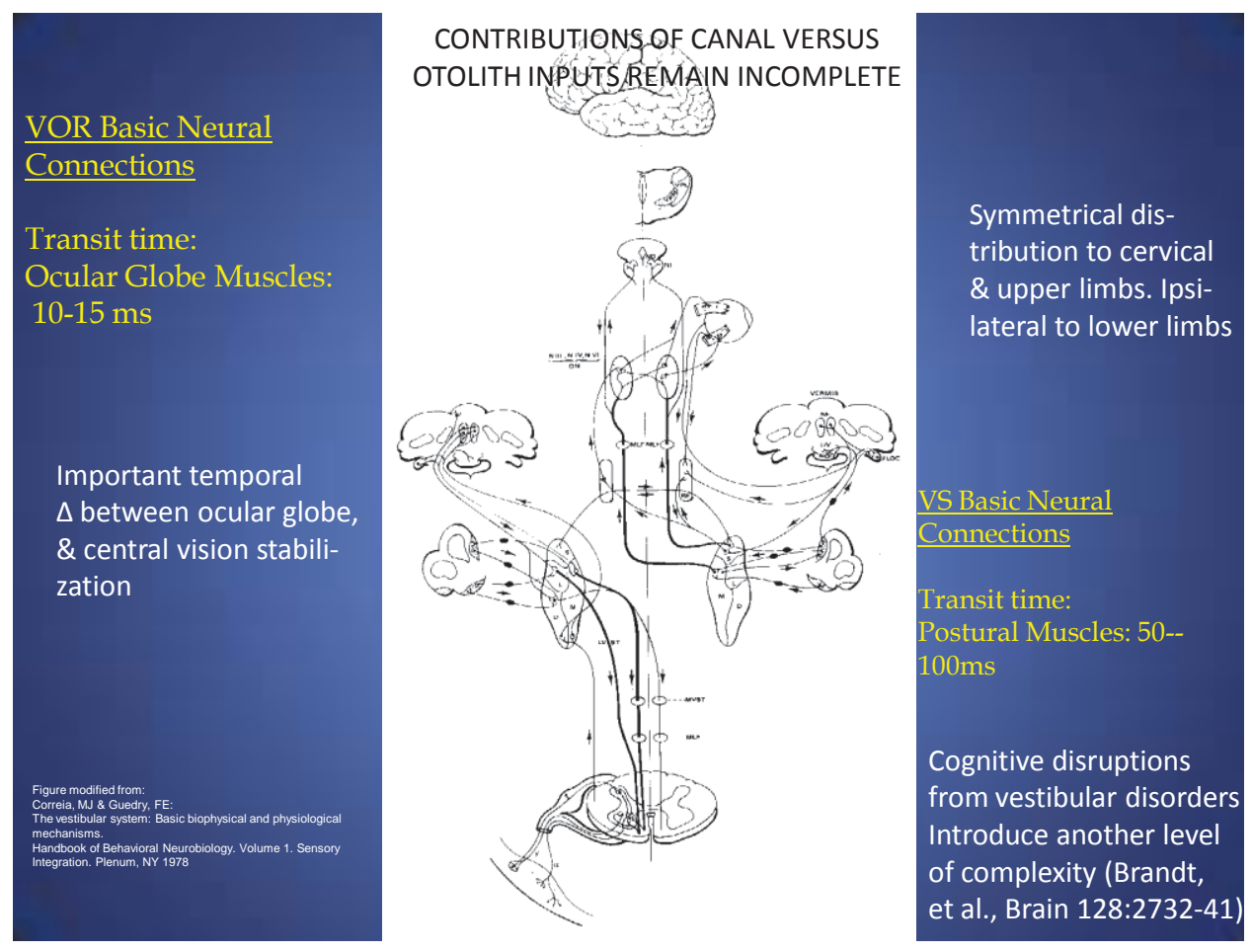

Slide 9

\section{A Missing Link}

Otolith Contributions to Vestibular Information Processing:

How does the brain differentiate head tilts from head translations?

1. Normal Subjects

2. Abnormal Subjects

Slide 10 


\section{GIF Resolution Hypothesis}

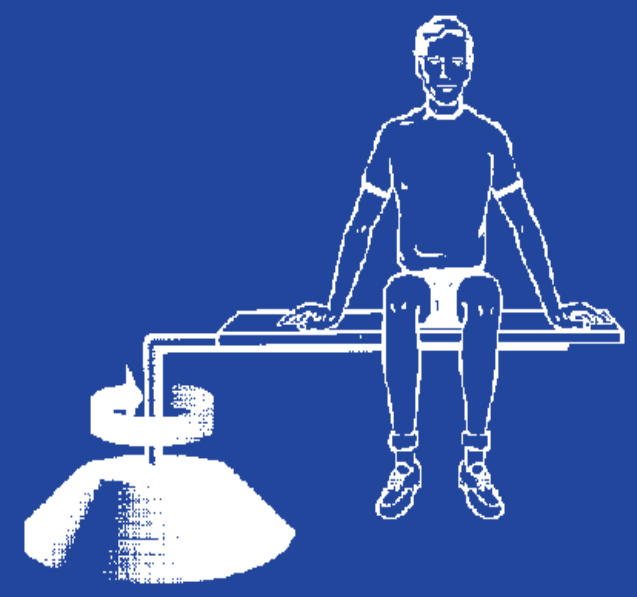

$f=$ Gravito-inertial force vector (GIV)

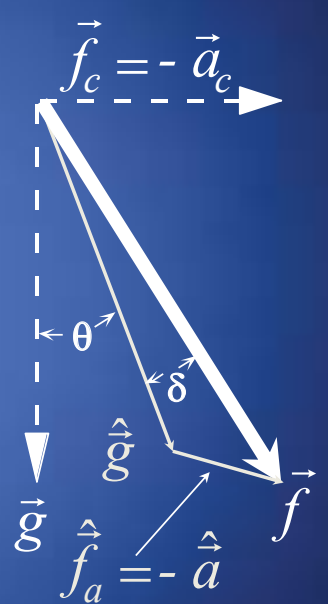

$\theta \square$ tilt, $\delta=$ translation $\theta \%$ or $(\theta+\delta) \%=$ roll tilt

Slide 11

Summary of Stimulus Paradigms:

Question:

How does the brain differentiate tilt from translation?

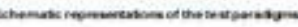

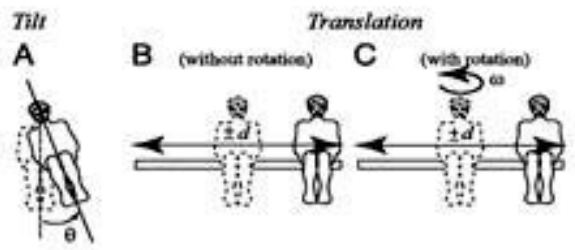

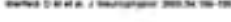

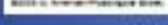

Responses studied:

1) VOR

Torsion

Horizontal

2) Verbal reports (including magnitude

estimation)

3) Somatosensory estimates of earth horizontal

Merfela, DM et al: Vestibuler Pexeption end Action Employ Qualitatively Dimerent Wexhenisms: L. Nourophysiol S4: 199-205, 2005.

Slide 12 
Summary of Stimulus Paradigms:

Question:

How does the brain differentiate tilt from translation?

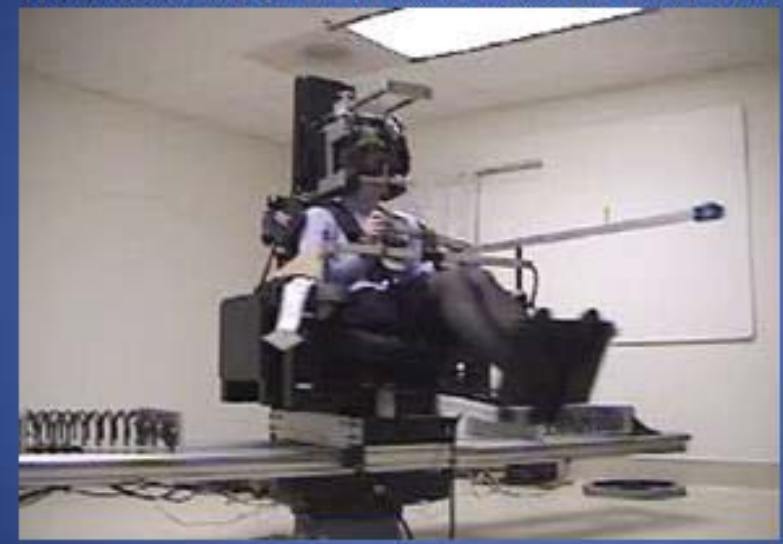

The report authors captured this image

from a video presented by Black.]

Mertela, DM et al: Vestibular Pezeption and Action Employ Quelitetivelf Diferent Meansniams:

1.J Mourophysial S4: 195-205, 2005.

Slide 13

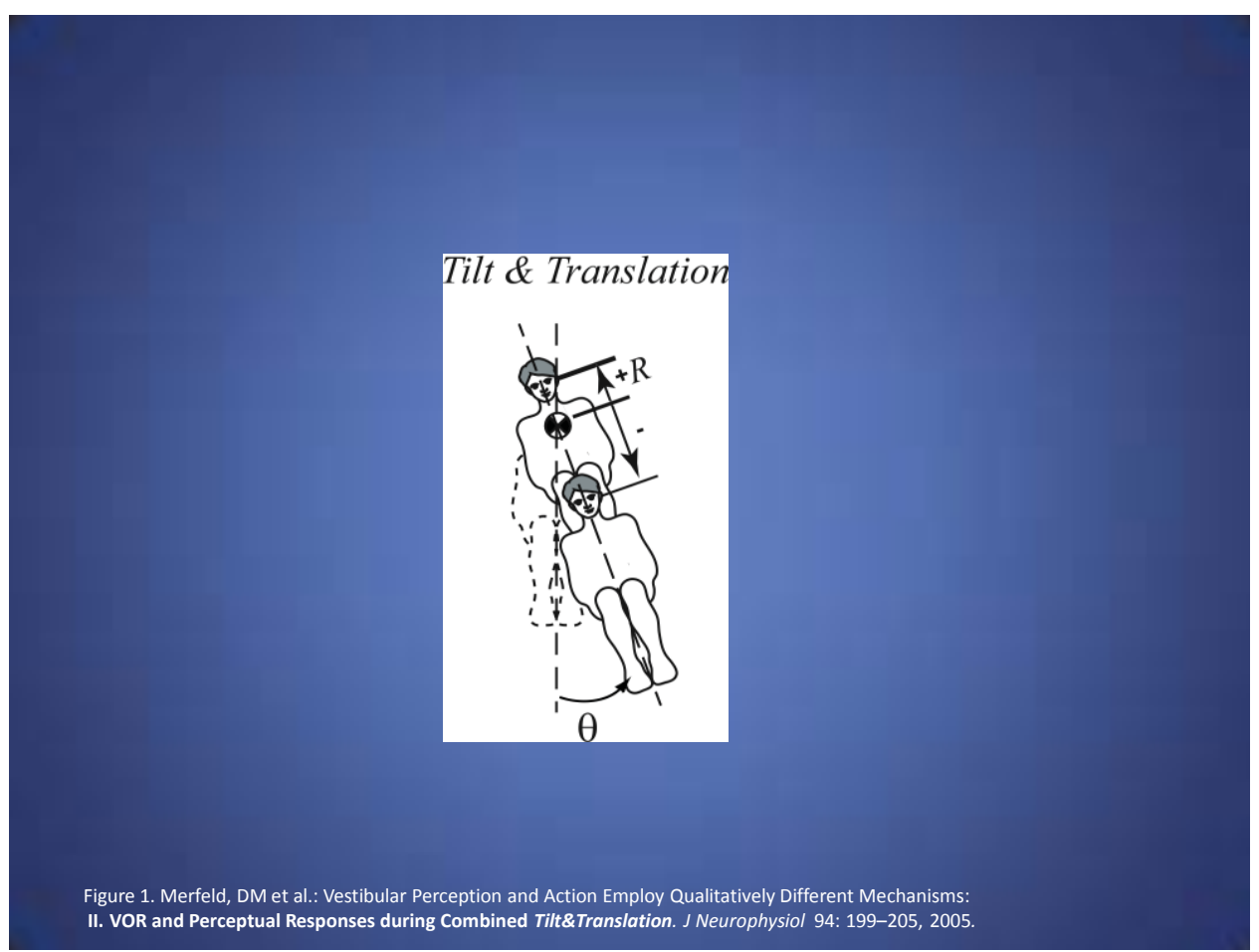

Slide 14 
Summary of Stimulus Paradigms:

Question:

How does the brain differentiate tilt from translation?

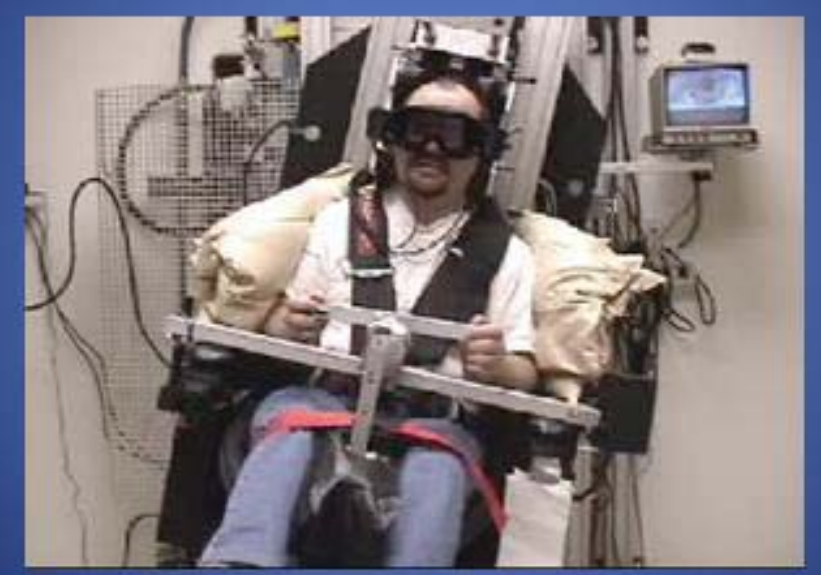

[The report authors captured this image from a videopresented by Black.]

Slide 15

\section{RESULTS}

Qualitatively different mechanisms contribute to human perception, action \& symptoms

Tilt perception clearly dependent on canal cues

Depending upon which system (VOR, verbal/cerebral or somatosensory) is being assessed, normal subject responses may be as much as an order of magnitude in error with respect to the motion dynamics!

FOB opinion: Abnormal vestibular mechanisms governing these systems unknown but are critical for the identification and successful management of vestibular disorders.

Merfeld, DM et al.: Vestibular Perception and Action Employ Qualitatively Different Mechanisms:

I. Frequency Response of VOR and Perceptual Responses during Translation and Tilt. J Neurophysiol 94: 186-198, 2005.

Black, FO: Why the history from vestibular patients is often misleading. U. CO Ultimate Ski Meeting, Vail, CO 2008

Slide 16 


\section{CONCLUSIONS}

\section{Qualitatively different mechanisms contribute}

\section{to human perception, action \& symptoms}

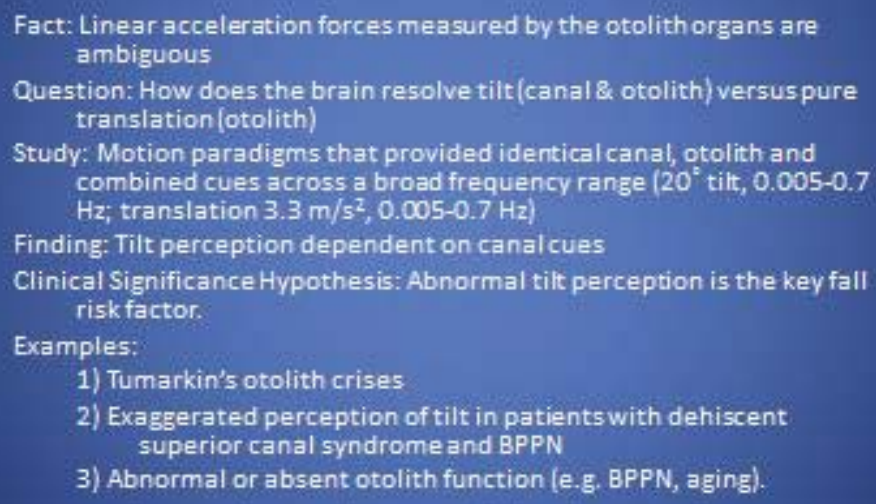

Slide 17

\section{Next Steps}

Study:

1) Vestibular fall risk factors in humans

2) Roll-tilt perception in patients with BPPN, aging \& dehiscent superior canal syndrome

3) Abnormal or absent otolith function CVEMP OVEMP

Slide 18 


\section{Complaint}

"When the plane banks, I feel upside down."

45 y/o otolaryngologist with a BS in Mechanical Engineering

Slide 19

\section{Complaint}

"When the plane banks, I feel upside down."

45 y/o otolaryngologist with a BS in Mechanical Engineering

? BPPN \& V

CVEMP: Threshold 60 dB (normal 90 dB)

CT Scan: Dehiscent Superior Canals

Slide 20 


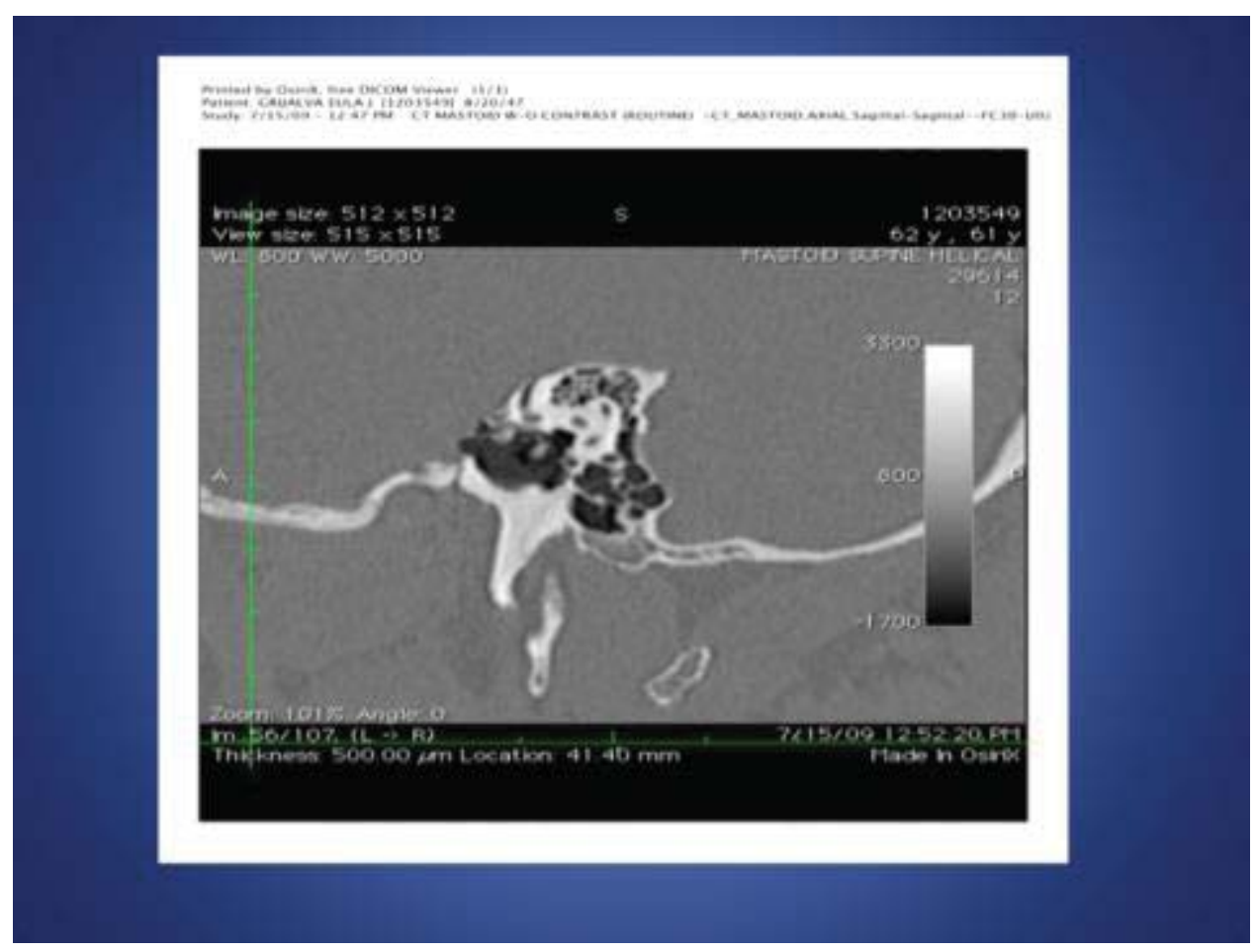

Slide 21

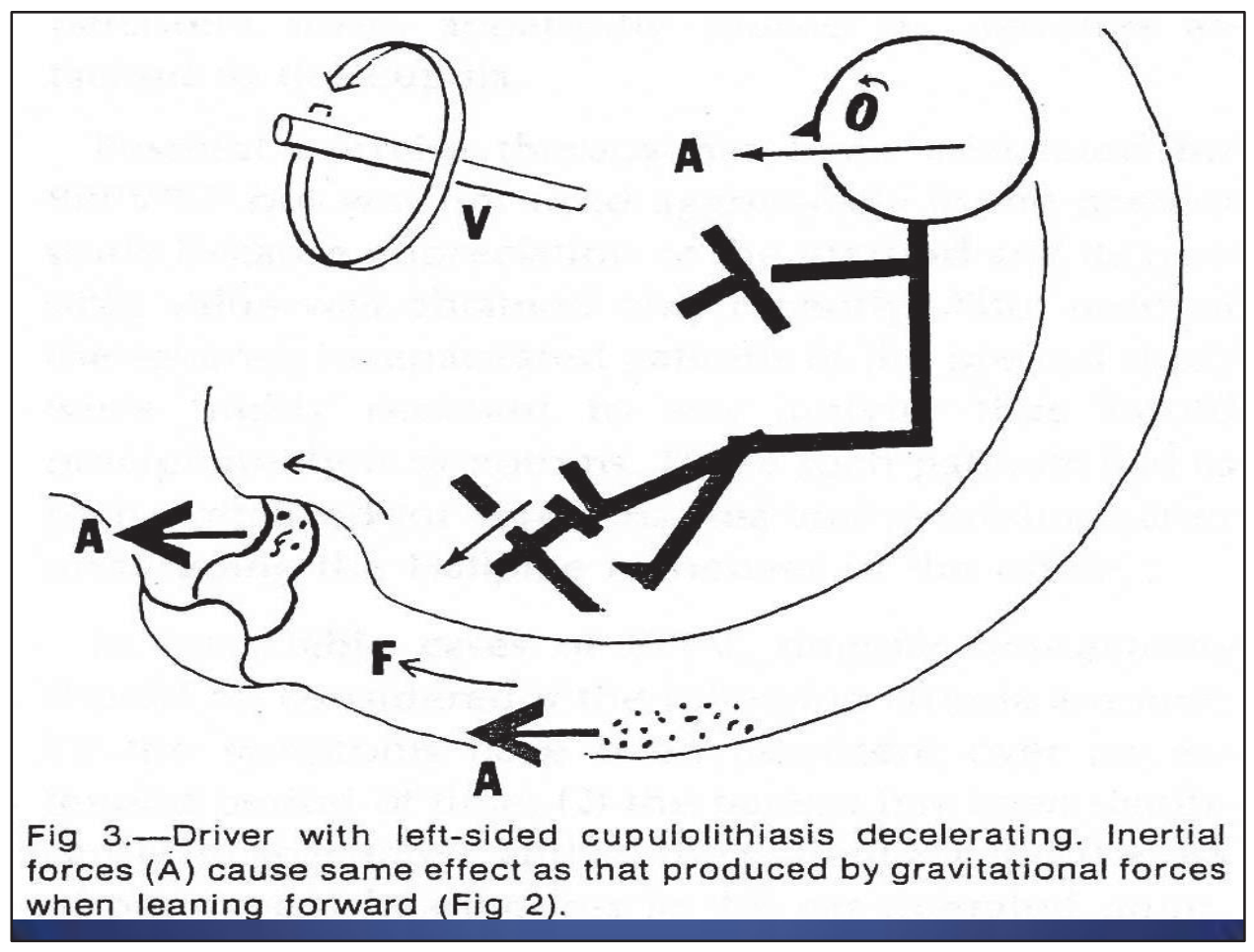

Slide 22 


\section{CONGRATULATIONS}

TO: Fred Guedry Students and Colleagues!

The Wheels of 1 ife
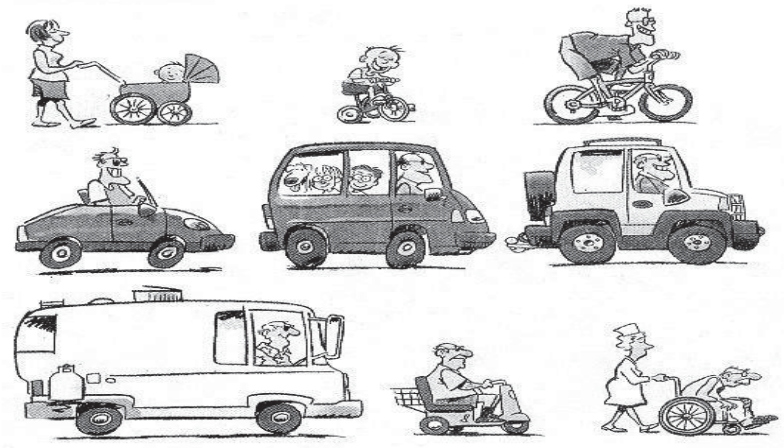

Slide 23 
Question and answer session

[Goldberg] [I have] two points: In the beginning of your talk you said that we don't perceive things, vestibular things, and I would agree, but I want to make sure that we're on the same page, which is to say that most proprioceptive systems, of which the vestibular is one, tend to refer things to the actual body movement, not as a distinct sensation. It only becomes a distinct sensation when it becomes nonveridical. That's what I mean. Is that what you mean?

[Black] Well, Jay [Goldberg], I am never on the same page as you are, because you are way ahead of me most of the time, but I think that what the vestibular system basically does is respond to change. So if the change is of a sufficient magnitude, then it will generate a perception, but under what are [known as] "normal systems" (and you can argue whether it is adaptation or conditioning or whatever) it just doesn't come to conscious level or perception levels.

[Goldberg] Well, Alan [Benson] is right here [with us], so if he disagrees with me, well I will be surprised. I move my head [after which] I don't have a distinct vestibular sensation. I say to myself-because it's veridical (the visual, the somatosensory, and the vestibular all are in congruency) - that I moved my head. I could probably tell you how many degrees I moved it. I could probably give you a less accurate estimate of how fast I moved it, but I don't have a distinct sensation. I'll remind you that we did not know there was a distinct vestibular system (it depends on when you want to do it) [i.e., which paper you cite as the discovery of a distinct vestibular system sensing acceleration], [until] maybe 1850, [due to] a strange observation of Goltz's, and then, the three people in 1875, Mach and Breuer and Crum Brown* . Am I making sense Larry [Young], or not?

\section{[Young] Yes.}

[Goldberg] If I move my hand, now I've got proprioceptive input coming from all kinds of limbs, but I don't describe that as an activation of receptors. I describe it as, 'I move my hand out from this to this’ [extends arm fully]. Does that make sense, Måns [M̉agnusson]?

[Magnusson] Yeah, but you are onto the efference copy now.

[Goldberg] Well, of course, but I guess what I'm saying is proprioception, when it works, is veridical, and when it is veridical we refer to the actual movement or to the position and not to a distinct sensation. If, on the other hand, the system gets screwed up, then we're consciously [aware]... but it's usually referenced to either motion of the body or motion of the world. It isn't the color blue or C-sharp. That's the only point I wanted to make.

[Black] It seems that one of the things that Fred taught me was... say for example, you are standing quietly and then you move, and you perceive that there is no movement in the periphery in your visual field. But if you look closely at something that is built to Earth's vertical, in fact, it is moving, but you don't perceive it as moving. And so, I think what I was trying to get across

\footnotetext{
"Early work on the vestibular system was done in the 1800s, e.g., by Flourens (1830), Mach (1873), Crum Brown (1874), and Breuer (1875).
} 
here is the patient or the normal subject usually doesn't describe the vestibular contribution to that movement as an interpretation of the world. That may be a better way of putting it, and that may be in the mapping system, the internal model system, that says that it is all consistent so there is nothing wrong. I think that is the point I was trying to make, and I see Alan [Benson] moving his head there, so maybe you want to comment.

[Benson] I essentially agree. There is a difference between active movement and passive movement. I do this [moves Goldberg's arm]. Now that I moved your arm, now that is a different situation.

[Goldberg] That's true because in one case I have efference copy, and in the other case, I don't.

[Benson] You make a statement saying, 'Yes. You have moved my arm.' There is that extra piece.

[Goldberg] Yes, but I certainly would not say 'it's C-sharp or yellow' or in that case, I would probably be able to describe the tactile input.

[Black] Jay [Goldberg], I often think about [studying] the vestibular system in an Earth gravitational environment as [analogous to] trying to study the auditory system with a hundred $\mathrm{dB}$ signals in the environment. When you go in orbit, the crew will describe [how] when they wake up - not knowing where on Earth any of their limbs are and they will have to move them to determine their orientation. Sometimes, they have to move [a limb] enough to move the body. So the veridical on Earth is really G-force generated. I'm not sure if that helps or confuses things.

[Oman] Owen [Black], can I [make] a comment and [ask] a question? The comment is that if we look carefully, as we did in astronauts when we started asking questions about oscillopsia (everybody has a little bit of oscillopsia), do you think that if we had better ways of measuring oscillopsia in patients, you know, putting them in a feedback loop and having them stabilize a visual environment, that we would get anything that would be valuable clinically? Or would it just be too variable?

[Black] As a matter of fact, [that relates to] the discussion that we had, regarding the Halmagyi tests (Curthoys-Halmagyi test for moving the head and the refixation saccade). As the subject begins to adapt or adjust to that, the subject will still describe - if the loss is severe enough - a shift to the visual surrounds. At this point, that is not very easily quantifiable. So, yes, I think it would [i.e., measuring oscillopsia would have practical application], and the reason that it is practical is that if the subject changes any - say they are walking around - they are still getting the heel strike which is distributed to the head, and if they change their surface, they will have trouble. They will describe it to you. There are some surfaces and some types of shoes that they cannot wear because of it, and yet, we cannot measure it. So yes, I think it would be valuable.

[Young] Owen [Black], let's return to this question of perception of motion, of which, part of it is the perception of vestibular inputs. I think we're all familiar with the distinctions Alan [Benson] laid out [i.e., explained], first of all, about type one, type two, and type three spatial 
disorientation. Type one: you are disoriented but you don't know anything about it; type two: you know that something is wrong; type three: you are just totally confused [e.g., by] vertigo. It's clear that the stimuli to the vestibular system can result in perceptions of motion if you are forced to attend to them. So perception indication of subjective angular velocity during postrotatory phase is clear. It has been described. It has been used for some time in so-called cupulograms in the late nineteenth century, right up through the twentieth century. It is also clear that they are dissociated as we've heard discussed a couple of times today and yesterday. They're dissociated from other quantitative physiological measures, like the slow-phase angular velocity of nystagmus. To me, what seems interesting (and what should be interesting to not only the neuroscientists, but also to the clinicians) is what is involved with that dissociation. I mean, let's just take that very simple case that I think we have all been exposed to. Rotate at a constant angular velocity; come to a stop. Your perception of angular velocity decays and overshoots. Your slow-phase angular velocity also decays and overshoots with two different time constants [for slow-phase velocity versus a faster, constant velocity], neither of which is the same as the cupula time constant. I think, considering that as a very simple example, we must pay attention to the value of the reports of perception that are based upon vestibular stimuli. The real issue, as Fred taught us very often, is how you ask the question. How do you ask the question in a way so that a subject can give you a rational, quantitative answer? Quantitative [responses] [such as], 'I am spinning at 10 degrees per second,' or 'I am no longer turning to the right.'

[Black] I certainly agree, and actually Claire Poulin and our group did a series of experiments (and this came out of some of the findings in our space experiments). What we were interested in was this very issue, that is, the issue of different time constants and perceptions after rotating and sudden stops. We did a series of experiments, and I think I actually talked to Fred about the paradigms we were using. So we had the subjects spin, and this was all presented randomly, by the way. We had them spin and tilt their heads which, of course, produces dumping, the time constants drops to the "nerve constant." We also had them perceive various body positions that they would experience in everyday life, like floating on a lake, and so forth. What is interesting is that none of those perceived positions produced any change in the time constant. It was only the actual movement of the head, the otolithic input, that produces change. One of the reasons we didn't report the perceptions was that we had no good way. The reports of the perceptions were all over the map. They were so variable that we just couldn't figure out a way to present them systematically. So what you say is very important, and it is very important to go to the abnormal case in patients who have the unilateral loss of vestibular function for whatever reason (a neurosection, a labyrinthectomy, or so on). The classical idea is that those patients adjust or compensate, but if you passively move their head, like Alan [Benson] said, they will forever have a sensation of continuing to move in the direction of the labyrinthectomy. And, of course, the time constant is fixed, it doesn't change, but they are still having this sensation of moving after a sudden stop in the direction of the abnormal ear. What is the mechanism for that?

[Young] Not to belabor it, except a little...

[Laughter.]

[Black] I was trying to suggest there was still some velocity storage... 
[Young] We are talking about what is potentially a difficult thing to describe. We are talking about trying to describe [perceptions of motion] even if we assume the body...

[Black] Oh, you are still focusing on the sensations then. Okay, alright.

[Young] Even if you are considering the body as a single rigid body (which, obviously, it is not), we are still talking about something that has 3 degrees of angular freedom, 3 degrees of linear freedom. It gets complex. Therefore, it seems to me you have to be clever about the question you ask and how you ask it. For example, [regarding] the things that Alan [Benson], Fred, and many before them did on perceptions of angular velocity; when you ask the question [in] a [certain] way, such as, 'when rotating about a vertical axis, tell me each time you click past 90 degrees,' that is [the kind of] question that can be answered. If you align to the perceived vertical, the SVV [subjective visual vertical] — you can do it. If you separate it out axis by axis [you can do it]. We just completed some complicated experiments in a flight simulator, in which we have the subject align a little stick to what he believes is the direction of the center of the Earth. Then we have them come back and do it again and have them indicate something else. I think these are not only possible, but they can be very valuable for us, maybe even for the clinicians as well.

[Black] I agree.

[Rupert] That is actually a very good point, Larry [Young]. One of the things that Fred always would emphasize is how you get that perceptual information, and you would try to do it in three ways. One, you would ask them what they had perceived. You would give them a doll or a dummy, and you would see that what they were describing [verbally] didn't match what they were physically doing [with the doll]. But, before you had done that experiment - and really that was the big advantage of being here in Pensacola-you would have flight students (sharp [skilled] people like John Beaton) who were mostly engineers and pilots, who were trained in understanding description of orientation in space. That's what I think helped make much of Fred's data, but there was more than one way of getting information. It was verbal. Sometimes you would see people say 5 degrees and they were holding [the doll] at 45, so something was going on there.

[Oman] I just want to repeat something that Dan [Merfeld] and I were discussing earlier this morning. I think we should also remember that the brainstem is basically an acceleration and velocity-based computer. If you are talking about orientation, particularly azimuth perception or place, you kind of have to go upstairs to [consider] the limbic system, to those direction cells and place cells and things like that. And there are some dissociations that can develop, which are reflected in things we discussed at this meeting (the dissociations between the sense of spinning and the angle turn and so forth). For example, I remember years ago I was asking Fred what is the best way to measure subjective angular velocity, and I think Fred answered, 'Well, you have a pointer, and you ask the subject to just kind of keep the pointer north and take the velocity of the pointer, and that's subjective velocity.' I'm not sure that's right ${ }^{*}$.

*Oman means he is not sure if he is quoting Guedry correctly. 
[Benson] The problem is you'll be dealing with basically intelligent, perceptive subjects. I think your problem is many of your patients are not intelligent, perceptive subjects* .

[Black] Exactly, and actually Jan Holly and I had a series of conversations about this. In the same paper [from which] I showed you the figure from John Epley, he presented a series of patients with BPPN and vertigo, of posterior canal (one canal) involvement. Then he put up the array of symptoms that the patients had and did singular neurectomies (that is, sectioned the nerve to that canal), and in most patients, all these array of symptoms went away, even though they were not consistent across subjects. But after the section [the neurectomies], there are still some symptoms produced by the Hallpike maneuver. Of course, the obvious question or concern with the patient with abnormal function is that these [effects] can be more distributed in the canal, but I think the point is that we need to take a look, systematically, at the symptoms that are produced that went away when you de-afferentiated the canal, and what the basis for them is, because that's the way the patients present. As a matter of fact, another problem with BPPN is that if you do a prospective study and you survey a group of subjects (say, for example, who are getting ototoxic drugs), glory be, a significant number of those subjects will show a BPPN if you test for it. A patient will not complain about it, but if the patient does complain about it, it is immediately assumed that because they are getting the ototoxic drug, that that is the cause [of the BPPN]. So not only do you have the confounding issues that you have just described, you have the confound of the clinician interpreting what the patient is describing as due to whatever situation or condition that is under examination. So, that is one of points that I had hoped to discuss, and that is why I think we need systematic studies, to understand these issues better. I have to say, Alan [Benson], the types of things that you and Fred have done have been immensely helpful to us, because, now, it has given us a way to look at these symptoms that I think we would not have had otherwise. The request that I had of Jan Holly is that we need to look at the eye movement and get the modeling for the actual eye movement. Then, we need to get a model for the perception and, then, if you could give us a library of these, we could present them randomly to the patient who can't describe what is going on, and that would be most helpful to us to, then, try to better understand these perceptions.

[Benson] Can I just go back to benign positional nystagmus? Is the idea no longer of cupulolithiasis?

[Black] Well, yeah. I'm sorry, I didn't mean to imply that cupulolithiasis is not a viable concept. It is, but the nystagmus and the nystagmus patterns are quite different between the cupulolithiasis and the canal lithiasis.

[Benson] Why?

[Black] Well, because the cupula is loaded, so you don't get the delay that you get with the clumps in the canals.

*Benson does not mean the patients are unintelligent, but rather that, on average, they are not as educated and trained as the aviator groups that are usually studied. 
[Goldberg] The kinetics I get [i.e., I understand], but my reading of the literature-certainly not as good as yours - is that most BP-whatever is due to canal lithiasis; am I incorrect?

[Black] Both of them are.

[Goldberg] Yeah both, but what percentage?

[Black] You know they're published, but I can't recall them offhand.

[Goldberg] Alright. It just was my impression that most people thought that...

[Oman] It depends what you call it too.

[Goldberg] If the otoconia are in the canal duct, it leads to different kinds of kinetics than if it is plastered against the cupula.

[Black] That is correct.

[Goldberg] Can I make two more points? [Laughter.] And then we can go. Firstly, you are absolutely wrong. [Laughter.] We are not sitting in a 1-g noise field. The fact is that if you are upright, you can take a line and align that to the Earth vertical within about a degree. That is not noise. That is a signal. Your otoliths know where you are, relative to gravity, I presume. The second point to be made, as I've heard other people talk, is the notion [that] the brain is a sensorium, that all this information goes into this sphere, and therefore, it's sort of surprising when things are different. When you consider all the components involved, including the cerebellum, which is really important, and as Chuck said, including the squash, ${ }^{*}$ which is certainly important (and may do more than just help us do path-finding), you've got a really complicated problem. So you said that it was difficult to understand the distinction between translation and tilt. Now, both Dan [Merfeld] and Dora Angelaki have come up with reasonably equivalent explanations, but there are still problems with them. For example, in humans, I'm told, you don't see linear eye movements, but in monkeys, you do. So what you can say is, 'hey the brain is complicated.' Obviously, in humans, we have different circuitry, because the brainstem circuitry is definitely not where we are computing this. It most likely is a nodulus or something like that. Okay, so we ought to think about [the fact that] this doesn't help you as a clinician but it certainly doesn't raise philosophical questions about the brain [being] screwed up or something like that.

[Black] Well, I don't think the brain is screwed up. I think the vestibular input is disturbed. When you say a person can align vertical: if they lose otolith function and you look at their ground reaction forces or measure their position relative to Earth's vertical, [you will see that] it is all over the map. So they need the vestibular input for that function.

[Goldberg] I actually looked that up because, as you know, we are writing a book and things become fairly noisy, but it's remarkable. You do have a proprioceptive system and you

\footnotetext{
*The authors conjecture that Goldberg may be referring to the hippocampus here, which can be studied via squash smears.
} 
can align the Earth's vertical to within 5 to 10 degrees, and actually that was work done in LD [labrynthine defective] subjects here.

[Rupert] But, your good friends in Chicago, Hain [Timothy] et cetera, are using subjective visual vertical all the time as a good measure of unilateral loss of function.

[Goldberg] Okay. I have no quarrel with that. It's just that with the...

[Rupert] Ian [Curthoys] has a question, back there, that he wants to...

[Curthoys] I don't want to cast any negative comment about it, but I just want to add a note of reality because I completely agree with you about how valuable investigations of patient perception can be for understanding basic vestibular function; there's no doubt about that in my mind. It's going to be difficult, and all of these questions we have been talking about (quantifying perception etc.) have got to be solved. But I came from Australia via Shanghai and the reality was brought home to me in Shanghai through Fudan University where they see 3,000 patients per day. So it seems to me the emphasis in terms of diagnosis-I mean, 3,000 busy people have to be evaluated and treated per day-the emphasis won't be on getting their perceptions, the emphasis has got to be on getting fast and accurate measures, and that's why I have been pushing so hard for these VEMPs [vestibular evoked myogenic potentials].

\section{[Black] I agree.}

[Curthoys] My only other comment is just something following up something [a question] Jay [Goldberg] raised. It is about the superior canal dehiscence, and the role of the superior canal, and relating that to the responses and Lloyd Minor's contribution, which is obviously true, but, it is obvious to me that it is not the whole story. We have written up [a report] this year [on] a patient that had bilateral superior canal dehiscence, where both canals collapsed. So in fact, neither canal was functioning, and we know that from [unintelligible] with the video. That patient had very large bone-conducted oVEMPS [ocular vestibular evoked myogenic potentials]. That is telling us, I think, that the utricle is, in fact, contributing substantially to those oVEMPS and is a factor in understanding the mechanism of superior canal dehiscence.

[Black] Well, you just described why we need systematic evaluation of those patients, and I'll give you another example of dehiscence of the semicircular canals. I had a patient who had bilateral dehiscence of the superior semicircular canals, very large dehiscences. She was an aging jockette. She wanted to continue to play sports and so on and so forth. To make a long story short, I plugged one of her canals (the most symptomatic side) telling her that she was going to need the operation on the opposite side. Two days later she calls me up and says she was asymptomatic. And so, I think you are right. I didn't measure her responses, but during the thrust test she didn't have any function in that opposite side. So you are absolutely right, but again, I think that understanding the perceptions that the people give to us in the form of symptoms are, in a way, not related to what people normally perceive from the vestibular system. And the second point that I would make is that the perceptions that the patients do present with are widely variable. And the third thing that I should say is that I think we need the documentation to justify, well first of all, to identify pathologies that are consistent with the 
abnormality and second of all, to do the planning. That was my point. Coupling the symptoms to those latter issues is the problem that the clinician has. Did I say that my friend Dennis O'Leary, my colleague, always chided me about being a clinician, [whom he joked is] a person who makes decisions on insufficient information? I think that's basically where we are. [Laughter.]

[Rupert] We are going to have one more comment before we break this session and it is going to come from the Swedish side... one last clinical comment.

[Magnusson] Could I make it two? [Laughter.]

[Rupert] Yes, Jay, you can make it two. [laughter - Rupert is talking to Magnusson as if he is Goldberg]

[Magnusson] Well, a Swedish 10 minutes is a trifle shorter than the Australian ones. [Laughter.] There is a paper by Jackson in 2007, ${ }^{*}$ I think, with 260 consecutive cases of posterior canal lithiasis (number one), lateral canal lithiasis (number two), lateral canal cupulolithiasis (number three), anterior canal cupulolithiasis, and then canal lithiasis, and then ending [with] posterior canal cupulolithiasis. It's a kind of gradual thing. This is how you see it, I mean, that is the comment. Owen [Black], don't you think, actually, we have a problem because the patients are not always telling us what they perceive? They are telling us how they interpret their perceptions.

[Black] That's correct.

[Magnusson] And to go backwards and find the perception is difficult.

[Black] Absolutely. Sometimes they describe their symptoms. Sometimes they describe how their problem affects whatever it is they are doing. That is another whole issue. And also, the situation that you described where you have multiple canal involvement is a totally different ball of wax.

*Jackson, L., Morgan, B., Fletcher, J., Krueger, W. W. 2007. Anterior canal benign paroxysmal vertigo: an underappreciated entity. Otology \& Neurotology. 28: 218-22 
Vibrotactile postural control in patients with sit-to-stand balance deficits and falls - Karen

\section{$\underline{\text { Atkins }}$}

Thank you very much, I'm Karen Atkins. I am a new Ph.D. researcher. I met Angus Rupert 20 years ago and was very interested in sensory enrichment, and went back at my tender age and worked on my doctoral degree, which I have attained. I did this for the sole purpose of bringing through [to fruition] the sensory enrichment cueing, and specifically, my dissertation was on the vibrotactile side of this [Atkins, 2010a; 2010b]. What I found with my dissertation (and of course I am a physical therapist) was that the patients responded to this very, very well — that we could teach our patients skills faster, and we could actually improve their functional outcomes almost by 100 percent. Of course, my subject cohort was a limited number of subjects, and we're now in the process of creating a large four site, if not eight site, clinical trial [slide 1, page 135].

This [slide 2] is in tribute to Fred [Guedry] because he created a monster out of Angus [Rupert]. [Laughter.] As many of you probably know, the idea of using vibrotactile sensory enrichment came from Angus when he was skydiving in the nude [Rupert, 2000; Rupert \& Kolev, 2008]. [Laughter.] The story goes, as told by Angus, that he was able to feel much better (in terms of how to move his limbs) so he could get the proper flight status with skydiving, through the sense of touch. What we have found is that, in fact, was a brilliant idea because the sense of touch, first of all, is the soonest [earliest] laid down neuro circuit in a developing fetus, and it is very much ingrained with the somatosensory cortex. I'm going to make a couple comments regarding why that's so important in a moment.

As a clinician, I have to consider several things [slide 3]. First of all, I have to consider how [in what condition] the patient comes to me. [For] a lot of the engineers in the room, I feel that there is a sense of uncomfortableness because you like to have all of your parameters very straightforward, solid, and consistent. I never get a single individual that's identical [to any other patient], and I have patients that range from 7 years old to 89 years old. The particular mandate that I was given, in terms of SBIR [small business innovation research], to develop a sensory enrichment device was for the military folks with mild traumatic brain injury, and of course, that's a more [physically] fit, younger population. I tend to work with (in my clinic) an older population, and their needs are similar in terms of diagnostics: Yes they have vestibular deficits, yes they have peripheral neuropathies, some of them have brain injuries, some of them have cognitive disorders, but no two individuals are alike. I have to look at the task I'm trying to achieve and I have been discussing at length [that] to teach somebody to stand still with their eyes closed is a very good thing, and there [are] a lot of ramifications and carry over with that. Indeed, in our study [Atkins, 2010a; 2010b] we learned that you can actually transfer knowledge to a different task and there is a time frame where you can do the task without the device. But, in reality, what we are looking at is how can you reintegrate into your normal activities of daily living. Of course, that incorporates locomotion, large movement tasks such as sit-to-stand, and every time you add another layer onto the dynamics of the task, you have to really think about that layer and how you're going to incorporate that into a training type of device.

This brings us to the point that we really need to consider: [the] technology available to us. When I was first introduced to Angus's work with the tactors, he was using them for wayfinding 
for naval divers who were going underwater to disarm bombs. They would use sonar on the top and then alert the guy [below the surface] to move to the buzzer [move according to signals from the buzzer, such as signals to] turn left [or] turn right. Now what I'm finding is that not only do I need to incorporate wayfinding so that I can train you to keep the tactors quiet [not firing], or I can train you to incorporate limits of stability and increase your sway, but I have to be able to deliver the information quickly, intuitively, adequately, so there are a lot of parameters.

So we want to use sensory enrichment for postural control: that's the one sentence statement of my mission, but there are a lot of parameters to consider. Now, because I'm not an engineer, and I am very comfortable with stepping into the unknown, I have to say, I really appreciate the feedback I've been getting from this crowd, which is that I need to be able to mine data; I need to be able to set normative parameters; I need to be able to consider pre- and post- training in a mathematical way, and I appreciate all those suggestions. Indeed, those will be incorporated into the design and we'll work in that direction. It's very unusual to be able to merge [the work of] a clinician, such as myself, with [that of] an engineer. I have to give a lot of credit to Bruce Mortimer because he was actually on my dissertation committee and we found that [merging] to be a challenging task, but I think we're very proud of the fact that we were, in my opinion, the first people that took a step in that direction and it's been very beneficial for both of us. It's still kind of interesting because no matter how hard we try to merge the two disciplines, I still am polarized on my clinical views and I still feel that there is a polarization (and I don't mean it in a bad way) in terms of merging the engineering side of this. So I would appreciate all of your input in that vein.

Most of you have never seen patients. This [slide 4] is a patient who has a vestibular problem and a sensorineural problem, and what I want you to take away from that is [that] to do a simple pivot turn doesn't mean that you can just tell them, 'this is how you do the activity.' You've got to realize that these people all have sensorineural deficits that go into the equation. With this particular person, you notice how she over-swayed [slide 4 shows video capture of patient swaying], and that's me catching her. One of the things I realized is that I use a lot of touching and tapping and grabbing to bring people back to center, or to push them off- center if need be.

This is a gentleman going from sitting to standing [slide 5]. You notice that he cannot decelerate, and to patients that are at risk for falling, or these multiple fallers, it's not the patient that just sits in the chair and can't get out of the chair [that is at risk], it's the patient that gets up and is mobile where there are consequences. Start looking at who is interested in slips, trips, and falls. The community that I live in is always driven by dollars and cents and they're going to pay in terms of what they consider worthwhile rehabilitation intervention. They don't care if someone had a slip [as simple as] 'oops I had a slip, and then I kept on walking.' There are no dollars attached to that. They are not even worried about people who have trips and are able to recover their balance and continue, although slips and trips are generally thought to be the precursors to falls and fall type activities. What they're interested in is what the dollar and cents consequences are, and what are the quality of life issues that are involved in postural control?

Now, what I would like to do is just take you through a couple of key factors, and these [images] are obviously offloaded from my device [BalanceSense, Limited Liability Company] (you know the software of my device). I did this because I think that what's on my device 
actually expresses the key factors in my personality, in terms of interpreting what's important for postural control. I noticed that there's some conversation [about], and I have some people who model postural control. I need to speak with you and learn in terms of that side of it, too. But what we've tried to do is correlate 3D functional activities onto a $2 \mathrm{D}$ screen, and one of the things we look at is spheres of motion available, and it's very difficult to take a sphere and put it onto a [2D] screen [slide 6]. In Lew's [Nashner] work [Nashner, Black, \& Wall, 1982; Nashner, 1997] (and I'm very influenced by Lew Nashner and NeuroCom ${ }^{\circledR}$ ), he actually will use elliptical information. We can do that, too, by just adjusting our boundaries for this, but my representation of a circle represents a full circle of motion, not just for static stance or for sway, but for locomotion for transitional activities.

One of the things that I've been finding is that when you start incorporating locomotion into a functional activity, it's quite interesting in that the patients don't necessarily have trouble with the first step. It's actually once you start generating a little bit of velocity, and it's the second step where they start having problems. I like to call this the "keyhole" [slide 7]. If I can give a visual representation of the second step, then it gives them a target to shoot for and we can set these limits so they can get vibrotactile information, as well. Not everybody is symmetrical. I did [treated] a cohort of patients that have Pusher Syndrome [Karnath \& Broetz, 2003; Karnath, 2007] and in Pusher Syndrome, not only do you have a stroke with a stronger side and a weaker involved side, but there is an actual misrepresentation of vertical in their brain. So if they're sitting to the left [leaning towards the left while sitting] and I say, 'you are not sitting straight,' they'll say, 'yes I am,' and they will defend that to the nth degree. And if you were to try and create a symmetrical pattern with these patients, you're not going to be successful in terms of increasing their functional ability. I had three Pusher Syndrome patients that had been Pusher Syndrome patients for over 3 years, and they ranged from their mid-forties to their mid-fifties. They had not been able to attain transition from sitting to standing, and by creating what I call a cue map [slide 8], [which provided to them] a visual representation of where they were supposed to go and what they were supposed to do, and by teaching them to dither (that is, to ride the side of the cue map with the vibration on), you can actually change their brain orientation in terms of [correcting] the direction that they perceived they wanted to go to a functional direction. I think that it is incredibly important that you should not assume that the best way to get from point A to point B is a straight line.

Another thing that I think is quite interesting (and I don't have a lot of clinical experience with this just yet) is downward force [slide 9], and the activity that I've used this [for] is sit to stand. Lew Nashner [Nashner, Black, \& Wall, 1982; Nashner, 1997] uses this on sit-to-stand too, and he calls it weight transfer. I'm changing the terminology to downward force so that I can do it with more than just something that requires a weight transfer forward. If you look at a normal sit-to-stand (and what I want you to key in on is the oscilloscope at the top [slide 9]), you get very characteristic patterns (as opposed to someone who cannot achieve sit-to-stand) and then, you start getting some really abnormal patterns [slide 10]. I'm not certain I know what this means just yet, but I think this is another avenue that we can start mining to look at where we need to go to start normalizing someone, and again, this has nothing to do with symmetry.

When you start looking at large movement activities, these activities can be broken down into the components of the activity. In sit-to-stand, for example, [the first component] is sitting, 
where you need to have a reasonable orientation with your sitting, not overly skewed to one side or the other. You [the patient] need to be able to do a prelift (which is a forward lean) so that you can create velocity to start the lift off. The post lift is a downward force. Then, to stand, you have to be able to decelerate to stop the forward momentum so that you can stand successfully without falling. Indeed, a large number of falls occur when someone is getting out of the chair and they cannot decelerate.

Now I'm showing you this [slide 11], can you hear the volume [speaker showed audience a video clip, from which slide 11 was captured]? This patient has dyskinesia with Parkinson's; this is prior to her being put on the tactor device. Now, she's training [slide 12] and what's happening is she's getting a vibrotactile cue, which is going to the somatosensory cortex, and what we think is happening is you can manipulate the cortex. So in other words, although the main deficit in Parkinson's Disease is located in the basal ganglia, a [few] researchers have a hunch that the whole idea of brain plasticity for movement control and postural control has something to do with manipulating primary cortices. For this particular gal, it was an "ah-ha" moment. She was only on the tactors, which is somatosensory, for about 2 minutes, and she was able to calm the dyskinesia. Then, there was also a carryover effect [slide 13] 7 days later — and she was one of my coworkers, so we watched her in the clinic. She did great, and then it [the dyskinesia] started to decline. You skeptics out there are going to say maybe her medication was changing, maybe her sleep patterns were changing, and I'm sure that all factored into it, but, her overall function was not swinging radically [as you would expect] with those types of changes [slide 14]. So there is a carryover effect with this. We were discussing with the Wicab [BrainPort $\left.{ }^{\circledR}\right]$ how there seems to be a take away effect [after the device is removed] that lasts for a certain amount of time. I can tell you, I've seen it, and I would agree with this, and I'm just dying to do [test the treatment of] Parkinson's with the sensory equipment. Watch her right hand [slide 15]. This is after 5 to 10 minutes of treatment, and she's unaware of the writhing with her hand.

[So that is what I wanted] to present to you. I wanted you to see what actual patients look like and to help bring this sensory enrichment idea forward. I think it's a very good thing. I think our patients would benefit from this. It's kind of disheartening for me that, in terms of physical therapy intervention, in general, not a lot of money is spent. That's because it's a profession that is deemed to be [limited to] TheraBand ${ }^{\mathrm{TM}}$ [treatment] and whatnot, but that's really not true. I agreed to that statement years ago, but the profession is advancing and is crying out for these types of interventions. So thanks for listening to me. 


\section{References}

Atkins, K. L. H. 2010a. Vibrotactile postural control in patients with sit-to-stand balance deficits and fall. (Doctoral dissertation). Nova Southeastern University, USA.

Atkins, K. L. H. 2010b. Vibrotactile postural control in patients that have sit-to-stand balance deficit and fall. Fort Rucker, AL: U.S. Army Aeromedical Research Laboratory. USAARL Report No. 2010-18.

Karnath, H. O., and Broetz, D. 2003. Understanding and treating "Pusher Syndrome." Physical Therapy. 83(12): 1119-25.

Karnath H. O. 2007. Pusher Syndrome - a frequent but little-known disturbance of body orientation perception. Journal of Neurology. 254(4): 415-24.

Nashner, L. M., Black, F. O., and Wall, C. 1982. Adaptation to altered support and visual conditions during stance: patients with vestibular deficits. The Journal of Neuroscience. 2(5): 536-44.

Nashner, L. M. 1997. Computerized dynamic posturography: clinical applications. In: Jacobson, G. P., Newman, C. W., and Kartush, J. M. (eds.). Handbook of balance function testing. (pp. 308-34). New York, NY: Delmar, Cengage Learning.

Rupert, A. H. 2000. Tactile situation awareness system: proprioceptive prosthesis for sensory deficiencies. Aviation, Space, and Environmental Medicine. 71(Suppl. 9): A92-9.

Rupert, A. H., and Kolev, O. 2008. The use of tactile cues to modify the perception of selfmotion. Proceedings of the Army Science Conferences $\left(26^{\text {th }}\right)$, Orlando, Fl, 1-4 December 2008. 
Vibrotactile Postural Control in Patients with Sit-to-Stand Balance Deficit and also Fall

\section{Karen Atkins PhD PT}

Slide 1

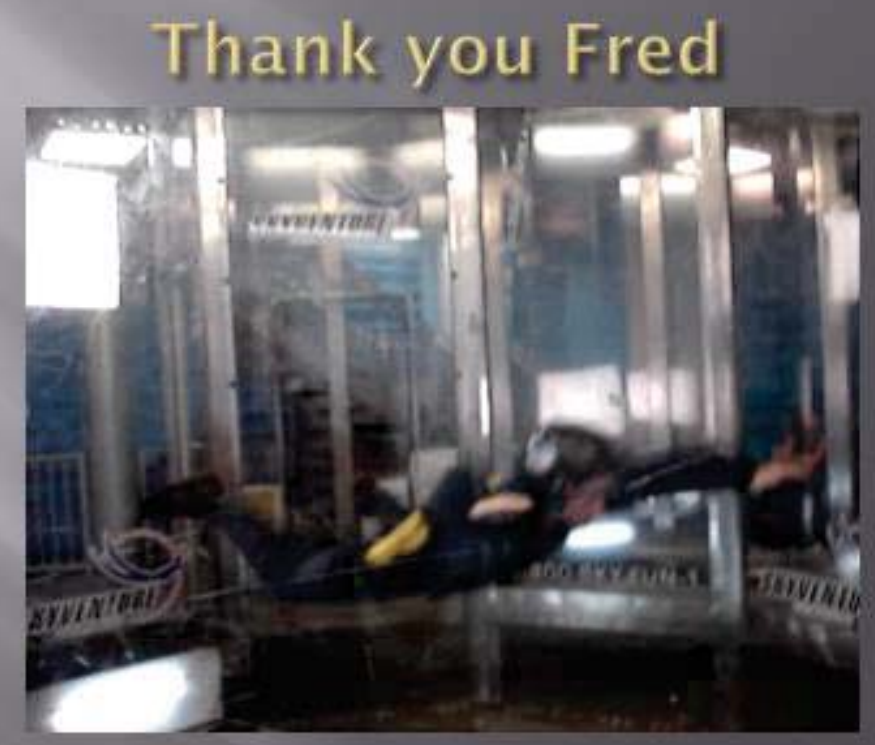

[The report authors captured this image from a video presented by Atkins.]

Slide 2 


\section{REQUIREMENTS OF POSTURAL CONTROL INTERVENTION}

1. Patient

2. Task

3. Technology

Slide 3

\section{Vestibular and Central Deficits}

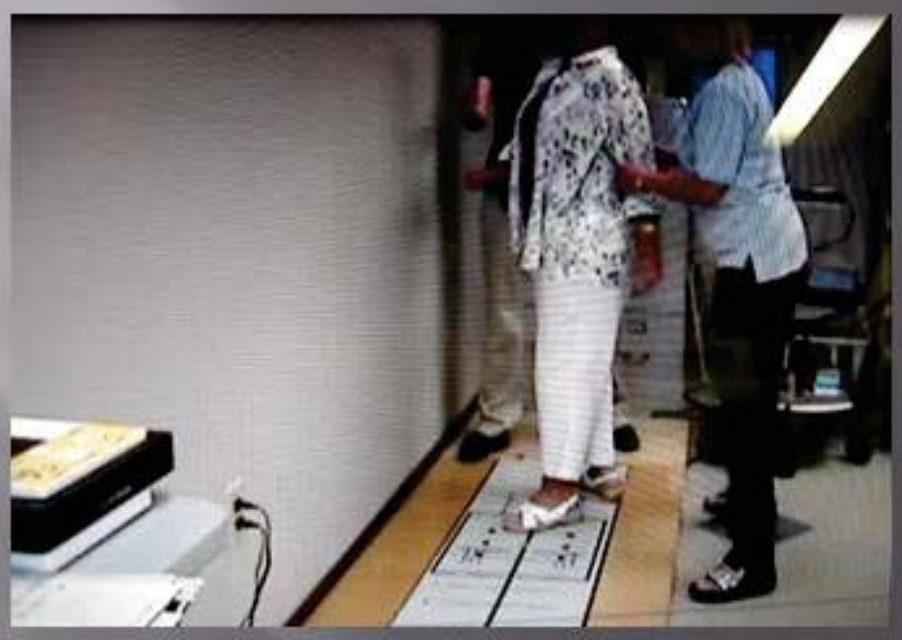

[The report authors captured this image from a video presented by Atkins.]

Slide 4 


\section{Deceleration}

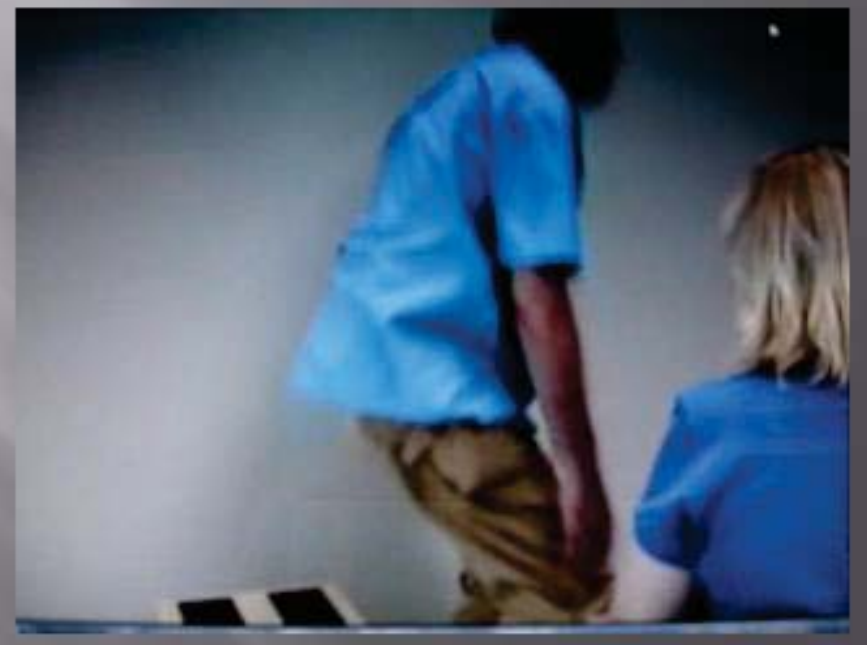

[The report authors captured this image from a video presented by Atkins.]

Slide 5

\section{Correlations}

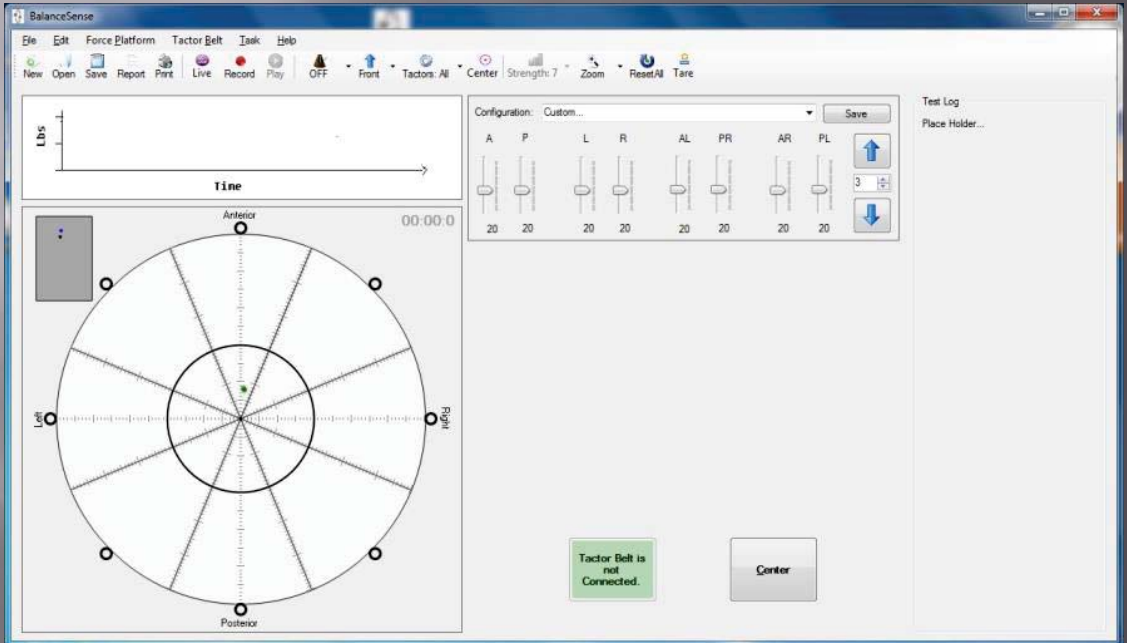

Slide 6 


\section{Keyholes}

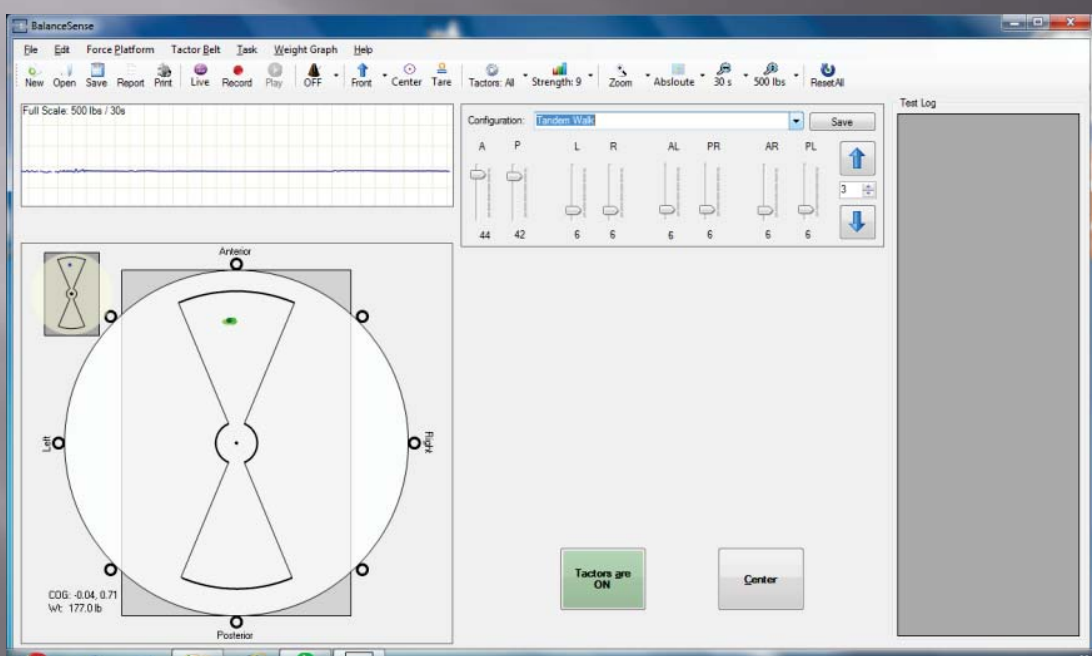

Slide 7

\section{Cue Map}

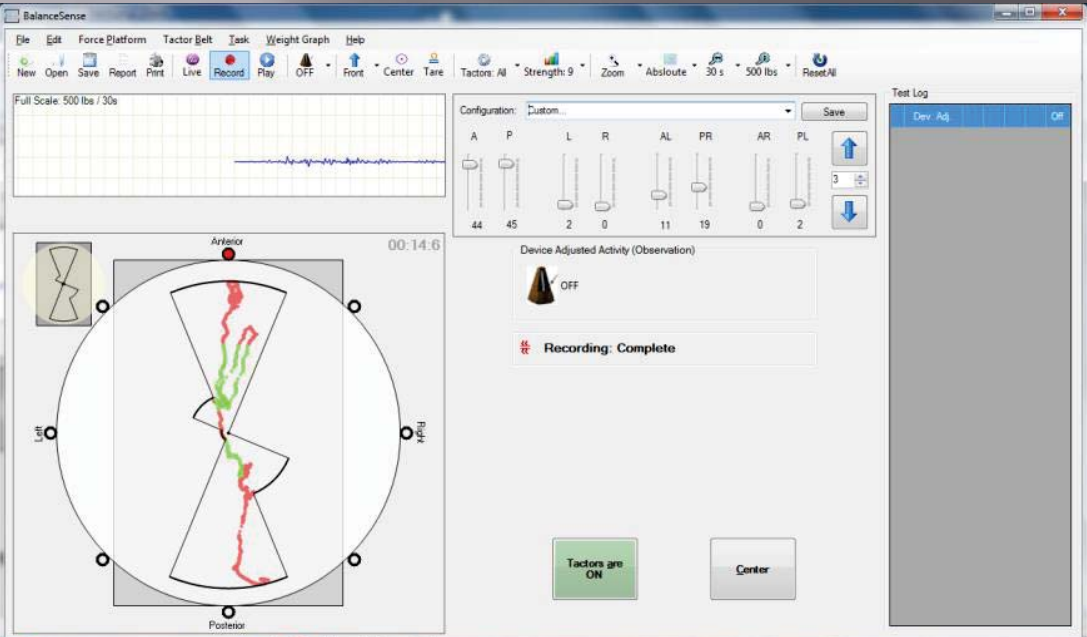

Slide 8 


\section{Downward Force}

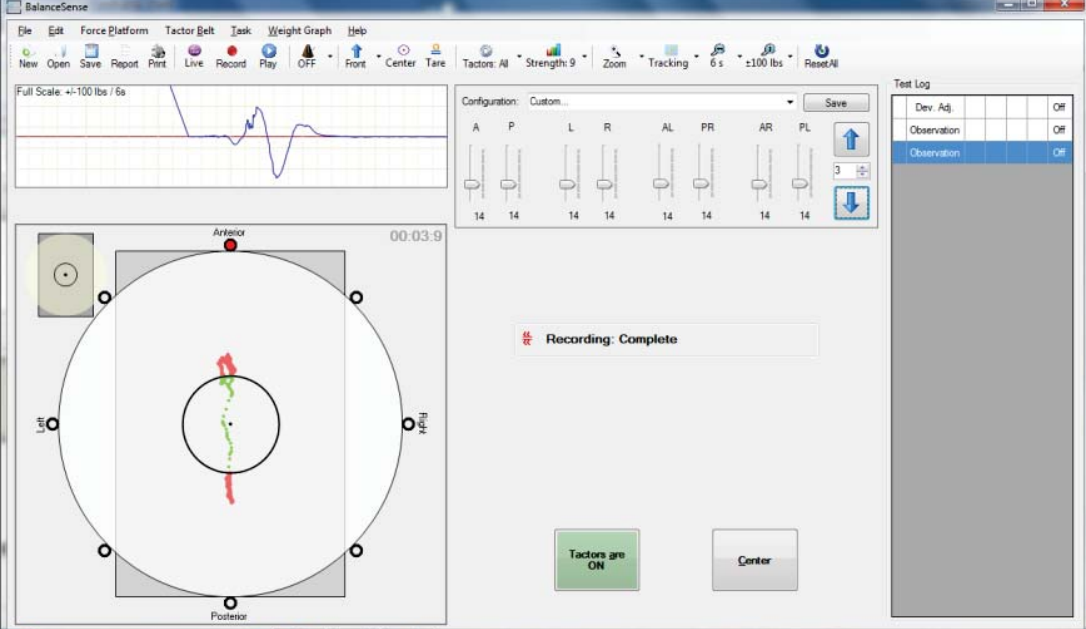

Slide 9

\section{Downward Force}

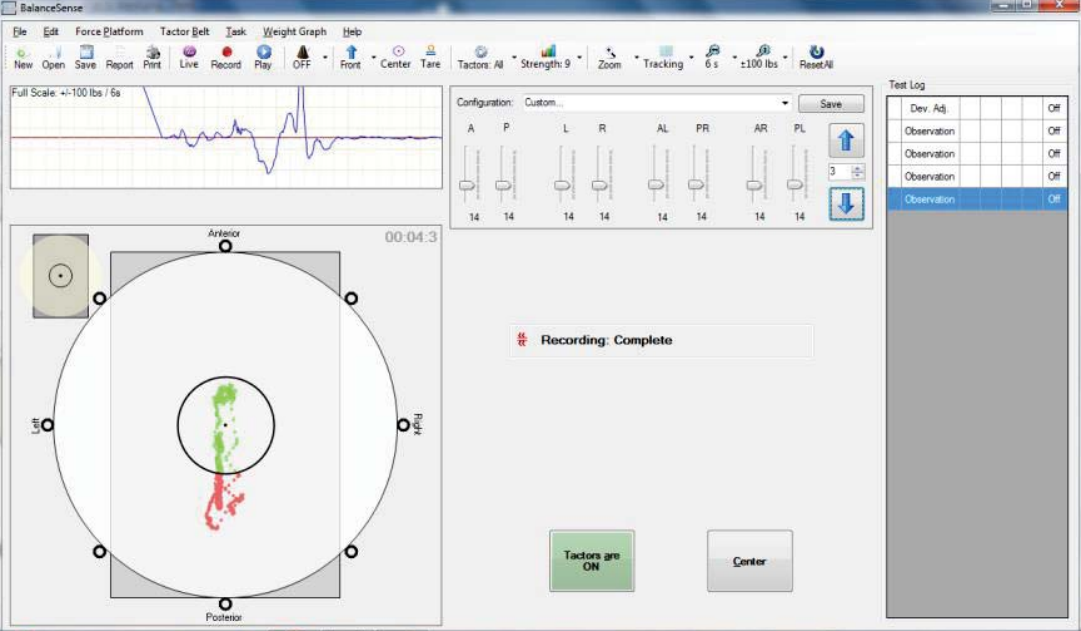

Slide 10 


\section{Sensory Enrichment versus Brain Plasticity}

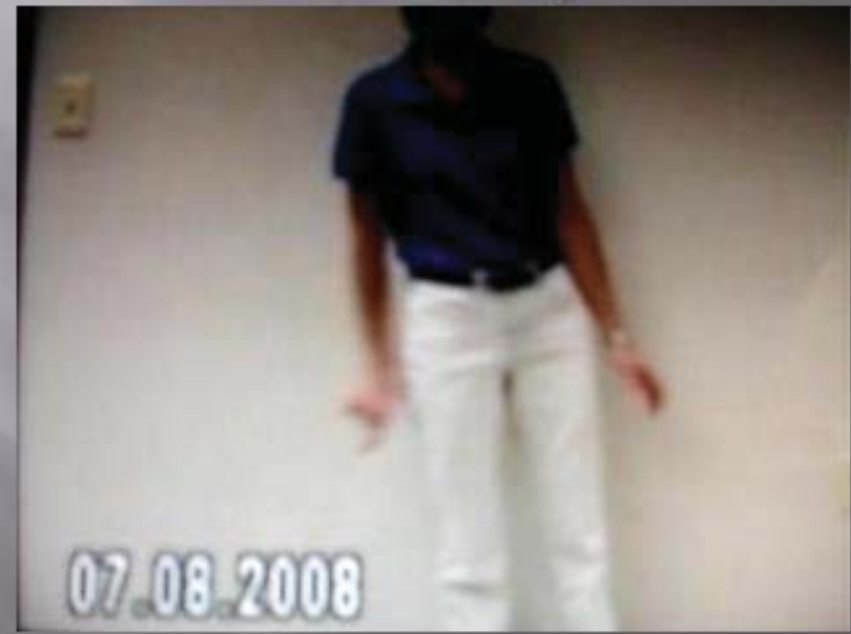

[The report authors captured this image from a video presented by Atkins.]

Slide 11

\section{Treatment 2 minutes}

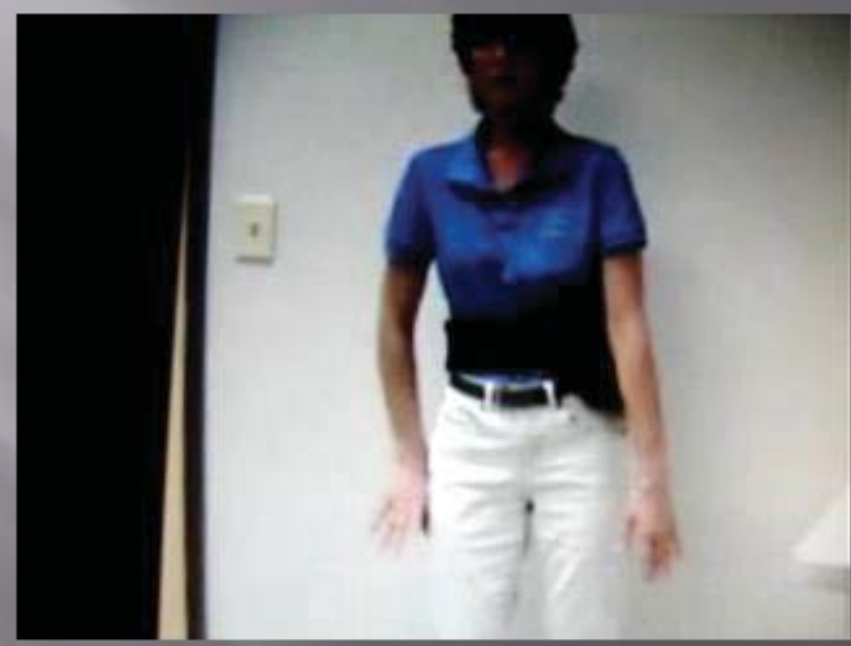

[The report authors captured this image from a video presented by Atkins.]

Slide 12 


\section{Carry over}

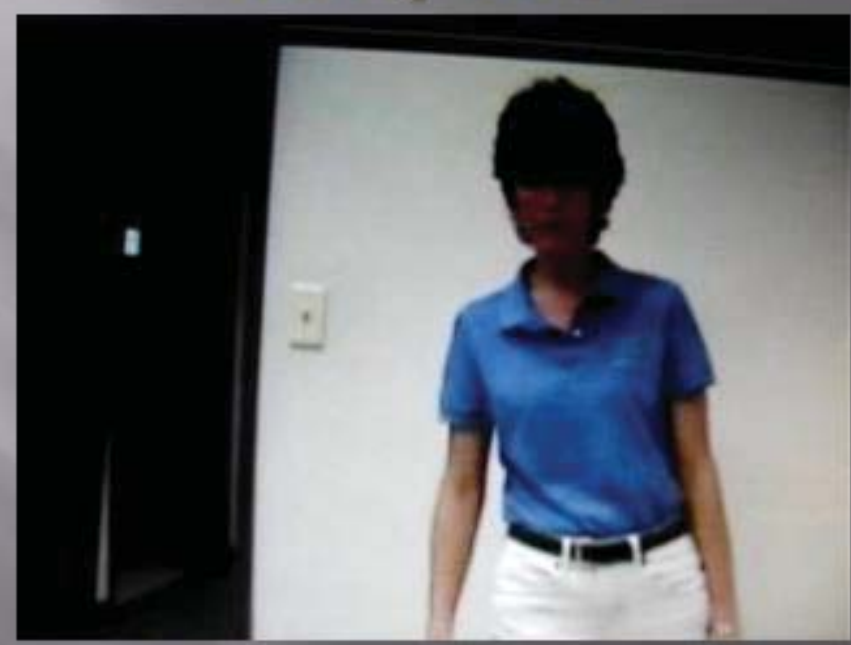

[The report authors captured this image from a video presented by Atkins.]

Slide 13

\section{Days Post First Treatment}

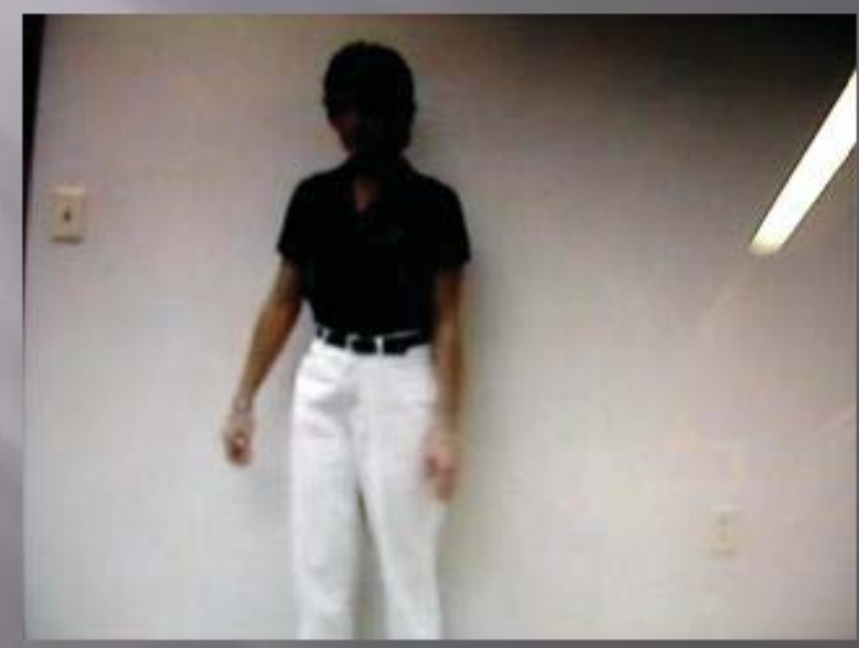

[The report authors captured this image from a video presented by Atkins.]

Slide 14 


\section{Post $2^{\text {nd }}$ Treatment}

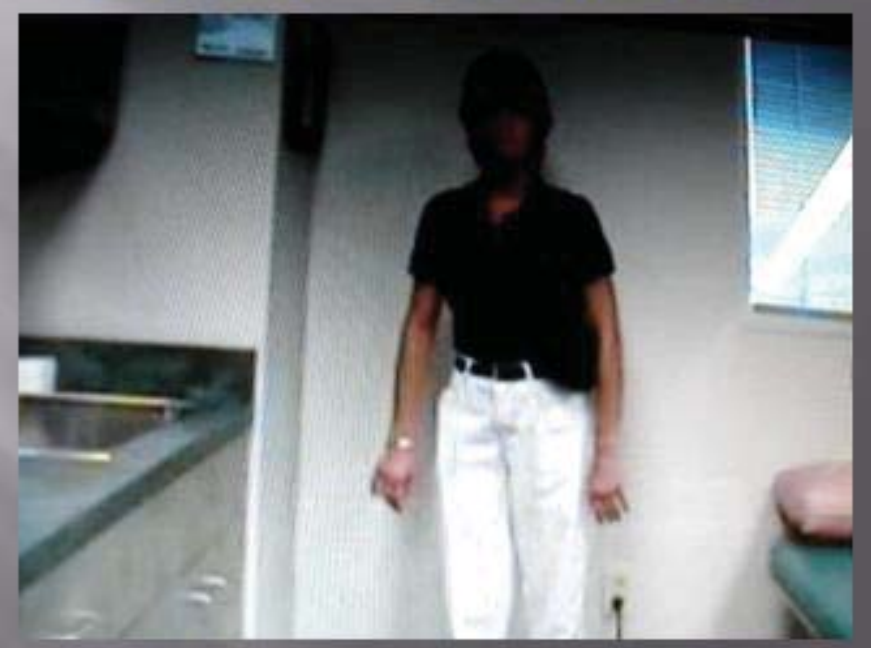

[The report authors captured this image from a video presented by Atkins.]

Slide 15 


\section{Vestibular physical therapy - Kim Gottshall}

[Slide 1, page 147] My population [of patients] right now is brain injury patients coming back from Iraq and Afghanistan. When I started at the ENT [ear, nose, and throat] department 12 years ago, it was mostly [most of the injuries were from] blunt head trauma accidents from Camp Pendleton and Twenty nine Palms. Now we're seeing a mix of blunt and blast head trauma with inhalation damage and other polytrauma as well [Hoffer, Donaldson, Gottshall, Balaban, \& Balough, 2009; Gottshall \& Hoffer, 2010]. There are differences between the blunt and blast head traumas, the blast is more diffused. There's not a sidedness, and there's no asymmetry. The blunt, of course, does have asymmetry. Both of them come to us with varied vestibulopathy. It may be as simple as BPPV [Benign Paroxysmal Positional Vertigo], it might be migraine associated dizziness, it might be exercise-induced dizziness, spatial disorientation, or some that have spatial disorientation and then start having Meniere's [disease] or vertiginous attacks on top of it.

What I wanted to do today was to show you some of the different types of exercises that we use in vestibular rehab [Gill-Body, 2001]. Customizing the program to the patient is really important, so not every patient is going to get every treatment shown in this presentation. Dr. Guedry mentioned a book when I first met him down in New Orleans. I want to just read this one sentence to you, and it kind of explains why we're trying to use some other adaptive modalities. Dr. Hickey ${ }^{*}$ said that the best way to adapt to a sensory motor rearrangement is to make a purposive movement and elicit unexpected sensory feedback. When this has been repeated several times, the unexpected feedback is [becomes] expected. In vestibular therapy, that is really true. The sensory tactors you see used in the two programs out here [the demonstration devices associated with the conference], (I hope you have tried them) are another type of sensory vibrotactile feedback that, once accepted and expected, the patient can use to plan their motor actions. Our guys coming back from [unintelligible] state there's been a disruption in that normal feedback. It could be a VOR [vestibular ocular reflex] disruption in the eye and head movement, it might be vestibular spinal, it might be simply posture spatial orientation, it might be gait, or gait when they're tasked with cognitive or other functions, or it might be general aerobic conditioning, or a combination of all of these [slide 2]. We design exercises based on what's wrong with them [slide 3]. So if it's VOR, we're going to give them targets to read with eye movement, head movement, two times when they move in opposite directions or sequences, and we can ramp this up or make it more difficult by [varying] the type of surface they walk on or stand on, or put them in busy environments with a lot of visual flow [slide 4] [Gottshall, Hoffer, Cohen, \& Moore, 2006]. So we will start in the clinic where they're walking in a hallway and have them walk where there are different pictures on the walls [slide 5], but sooner or later we're going to get them outdoors where it's going to be more realistic, [the context] where they're going to have to perform [slide 6]. We're going to vary the different types of surfaces; they may be on small rocks, large rocks, walking on the beam or ramps, or balance beams.

If they're underwater demolition teams or [Navy] SEALs, we put them in the water. We're going to do a lot of training in the pool, and then we're going to take them out in the ocean: the

*The speaker did not provide a citation and the authors of this report could not find one, but the concept is described in detail by Welch, R.B. 1978. Perceptual modification: Adapting to altered sensory environments. New York, NY: Academic Press. 
bay first, and then out in rough water [slide 7].

If [the patient is experiencing] a cervical-ocular reflex problem, we're going to definitely attend to the neck [slide 8]. If [the problem is] depth perception, we're going to have them doing exercises at different heights [slide 9]. So we may take them up to the third deck of the hospital; have them look out over something that would be similar to when they're on the ship looking off of it. We're going to have them stand on softer surfaces; first, in a protected environment (like in the parallel bars where if they have to, they can reach out) [slide 10]. But, we're going to break them out of that and get them into open areas [slide 11]. We can use different types of adaptive equipment that have pitch or roll [slide 12]. We can create the pattern or it can be random.

We can have them do course stability exercises, and we do so for general conditioning. We're going to get them to do some TRX ${ }^{\circledR}$ Training [suspension], as well as Swiss Ball training [slide 13]. Kettle bells are really big [popular] with the guys right now as far as general strength conditioning goes [slide 14]. We'll try and incorporate eye and head motion positional changes into some of the activities that they might use in the gym. We have the Total Gym ${ }^{\circledR}$ and several Pilates pieces of equipment [slide 15]. We will use manual therapy with patients that have had more of a moderate traumatic brain injury, [those] that really need motor pattern reestablishment. We'll resist the normal pattern into the appropriate postures with lifting, chopping, rolling, more functional things, moving [eventually] to gait [slide 16].

We have some virtual reality systems where the person can see themselves in the scene [slide 17]. We have an "altered G" [simulation] where you can suspend the weight up to 75 percent, and [then] unweight them as they train to run with and without head motion [slide 18]. We'll take them out, have them climbing ladders, going up and down flights of stairs, [traversing] different heights on ramps on different types of surfaces, using the heave of the mini ramp and eventually we're going to have them go to actual classes [such as] dancing if they want to [slides 19-25]. Not too many of them vote for that [dancing]; more of them vote for the rock wall, so we'll take them out and train them on the rock wall [slide 26].

We do have surf clinic one day a week. We have surf clinic, paddle board clinic, and kayak clinic for our vestibular patients [slide 27]. So when they come to us, we try to pick a different group and different things that they might need to do or be exposed to, so that they're not having a problem with their confidence and they're not leery about participating [slides 28-30].

The other thing we've developed for brain injury patients is the POWER Program ${ }^{*}$ (the program of wellness, education, and recovery) because when they come to us, we realize that brain injury is [involves] a lot more than just the vestibulopathy [slide 31]. We want to work on the rehab part as far as vestibular issues go, but there are other people on the team working on the cognitive part and the emotional part, especially if there's a Post Traumatic Stress Disorder [slide 32].

So when they come into our TBI [traumatic brain injury] program, they're there 5 days a week, from 7:30 to 5:00 o'clock in the afternoon [slide 33]. For 8 weeks, they belong to us.

*http://www.rhd.org/Program.aspx?pid=121 
They live in the building next to the hospital; they get evaluation by the physical medicine and rehab team, neuropsychology, myself, neurooccupational therapy, speech therapy, and mental health [slide 34]. There's a core set of appointments: They're for sure going to come for vestibular [rehab] one or two times a week and [be given] speech, mental health, and primary care, and then the rest of their appointments are tailored to what they need [slide 35]. In the vestibular balance, safety, and awareness class, I've picked out certain things I want to include. Other people have put things into a sleep hygiene class, headache class, CogSMART (which is a cognitive computer based training), operational stress control classes, and nutrition classes [slide 36]. This [slide 37] is just [a] sample of some of the things I included in my vestibular balance awareness and safety class. I want to give them some education about vestibular disorders, what they can do to improve, and different types of exercises. In addition (and I'm surprised it came up here), you mentioned meditation being a factor in anxiety control and confidence [Mike McCauley brought up the subject of meditation during the question and answer session following Angus Rupert's lecture]. We did try and incorporate Tai Chi, but our guys have liked the [sitting] meditation better. We've started mantra training which is a program that was piloted by the VA [Veterans Affairs Hospital]. They do have 8 weeks of mantra repetition for meditation and they like it.

We're also doing acupressure and battlefield auricular acupuncture for the people with headaches to try to get the headaches under control; we've incorporated that into the program. As I said, we've got a program that goes for the full day: 5 days a week for 8 weeks [slide 38]. They have care conferences with our multidisciplinary team when they first come into the program (and then every few weeks), so that the patient's goal and our goal are stated, and they're supposed to be the same [slide 39].

They have a care conference at the end of the program [slide 40]. If they need to stay longer, they do, but hopefully, with modalities like the tactor belt and some of the other equipment that you can see here (and as we add different modalities), [we] will help them and get them better [improve their health] early on [so that] they won't be staying for all portions of the team [all levels of rehab] [slide 41].

We've had really good results. As you might know, vestibular patients tend to get better in 6 to 8 weeks. That is a very traditional amount of time to have patients in vestibular therapy. Some of them get better quickly, within 3 weeks. Some of them (if the migraines aren't under control or if they're really and truly having Meniere's vertiginous attacks with crisis of Tumarkin) might take longer than that. Those we' re going to keep longer, and depending on the polytrauma, some may stay [even] longer. If anyone has any questions about that, that's just an overview of our program at San Diego Naval Medical Center. 


\section{References}

Gill-Body, K. M. 2001. Current concepts in the management of patients with vestibular dysfunction. PT Magazine. 9(12): 40.

Gottshall, K. R., and Hoffer, M. E. 2010. Tracking recovery of vestibular function in individuals with blast-induced head trauma using vestibular-visual-cognitive interaction tests. Journal of Neurologic Physical Therapy. 34(2): 94-7.

Gottshall, K. R., Hoffer, M. E., Cohen, H., and Moore, R. J. 2006. Active head movements facilitate compensation for effects of prism displacement on dynamic gait.

Journal of Vestibular Research. 16(1-2): 29-33.

Hoffer, M. E., Donaldson, C., Gottshall, K. R., Balaban, C., and Balough, B. J. 2009. Blunt and blast head trauma: different entities. International tinnitus journal. 15(2): 115-8. 


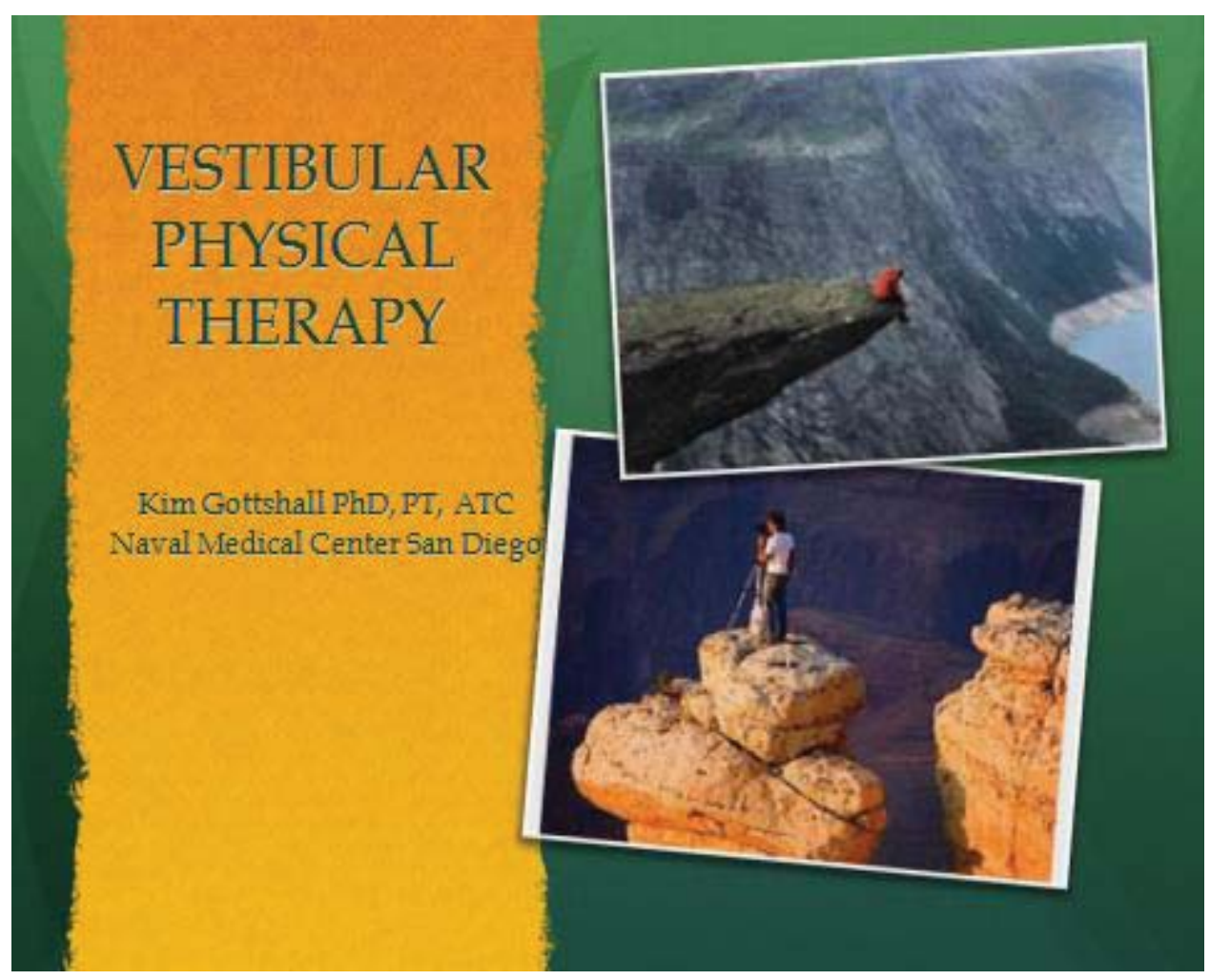

Slide 1

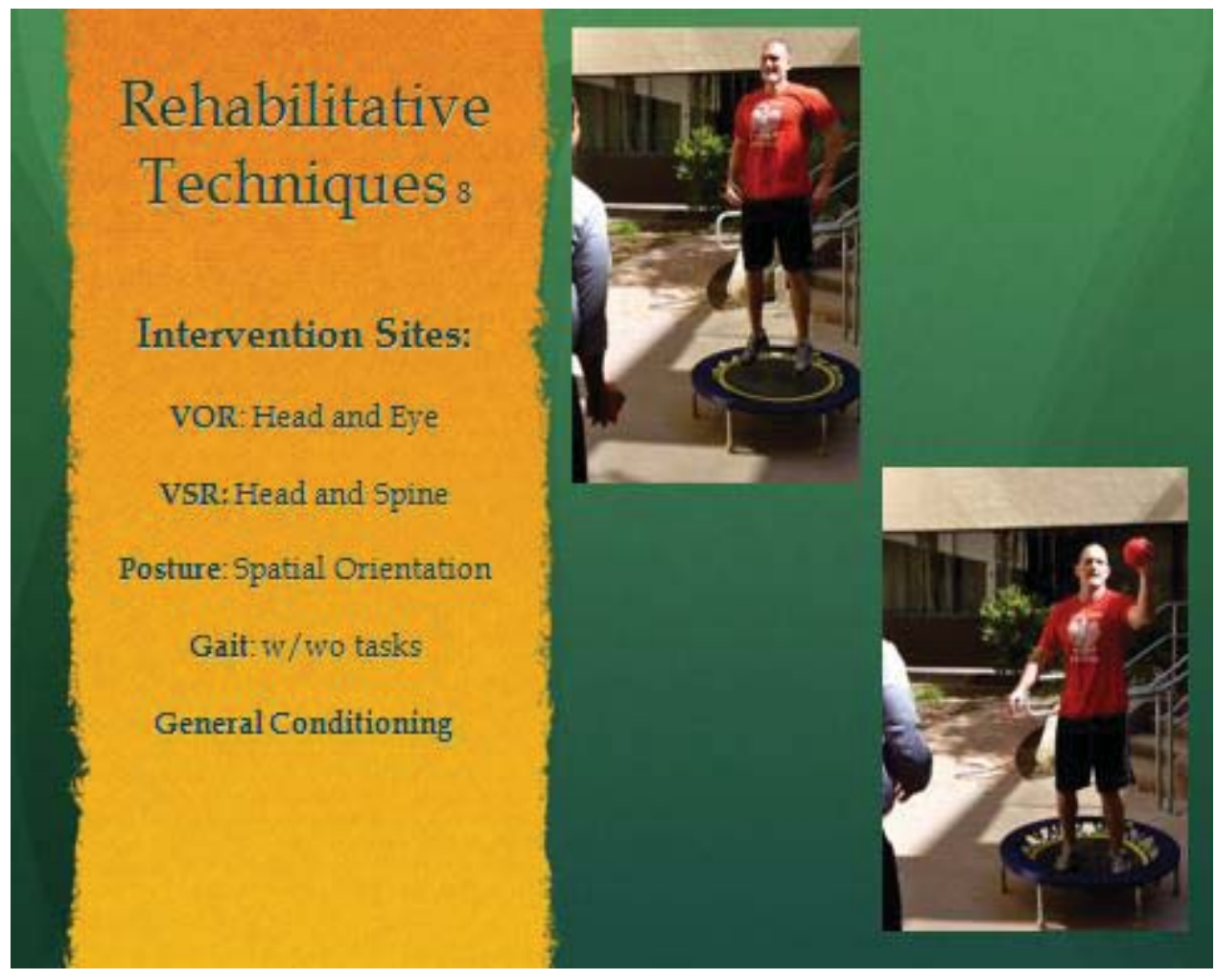

Slide 2 


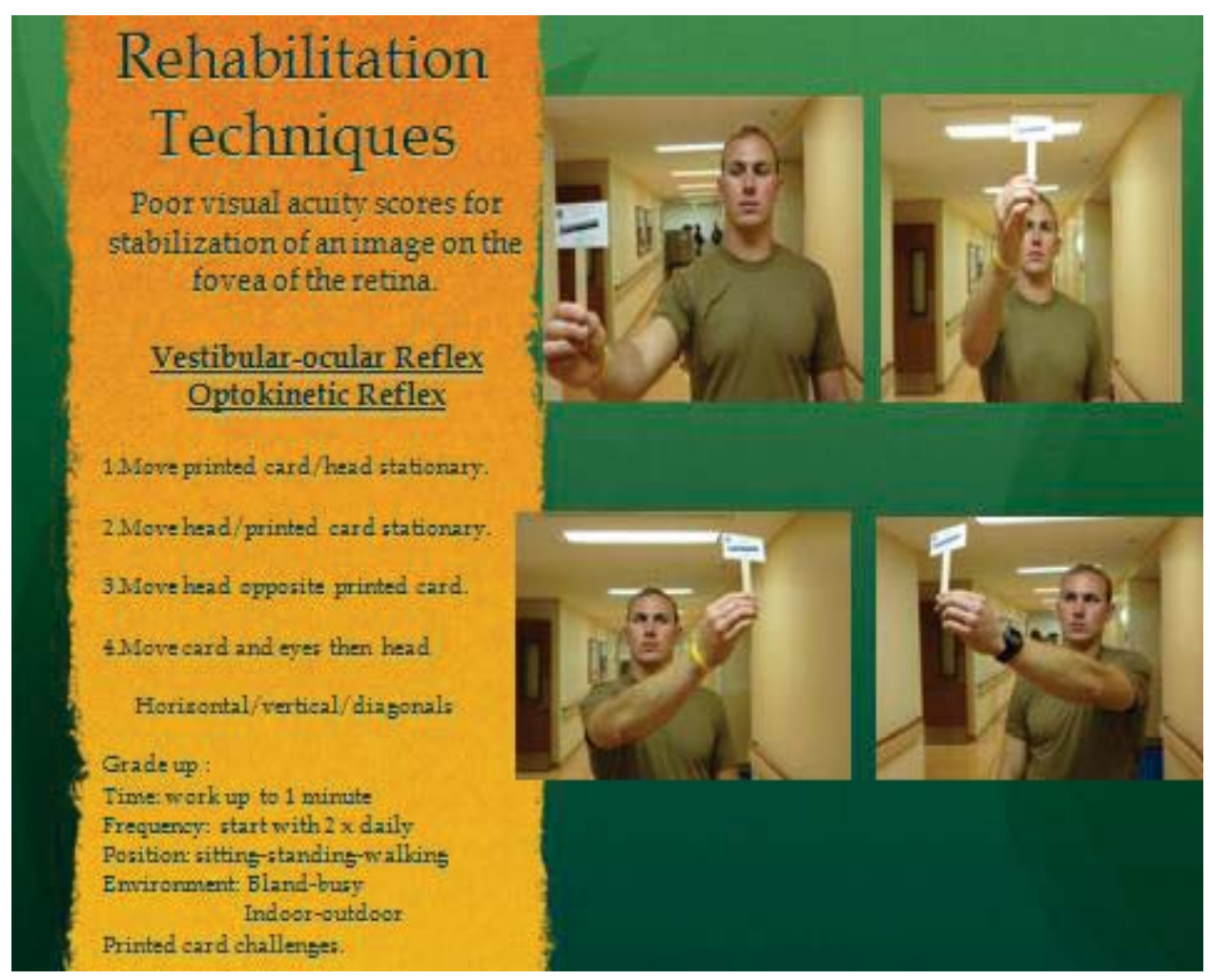

Slide 3

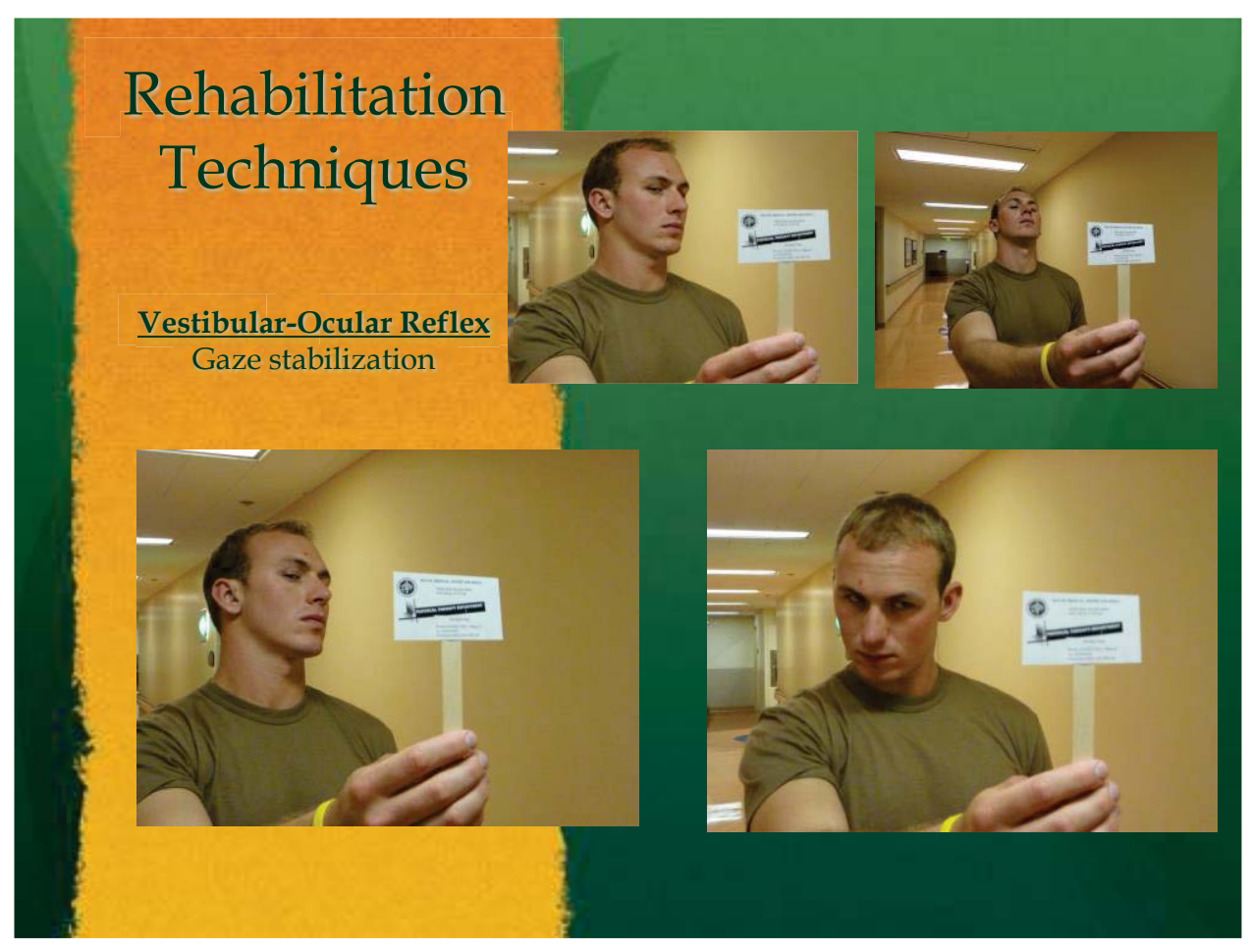

Slide 4 


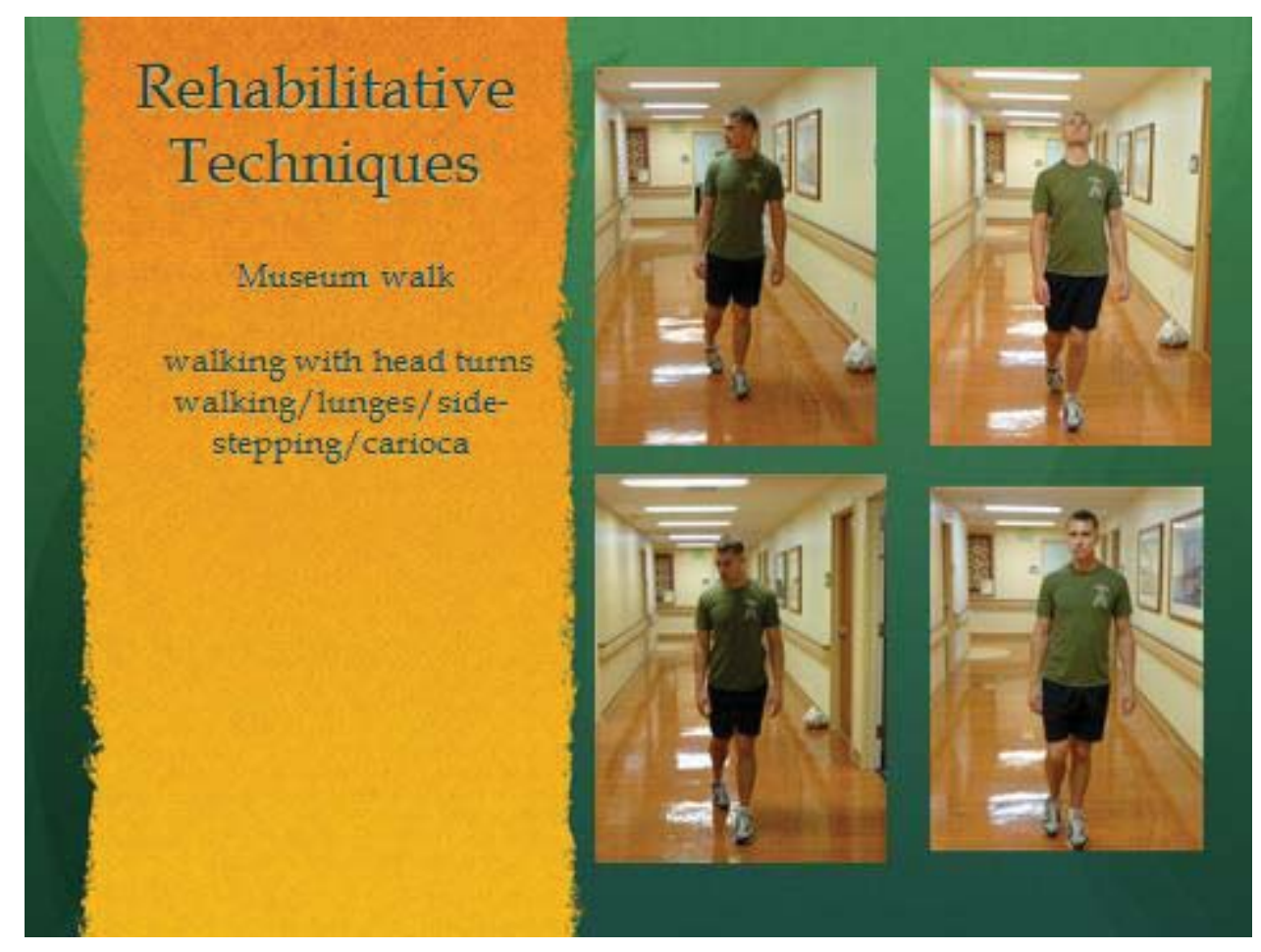

Slide 5

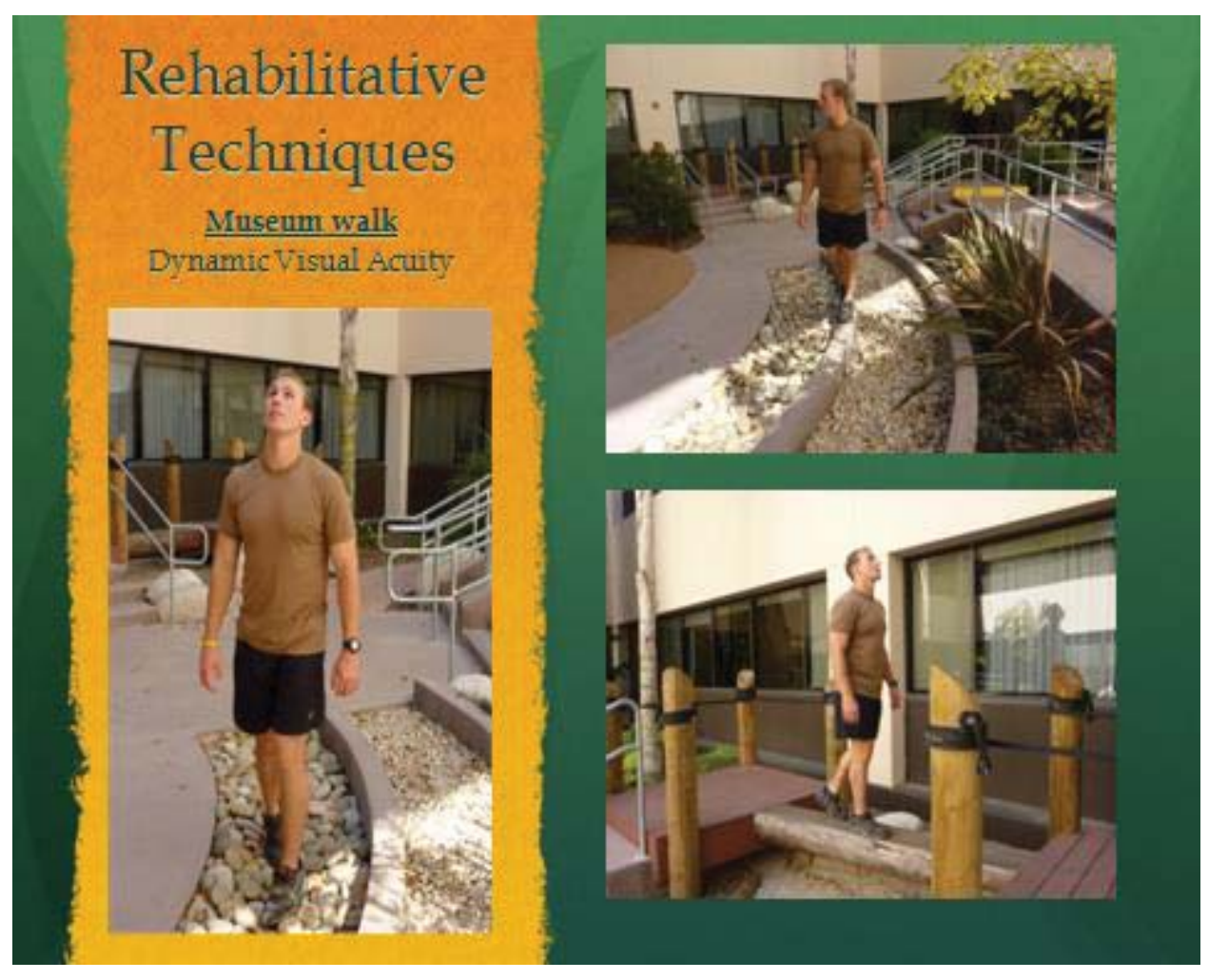

Slide 6 


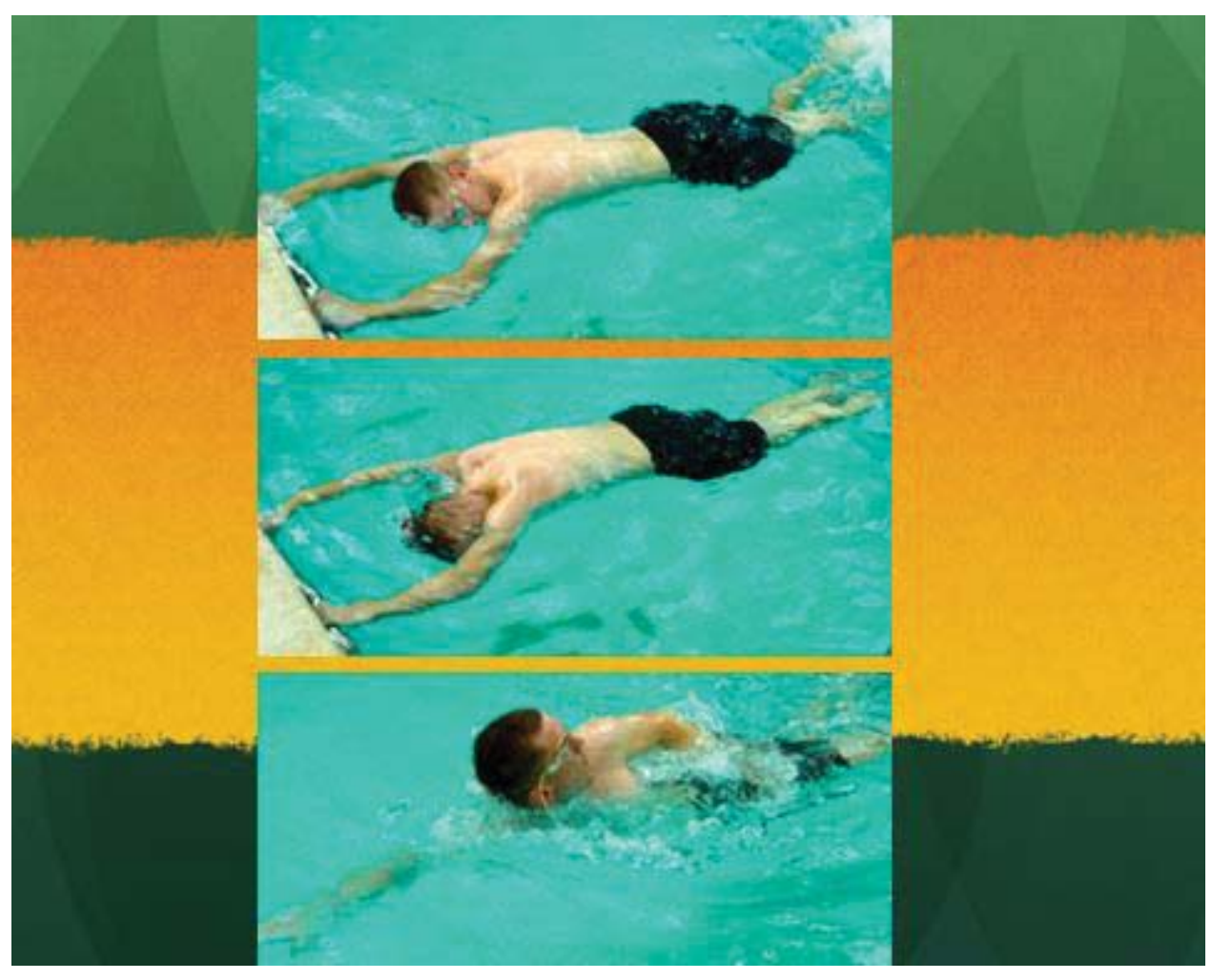

Slide 7

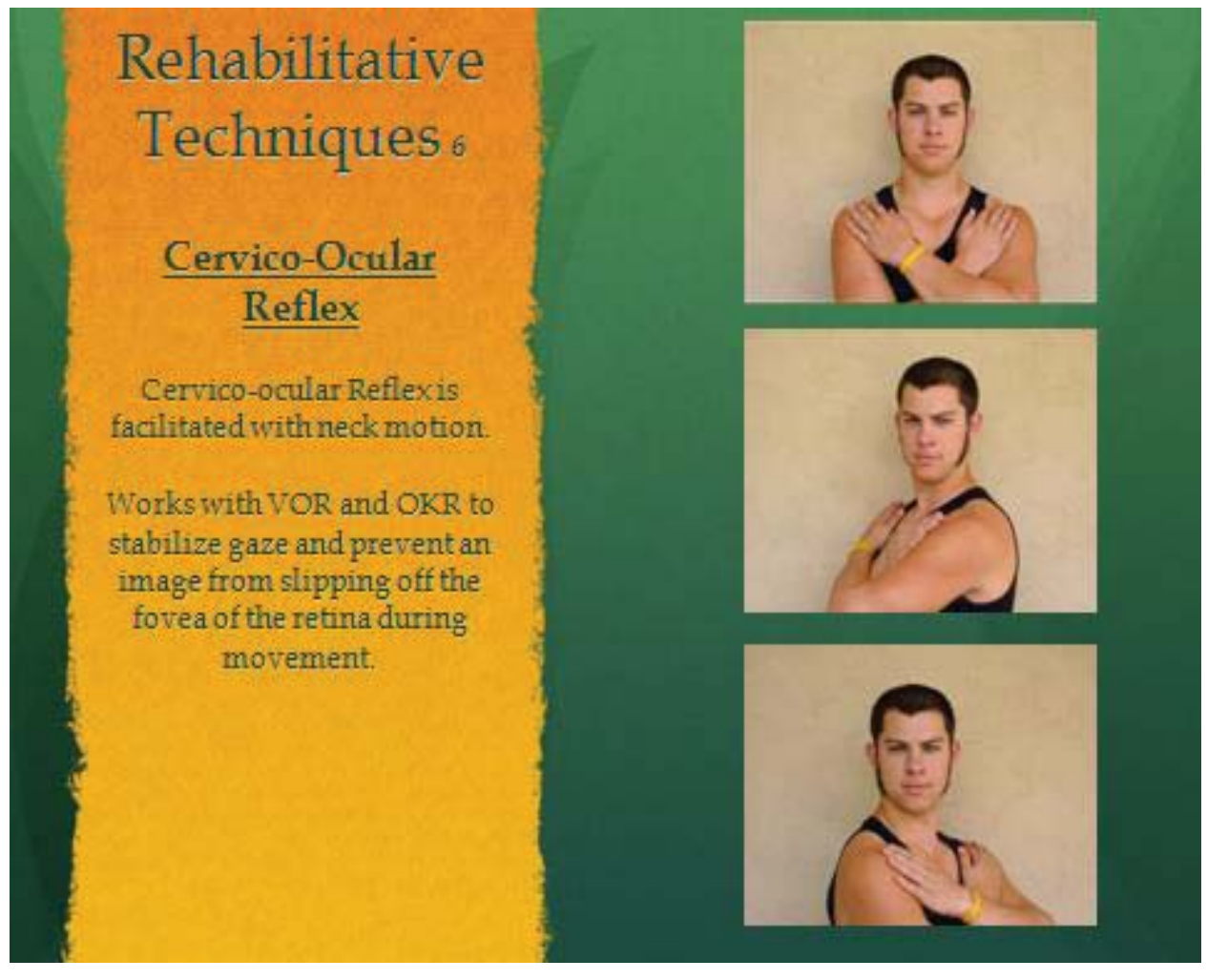

Slide 8 


\section{Vestibular Rehabilitation}

\section{Depth Perception}

\section{Wall push-ups with focal point Convergence/Divergence}
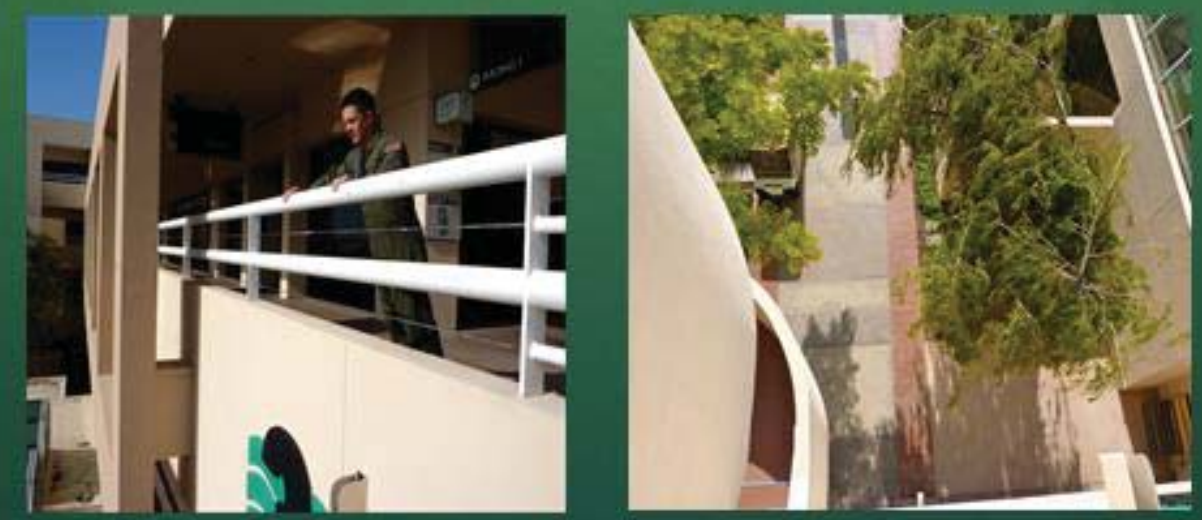

Slide 9

\section{Rehabilitative \\ Techniques}

\section{Somatosensorv}

Strategies for ankles and hips to

help maintain balance.

Eyes closed: Level/Airex/Bosu
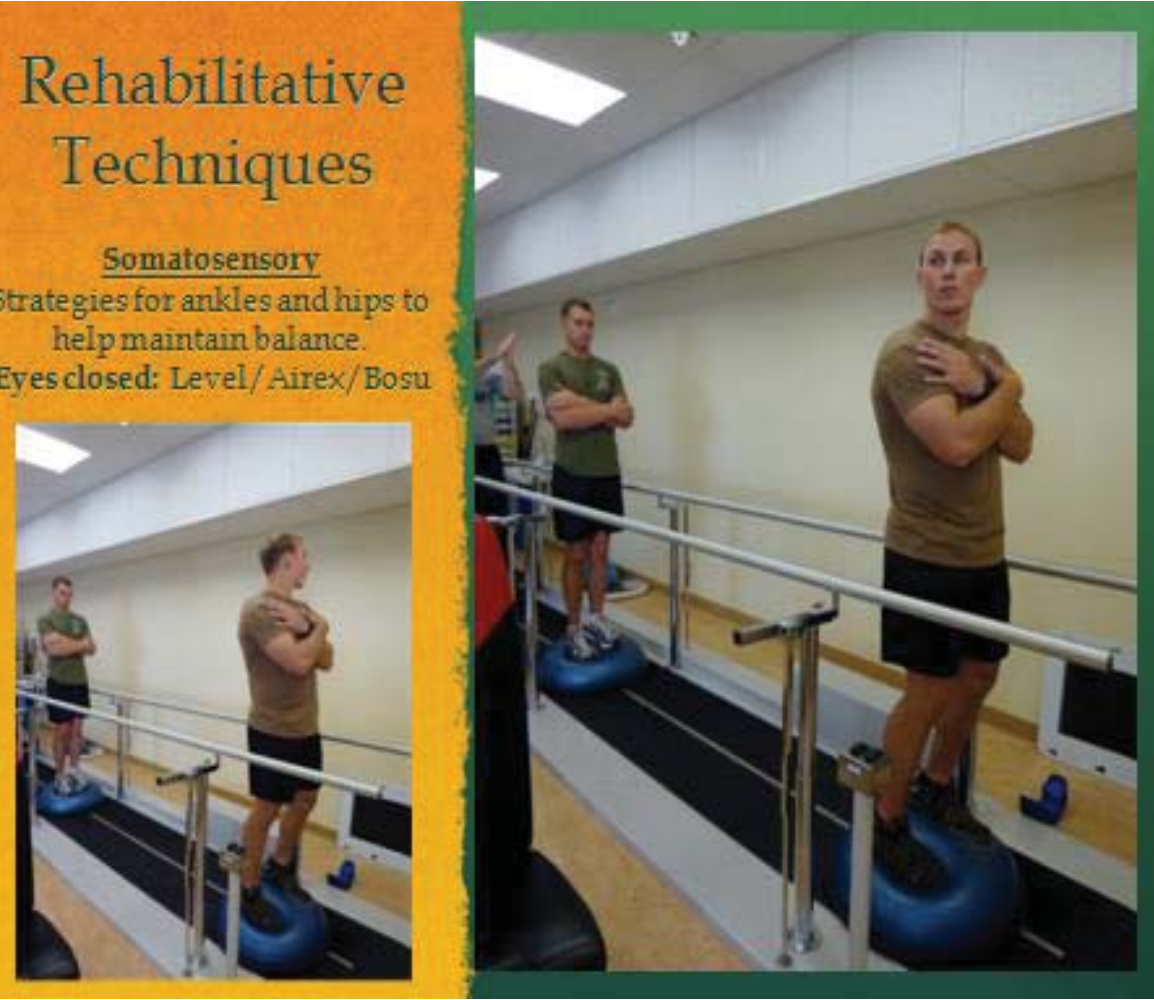

Slide 10 


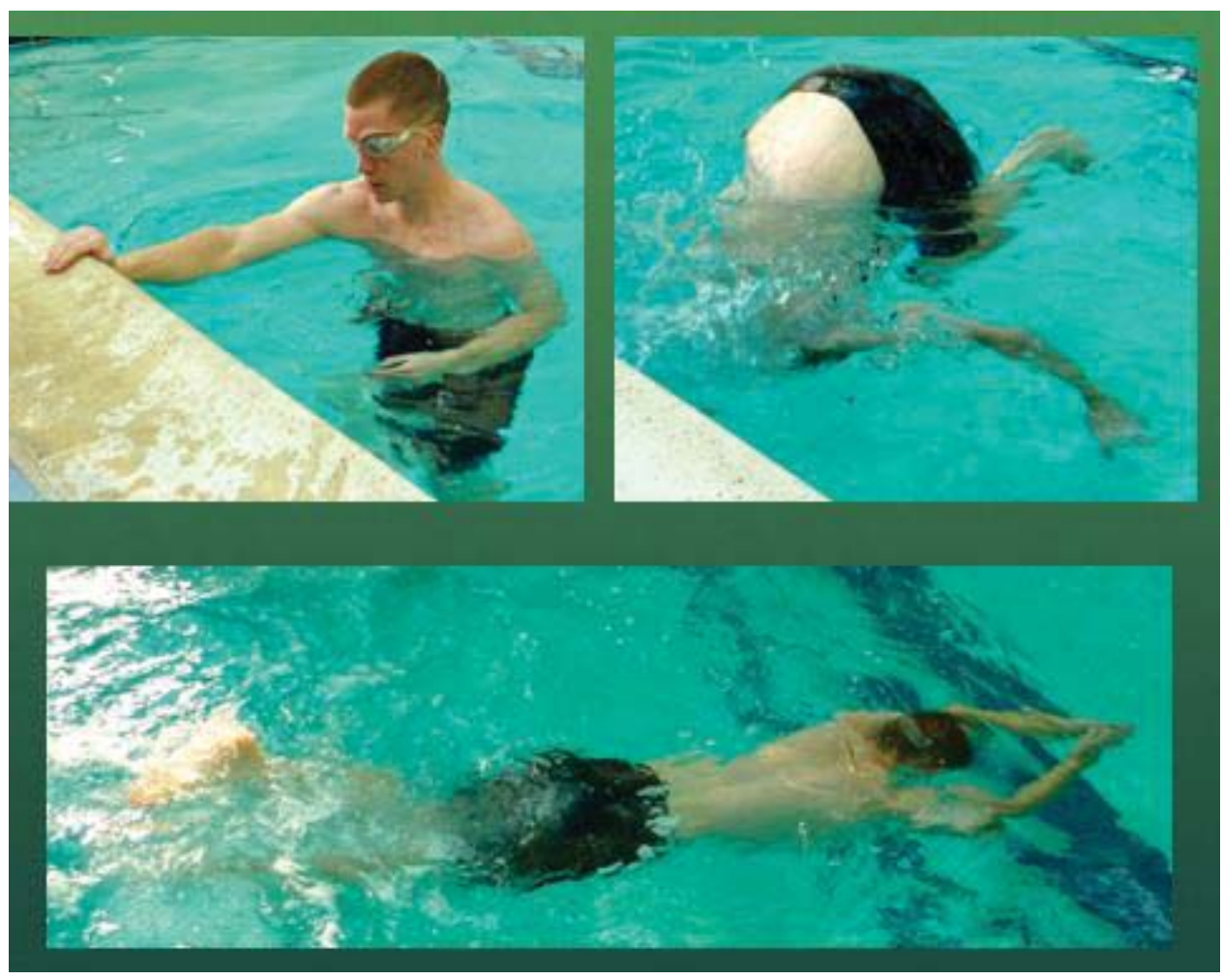

Slide 11

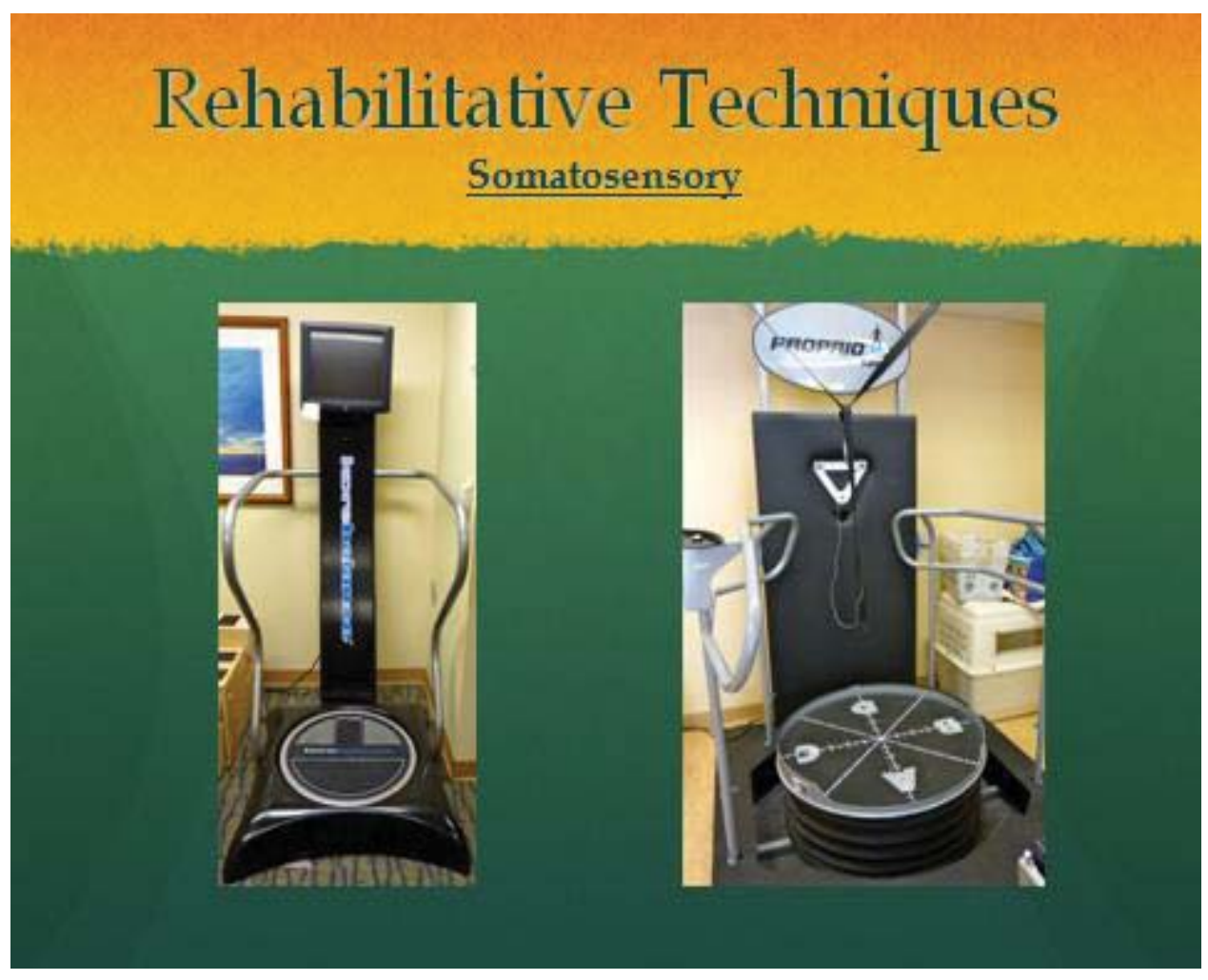

Slide 12 


\section{Rehabilitative Techniques}

\section{Core Stability}

Corestability plus Eyes closed/head turns
CoreStability plus Eyes closed/head turns
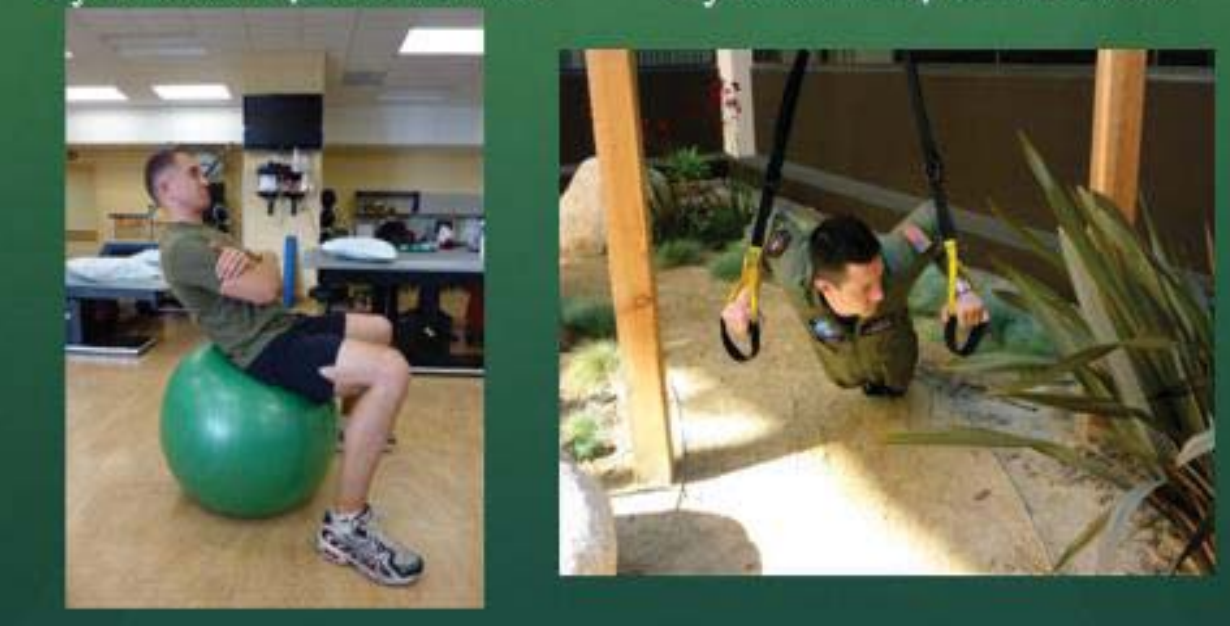

Slide 13

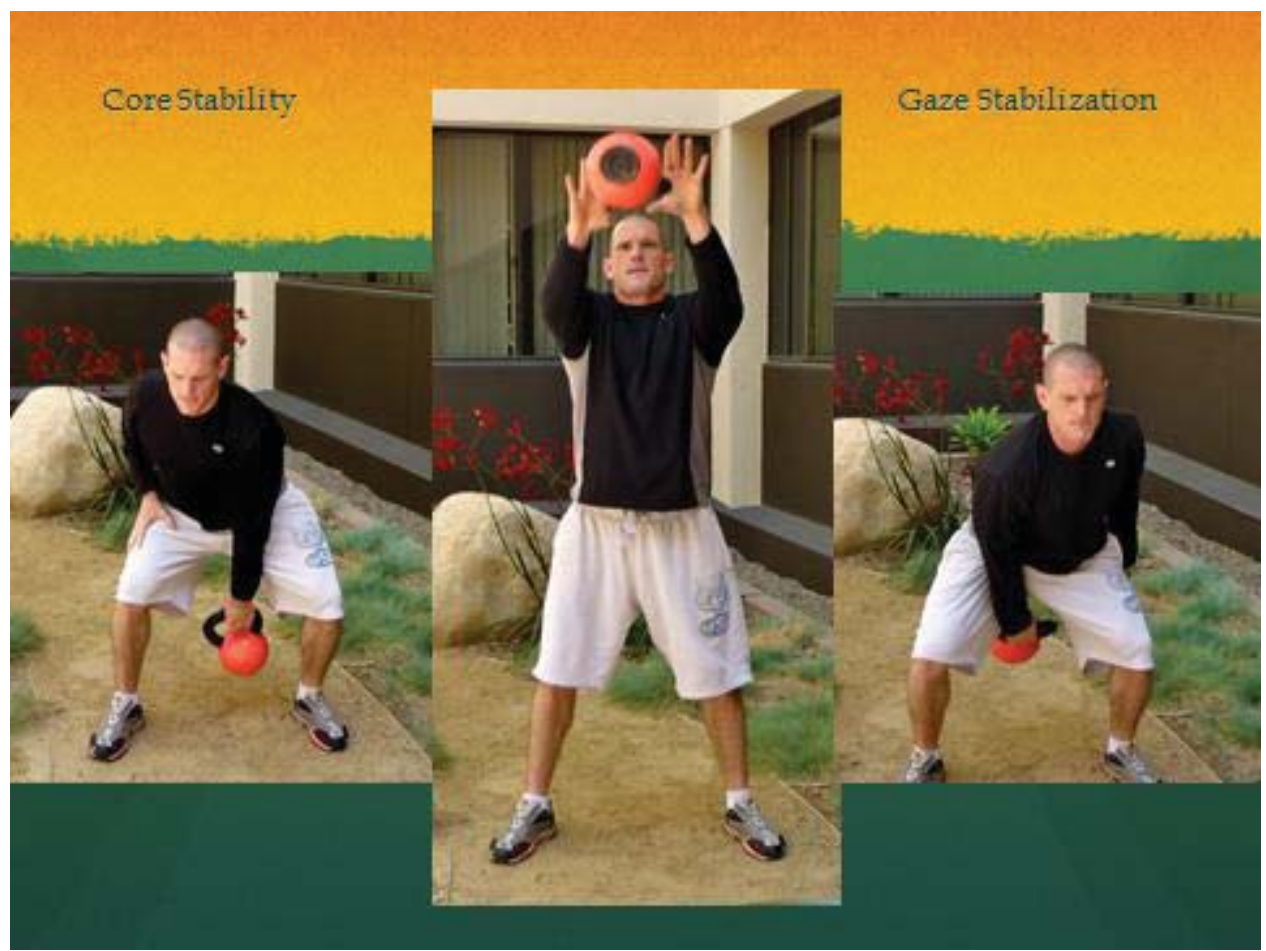

Slide 14 


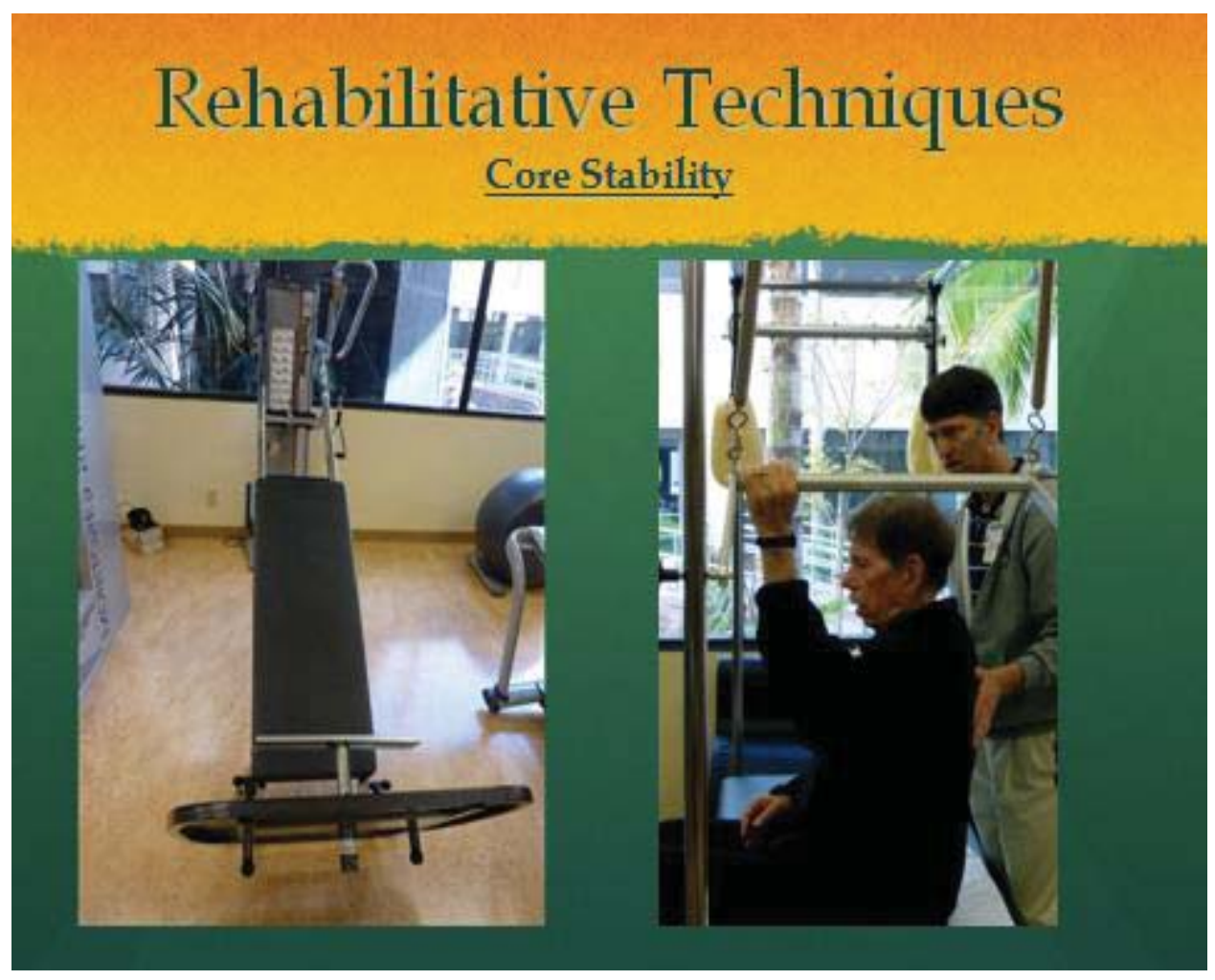

Slide 15

\section{Rehabilitation Techniques}

Hasten neuromuscular mechanism by stimulating proprioceptors to inhibit or excite a response in the targeted muscle(s).

Full body (head \& trunk) amplitudes in rotational \& diagonal patterns.

PNF:
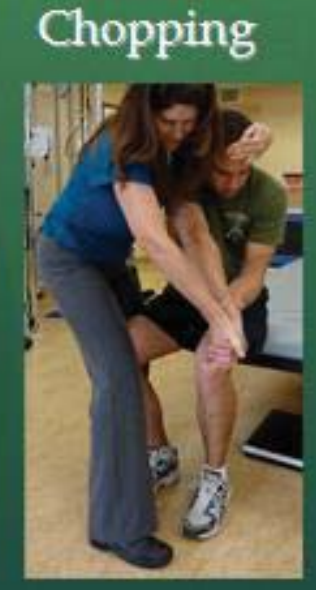

PNF:
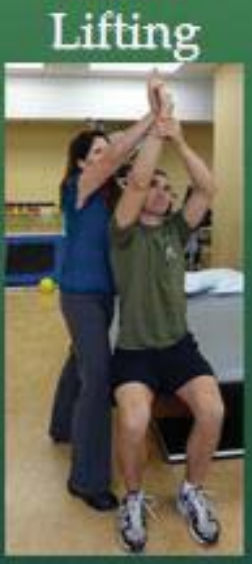

Slide 16 


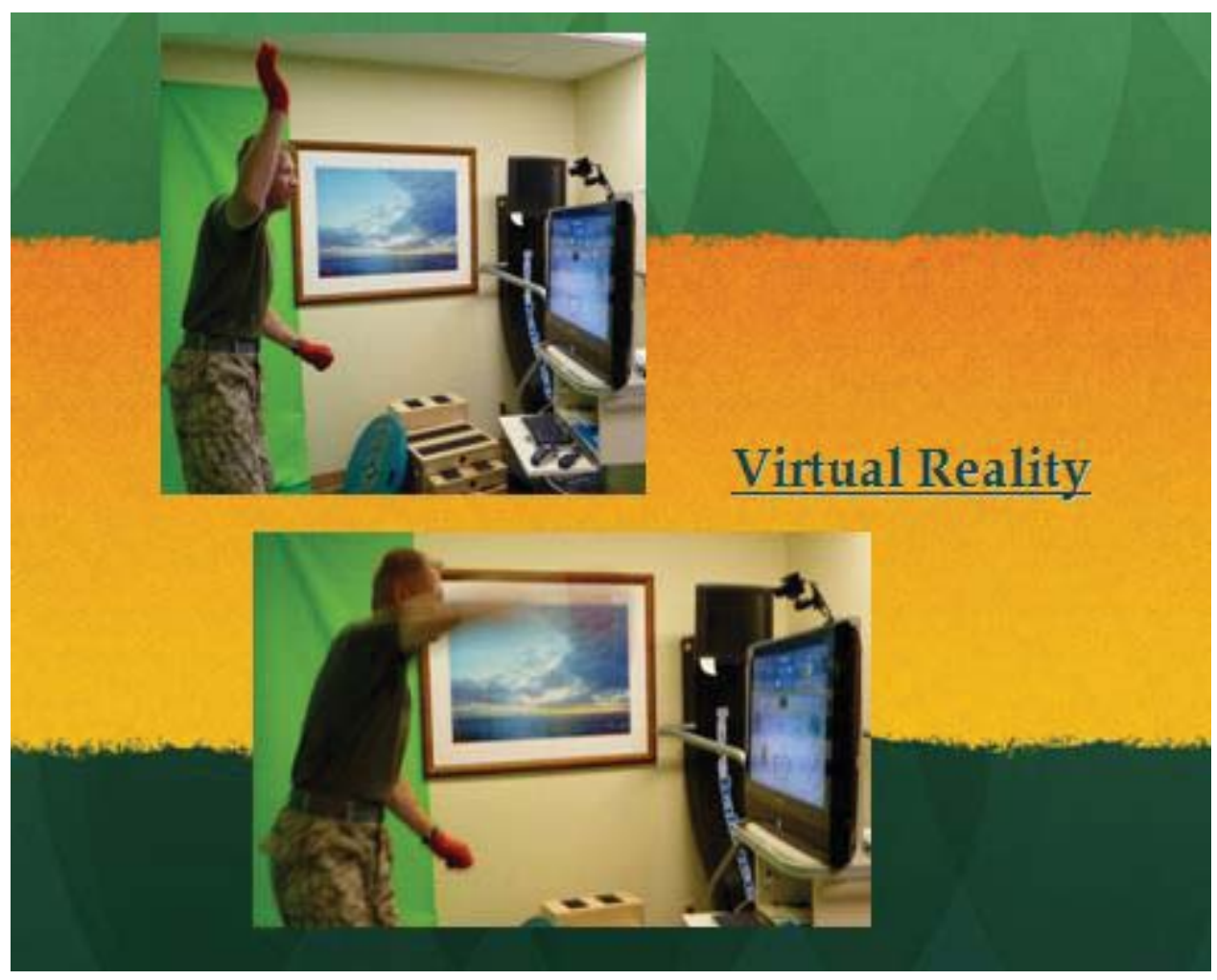

Slide 17

\section{Rehabilitative Techniques Cardiovascular}
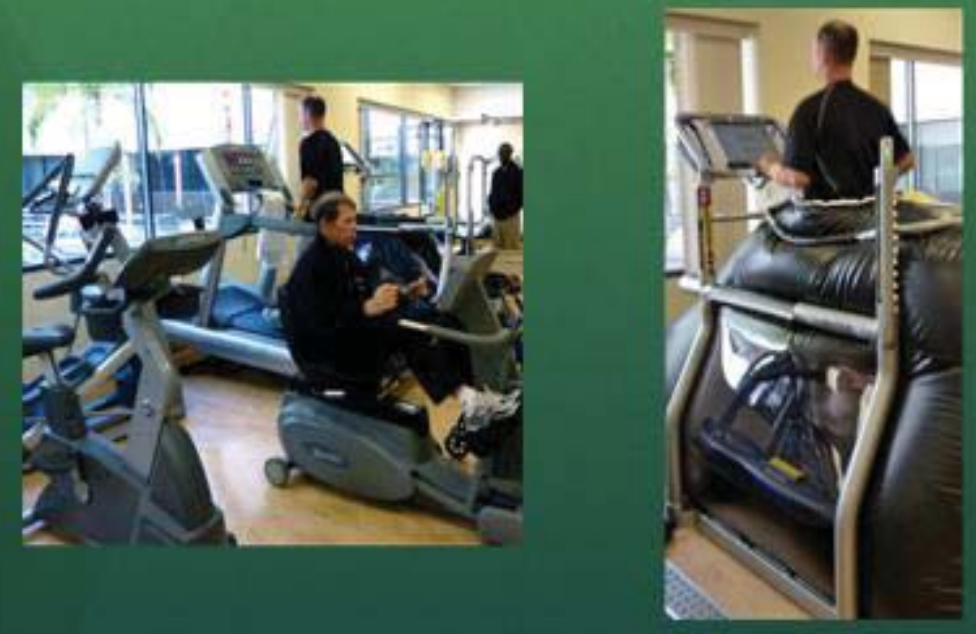

Slide 18 


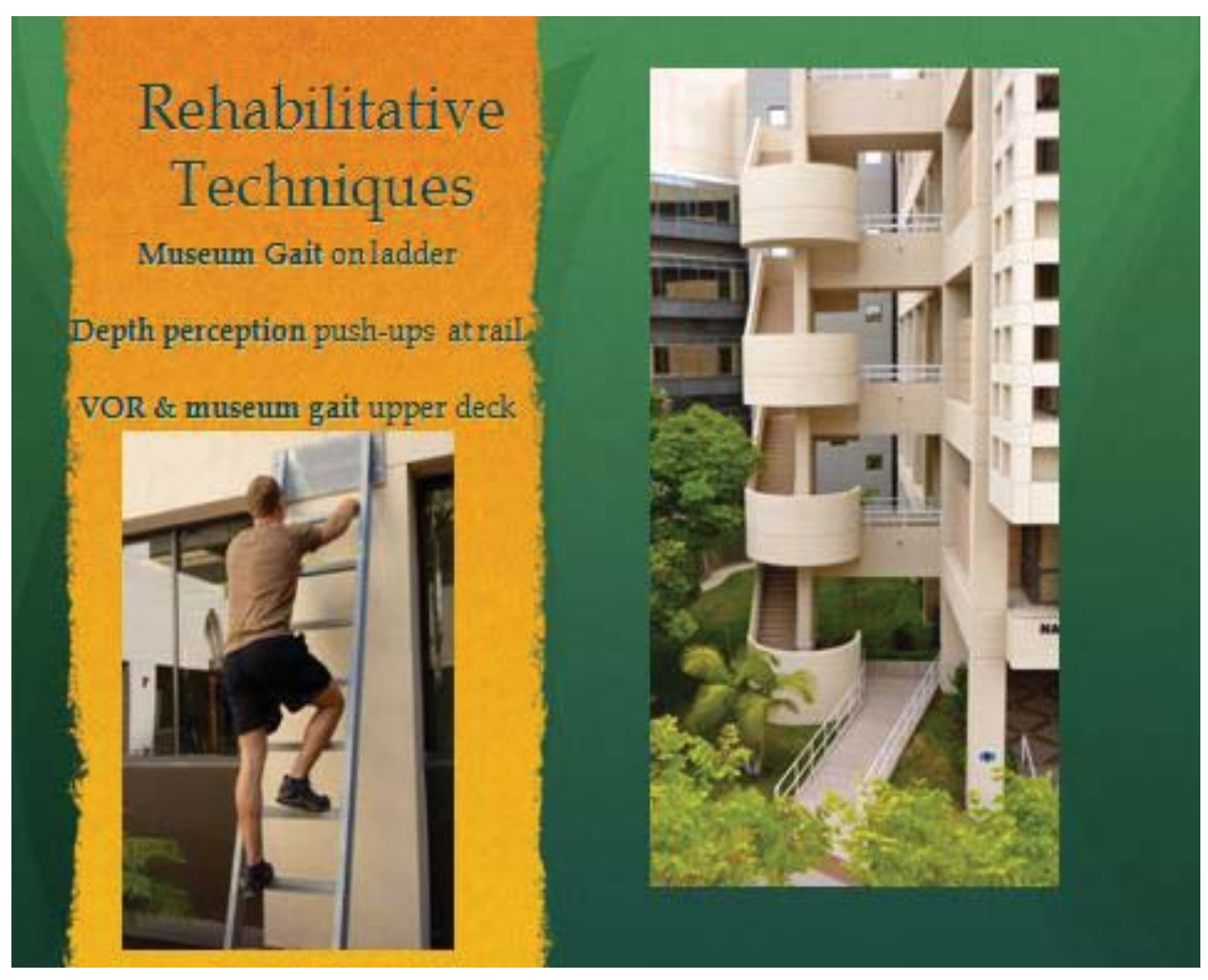

Slide 19

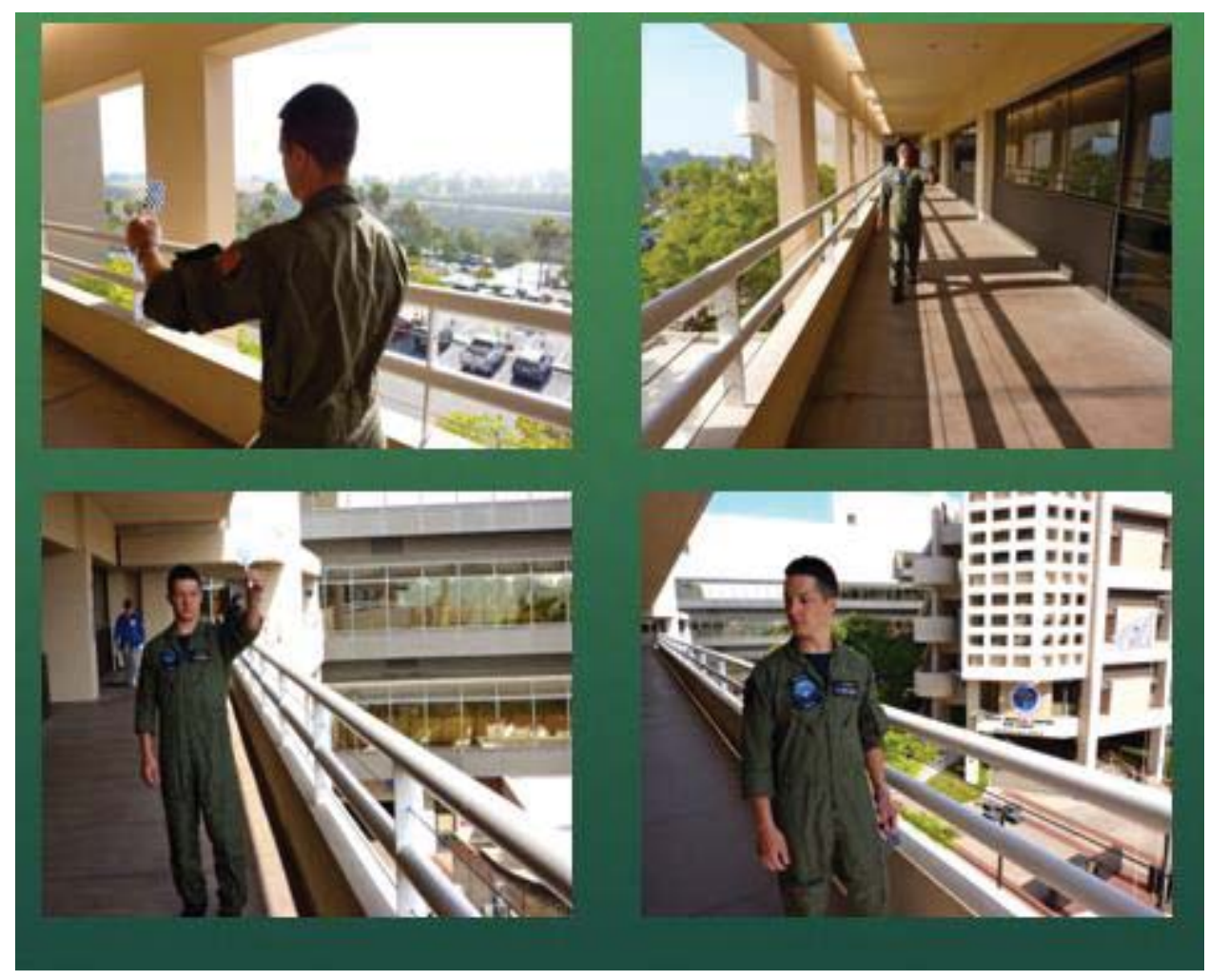

Slide 20 


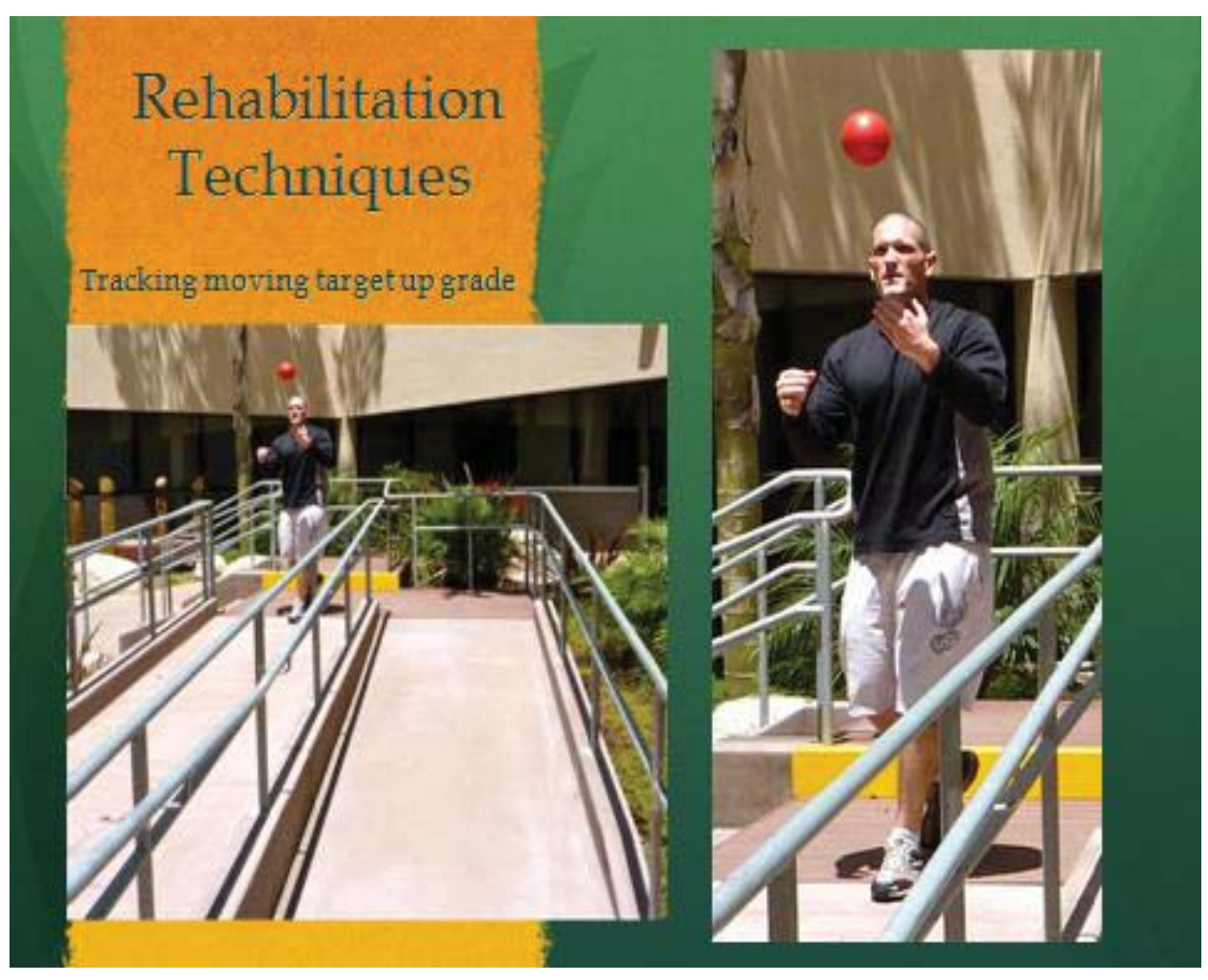

Slide 21

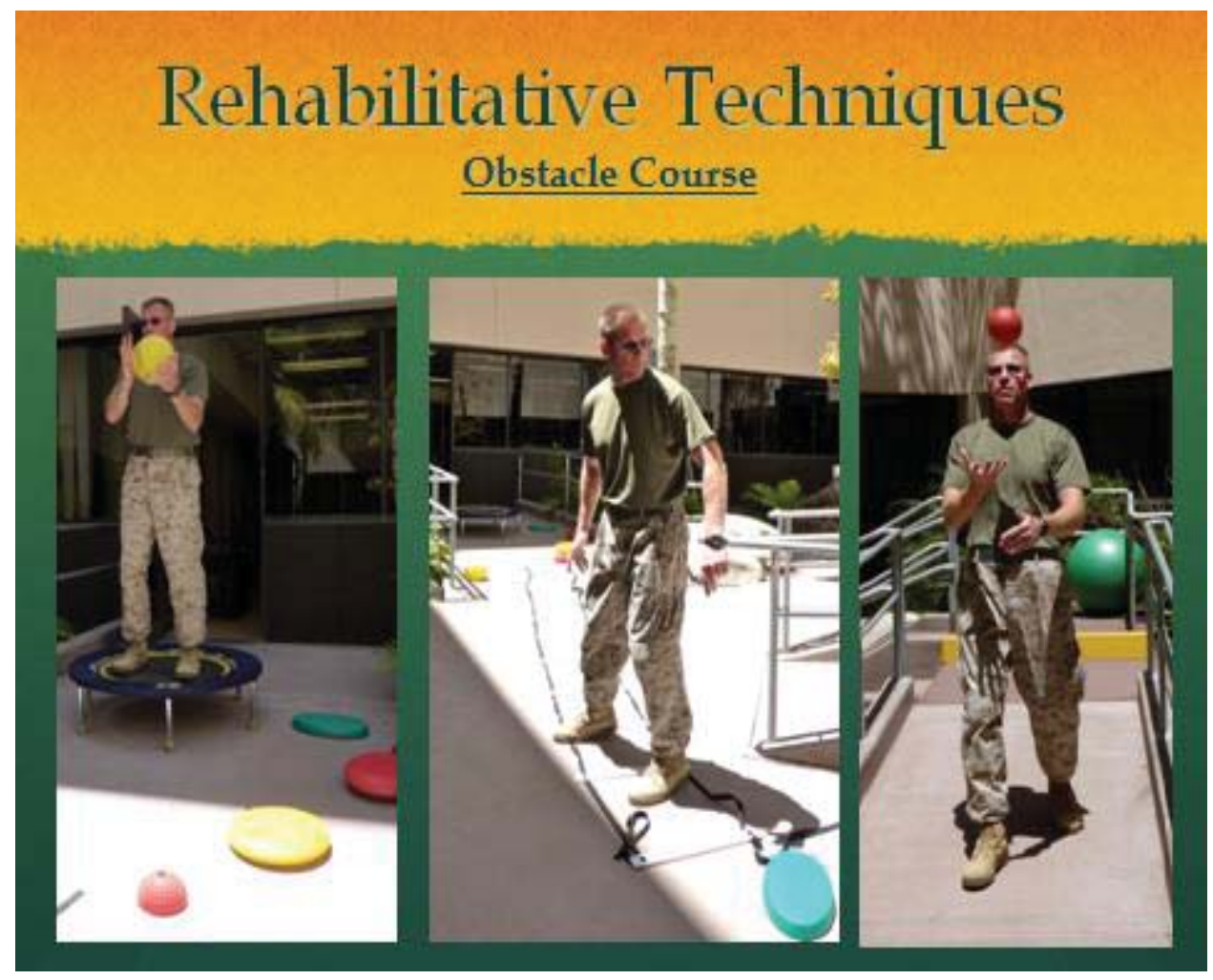

Slide 22 


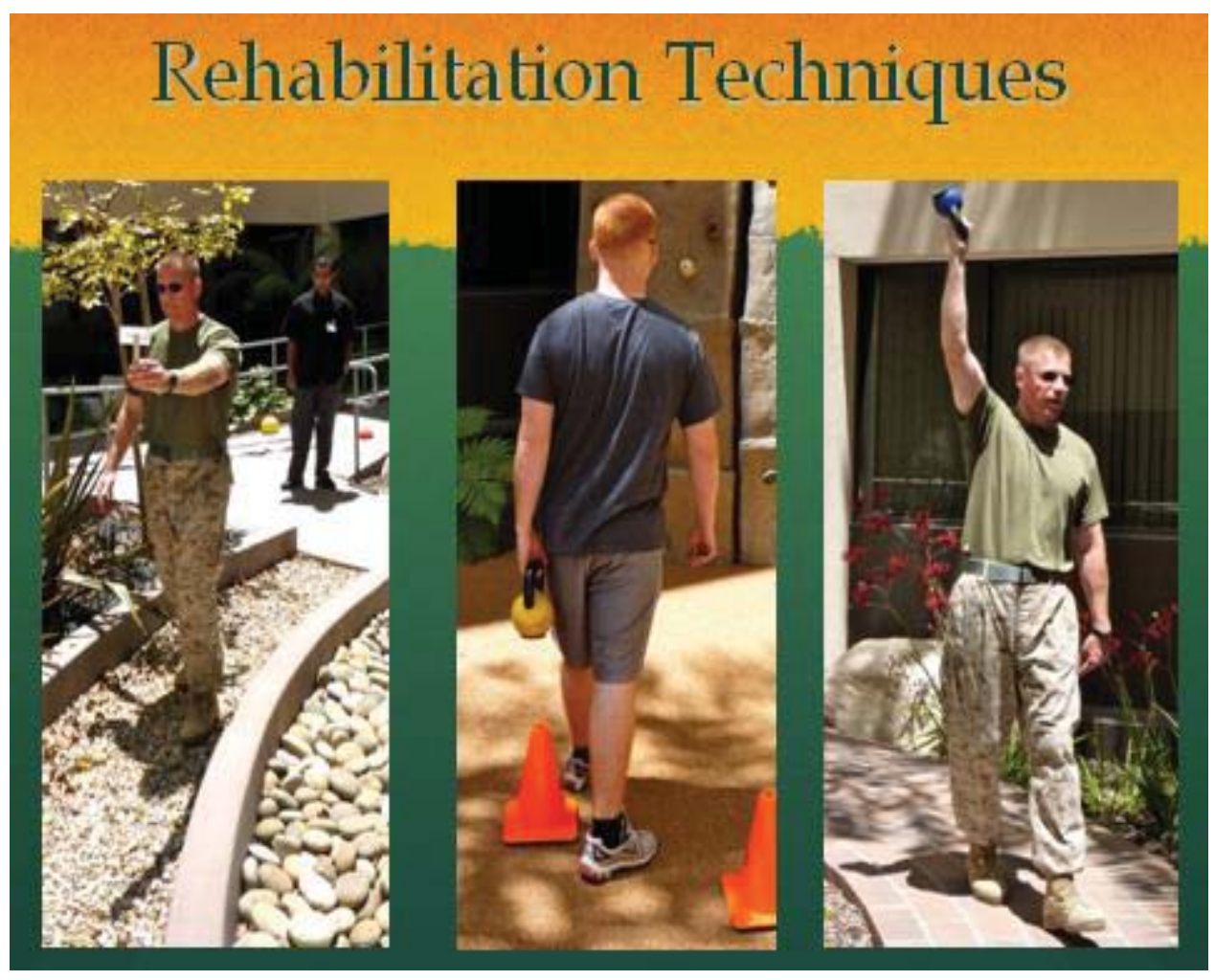

Slide 23

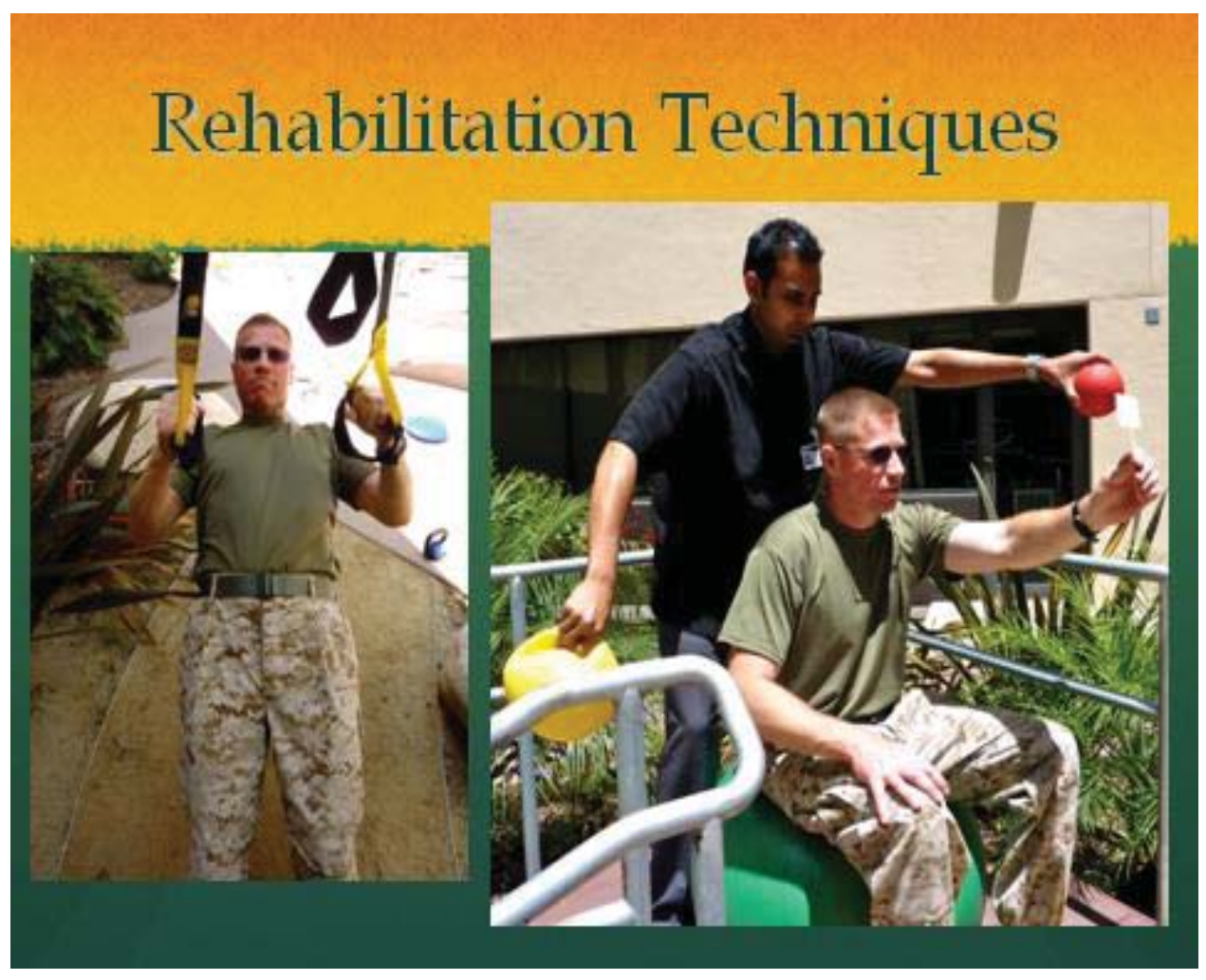

Slide 24 


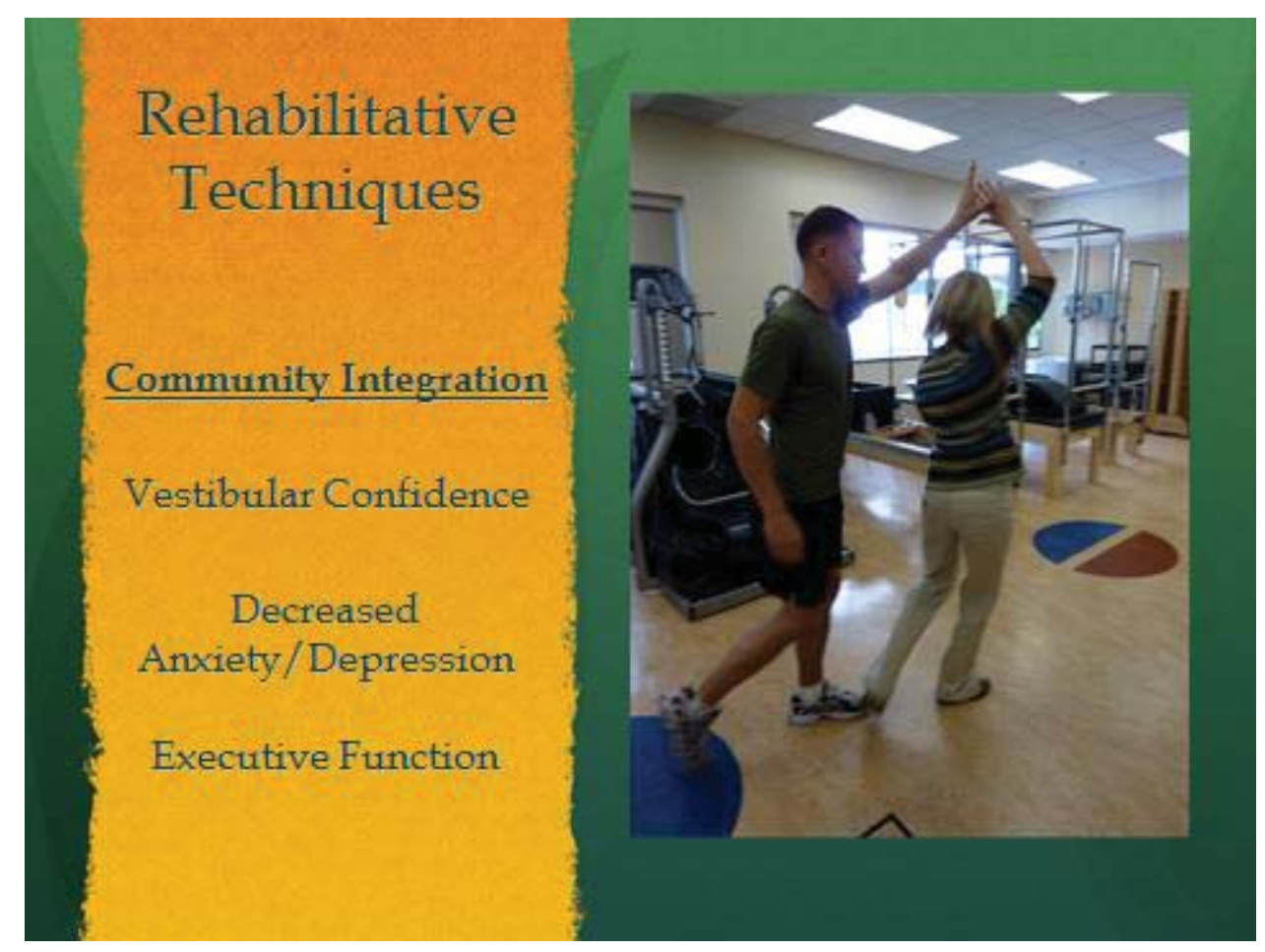

Slide 25

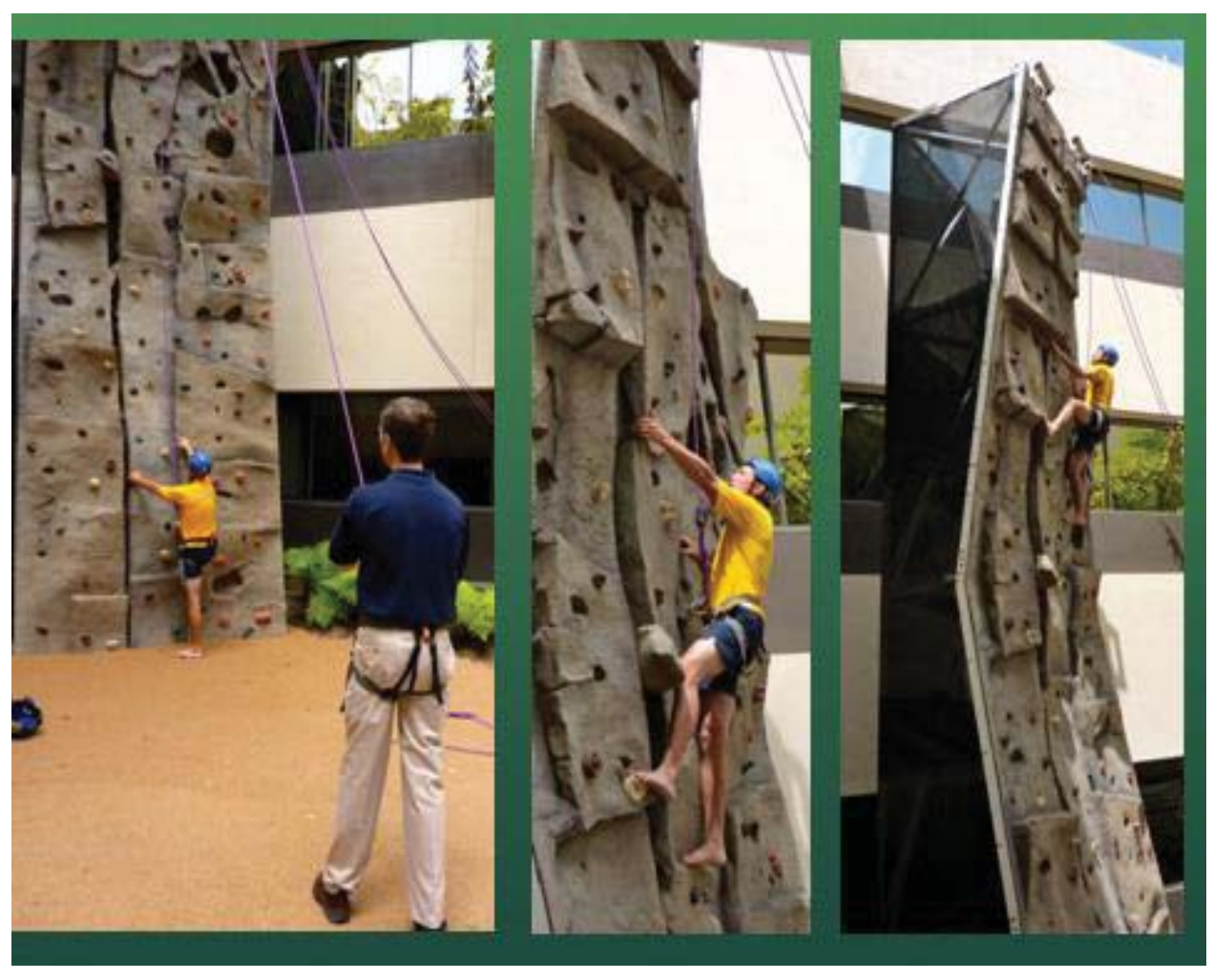

Slide 26 


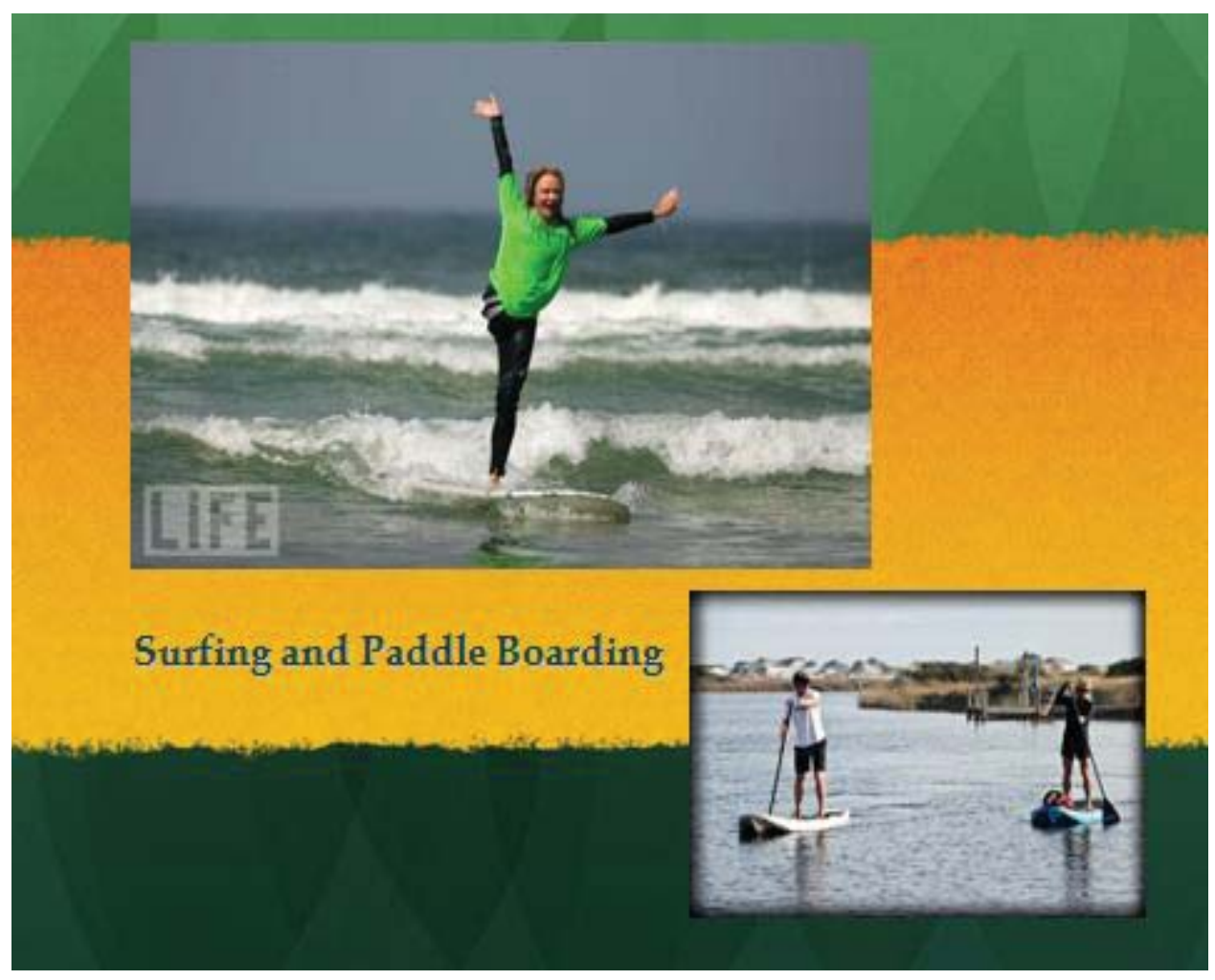

Slide 27

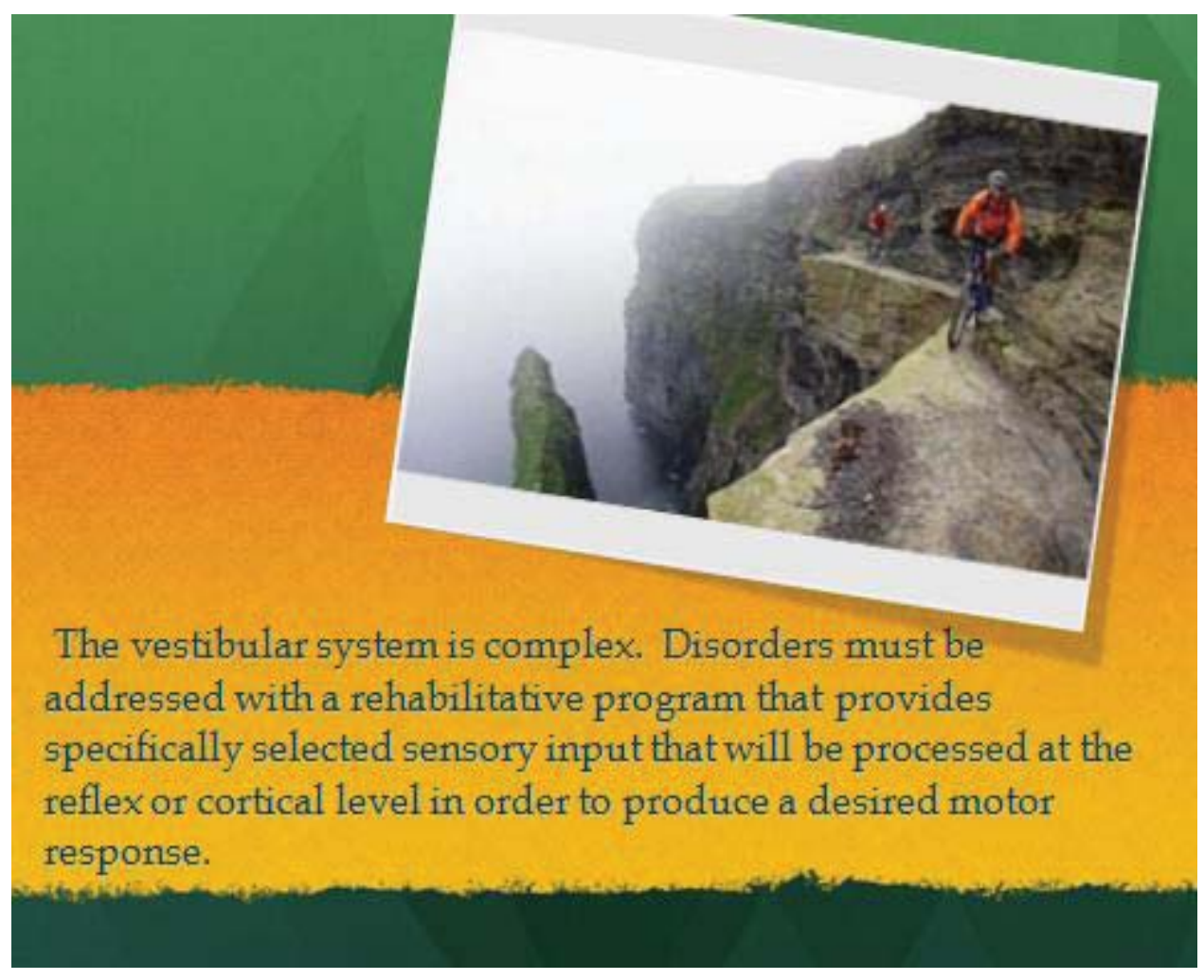

Slide 28 


\section{References}

1. Gill-body, K.M. "Current Concepts in Vestibular Dysfunction." PT. Mazaxine ef Plyssial Therapy 1065 - 5077 (2001)

2. Gottshall K, Drake A, Fray N, Mc DonaldE, Hoffer ME. 'Objective Vestibular Tests as Outcome Measures in Head Injury Patients." Lanngoscoge 113.10 (2003): 1746 50.

3. Herdman, Sasan L. Vestibular Rehabilitation Philadelphia: FA Davis Company, 2000

4. NeuroCom International, Inc. "Clinical tategration Seminar," NeuroCom Intermational ins Clackamas NeuroCom International, ins. 2005.6-24

5. Vestibular Disorders Asssociation, Vestibular Rehabilitation Therapy 5 April $2010<$ http://vestibular.org/vestibular-disorders/treatment/vestibularrehabuphips.

6. W.P.A. Kelders, G]. Kleinrensink, IN. van der Geest. "Compensatory increase of the cervico-ocular reflex wih age in healthey humans," losmal of Physiology 533.1 (2003): $311-317$.

Slide 29

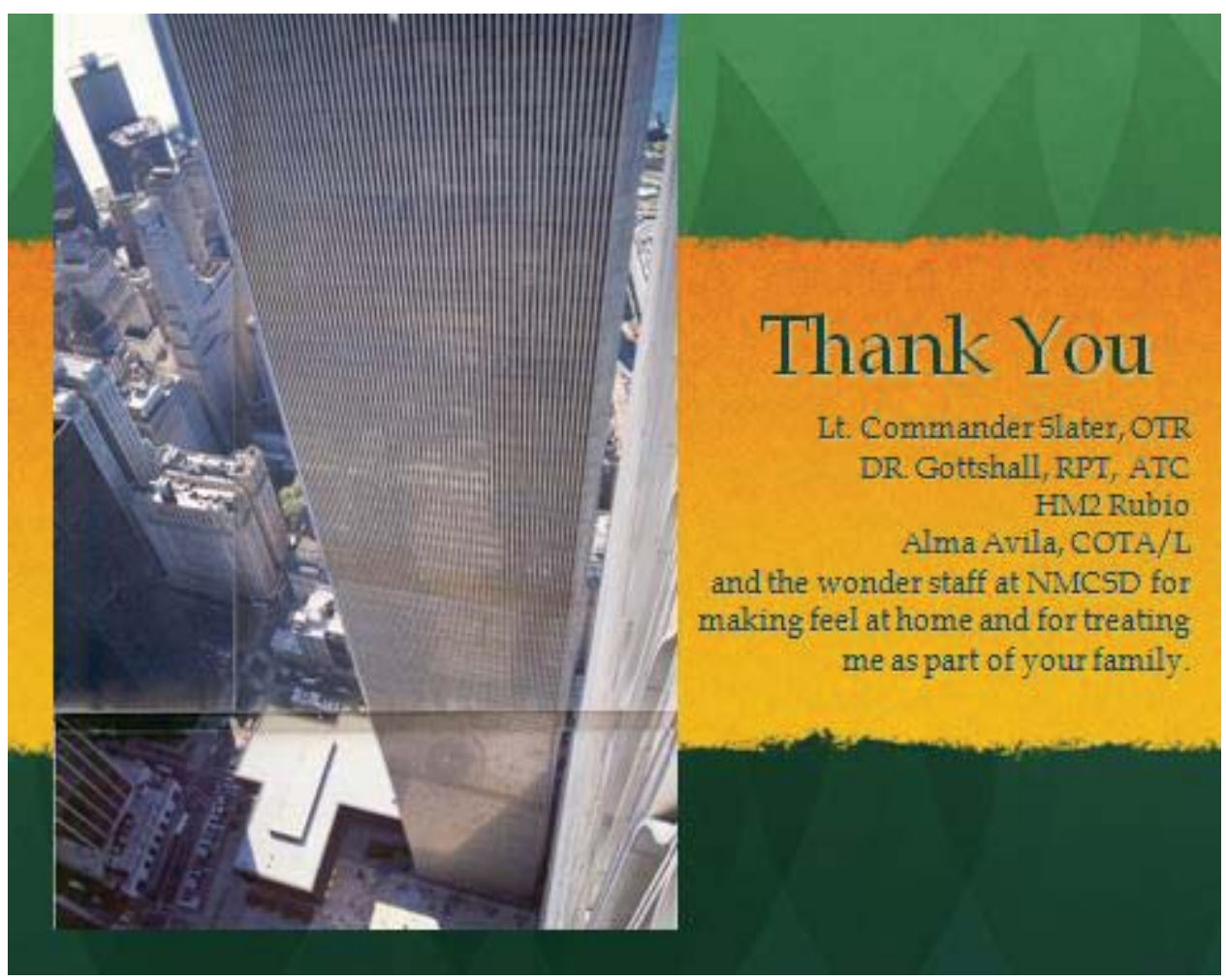

Slide 30 


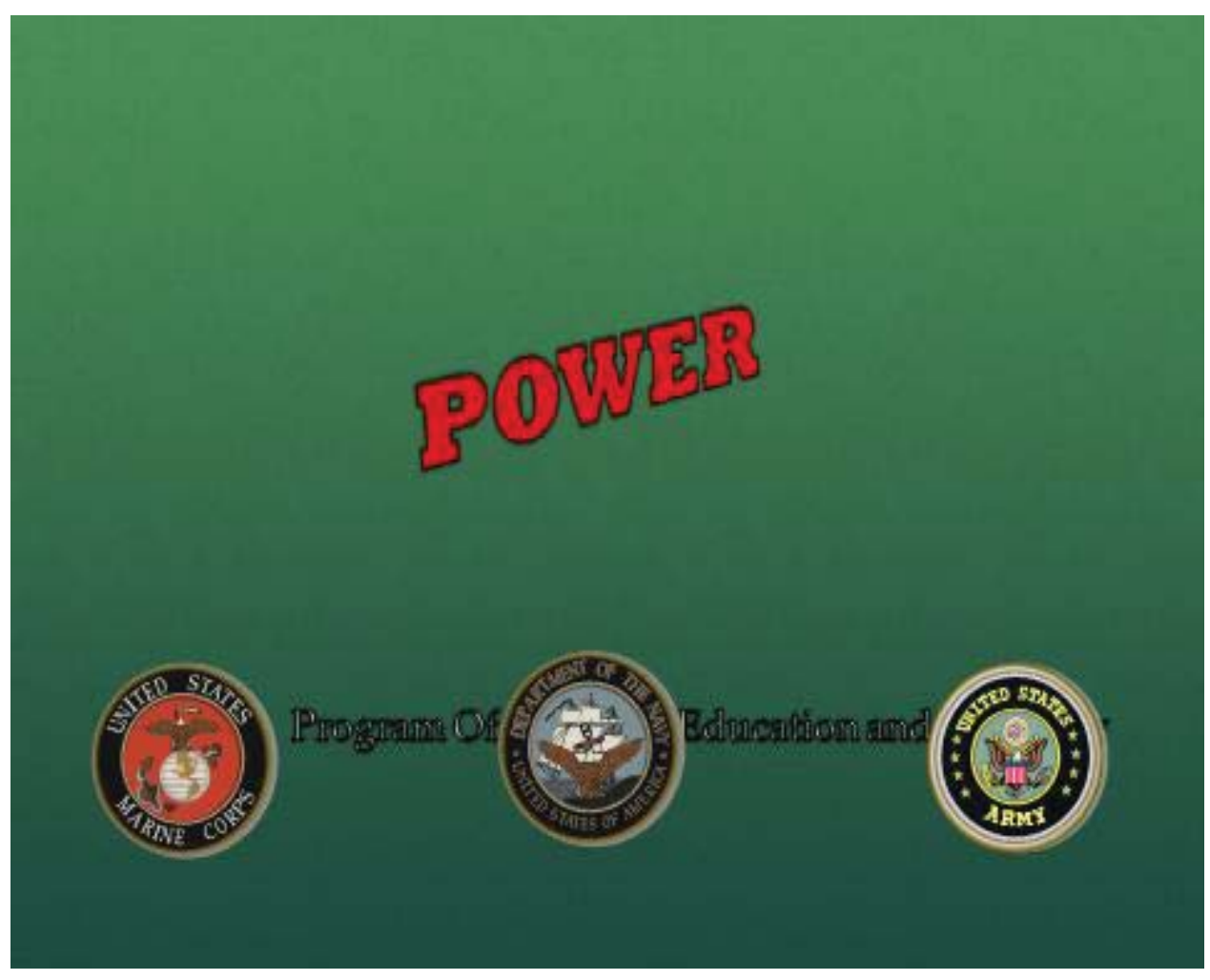

Slide 31

\section{Program Overview}

- Program of rehabilitation for the population of patients who have been diagnosed with a mild traumatic brain injury (MTBI) and have persistent complaints of physical, cognitive and emotional symptoms

- Program that focuses on wellness and education with a positive expectation of recovery and retum to duty

Slide 32 


\section{Program Overview}

- Organizing and coordinating the services offered by NMCSD into a structured program with a focused interdisciplinary approach to patient care

- Individualized treatment plan based on symptom complaints and needs

- $5 \mathrm{~d} / \mathrm{wk}, 8 \mathrm{hrs} /$ day, for 8-12 weeks

Slide 33

\section{Prior to Admission}

- Initial evaluations by the core treatment team

Physical medicine and rehab

Neuropsychology

Vestibular physical Therapy

Neuro-occupational Therapy

Speech Pathology

Mental health

Slide 34 


\section{Individualized Treatment Plan Core Appointments}

- Individual Appointments scheduled to meet patients needs

- For Example:

Vestibular $1-2 x /$ wk for $8-12$ weeks

Speech 1-2x/wk for 8-12 weeks

Mental Health $1-2 x /$ wk for $8-12$ weeks

Primary Care $1 \mathrm{x}$ week and as needed

Slide 35

\section{Individualized Treatment Plan Core Classes}

Vestibular Balance Awareness \& Safety Class

Sleep Hygiene Class

Headache Class

Cog Smart Psychoeducation Class

Operational Stress Control

Nutrition Classes

Slide 36 


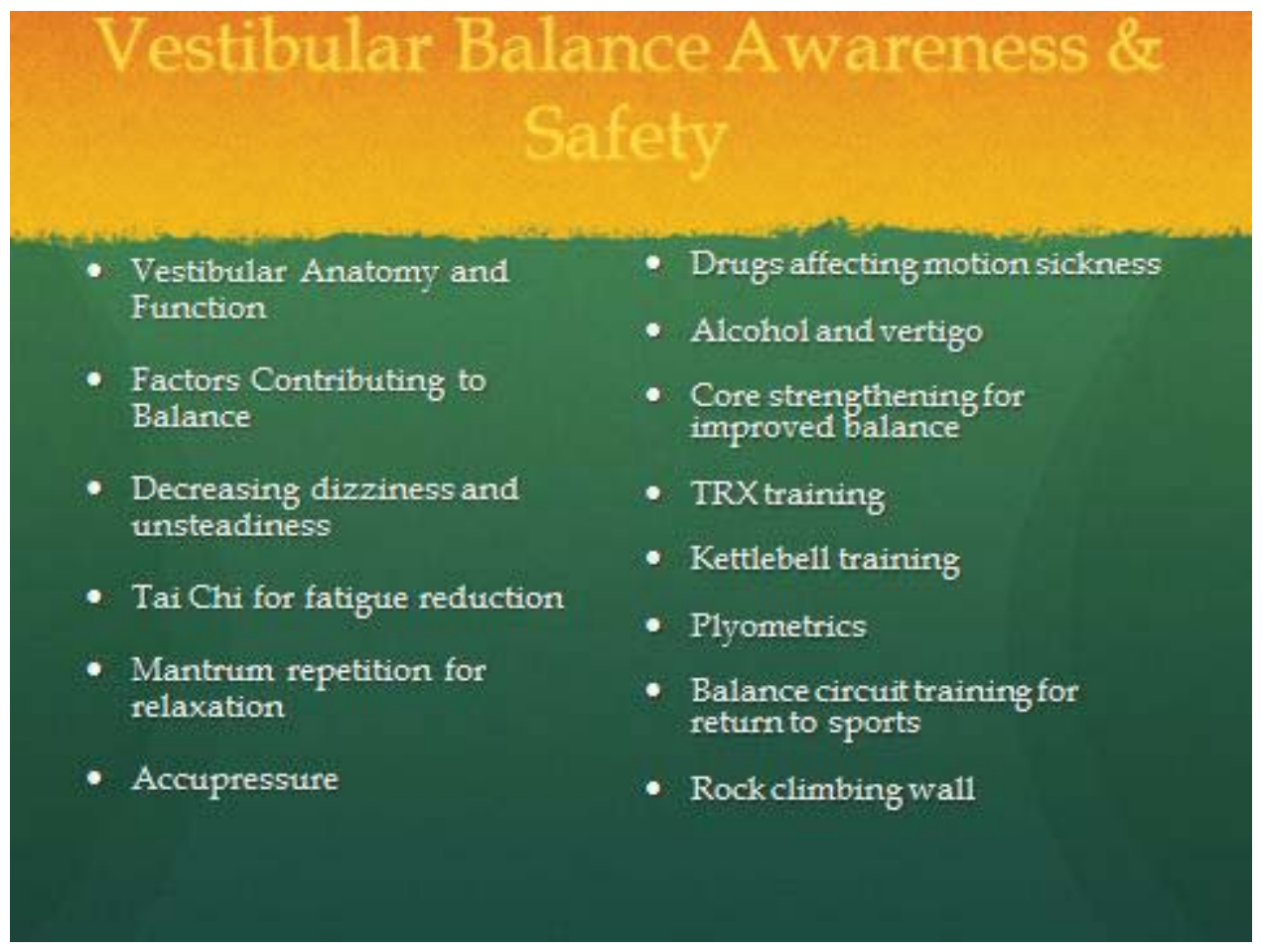

Slide 37

\section{Sample Patient Schedule}

\begin{tabular}{|c|c|c|c|c|c|}
\hline & Mordas & Tuesay & Wercests & Thesela & Friale \\
\hline$\infty \times \infty$ & Prang Mant & Fogen Muxe & Tegan Nkx= & 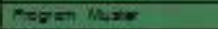 & Tagan Morw \\
\hline $\cos 0$ & & \multirow{3}{*}{$\begin{array}{l}\text { Secel Camuraten } \\
\text { Geup }\end{array}$} & \multirow[t]{3}{*}{ Hor Geve } & \multirow{3}{*}{ 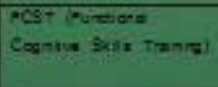 } & \multirow[t]{7}{*}{ CCSt aitrs } \\
\hline $0 \times 00$ & & & & & \\
\hline 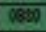 & & & & & \\
\hline 1000 & \multirow{4}{*}{ 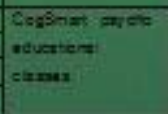 } & \multirow{2}{*}{ 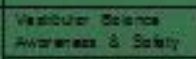 } & \multirow[t]{4}{*}{ CSC Censex } & Wistur teinnos & \\
\hline 5850 & & & & Anarem is Stisty & \\
\hline 1100 & & \multirow{2}{*}{$\begin{array}{l}\text { Heduets ewater } \\
\text { cien }\end{array}$} & & & \\
\hline 1100 & & & & & \\
\hline$\frac{1200}{1200}$ & WESC4 & tage cesta & Esict & LWVOH & $\begin{array}{l}\text { Wver wat: and } \\
\text { Datret aters } 8 \text { ant }\end{array}$ \\
\hline 1000 & \multirow[t]{2}{*}{$\begin{array}{l}\text { noe infordy } \\
\text { artal }\end{array}$} & \multirow[t]{2}{*}{ Nuris } & \multirow[t]{2}{*}{ 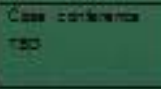 } & Sous thane dowo & \multirow[t]{3}{*}{ Natianey scule } \\
\hline 1830 & & & & & \\
\hline 1500 & & & & & \\
\hline$\frac{1500}{\frac{1200}{120}}$ & 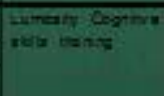 & 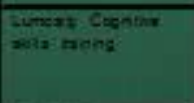 & 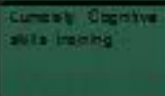 & 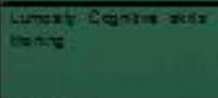 & 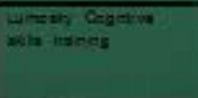 \\
\hline $18 \mathrm{~s}$ & Prontas & Protan & & Prinem & Tin:ax \\
\hline
\end{tabular}

Slide 38 


\section{Interdisciplinary Patient Care Conference}

- Care Conference with patient approximately 2 weeks into the program

- Team Approach

- Patients healthcare teammeets together with the patient

- Discusses with patient their progress, needs, and goals

- Patientcan discuss concerns and personal goals with team

Slide 39

\section{Interdisciplinary Patient Care Conference}

- Patient will have another care conference if needed mid program

- 1 week before the end of the patients program they will have a final care conference

- Accomplishments/goals reached

- What patient needs to continue to work on

- Can the patient go back to full duty or need a medical board

- Included in on conference is a provider and case manager from patients command for continuation of care and seamless transition

- Follow up with primary care

Slide 40 


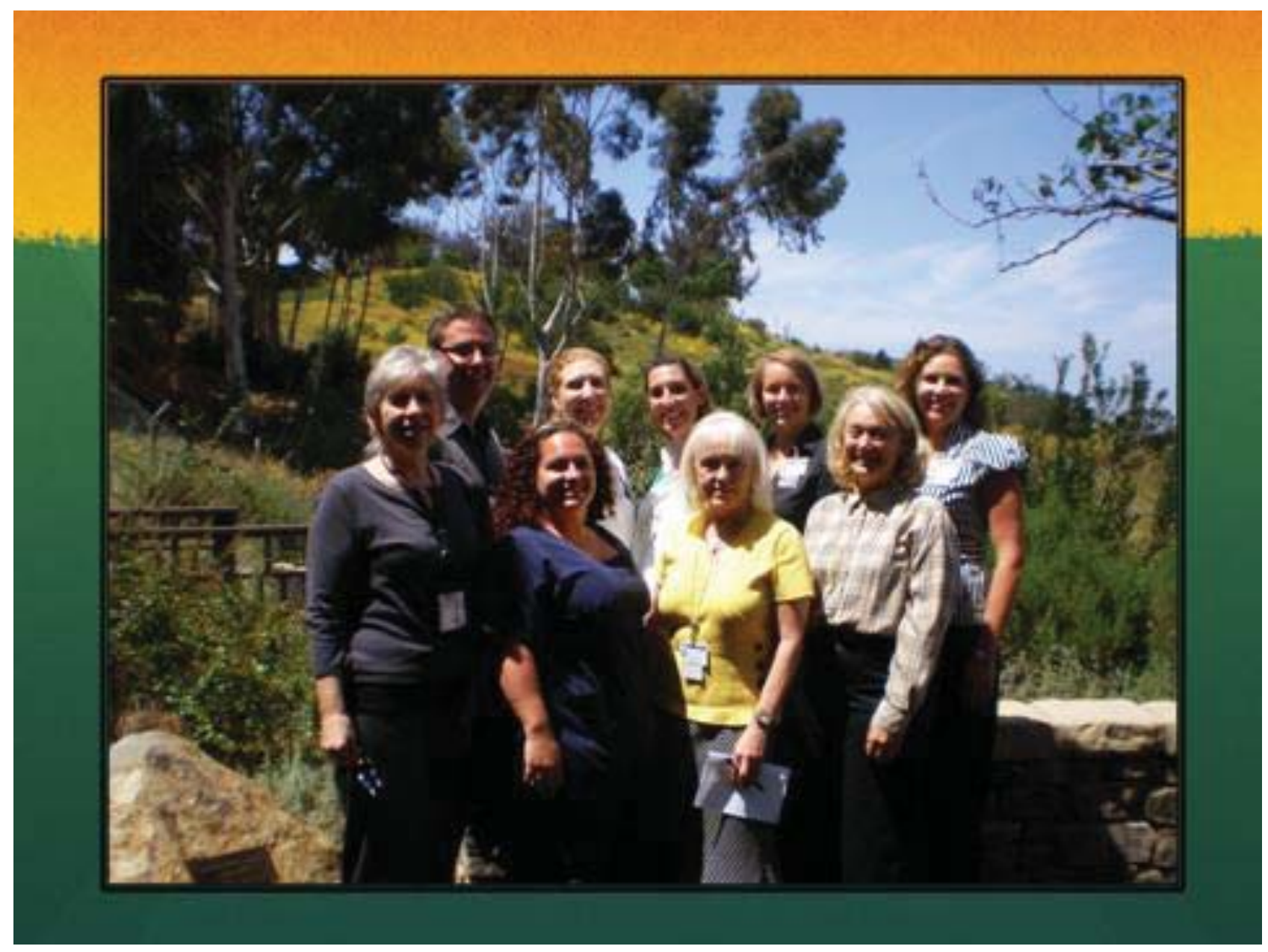

Slide 41

Question and answer session

[Young] How many people do you lose, [who are] riding their bicycle on the mountain?

[Laughter.]

[Gottshall] Yes, we haven't had too many cyclists. [Laughter.] Our recreational therapists will take them out on cycling programs, but not on the side of the mountain.

[Oman] Is combat-induced migraine a phenomenon?

[Gottshall] There's blast-induced. So you know, when they get blasted, it [the extent of injury and symptoms] depends what went off, how close were they [to the blast], were they inside something or not, were they thrown in the air and came down on their head, or what have you. But, yeah, migraine associated dizziness is a problem. 
[Black] How many of those patients have low pressure headaches from perilymphatic fistulas [PLF]?

[Gottshall] I think last year they did 11 PLF repairs at our ENT department, and I don't know how many [hospitals such as] Landstuhl might have done, or Bethesda, or Walter Reed, because they don't all come directly to us.

[Benson] You've got a lot of different procedures at your facility. What do you do to evaluate the relative benefit of one particular therapy over another?

[Gottshall] We have several different research protocols in now where they [vestibular patients] just get a traditional therapy, or therapy with advanced dynamic visual acuity training, or advanced tactor belt training, or everything [all forms of therapy]. So we are trying to have different subgroups do different things. If they fail one, they would get another until they are better. So we have research protocols in place to look at that. 


\section{Anthrocentric multisensory interfaces - Anil Raj}

Hello, I'm going to start a little bit backwards here; I'm going to start with thanks to you [slide 1, page 178]. Thank you all for coming to the institute for this meeting, I'm really glad we had such a turnout. I'd also like to thank folks like Chuck [Oman], who actually kick-started me into this direction, so I can either blame him or thank him [speaker is joking]. Looking across the room here, I see that I've worked with, or collaborated with, or been involved with more than two-thirds of this room, and I can say honestly that more than half of you make me sick [slide 2], to the point that Ralph Jell (who is not here), told me that he'd never seen anyone fill up as many barf bags as I did on a KC-135 flight. [After] the seventh bag I handed back to him, that's what he said to me. Actually, [I have a] funny story on that: Since I know I have a very sensitive vestibular system (based off the testing we did at Conrad Wall's lab when I was a research assistant there), I always take compazine or phenergan before I get onto a boat or anything else that might be terribly provocative. Of course, my wife had never been sea sick or motion sick before, until we went out on a boat to Hamilton Island. Chuck [Oman] was at the tiller and went out into the straights, and my wife got very ill for the first time ever. That really pointed out to me how little we understand motion sickness because here we are, on a boat full of vestibular and motion sickness researchers, and she was getting about 10 or 12 different instructions on what to do [laughter]: 'look at the bow,' 'look out at the horizon,' 'get to the rail,' 'lay down,' 'no sit up.' She was [saying] 'just leave me alone, let me be sick.' So it really points out how much more there is to [learn in] balance and in motion sickness.

My area of research is something that we're calling anthrocentric multisensory interfaces [slide 3]. We had to come up with our own name, just to really separate ourselves from humancentered computing because really, human-centered computing, or human-centered interface, is what we do here at the institute, in general, but it's got a lot of connotations and a lot of political baggage with that, so we're trying to carve out our own niche. We stole anthrocentric from Corey Lathan, [who is] also a Conrad Wall [Wall, Merfeld, Rauch, \& Black, 2003] alumna and an MIT [Massachusetts Institute of Technology] alumna, and then we threw on the multisensory part of it to indicate that we're talking about pushing information to people, using normal sensory capabilities, as well as extracting information effectively for systems that we're interacting with, so that the systems understand us better and we can understand the systems we're involved with more effectively, as well. Now, the systems that I use typically include auditory displays. That's [a picture of the display on] the lower right there [slide 4]. It's a surround sound system that we have installed in the lab, and you might have noticed that in my lab area we have 10 speakers that were mounted in the ceiling that gives us very good azimuth and distance sound capability. We also use the three tactile displays that I showed you yesterday. The upper right one [slide 4] is the VideoTact ${ }^{\mathrm{TM}}$ from ForeThought Development [Limited Liability Company] up in Wisconsin. The middle one is our version of the TSAS [tactile situation awareness system] that we've been working with. You can see we've gone away from a regular grid there, [it] turns out we don't need one, and so we can close the loop around perception [Raj, Suri, Braithwaite, \& Rupert, 1998; Raj, Kass, \& Perry, 2000; McGrath, Estrada, Braithwaite, Raj, \& Rupert, 2004]. And then, the last one there on my right is the tongue display, the BrainPort ${ }^{\circledR}$, a vision device display with 600 electro tactile transducers on the tongue, and that's also one that we showed you yesterday. 
A couple things that we've been doing with it is trying to replace vision, as well as trying to replace audition. We've also been looking at augmentation of balance. The auditory slide there in the middle [slide 4] is something that we've been doing some pilot work with. We take ambient audio sound and present that tactually, either on the tongue or on the abdomen, in the form of a real-time spectrograph [Greene, Pisoni, \& Carrell, 1984; Liberman, Copper, Shankweiler, \& Studdert-Kennedy, 1968], and train people to recognize human speech. So we do a couple things: One, we use speech recognition technology to identify human phonemes in the background noise, so that we can increase the saliency of human speech components against things like the home air conditioner or the fan in the computer, and we can pretty accurately recognize, at least from a limited vocabulary set, the words that would've been spoken. So, with this tactile transduction onto the abdomen, my graduate students have been hitting about 70 percent and that seems to carry over weeks after the initial training, as well. The other thing we're doing is augmenting vision capabilities, and I'll show you a lot of that because that's where we're just at [recently]. We finished our pilot study about a year ago, and we're getting ready to start our full-up study on the 20 blind subjects, soon, if we can get the IRB [institutional review board] approval from the Army. But one of the things that we are incorporating, hopefully before we have to finalize the IRB, is 3D models in real time. This [bottom right-hand corner of slide 4] is actually video from Kinect sensors from the Xbox 360, [which] just got released about 2 weeks ago. It has already been hacked very effectively to be able to feed into any computer system, and you can actually extract, very quickly, real time 3D models of the environment.

The three areas that I typically talk about are sensory substitution, sensory transposition, and sensory replacement [slide 5]. The one we focus the most on is sensory substitution and that is to provide sensory information through an alternative pathway. So it [the problem] may be an intact pathway versus a broken pathway, say for the blind individuals that have lost their visual sense, but it could also be somebody who's in an aircraft cockpit and now their balance sense is not necessarily damaged, but it's irrelevant or illusory. And so, we would provide tactile cues, auditory cues, or visual cues, to bypass the incorrect vestibular information. Transposition [is something] we typically think of in terms of moving the same sort of signal to a different location in the sensory environment that is the same type of channel. With the exoskeleton, we have individuals who are paraplegics, and we want to reflect the ground contact forces that they would normally sense through their feet back to some other location on the body. The easiest way to do that is to use another tactile sensory channel, and so [there are] a couple of areas that we're looking at, [including] putting pressure sensors in the shoes of the paraplegics and then on their torso or on their tongue, and putting the ground contact force information onto that part of the sensory capability. The area that we typically don't work on is replacement, and that is, essentially, [placing] cochlear implants, or retinal implants, or even cortical implants, but essentially going directly into the same channel. So if you've lost your vision, you get a retinal implant, maybe you've lost your eyes, so you get a cortical implant on your visual cortex. I don't really like getting involved with those too much because they're very messy, and with the rapid advance of technology, the other mechanisms that we work on are all noninvasive. So just in the period of a year, we went from 100 pixel tactile array on the tongue to a 625 pixel array on the tongue, and if that had been an implanted device, it would've been a choice for a user to decide whether it was a big enough improvement to warrant another surgical procedure. One of the things I want to make a point about here is we don't try to represent virtual reality or virtual 
environment type immersion to people that are using sensory substitution or multisensory interfaces. We try to do [represent] the difference between an aerial photo [and a map]. This [slide 6] was going to AsMA [Aerospace Medical Association] last year, leaving the airport and getting to the hotel. I printed out a map from Google, and I also printed out the satellite view from Google and obviously the map was a lot more useful to me, even though [there was] more information, more realistic information, on the satellite image. I didn't really care how many buildings there were. What I really wanted to know was which [roads] were the freeways and where the one-way streets were, and exactly where on that block the hotel was. That's the sort of thing we try to do; we try to only provide as much information as necessary to get the task done, and that avoids a lot of computational intensity, and it also [eliminates] a lot of the chaff [from] the signal that we don't necessarily need to do a given task.

I just want to show real quickly one of our first sensory substitution collaborations we had with Angus [Rupert]. This [slide 7] is [Navy] Captain Jim Baker in the backseat with no instruments, [he is] going to do an aileron roll using an early version of the TSAS system that we put together with Angus. Here [slide 8] he is entering the roll, and this is the over-the-shoulder view of the safety pilot in the front seat. You can see that his hand is not actually on the stick. Even though he reaches for it every now and again, he does let Jim control the aircraft and level the aircraft back out here very effectively.

From a vision standpoint, this is where I've been working primarily: looking at augmenting service members who've lost their sight during the two conflicts we have going on right now [Operation Enduring Freedom and Operation Iraqi Freedom]. All of our participants came in with less than 5 years of blindness and no eyes. They either had two prosthetic eyes or one prosthetic eye and an empty socket. They were able to very rapidly learn to do all the tasks that you see here [slides 9-11]. The first slide here [slide 9]: we didn't even tell the gentleman that we were going to have a buffet; we just said we're going to go get lunch. He recognized that the table was to his side and that there were bowls of food out there, and asked us if that was lunch. Interestingly enough, once we pointed out that one was chicken salad, one was shrimp salad, and one was tuna salad, he was able to point them out to his wife and have her put a plate together for him. We've also had our service members learn to be able to read again. We actually got up to four or five word sentences with them pretty easily, and [they were] reading eye charts down to about 20/80 with the interim system that only had about 300 pixels on the tongue. And here's [slide 10] one of our service members playing tic-tac-toe with one of my research assistants. We've also piped the internet, or a computer video, directly into the tongue, as opposed to going through a camera system. That allows, for example, somebody who's blind to be able to interact with the computer without having to actually sit in front of it. We set it up the way we did so we could see what's going on, but there's no reason why somebody who's a blind individual has to sit in front of a computer screen. In fact, a lot of these guys have other orthopedic injuries and can't sit for extended durations of time. What we're looking at is trying to provide assistive technologies that can fit this gap (as Ken [Ford] was talking about yesterday) between systems and the needs of the individuals. [We] try to match it so that they can go out in the real world, and they can use the real internet, and they can use real systems that normally sighted individuals would just take for granted. And my long-term goal is to make it so [that] it's unobtrusive and not obvious to an observer that a particular person might be blind, and so that they [the blind] would be able to navigate the world effectively. 
Here are a couple other things that they've been able to do very effectively [slide 11], such as catching balls that are rolled across the table. This gentleman here [right farthest picture on slide 11] was actually able to recognize that his son's hair was standing up on the back of his head after taking a nap, and his wife was laughing because how the heck would he know that, and this is a child that he's never seen before because the child was born after he was blinded. We're setting up to do a new study here that'll be a little more complex than the tasks that we did. This [bottom row of pictures on slide 11] is my lead research assistant, Jameson [Beach] (that you met upstairs yesterday), going through the procedures as we're working out the protocol. One of the things that we're going to add to the task is color recognition, and this, I think, is going to be a real unique result if it actually works. But so far, it's actually working. That's a Rubik's Cube he's holding there [bottom left picture on slide 11], and the goal would be to identify a given color and place that [Rubik's Cube] down on the table with the red side up, or the blue side up, or the green side up. And again, we're looking at people who have no eyesight at all. Now, this [pictures on the bottom row of slide 11] is navigation in an unfamiliar environment. We're actually going to throw obstacles in the way. We haven't done that before. [Before], we just let them walk in an empty hallway, but [now] they're going to have to avoid these blocks and step over the blocks on the ground, and hopefully we'll have as good results as we've had in the pilot runs that we've done previously. This [slide 11] is just using the tongue array, and this was made by the Wicab Incorporated up in Wisconsin. This [slide 12] is one of our service members walking down a hallway. He had never been down this hallway before; he's following the track on the ground and seeing the walls. Here [slide 13] he is actually exploring (using a touch screen) a picture of his son, and we didn't tell him what it was, we just said this is a photograph. We didn't tell him who it was, and [he] pretty quickly figured out [that] it was a face because he could identify the eyes, the nose, and the mouth, and pretty quickly after that he recognized that it was his son. Now, it was a little bit of a cheat because who else would we put up there, but, the fact is, he recognized it was a face, and he was pretty quickly able to figure out that it was a picture of his son on the screen. And, essentially, here [slide 13] we are piping directly to the tongue. The pixel is underneath his finger, so as he's moving his hand on the smooth touch screen glass, the 100 pixels that are underneath his finger are being reflected back onto his tongue. And again, that was only a 100 pixel array; we're up to 625 now on the current systems.

This [slide 14] is some of the balance work that Wicab [Inc.] has been doing. You've probably heard that they've been doing some clinical trials, [but experiencing] a little trouble getting recruitment numbers up, so some of the trials have closed recently. These ${ }^{*}$ are all LD [labyrinthine defective] folks, mostly a result of gentamicin toxicity, some were [status post] acoustic neuromas, but you can see that they all have disturbances that are very obvious. Then, post training with the device that I showed you guys yesterday, you can see that they become very stable [slide 15], and you can also see that they're not wearing anything; they don't have the prosthetic device with them right now [in the post training section of video that Dr. Raj presents]. They just used it during the rehabilitation therapy portion of the training.

\footnotetext{
*Dr. Raj presented a video featuring several patients who had received balance therapy. The video shows clips of the patients walking a straight line, pre- and post- training. All patients showed great improvement. The authors of this report captured images from the video of the patient with the most dramatic improvement.
} 
So this is something that really excited us, and we wanted to see if we could duplicate this, particularly with the service members that were coming back with mild traumatic brain injury related balance disorders. Ben Balough, [who works as an MD] down at Naval Medical Center San Diego, came up and said, 'hey I've got this big backlog of people who are medically ready to go back to their units, but they have this balance disorder that is not improving with the normal vestibular therapy that we've been doing.' And so, we collaborated with Ben [Balough] and Kim Gottshall, and put together a study. I saw Al Mateczun here earlier. I wanted to thank him for actually approving the IRB [Institutional Review Board] [signing the IRB approval forms] because by the time the IRB made its recommendation that it could be approved, there was nobody at the hospital who could actually sign for it; nobody was willing to take that authority, and Al stepped in and took it and said, 'OK I'm going to approve this IRB.' So the data I'm gonna show you [slide 16] was actually presented at ARO [Association for Research in Otolaryngology] [in] February, out in Anaheim [California], as a poster presentation [StegnerWilson, Balough, Gottshall, Raj, \& Hoffer, 2010]. At that time, we had 11 active duty males, and essentially these were all people who had plateaued on the normal vestibular therapy at the vestibular clinic at the San Diego Naval Medical Center. Since that time, six more patients have been enrolled, so they're not actually included in this data. But just looking at the results [slide 17], we looked at two main variables: the Dynamic Gait Index [DGI] and the Sensory Organization Test [SOT] off the NeuroCom, ${ }^{\circledR}$ and actually it's all the sensory organization tests averaged together. We haven't teased out the individuals. I imagine [trials] four and five are obviously going to be worse performances than the rest of them. But essentially, out of the 11 participants that we had, 6 normalized, 4 didn't get any better, 1 got worse with the DGI. Again, it's a very subjective number. But, on the SOT average, we had much improved on six of them, and [observed] normalization on four of them, who were not normal prior to that. So 10 out of 11 actually got better, and then the decline is actually a little bit in error because that actually should have been a 1 . I'm sorry, that was an error on the slide [i.e., decline $=3$ should be replaced with decline=1 on slide 17] [slide 17]. Knowing that we had reasonably good results with just the BrainPort ${ }^{\circledR}$ device, we also know there's more to balance than just posture. So what we wanted to do is start a study that's going to look at augmenting balance with a more complete balance system. So yes, we're still going to look at the BrainPort ${ }^{\circledR}$ by itself, but we're also going to look at adding in TSAS, and the VideoTact ${ }^{\mathrm{TM}}$ abdominal array, and the motion capture system we showed upstairs yesterday (that Jameson [Beach] was wearing), and the insole pressure platform. In this particular example [slide 18], one of my other graduate students is wearing it [the motion capture system], and you can see, even in a complex stance, we can calculate what the stability platform should be under her feet. [The calculation involves] knowing where all her limbs are, and the masses of her limbs, and also knowing the contact force against the ground with the foot pressure transducers. The CG [center of gravity] against the stability area is the dot in the polygon at the bottom of the center inset there [slide 18]. We normalize that and we can put that back on the tongue, and that's what you saw in the lab yesterday. The crosshairs that were on the tongue are normalizing based off of that polygon that's down there, so they're always knowing where they are relative to the edge of stability. Even in complex maneuvers like reaching down to pick up your keys and things like that, we should be able to provide reasonable cueing for the individual.

You saw that the motion capture system is wireless and wearable, and that is fairly unencumbering for lab work, but, it's probably overkill for most things. That's why we're 
looking at the Xbox 360 Kinect over there [in the laboratory in which Raj works]. I'm not trying to sell it, but it's a really cheap RGB [red, green, and blue] in-depth camera. So for $\$ 150$ you get something that used to cost about $\$ 1200$. We got two of them on Wednesday and my guys already have them integrated so it's a pretty fast update. So hopefully, we [can] start doing some testing with that after the holidays. I talked about some of the other areas that we're working with, [like the] 3D audio [slide 19]; we don't do a lot there because we don't have the money to buy a nice 3D audio system. But what we find is if we mix it with good 3D visuals and good tactile cues, we get the equivalent of having a really good 3D audio system, even if we're only using surround sound to provide us azimuth and elevation from the tactile interface. We're getting some fairly complex systems right now. We've done a lot of work recently for the Air Force on controlling multiple UAVs [unmanned aerial vehicles]. A big problem in the military right now is [figuring out] how to take somebody and help them control multiple vehicles and be able to manage a theater without having to put four or five people on each vehicle, which is typically what they do right now. So we are trying to take some of the algorithms that we've come up with for hierarchical control of very complex systems, and apply that back to the complex system of controlling your own body. The other aspect of multisensory interfaces that I talked about earlier is not just the push of information, but extraction of information. So one of the systems that we just got in recently is this dry electrode EEG [electro-encephalography] wireless headset [slide 19]. Essentially, you put it on, jiggle the electrodes a little bit, and in about 20 seconds you're getting great EEG [readings] off the system with no cap, no gel, no impedance settling issues that we have to worry about [Estepp, Christensen, Monnin, Davis, \& Wilson, 2009], and it's pretty robust to DC [direct current] signals in the environment. So, [we don't have to deal with] things like the TSAS switching on and off, and the BrainPort ${ }^{\circledR}$ switching on and off. Delivering signals don't seem to contaminate the signal as much as they did on the wet electrode systems that are out there. So, we're actually the first non-military organization to get one of these because I've been working with QUASAR ${ }^{*}$ for about 5 years, and badgered them into putting us into the queue, because every single one of them they've been making has been going to the Army. One of the things we've been working on, in concert to this, is a software agent infrastructure that allows us to tie all these pieces of information together [slide 20]. The data streams can be passed from any of the sensors to any of the displays which allow us to test different hypothesis very quickly. For example, as I mentioned, we just bought these Kinect sensors. I got them Wednesday night after I took my wife out to dinner, we stopped at the mall on the way back, and by Thursday, we had them integrated and ready to try some things out with it. So the architecture has really been a strong capability, and one of the frustrations I had when I first started doing research here is that it would take a very long time to get software coded up for a new experiment, and now we can almost have a psychology grad student put together an experiment with all of the software components already ready.

This [slide 21] is an auditory and tactile representation of one of our surgical robots that we showed yesterday, and here you can hear [that] the tone is changing [slide 21 was captured from a video presented by Dr. Raj], [but] what you can't appreciate here is that the position of the tone is changing, depending on the location of those robots arms. The tongue display there [left side of slide 21] is representing the amount of openness or closedness of the

\footnotetext{
*For further information on this company, visit http://www.quasarusa.com/
} 
graspers, as well as how much force is being applied. The left grasper is grasping a much thinner cup, so it's closed all the way before any force is generated, whereas, the white cup that's being dropped on the inside is thicker [shown on the right side of slide 21]. So the operator can perceive that they've already hit resistance (and that it's a noncompliant resistance) and manage their force, whereas trying to do this only through visual [cues] (just like flying an aircraft) becomes a very cognitively demanding task. Here's [slide 22] our system we showed yesterday, and [I will discuss] a couple of things I didn't get to point out to the folks that came through. The upper left inset there [on slide 22] is showing a camera being positioned instead of the operator there, so it's not quite synchronized. But essentially, the head is being tracked and driving the camera directly, which means that we get the sensation of 3D perception because parallax still applies here. So if he tips his head one way or the other, you can see around the object and it's very convincing [that it is] 3D when you're sitting at that eye point. If you're a little bit off, it doesn't make any sense, it just looks flat to you. But, if you are right on the axis, [than] very quickly, you [will] start perceiving the environment in $3 \mathrm{D}$ and this is a simulated environment. What we want to do is use the Kinect cameras to build these 3D models of the internal anatomy rapidly, and allow somebody to have good 3D visual cueing when they're doing a task like this. Again, this is very similar to what we find on aircraft, in that all the kinesthetic and somatosensory and balance cues have nothing to do with the orientation of what's going on inside the body, and you have to use vision almost entirely to navigate around, currently.

Most of you went over to the robot lab yesterday, down the street. This [slide 23] is our powered exoskeleton for individuals with paraplegia, and you saw, essentially, the effective capabilities of the system [slide 23]. This is actually one of our paraplegics walking, really, for the first time. We will have one more session with him where we'll actually take out the parallel bars and he'll only be using his normal forearm crutches to walk and to control the exoskeleton and his balance. But right now, it's still an open loop system and what we want to do is to add the pressure sensors back in, the motion capture system back in, the multisensory interfaces back in, such that we can have the user actually control the system (change the speed, turn, stop, and control balance) because from the waist up, he's fine and he's got a very much intact balance system. So if we can provide him [with] the signaling that he would've gotten if he was still neuromuscularly intact, we can hopefully close that sensory motor loop through the multisensory interfaces. I did point out that this is our powered exoskeleton. We also have a passive exoskeleton that we've been working on.

This [slide 24] is a gentleman who had an intracranial bleed due to an AVM [arteriovenous malformation] that ruptured. He was in a coma for 3 months, he woke up, had no control over his left side. You can see [that] he's got a little bit of contracture of his [left] arm. This is about 7 months after he woke up and about 4 months after he learned to speak again. Here [slide 25] he is again about 7 months after he woke up from his coma, walking with a passive exoskeleton. This [exoskeleton] actually has batteries, but that's only to have the LEDs [light-emitting diode] turn on to show when the knee automatically locks. He used it for about 10 or 15 minutes, [then] we took it off and we said, 'we didn't get any before image or video so let's take it off and try to have you walk without it,' and he said, 'nah, nah, I don't need it, I don't even need my cane.' This [slide 26] is the first time he's walked since going into his coma, and you can see it's a much faster gait than [before, which was shown on a video presented by Dr. Raj, captured in slide 25]. We had to go to his mother and get some pre-imagery of him in the hospital and you 
saw how slowly he was walking with two assistants and a cane. Here [slide 26] he is walking with no assistance at all after about 10 or 15 minutes of using the passive exoskeleton. The passive exoskeleton forced his leg to move in the path of a normal trajectory with a hip swing initiation. Our walking is very efficient energetically, so all you have to do is initiate a hip swing and the leg should swing and be physically in the right spot, and then as you load it, the Achilles tendon and patella tendon shift and cause the knee and the ankle to support your body with very little active muscle control. Now, what we think is happening is something similar to what we think is happening with the balance prosthetic, causing an aftereffect. He was so afraid of falling because he'd fallen so many times after he'd woken up that he was always very cautious, [thinking] 'is my foot in the right spot, I can't feel it but I have to start loading it slowly and seeing whether it's stable.' Then [he would] take the next step, and do that for every step. [After treatment with the exoskeleton], he realized he didn't really have to do that as long as he initiated a normal hip swing, and he was still intact there [in the hip area] enough that the leg would pretty much be where it needed to be. Now, I would not put him across the steps, or on the obstacles, or on uneven terrain with just that little bit of training; but, we feel that if we can improve the sensory capabilities that he has [by] putting the sensors back in the foot and giving him the ability to feel that, he'll be able to train himself to handle uneven terrain more effectively. So, this is my real last slide [slide 27], and we've got some newsletter invite addresses here, and our web site is on here, as well. I welcome you guys to send me an email if you want to get our regular newsletter, it comes out about three times a year and does review a lot of the research that we're doing. And I'll entertain any questions. 


\section{References}

Estepp, J. R., Christensen, J. C., Monnin, J. W., Davis, I. M., and Wilson, G. F. 2009. Validation of a dry electrode system for EEG. In: Proceedings of the Human Factors and Ergonomics Society 2009 annual meeting, 1171-75. San Antonio, Texas: SAGE journals.

Greene, B. G., Pisoni, D. B., and Carrell, T. D. 1984. Recognition of speech spectrograms. AMI: An adaptive multiagent framework for Augmented Cognition. In: The Journal of the Acoustical Society of America, 76(1): 32-43. Proceedings of the $11^{\text {th }}$ International Conference on Human-Computer Interaction, July 2005, at Las Vegas, NV.

Liberman, A. M., Copper, F. S., Shankweiler, D. P., and Studdert-Kennedy, M. 1968. Why are speech spectrograms hard to read? American Annals of the Deaf. 113(2): 127-34.

McGrath, B. J., Estrada. A., Braithwaite, M. G., Raj, A. K., and Rupert, A. H. 2004. Tactile situational awareness system flight demonstration final report. Fort Rucker, AL: United States Army Aeromedical Research Laboratory. USAARL Report No. 2004-10.

Raj, A. K., Suri, N., Braithwaite, M. G., and Rupert, A. H. 1998. The tactile situation awareness system in rotary wing aircraft: Flight test results. In: Proceedings of the Research and Technology Organization/Human Factors and Medicine Panel symposium on current aeromedical issues in rotary wing operations. Neuilly-sur-Seine: Cedex, France. RTO NATO HF, RTO-MP-Vol. 19: 16.1-16.7.

Raj, A. K., Kass, S. J., and Perry, J. F. 2000. Vibrotactile displays for improving spatial awareness. In: Proceedings of the human factors and ergonomics society annual meeting, 44(1): 181-84. University of West Florida Institute for Human and Machine Cognition. Pensacola, FL.

Stegner-Wilson, M., Balough, B. J., Gottshall, K., Raj, A. K., and Hoffer, M. E. 2010. Preliminary results using sensory substitution for balance disorders. Presented at the Association for Research in Otolaryngology, $23^{\text {rd }}$ Midwinter Meeting, at Anaheim, CA.

Wall, C., Merfeld, D. M., Rauch, S. D., and Black, F. O. 2003. Vestibular prostheses: the engineering and biomedical issues. Journal of Vestibular Research: The engineering and biomedical issues. 12(2-3): 95-113 


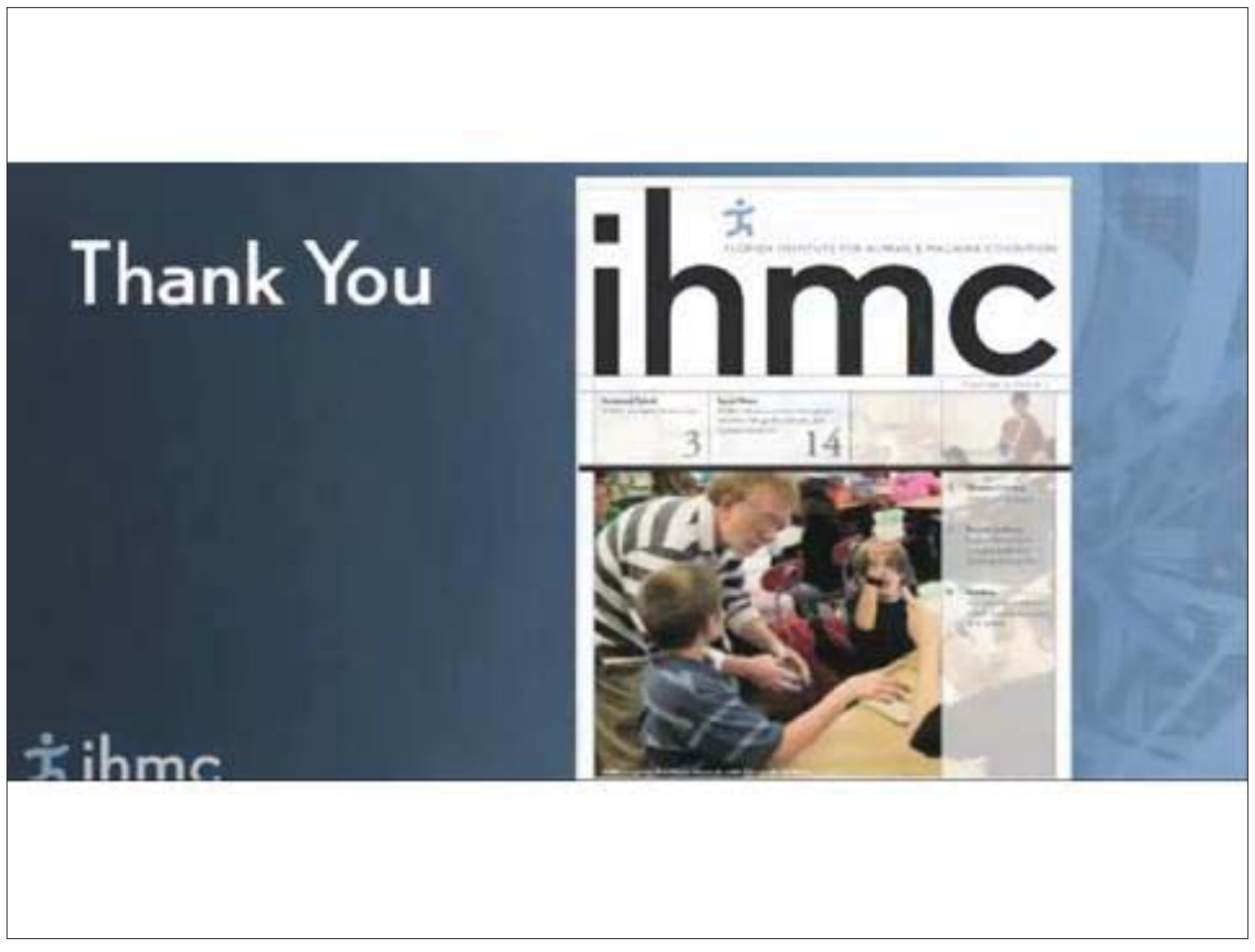

Slide 1

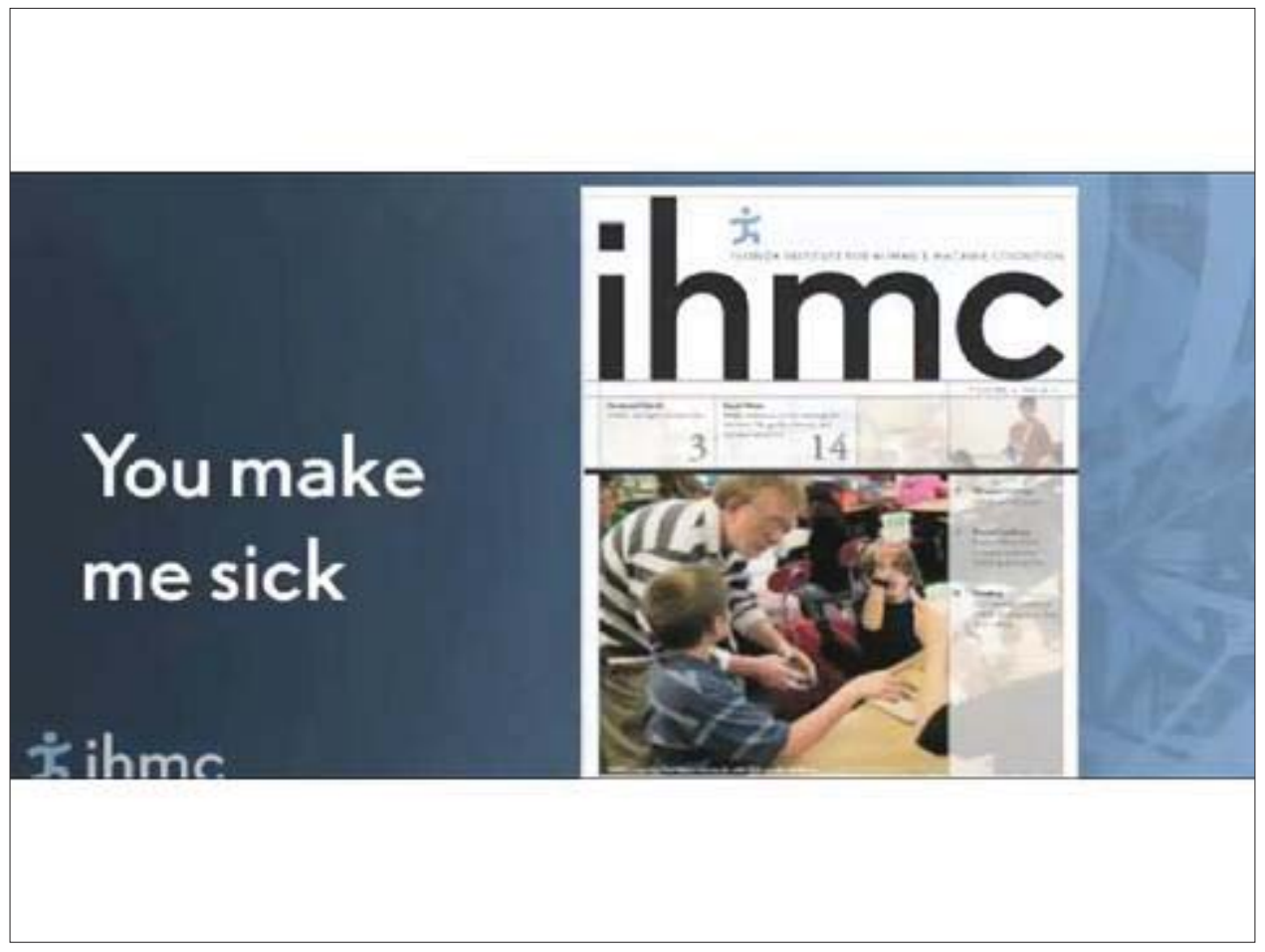

Slide 2 


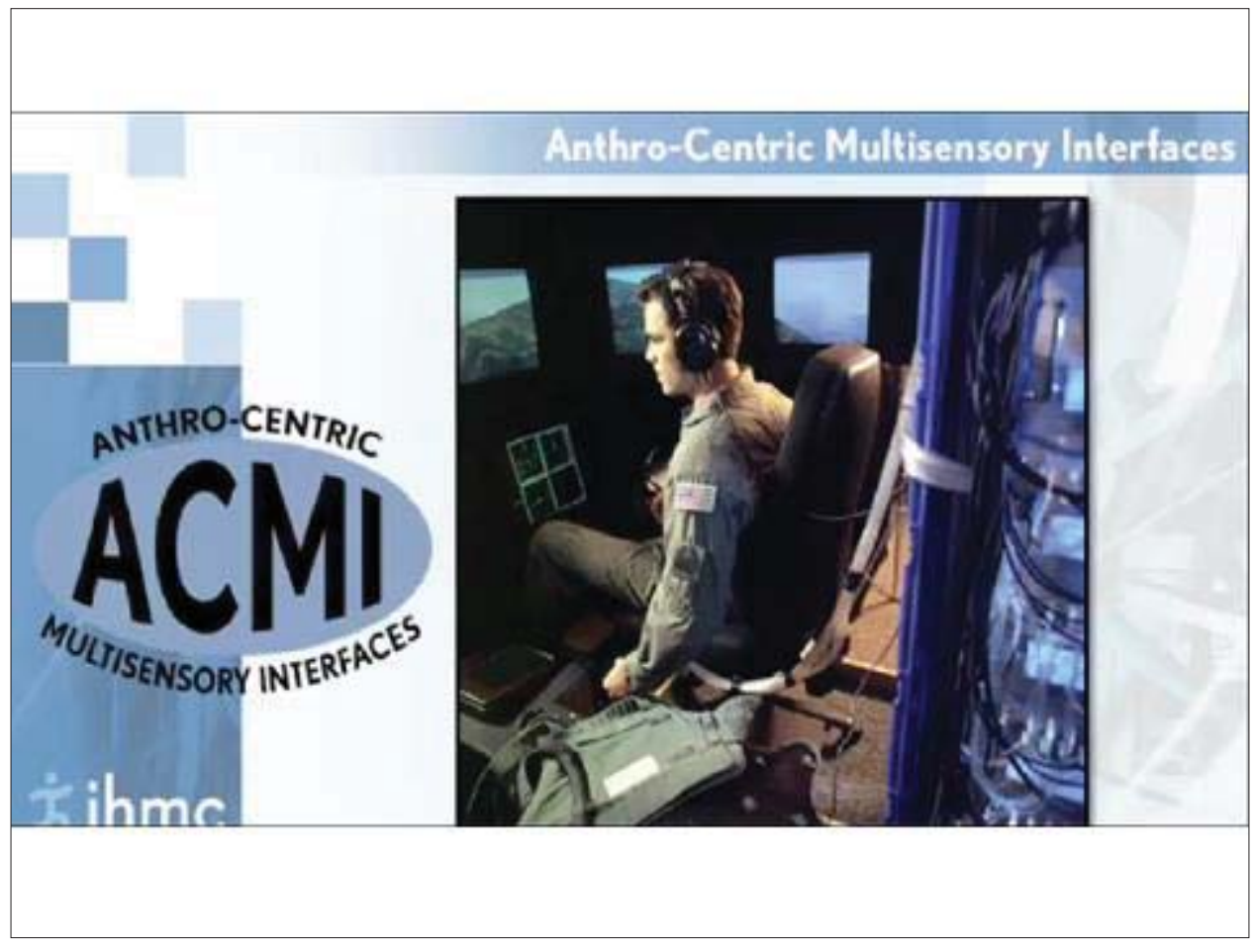

Slide 3

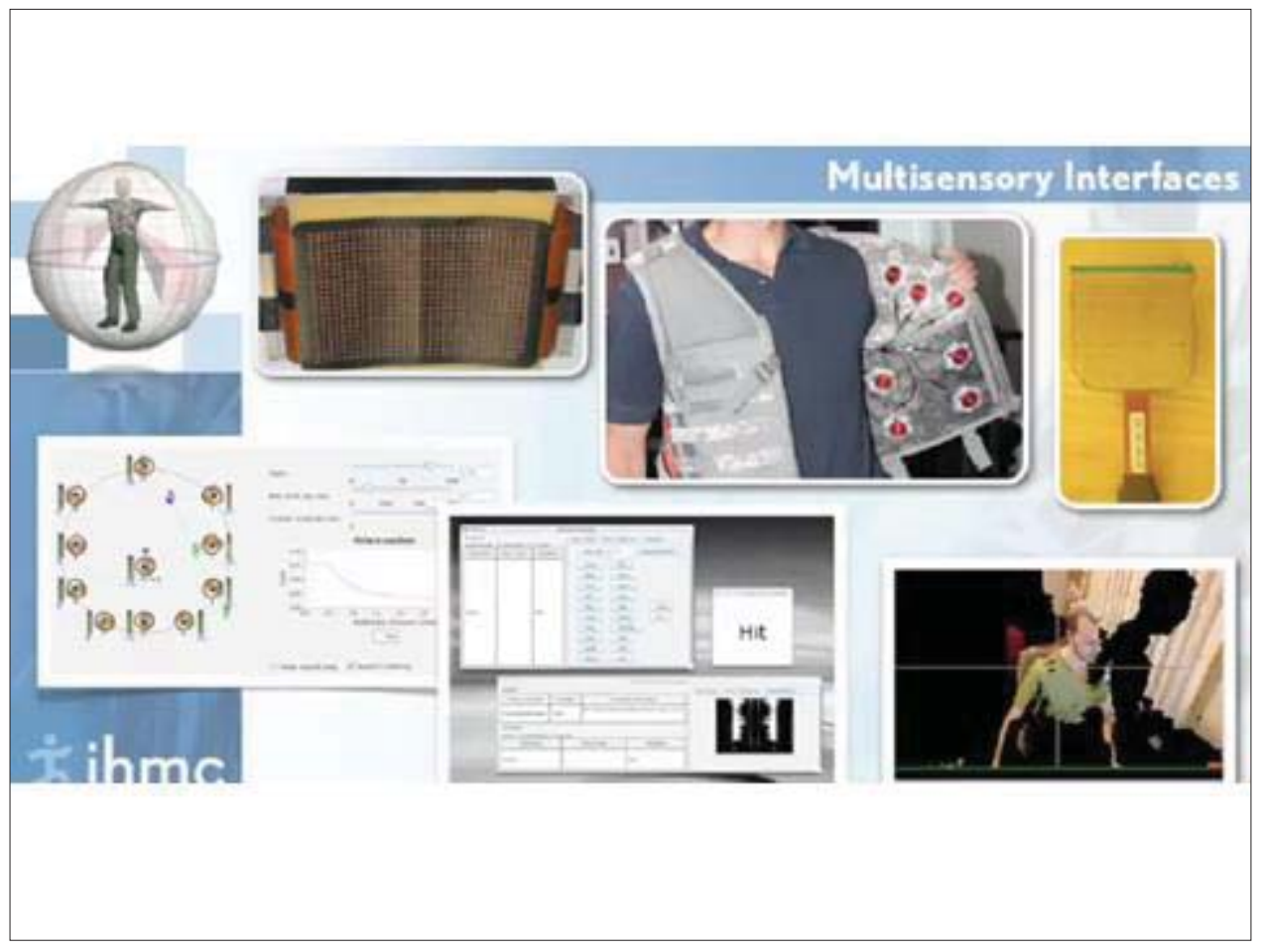

Slide 4 


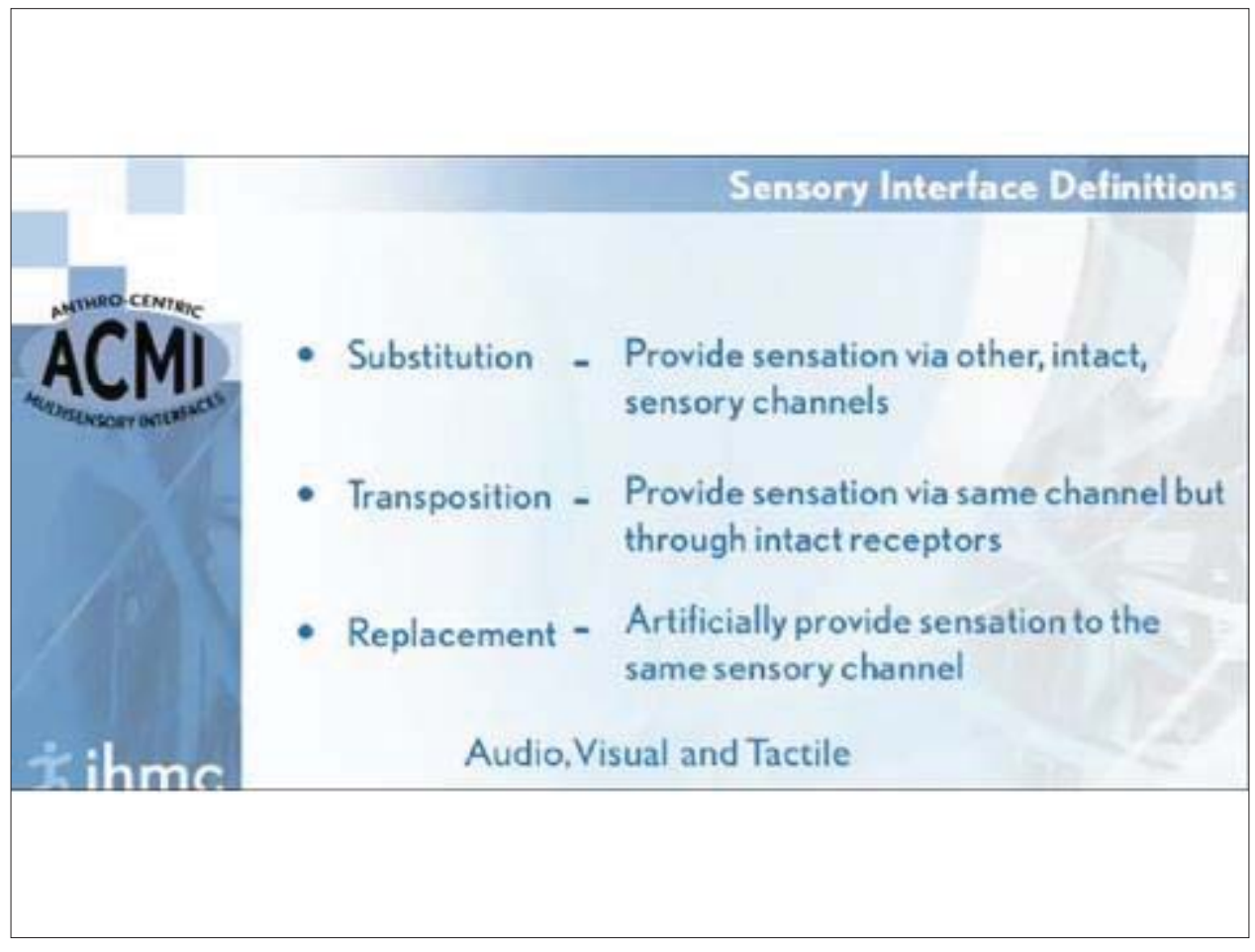

Slide 5

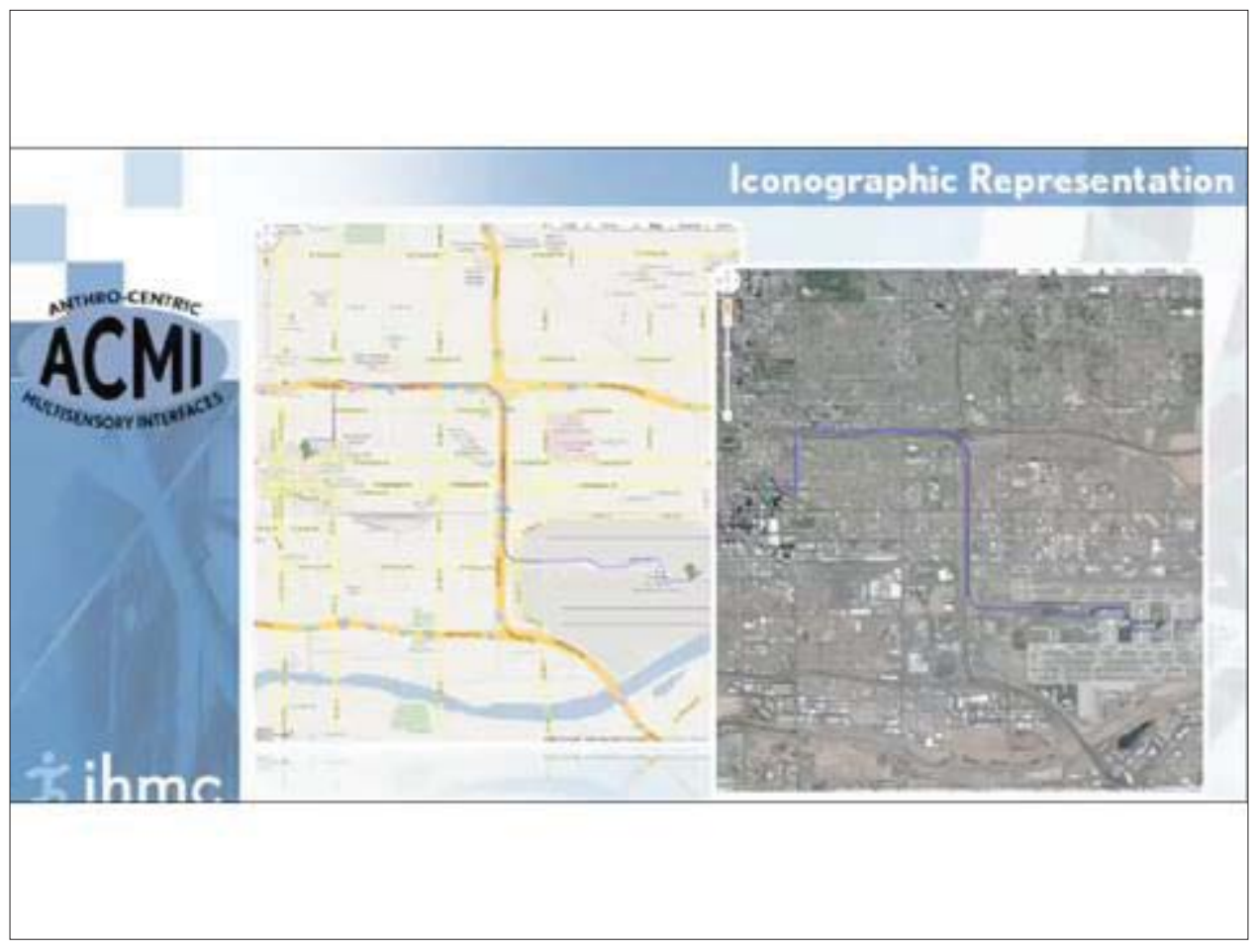

Slide 6 


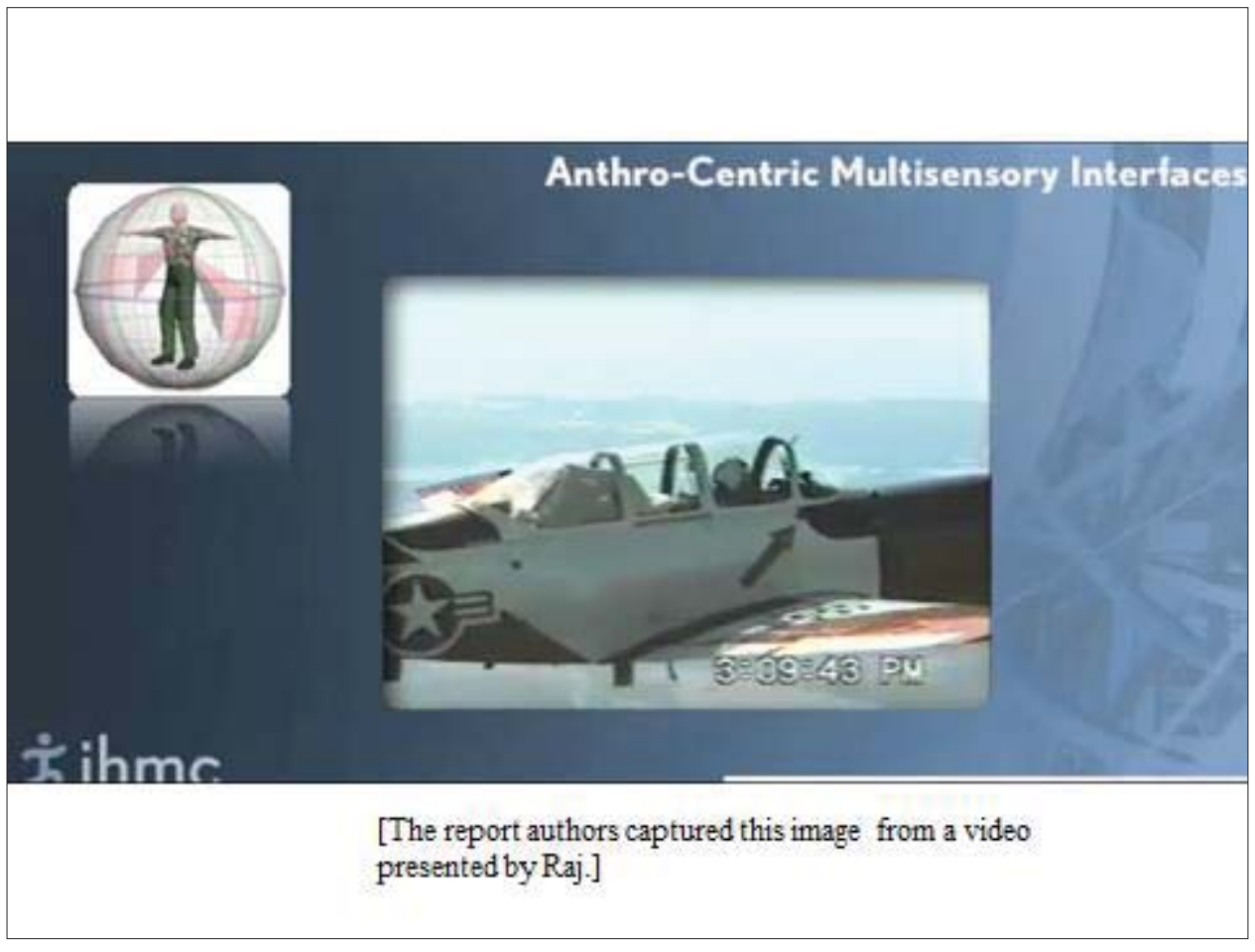

Slide 7

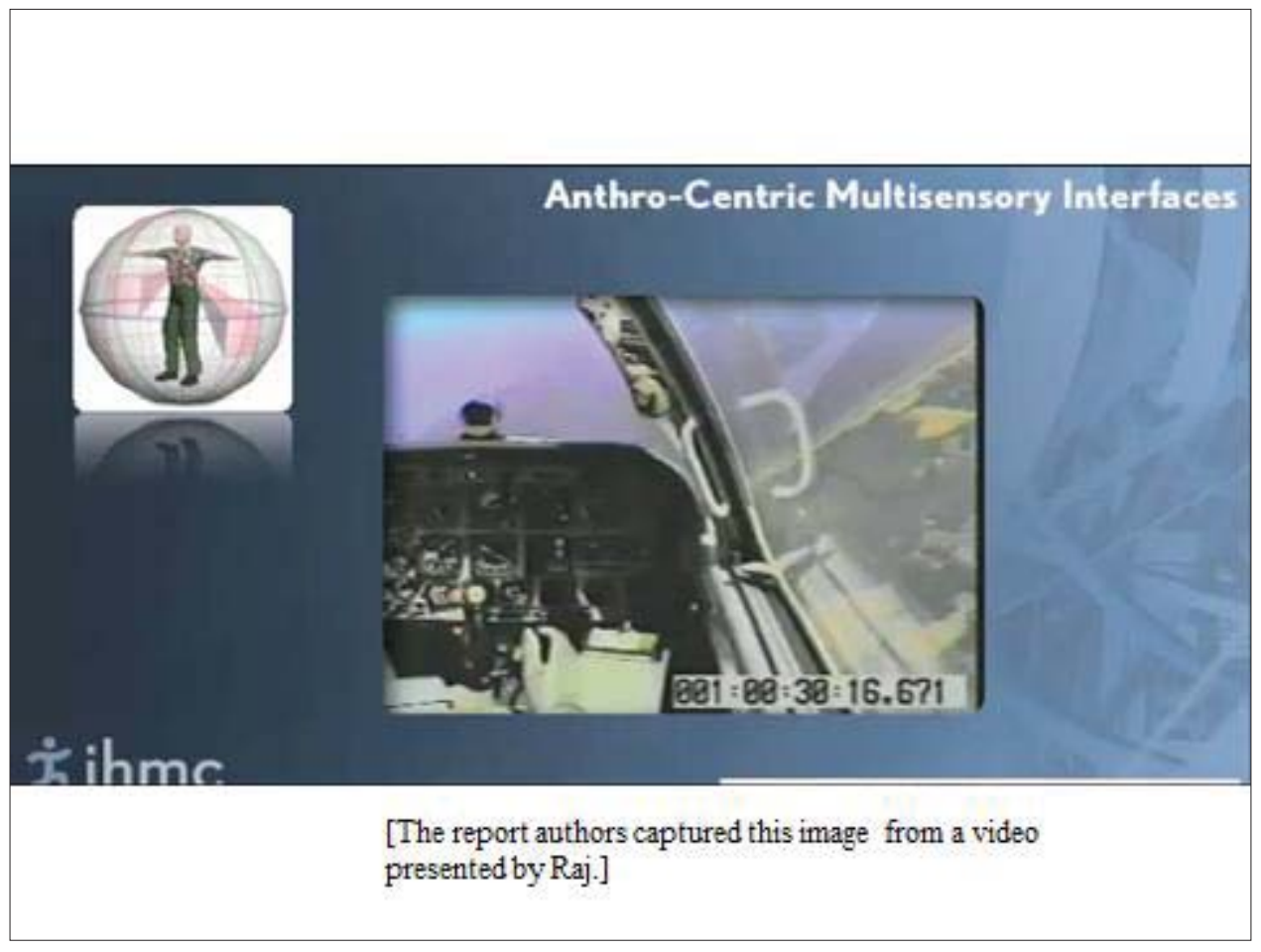

Slide 8 


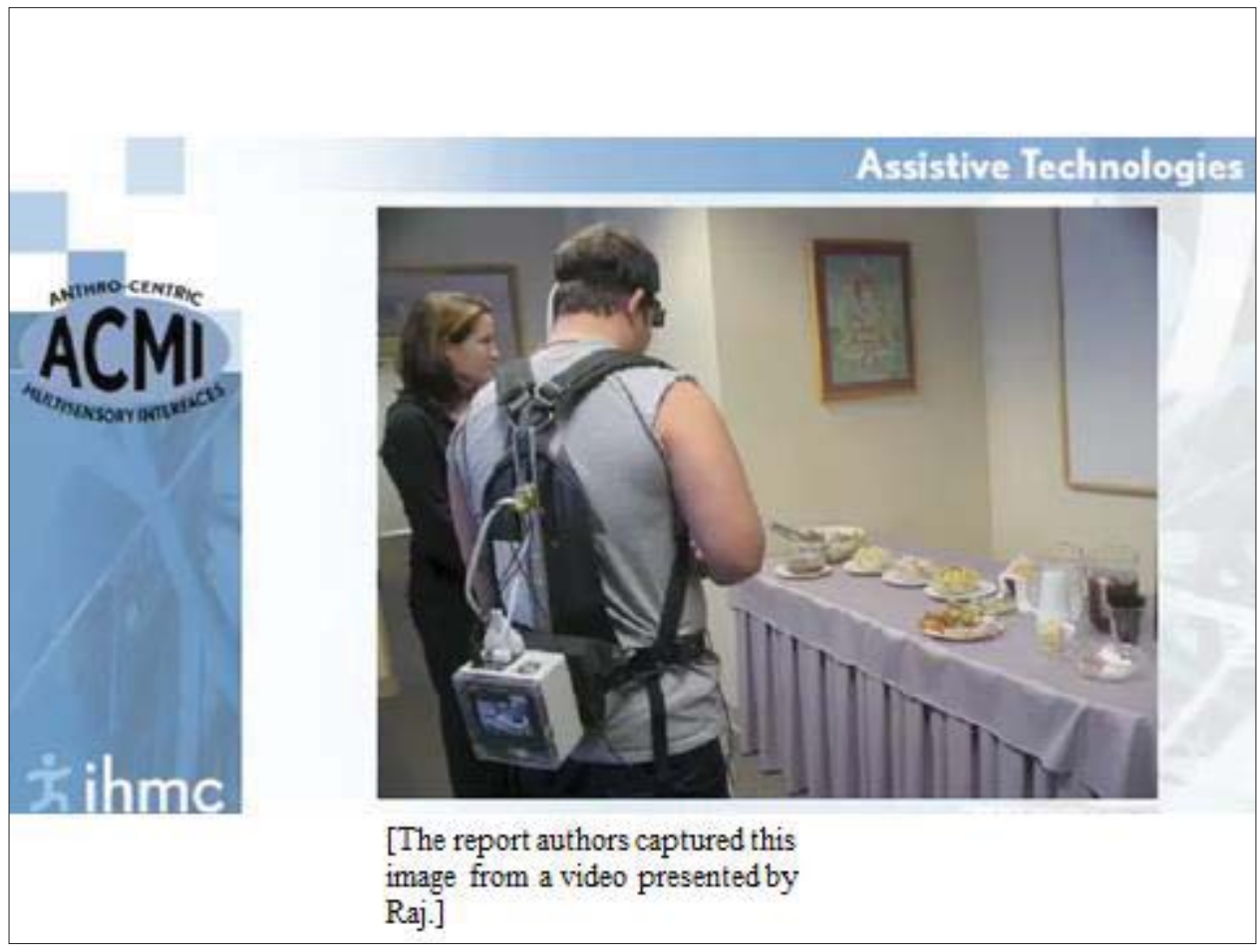

Slide 9

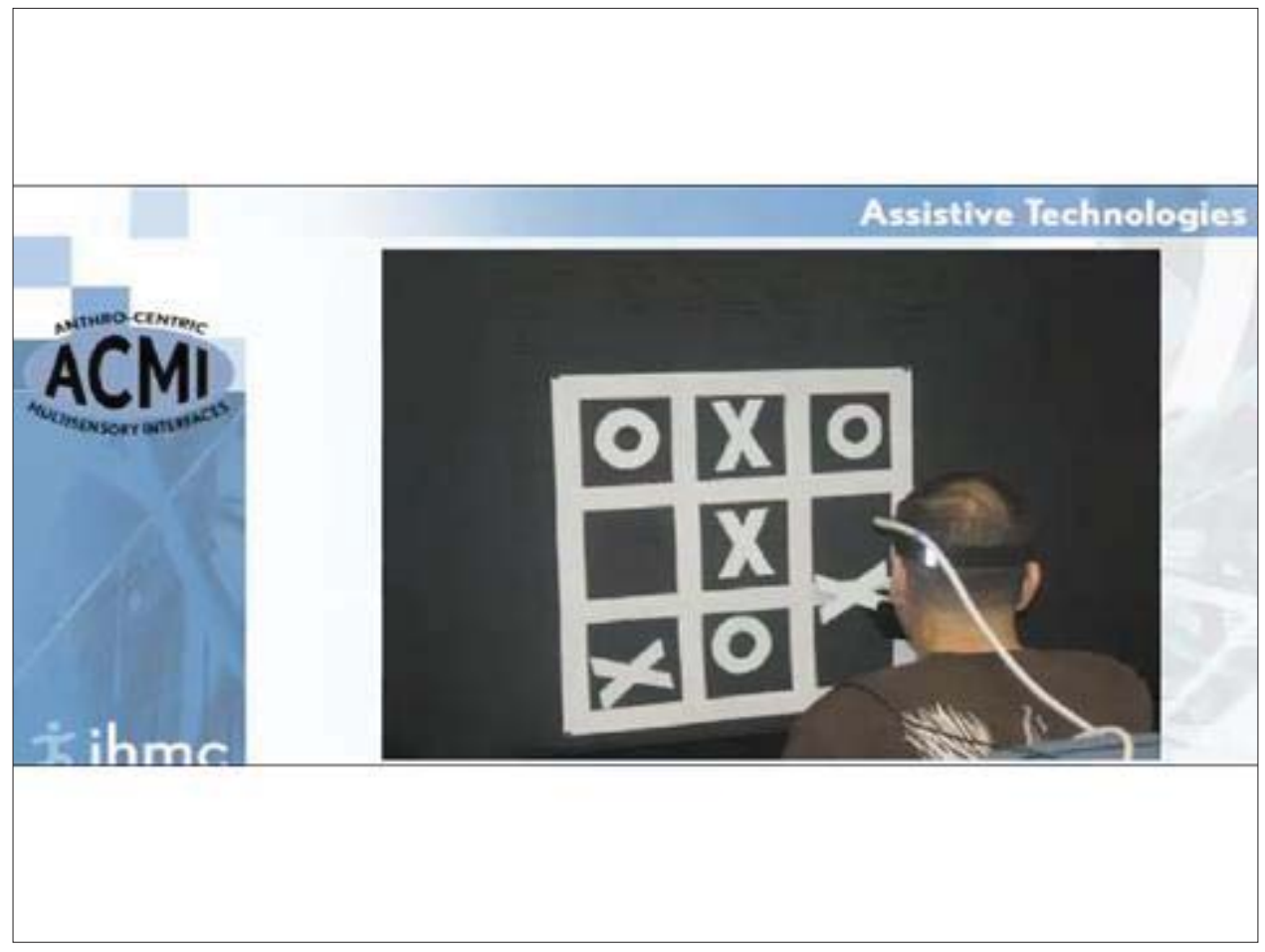

Slide 10 


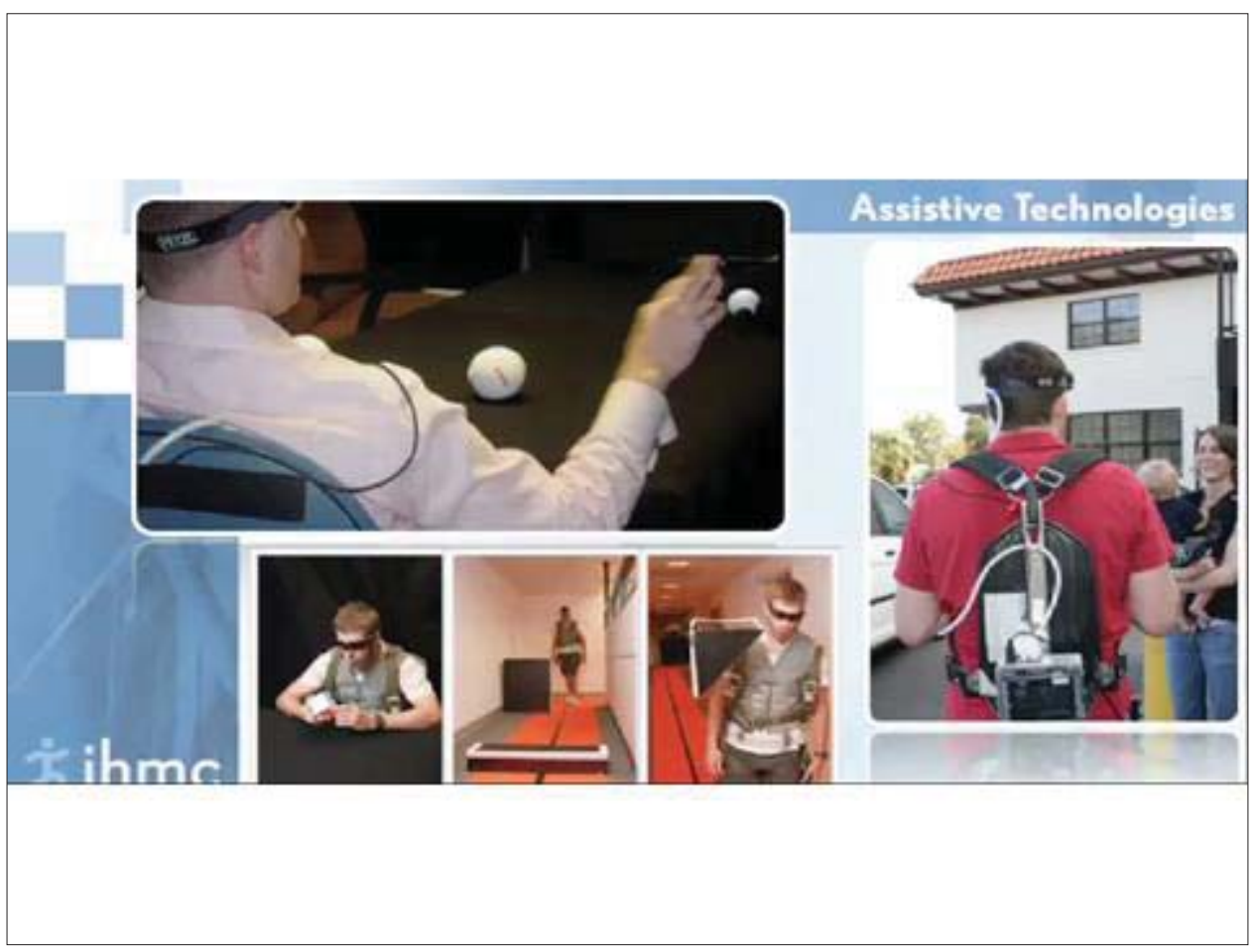

Slide 11

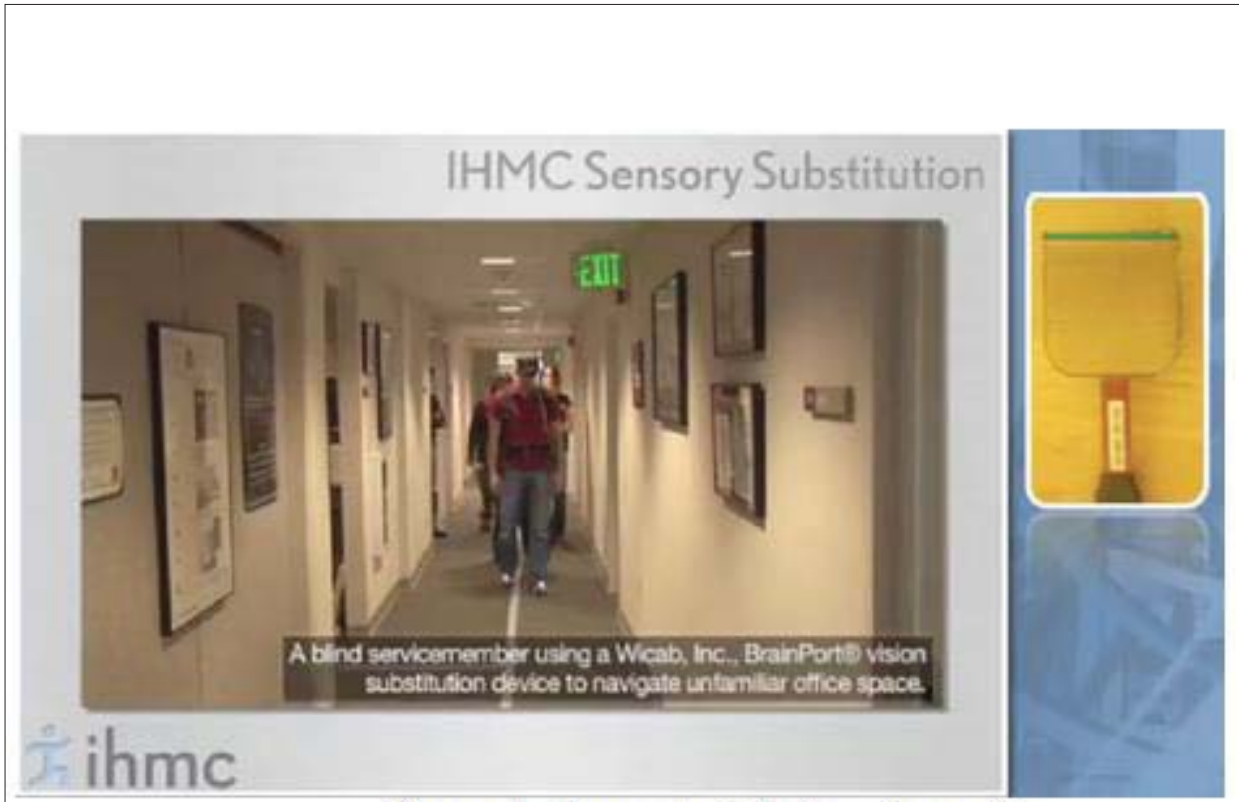

[The report authors captured this image from a video presented by Raj.]

Slide 12 


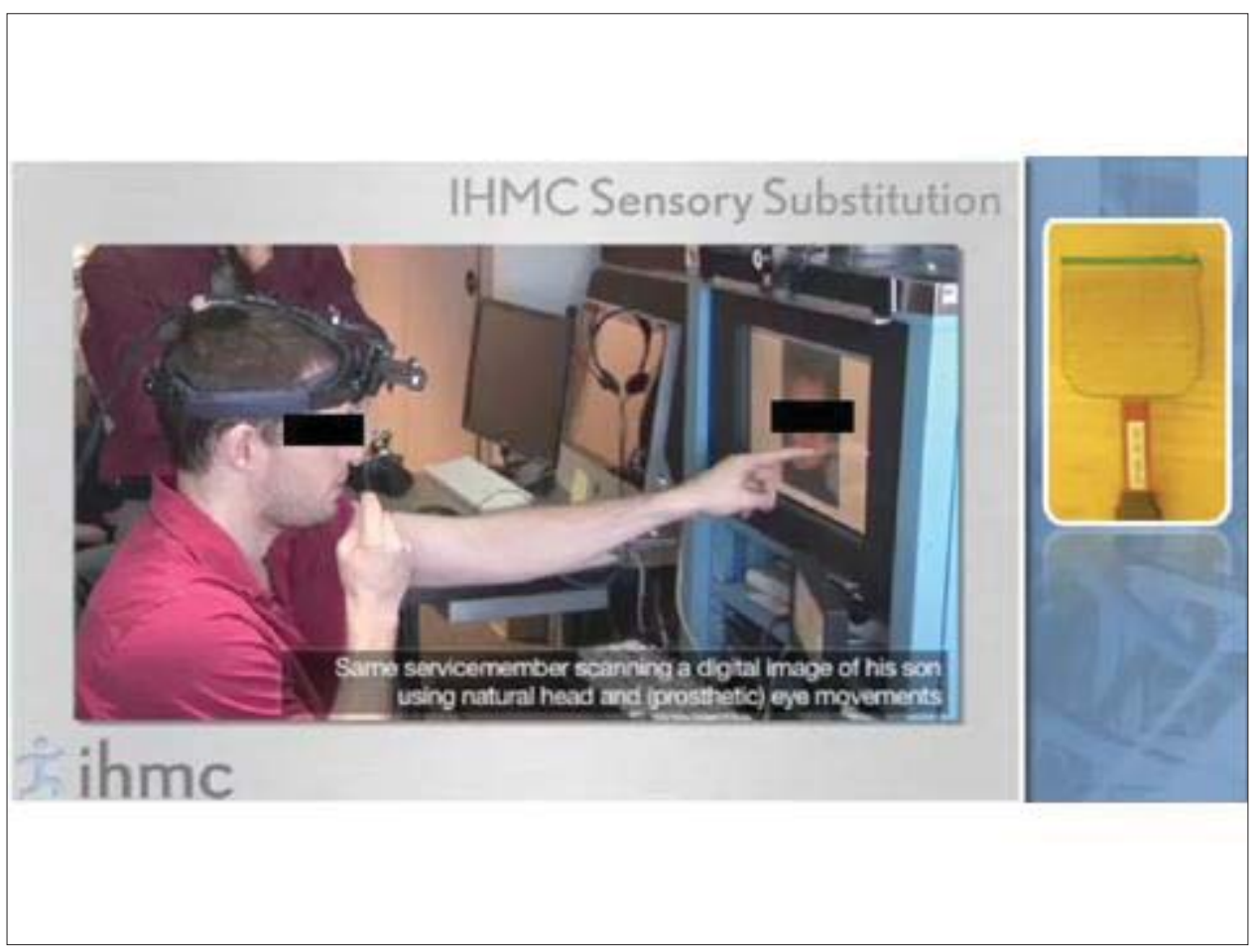

Slide 13

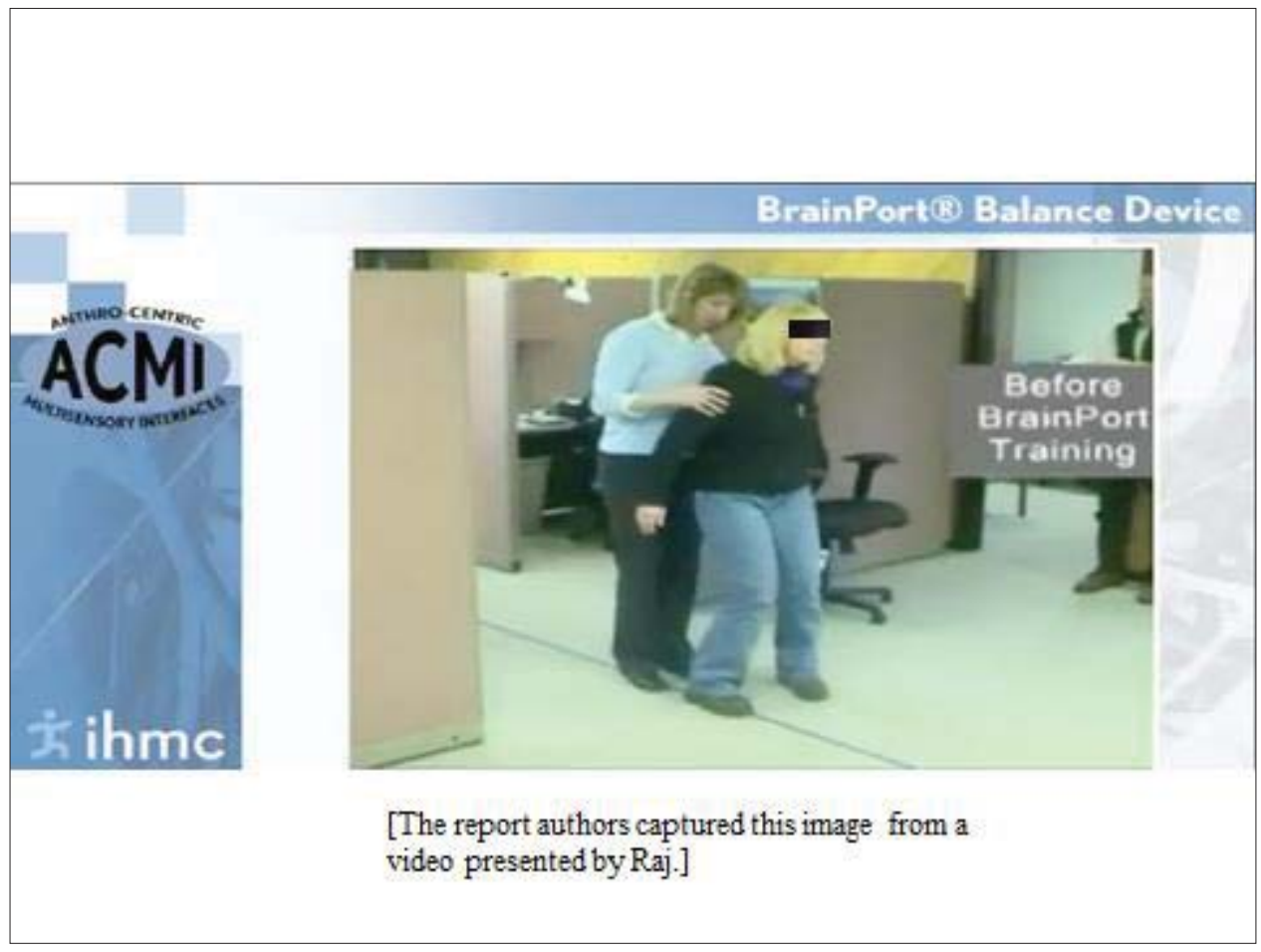

Slide 14 


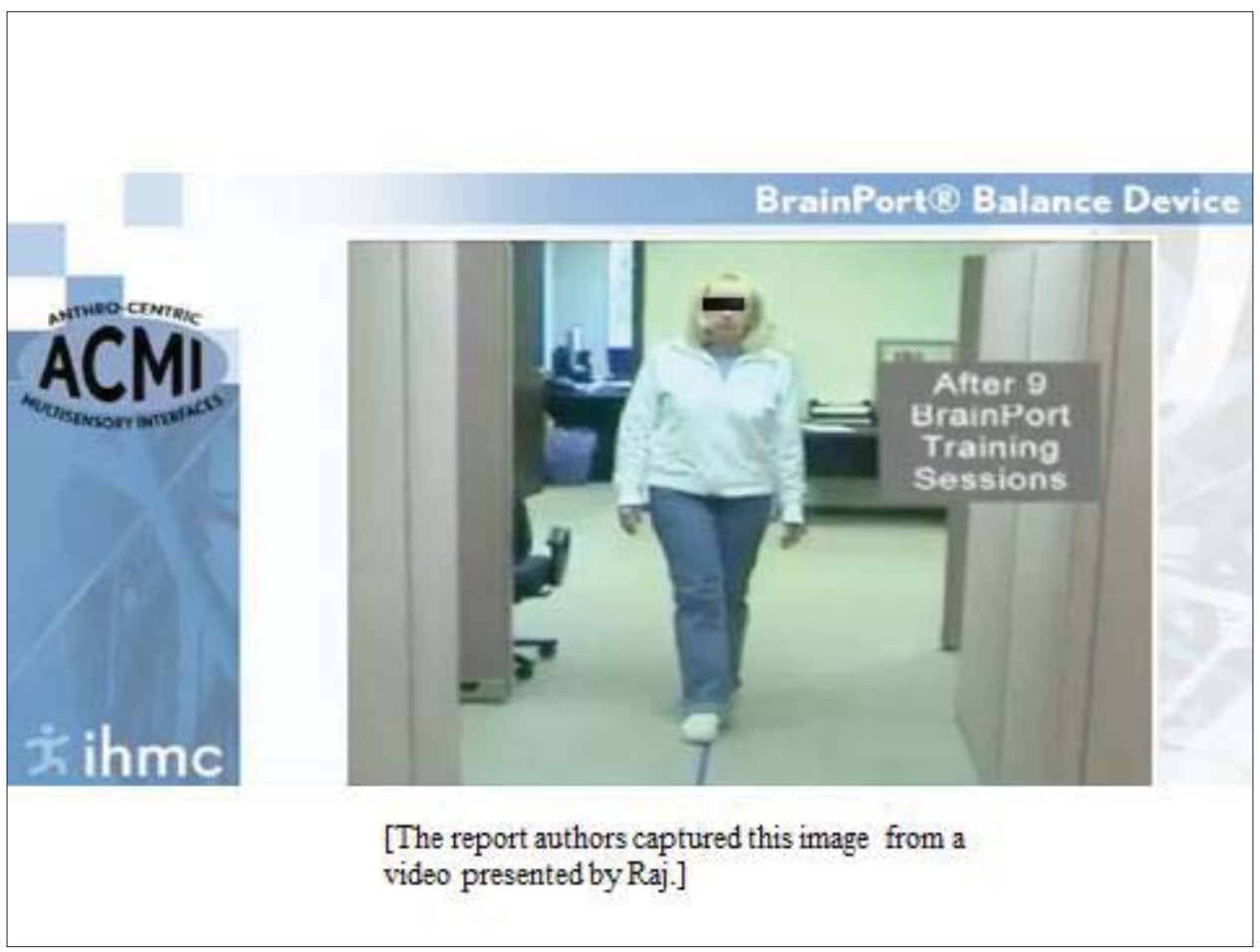

Slide 15

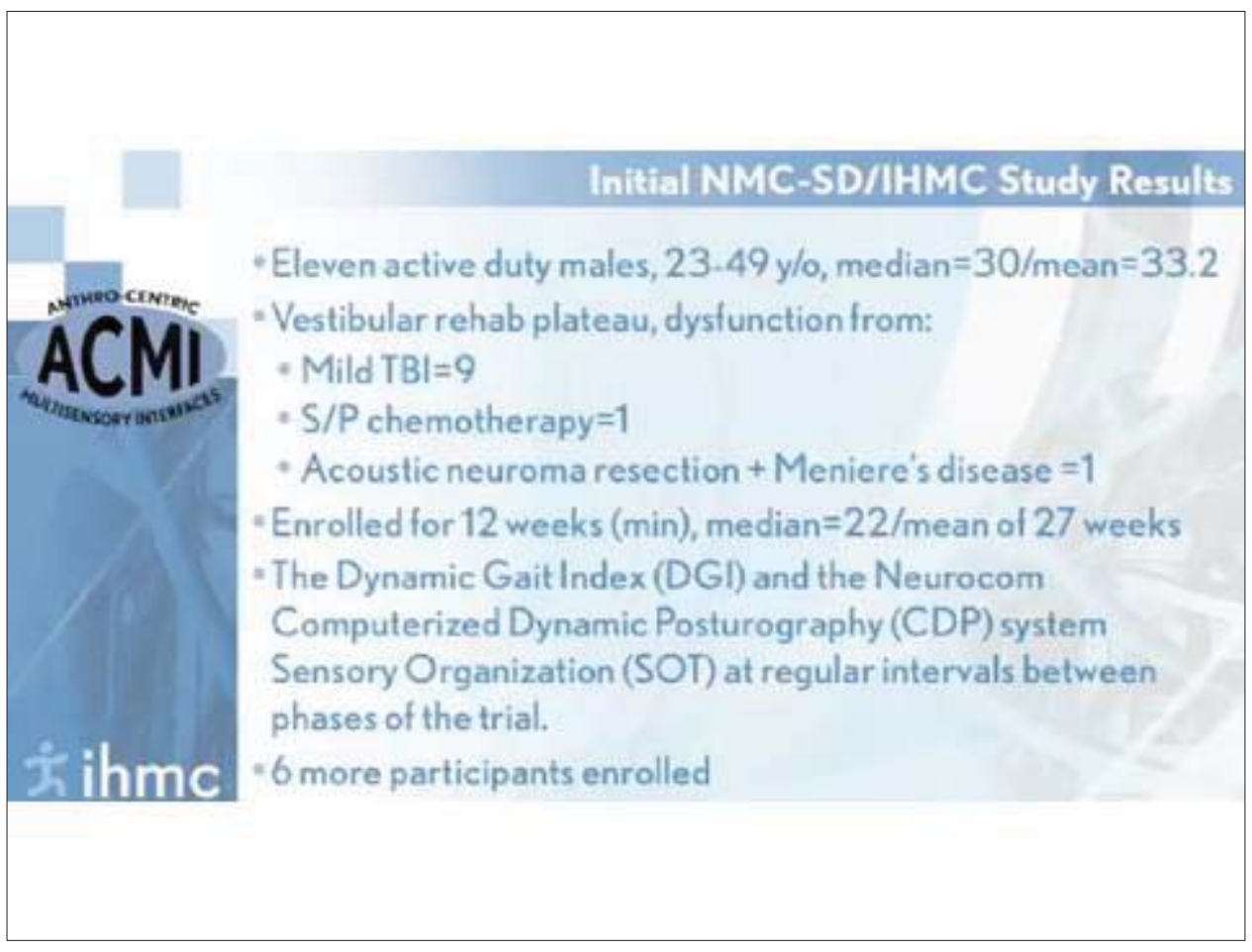

Slide 16 


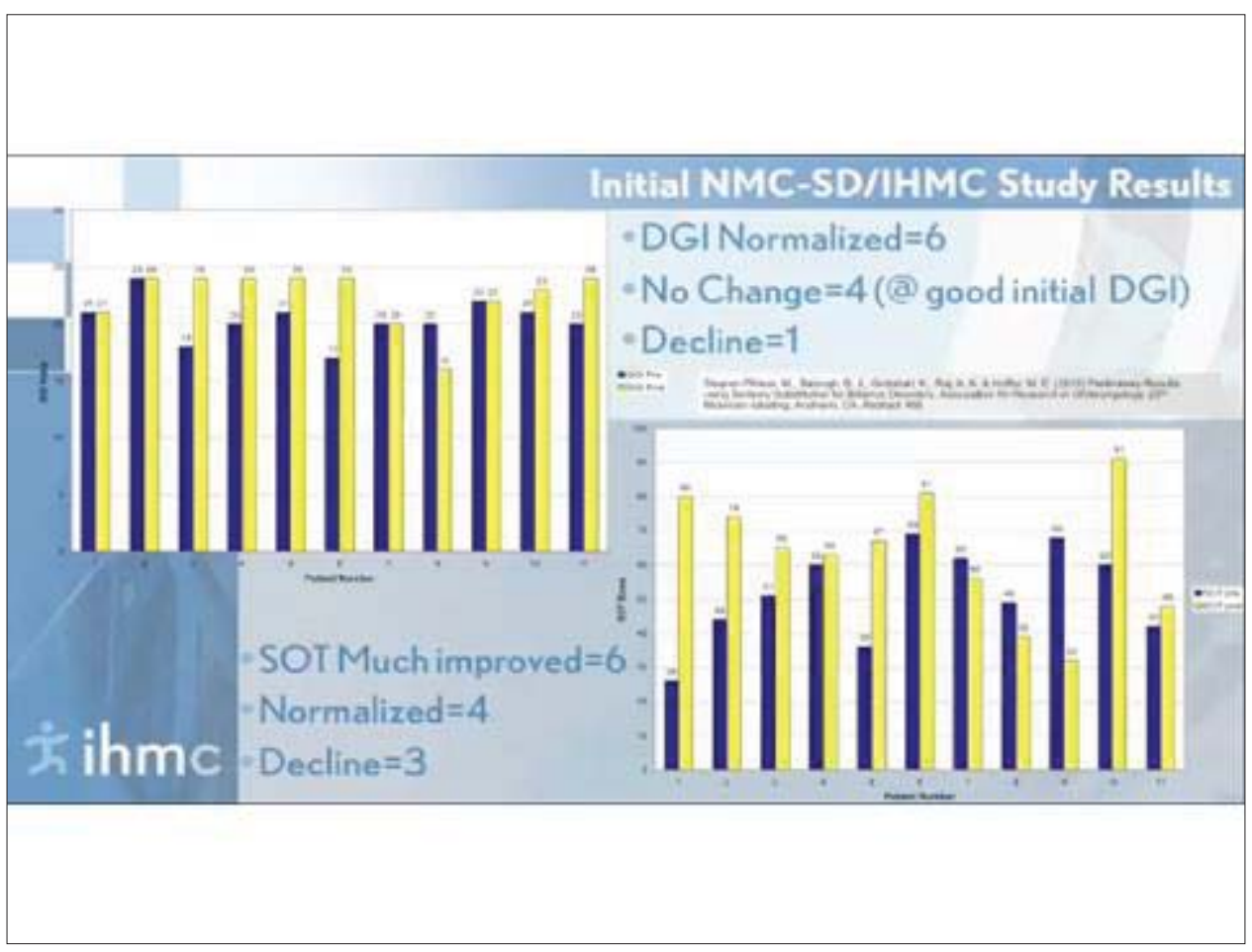

Slide 17

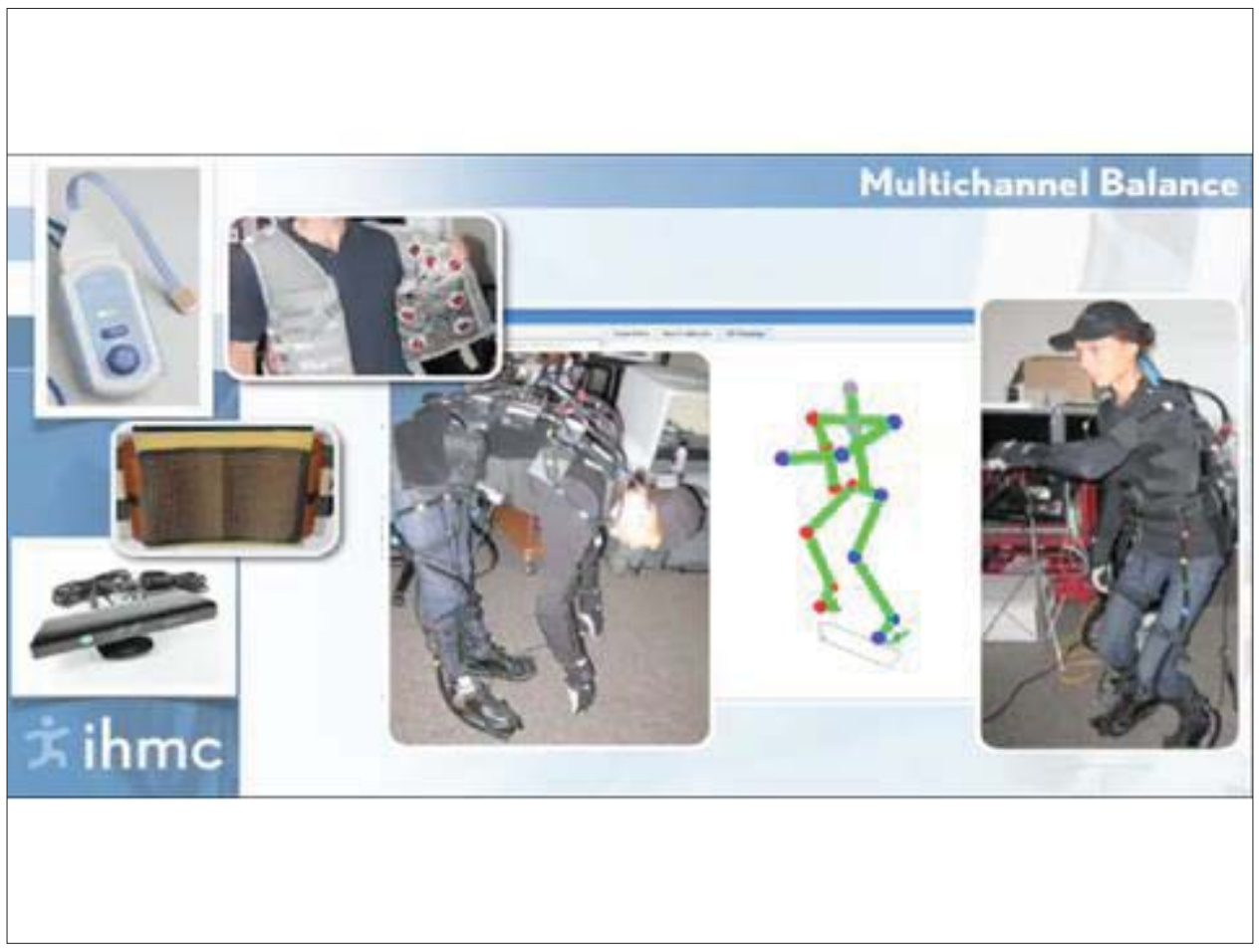

Slide 18 


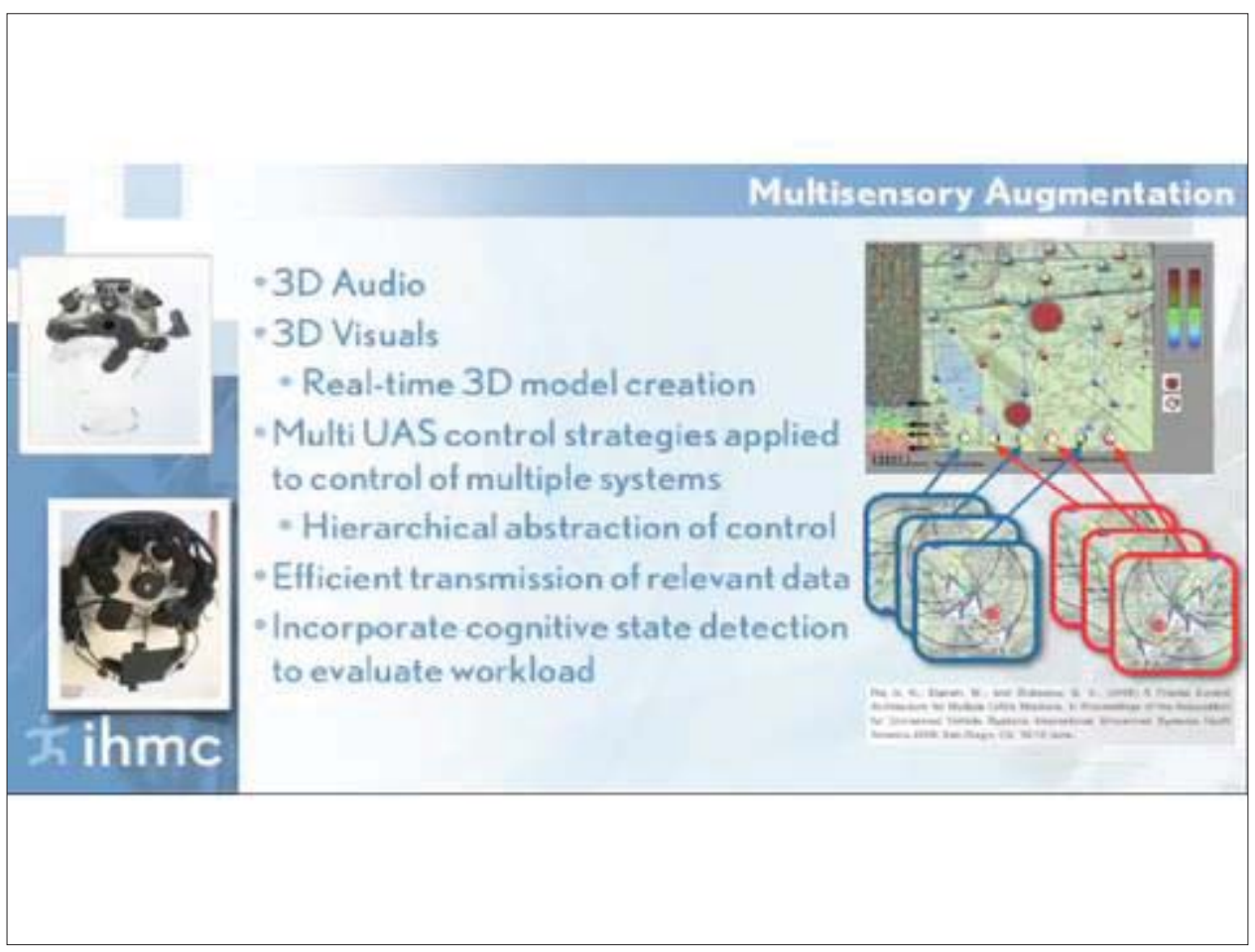

Slide 19

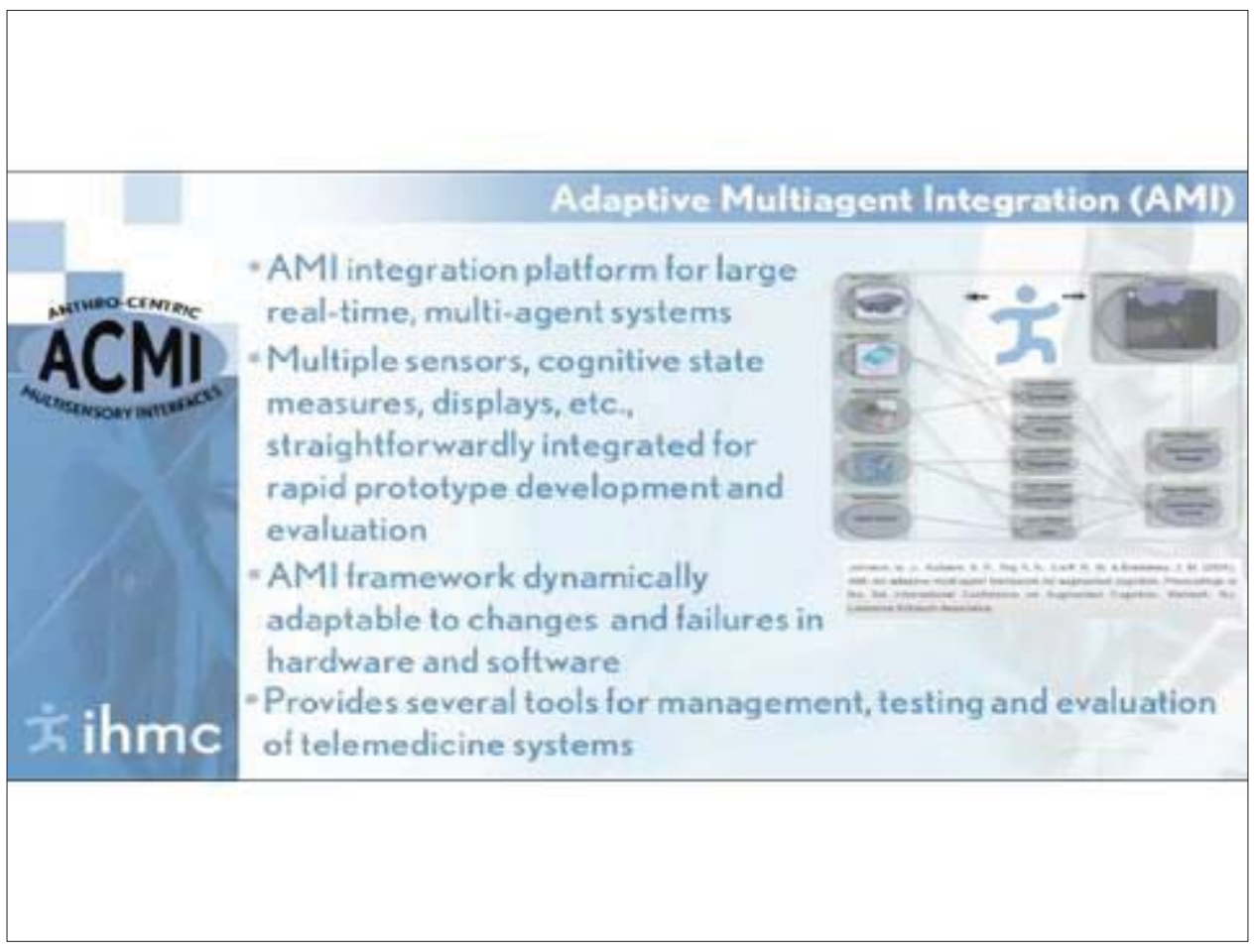

Slide 20 


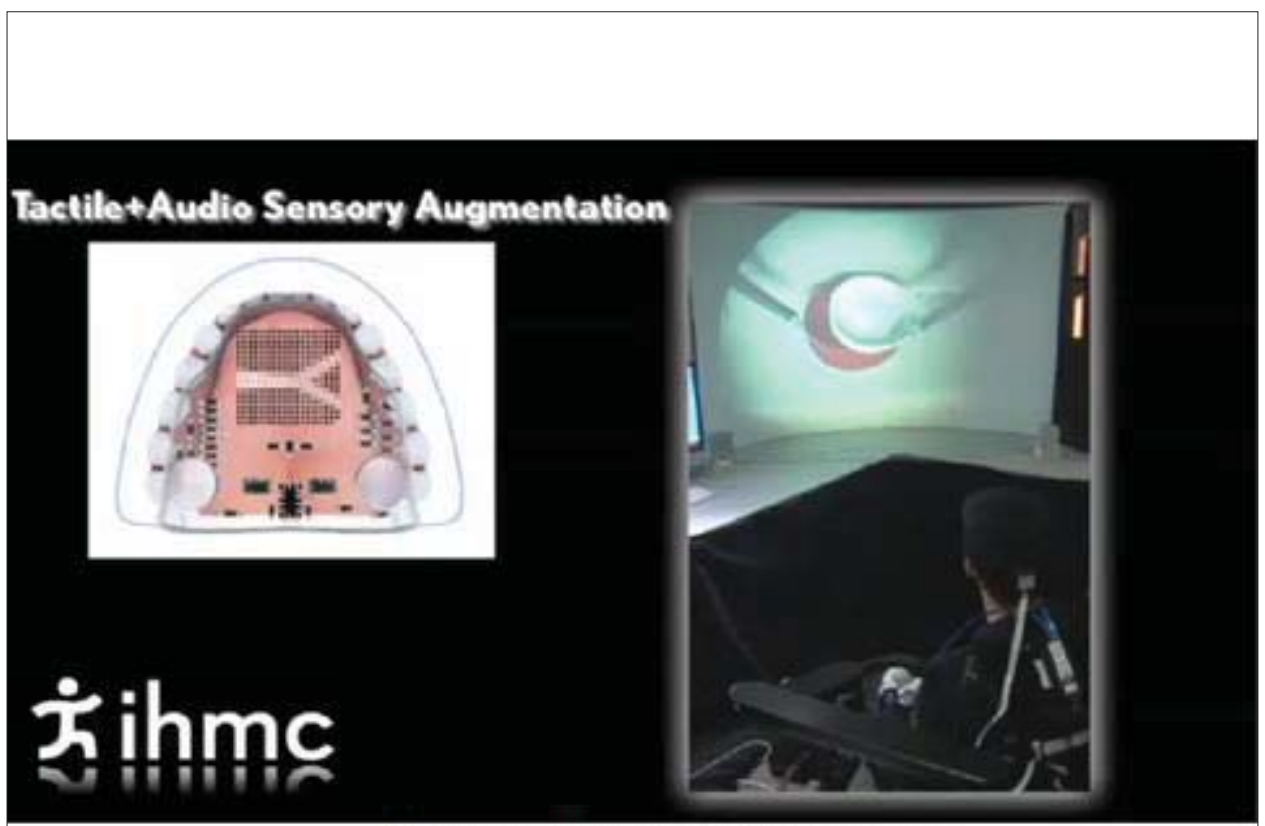

[The report authors captured this image from a video presented by Raj.]

Slide 21

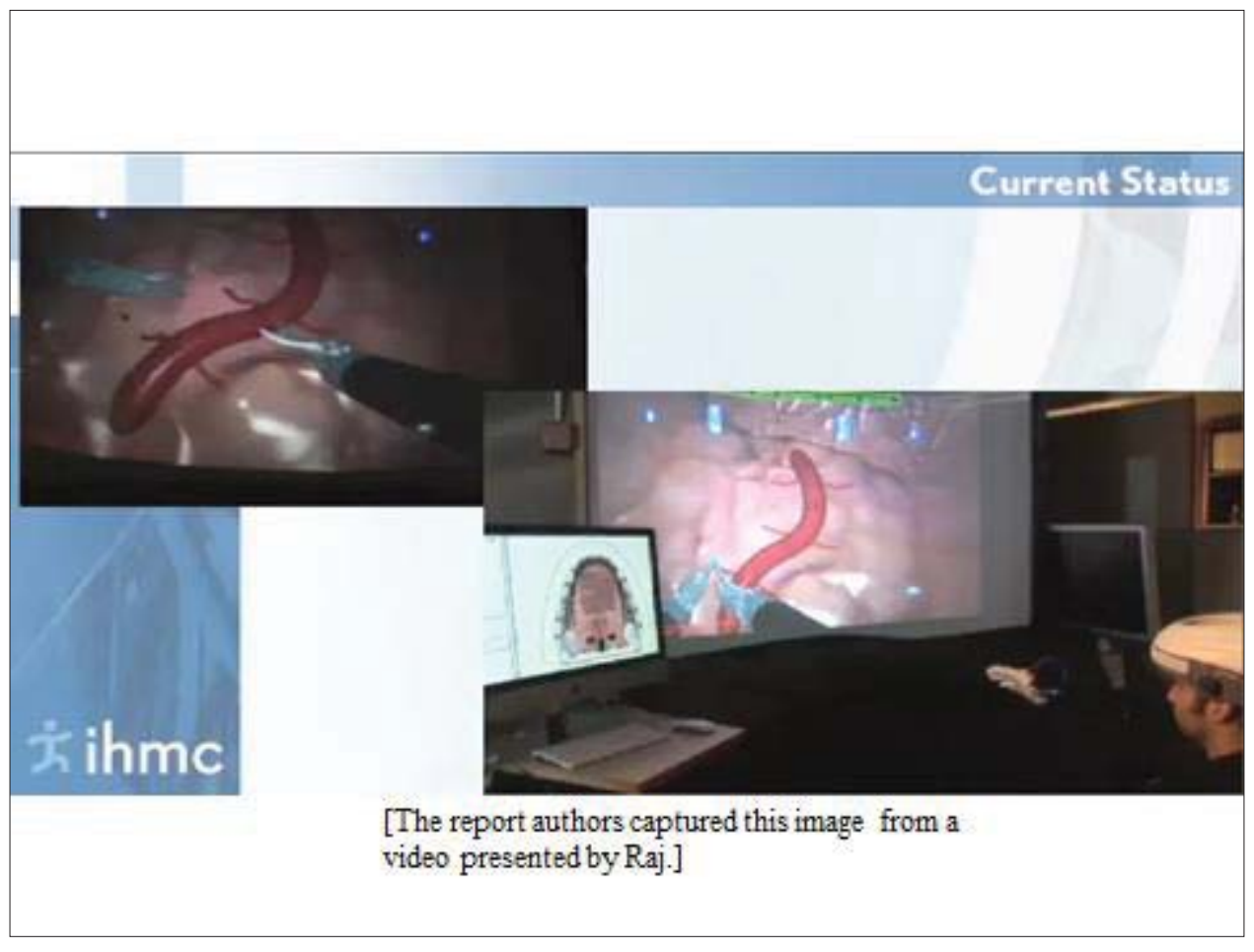

Slide 22 


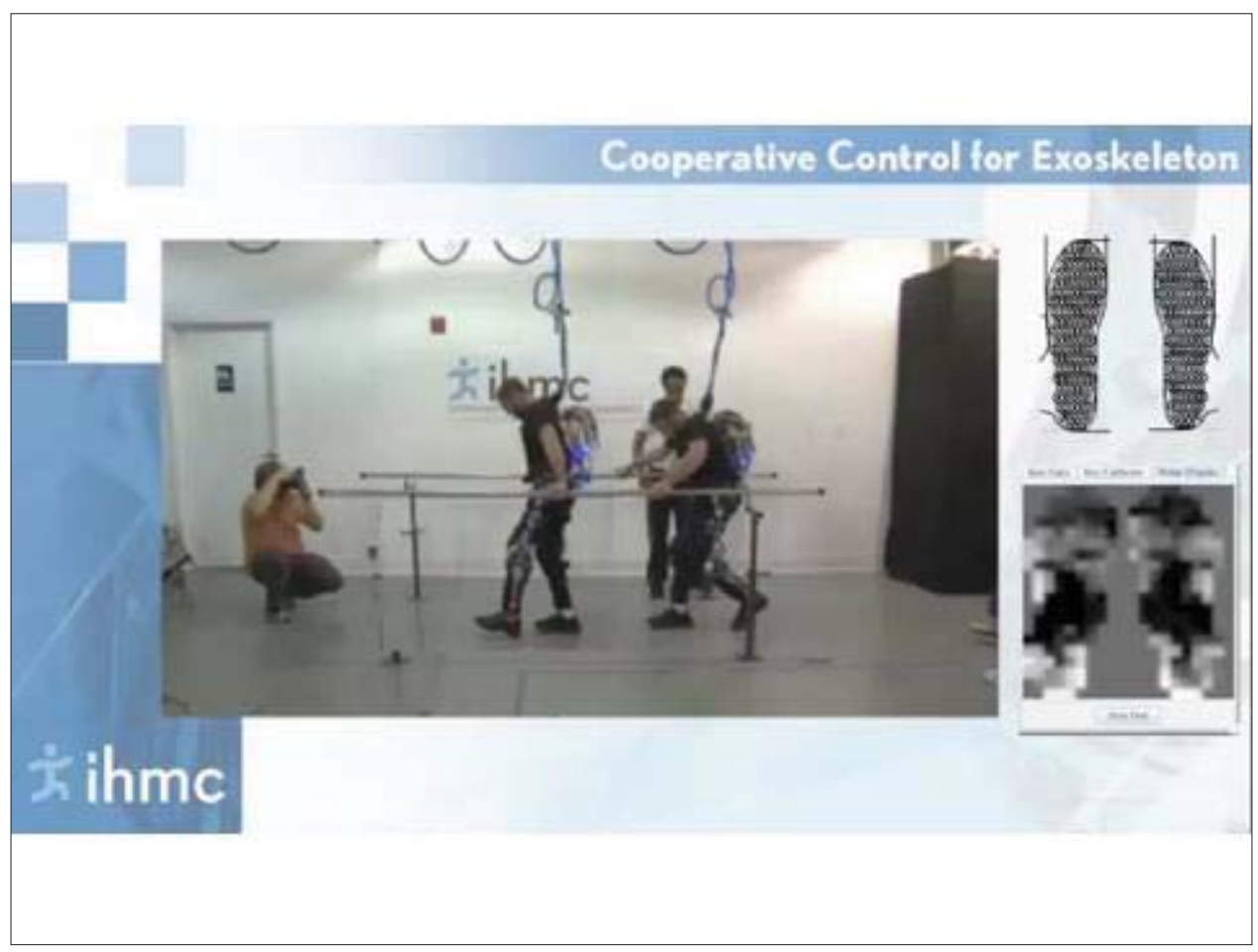

Slide 23

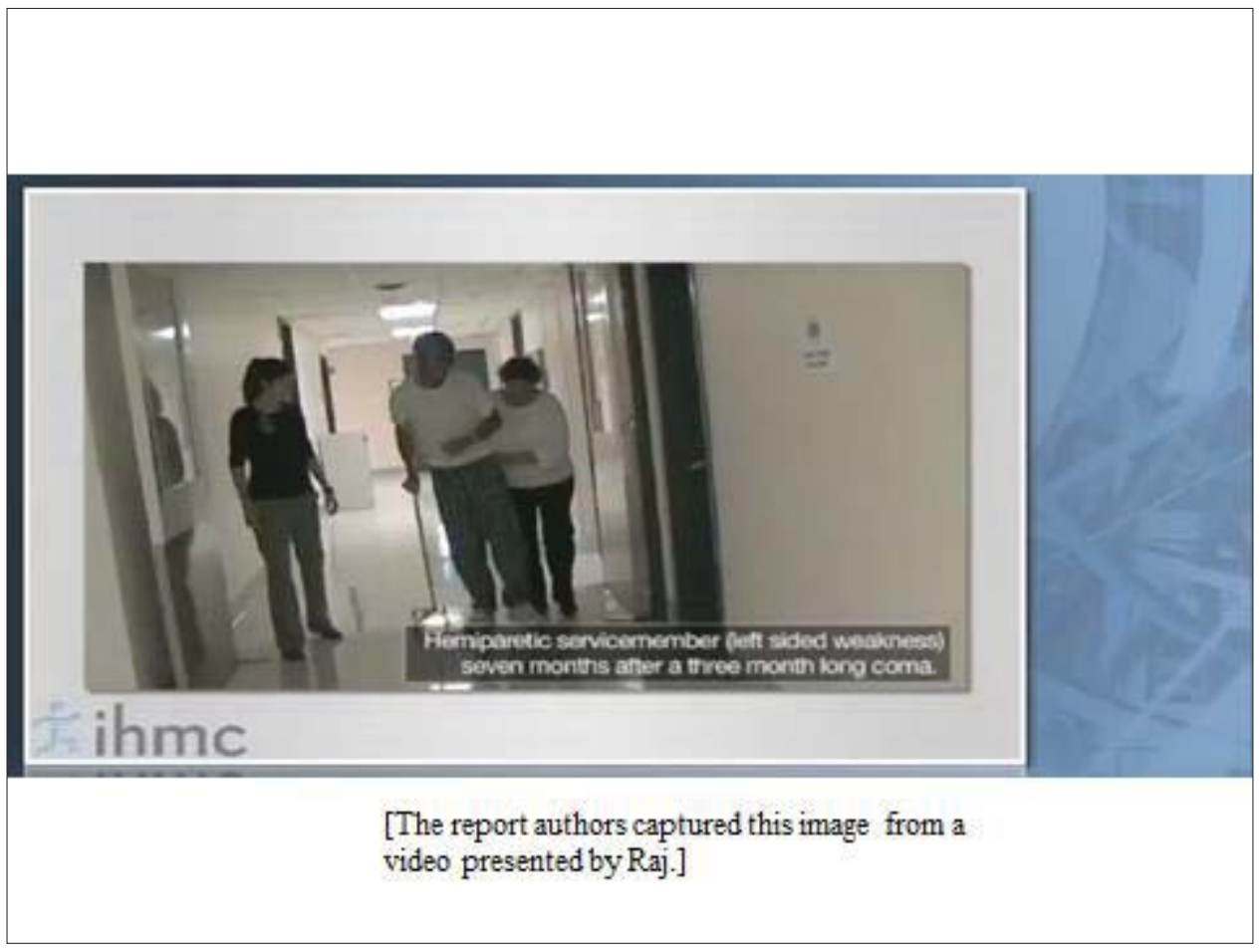

Slide 24 


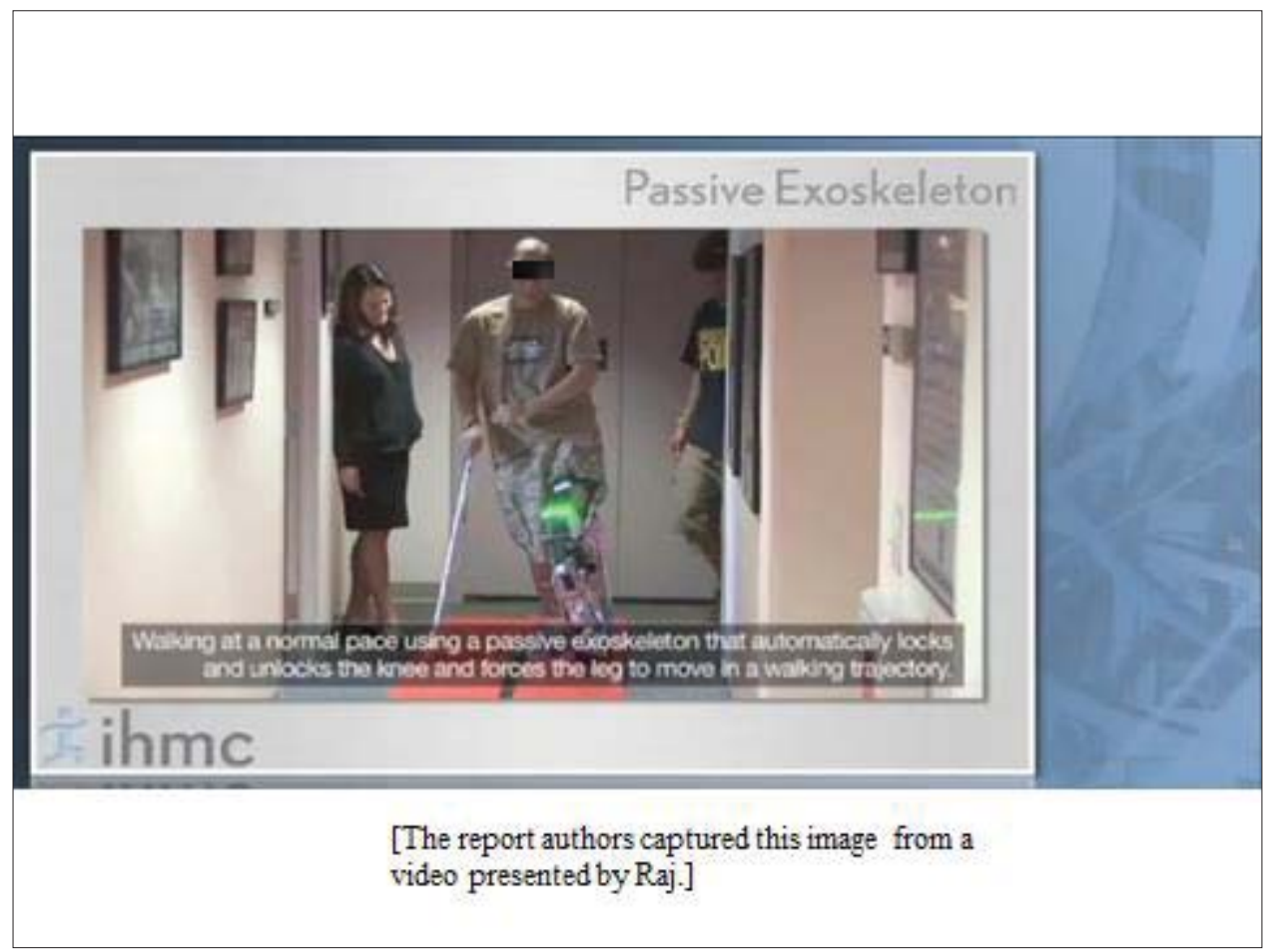

Slide 25

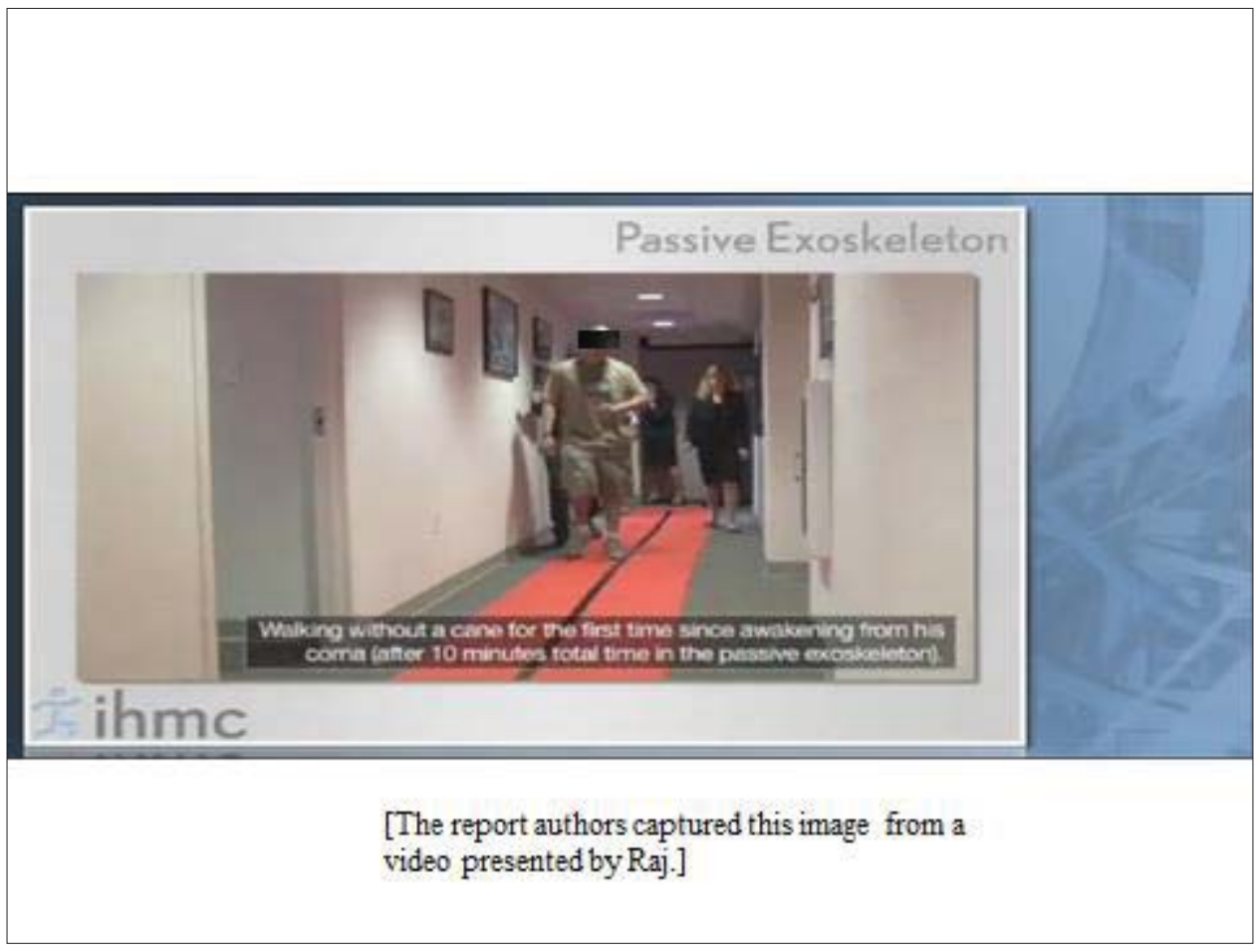

Slide 26 


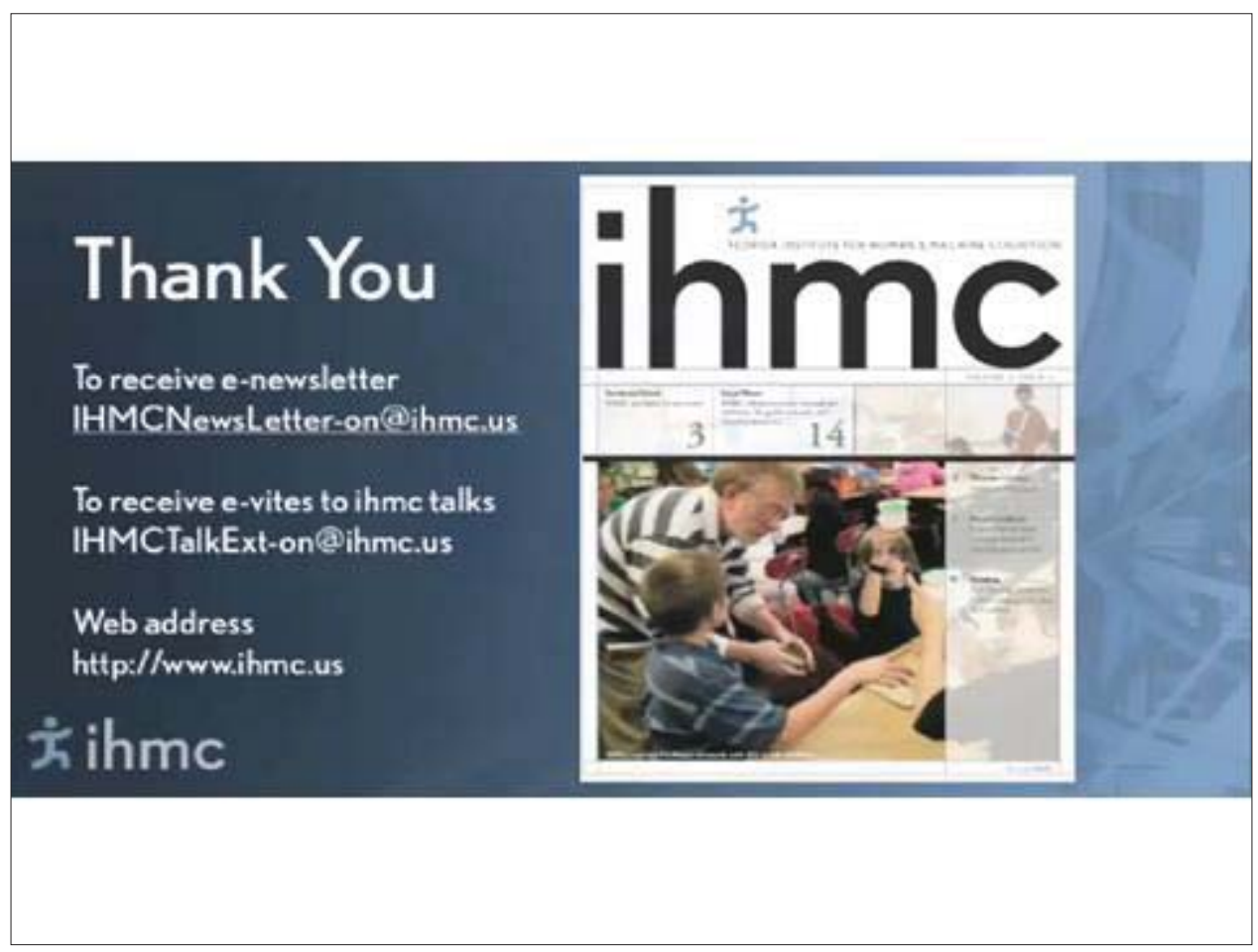

Slide 27

Question and answer session

[Oman] Anil [Raj], we started to talk about this yesterday. You brought up the carry-over effect and obviously you think confidence is a big factor. I wonder, have you talked to others who do rehab, or maybe others in this room could comment... is it a general characteristic during postural and locomotion rehab that breaking through a confidence barrier is really sort of the key thing?

[Raj] I would say that I think that's a big chunk of it. The whole desensitization type retraining gets you past the sense of, 'I'm going to throw up. I'm going to get dizzy. I'm going to fall.' But, I'd like to hear some comments from other folks.

[Oman] I guess what I'm really focusing on is how important is the technology, as opposed to just the intervention of the therapist and convincing people that yes, you can do this [convincing patients they can overcome their obstacles]?

[Raj] Well, just to speak to the study that I showed that we did with San Diego; those were all folks who had already plateaued with normal vestibular therapy rehab, so they weren't getting any better at that point, and they were actually able to augment from there.

[Gottshall] So, I guess it [a key factor] is adding another input, another afference, and if you can teach them how to correctly posture and walk with an additional afference so they know what not to do, so it gives them an image of 'they have to do this and not that.' I think that tailors their 
choices. They have so many choices of 'should I do this or that' to try to stay balanced. So if you can narrow that down to what they really need to do and not have the distractors of all the others, then they do better. And [it's] the same thing with the motor control and gait. If you can establish them doing the correct pattern and not wasting energy on everything else, they'll do better and that motor memory starts to come back and reinforce them to do that and not the other things. So with a brain injury, there is so much disruption (some of it's blunt head trauma, some of it's blast, some of it's inhalation of toxins) that it is really a diffuse injury and this becomes even more important.

[Magnusson] I will just add a short one [point], and that is that it must depend on the type of lesion, of course. In some cases, of course, there is this matter of confidence, that you can trust what you really feel. You see a lot of that, that people are afraid of falling and do avoidance behaviors, and then you have to come through with that. That's one part of it. The second is the motor learning, and the motor of learning, as Kim [Gottshall] points out. I think this helps very well. But, sometimes just a machine is a good thing.

[Raj] Yeah, and in talking to Paul Bach-y-Rita before he died, one of his thoughts was that with many of these people, there may be some residual vestibular function left, but so much of it was lost so rapidly that it's "lost in the noise." And having a crutch that helps them not fall while they are learning to use the new system, or the new capabilities of what their biological system has left, gave them the confidence to do that, to say, 'okay, I can try to provoke myself and see what happens and see how I need to recover myself, and then when I don't use the system anymore, I'll still have that available to me.'

[Magnusson] Some little time ago, we looked at children and the difference between children and grownups learning postural control, and it looks like the children challenge it all the time. They are on the edge all the time. We put it as an "accept to fall" strategy. The grownups don't [accept frequent falling] because falls in a grownup, especially in elderly or a frail subject of some kind, have consequences. Assuming the security of not falling, and assuming the security of not getting another injury, is perhaps what really makes the trick.

[Raj] Yeah. I tend to agree. 


\section{$\underline{\text { Experimental acute bilateral vestibular loss - Måns Magnusson }}$}

[The following is an extemporaneous commentary by Dr. Magnusson concerning a video he shared with the group.][Slide 1, page 194]

We did a bilateral middle ear infusion of 2 percent lidocaine in both the left and right ear drums, and then we had him [Dr. Magnusson's colleague] positioned like this [slide 2] for about an hour. As long as he was positioned like that, he was very happy. He mixed it [the lidocaine] himself, so I won't go to jail (if it came out) [speaker is joking]. Here [slide 3], he's trying to get up at about 1 hour [after the administration of lidocaine] and he felt fine until now [about 15 minutes after getting up]. Now he realizes that this was not a good idea. There's a really nice soundtrack to this, but I will spare you from that. Now, he just has to get to the men's room. This is what happens, [he finds it] quite difficult to stand. I checked him before this and he didn't have any kind of nystagmus.

This is what he's tried to do, he tried to walk and you can see the walk is very difficult. Then, he tried to do Romberg. He closes his eyes and he barely manages to do it, by help of his feet, and he really had not a very good time. But he needs to go to the toilet, which is a good sign, and he starts walking again, and this is how he walks [slow and wobbly]. This is quite a fit guy otherwise. Ian [Curthoys], you know him? [Ian says “yes.”]

Now, it's starting to become critical, and here comes the barf bag. What he says is, "It's all for science." [A doctor appears in the muted video, smiling wanly and saying something]. And this is what happens: he spent about 15 minutes on the toilet, then we got him out and this how he looks after that [slide 4]. Everything is moving for him, and he can barely move like this without vomiting. There he's taking a little rest [slide 5].

[Summary of speaker's points on slide 6]. 


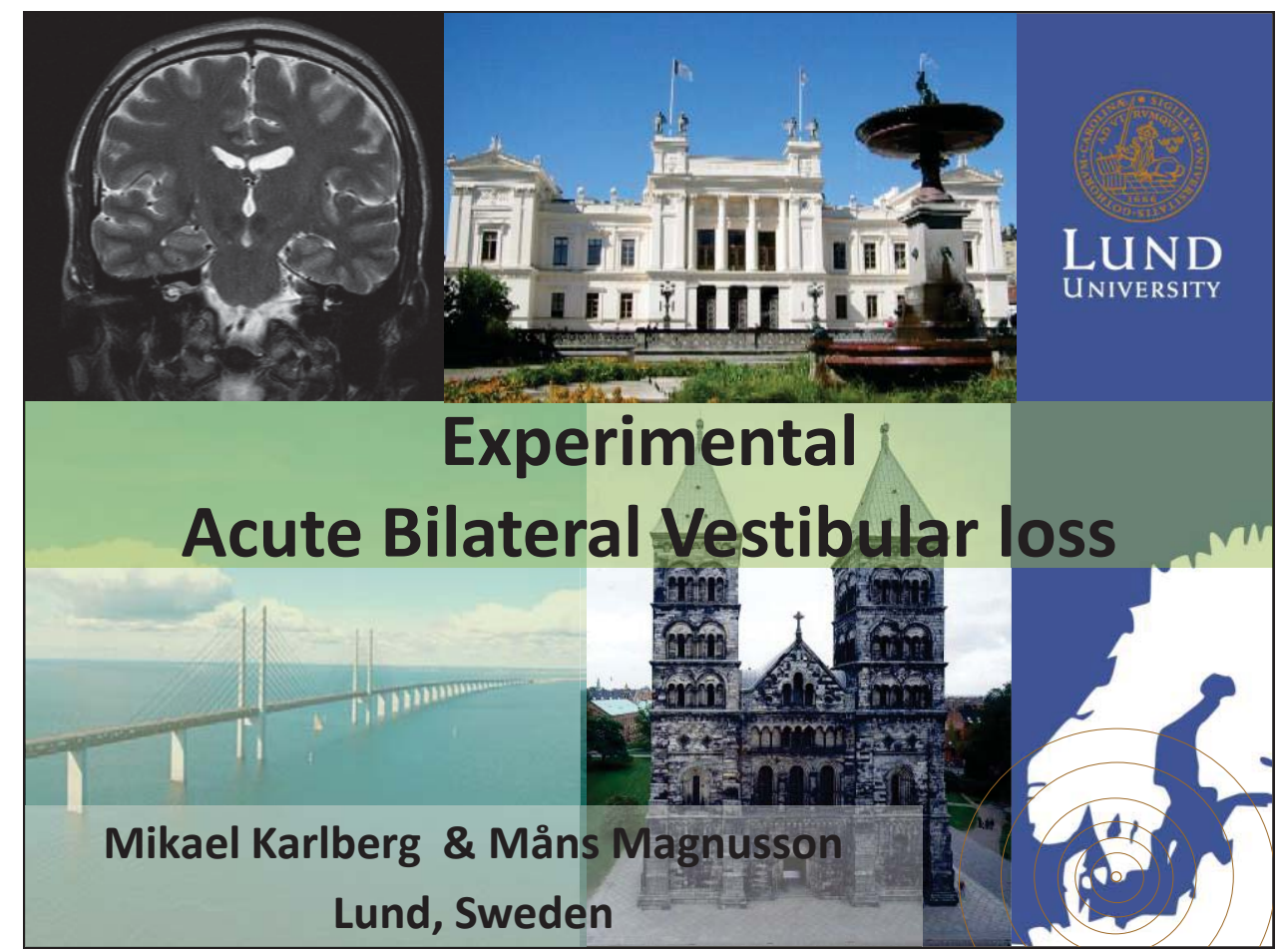

Slide 1

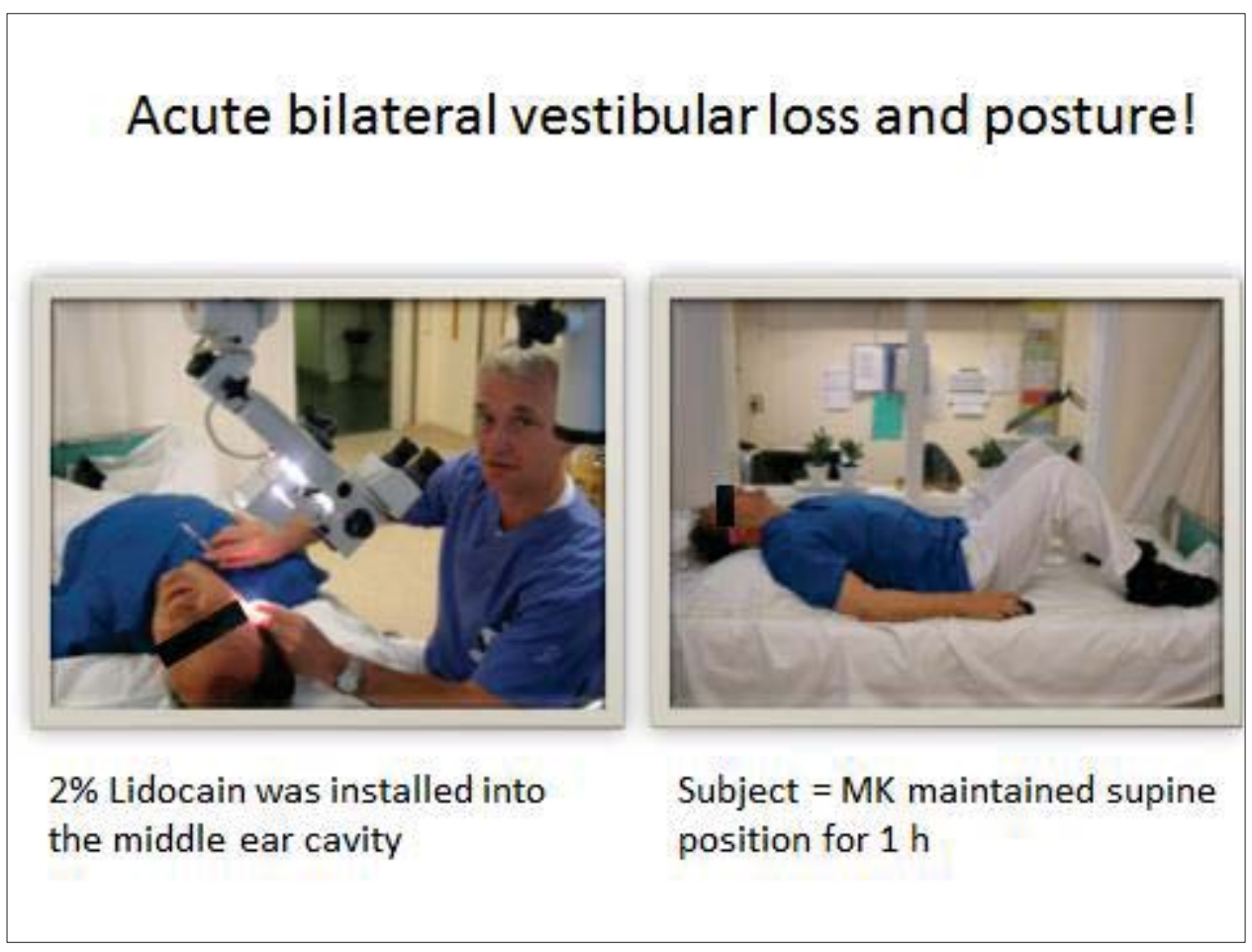

Slide 2 


\section{Acute bilateral vestibular loss and posture!}

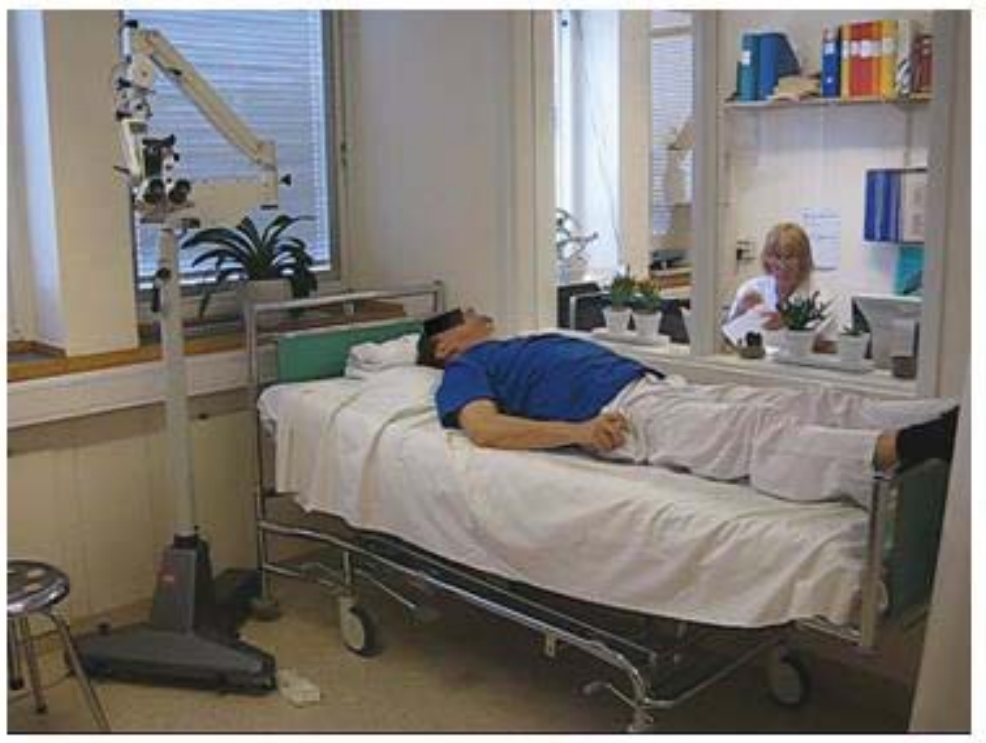

Slide 3

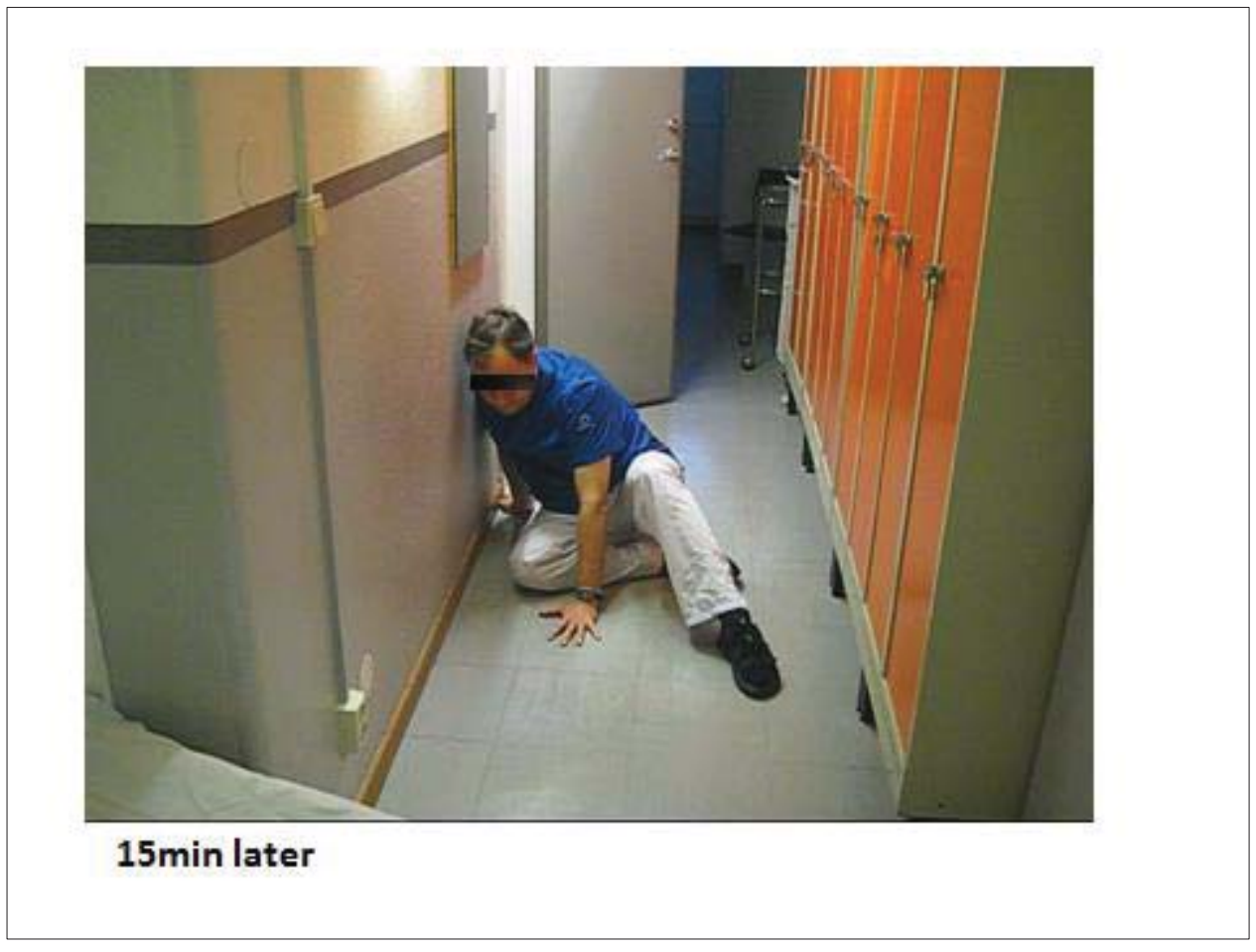

Slide 4 


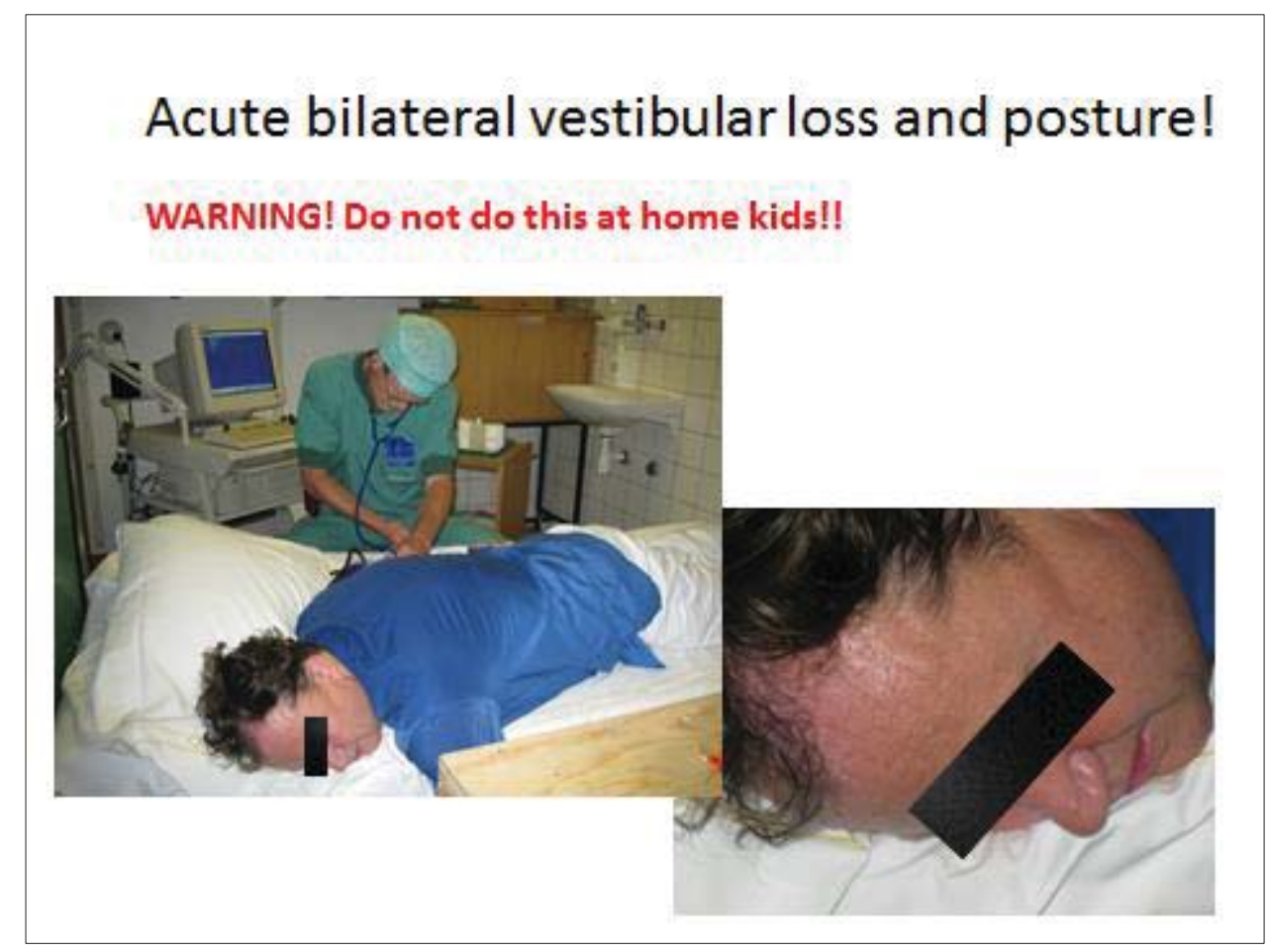

Slide 5

An acute bilateral vestibular lesion induces:

1. Severe nausea

2. Pronounced balance problem

3. Vestibular ataxia

4. Oscillopsia

5. Cognitive 'loss'

Duration 6-7h

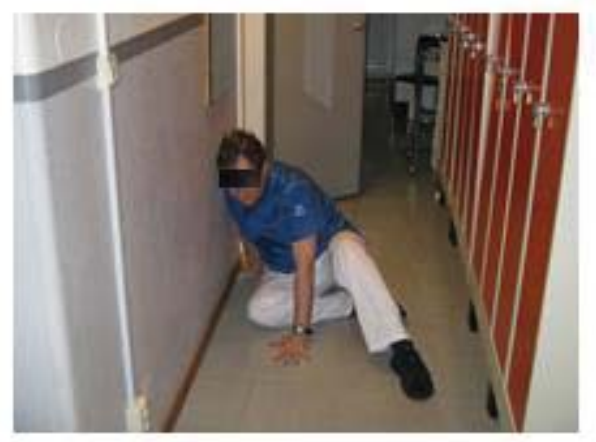

Slide 6 
Question and answer session

[Goldberg] So the notion that you need the labyrinths to get motion sickness is inoperative in the acute phase?

[Magnusson] In the acute phase you don't need the labyrinth, and you can still be motion sick.

[Goldberg] I think that is a very important observation.

[Black] May I offer an alternative notion? It is the rapidity of the loss that is important here. What you just saw is an acute bilateral ototoxicity and we see this in other forms of ototoxicity. Initially, when patients are receiving, say, a drug like gentamicin (which by the way is the most dangerous beta-galactoside drug on the market for vestibular toxicity), the acute phase is exactly what you see here. It occurs precipitously and unpredictably. The notion that a sudden bilateral loss can't cause nausea and vomiting is just not true. It is almost universally observed. But, if the patient loses function slowly it doesn't occur.

[Magnusson] Wouldn't you agree that it depends a little bit on how slowly the patient loses it?

[Black] I don't know that anybody knows that.

[Magnusson] Do you have the observation of patients losing it over a couple of days like in a bilateral, like in neurosarcoidosis, for example?

[Black] You know, I can't say that for sure. I don't know of any study that has noted the rapidity except for this acute type of demonstration that you've made. Maybe I should make one other comment. General medical people, nurses and physicians, are naïve observers. They almost invariably interpret this as a loss of orthostatic hypertension or neuromuscular loss and clearly it is not.

[Unknown Speaker1] Does Meniere's disease look like this?

[Black] No, Meniere's disease doesn't look like that. Meniere's disease can cause bilateral loss, but it occurs in a fluctuating manner. It usually doesn't occur suddenly. Now, you can get patients with other types of bilateral labyrinthine loss, for example, bilateral occlusion of the internal auditory arteries will produce it, as well. There is one other point: This is not a cerebellar type of gait. This type of gait is very different. I'm sorry Måns [Magnusson], I didn’t mean to steal your thunder here, but this gait is very different from a cerebellar type of ataxia.

[Atkins, James] There was a time when we were using unilateral lidocaine for tinnitus. There were some studies that came out of Memphis that showed that might be adequate, and you would get a similar effect; although, it was much more nauseogenic because you were actually performing an acute unilateral labyrinthectomy on those patients. The one other thing I want to add to what Owen [Black] said is, I don't know if you can absolutely assume that you have the same amount of labyrinthine loss bilaterally. There are a lot of indications that depend on round window permeability and all sorts of other things, as to exactly how much loss you get. I don't 
know that we can assume he had a hundred percent bilaterally. It could have been a 100 [on one side] and 80 [on the other], and if he has any discrepancy between the two sides it is going to be certainly a lot more nauseating.

[Correia] Would you assume he had a nystagmus then?

[Atkins, James] You would assume that exactly if there was a discrepancy between the two sides. Absolutely.

[Magnusson] And he didn't [have a nystagmus]. Secondly, he didn't have any symptoms until he started to move, which I think is a little bit indicative that he was fairly well-balanced. If he would have had some kind of imbalance he probably would have experienced some symptoms even before he started to move. But when he started to move, then everything started as well. I agree with Owen [Black] that if you have a slow bilateral loss, those patients don't experience many symptoms more than unsteadiness. But I've seen very, very few cases (and probably some of you have as well) of patients who have a bilateral loss (for example, by granulomatosis from neural diseases) where the loss is over a fairly short period. They have unsteadiness. They report quite a bit of unsteadiness. That's, again, clinical observations but this was an experiment. For sure, I can't guarantee that there weren't a couple of cells that were still working somewhere but we couldn't see any asymmetry in this case. 


\section{Dr. Angus Rupert's banquet toast to Guedry}

\section{Fred Guedry: A national treasure}

For those of us that know Fred, that really and truly is a statement that I think we can all stand by [Fred is a national treasure]. As I mentioned to the group this morning, if Fred is like the rest of us, when he gets up each morning, he looks into the mirror and this is exactly what he sees [slide 1, page 203]. I know when I look into the mirror I certainly don't see what you're looking at now. [Laughter.] This is a picture of Fred at age 15 and he's on the pitcher's mound [slide 2]. You probably can't read from the back but it says, "Holy Cross." This is Fred in New Orleans pitching a game. This is a no-run, no-hit game, and you can see this long, lanky kid. I can't even see the ball. I know it's in his hand, there, somewhere. Ben [Lawson] and I were looking and saying, 'he doesn't even have a ball in the hand.' But it's hidden in there somewhere, with a spin, I'm sure. This is Fred, as I said, at age 15, but most of us, when we were 15, had not graduated from high school. Fred had graduated from high school and he was just ready to start playing baseball for Tulane University. Just a little less than a month ago, I asked a friend from the Bureau of Medicine, who is a Navy historian, to come down and do an oral history on Fred, and he did. I learned more about Fred in that oral history than I had learned about him, from him, in the last 25 years [a review of the oral history is provided in appendix D on page 257]. That's because Fred doesn't talk about himself, he's a very modest person. He was being questioned about baseball as he went on through the University, and when asked, you know, what his best game was, he said it was when they beat LSU [Louisiana State University]. There is a little rivalry between Tulane and LSU. I guess those of us that don't live in the state of Louisiana can't really understand that. He [historian] asked what the score was. I think it was 7-6. Fred may correct me but it was a 1 point difference. But Fred was just a relief pitcher in that game. When asked when he came into the game, Fred said he came into the game in the first inning. [Laughter.] The score was 5-nothing, the bases were loaded, and they brought Fred into the game. Well, they won that game 7-6. That may not seem too impressive but LSU was a powerhouse at the time. LSU, just a couple weeks before, had beaten a major league baseball team in an exhibition game, [the team was] called the New York Yankees. So that gives you an idea of Fred's background. Most of the people that knew Fred while he was here in Pensacola know him as an incredible athlete from the perspective of tennis. Fred was the president of the local tennis club for 5 years and played a lot of nationally ranked people. I'm going to call upon Manning Correia, who is a tennis player as well. I had seen a picture of Manning when he was playing for Emory [University]. Now, Fred is very competitive and Fred will hold a grudge forever, especially if somebody that he is playing pairs with loses the game because they did something stupid. Now, I don't think it was you, Manny. [Laughter.] Was it you? It was! Manny is confessing now. Actually, I was going to attribute it to Bob Kennedy because he's not here. [Laughter.] You can tell a little story about that a little later, then, I'm sure.

Well, that was Fred when he was 15. This is Fred 9 years later [slide 3]. Nine years later he's graduated from Tulane University and a couple days out of Tulane he finds himself in school again, except I think this is sort of a midshipmen school. He departs there to get on board this ship called LST [Landing Ship, Tank] 273. LSTs at that time were big boats that basically were floating supply ships, usually carrying fuel on the decks, lots of 55-gallon drums for aircraft, and ammunition, of course. It has tanks as well, and a lot of Marines. Fred is dead center of this 
picture. Fred is looking a little bit sad in this picture. You have to look close but even looking very close I can't see that he has a half-day growth of beard. Fred is always the most cleanshaven, handsome man, and always takes pride in that, and his complaint was that the executive officer [XO] had not told him that the photo was going to be taken ahead of time. So he was upset with the XO because he wasn't clean shaven for this picture. Now we will take another picture here, tonight, against the background of the USS Cabot, and Fred will be clean shaven for this picture, so we will make up for it [the picture taken after the banquet can be found in appendix E on page 266]. I just realized this is the USS Cabot and there's someone sitting at Fred's left-hand side [tonight], Captain Bob Mitchell. Captain Bob Mitchell has walked on the decks of the USS Cabot while it was afloat. Of course, Bob Mitchell is a very old man compared to Fred. Bob is 92 at this point. He'll be celebrating his $93^{\text {rd }}$ birthday soon.

I should give an indication of where this boat has been. I went to the web to find out where it had been [the LST 273]. Fred was busy in 1944 [slide 4]. [He was in the] Marshall Islands, occupation of Kwajalein and Majuro Atolls, [in] January and February. [He] started off busy. [In] February [he was involved in] Occupation of Eniwetok Atoll. Then, it got very busy: capture and occupation of Saipan, June and July 1944, Tinian island capture and occupation, July, the next month. These are just one island after the other where Fred is putting the Marines ashore, picking up the casualties, decks filled with casualties, and also filled with lots of fuel on board. Western Caroline Islands, capture and occupation of southern Palau Islands, September and October ' 44 [Dr. Rupert is reading from slide 4]. I guess it continued into the next year: Luzon operation, the Gulf landing in Lingayen. Okinawa, assault and capture of Okinawa Gunto, April '45. It was just one island after the other and Fred is on board this ship. The historian gathering this information, while I was with him, asked Fred if he was in Hawaii on a certain date ${ }^{*}$. Sure enough, Fred had been in Hawaii on that date and six of these ships blew up, literally, on all sides of Fred. The man was asking where Fred was and he said he was standing on top of the aviation drums on the decks, with a fire hose trying to keep them from being caught by the bits and pieces of shrapnel coming on the ships on all sides. We're glad that Fred's here with us today. This is the LST 273 [slide 5]. Fred is probably in this picture (off Saipan, June 16, 1944). Well, at the end of the war there were a lot of clean-up operations, and they did that. So the next year, Fred is in some place called Guadalcanal and only one engine is operating, but Fred does want to get back home [safely to base] because when he gets back, he's supposed to get off the boat and go home. So he brings it back to Long Beach, California on one engine. [He] gets to Long Beach, California, and finds that there's nobody there to sign his discharge papers. So Fred signs his own discharge papers. So, you can refer to LT JG [junior grade] Guedry, here tonight, as probably the youngest LT JG currently in the U.S. Navy. [Laughter.] Now, when the historian was talking to him, Fred said, 'well I haven't been receiving any paychecks.' [Laughter.] I am sure that if someone goes back and finds that paperwork, Fred may get some backpay but he also will probably find himself in Leavenworth. [Laughter.] So don't mention that to anyone when you go home tonight.

Well, after that Fred went to be the Chief of the psychology research group at Fort Knox [slide 6]. Many people don't realize that Fred was with the U.S. Army for a period of time before he came here [to Pensacola]. As a matter fact, Fred ran a group that was bigger [at Fort Knox]. So someone else was pointing out that a "national treasure" really refers to the time when Fred was

*7 December, 1941 - The bombing of Pearl Harbor. 
at Fort Knox, where all the gold was. Well, Fred was talked into coming down to Pensacola. He had lots of visitors when he was in Fort Knox [slide 7]. [In this picture, there are] some people [that] a few of you may recognize: Cesar Fernandez on one side, who has worked with Jay Goldberg in Chicago; John Lindsay; and Bo Gernandt. Those were three of the biggest names. A lot of famous people were always coming to visit Fred and it's always [for] the same [reasons]. It's called Fred's House of Vestibular Toys, a beautiful building [slide 8]. It's still here but no longer has any toys in it.

Well, you don't have vestibular toys unless you have engineers and nobody wants to admit that engineers are important for anything. [Laughter.] It does turn out that if you want to have toys, they're [engineers are] very important. Here [slide 9] is the toy master, Carroll Hixson. Laurel Hixson [his widow] is here tonight. Laurel, would you please stand up? [Applause.] This [slide 9] is a picture of Carroll doing what he always did: instrumentation, making sure that things work, designing things. There are a few engineers here tonight that are probably happy to hear me say that, yes, engineers are important.

Not all the devices are big. This [slide 10] is one of my favorite devices. It's called the Pate Device. I believe Fred ordered this over the phone. It was built and delivered in 6 weeks. That's why it's got the "sixes" [on slide 10]. It costs $\$ 6,000$, and Fred had done the first experiment on it within 6 months of the phone call. I keep meaning to ask Fred about the IRB [Institutional Review Board]. [Laughter.] I just don't understand that.

So anyway, [let's get back to] big devices. This [slide 11] is called the Coriolis Acceleration Platform, built by NASA, it later became a Slow Rotation Room. [This is] a Human Disorientation Device, many people are familiar with that [slide 12]. This [slide 13] is, of course, one of the things that made this place famous, as well, with the great subjects that came here (the folks at Gallaudet College, the folks that had nonfunctioning labyrinths). This [slide 14] is Fred giving advice to other people who really needed advice [speaker is joking]. This is some guy named... Werner Von [Braun]... yea, Fred's telling this guy how to build rockets. It's a good thing that he got those words in and they got it right. I think that's the only program we've had that never had a failure of any sort. Thank you, Fred. Oh there's another picture with him [slide 15].

Here's [slide 16] Fred with the Slow Rotation Room and this lady is from Channel 3. I don't know what they're pointing to, but Fred probably gave a lot of words of wisdom to everybody. This [slide 17] is the slide I showed earlier in the day. This is Ilte Niven and someone who didn't make it to the meeting tonight [Robert Kennedy]. I think, Dr. Mitchell here, you do recognize that cherub-like face over there? Yea, he's supposed to be here tonight and Bob Kennedy, who has of course thinned up considerably over the years. That's what you get when you don't show up you know, you get attacked. [Laughter.] Oh, and here's [slide 18] another device. This wasn't exactly one of the toys that Fred built but Fred and Alan Benson, who is seated at his right side, are really responsible for this. This comes about as a result of jealousy. [Laughter.] What happened was they had a meeting (I think [in] '72, or '71, was it?). The meeting [was] on what was needed for some training devices. So Alan was able to build one of these, a 2-person one, if you will, in England. Only one-person; I'm sorry, I didn't mean to exaggerate. He [Benson] says it's a much smaller Air Force. [Laughter.] Well, of course, as soon as the U.S. Navy found out 
that the British had a one-passenger (shall we say a one-capsule) trainer, we, of course, went out and built a 10-person trainer [the multi-station disorientation demonstrator]. But, it would never have happened had they not had this meeting in the early '70s. Fred also got to play with other toys. This [slide 19] is probably the best vertical linear accelerator (with large displacement) of anywhere in the world. Manny Correia had gone up there and we had done some interesting experiments. So Fred had big toys, too. And, of course, [here is a picture of some of] the work that was done with NASA on the Vomit Comet [slide 20].

I'll backtrack a little bit to the gentleman on Fred's left. This [slide 21] is Captain Bob Mitchell [applause] and, as I mentioned, he had been Fred's boss for a period of time. Fred had probably good bosses and bad bosses. Those of us that have been in the military recognize that you can get some of each. But he's had a couple of very good ones and Bob Mitchell was one person who certainly saw to it that research was always kept at the front, maintaining a proper sense of respect. We also have another gentleman here [slide 22], Al Mateczun. Al, where are you? Could you stand up for just a second? [Applause.] Al will know several other people that are here, as well. We have been meeting here for the last couple of days and Dr. Anil Raj, who's working at the institute [IHMC], hosted that meeting. He was making a comment, basically, that Al had the ability to make things happen, to take risks, [which] is something we're very much averse to doing nowadays. I'm going to stop, then, I'm going to turn it over to anybody else who wants to say something. Ben Lawson has put together a montage and we'll let him regale you with some comments. 


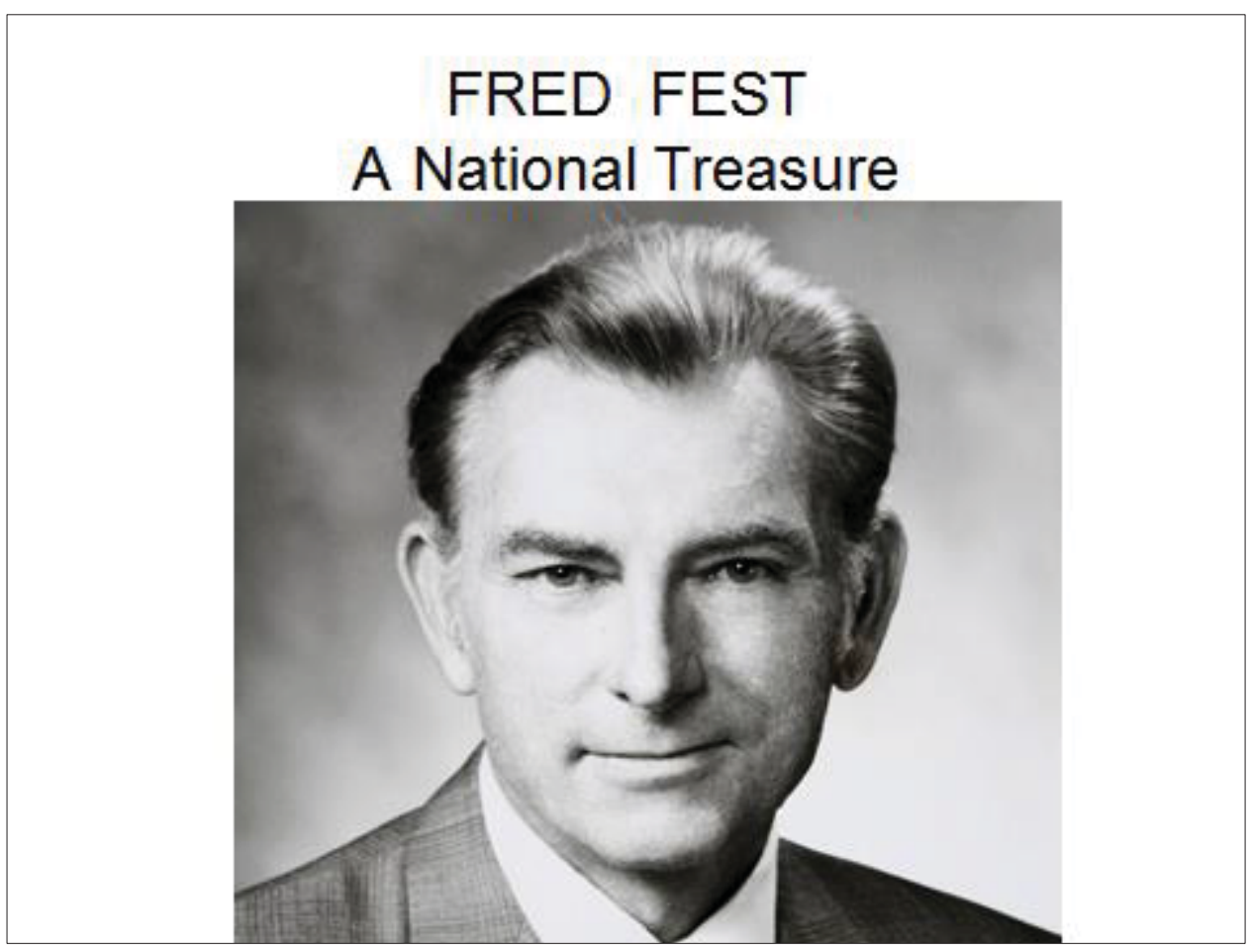

Slide 1

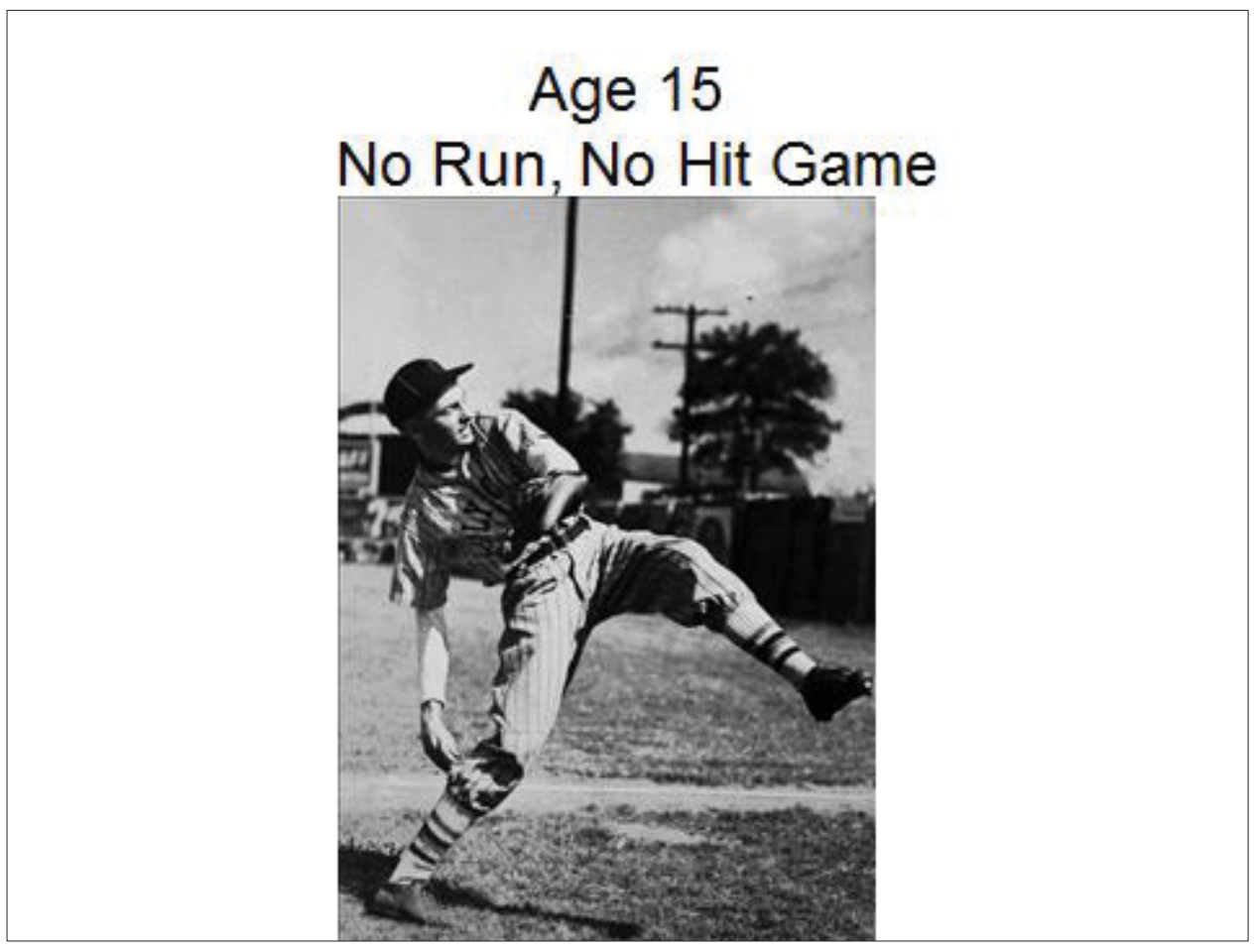

Slide 2 


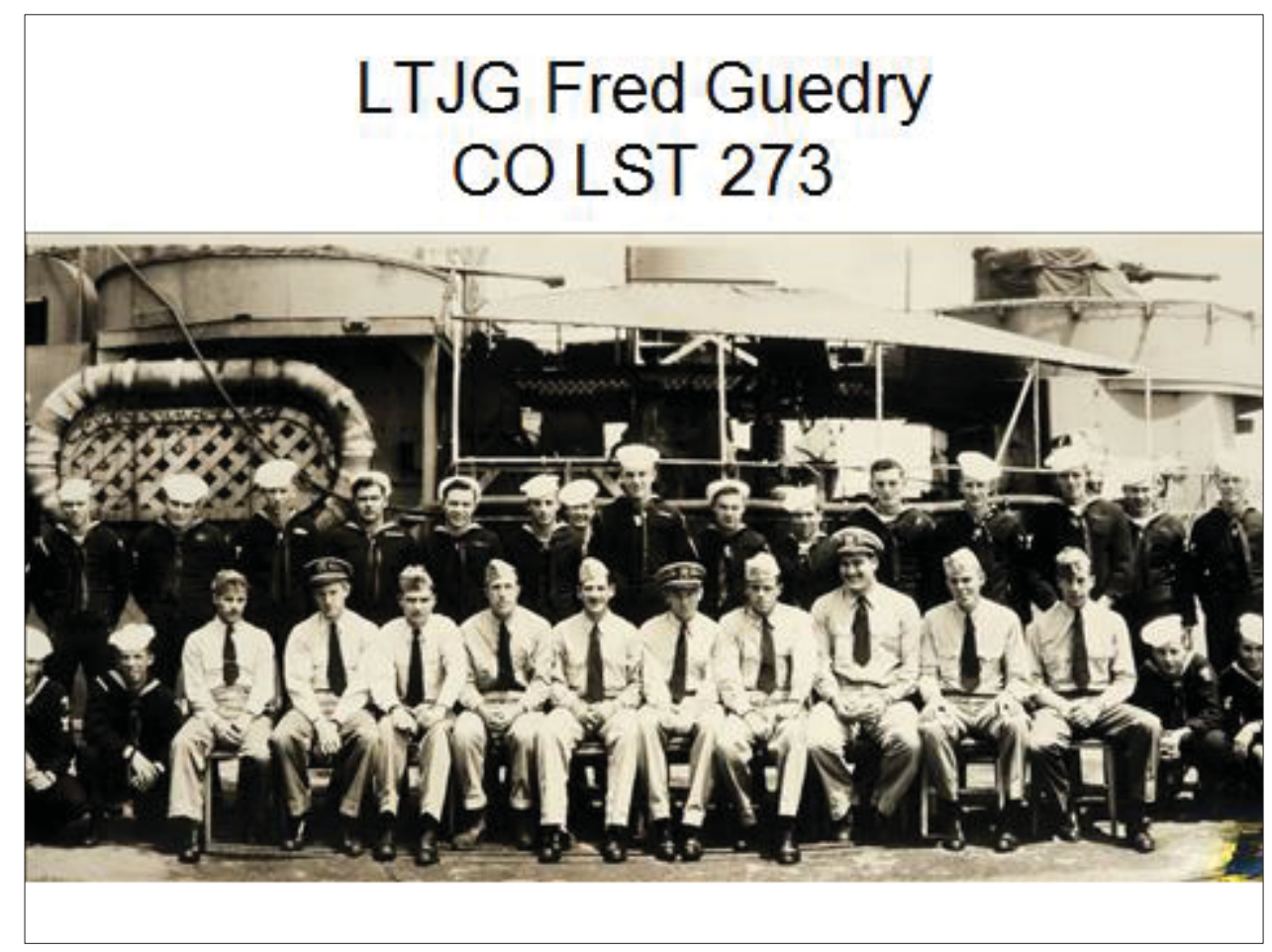

Slide 3

\section{LST 273}

- Marshall Islands operation;

(a) Occupation of Kwajalein and Majuro Atolls, January and February 1944

(b) Occupation of Eniwetok Atoll, February 1944

- Marianas operation;

(a) Capture and occupation of Saipan, June and July 1944

(b) Tinian capture and occupation, July 1944

- Western Caroline Islands

(a) Capture and occupation of southern Palau Islands, September and October 1944

- Luzon operation;

(a) Lingayen Gulf landing 9 January 1945

- Okinawa Gunto operation;

(a) Assault and occupation of Okinawa Gunto, April 1945

Slide 4 


\section{LST 273 Off Saipan June 16, 1944}

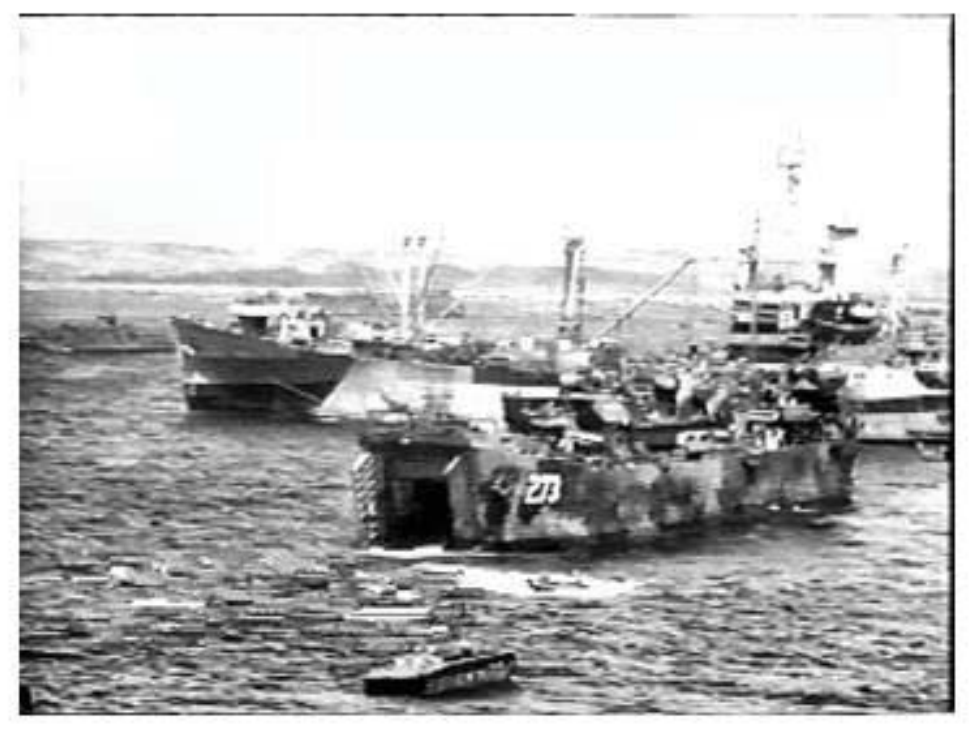

Slide 5

\section{Ft Knox - Chief of Psychology}

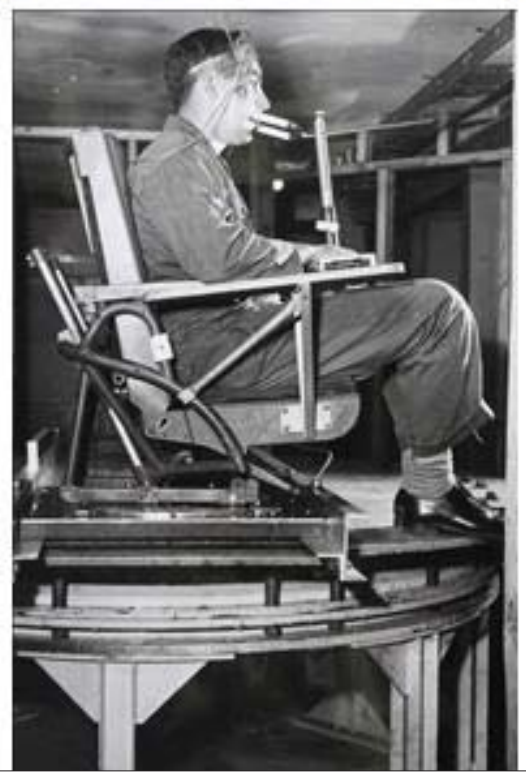

Slide 6 


\section{Cesar Fernandez, John Lindsay, \& Bo Gernandt \\ FT Knox Feb 17,1959}

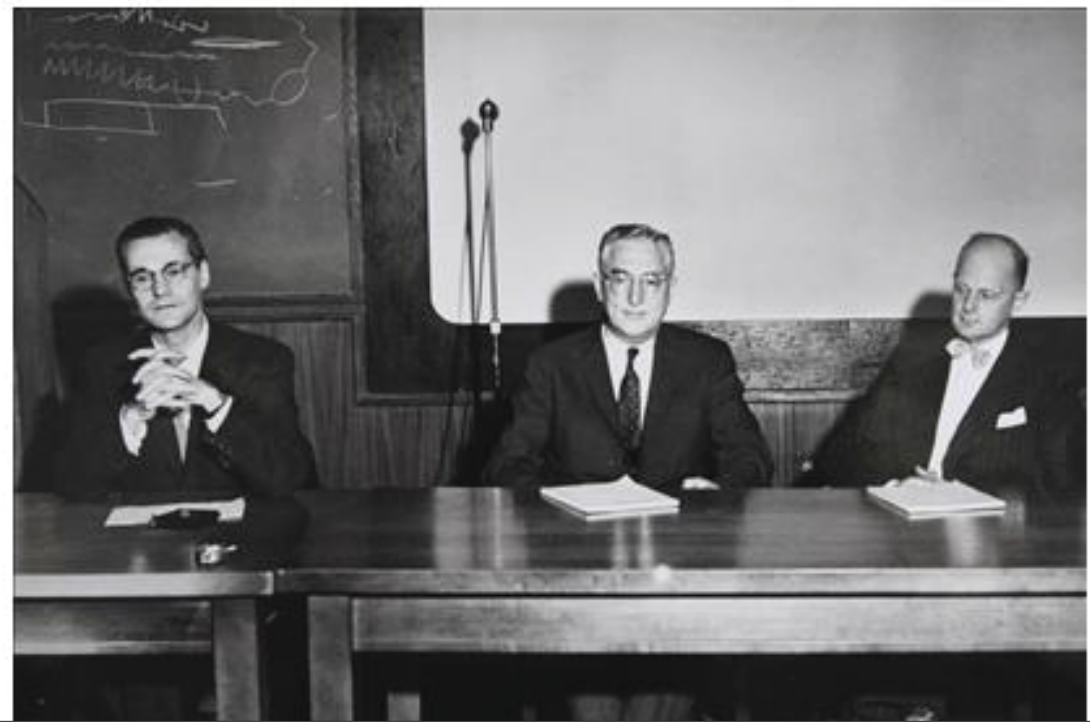

Slide 7

Fred's House of Vestibular Toys

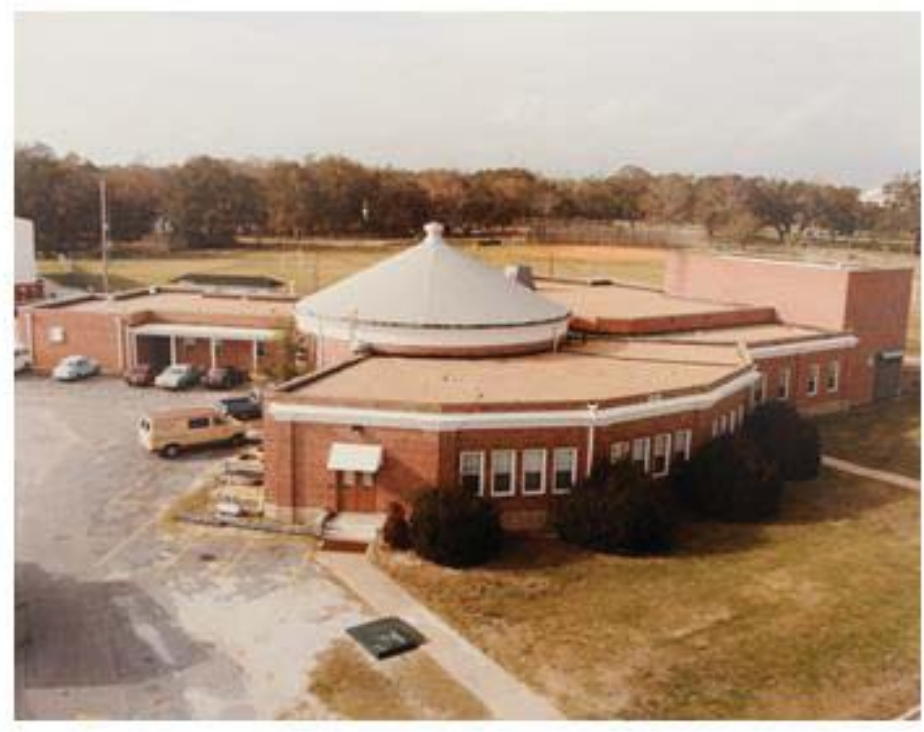

Slide 8 


\section{Toy Master Carroll Hixson}

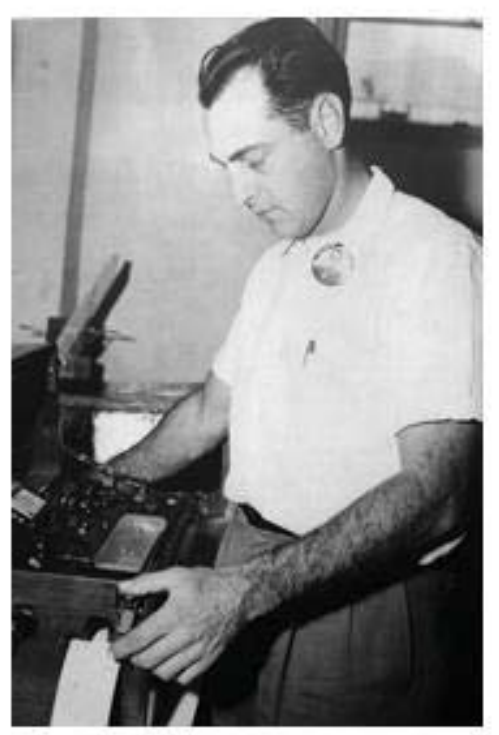

Slide 9

\section{Pate Device "sixes"}

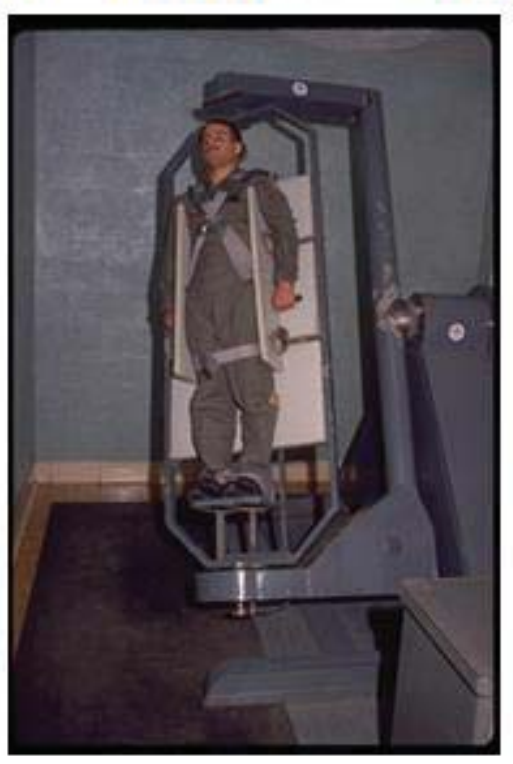

Slide 10 


\section{Coriolis Acceleration Platform}

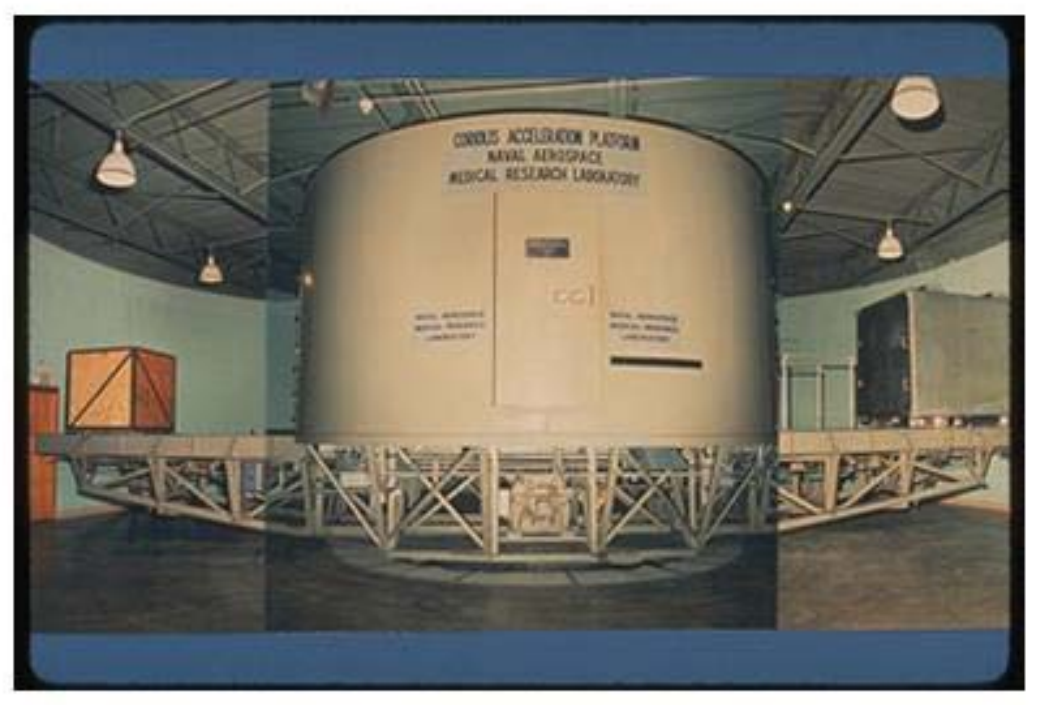

Slide 11

\section{Human Disorientation Device}

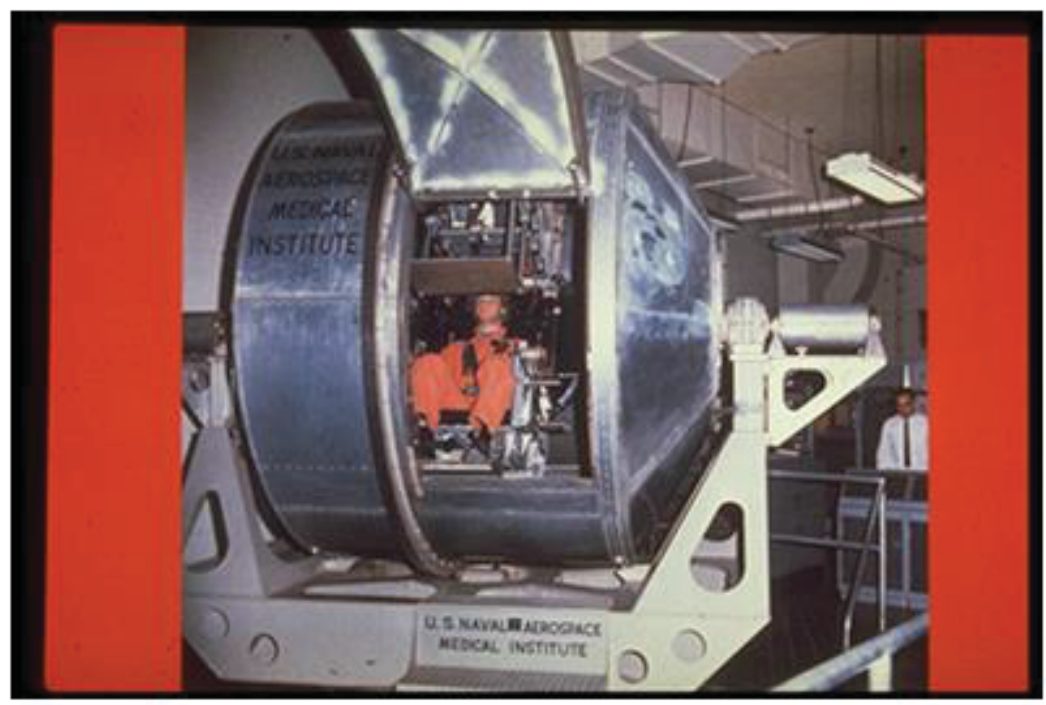

Slide 12 


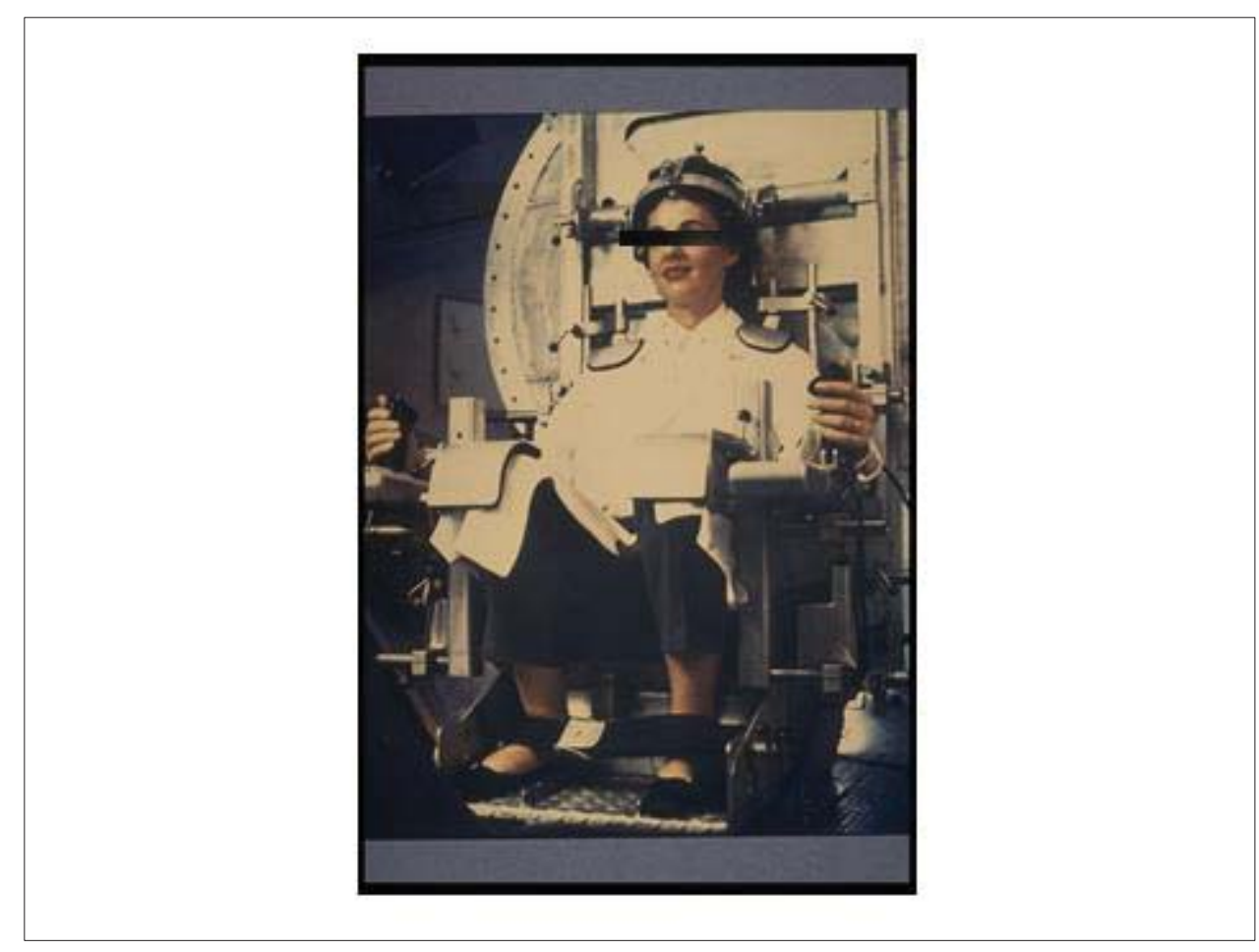

Slide 13

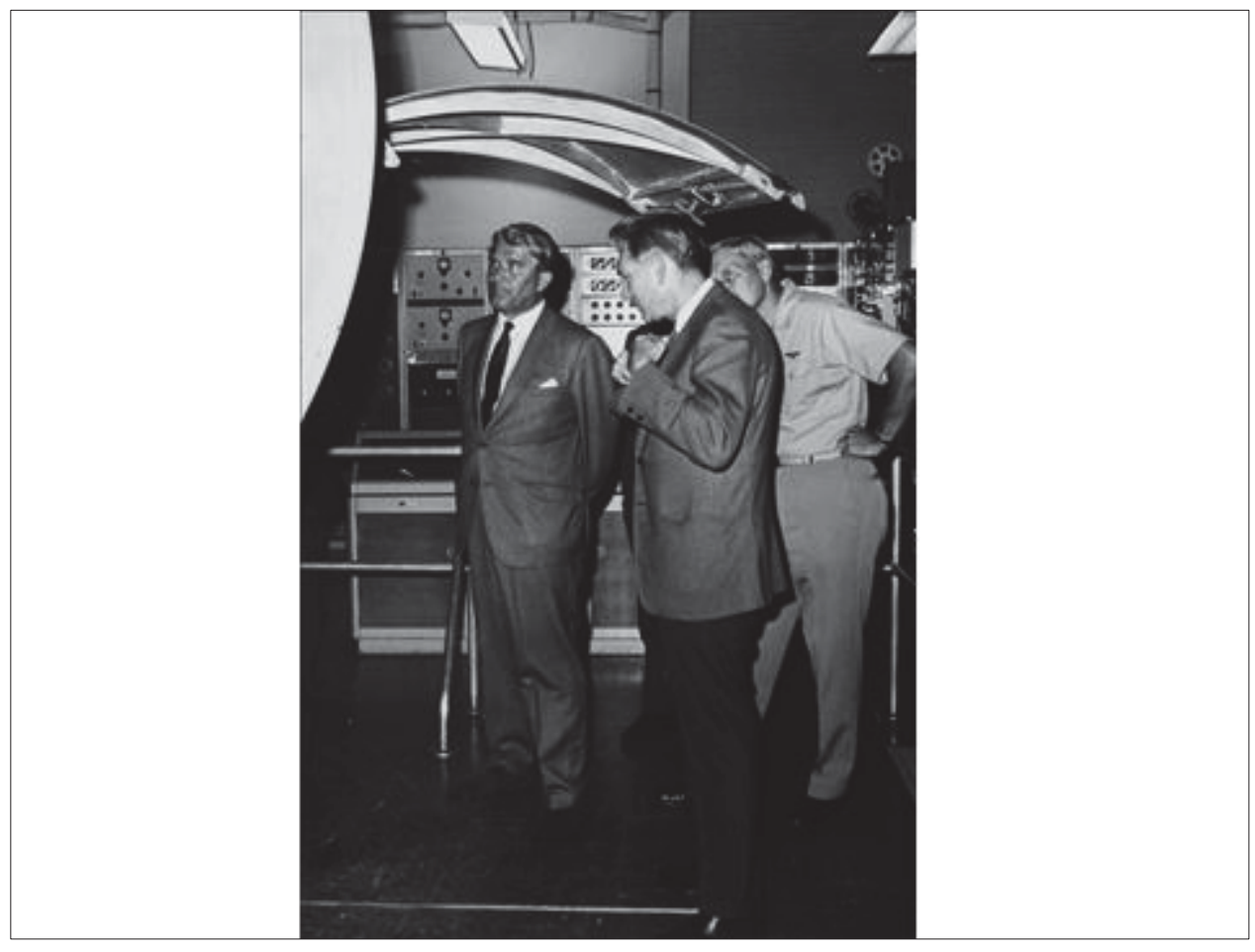

Slide 14 


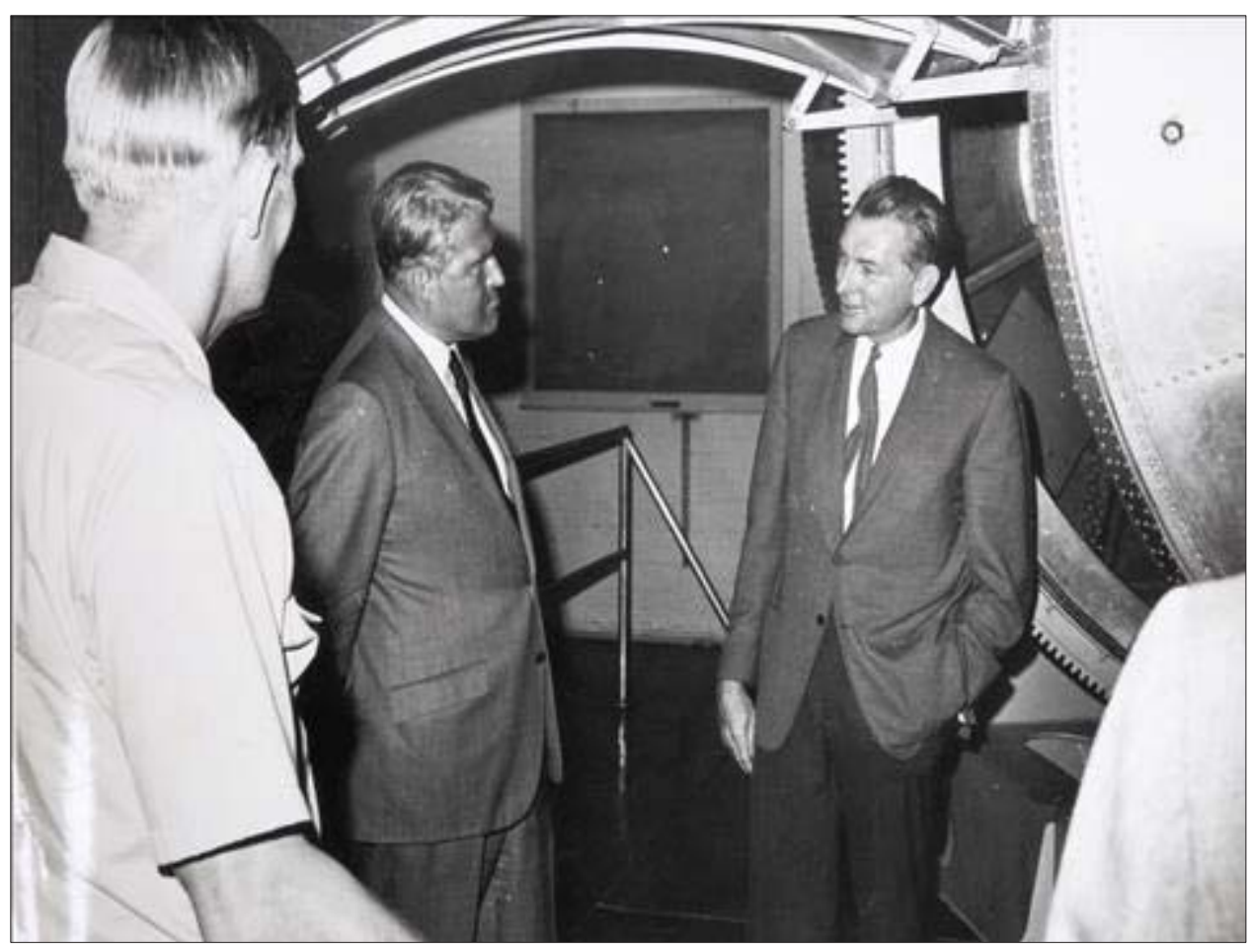

Slide 15

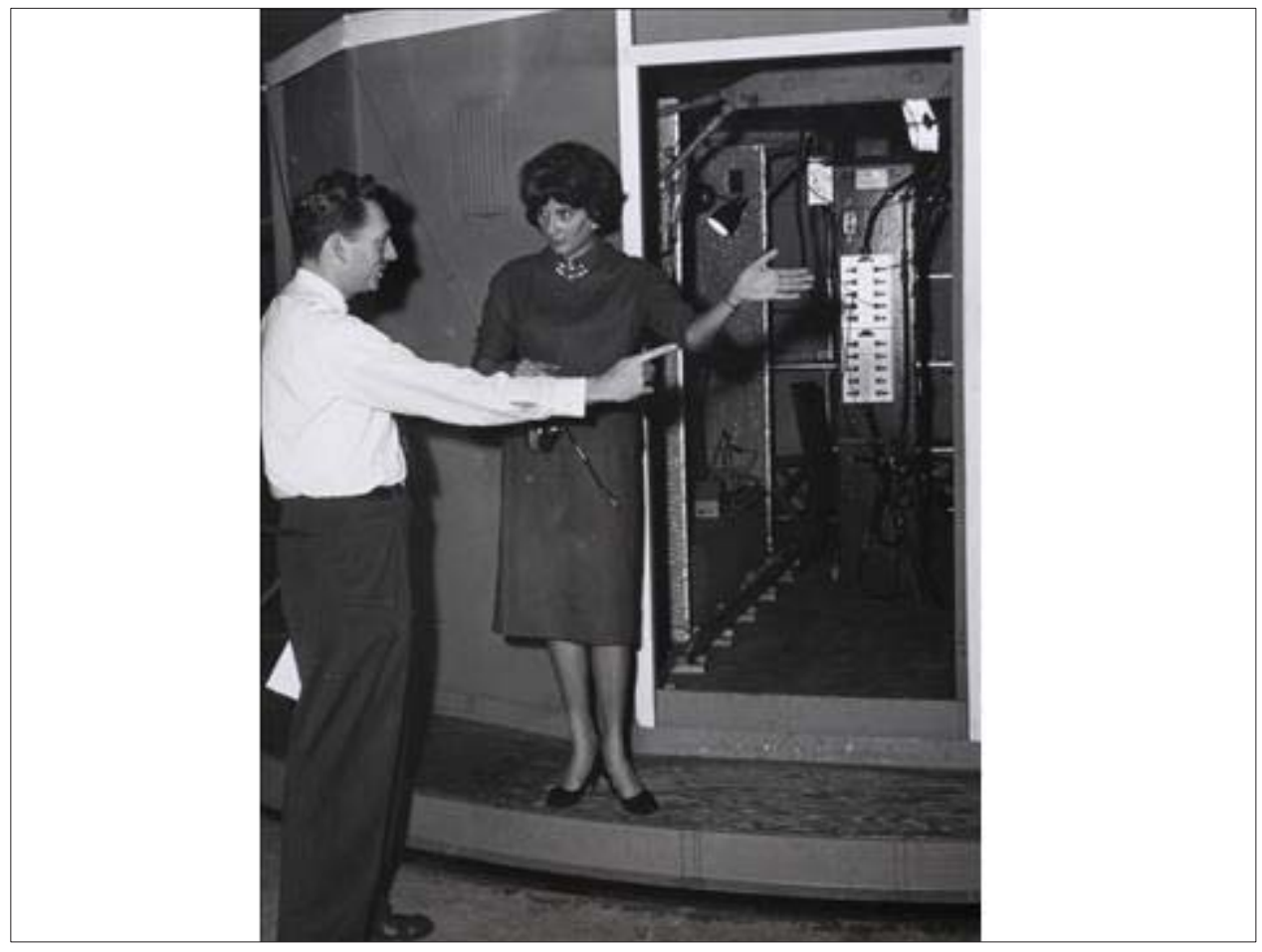

Slide 16 


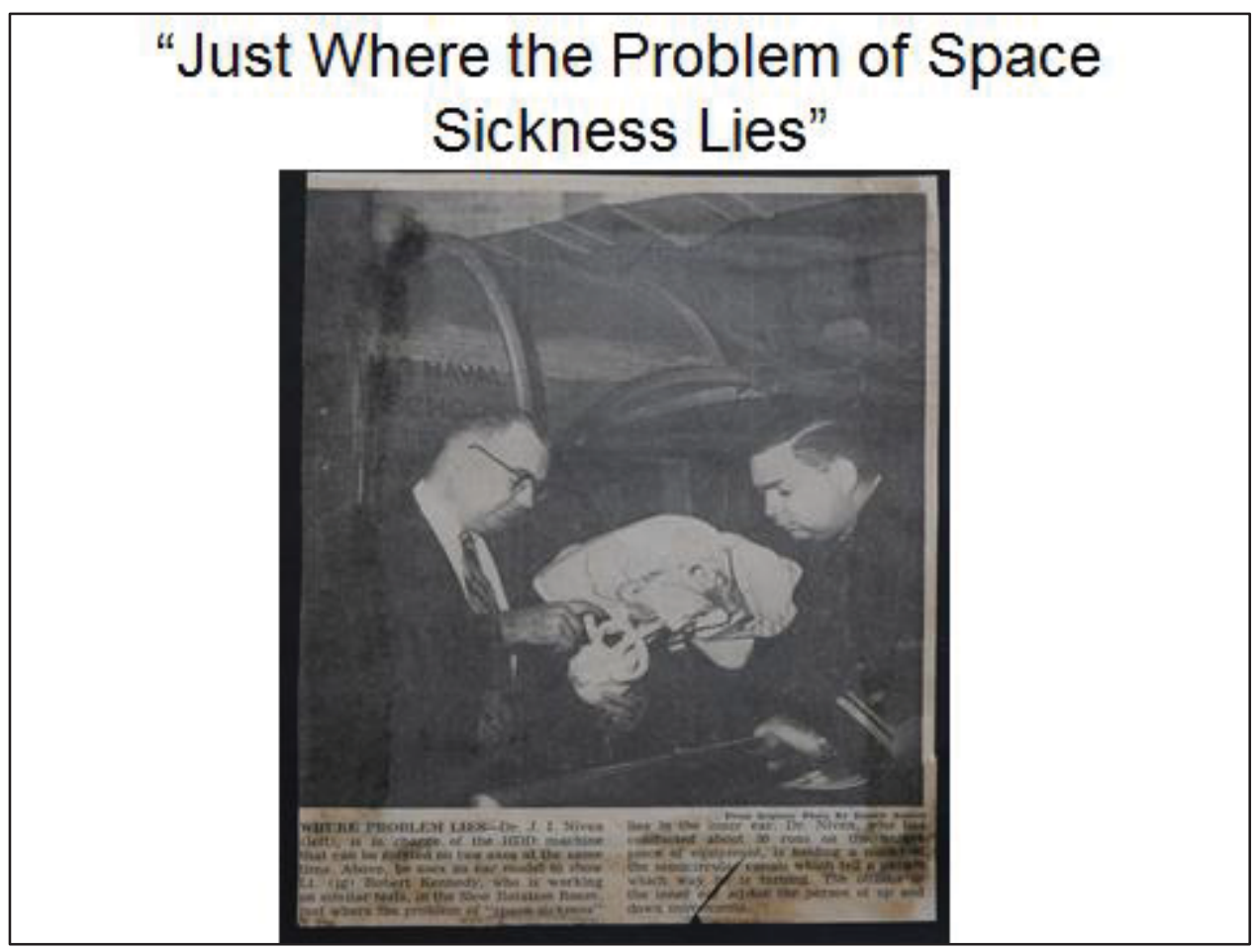

Slide 17

\section{Multiple Station Disorientation Demonstrator}

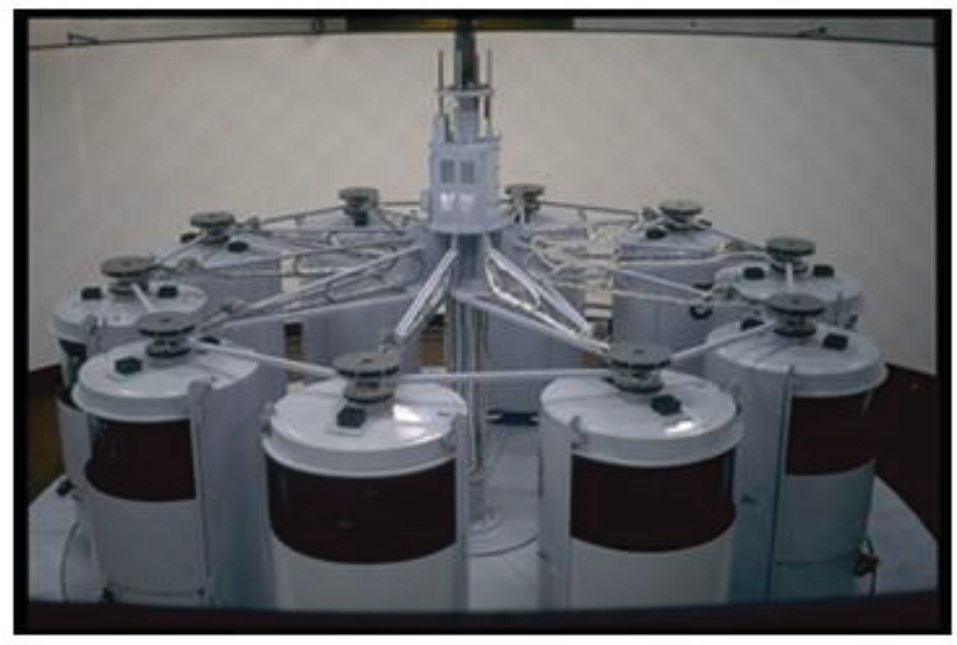

Slide 18 


\section{Otis Elevator Test Tower}

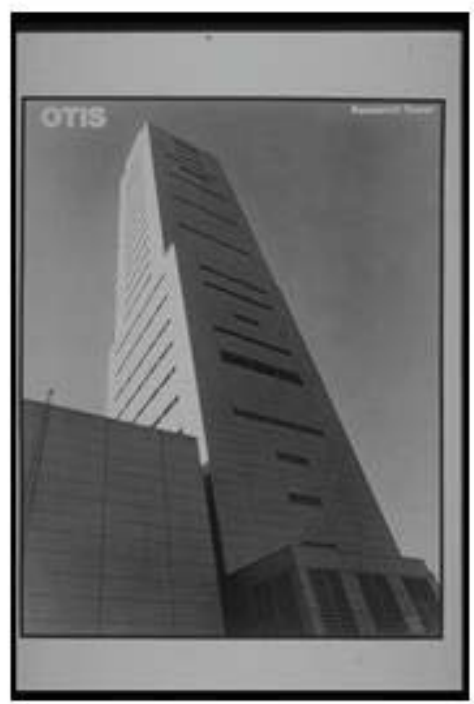

Slide 19

\section{Boeing 727}

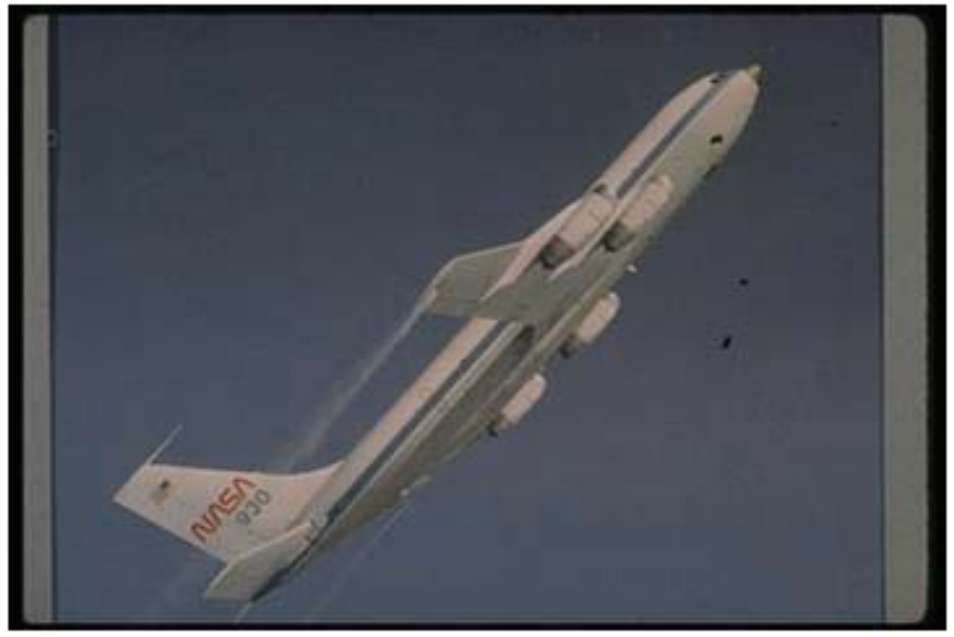

Slide 20 


\section{CAPT Bob Mitchell CO NAMRL}

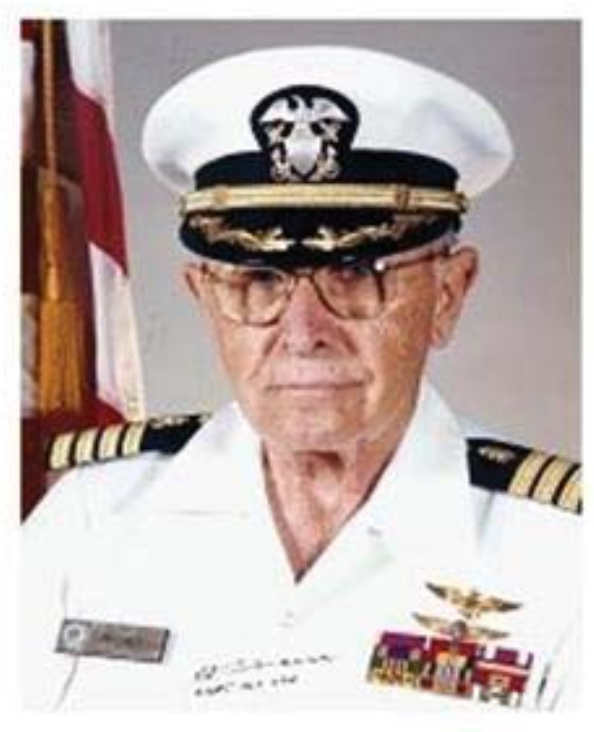

Slide 21

\section{CAPT Al Mateczun CO NAMRL}

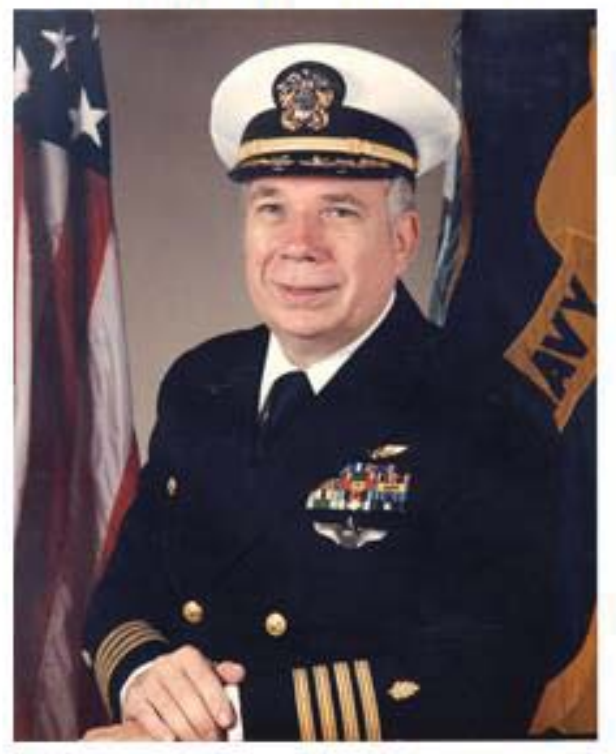

Slide 22 


\section{Dr. Ben Lawson's banquet toast to Guedry}

\section{Meetings with a remarkable man}

There's one person we haven't recognized yet, Angus Rupert. [Applause.] Only the gravitas of Fred and the charisma of Angus could have pulled this particular group together. Also, I'd like to thank Anil Raj, Casey Harris, and others who have helped to make this meeting a success.

I'd like to start out by stealing a joke from John F. Kennedy, from a speech he gave to Nobel Prize winners. My version is that this is perhaps the finest assembly of brain power in vestibular science I've ever seen in one room, with the possible exception of when Fred Guedry worked alone in his office on Moreno Street [Pensacola, Florida]. [Laughter.]

I'd like to look forward (instead of looking back), just as Fred always did, and still does (he's a man of the future) [slides 1-5]. So I'd like to send a message to the younger investigators: you're in a very young field. It has only been about 135 years that we've even knew what this thing [the vestibular organ] was for [points to ear], [while] it has been thousands of years that we've known that this [points to eye] was the organ of sight. We're at the beginning, we are at the stage where chemistry was in the Dark Ages, the stage of alchemy, the stage of looking for patterns, the stage of [having] no unifying theory, and during that stage in a science, it's very important that you get up tonight and you introduce yourself to the elder scientists because they're walking encyclopedias of information that cannot be obtained in a text book yet; [ours is] too young of a science for that, so please do that.

Now I'm going to tell you a story of two young men, myself and Fred (my part is very small). I [spent my undergraduate years] at the University of California Davis, [in] the great farm land of California (by the way I did most of my [Bachelors of Science] degree work while sitting on the women's lacrosse field in a lawn chair) [slide 6]. [Laughter.] After graduating, I went on a trip around the country with my best buddy, and when I say we went around the country, we really went around the country, 18,000 miles to different locations in a '69 Chevy van [slide 7]. We were riding in style. I got this van from a hippie in North Beach, San Francisco. I had to clean the pot smell out of it, and so forth, and we had three-on-the-tree and we were sailing in style. This van had a very advanced drowsiness prevention feature. You see, the engine was located in the interior [under a cowling between the two front passengers] and it would build up tremendous amounts of heat, so if, at any moment, you would start to fall asleep while driving, you would receive a second-degree burn on your leg and wake up immediately. [Laughter.]

The reason I tell you all this is that was the first chance I had to meet Fred Guedry and Angus Rupert, and, of course, like pearls before swine, I didn't do so. I had been around the country looking at every possible aerospace museum, aerospace this and aerospace that, and we got to Pensacola and my friend said, 'you know, there's a lab there, maybe we should drop by,' and I said, 'no let's just go to the beach.' So I avoided that opportunity and missed it completely, and it was an absolutely wrong decision for me because that evening I got to meet the red fire ants in the Deep South and got about 10 ant bites. I'd never encountered such a thing so I just kind of let them bite me and went [mildly], "oh wow, that hurt" (I did not realize how bad the pain would get moments later) [slide 8]. That same night I got to meet Pensacola's finest. We were rousted 
out of our van at 2 in the morning by cops with hands on their guns, but that's another story. So you can see, like in any great story, what happens to you when you try to avoid your fate. The Fates redirect you, the gods redirect you. [Laughter.]

The first time I actually did lay eyes on Fred Guedry was at the Man In Space Conference. I saw him walk in and all the students were kind of like [whispering] 'Fred Guedry, hey it's Fred Guedry, Fred Guedry...' He was already an old lion of our field. But unlike most old lions, he actually looked like an old lion and this is how he appeared to me [slide pops up with Fred's face on a lion] [slide 9]. [Laughter.]

Towards the end of graduate school [slide 10] I was looking for a postdoctoral fellowship, and at the time, honestly, I was probably a little bit more interested in martial arts than I was in vestibular science, but by luck, I had a karate student who told me about a poster he had seen: The American Society For Engineering Education postdoctoral fellowships in vestibular science, motion sickness, spatial orientation. You know, it was like reading my name... 'Ben Lawson, Ben Lawson, Ben Lawson,' and I thought 'oh my god, I've got to find out about this.' Then I found out Fred Guedry was there and active so I had to go check this out. So I came back to Pensacola again, this time for good [slide 11].

I met some very interesting people. There was the fellow at the front gate as we first came into the base [picture of Angus Rupert holding his vest open displaying TSAS] [slide 12], he was selling watches out there and he completely hypnotized me. He told me 'anything you want, you just send a memo to the engineers, they'll do whatever. You know, we don't want you to soil your hands,' and he was literally the energy and the life of the place. So I gave my dissertation presentation there. I was in a room with Fred Guedry and Angus Rupert, telling them about my dissertation findings, and I thought, 'It's going to be wonderful,' but it was going horribly. I was mortified because one of the people in the room, we won't say who [points at picture of Dr. Rupert], fell dead asleep while I was speaking. I thought that was a very bad sign for my future [slide 13]. [Laughter.] Fortunately, one of the other people in the room [indicates Fred] was fascinated and perking up. This was not even a particular area of specialty for him but he was showing a tremendous amount of enthusiasm and excitement about it, which is something that really impressed me. I will say that he's more excited by new information than most people I've ever met.

As a postdoctoral fellow, I thought, 'now I've got my degree, not only should I have things to learn, I should have things to teach as well, so I'll teach my perspective,' and it was wonderful because I was completely wrong [slide 14] [shows picture of tiny Ben standing next to huge legs of giant Guedry]. [Laughter.] This is pretty well how the situation was (this would be the Guedry and Lawson) and I had a lot more to learn than I had to teach, so it was quite overwhelming, really. Now, in order to understand why that's the case (why I had so much to learn, why this other person knew so much more), you need to go back with me in time, going in the Way Back Machine to a time when laboratories looked like laboratories [slide 15], back when scientists looked like scientists [slide 16], back when another man graduated from college and he also got to go on a very interesting graduation trip [showing slides of Guedry's Navy service, slide 17]. He also saw a very interesting poster (I imagine for WWII recruitment) and went to many “interesting" places. He had a very interesting graduation trip, he got to stay in some really 
interesting places [slide 18], he got to have some very exciting times [slide 19], and he got to meet some very interesting people [Kamikaze pilot, slide 20]. When he came to the laboratory here [in Pensacola], there was a brand new device that he helped to bring online [slide 21]. [There were] great toys to play with. There was a new toy that was about to be built, something with incredible capabilities [slide 22]. And he was actually here, at this laboratory, at the moment [Bob] Kennedy learned where the problem of space sickness lies [slide 23].

He ran a lot of subjects, some with better fashion sense than me [slide 24], he collected a lot of data, he wrote a few papers (a few hundred) [slide 25]. He kept some administrative personnel quite busy [slide 26] and he began to win honors (small honors, medium sized ones, large ones) [slide 27]. He even got inducted into the Rat Pack [slide 28]. Now, is that a slick looking dude or what? He helped to build his own devices, not just for science, but to help keep people from dying [slide 29]. And you might say he became indispensable, and one of the awards for his indispensability was to occasionally have his leave rejected [slide 30]. [Laughter.]

I'm honored to have been part of that same laboratory and to have crossed paths with him and Angus Rupert and so many other people [slide 31]. We had some wonderful memories [slide 32]. There were a few awkward moments that we all just tried to get through somehow [slide 33], and there were a few bad eggs [slide 34]. But overall, we had a unique perspective [slide 35], and we enjoyed some very high times, and through it all, our spiritual leader was Guedry, like Theseus, who entered the labyrinth and discovered its secret [slide 36]. It's no coincidence that the labryinth was created by Daedalus, the Father of Aviation. It's no coincidence that when Galen [of Pergamon] looked upon this strange thing in the head [the vestibular apparatus], he said 'it's a mystery to me, it's like a labyrinth.' But Theseus [Guedry] led us in and he led us out again. He was a man of vision, and still is [slide 37]. He said the following words: "NASA is particularly concerned about the maintenance of proper research atmosphere, which is a problem in many service-connected research activities, and I have gathered that the services may be losing considerable budgetary support because of this one item." Now, what you may not know is that he said that in his acceptance letter to Ashton Graybiel before he'd even arrived here [at his new job in Pensacola].

He was stellar in every respect, and is stellar today [slide 38]. He was always very stellar as a Chief Scientist, a Division Director, and the PI [principal investigator] of multiple projects. There's only one place he was criticized, he just didn't measure up — only one area: division administration. This is one of his performance evaluations: 'Dr. Guedry is an invaluable asset to the Navy as a scientist but is not our best administrator. He has neither the interest nor the time to do this effectively.' [Laughter.] I wonder why?... I wonder why? So, you can imagine that he wanted to improve in that area and you can imagine that of all the honors and achievements, probably some of his proudest ones were these types of achievements that he made. This [slide 39] is his certificate for having completed 12 hours of instruction in performance appraisal and setting performance standards.

Now, I'd like to leave you with some "quotes" from Fred [slides 40-41]. I put the word quotes in quotes because they're not literally quotes, they are things I remember him repeatedly saying and I paraphrased, so I apologize if I got the words a little off: 
- I thought I was starting to learn about motion sickness when he said, 'Motion sickness is too complicated.' Well, that was quite a thing to learn, coming from Fred Guedry.

- Regarding workplace politics, he said something along the lines of, 'Don't worry about that stuff, let your work be the wall that defends you.' That's excellent advice for anyone.

- In 2007, when I had the honor to drive to New Orleans [and back] with him for the AsMA conference, I had about 9 hours of uninterrupted conversation (a privilege) and it was a tough year and he said, 'Don't worry about setbacks, just keep moving forward and stay in the game.'

- Regarding human subject safety, he said 'Safety committees get wrapped up in administration at the expense of real safety,' and that can happen sometimes.

- Regarding journal reviewing, this is a very important lesson I learned: 'Don't find reasons to reject something, find reasons to accept something, as long as there is something in there that someone could use. If there's nothing in there that anyone could use (some data, a new approach, a new measurement), then reject it.' I've created my own corollary that I teach to every student: The easiest thing in the world is to criticize someone else's mediocre study, the hardest thing in the world is to do your own damn mediocre study. So go out and do your own damn mediocre study!

- My personal favorite [Guedry quote], and the highest compliment he ever paid me, 'Relax, I was almost as clueless as you when I first came here.' [Laughter.] And if you consider where he came from [Fort Knox as the head of a large research department], that actually was a very high compliment.

Now, I'd like to leave you with three rules [slide 42]. I would say they're my rules that I would view as Fred's. He never expressed [them explicitly] as rules, but he showed by his example the rules that researchers should live by.

Number one is to 'Doubt everything, question everything, probe everything, but don't be shy about arguing your position, either.' It's not like you're going to automatically [abandon a] position, you have to be moved out of it. [This is] something he shares with Wilhelm Wundt, by the way. Wilhelm Wundt zealously guarded the fundamentals of his position, and that's ok.

Number two: 'Be passionate, stay curious and excited about new information, don't ever get jaded and think you've seen it all.'

Number three: I think probably the most important is to 'maintain a sense of urgency.' We're trying to get something done here. I know this is the government, but we want to get it done before the sun becomes a red giant. But, the race also does belong to those who keep running, so you also have to pace yourself a little bit. 
Those are rules I think would be excellent for anyone to live by and my fondest hope is that my own sons can live by those rules. These [slide 43] are two of my boys with their science projects. I'm not so sure about the other one [shows slide of sleeping child]. [Laughter.]

So with that, I conclude my toast to Fred Guedry and Angus Rupert, and thank you for being here [slide 44].

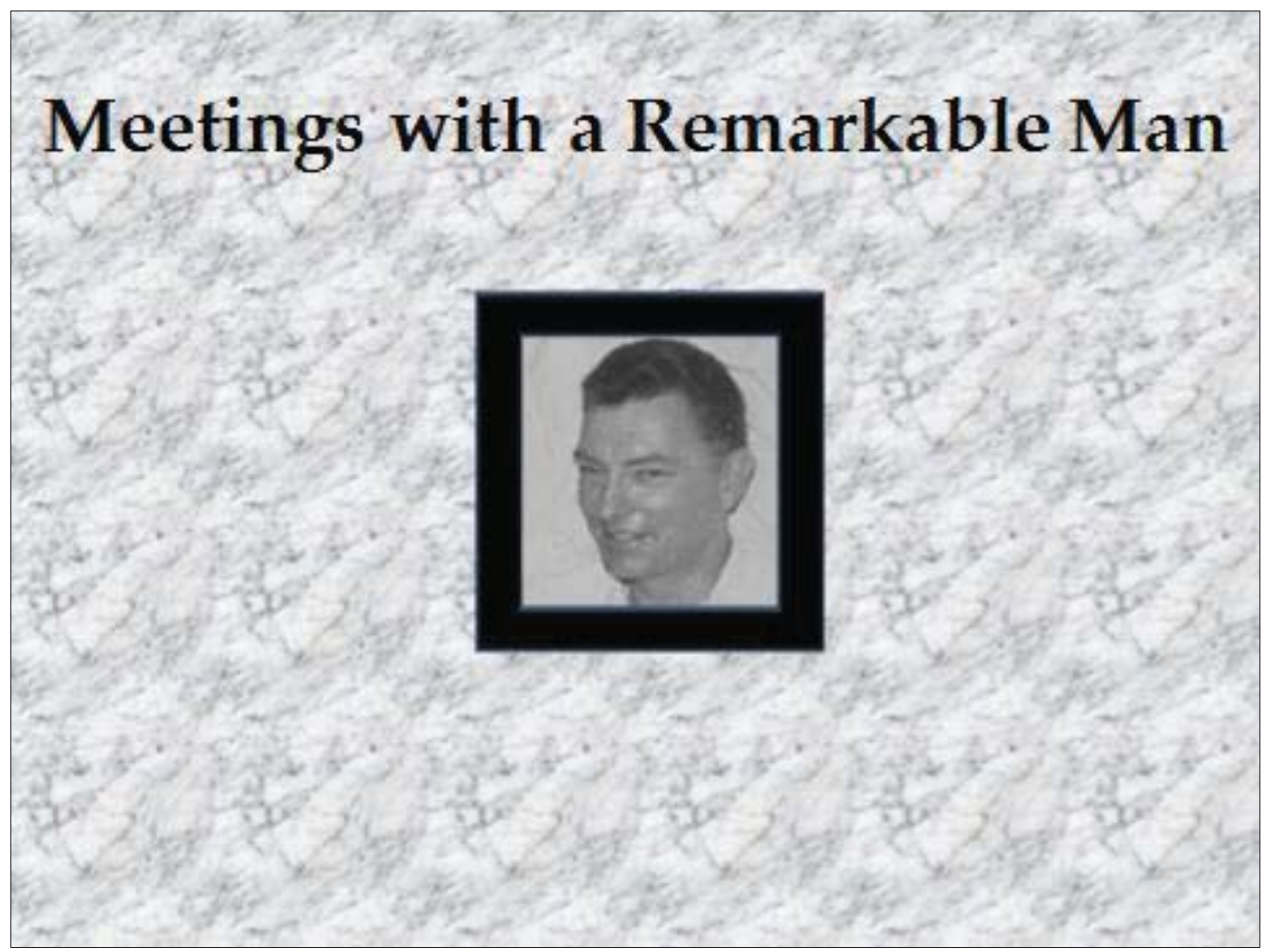

Slide 1 


\section{Meetings with a Remarkable Man}

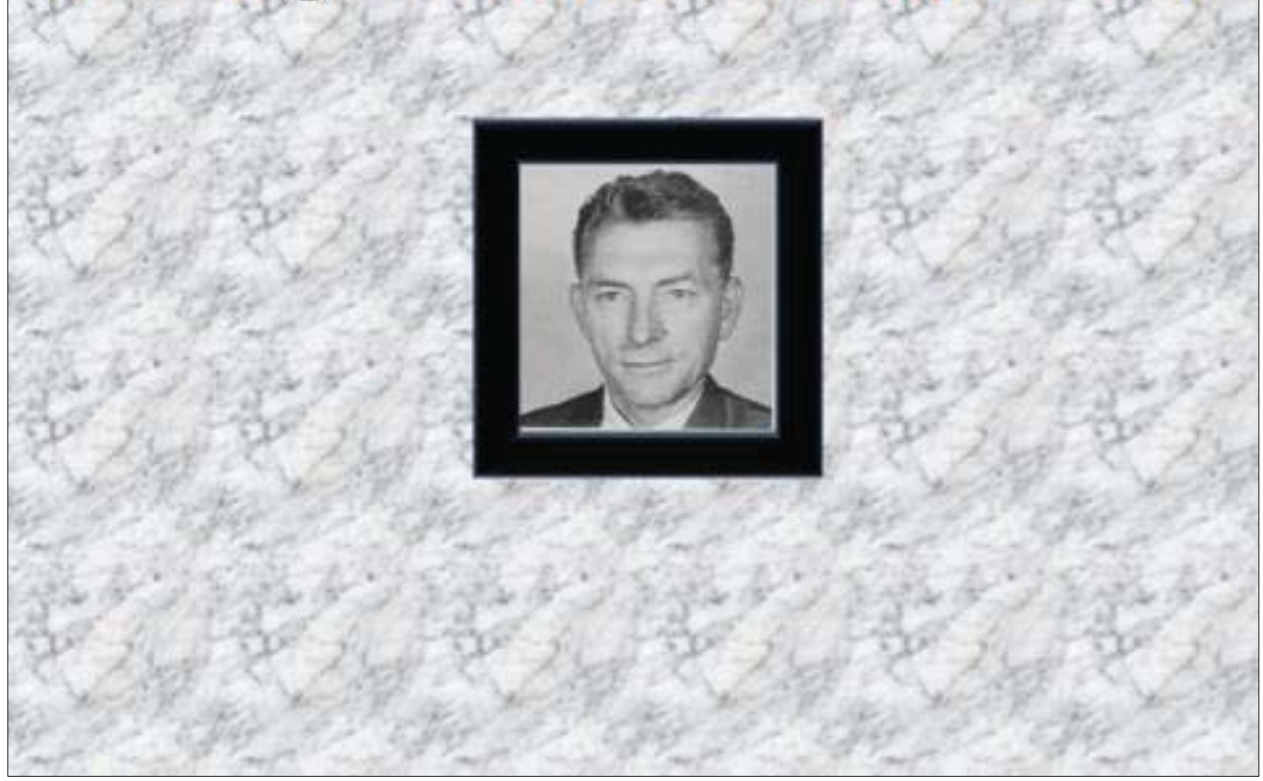

Slide 2

\section{Meetings with a Remarkable Man}

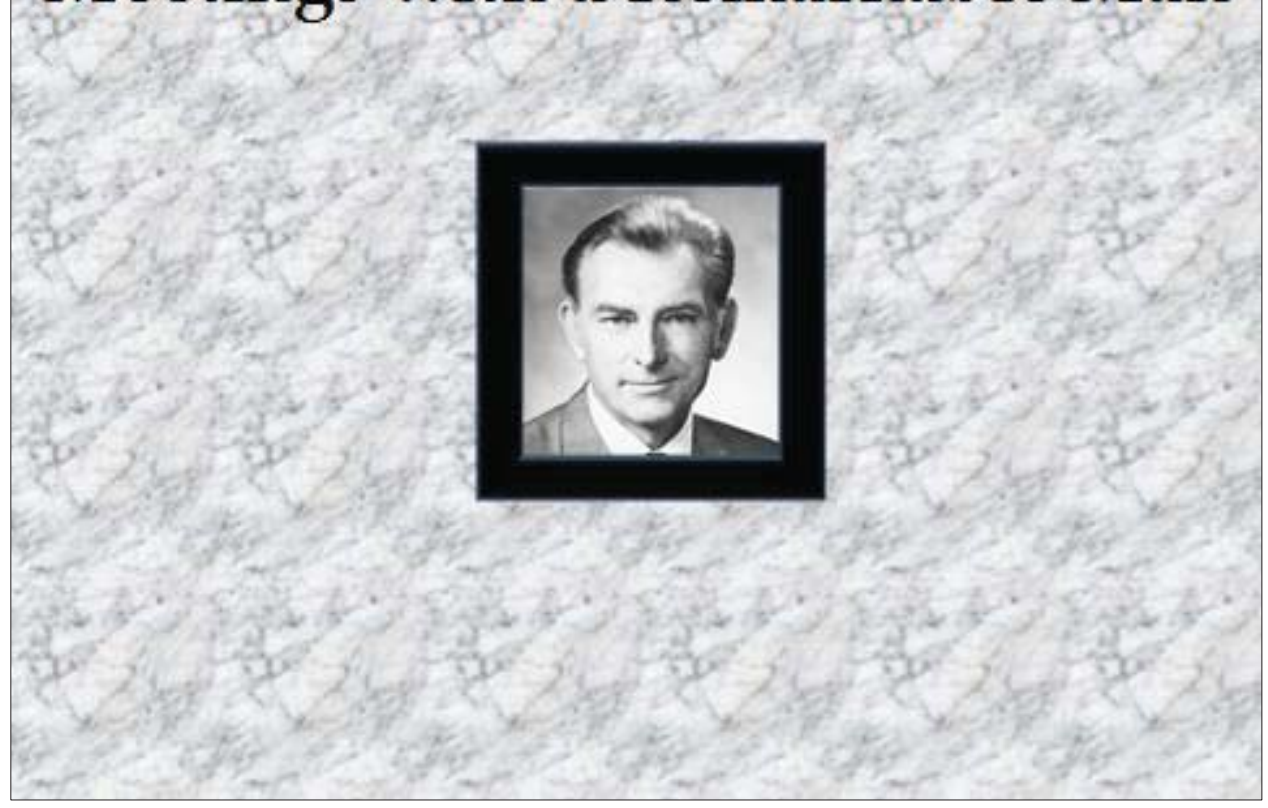

Slide 3 


\section{Meetings with a Remarkable Man}

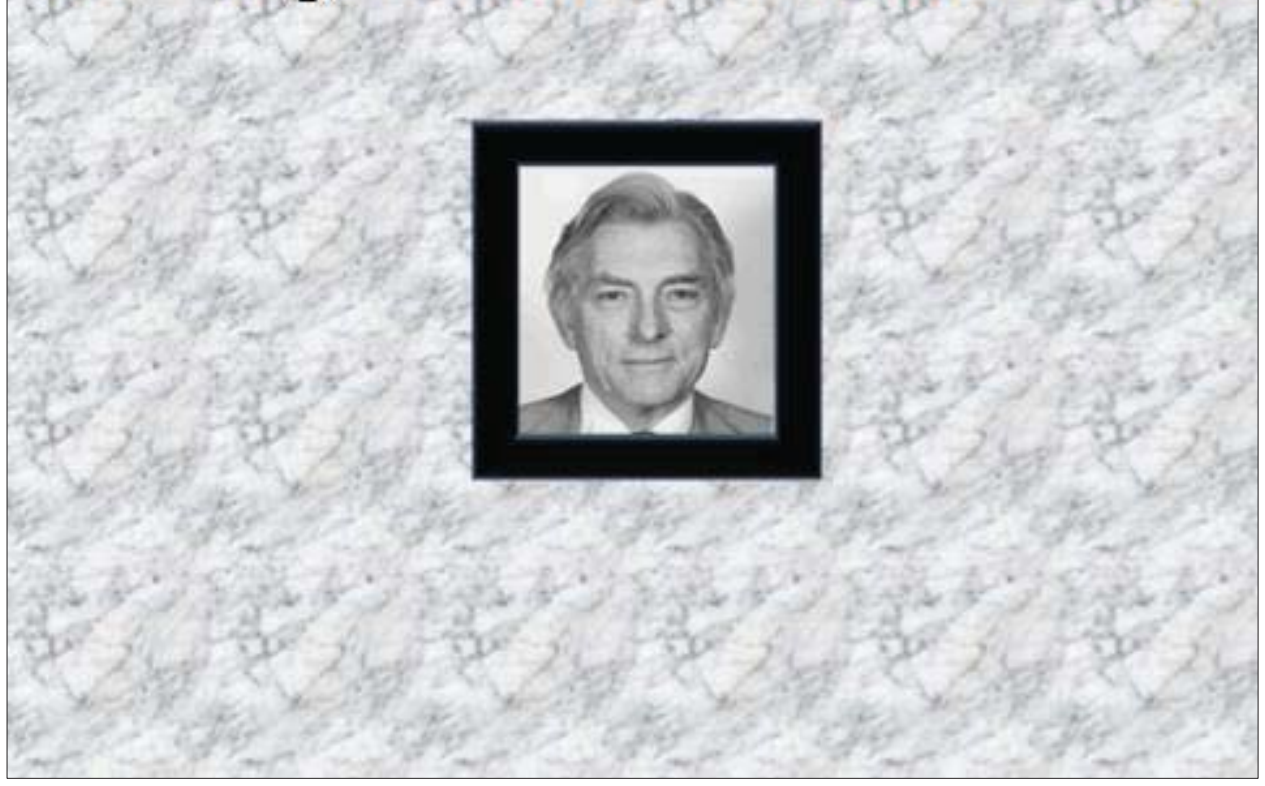

Slide 4

\section{Meetings with a Remarkable Man}

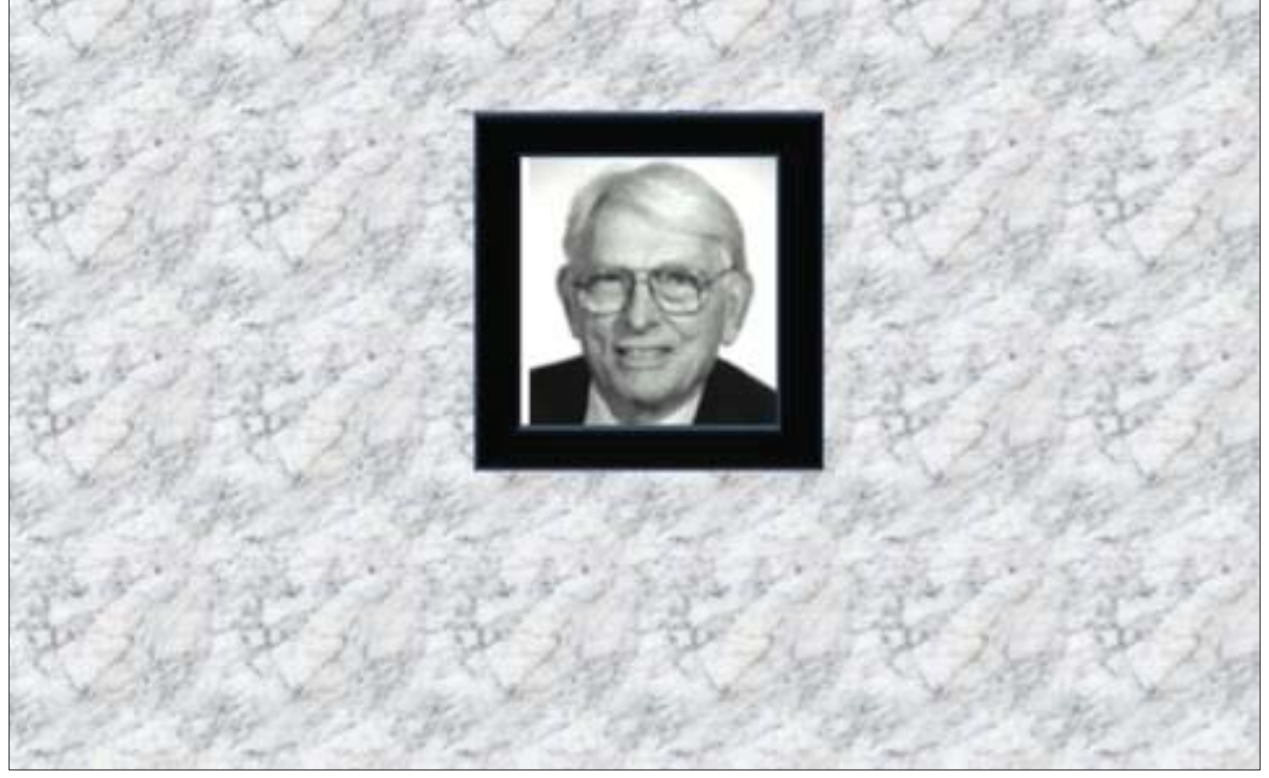

Slide 5 


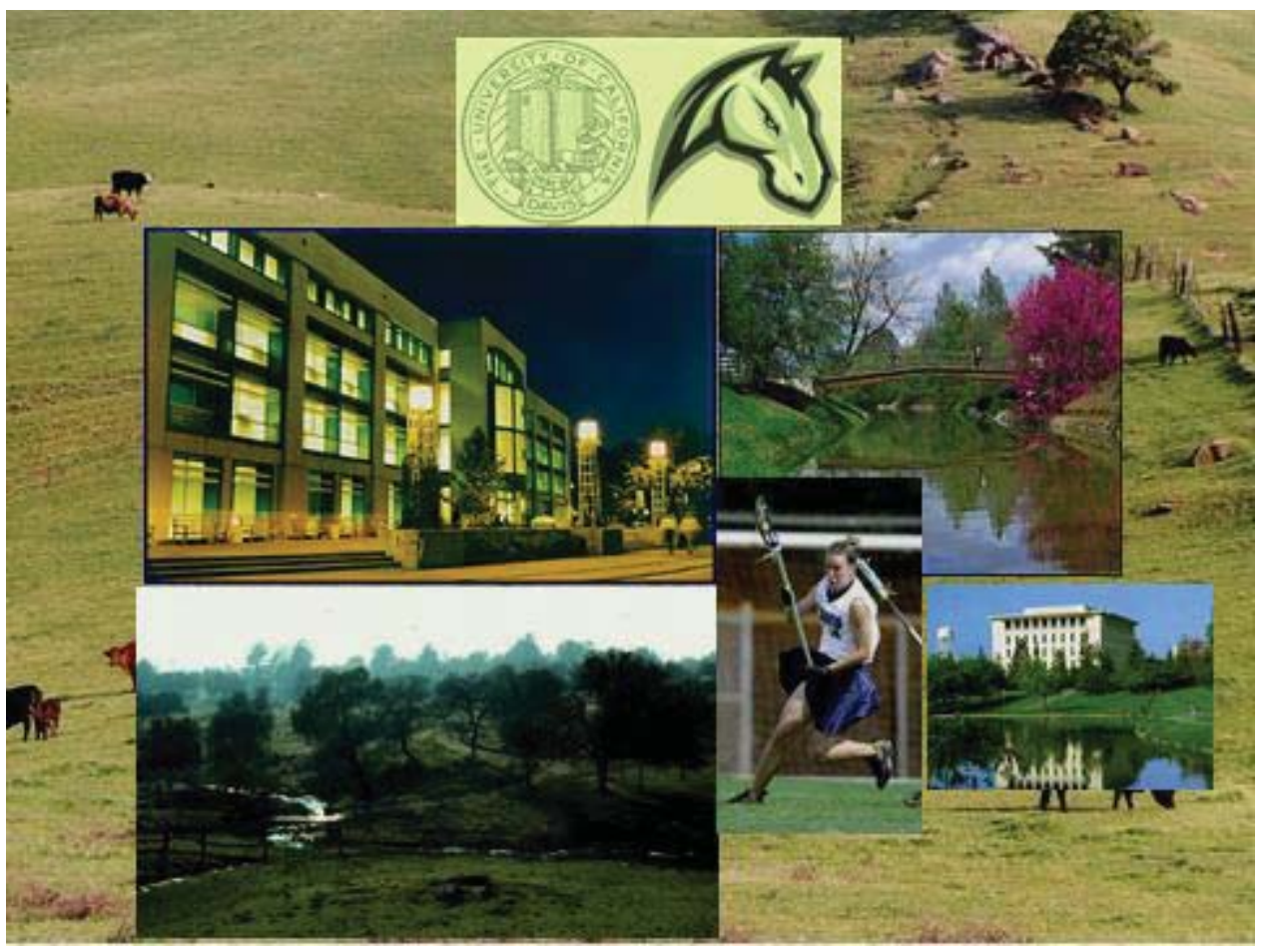

Slide 6

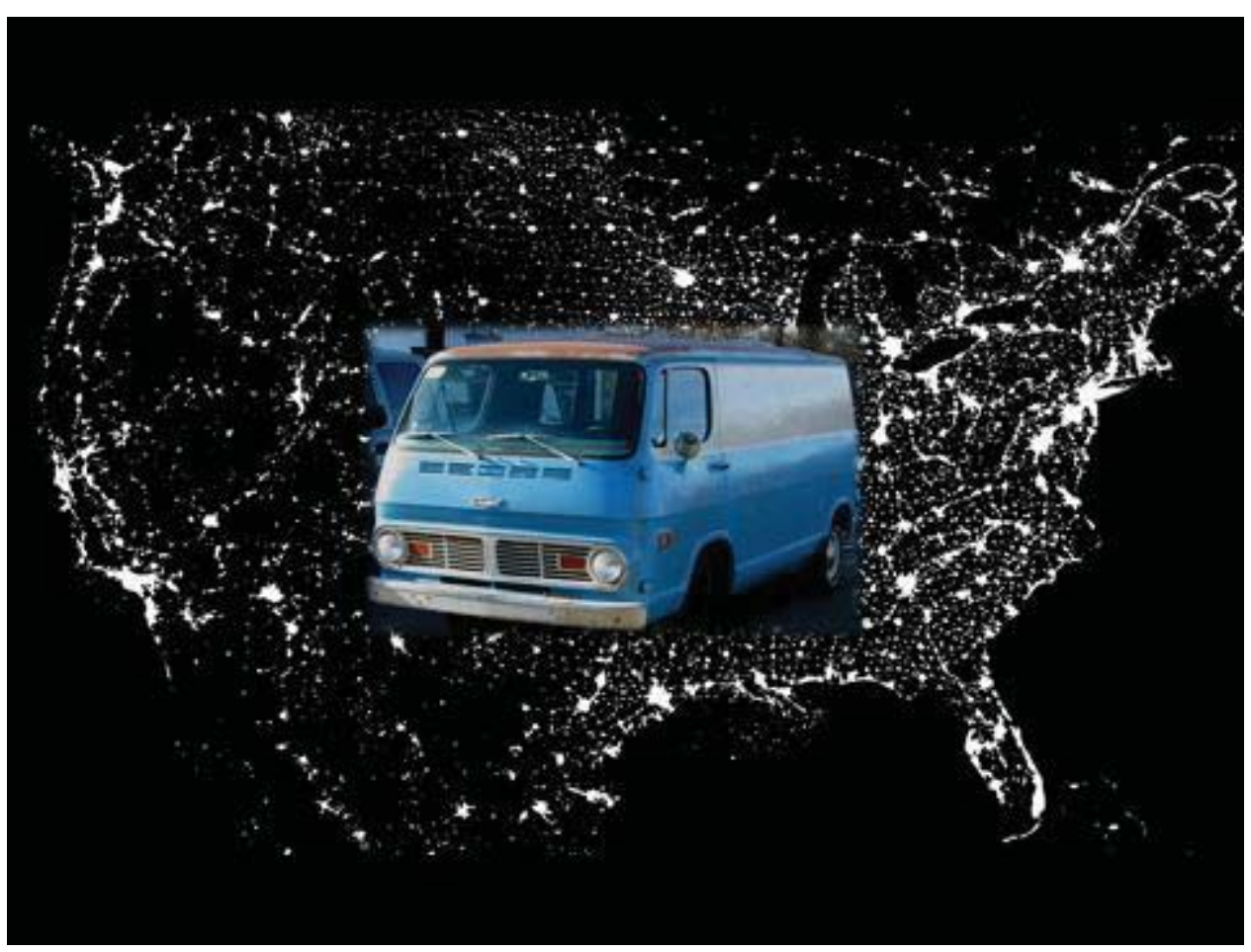

Slide 7 


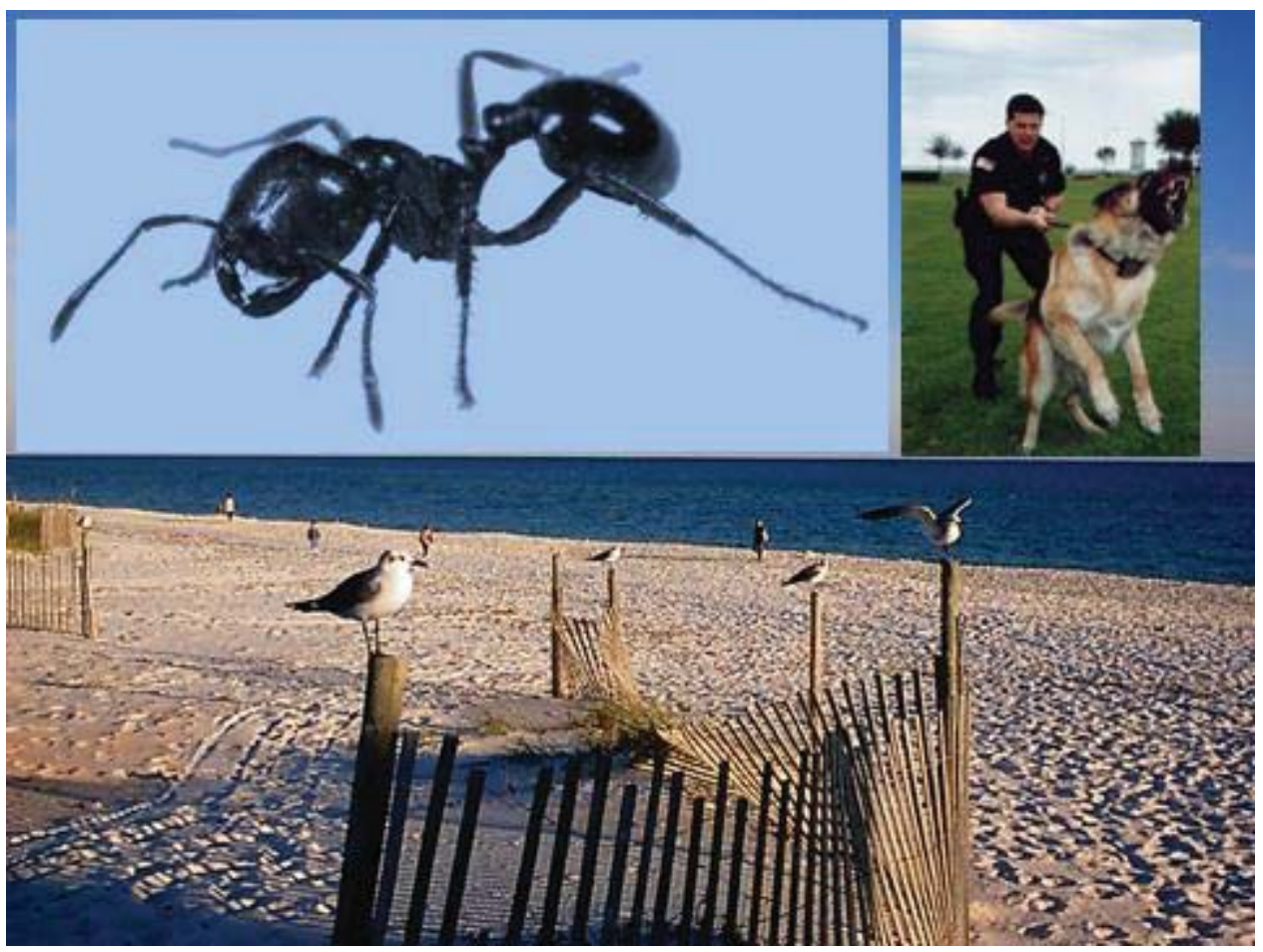

Slide 8

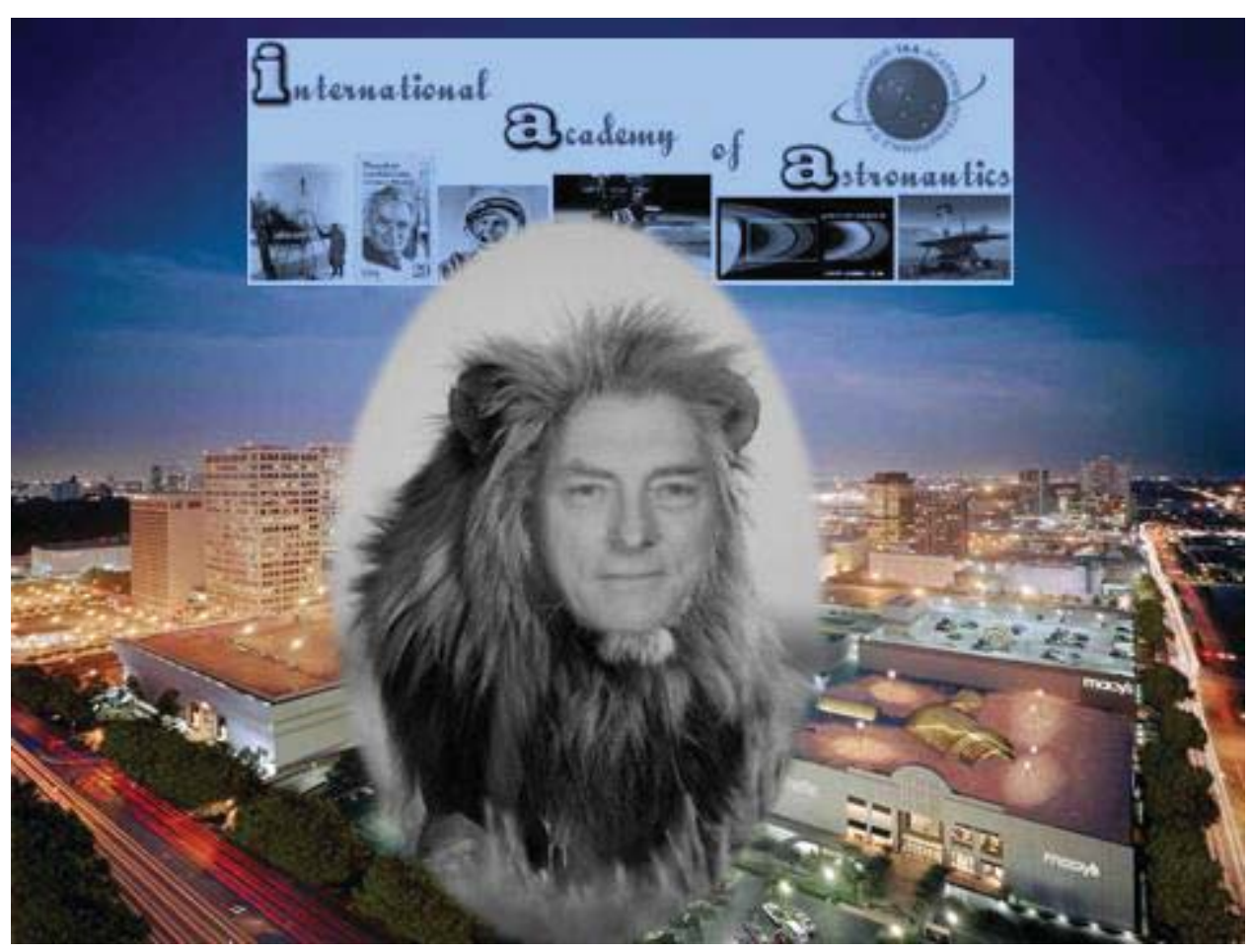

Slide 9 


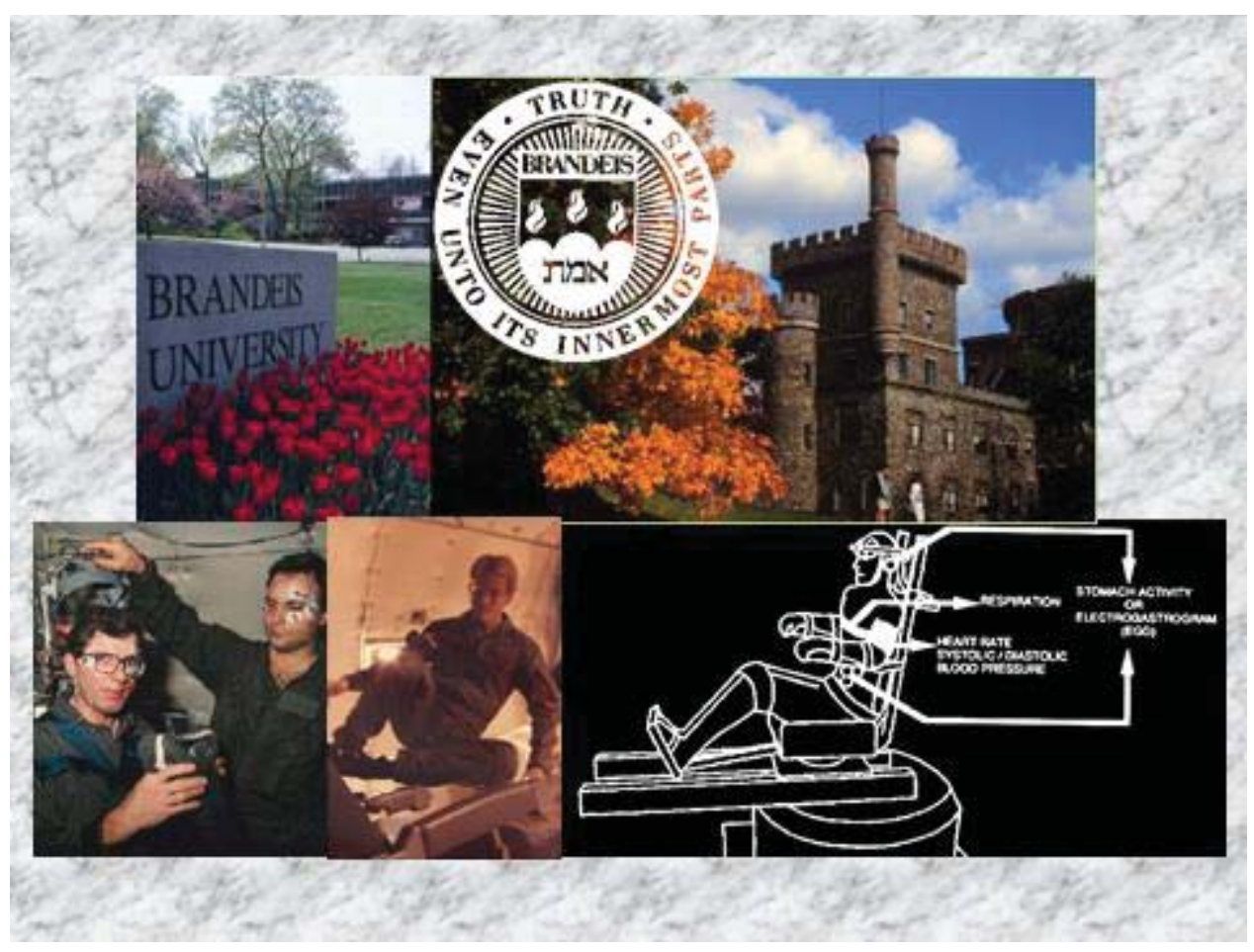

Slide 10

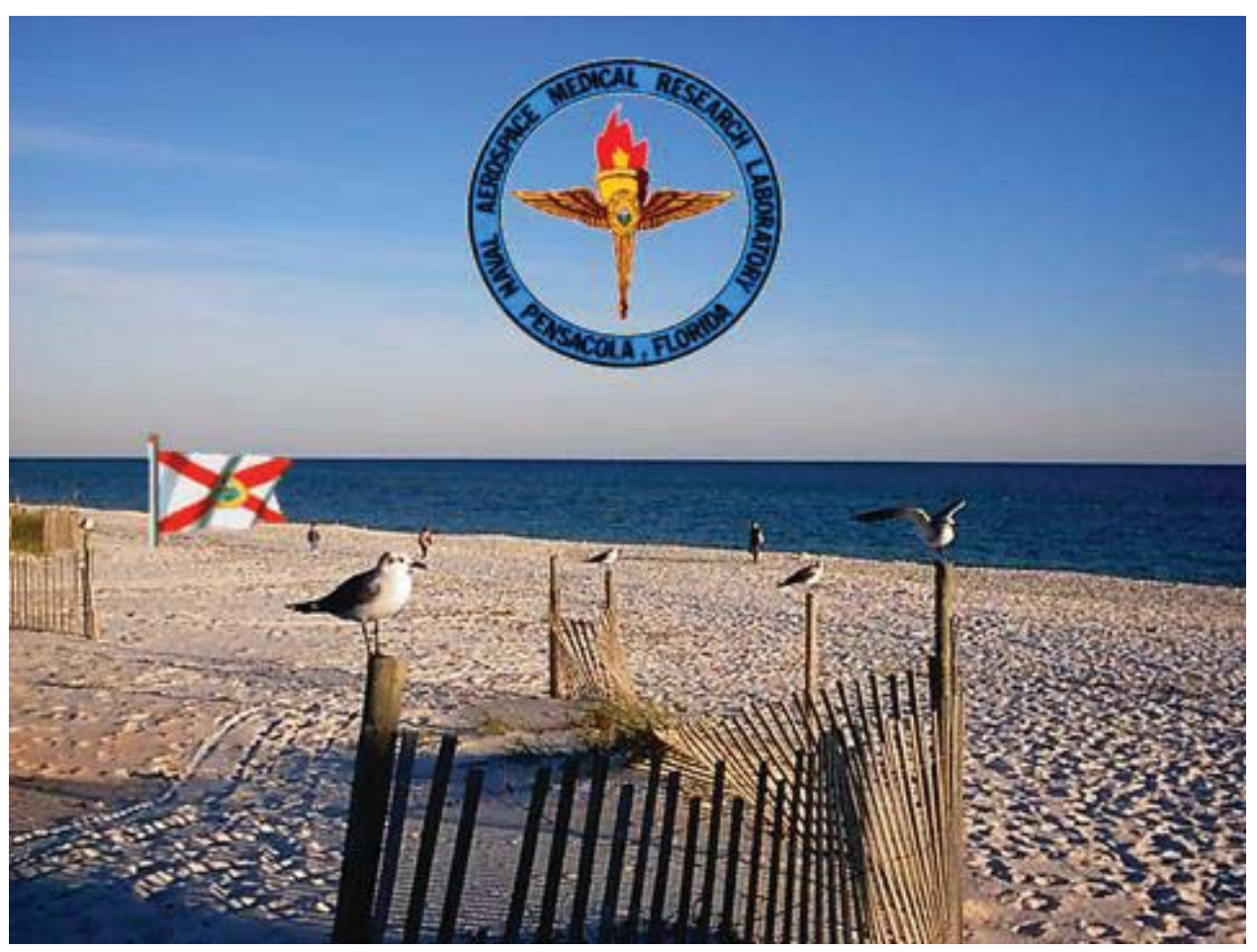

Slide 11 


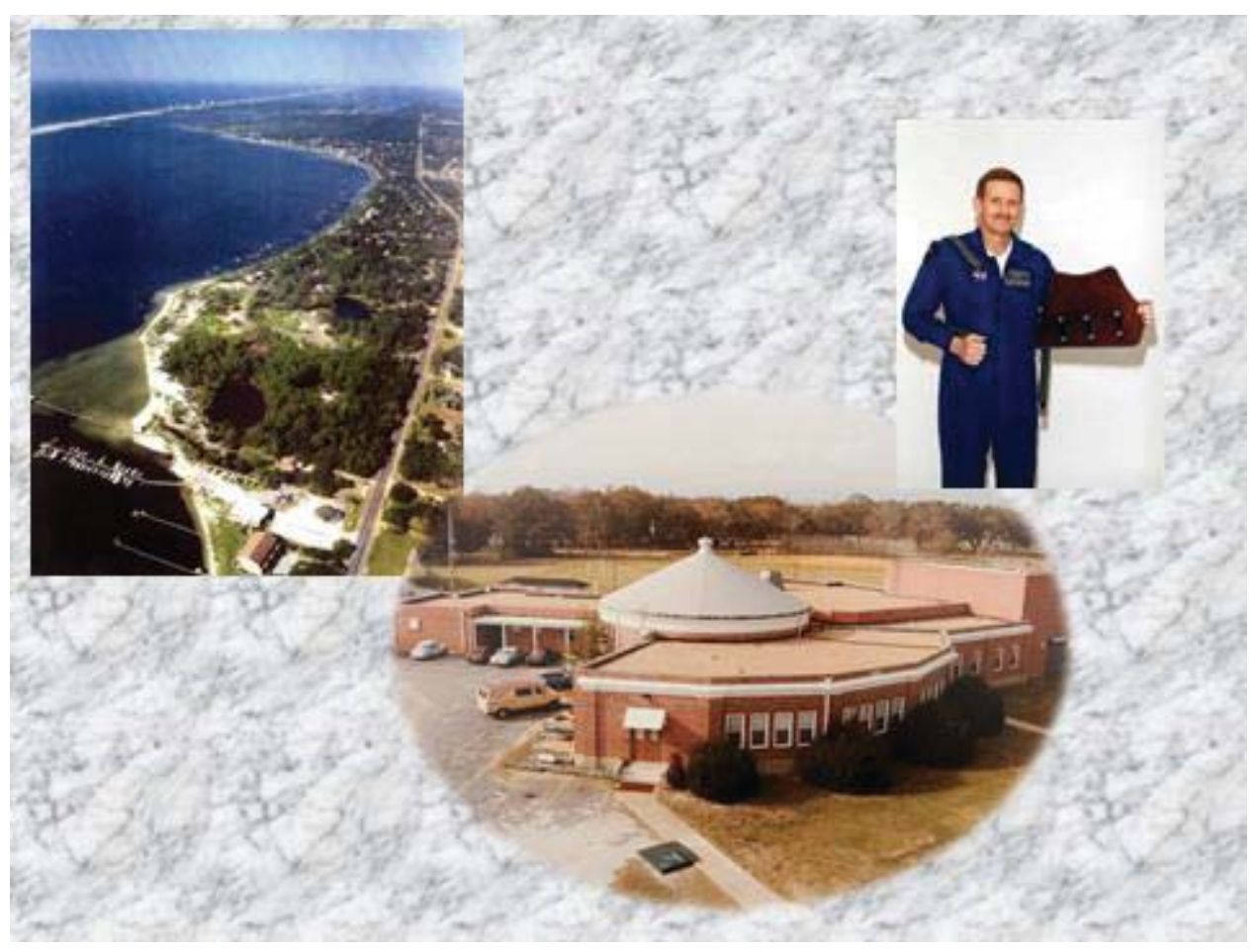

Slide 12

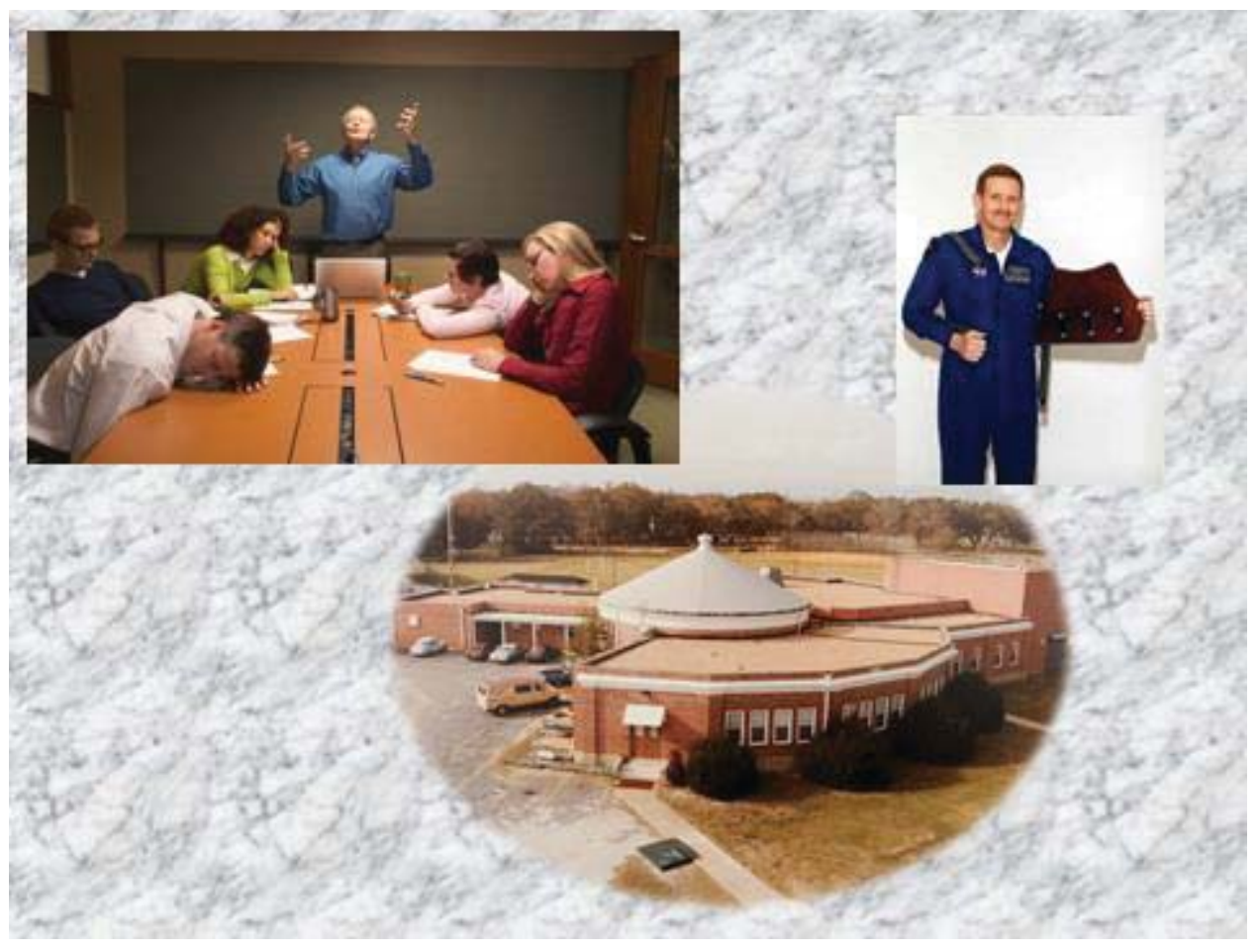

Slide 13 


\section{Things to Learn, Things to Teach...}

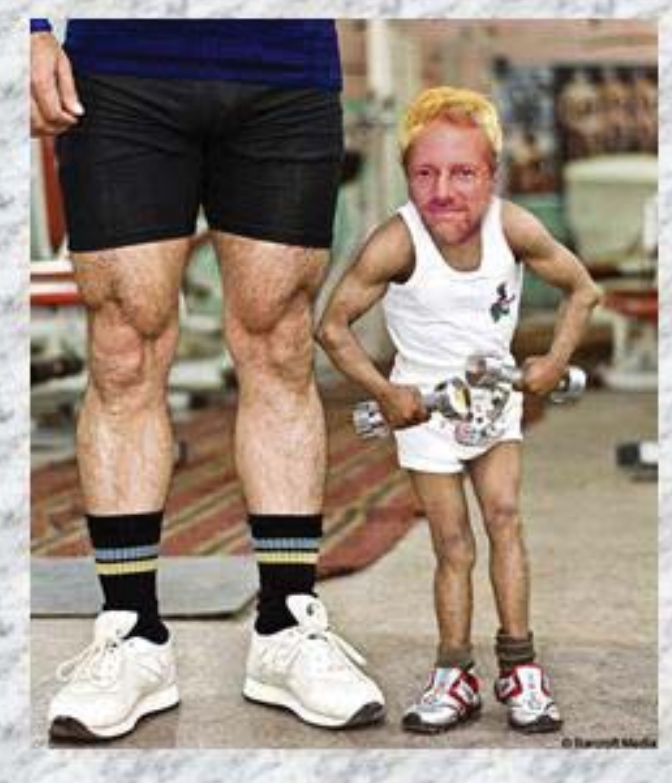

Slide 14

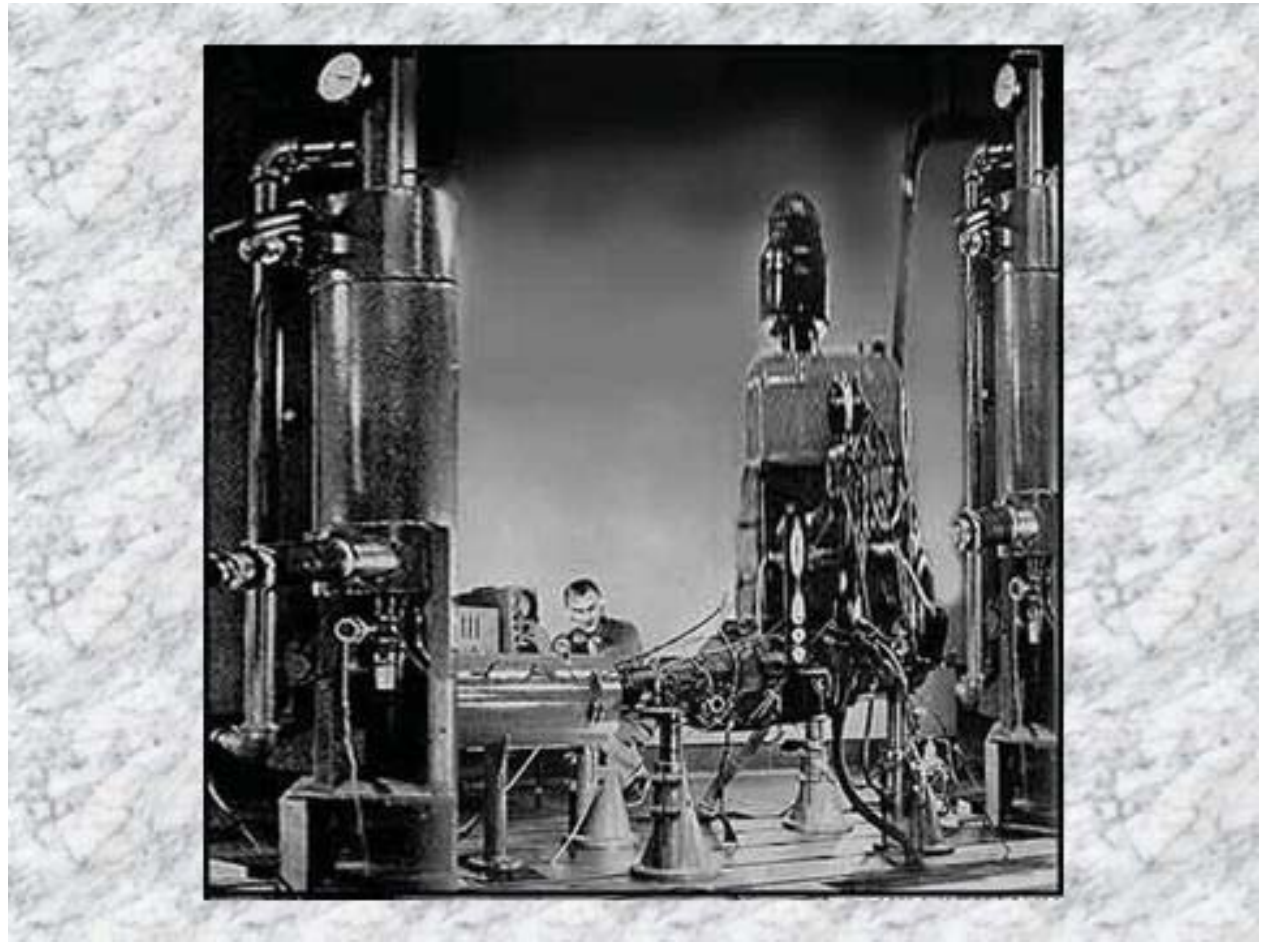

Slide 15 


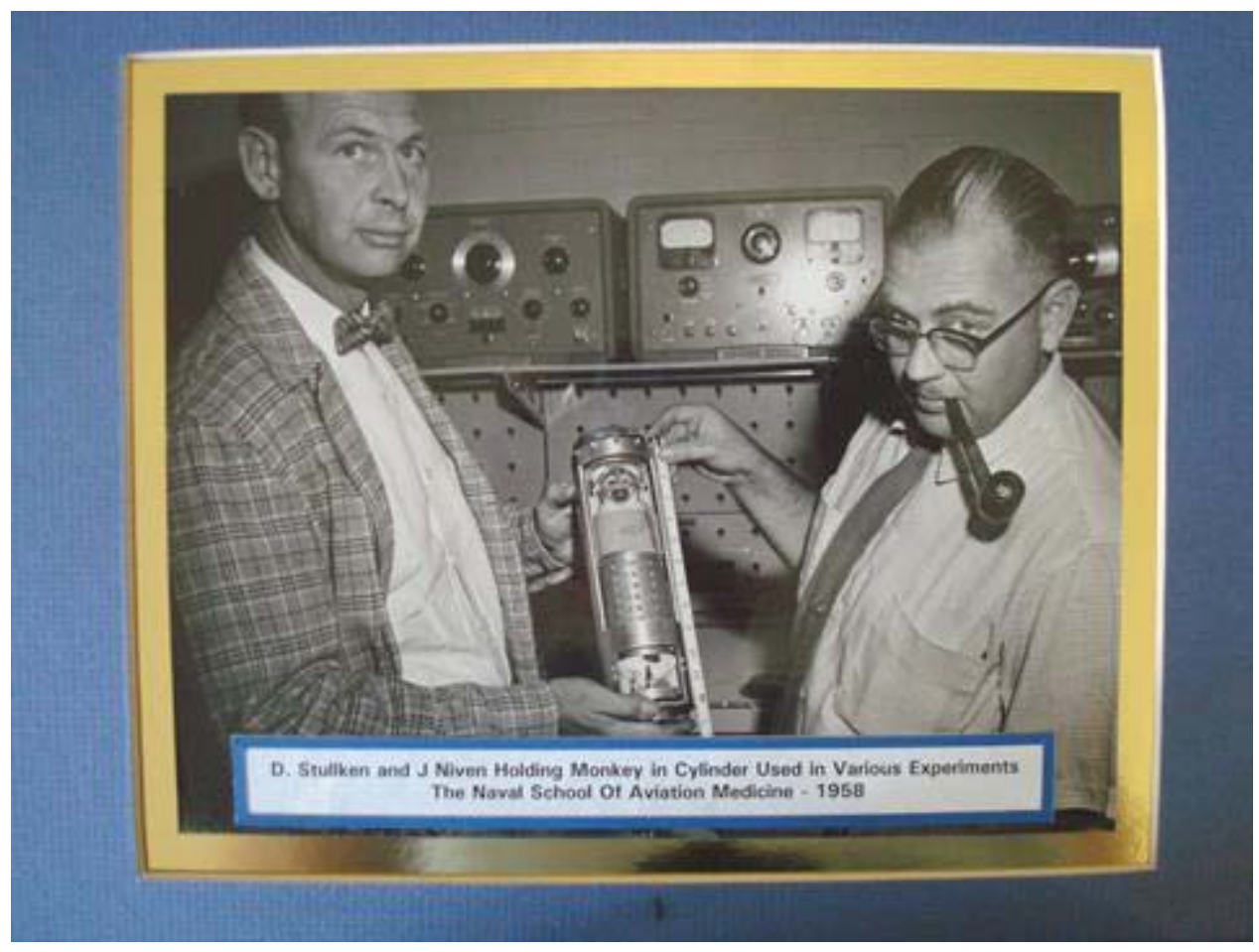

Slide 16

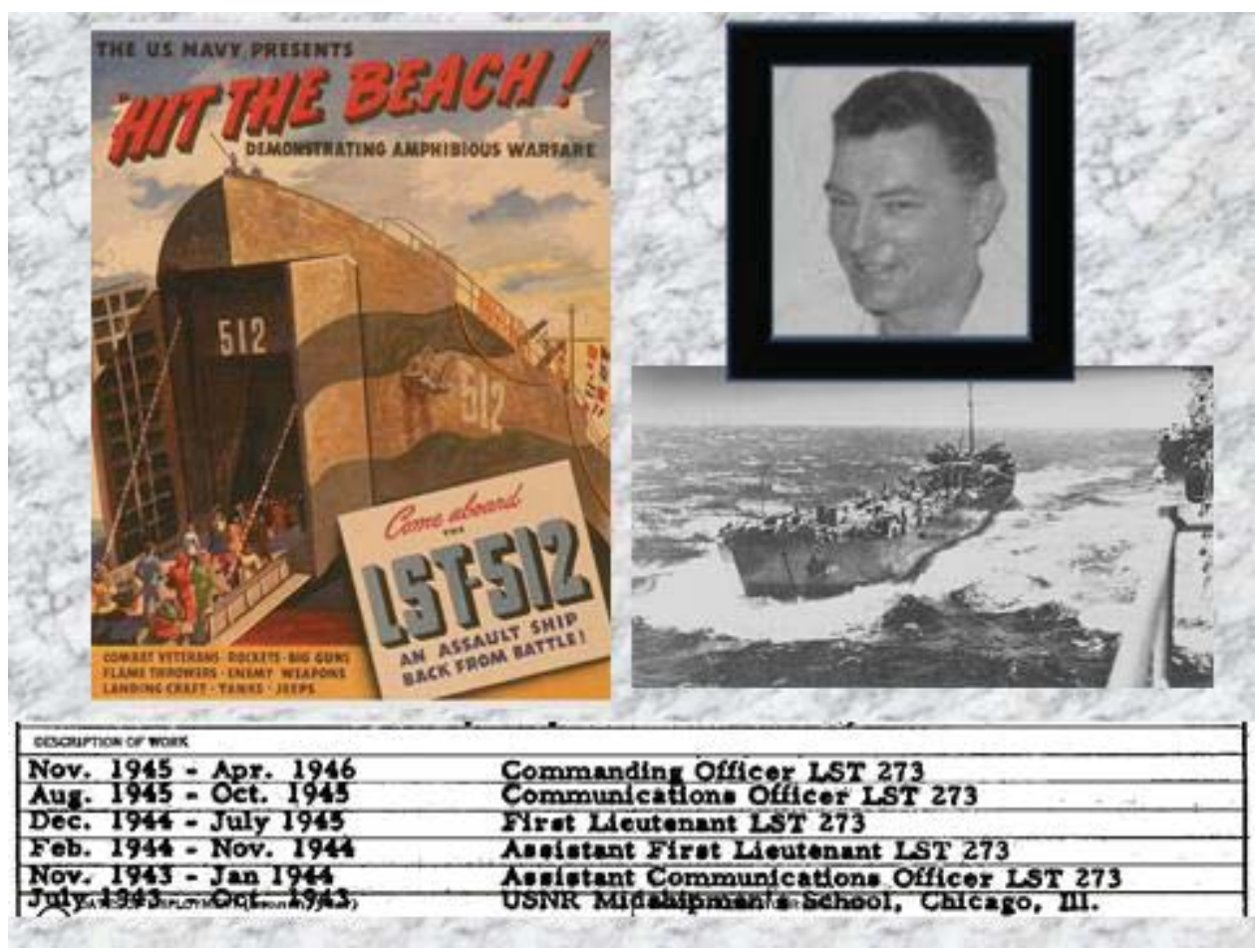

Slide 17 


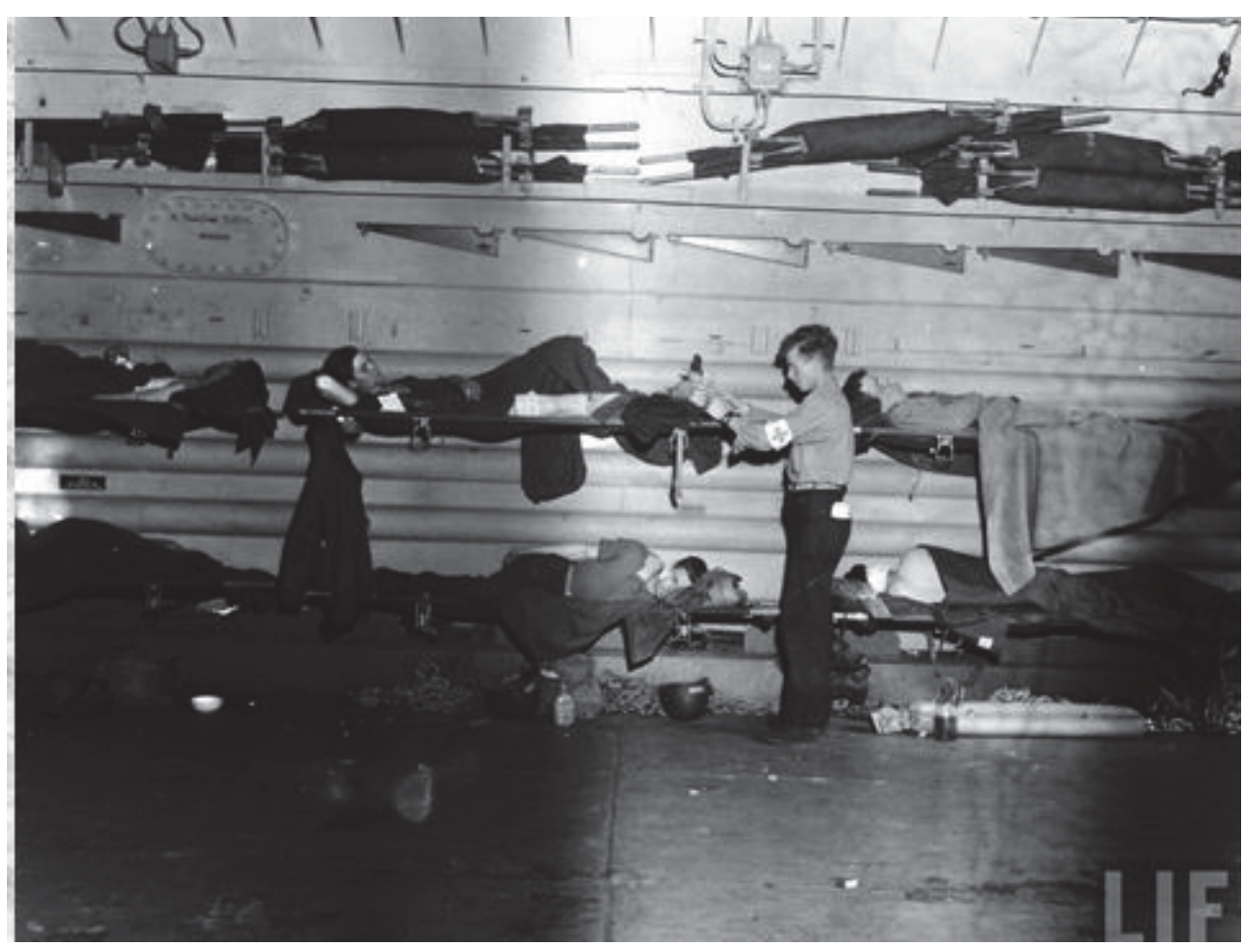

Slide 18

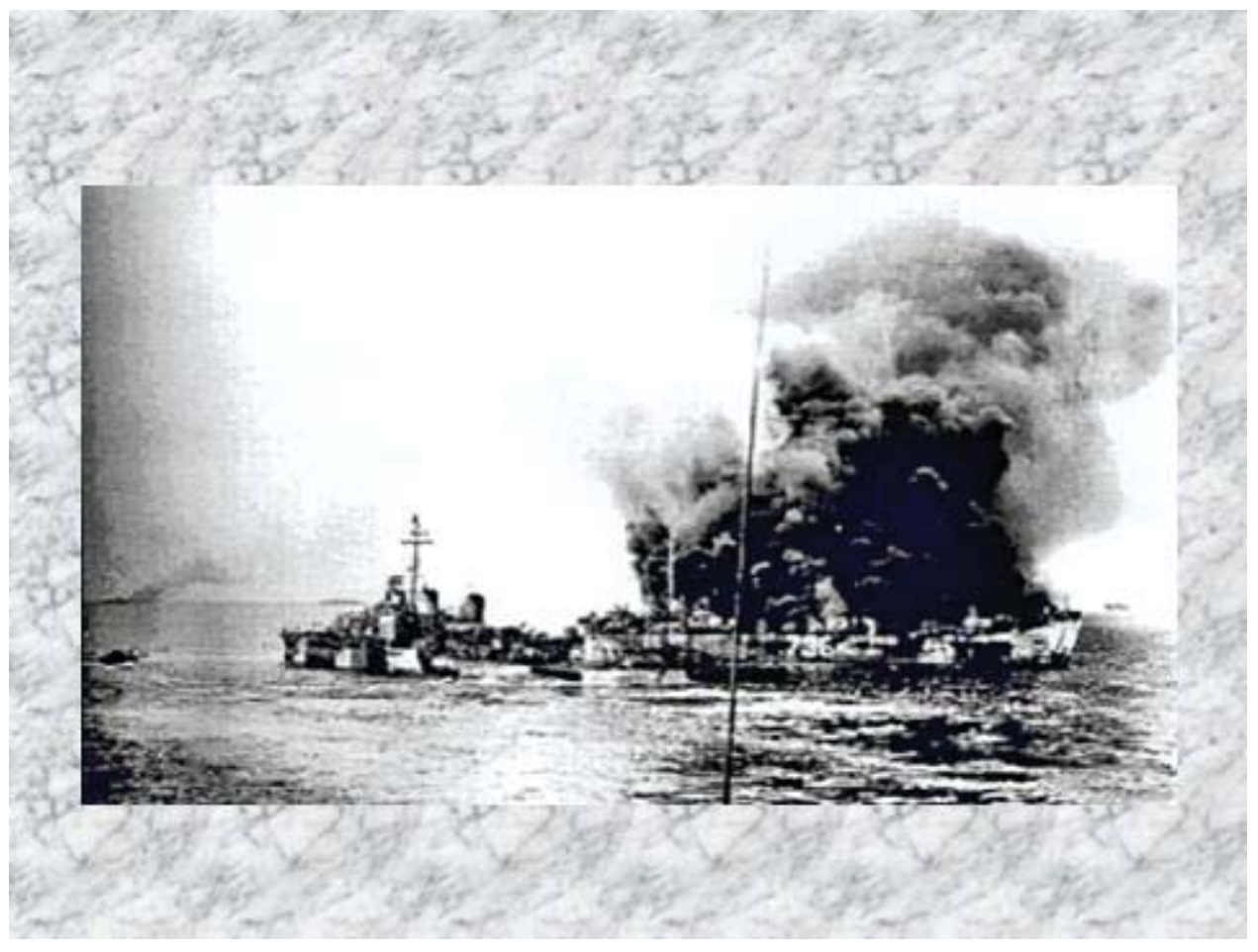

Slide 19 


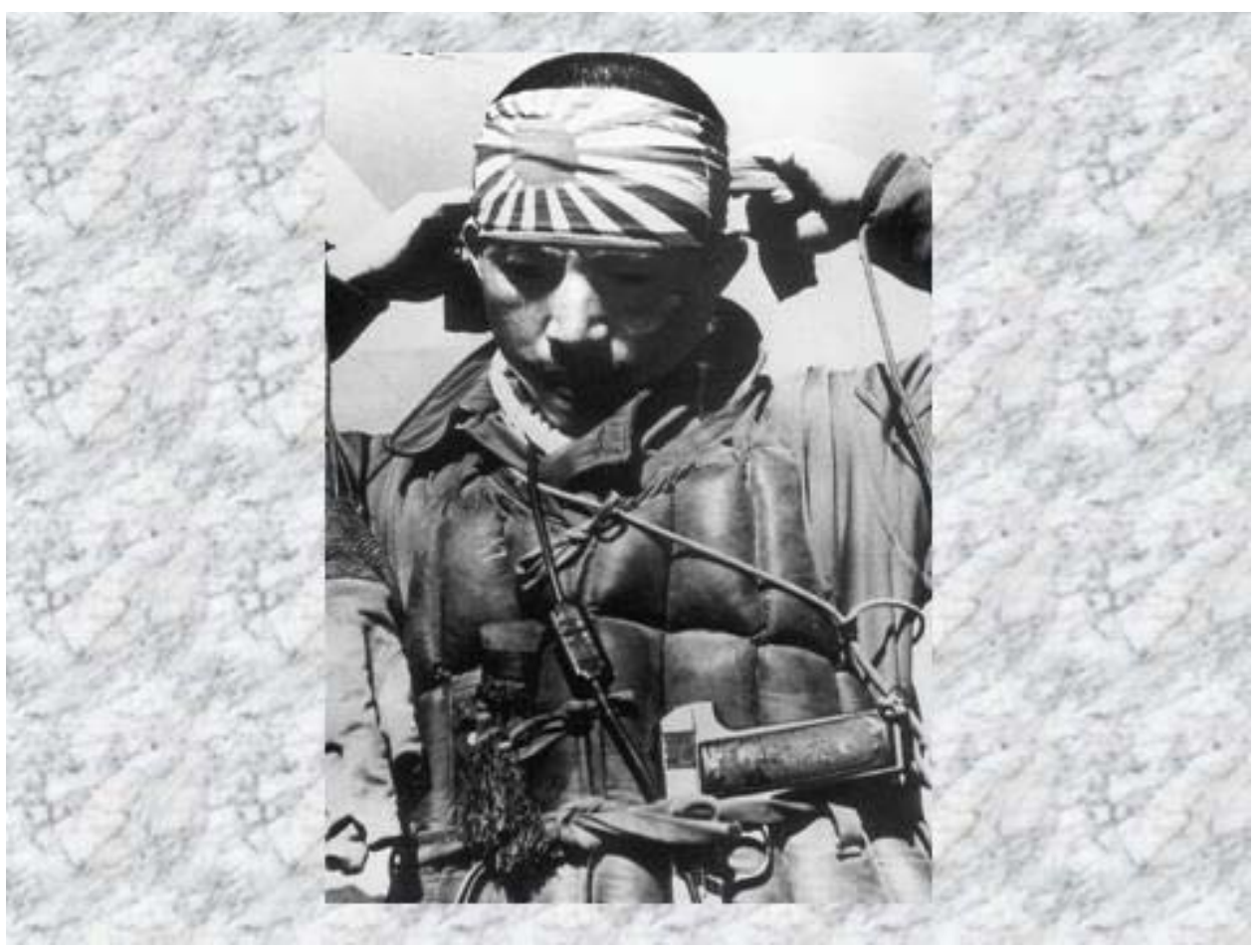

Slide 20
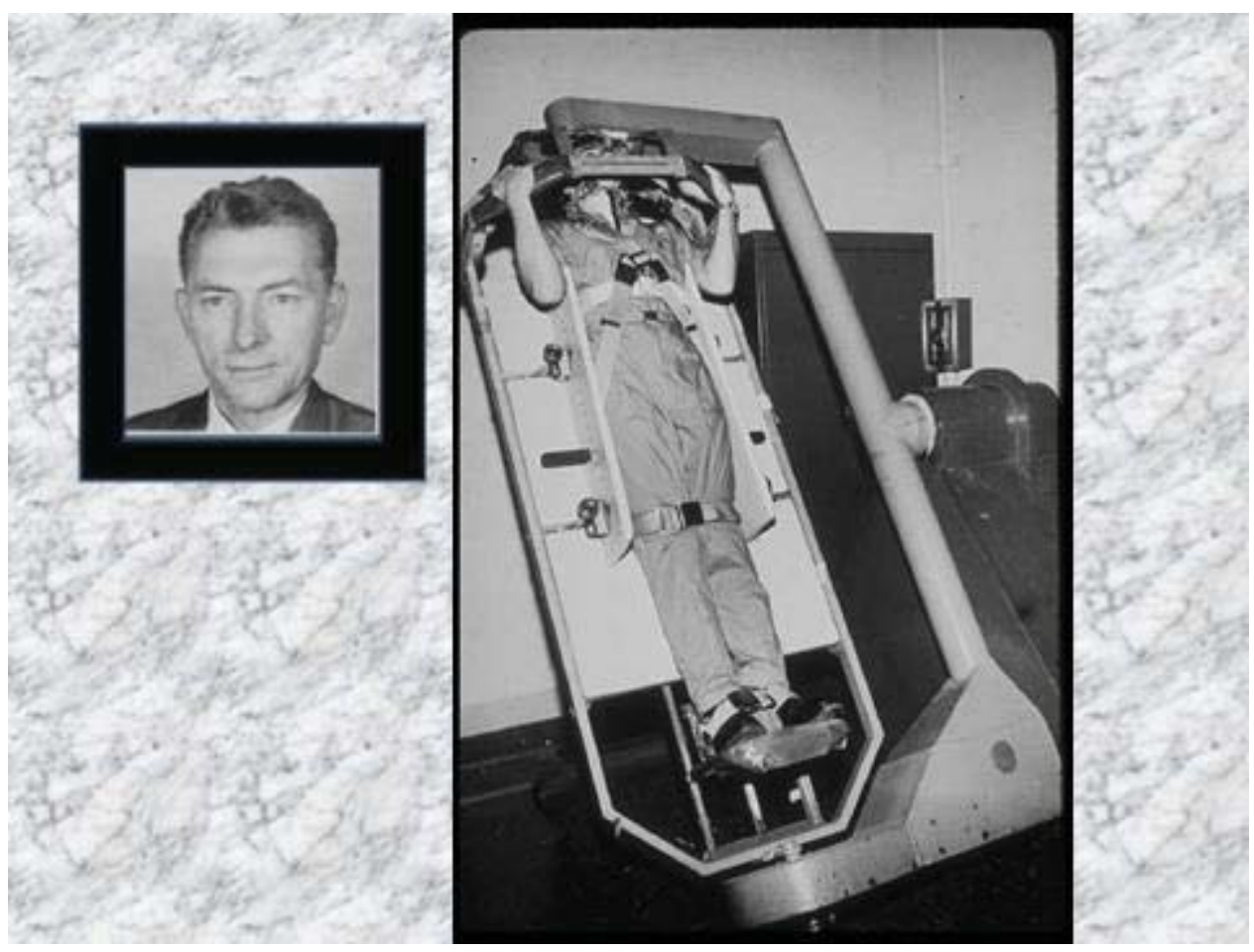

Slide 21 


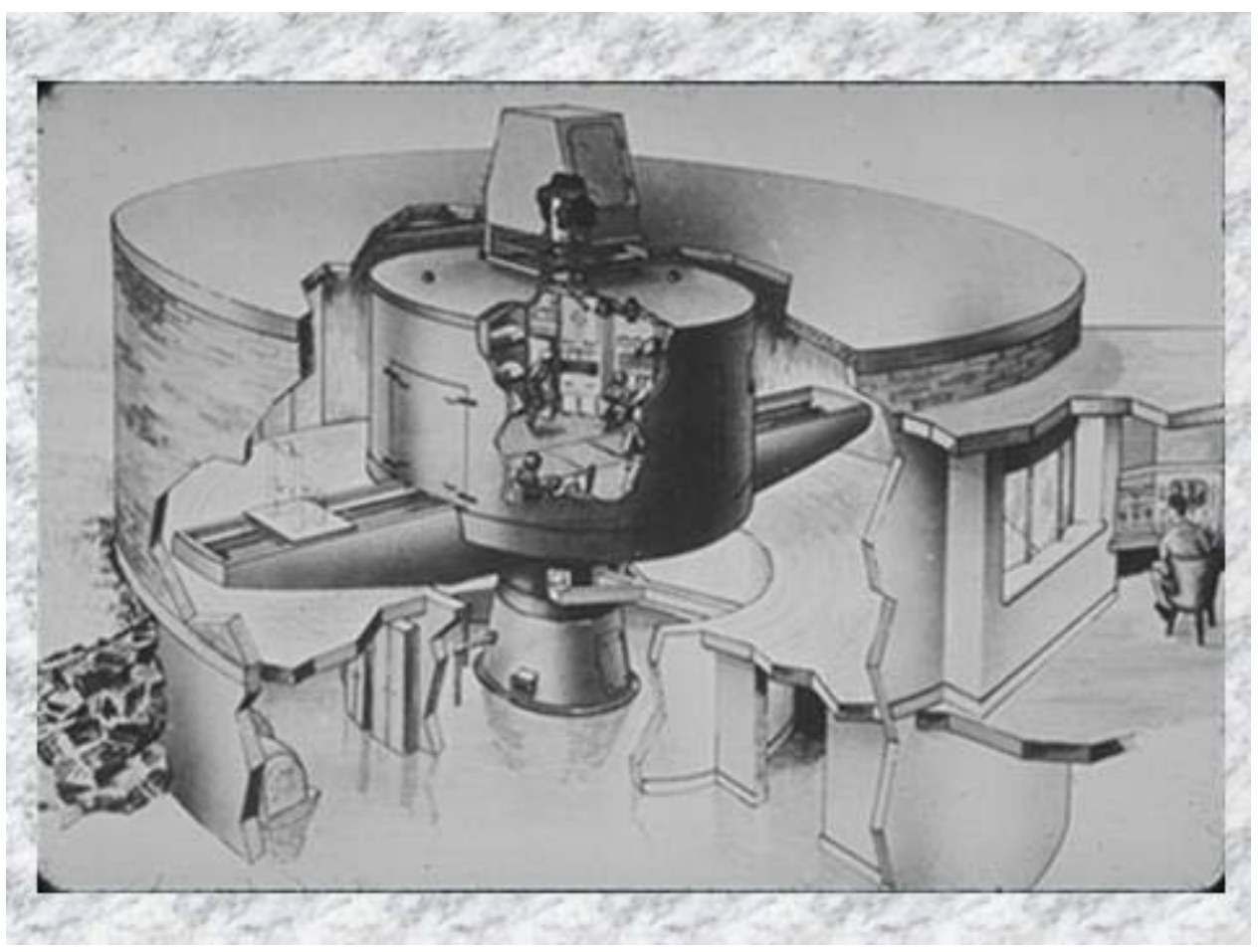

Slide 22

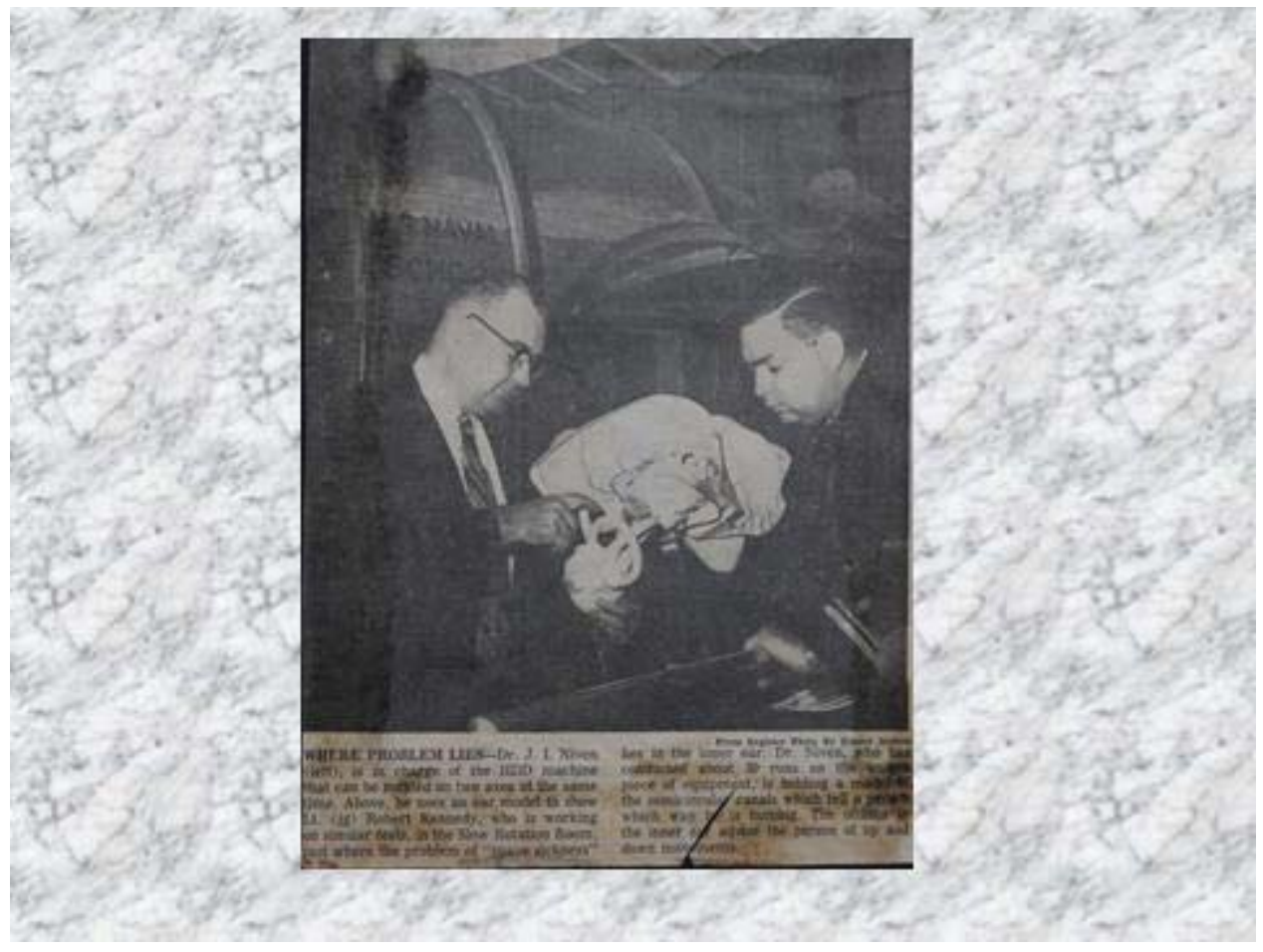

Slide 23 


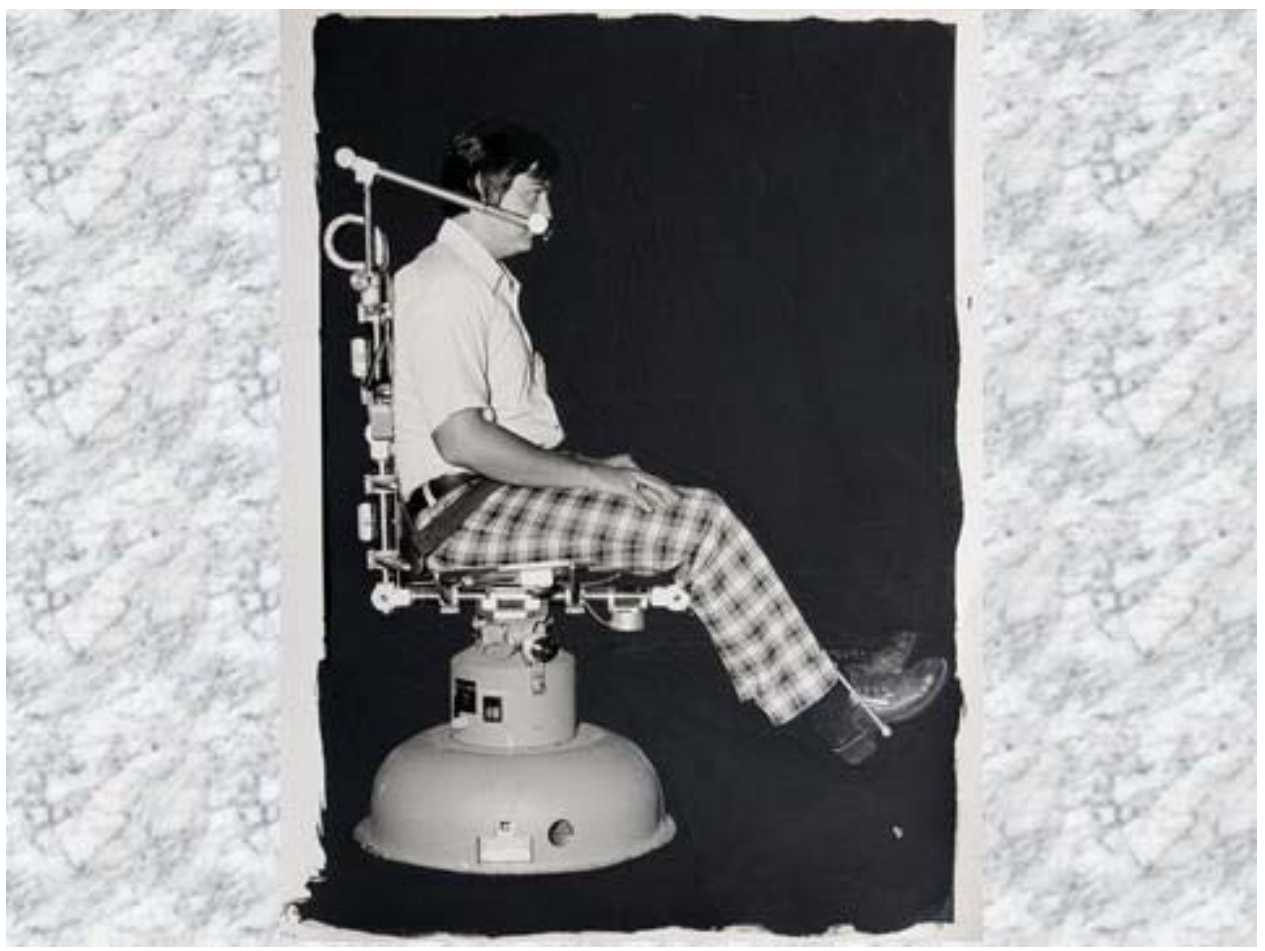

Slide 24

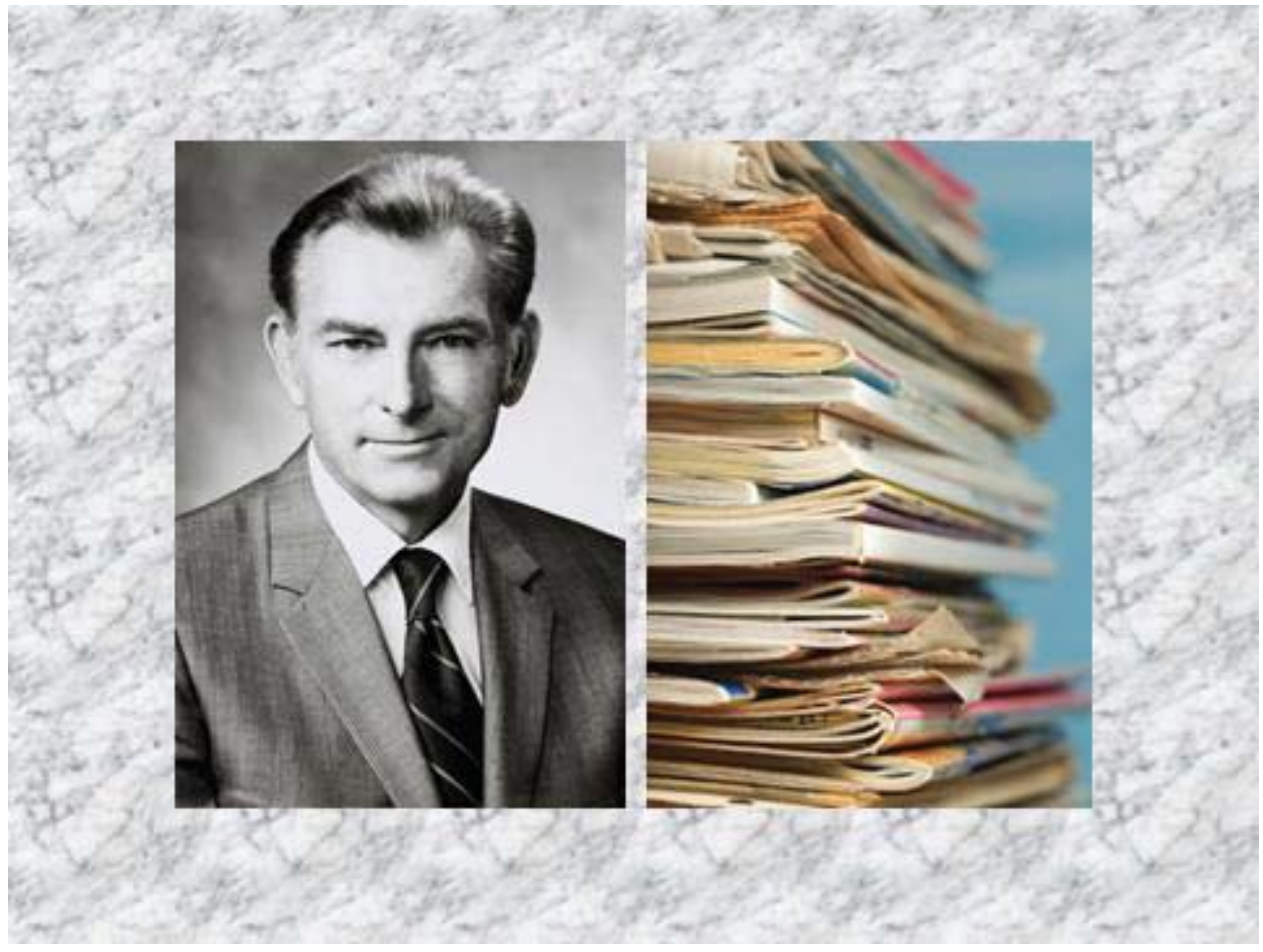

Slide 25 


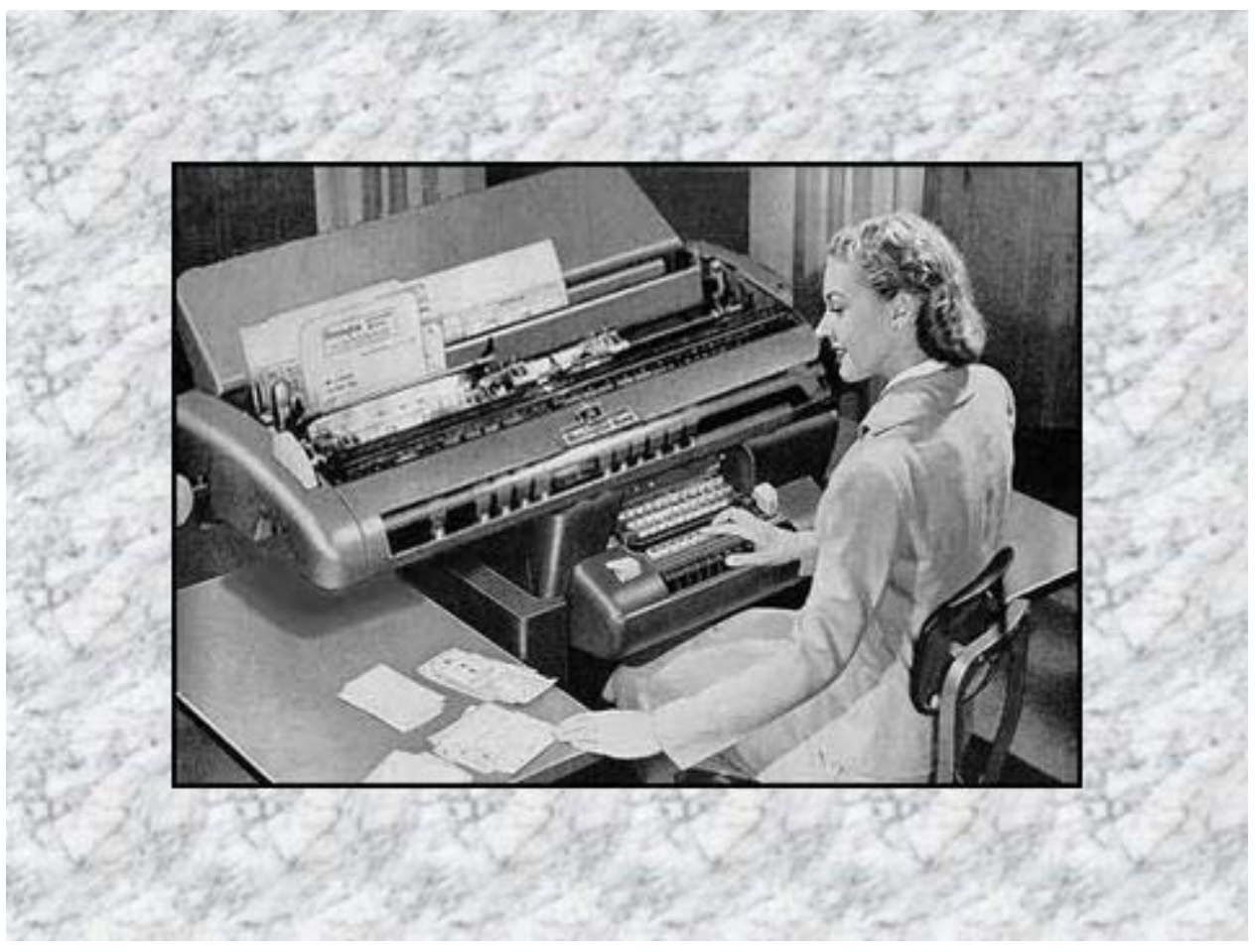

Slide 26

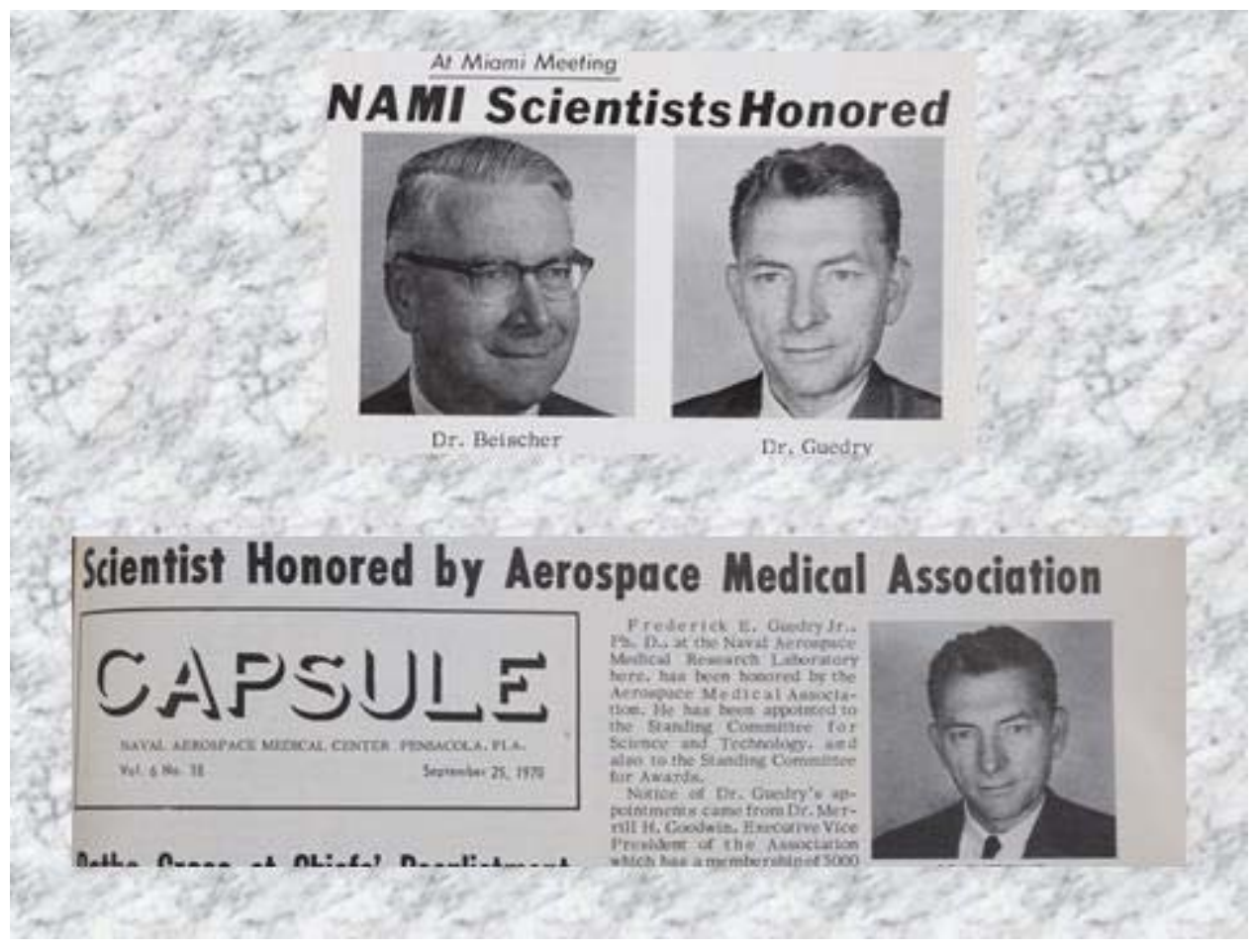

Slide 27 


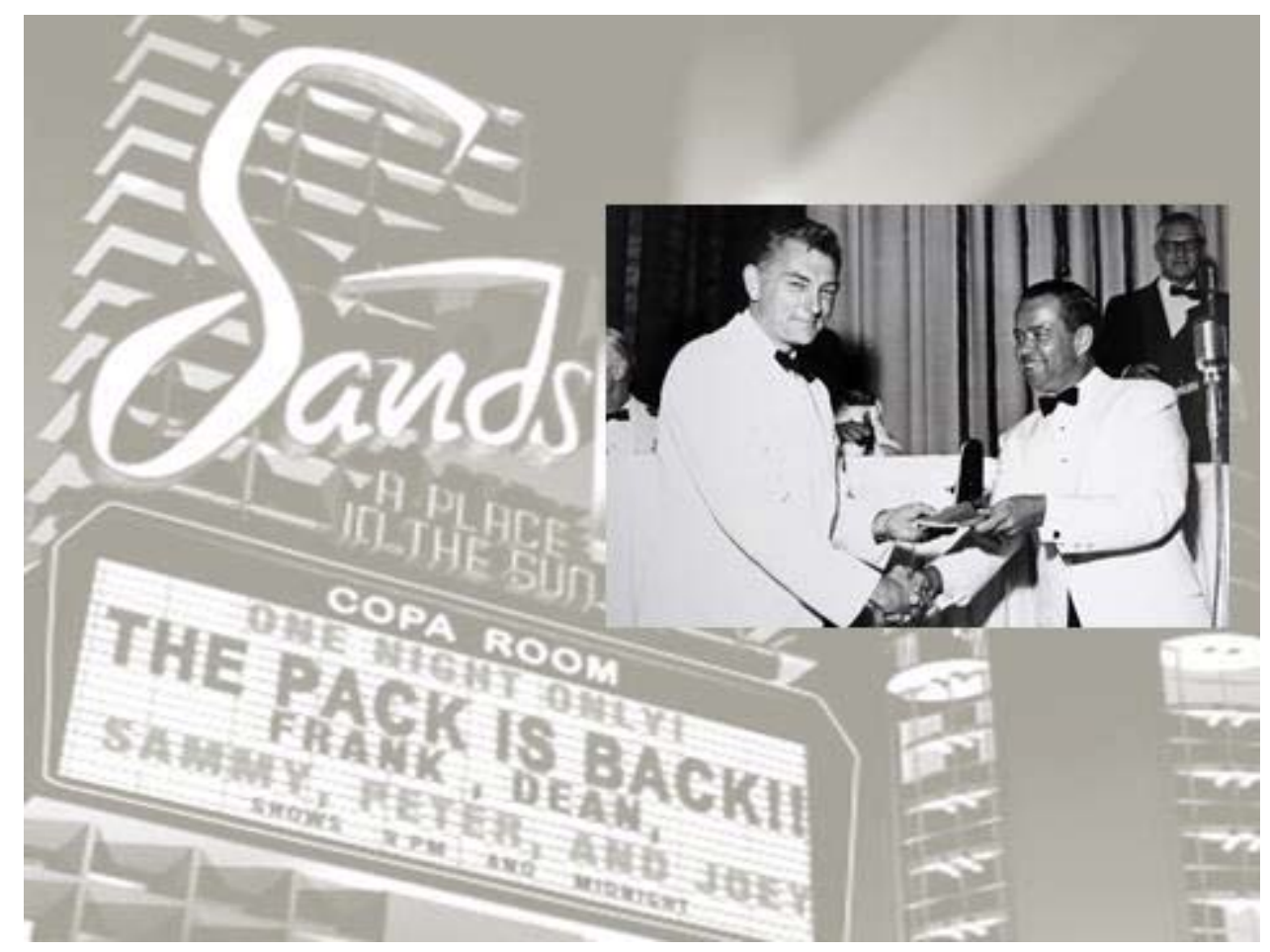

Slide 28

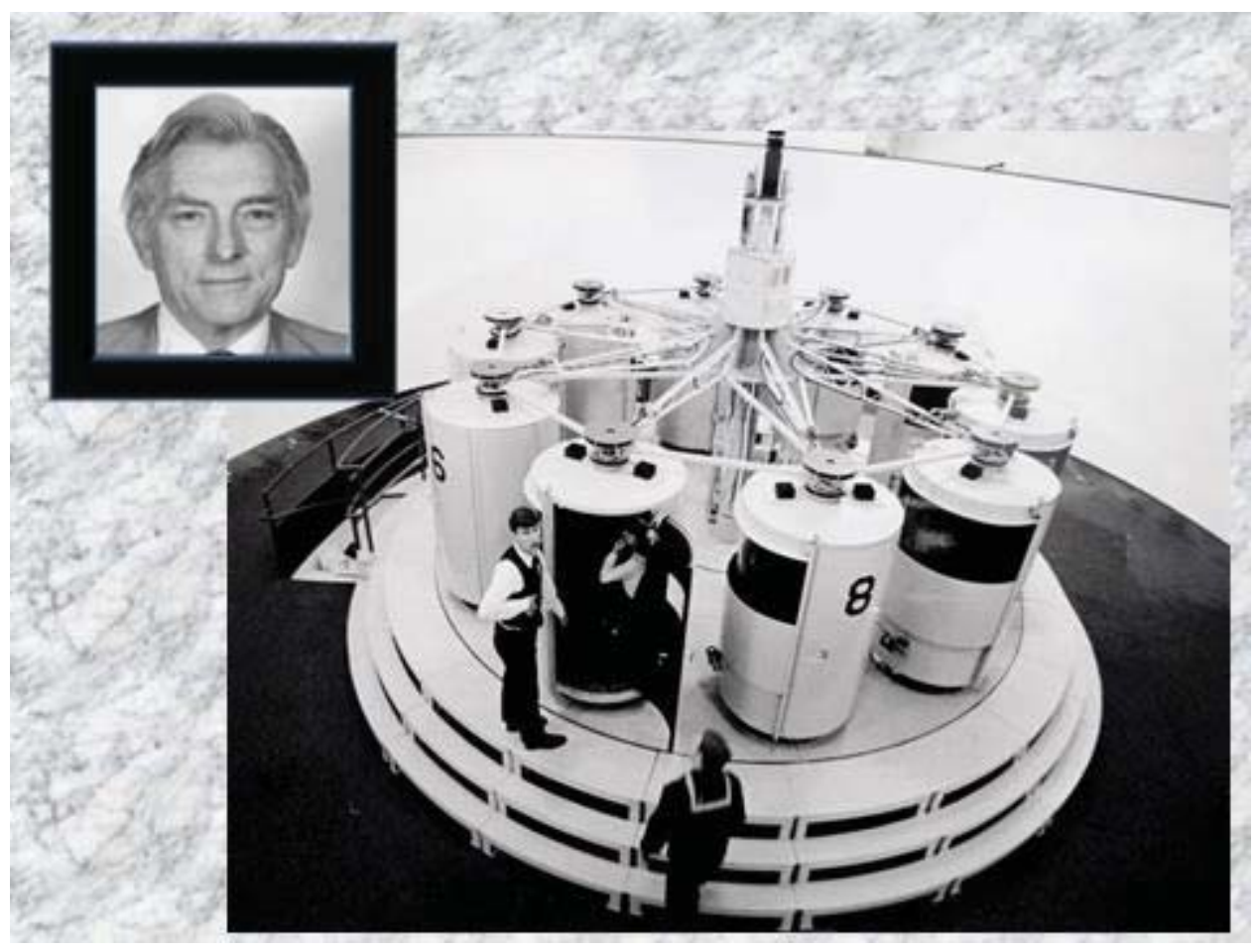

Slide 29 


\section{"Cannot be spared."}

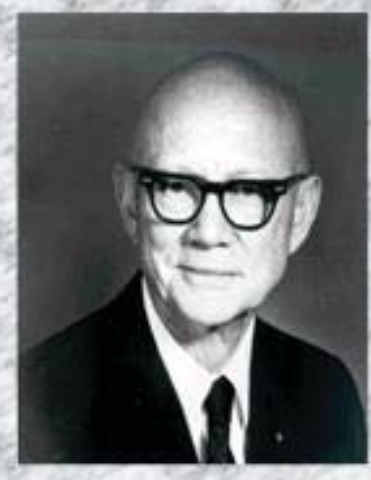

Slide 30

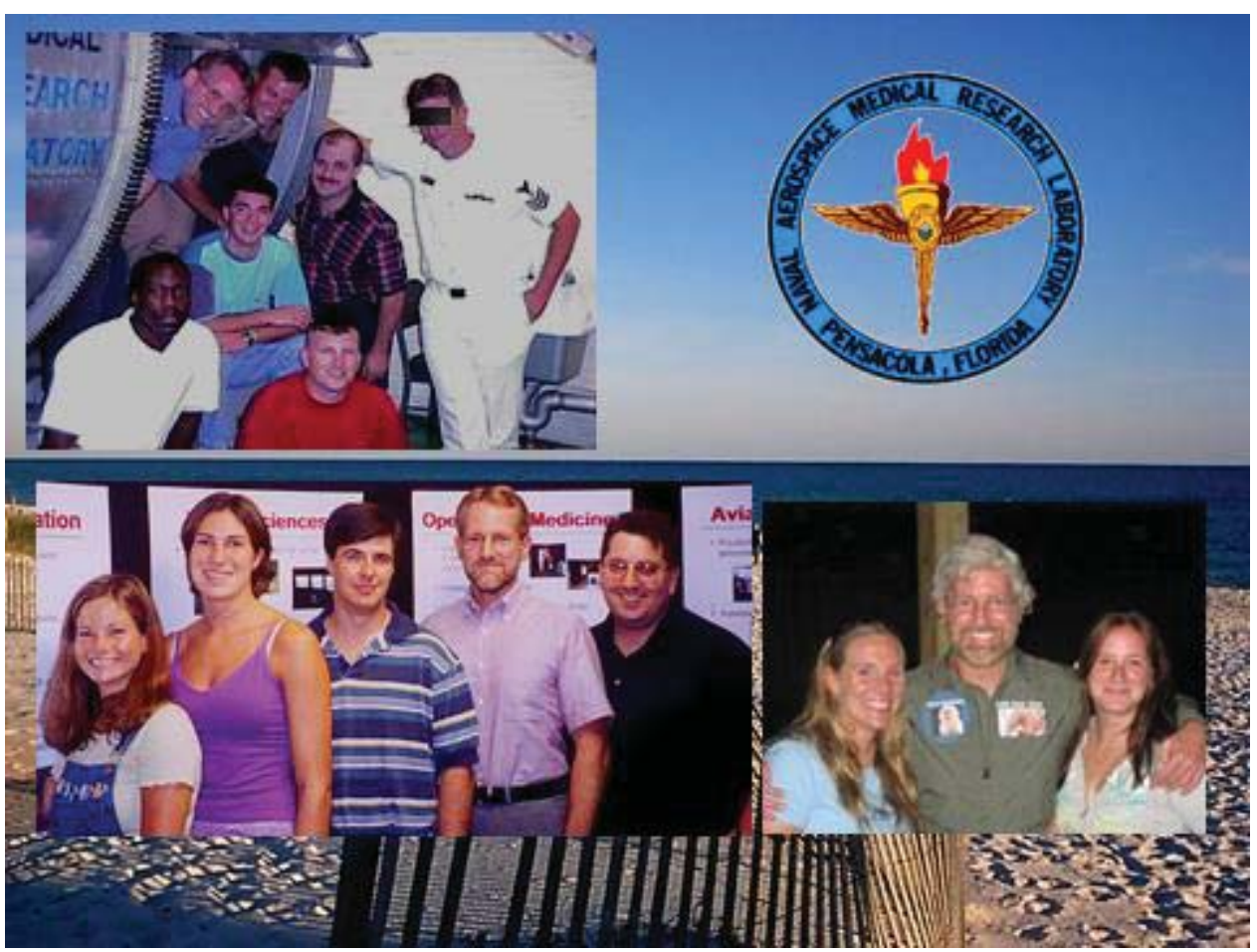

Slide 31 


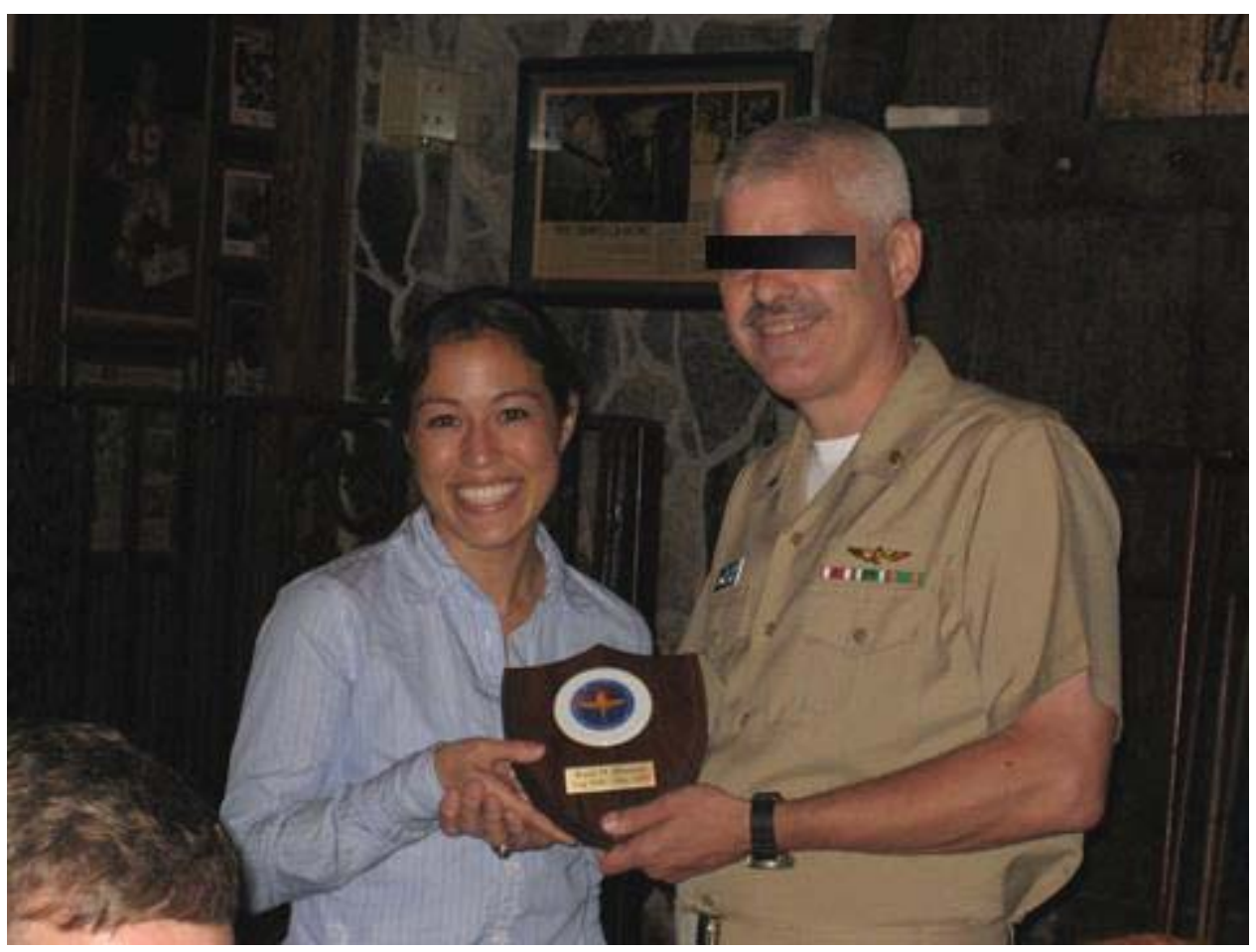

Slide 32

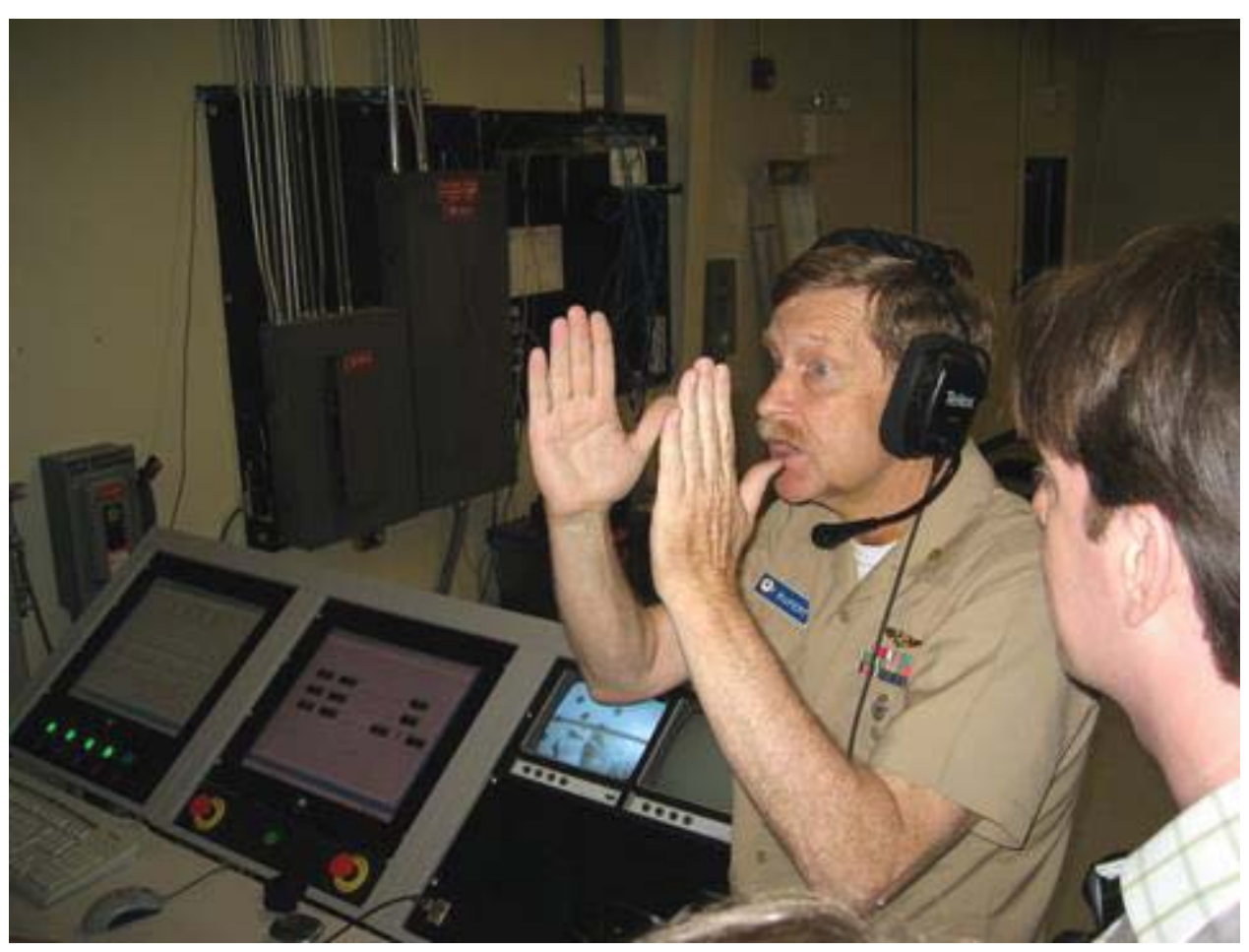

Slide 33 


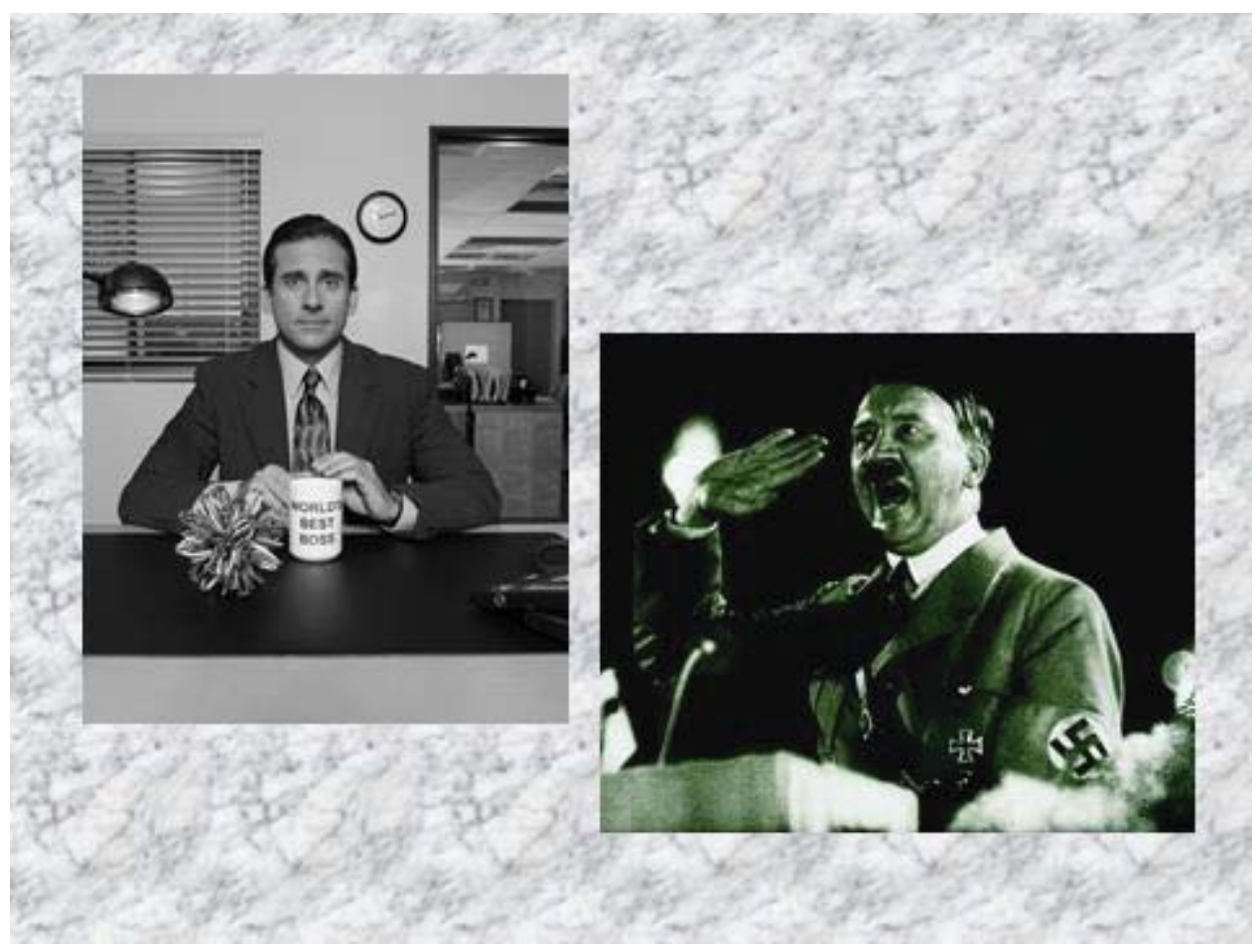

Slide 34

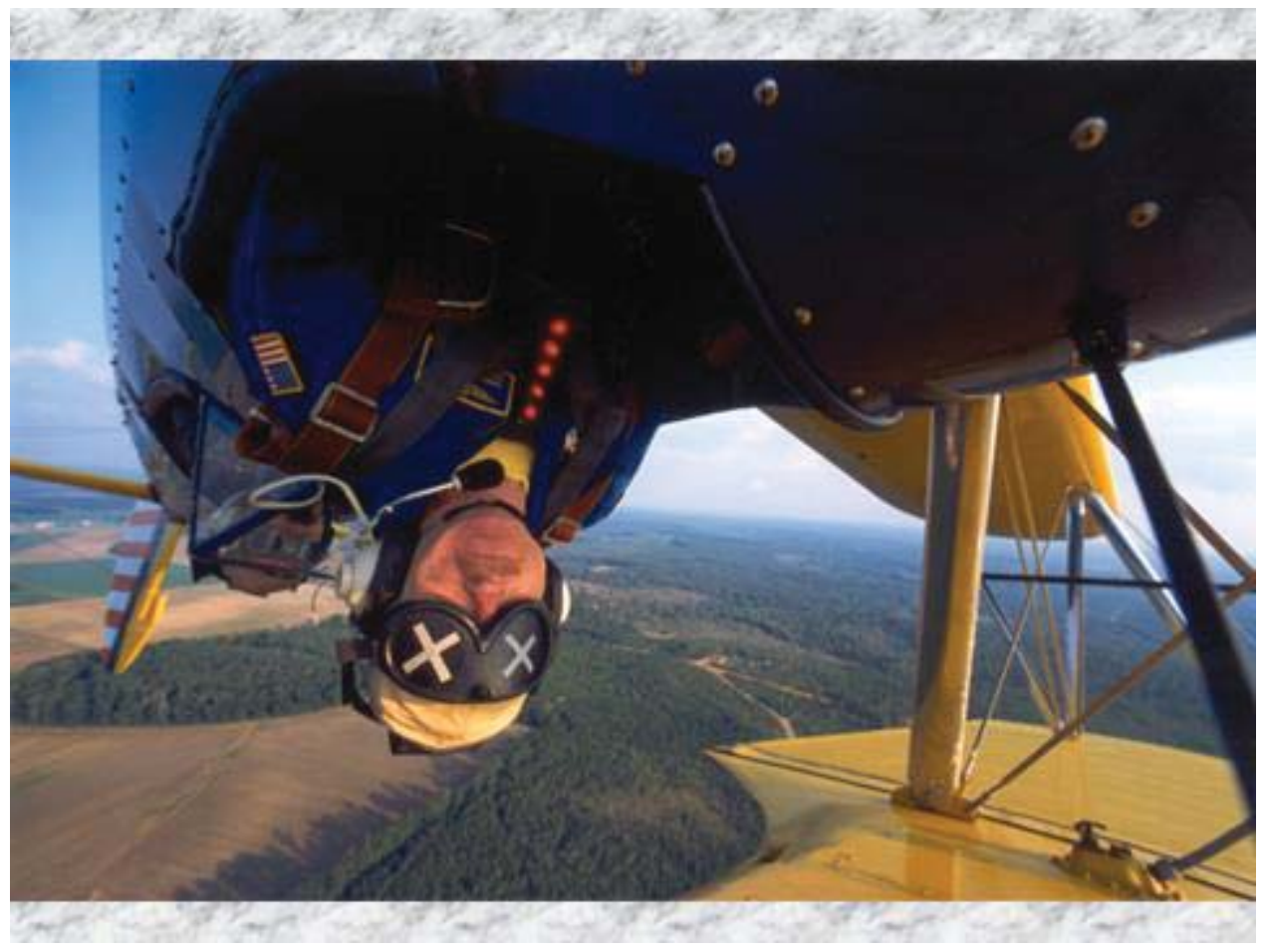

Slide 35 


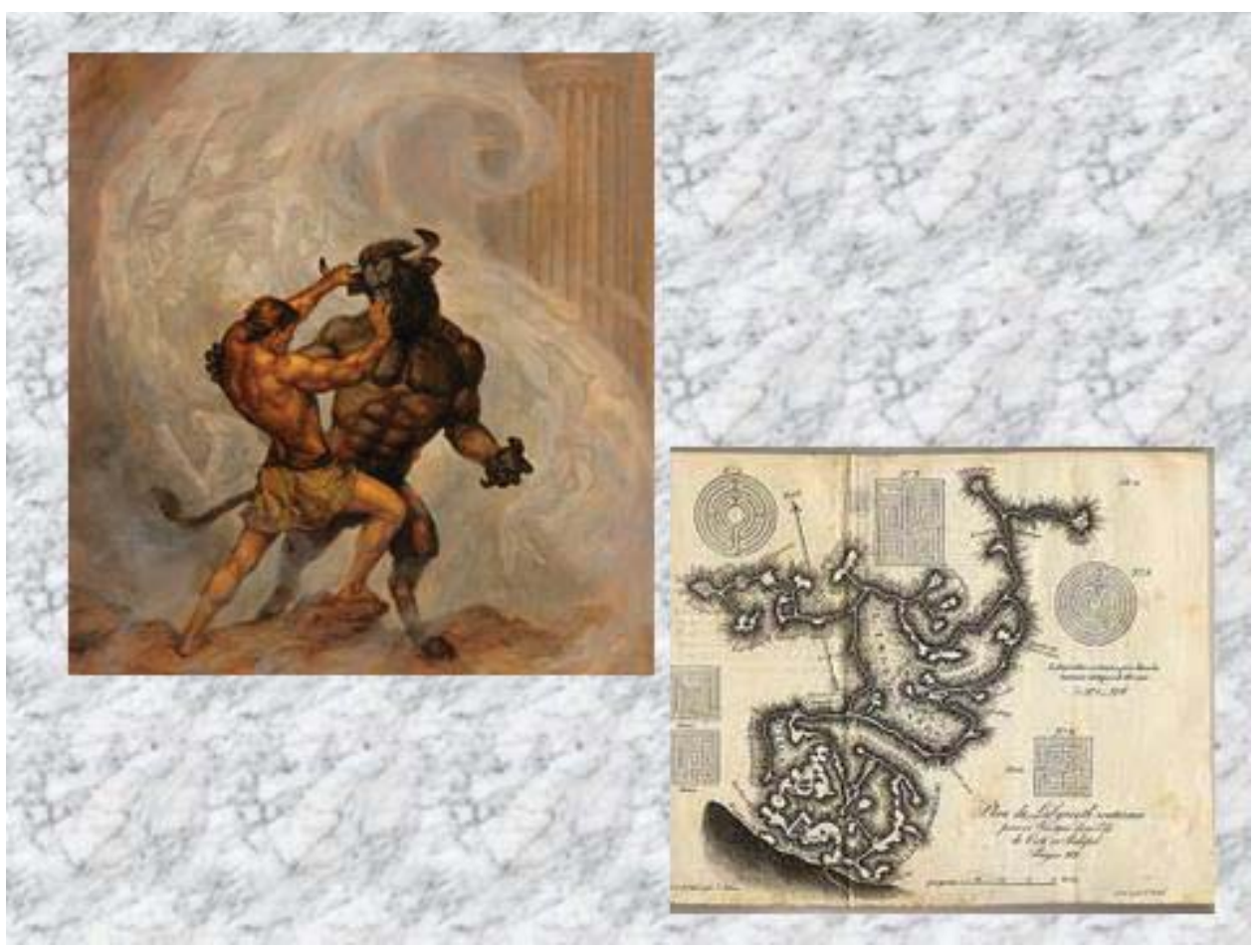

Slide 36

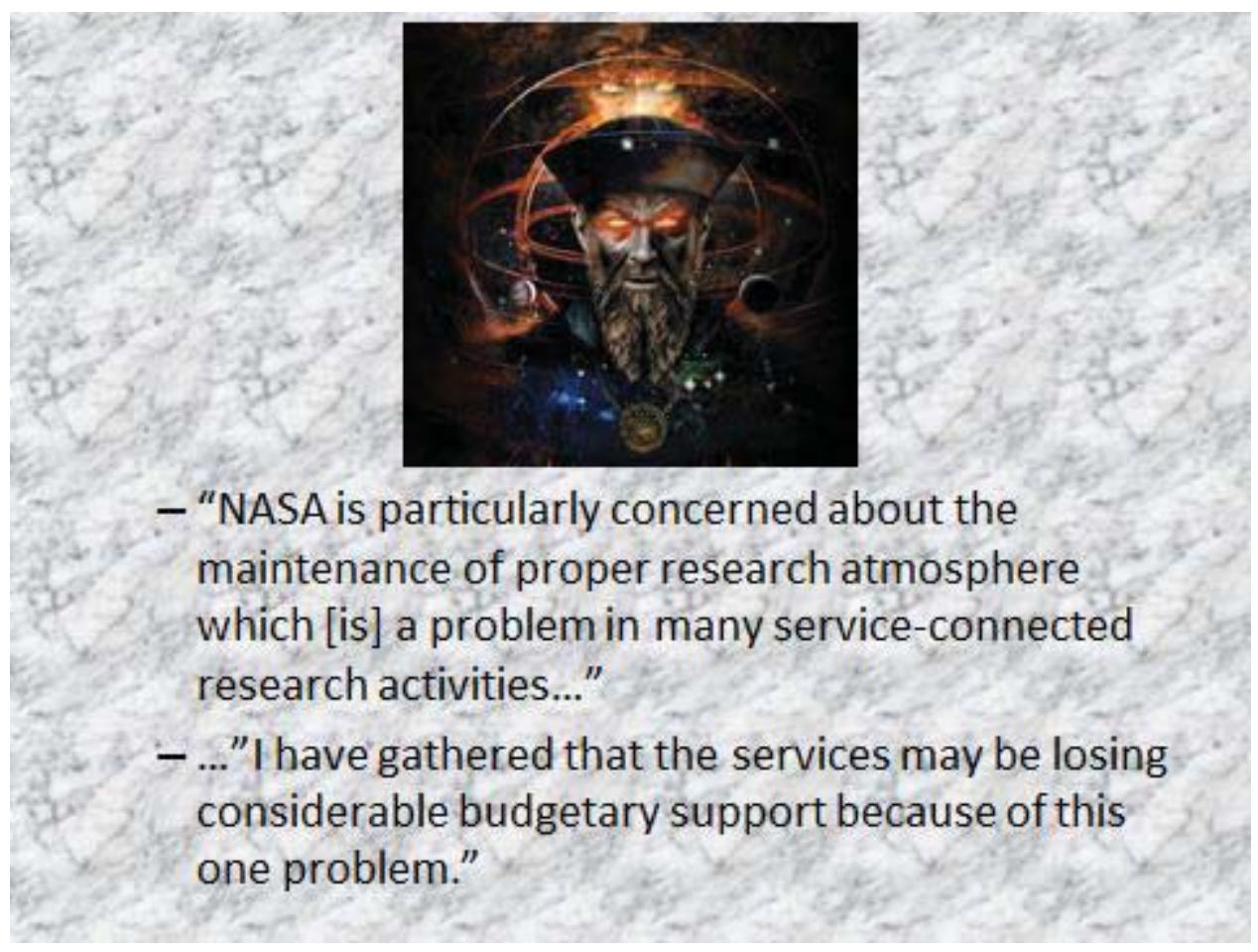

Slide 37 


\section{- Stellar as}

- Chief Scientist

-Acceleration Division Director

-PI of several projects

\section{-Only one area of criticism:}

\section{Division admin...}

"Dr. Guedry is an invaluable asset to the Navy as a scientist but is not our best administrator. He has neither the interest nor the time to do this effectively."

Slide 38

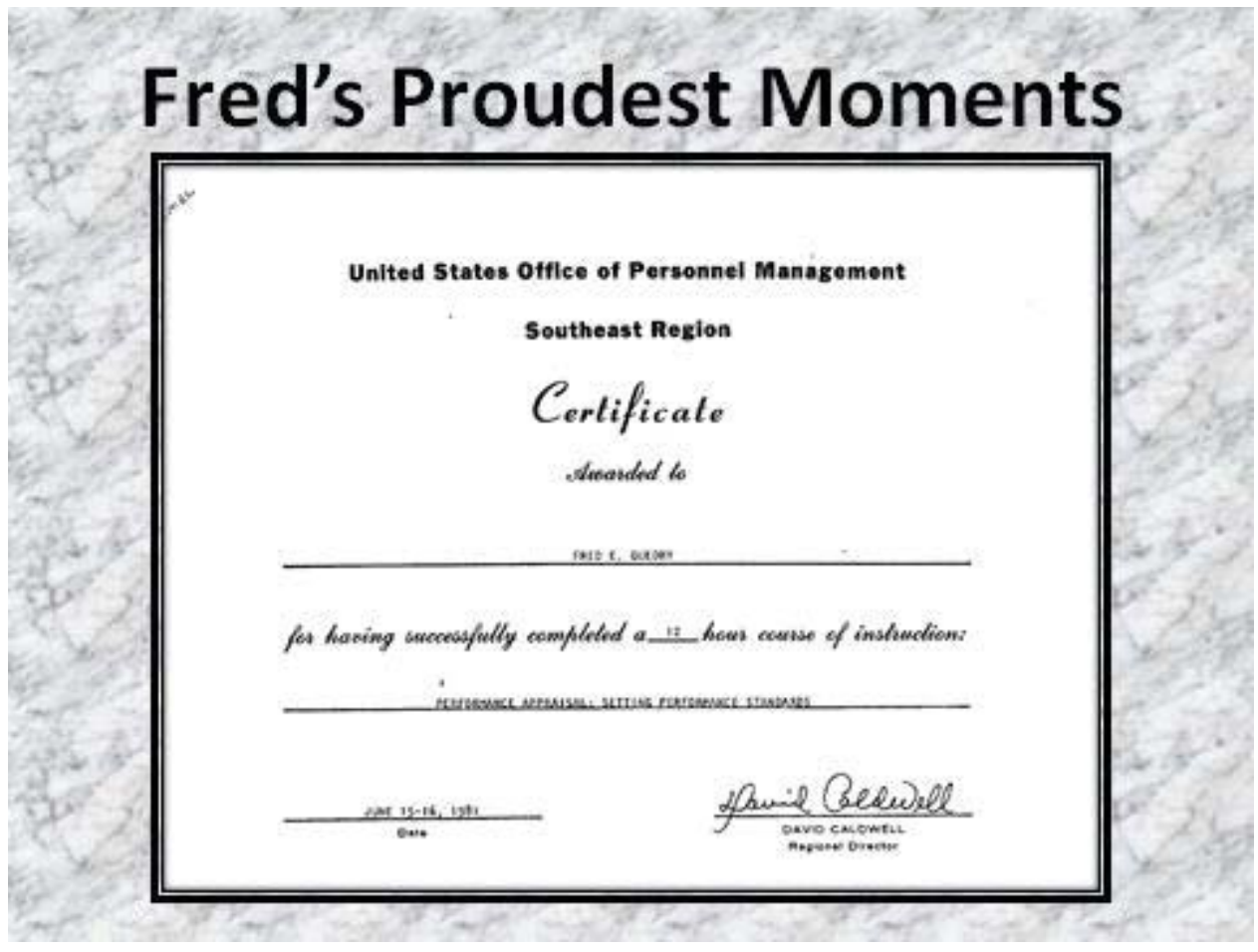

Slide 39 


\section{Fred "Quotes"}

- Re. research topics:

- "Motion sickness is too complicated."

- Re. workplace politics:

- "Let your work be the wall that defends you."

- "Don't worry about setbacks and theft, just keep moving forward and stay in the game."

- Re. human subject safety:

- "All the safety and subject committees get wrapped up in administration at the expense of real safety."

Slide 40

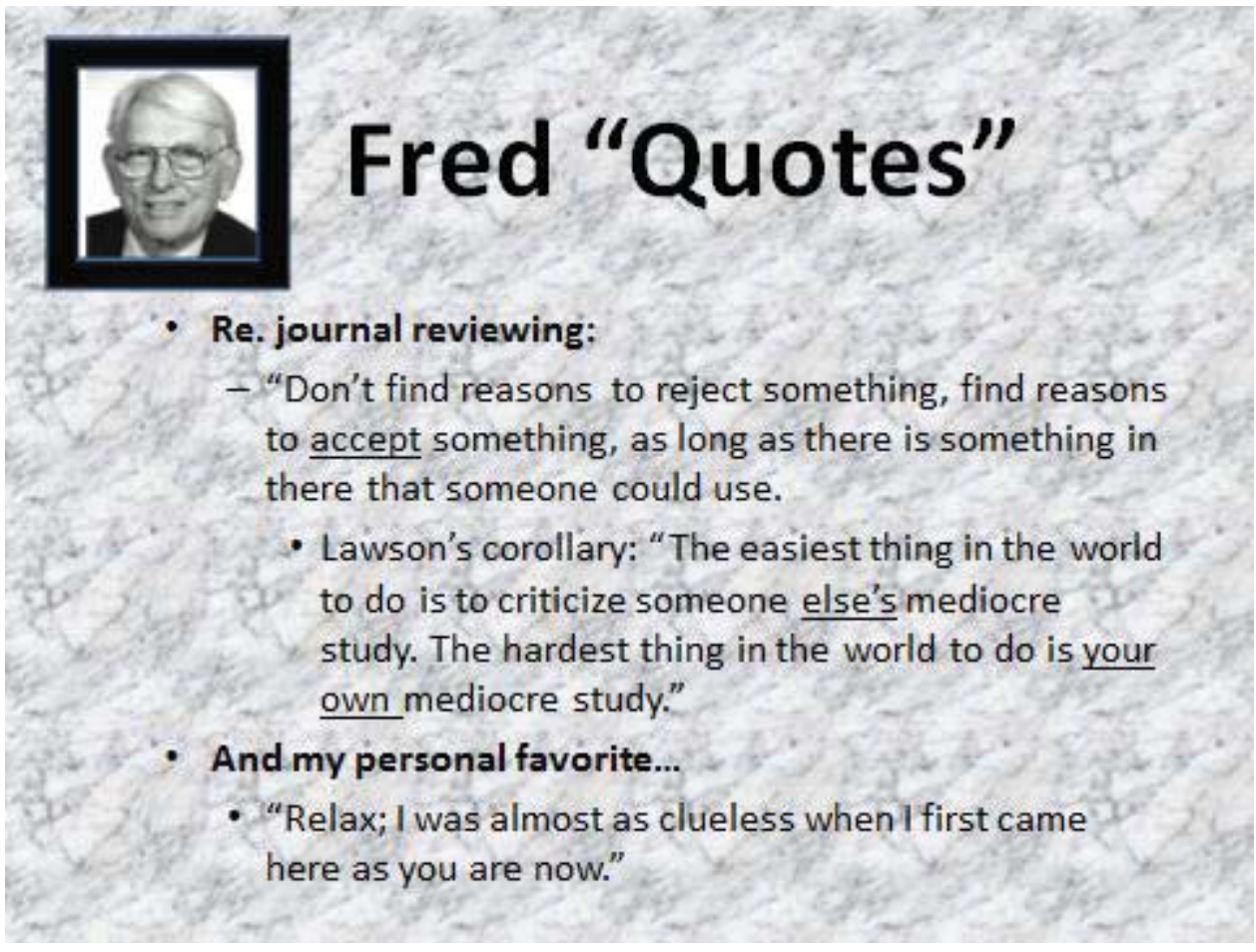

Slide 41 


\section{Three "Rules" (by Example)}

1. Doubt everything

- But don't be shy about arguing yourposition

2. Be passionate

- Stay curious and excited about new information

3. Maintain a sense of urgency

- But the race belongs to those who keep running

Slide 42

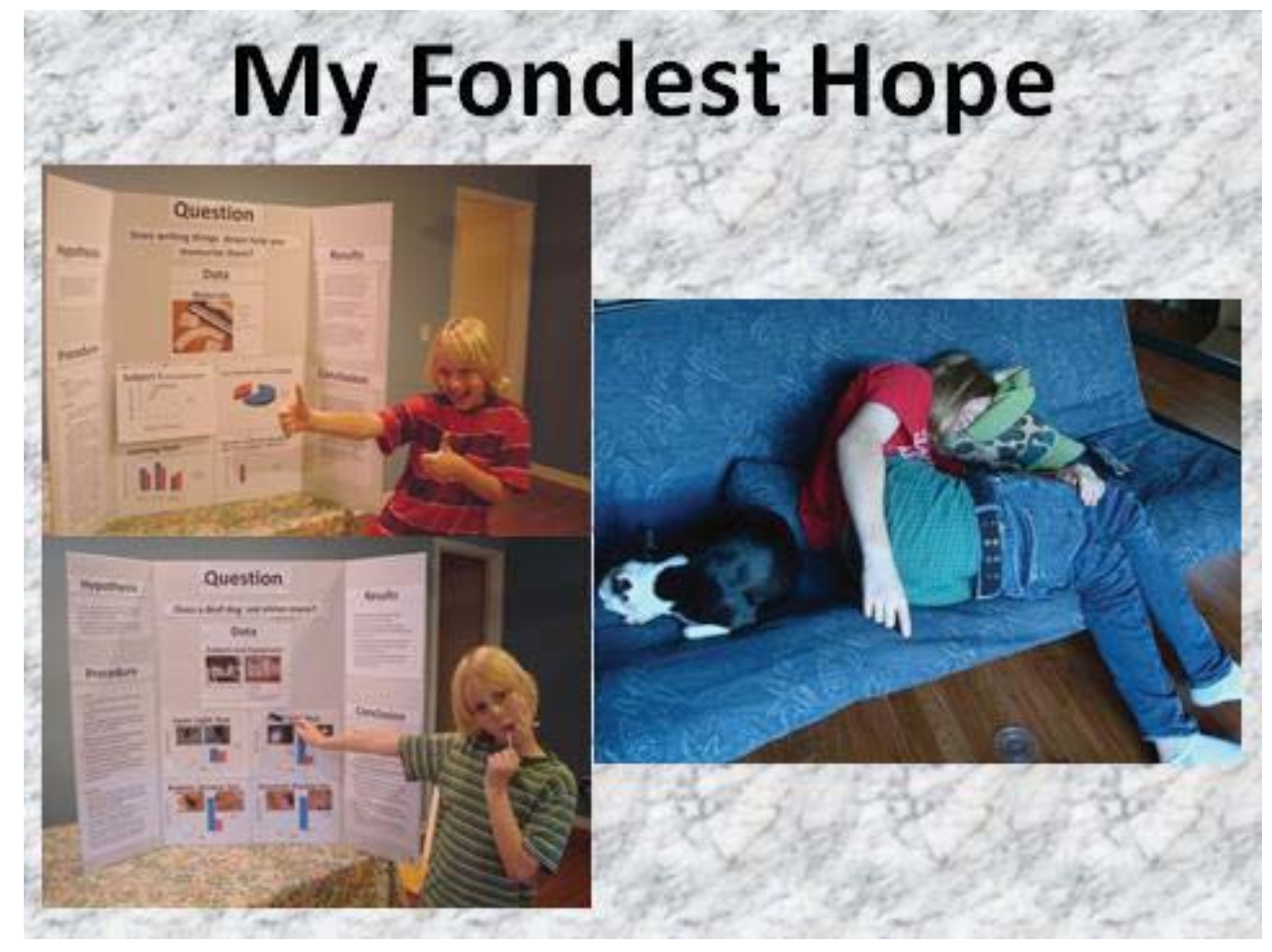

Slide 43 


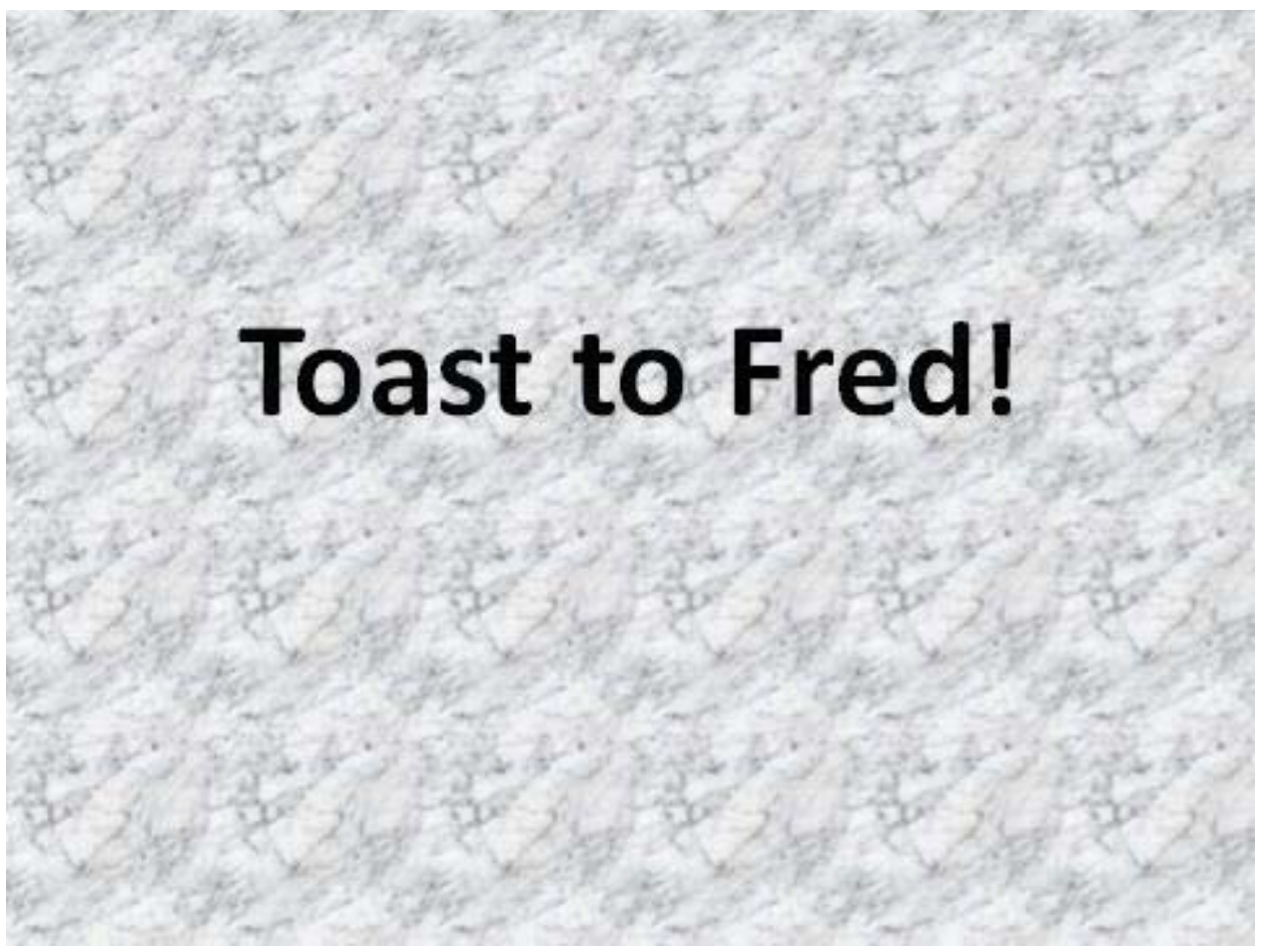

Slide 44 


\section{Appendix A.}

\section{Knowledge map.}

A Knowledge Map (KM) was created for the symposium held in November 2010 at the Institute for Human and Machine Cognition (IHMC) in Pensacola, Florida. The front page for the $\mathrm{KM}$ is shown in figure F-1. The purpose of the KM was to organize and display the expert knowledge specific to current research in vestibular system function for easy dissemination and understanding by other researchers and interested parties.

During the 2-day meeting, presentations were given by 14 experts and covered topics relating to their research on vestibular function and motion sickness. Topics included: models of the vestibular system, vestibular function and motion sickness, advances in tests and therapies, new technology, and spatial orientation. All of the presentations were video recorded, including the tribute to Dr. Fred Guedry held at the Naval Aviation Museum, where Drs. Rupert and Lawson spoke about their personal experiences working with him and discussed some of his achievements, honors, and publications. For further review of the knowledge map and video recordings of the lectures presented at this symposium, visit www.ihmc.us/GuedrySymposium.

USAARL research staff first transcribed the presentation narratives and tribute speeches, then IHMC staff extracted the content from the transcripts to create a concept map based KM using IHMC's CmapTools software toolkit. Preliminary concept maps (explicit graphical representations of knowledge) were created based on the information in the transcripts. These maps then went through a series of edits and revisions, during which the research team organized the material by subtopics covered in each presentation (figure F-2).

Concept maps created from the transcriptions of the Fred Guedry tribute focused on encapsulating a biographical outline of his work, achievements, honors, and interaction with other scientists. Concept maps were also created to highlight the current research needs and scientific challenges in the field of vestibular research. The information represented in these maps was extracted from responses to surveys provided to each of the workshop participants (figure F-3).

After completing the individual maps, cross-links between maps of related content were added. In addition, the video presentations were edited and cut into concept-specific video clips and lecture summaries for each of the presentations. The video clips and summaries were added as resource links within the concept maps to provide further explanation of specific topics and complete the KM (figure F-4). 


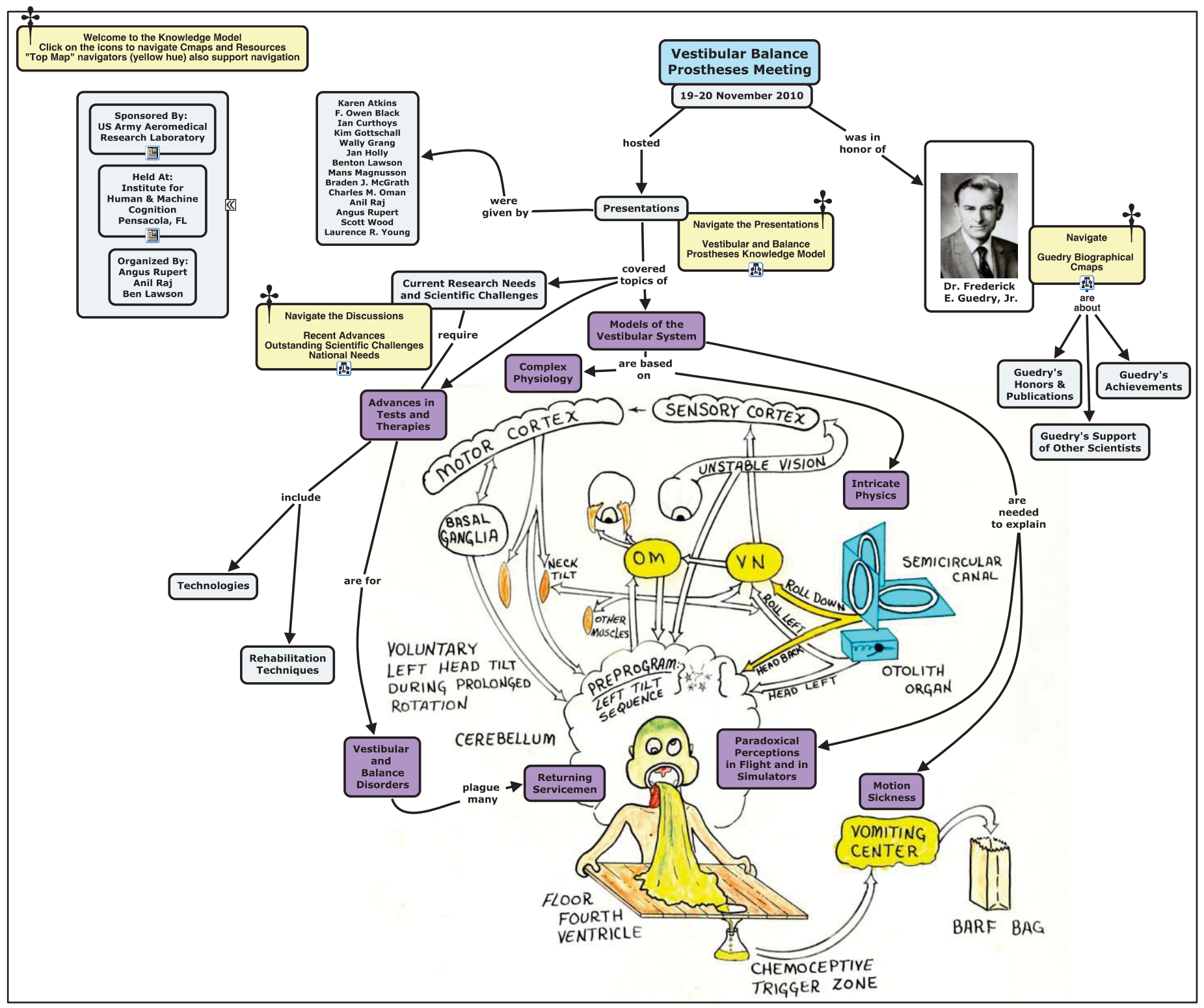

Figure F-1: Concept Map of Vestibular Balance Prostheses meeting. Light yellow nodes denoted with " $\uparrow$ " indicate links to significant subtopic maps. The yellow node next to the photograph of Dr. Guedry (upper right) links to the tribute maps. Fred Guedry drew the cartoon in figure F-1. 


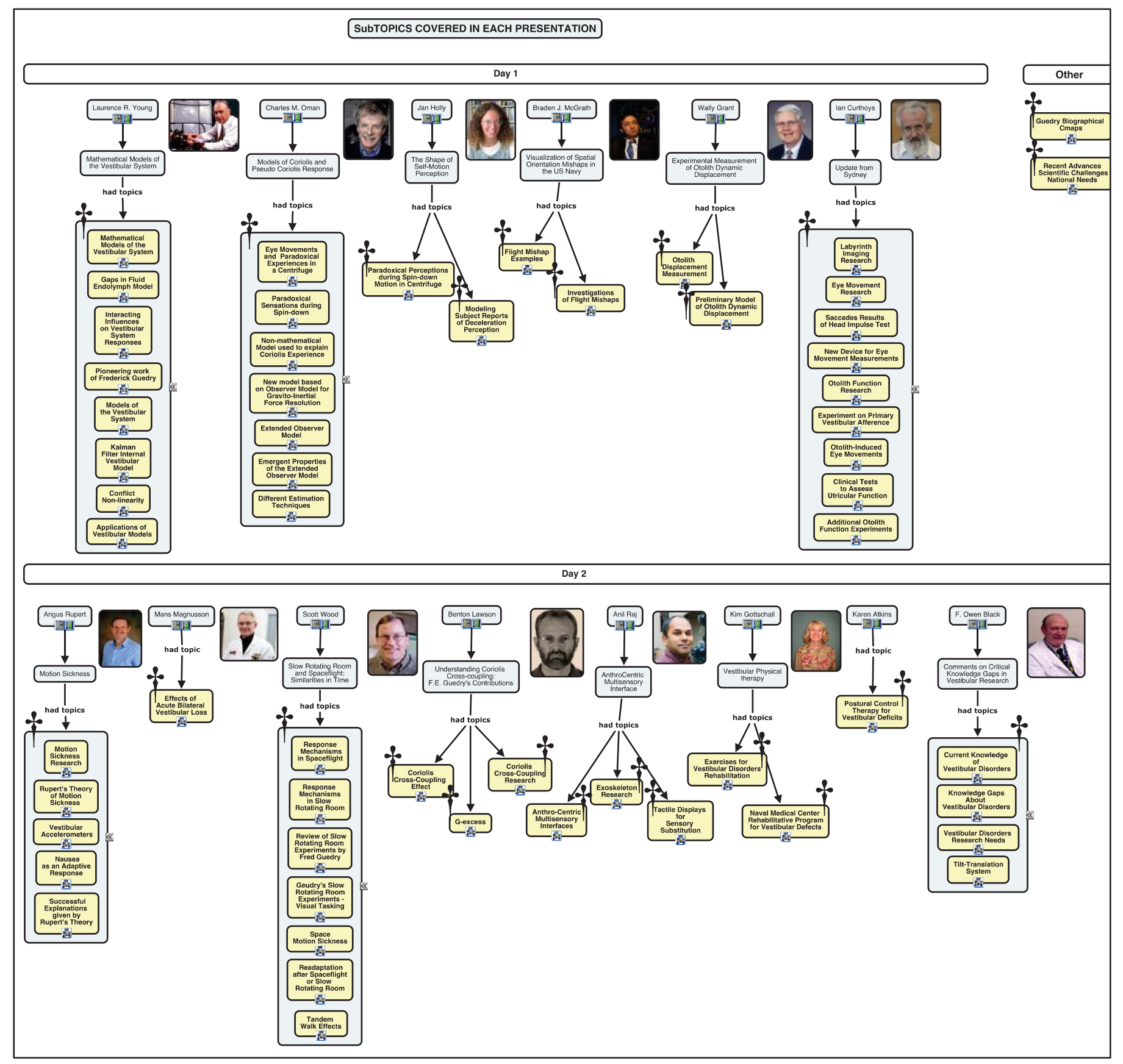

Figure F-2: Presentation top level map organized by workshop day, speaker and topic. Light yellow nodes denoted with " $\uparrow$ " indicate significant subtopic maps that can be accessed by clicking on the resource icon at the bottom of the concept node. 


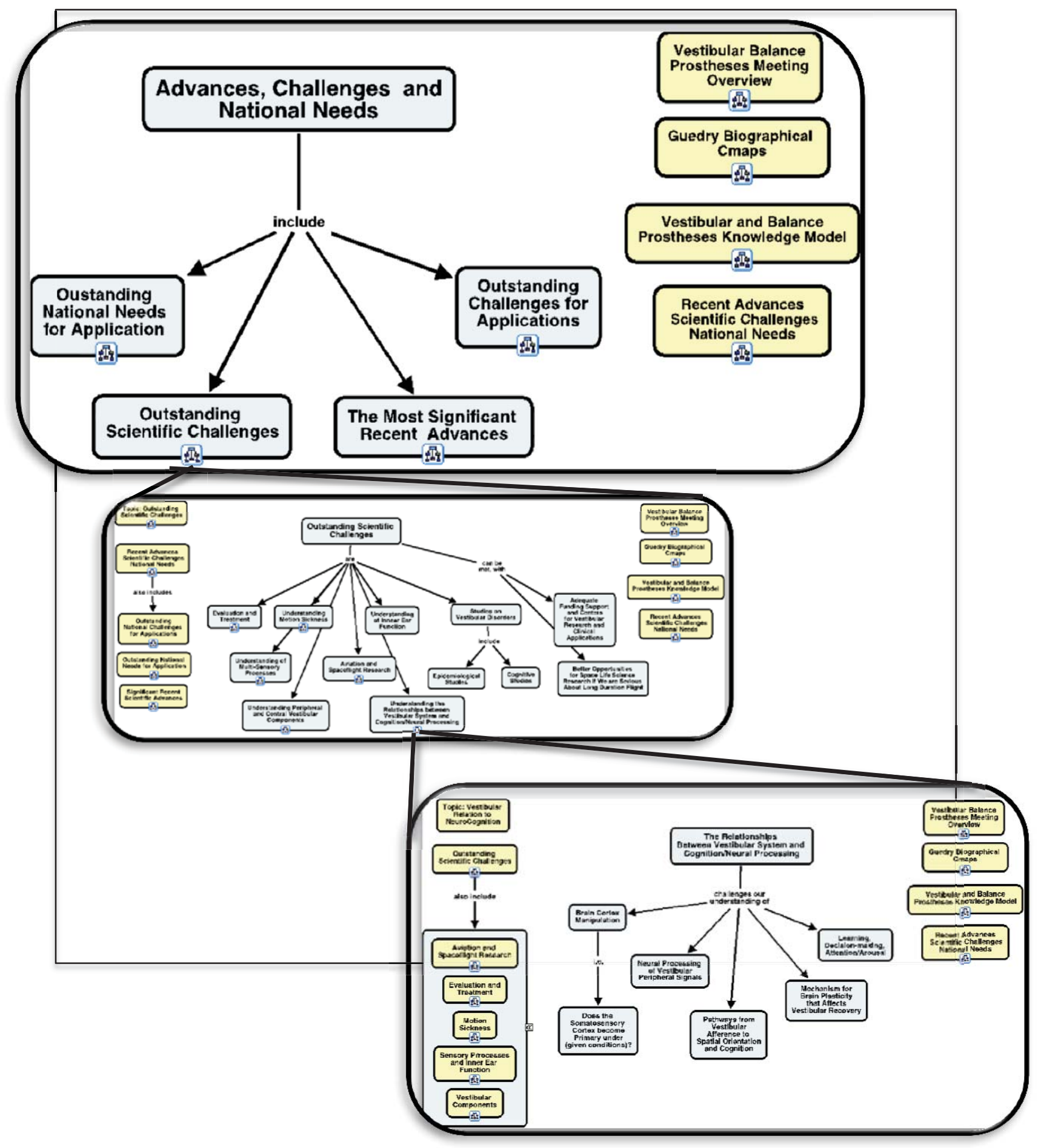

Figure F-3: Top map for Challenges subtopic (top) showing submap for Outstanding Challenges (center) and Vestibular/Neurocognitive Relationships (bottom). Subtopics can be accessed by clicking on resource icons attached to specific concepts. Users can return to higher level maps by clicking on the back arrow icon or jump directly to any other resource or map linked with an icon. Concepts relate to others with explicit linking phrases; each triad of concept-linking phrase-concept should describe a relationship independent from the rest of the map. 


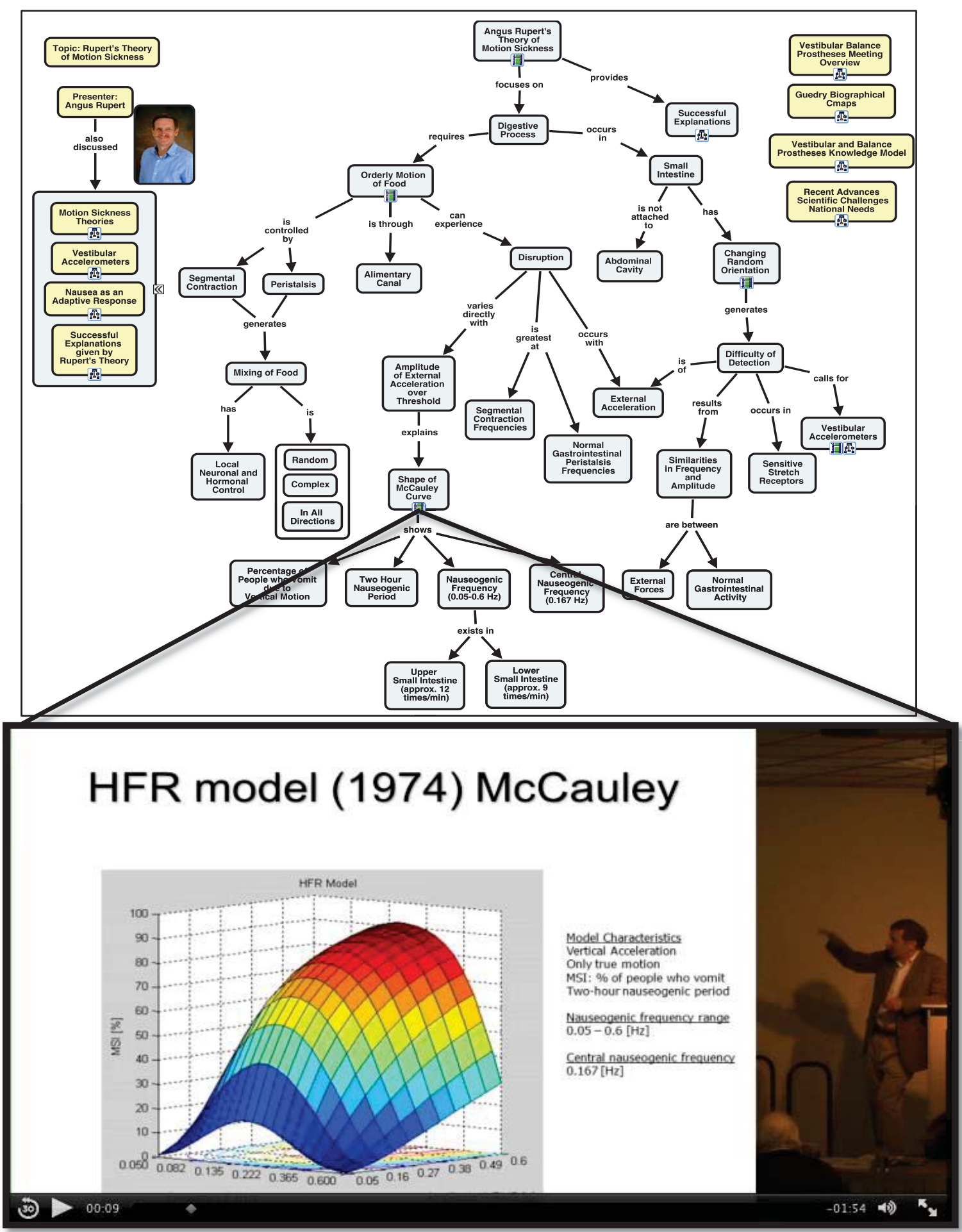

Figure F-4: Rupert's motion sickness theory map (top) with still from video clip (bottom) accessible from Shape of McCauley Curve node. Users can navigate the knowledge map in a non-linear way and see explicit and implicit relationships between topics when exploring the KM in a more natural fashion than when reading a printed text. Finally, the top-level "presentation map" was created as an overview of the KM to allow the user to easily navigate through all of the information. 


\section{Appendix B.}

\section{Bucket list survey and answers.}

Dr. Anil Raj informally polled the Fred Fest attendees concerning their opinions about the most important areas of interest in vestibular research. The four topics addressed by the survey are as follows:

- The most significant scientific advances in this area, last 5 or so years.

- The outstanding scientific challenges.

- The outstanding methodological challenges.

- The outstanding national needs for applications.

The respondents were invited, but not required, to list up to five responses to each inquiry. Out of 36 total attendees, 29 were vestibular experts, 16 of whom returned replies to the survey. A table of the responses of 16 attendees is shown as follows:

\begin{tabular}{|c|c|c|c|c|}
\hline & $\begin{array}{l}\text { The most significant } \\
\text { scientific advances in this } \\
\text { area, last } 5 \text { or so years }\end{array}$ & $\begin{array}{l}\text { The outstanding scientific } \\
\text { challenges }\end{array}$ & $\begin{array}{l}\text { The outstanding } \\
\text { methodological challenges }\end{array}$ & $\begin{array}{l}\text { The outstanding national } \\
\text { needs for applications }\end{array}$ \\
\hline \multirow[t]{5}{*}{ Respondent 1} & $\begin{array}{l}\text { The realization that some } \\
\text { otolithic efferents respond } \\
\text { to bone conducted } \\
\text { vibrations }\end{array}$ & Vestibular efferents & $\begin{array}{l}\text { Recording from vestibular } \\
\text { efferents }\end{array}$ & $\begin{array}{l}\text { Fast diagnosis of vestibular } \\
\text { clinical disorders }\end{array}$ \\
\hline & $\begin{array}{l}\text { Pseudorandom Galvanic } \\
\text { Vestibular Stimulation } \\
\text { (PREVS) }\end{array}$ & $\begin{array}{l}\text { Understanding the } \\
\text { mechanism by which } \\
\text { vibration affects otolithic } \\
\text { receptors }\end{array}$ & $\begin{array}{l}\text { Try to establish vestibular } \\
\text { function of efferents } \\
\text { experimentally }\end{array}$ & $\begin{array}{l}\text { Getting good predictors of } \\
\text { motion sickness } \\
\text { susceptibility using PREVS }\end{array}$ \\
\hline & $\begin{array}{l}\text { Use of inertial } \\
\text { measurement units for } \\
\text { quantifying motion and } \\
\text { perception }\end{array}$ & $\begin{array}{l}\text { Moving research from } \\
\text { unnatural low acceleration } \\
\text { to natural high } \\
\text { accelerations }\end{array}$ & $\begin{array}{l}\text { Improving human eye } \\
\text { movement recording } \\
\text { (smaller, faster video } \\
\text { cameras) }\end{array}$ & $\begin{array}{l}\text { Developing a properly } \\
\text { quantified measure } \\
\text { of success-rehabilitation }\end{array}$ \\
\hline & & $\begin{array}{l}\text { Using PREVS to } \\
\text { understand motion sickness } \\
\text { and motion sickness } \\
\text { susceptibility }\end{array}$ & & \\
\hline & & $\begin{array}{l}\text { Why is active movement } \\
\text { so less provocative than } \\
\text { passive movement }\end{array}$ & & \\
\hline \multirow[t]{2}{*}{ Respondent 2} & Saccular diagnosis & $\begin{array}{l}\text { In-orbit demonstration of } \\
\text { artificial gravity } \\
\text { effectiveness }\end{array}$ & $\begin{array}{l}\text { Low cost eye movement } \\
\text { measurement }\end{array}$ & $\begin{array}{l}\text { Fall protection for the } \\
\text { elderly: standards, } \\
\text { equipment, education }\end{array}$ \\
\hline & $\begin{array}{l}\text { Demonstration of the role } \\
\text { of efferents in active head } \\
\text { movement }\end{array}$ & & & \\
\hline
\end{tabular}




\begin{tabular}{|c|c|c|c|c|}
\hline & $\begin{array}{l}\text { The most significant } \\
\text { scientific advances in this } \\
\text { area, last } 5 \text { or so years }\end{array}$ & $\begin{array}{l}\text { The outstanding scientific } \\
\text { challenges }\end{array}$ & $\begin{array}{l}\text { The outstanding } \\
\text { methodological challenges }\end{array}$ & $\begin{array}{l}\text { The outstanding national } \\
\text { needs for applications }\end{array}$ \\
\hline \multirow[t]{2}{*}{ Respondent 3} & $\begin{array}{l}\text { Development of tactor- } \\
\text { based sensory information } \\
\text { devices and their } \\
\text { application to real world } \\
\text { problems }\end{array}$ & $\begin{array}{l}\text { Understanding basic } \\
\text { mechanism of motion } \\
\text { sickness }\end{array}$ & $\begin{array}{l}\text { Development of rapid and } \\
\text { specific vestibular tests }\end{array}$ & $\begin{array}{l}\text { Rehabilitation of patients } \\
\text { with vestibular and CNS } \\
\text { (central nervous system) } \\
\text { lesions }\end{array}$ \\
\hline & & & & Military applications \\
\hline \multirow[t]{4}{*}{ Respondent 4} & $\begin{array}{l}\text { Hair cell biomechanics and } \\
\text { electrophysiology }\end{array}$ & $\begin{array}{l}\text { Peripheral vestibular } \\
\text { mechanics-Define central } \\
\text { input }\end{array}$ & $\begin{array}{l}\text { Creating math models of } \\
\text { neural systems of vestibular } \\
\text { systems }\end{array}$ & $\begin{array}{l}\text { General population } \\
\text { medical diagnosis of } \\
\text { vestibular disorders }\end{array}$ \\
\hline & $\begin{array}{l}\text { Some understanding of } \\
\text { motion sickness }\end{array}$ & $\begin{array}{l}\text { Neural processing of } \\
\text { vestibular peripheral } \\
\text { signals }\end{array}$ & & \\
\hline & & $\begin{array}{l}\text { Application of basic } \\
\text { science to medical } \\
\text { diagnosis for pathologies }\end{array}$ & & \\
\hline & & $\begin{array}{l}\text { Application of basic } \\
\text { science to aviation and } \\
\text { space medicine }\end{array}$ & & \\
\hline \multirow[t]{2}{*}{ Respondent 5} & & $\begin{array}{l}\text { A safe, highly effective } \\
\text { medication of all types of } \\
\text { motion sickness }\end{array}$ & $\begin{array}{l}\text { A simple, inexpensive } \\
\text { platform to induce motion } \\
\text { sickness }\end{array}$ & \\
\hline & & $\begin{array}{l}\text { Medication noted above } \\
\text { available in multiple } \\
\text { forms-oral, sublingual, } \\
\text { transdermal, etc. }\end{array}$ & & \\
\hline \multirow[t]{4}{*}{ Respondent 6} & $\begin{array}{l}\text { O-VEMP (ocular } \\
\text { vestibular-evoked } \\
\text { myogenic potential) }\end{array}$ & $\begin{array}{l}\text { Central vestibular } \\
\text { components }\end{array}$ & & Mal disembarkment \\
\hline & $\begin{array}{l}\text { VOR (vestibulo-ocular } \\
\text { reflex) recording using } \\
\text { mini camera }\end{array}$ & Vestibular prosthesis & & \\
\hline & $\begin{array}{l}\text { Multimodal balance } \\
\text { therapy }\end{array}$ & & & \\
\hline & $\begin{array}{l}\text { Recognition of SSCD } \\
\text { (superior semicircular } \\
\text { canal dehiscence) }\end{array}$ & & & \\
\hline \multirow[t]{2}{*}{ Respondent 7} & $\begin{array}{l}\text { BPPV (benign paroxysmal } \\
\text { positional vertigo) dx, } \\
\text { VEMP }\end{array}$ & $\begin{array}{l}\text { Identifying the vestibular - } \\
\text { emetic linkage } \\
\text { (physiology, pharmacology } \\
\text { and anatomy) in motion } \\
\text { sickness }\end{array}$ & $\begin{array}{l}\text { Measurement of subjective } \\
\text { orientation }\end{array}$ & $\begin{array}{l}\text { New ways of measuring } \\
\text { perceptual deficits and } \\
\text { oscillopsia during active } \\
\text { movements in patients (and } \\
\text { astronauts) }\end{array}$ \\
\hline & $\begin{array}{l}\text { Hair cell transduction } \\
\text { mechanisms and } \\
\text { regeneration }\end{array}$ & $\begin{array}{l}\text { Understanding how } \\
\text { vestibular pathology } \\
\text { influences place, grid, } \\
\text { direction cell respiration } \\
\text { and way finding in } \\
\text { chemicals (and patients) }\end{array}$ & & \\
\hline
\end{tabular}




\begin{tabular}{|c|c|c|c|c|}
\hline & $\begin{array}{l}\text { The most significant } \\
\text { scientific advances in this } \\
\text { area, last } 5 \text { or so years }\end{array}$ & $\begin{array}{l}\text { The outstanding scientific } \\
\text { challenges }\end{array}$ & $\begin{array}{l}\text { The outstanding } \\
\text { methodological challenges }\end{array}$ & $\begin{array}{l}\text { The outstanding national } \\
\text { needs for applications }\end{array}$ \\
\hline \multirow[t]{4}{*}{ Respondent 8} & $\begin{array}{l}\text { Better theoretical and } \\
\text { empirical understanding of } \\
\text { vestibular function as a } \\
\text { "system of systems, i.e. its } \\
\text { multisensory integration of } \\
\text { vestibular inputs with other } \\
\text { senses (somatosensory, } \\
\text { visual and auditory). e.g., } \\
\text { for improved 3D } \\
\text { localization of targets }\end{array}$ & $\begin{array}{l}\text { Preventing falling and } \\
\text { ataxia } \\
\text { (disequilibrium/balance) } \\
\text { problems among elderly, } \\
\text { TBI (traumatic brain } \\
\text { injury) victims, etc. }\end{array}$ & $\begin{array}{l}\text { Better measures of } \\
\text { orientation/motion, vestibular } \\
\text { dysfunction, } \\
\text { imbalance/ataxia, motion } \\
\text { sickness. Better measures of } \\
\text { balance-intensive mission- } \\
\text { related sensorimotor } \\
\text { activities, such as dynamic } \\
\text { shooting. Production of low- } \\
\text { frequency otolithic stimuli } \\
\text { and quantification of their } \\
\text { perceptual effects }\end{array}$ & $\begin{array}{l}\text { Improved } \\
\text { balance/gait/disequilibrium } \\
\text { technologies to assist } \\
\text { balance, gait, and } \\
\text { orientation (e.g., improved } \\
\text { devices and protocols for } \\
\text { rehab., assistance, } \\
\text { prosthesis, cueing, and } \\
\text { support) }\end{array}$ \\
\hline & $\begin{array}{l}\text { Better understanding of } \\
\text { relation between vestibular } \\
\text { function/dysfunction and } \\
\text { cognition (concentration, } \\
\text { spatial memory/neglect, } \\
\text { etc.) }\end{array}$ & $\begin{array}{l}\text { Understanding the relation } \\
\text { between vestibular } \\
\text { processes and cognition } \\
\text { (learning, decision-making, } \\
\text { attention/arousal) }\end{array}$ & $\begin{array}{l}\text { Better countermeasures for } \\
\text { vertigo, disorientation, } \\
\text { motion maladaptation. } \\
\text { Expansion of development of } \\
\text { non-pharmacological and } \\
\text { materiel countermeasures. }\end{array}$ & $\begin{array}{l}\text { Improved orientation } \\
\text { displays to prevent SD } \\
\text { during vehicle control } \\
\text { (e.g., aircraft) }\end{array}$ \\
\hline & $\begin{array}{l}\text { Better tests of vestibular } \\
\text { function (especially visual- } \\
\text { vestibular tests, e.g., } \\
\text { oVEMP, GST (gaze } \\
\text { stabilization test), new } \\
\text { DVA (dynamic visual } \\
\text { acuity) variants, threshold } \\
\text { tests) }\end{array}$ & $\begin{array}{l}\text { Preventing/reducing } \\
\text { motion maladaptation } \\
\text { (motion sickness, mal de } \\
\text { débarquement, motion } \\
\text { sensitivity (e.g., during } \\
\text { exercise), sopite syndrome } \\
\text { (and related fatigue } \\
\text { effects), space adaptation } \\
\text { syndrome, } \\
\text { simulator/cybersickness). } \\
\text { The largest gap emerging } \\
\text { is cybersickness, e.g., } \\
\text { associated with virtual } \\
\text { soldier training systems, } \\
\text { proliferation of virtual } \\
\text { reality applications, in- } \\
\text { cockpit head mounted } \\
\text { displays, etc. }\end{array}$ & $\begin{array}{l}\text { Better theories/models of } \\
\text { balance/gait, multimodal } \\
\text { orientation, etc }\end{array}$ & $\begin{array}{l}\text { Better predictive models } \\
\text { for multisegmental } \\
\text { coordination of } \\
\text { standing/balance/falling, } \\
\text { spatial disorientation } \\
\text { incidents/mishaps, etc. } \\
\text { Better orientation and } \\
\text { human factors models } \\
\text { concerning prediction of } \\
\text { perceptual and motion } \\
\text { maladaptation reactions } \\
\text { during various real or } \\
\text { apparent acceleration } \\
\text { stimuli. }\end{array}$ \\
\hline & $\begin{array}{l}\text { More automation/ } \\
\text { standardization of } \\
\text { vestibular tests (e.g., for } \\
\text { Benign Paroxysmal } \\
\text { Positional Vertigo) }\end{array}$ & $\begin{array}{l}\text { Understanding normal } \\
\text { spatial orientation } \\
\text { perception and control of } \\
\text { voluntary active } \\
\text { movement, gait, etc. }\end{array}$ & $\begin{array}{l}\text { Balance } \\
\text { measures/countermeasures/pr } \\
\text { edictive models tailored to } \\
\text { individual and mission needs, } \\
\text { e.g., age-appropriate (aviator, } \\
\text { soldier, astronaut) approaches } \\
\text { which are multivariate, } \\
\text { idiographic, or capable of } \\
\text { improvement with increased } \\
\text { "learning" (e.g., genetic } \\
\text { algorithms) }\end{array}$ & $\begin{array}{l}\text { Non-sedating motion } \\
\text { sickness countermeasures } \\
\text { (via drugs and/or } \\
\text { adaptation and/or } \\
\text { technologies). E.g., testing } \\
\text { of emerging solutions }\end{array}$ \\
\hline
\end{tabular}




\begin{tabular}{|c|c|c|c|c|}
\hline & $\begin{array}{l}\text { The most significant } \\
\text { scientific advances in this } \\
\text { area, last } 5 \text { or so years }\end{array}$ & $\begin{array}{l}\text { The outstanding scientific } \\
\text { challenges }\end{array}$ & $\begin{array}{l}\text { The outstanding } \\
\text { methodological challenges }\end{array}$ & $\begin{array}{l}\text { The outstanding national } \\
\text { needs for applications }\end{array}$ \\
\hline \multirow[t]{2}{*}{$\begin{array}{c}\text { Respondent } 8 \\
\text { (continued) }\end{array}$} & $\begin{array}{l}\text { Clinical: Increased } \\
\text { development/testing of } \\
\text { emerging sensory sway } \\
\text { feedback/rehab systems } \\
\text { (e.g., TSAS (tactile } \\
\text { situation awareness } \\
\text { system) applied to balance } \\
\text { problems and other rehab., } \\
\text { assistance, and prosthetic } \\
\text { devices) }\end{array}$ & $\begin{array}{l}\text { Understanding the relation } \\
\text { between vestibular } \\
\text { processes and cognition } \\
\text { (learning, decision-making, } \\
\text { attention/arousal) }\end{array}$ & $\begin{array}{l}\text { Better fundamental micro- } \\
\text { level understanding } \\
\text { (especially concerning } \\
\text { possible treatments to emerge } \\
\text { from the field of genetics, } \\
\text { and pharmacological } \\
\text { methods of hair cell } \\
\text { regeneration) }\end{array}$ & $\begin{array}{l}\text { Non-sedating motion } \\
\text { sickness countermeasures } \\
\text { (via drugs and/or } \\
\text { adaptation and/or } \\
\text { technologies) }\end{array}$ \\
\hline & & $\begin{array}{l}\text { Understanding vestibular } \\
\text { effects of vibration and } \\
\text { sound. Vibrations of } \\
\text { interest include those in } \\
\text { various vehicles and very } \\
\text { low-frequency linear } \\
\text { accelerations. Sounds of } \\
\text { interest include very low } \\
\text { frequencies. Effects of } \\
\text { interest include motion } \\
\text { maladaptation, vestibular } \\
\text { control of gaze, and } \\
\text { fatigue-related syndromes. }\end{array}$ & $\begin{array}{l}\text { Improved cooperation and } \\
\text { collaboration with fellow } \\
\text { services to best utilize } \\
\text { advanced vestibular testing } \\
\text { and research devices } \\
\text { currently available to all } \\
\text { services. }\end{array}$ & $\begin{array}{l}\text { Less-than-lethal weapons } \\
\text { knowledge or other } \\
\text { product spin-offs from } \\
\text { studies of vestibular effects } \\
\text { of sound, e.g., soldier } \\
\text { protection devices which } \\
\text { project low frequency } \\
\text { sound while protecting the } \\
\text { user. }\end{array}$ \\
\hline \multirow[t]{5}{*}{ Respondent 9} & $\begin{array}{l}\text { Understanding of } \\
\text { active/passive movement } \\
\text { processing }\end{array}$ & $\begin{array}{l}\text { Understanding adaptive } \\
\text { processes, use-dependent } \\
\text { versus error-based } \\
\text { learning, etc. }\end{array}$ & $\begin{array}{l}\text { Non-invasive comfortable } \\
\text { measurement of } \\
\text { head/body/eye movements in } \\
\text { natural circumstances }\end{array}$ & $\begin{array}{l}\text { Home-based monitoring } \\
\text { and rehab for balance } \\
\text { disorders }\end{array}$ \\
\hline & $\begin{array}{l}\text { Convincing demonstrations } \\
\text { of internal model concept } \\
\text { and multisensory } \\
\text { integration }\end{array}$ & $\begin{array}{l}\text { Understanding } \\
\text { multisensory/multieffector } \\
\text { processes for balance, } \\
\text { motor control, etc. }\end{array}$ & $\begin{array}{l}\text { Non-invasive recording from } \\
\text { single neurons }\end{array}$ & $\begin{array}{l}\text { "National laboratory" for } \\
\text { state-of-the-art work on } \\
\text { motion, balance, spatial } \\
\text { perception, etc. }\end{array}$ \\
\hline & $\begin{array}{l}\text { Optimization principles in } \\
\text { sensorimotor processing } \\
\text { (revisiting and updating } \\
\text { work that began in the } \\
\text { 1970s) }\end{array}$ & $\begin{array}{l}\text { Practical vestibular } \\
\text { prosthesis }\end{array}$ & $\begin{array}{l}\text { Reliable and widely accepted } \\
\text { otolith assessment }\end{array}$ & $\begin{array}{l}\text { Better opportunities for } \\
\text { space life sciences research } \\
\text { if we are serious about } \\
\text { long-duration flight }\end{array}$ \\
\hline & $\begin{array}{l}\text { Importance of sensory } \\
\text { substitution in } \\
\text { compensating for } \\
\text { pathologies }\end{array}$ & $\begin{array}{l}\text { Motion sickness: It's so } \\
\text { messy that many of us } \\
\text { have given up on it as a } \\
\text { specific problem }\end{array}$ & $\begin{array}{l}\text { Brain imaging during } \\
\text { head/body motion }\end{array}$ & $\begin{array}{l}\text { Increased recognition of } \\
\text { ubiquity of vestibular } \\
\text { disorders }\end{array}$ \\
\hline & & $\begin{array}{l}\text { Pathways from vestibular } \\
\text { afferents to spatial } \\
\text { orientation and cognition }\end{array}$ & & \\
\hline
\end{tabular}




\begin{tabular}{|c|c|c|c|c|}
\hline & $\begin{array}{l}\text { The most significant } \\
\text { scientific advances in this } \\
\text { area, last } 5 \text { or so years }\end{array}$ & $\begin{array}{l}\text { The outstanding } \\
\text { scientific challenges }\end{array}$ & $\begin{array}{l}\text { The outstanding } \\
\text { methodological challenges }\end{array}$ & $\begin{array}{l}\text { The outstanding national } \\
\text { needs for applications }\end{array}$ \\
\hline \multirow[t]{5}{*}{ Respondent 10} & $\begin{array}{l}\text { Neuro modeling of the } \\
\text { vestibular ocular reflex }\end{array}$ & $\begin{array}{l}\text { The process of adaptation / } \\
\text { maladaptation }\end{array}$ & $\begin{array}{l}\text { Measuring the VOR } \\
\text { [vestibular-ocular reflex] } \\
\text { non- invasively }\end{array}$ & $\begin{array}{l}\text { Making Vestibular } \\
\text { Rehabilitation Therapy } \\
\text { effective and getting } \\
\text { primary health service } \\
\text { providers to correctly } \\
\text { identify patients and refer } \\
\text { them to specialists }\end{array}$ \\
\hline & $\begin{array}{l}\text { O-VEMP [ocular } \\
\text { vestibular-evoked } \\
\text { myogenic potential] }\end{array}$ & $\begin{array}{l}\text { Understanding the } \\
\text { mechanism in Meniere's } \\
\text { disease }\end{array}$ & $\begin{array}{l}\text { Variations in clinical studies } \\
\text { and control groups - lack of } \\
\text { objective measures and } \\
\text { blinding }\end{array}$ & $\begin{array}{l}\text { Dealing with the large } \\
\text { number of aged/stroke and } \\
\text { mTBI/TBI [mild/tramautic } \\
\text { brain injury] balance } \\
\text { dysfunction patients } \\
\text { (economically and } \\
\text { effectively) }\end{array}$ \\
\hline & Sensory substitution & Vestibular prosthesis & & $\begin{array}{l}\text { Preventing vestibular } \\
\text { injury from blast injuries }\end{array}$ \\
\hline & $\begin{array}{l}\text { Sensory augmentation } \\
\text { using vibro-tactile arrays }\end{array}$ & & & \\
\hline & $\begin{array}{l}\text { CDP (computerized } \\
\text { dynamic posturography) }\end{array}$ & & & \\
\hline \multirow[t]{4}{*}{ Respondent 11} & $\begin{array}{l}\text { Not much. Primarily due } \\
\text { to recognition of problems } \\
\text { and lack of funding }\end{array}$ & $\begin{array}{l}\text { Coupling of inner ear } \\
\text { mechanics with hair cell } \\
\text { transduction }\end{array}$ & $\begin{array}{l}\text { Treatment of motion } \\
\text { sickness and preventing } \\
\text { disorientation }\end{array}$ & $\begin{array}{l}\text { Drugs to prevent motion } \\
\text { sickness }\end{array}$ \\
\hline & $\begin{array}{l}\text { Basic science has } \\
\text { progressed through NIH } \\
\text { (National Institute of } \\
\text { Health). Understanding of } \\
\text { hair cells is probably the } \\
\text { most significant } \\
\text { advancement. }\end{array}$ & $\begin{array}{l}\text { Understanding the origin } \\
\text { of motion sickness }\end{array}$ & & $\begin{array}{l}\text { With autonomous aircraft } \\
\text { making up the future of } \\
\text { military aviation, what are } \\
\text { the problems that need to } \\
\text { be addressed in manned } \\
\text { aircraft? Disorientation } \\
\text { may be the paramount } \\
\text { problem in the future }\end{array}$ \\
\hline & & $\begin{array}{l}\text { How can a person be } \\
\text { evaluated as susceptible to } \\
\text { motion sickness, and space } \\
\text { motion sickness syndrome }\end{array}$ & & $\begin{array}{l}\text { Are manned space craft } \\
\text { going to play an important } \\
\text { part of future space } \\
\text { exploration? If so, } \\
\text { solutions to long-term } \\
\text { space habitation need to be } \\
\text { addressed. Long term } \\
\text { needs: Exposure to } \\
\text { ionizing radiation, } \\
\text { weightlessness, cognition }\end{array}$ \\
\hline & & & & $\begin{array}{l}\text { Clinical tests for inner ear } \\
\text { function need to be } \\
\text { developed. Today there are } \\
\text { very little for clinicians. }\end{array}$ \\
\hline
\end{tabular}




\begin{tabular}{|c|c|c|c|c|}
\hline & $\begin{array}{l}\text { The most significant } \\
\text { scientific advances in this } \\
\text { area, last } 5 \text { or so years }\end{array}$ & $\begin{array}{l}\text { The outstanding scientific } \\
\text { challenges }\end{array}$ & $\begin{array}{l}\text { The outstanding } \\
\text { methodological challenges }\end{array}$ & $\begin{array}{l}\text { The outstanding national } \\
\text { needs for applications }\end{array}$ \\
\hline \multirow[t]{5}{*}{$\begin{array}{l}\text { Respondent } \\
12\end{array}$} & $\begin{array}{l}\text { Better understanding of } \\
\text { information processing in } \\
\text { the spatial orientation } \\
\text { systems, especially the } \\
\text { dynamics of these systems } \\
\text { (see, for example Park S, et } \\
\text { al. })\end{array}$ & $\begin{array}{l}\text { Development of better } \\
\text { educations programs at all } \\
\text { levels and all disciplines } \\
\text { regarding vestibular and } \\
\text { converging systems }\end{array}$ & $\begin{array}{l}\text { Improve binocular imaging } \\
\text { techniques for use during } \\
\text { both active and passive } \\
\text { dynamic conditions }\end{array}$ & $\begin{array}{l}\text { Establish a separate NIH } \\
\text { Vestibular Institute - } \\
\text { Vestibular disorders are three } \\
\text { times more common than } \\
\text { hearing loss (See Agrawal, Y., } \\
\text { Carey, J. P., Della Santina, C. } \\
\text { C., Schubert, M. C., \& Minor, } \\
\text { L. B. 2009. Arch. Intern. Med. } \\
\text { 169(10): 938-944.) }\end{array}$ \\
\hline & $\begin{array}{l}\text { Development of reliable } \\
\text { clinical methods for otolith } \\
\text { assessment: Vestibular } \\
\text { evoked myogenic } \\
\text { potentials (cVEMP and } \\
\text { oVEMP) }\end{array}$ & $\begin{array}{l}\text { Development of adequate } \\
\text { funding support and } \\
\text { centers for vestibular } \\
\text { research and clinical } \\
\text { applications }\end{array}$ & $\begin{array}{l}\text { Improve body segment } \\
\text { (especially head and trunk) } \\
\text { recording dynamics during } \\
\text { exposure to novel inertial } \\
\text { environs }\end{array}$ & $\begin{array}{l}\text { Better educational programs } \\
\text { for all health care providers }\end{array}$ \\
\hline & $\begin{array}{l}\text { Development of vestibular } \\
\text { prostheses }\end{array}$ & $\begin{array}{l}\text { Implementation of } \\
\text { prospective } \\
\text { epidemiological studies on } \\
\text { vestibular disorders }\end{array}$ & $\begin{array}{l}\text { Develop better statistical } \\
\text { methods for data comparison } \\
\text { (e.g., psychophysical and } \\
\text { physiological data) }\end{array}$ & $\begin{array}{l}\text { Develop better professional } \\
\text { certification programs }\end{array}$ \\
\hline & $\begin{array}{l}\text { Development of reliable } \\
\text { epidemiological data (See, } \\
\text { for example: Agrawal, Y., } \\
\text { et al.) }\end{array}$ & $\begin{array}{l}\text { Expand studies on } \\
\text { cognitive disruption } \\
\text { associated with exposure to } \\
\text { novel inertial environments } \\
\text { and vestibular disorders }\end{array}$ & $\begin{array}{l}\text { Develop imaging techniques } \\
\text { that can be used during } \\
\text { dynamic conditions }\end{array}$ & $\begin{array}{l}\text { Promote studies focusing on } \\
\text { performance consequences of } \\
\text { exposure to novel motion } \\
\text { environments and effects of } \\
\text { vestibular disorders on } \\
\text { performance, (e.g., driving) }\end{array}$ \\
\hline & $\begin{array}{l}\text { Neural imaging techniques } \\
\text { for vestibular pathways }\end{array}$ & $\begin{array}{l}\text { Development of standard } \\
\text { technologies for evaluation } \\
\text { of the vestibular sensors } \\
\text { and converging systems }\end{array}$ & $\begin{array}{l}\text { Better methods for assessing } \\
\text { the various components of } \\
\text { motion sickness }\end{array}$ & $\begin{array}{l}\text { Continue development of } \\
\text { vestibular prostheses }\end{array}$ \\
\hline \multirow[t]{3}{*}{$\begin{array}{c}\text { Respondent } \\
13\end{array}$} & $\begin{array}{l}\text { Clinical tests for otolith } \\
\text { function }\end{array}$ & $\begin{array}{l}\text { Explaining and predicting } \\
\text { motion sickness }\end{array}$ & Respondent 13 & $\begin{array}{l}\text { Clinical tests for otolith } \\
\text { function }\end{array}$ \\
\hline & & $\begin{array}{l}\text { Explaining and predicting } \\
\text { perception of complex } \\
\text { motion }\end{array}$ & & \\
\hline & & $\begin{array}{l}\text { Understanding differences } \\
\text { between eye movements } \\
\text { and perception }\end{array}$ & & \\
\hline $\begin{array}{l}\text { Respondent } \\
14\end{array}$ & & & & $\begin{array}{l}\text { Create the website as } \\
\text { described below and keep it } \\
\text { updated with the latest } \\
\text { information and presentation } \\
\text { technology }\end{array}$ \\
\hline
\end{tabular}

\footnotetext{
* The respondent is likely referring to such articles as the following two: 1) Park, S., Horak, F. B., \& Kuo, A. D. 2004. Postural feedback responses scale with biomechanical constraints in human standing. Experimental Brain Research, 154(4), 417-27. 2) Merfeld, D. M., Park, S., Gianna-Poulin, C., Black, F. O., \& Wood, S. 2005. Vestibular perception and action employ qualitatively different mechanisms. I. Frequency response of VOR and perceptual responses during translation and tilt. Journal of neurophysiology, 94(1) 186-198. Additional publications by Park can be found at http://www.pubfacts.com/author/Sukyung+Park.
} 


\begin{tabular}{|c|c|c|c|c|}
\hline & $\begin{array}{l}\text { The most significant } \\
\text { scientific advances in this } \\
\text { area, last } 5 \text { or so years }\end{array}$ & $\begin{array}{l}\text { The outstanding scientific } \\
\text { challenges }\end{array}$ & $\begin{array}{l}\text { The outstanding } \\
\text { methodological challenges }\end{array}$ & $\begin{array}{l}\text { The outstanding national } \\
\text { needs for applications }\end{array}$ \\
\hline $\begin{array}{l}\text { Respondent } \\
14 \\
\text { (continued) }\end{array}$ & & & & $\begin{array}{l}\text { Develop the hardware and } \\
\text { software to allow the } \\
\text { NAMRL (Naval Aerospace } \\
\text { Medical Research } \\
\text { Laboratory) model to be } \\
\text { incorporated with onboard } \\
\text { aircraft avionics and for } \\
\text { those cases in which it } \\
\text { cannot be integrated into the } \\
\text { avionics; develop the } \\
\text { hardware and software for } \\
\text { an independent unit that can } \\
\text { be brought onboard }\end{array}$ \\
\hline \multirow[t]{2}{*}{$\begin{array}{l}\text { Respondent } \\
15\end{array}$} & $\begin{array}{l}\text { Realization that mTBI } \\
\text { included vestibular deficit }\end{array}$ & $\begin{array}{l}\text { Mechanism for brain } \\
\text { plasticity that affects } \\
\text { vestibular recovery }\end{array}$ & $\begin{array}{l}\text { Language regarding } \\
\text { vestibular function is not } \\
\text { quantified except when using } \\
\text { Sensory Organization Test } \\
\text { (SOT) outcomes. For } \\
\text { example, knowing percentage } \\
\text { of sensory system } \\
\text { engagement under which } \\
\text { conditions would be helpful } \\
\text { for maximizing functional } \\
\text { control of sway. } \\
\text { Is there a possibility of } \\
\text { creating a "vestibiometer?" } \\
\text { Do we look towards VOR, } \\
\text { vestibular nerve EMG } \\
\text { (electromyographic), } \\
\text { measurement of sway, or } \\
\text { some other objective } \\
\text { measurement }\end{array}$ & $\begin{array}{l}\text { Cost effective way to } \\
\text { measure vestibular function }\end{array}$ \\
\hline & $\begin{array}{l}\text { BPPV is more prevalent } \\
\text { than first thought }\end{array}$ & $\begin{array}{l}\text { Brain cortex manipulation } \\
\text { For example, does the } \\
\text { somatosensory cortex } \\
\text { become primary under... }\end{array}$ & & \\
\hline \multirow[t]{2}{*}{$\begin{array}{l}\text { Respondent } \\
16\end{array}$} & $\begin{array}{l}\text { Improved tests coming } \\
\text { online (i.e., VEMP, } \\
\text { cVEMP) leading to } \\
\text { diagnosis }\end{array}$ & $\begin{array}{l}\text { Biggest issue is reducing } \\
\text { "slips, trips, and falls" }\end{array}$ & $\begin{array}{l}\text { Technology that provides real } \\
\text { time accurate measure of } \\
\text { cycle CoG and CoP to create } \\
\text { ambulatory multisensory } \\
\text { prostheses to prevent falls }\end{array}$ & $\begin{array}{l}\text { Techniques to measure } \\
\text { balance impairment and } \\
\text { compare patients between } \\
\text { practitioners providing } \\
\text { treatment }\end{array}$ \\
\hline & $\begin{array}{l}\text { Acceptance of Epley } \\
\text { treatments for most } \\
\text { frequent dizziness cause } \\
\text { BPPV }\end{array}$ & $\begin{array}{l}\text { Understanding the } \\
\text { etiology or basis for M.S. } \\
\text { so solutions can be } \\
\text { developed based on } \\
\text { understanding the cause }\end{array}$ & $\begin{array}{l}\text { Algorithm development for } \\
\text { multisensory prostheses }\end{array}$ & $\begin{array}{l}\text { Prostheses to prevent falls } \\
\text { and improve orientation }\end{array}$ \\
\hline
\end{tabular}




\begin{tabular}{|l|l|l|l|l|}
\hline & $\begin{array}{l}\text { The most significant } \\
\text { scientific advances in this } \\
\text { area, last 5 or so years }\end{array}$ & $\begin{array}{l}\text { The outstanding scientific } \\
\text { challenges }\end{array}$ & $\begin{array}{l}\text { The outstanding } \\
\text { methodological challenges }\end{array}$ & $\begin{array}{l}\text { The outstanding national } \\
\text { needs for applications }\end{array}$ \\
\hline $\begin{array}{l}\text { Respondent } \\
\text { (continued) }\end{array}$ & $\begin{array}{l}\text { Acceptance of tactile cueing } \\
\text { as methodology for balance } \\
\text { rehabilitation }\end{array}$ & $\begin{array}{l}\text { Incorporating into the model } \\
\text { of orientation the quantitative } \\
\text { contributions from skin, } \\
\text { muscle, joint, visual, and } \\
\text { auditory systems }\end{array}$ & $\begin{array}{l}\text { Techniques of measuring gait } \\
\text { \& balance performance that } \\
\text { clinicians and therapists can } \\
\text { use to measure and assess } \\
\text { level of performance }\end{array}$ & $\begin{array}{l}\text { Develop systems to provide } \\
\text { sensory information for } \\
\text { elderly and patients } \\
\text { challenged by sensory } \\
\text { deficits }\end{array}$ \\
\hline & $\begin{array}{l}\text { Increasing acceptance of } \\
\text { vestibular rehabilitation by } \\
\text { clinicians as treatment }\end{array}$ & $\begin{array}{l}\text { The etiology of Meniere's } \\
\text { Disease }\end{array}$ & $\begin{array}{l}\text { Difficulty in developing } \\
\text { biochemical solutions when } \\
\text { biochemistry of } \\
\text { neurophysiology is not } \\
\text { understood }\end{array}$ & $\begin{array}{l}\text { Understand the role and } \\
\text { mechanism of action of } \\
\text { vestibular efferent system }\end{array}$ \\
\hline $\begin{array}{l}\text { Basic science understanding } \\
\text { of both neurophysiology and } \\
\text { biochemistry of adaptation } \\
\text { and "learning" at brain stem } \\
\text { level }\end{array}$ & $\begin{array}{l}\text { Developing quantitative } \\
\text { measure of performance for } \\
\text { PT community to both } \\
\text { evaluate and monitor } \\
\text { progress of patients }\end{array}$ & $\begin{array}{l}\text { Solving the hair cell } \\
\text { regeneration problem for both } \\
\text { hearing and vestibular }\end{array}$ & $\begin{array}{l}\text { Silver bullet to counteract } \\
\text { M.S. }\end{array}$ \\
\hline
\end{tabular}




\section{Appendix C.}

Frederick Guedry obituary and funeral oration.

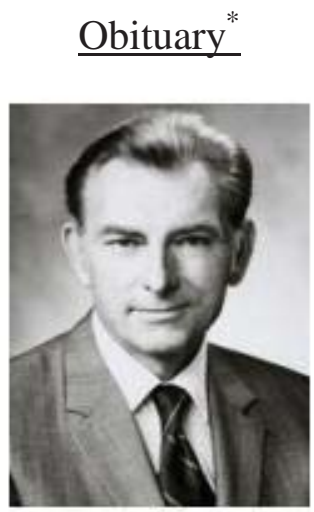

Dr. Frederick E. Guedry, Jr. 1921-2011

Dr. Frederick E. Guedry, Jr., 89, of Pensacola, FL died February 5, 2011. He was born on December 10, 1921 in New Orleans, LA, the only child of Emily Spalding Guedry and Frederick Ernest Guedry, Sr. Fred was a true son of his city. He learned to play baseball with neighborhood boys in abandoned lots and started his education with the Jesuits at Holy Cross.

He enrolled at Tulane and took a degree in psychology. While an undergraduate, he lettered in baseball and pitched a no-hit game against LSU, an accomplishment he remembered fondly all his life. He belonged to the Pi Kappa Alpha fraternity.

After graduation, he enlisted in the Navy in 1943 and became Assistant Communications Officer aboard the USS LST 273. Fred participated in 7 major invasions and 10 landings on Japanese held islands in the Pacific Theater of Operations. Though promoted four times to become Commanding Officer of LST 273 by age 23, he considered the true heroes of World War II the disabled and dead whose terrible losses he never forgot.

After the war, Fred returned to Tulane and received his master's and doctorate degrees in 1948 and 1954. During this time he taught at Newcomb College, New Orleans and engaged in research at both Tulane University and the School of Aviation Medicine, Pensacola. He moved to Fort Knox, Kentucky when he joined the Army Medical Research Laboratory in 1954 and there was appointed Director of the Psychology Department in 1958. He returned to Pensacola in 1961 to the School of Aviation Medicine, renamed the Naval Aerospace Medical Research Laboratory (NAMRL). At NAMRL, he served as Chief, Perception and Behavioral Sciences Department from 1961-1980; Head, Sensory Sciences Department, 1980-1983, Senior Scientist, 1983-1986, and Chief Scientist, 1986-1990. He continued his research under the shared auspices of NAMRL and the University of West Florida as Scholar Scientist/Professor of Psychology with the Institute for Human and Machine Cognition. His association with UWF and the Institute officially came to an end when he retired; however, the indefatigable "Dr. Dizzy," as he

*http://www.legacy.com/obituaries/pensacolanewsjournal/obituary.aspx?n=frederick-e-guedry\&pid=148479261 
has been called, continued to consult and research from his home office up to the time of his death.

His professional honors, awards, and publications are too numerous to list in entirety. Among them: Elected Fellow American Association for the Advancement of Science; Elected Fellow Aerospace Medical Association; Raymond F. Longacre Award for Outstanding Accomplishment in Psychological and Psychiatric Aspects of Aviation Medicine, Aerospace Medical Association; Elected to the Bárány Society; Elected Fellow American Psychological Association; Eric Liljencrantz Award of the Aerospace Medical Association for Research in Problems of Acceleration; John Jeffries Medical Research Award for Outstanding contributions in the Advancement of Aerospace Medical Research from the American Institute of Aeronautics and Astronautics; AGARD, North Atlantic Treaty Organization, multiple aspects of engagement and consultation; author of close to 200 research articles and chapters in the areas of sensory motor function, spatial orientation and motion sickness; presenter of numerous papers at international scientific meetings in Germany, Holland, Sweden, Japan, France, England, Italy and Australia. He belonged to numerous professional organizations in addition to those already mentioned, some of them: Southern Society for Psychology and Philosophy, Society of Sigma Xi, the Association for Otolaryngology, and the National Academy of Sciences.

In November of 2010, longtime friend Dr. Angus Rupert organized to have friends and colleagues, both national and international, gather in Pensacola at the Institute of Human and Machine Cognition to consider the implications and continuing research Dr. Guedry has inspired. After this series of meetings, a special program held at the Naval Aviation Museum, dubbed the Fred Fest, celebrated Dr. Guedry's years of exceptional achievement as well as his generous support of other scientists.

In addition to his professional associations, Fred was a member and former Board Member of First United Methodist Church; member and past president of the Greater Pensacola Tennis Association; member of the Pensacola Racquet Club; and member of the Pensacola Yacht Club.

He is preceded in death by his father, Frederick Ernest Guedry, Sr., his mother, Emily Spalding Guedry, and his first wife Kathryn Clark Guedry.

Survivors include his wife of 44 years, Alma Bailey Guedry; daughter, Charlene Tittemore Leinback, daughter, Kathleen Guedry Lovan (Dr. Wendell), daughter, Deborah Guedry Brothers (Capt. E. E. "Buddy"); grandchildren, Elizabeth Anne Leinback, Michael Bailey Mooney, Kevin Patrick Mooney, and Hannah Christie Brothers; his cousin Dr. Archie Guedry Addison (Dr. Monique), sisters-in-law Jan Busbee, Bea Rivers, Barbara Graves, Myrtle Bailey, and Linda Snow (Bob); brothers-in-law Grover Bailey (Sue), Ben Bailey (June), Wayne Bailey, and Tom Clark (Betty Ann); numerous nieces and nephews; many exceptional colleagues and friends; and one very special big orange cat, Zan.

Funeral services for Dr. Guedry were held on Friday at 2 p.m., February 11, 2011 at the First United Methodist Church, 6 Wright Street, Pensacola with Dr. Wesley Wachob officiating. Visitation was held at 1 p.m., also at the church. Burial was at Bayview Memorial Park immediately following the funeral service. Memorials may be made to the First United Methodist Church or to the Pensacola Humane Society. 


\section{Funeral Oration.}

(Numerous moving eulogies were given at Fred Guedry's funeral. The following eulogy was given by Dr. Ben Lawson.)

This week I had the sad task of compiling information which might help with the writing of Fred's obituary. As I did that, it seemed strange that soon someone would try to summarize this man's life in a few paragraphs. That's like trying to convey the transcendence of an eagle's flight by describing the structure and articulation of its dried and mounted bones. I am not a Tom Brokaw fan, but when I think of Fred I find myself able to believe in the concept of the "Greatest Generation," because Fred embodied that concept.

I can't speak authoritatively on the afterlife since I haven't been there yet, but I can tell you this for sure: Fred's deeds during his life have already made him immortal in the Shakespearean sense because he will live forever in the memory of those who have known him or have read his work. I'm also sure of how lucky I am that our paths crossed and that I had the chance to tell him exactly how I felt about him at the recent scientific meeting we held in his honor.

Godspeed, Fred Guedry! 


\section{Appendix D.}

\section{Historian Interview.}

In addition to his many contributions to vestibular research, Dr. Guedry participated significantly in combat actions during WWII. This is a transcript of an interview by Jan Herman of the Navy Bureau of Medicine, discussing Fred's wartime experiences and his initial entry into research following the war. The interview was held in Pensacola, Florida on October 21, 2010.

Herman: How did you get into LSTs [Landing Ship, Tank]? That's what I want to know.

Guedry: You went wherever they sent you. I requested PT (patrol torpedo) boats.

Herman: PT boats?

Guedry: Yeah. But I didn't get them.

Herman: What kind of training had they given you in the Navy prior to going out to the Pacific?

Guedry: Three months at Northwestern.

Herman: You're from Louisiana, aren't you?

Guedry: New Orleans, yeah. When I finished my training, I had 4 days to proceed and report. I reported in 4 days and they said, 'Go home and pack. You got your shift.' So, that night I was in the Gulf of Mexico.

Herman: Where had that LST been built?

Guedry: Probably in Pittsburgh.

Herman: Uh huh.

Guedry: I Googled the LST 273 and it said it came down the river in November. I think, to me, it was earlier than that but I know we were in San Francisco for Christmas of ' 43 and we went from New Orleans to Guantanamo Bay to the Canal Zone, then, from there to San Diego, where I became the radar officer, and from San Diego to San Francisco.

Herman: And then you took it across the Pacific? Where did you go from San Francisco?

Guedry: To Pearl Harbor.

Herman: You went to Pearl on the LST? On the 273?

Guedry: Yeah. 
Herman: And what were your orders from there? From Pearl?

Guedry: Well, we didn't know. We went to Kwajalein and Enewetak, but we didn't know. You know, they didn't ... in those days nobody knew except whoever ordered the Commanding Officer to go.

Herman: So you had went to the campaign already, it was '44, and Enewetak and Kwajalein had already been taken? Or did you take troops there?

Guedry: No, no. We went, we took Kwajalein and Enewetak, and Enewetak, we went back to Kwajalein, a lot. And I don't know what was going on but I had a pretty athletic background. I guess that's the reason I was selected. This was very risky in a small boat. From my ship to a battleship, which I think Nimitz was on, I'm not sure. Anyway, I picked up a whole bunch of orders and from there we went from one LST to the other, to the other, and that was, I guess, orders for Saipan. I don't know exactly what was going on then.

Herman: I guess Saipan and Guam were the next on the list?

Guedry: Saipan and Tinian.

Herman: Saipan and Tinian and Guam.

Guedry: No, we didn't go to Guam.

Herman: You didn’t go to Guam. OK. But Tinian and Saipan were the big ones.

Guedry: Saipan actually was, in a way, one of the worst invasions for me because I was in charge of letting the LVT [landing vehicle tracked] off, and bringing them back. I also was helping the docs and we were bringing people aboard that were wounded. And the first guy I brought aboard, his guts dropped out and I almost passed out. And then the doc gave me little packets, I guess it was sulfa, to pour in the open wounds, which I did. Then, in the board room was a guy with a horrible facial injury, and finally we got so many the doc couldn't take anymore, so I had to go to the rail and tell a small boat that we were coming out with wounded, and that we couldn't take anymore. I had one guy cuss me out. You could actually see his shoulder bone exposed. And, well, interesting, you knew there were six ships blown up in Pearl Harbor from the...?

Herman: The big accident? The ammunition accident? West Loch was it?

Guedry: West Loch, yeah. TNT is what...TNT bigger than this whole room in the back end of the tank deck. And when we got to Saipan they could fire at us from Tinian, and the ship that we were supposed to use to go ashore and discharge our cargo.

Herman: On Tinian? 
Guedry: No, on Saipan. And Captain John James, who I think had been an All-American football player at Princeton, he kicked the back of the stern anchor off and he got caught in the cable, and so he was severely injured and we got him back on board. And I imagine he was alright, but his testicles were about that big [gestures with hands]. So we didn't beach. But the ship that did beach was hit and he was requesting permission to retract, and then the commission finally came through and he says he can't retract. A shell had just went through his engine room. But, fortunately, his cargo had already been discharged.

Herman: This was an LVT?

Guedry: LST.

Herman: Oh, it was an LST that was on there. OK.

Guedry: Yeah.

Herman: So it was close to the beach?

Guedry: On the beach. Yeah, we beached a lot of places.

Herman: I was over at Saipan just a few years ago with the landing beaches and you can still see the coral tanks, with their guns just sticking above the water, that are still out there after all these years.

Guedry: Yeah, well, that had to be a horrible invasion for the Marines because their idea was to take a point ASAP, and the Army was much better. They progressed gradually until they had taken a place and then they took another one. But the Marines had a target to take, such-andsuch a hill in record time, which they did, but they really lost a lot of men. I didn't like to have the Marines on board.

Herman: Saipan was the first time they really had encountered a large number of civilians. There were still a lot of civilians left on Saipan.

Guedry: I didn't know this at the time but I heard later on that they were terrified of us and some of them just jumped into the ocean and drowned.

Herman: You didn't see any of that did you?

Guedry: No, but I did get ashore after the invasion was supposedly safe, and walking down the road there was a hand sticking up they had not quite buried. Then I got to an area where they had a whole bunch of, not soldiers, but civilian Japanese in a fence* .

\footnotetext{
*Original text read "Japanese in offense." The authors believe this was transcribed incorrectly, because "in offense" does not fit the context of Dr. Guedry’s statement.
} 
Herman: Was it Saipan that was the last one you were involved in or were you involved in campaigns after that?

Guedry: Oh a lot of them after that. Let's see, Saipan, Tinian, Peleliu and the Palau Islands. In the gulf, twice, we took some big pontoons that were on the sides of our ship. I was in charge of releasing them and I did it perfectly but the guys on shore didn't catch the end of it so that didn't work. We managed to get a load of stuff off but it took a long time. Incidentally, before we left on the $2^{\text {nd }}$, I had my second Christmas on board a ship, and we took a tremendous load on. I tried to stop them because I had somebody keeping count of the load. The period of roll on the LST is about 5 seconds and it increased to 8 seconds. But on the way to the gulf, I could see the firing and I guess this was the big ships. The battleships with the U.S. and the Japanese battleships were [big].

Herman: The big battle in Lingayen Gulf. You saw that?

Guedry: Yeah. At night. I could see the firing I could hear it but we were pretty far away, fortunately. Then when we went in to the Lingayen Gulf I saw my first suicide plane. Just one, though. After Lingayen Gulf we went somewhere then we came back. We beached on New Guinea for some reason, I don't know why. I got something called iron wood. It wouldn't float. And from there we went to Okinawa. Our load was 4,000 drums of 100 octane gasoline. And we sat off the beach for 16 days.

Herman: Not a good place to be sitting with all that aviation fuel.

Guedry: Well, hundreds and hundreds of suicide planes.

Herman: That's what I mean. You were a target. Did you see any of them then?

Guedry: Oh boy, yes we did. And one night, I guess it was a Jap Betty [Mitsubishi bomber], dropped a bomb on one side of a ship, and the ship went up [in flames] and then it [the Mitsubishi bomber] just dropped a string of bombs and, fortunately, it didn't hit us. Anyway, that's pretty much the end of the story. After 16 days, we went back to the states.

Herman: Were you taking on your cargo for these all at Pearl, or where were you taking the cargoes on?

Guedry: A lot of places. Tulagi is right across from Guadalcanal and down further, I can't remember the name of it, but I remember there were nurses, so everybody got binoculars to see the nurses and we took on cargo there, I guess.

Herman: So the cargoes were mixed, one time it could be fuel, another time it could be other equipment.

Guedry: We usually had 200 drums of 100 octane gas on our boat but when we had the 4,000 drums of 100 octane we just had the ammunition on the boat. 
Herman: You were like a time bomb out there with all that stuff.

Guedry: Yeah, we were.

Herman: I imagine. I understand from people I've spoken with who were at Okinawa and who were subjected to the kamikaze attacks that the anxiety was about as high as it could possibly get.

Guedry: It was. It was incredible. I didn't shave for 16 days. You were up almost all night because every time you'd hit the sack, general quarters would go off. I spent most of my time up on the second deck under the focsle [forward part of the ship] because my duty was on the focsle. It was a rough one.

Herman: Did your job as a radioman...

Guedry: No, I wasn't a radioman. I was first LT from Saipan on.

Herman: So what were your duties at that point?

Guedry: Well, you were supposed to be in charge of the deck gang and take care of the ship and make sure the ship is chipped and painted and that kind of thing. Also we had to repaint the numbers on the bow of our ship and things like that. But that main duty during the invasion was discharging and taking the LVTs back on and we had a good system. You'd throw the lines out and we' $d$ criss-cross them like that [makes hand gesture], and we had about 15 guys on each rope, and when the LVT's tracks got into the ramp I would call them back and then you had to run because this thing would come charging up and if a wave caught it, it came in really fast. Fortunately, we never had one criss-cross. We got them all back.

Herman: And once you got the LVTs back aboard then it was back to another base for their repair?

Guedry: Well, it would come back to refuel and get more ammunition, I guess. I can't remember exactly because I wasn't paying much attention to that because I was doing other things. But they did come back and then they'd go back again.

Herman: With the LST to discharge the LVTs, that could be done off the beach couldn't it?

Guedry: Oh yeah.

Herman: You would discharge and the clamshell doors would open and they would go right in off the ramp.

Guedry: Yeah, well that was the typical way. I don't think we ever discharged them on the beach.

Herman: So after Okinawa, of course, that was pretty much the last campaign of the war... 
Guedry: Of course, we didn't know that.

Herman: Well, where were you when you heard about the bomb?

Guedry: I didn't, I was flying from my home. We had 10 days leave. Somewhere between-I don't know whether they went to San Francisco or Long Beach-but anyway somebody woke me up and said something... I don't remember exactly what they said, because I didn't realize at that time that the war was over. And it wasn't until we got back and got out a little bit that we found out that the war was really over. And then we went on out to Pearl Harbor, and from Pearl Harbor we went to Guam, and from Guam we went back to Okinawa because a typhoon had pretty much destroyed the supplies the troops had there, so we resupplied them. And we had a new captain named Briby, and we went from Okinawa back to Guam, and that's when I became commanding officer.

Herman: So you became commanding officer of the 273? How'd you feel about that? You'd been on a ship all that time and now you were going to be calling the shots.

Guedry: Well, I had had a lot of time controlling the ship. You know, we had convoys and we would shift, zigzag along, and had a lot of experience avoiding other ships and things like that, and sometimes one would break down or something. From Guam we went to Guadalcanal, and New Caledonia, and Auckland, New Zealand, and we had picked up a whole bunch of bulldozers. The pilot going into Auckland said, 'what's your cargo?' and I said, 'bulldozers,' and he says, 'oh, we got a lot full of those things.' American industry didn't want to have them coming back. [We] went from Auckland, New Zealand to Wellington, New Zealand. In Wellington, we picked up 440 Japanese prisoners.

Herman: Were they going to be repatriated now, being that the war was over?

Guedry: Well, I don't know what happened to them.

Herman: Where did you take them?

Guedry: [I] took them to Guam but I was supposed to take them to Japan and, fortunately, my dad needed help at home and he had contacted... he had been in the Navy in World War I. So my orders to get off my ship and take these guys to Japan were counteracted and I ended up... shortly after we left Guadalcanal, one engine went out, so we went from Guadalcanal. Eventually we got to Pearl Harbor. From Pearl Harbor we got to Long Beach, California, and that's where I got off the ship.

Herman: One question. You spent at least 2 years, maybe 2.5 years on that LST?

Guedry: I had three Christmases on it. I don't know.

Herman: Three. I understand from the reading I've done-and I've not been on an LST except as a museum piece - my understanding is that they weren't the greatest vessels around for a smooth ride, especially in rough water. You have any comment on that? 
Guedry: We had - I don't remember where we were going - we had huge waves, 75 feet, going into Ulithi. That was just a place to get out of the storm, and when we got in there, a bow had been broken off. I don't know if it was a battle cruiser or what, but it was a big ship. That's where the destroyers did a 180. I guess they were between the Phillipines, and I guess it was China, and I don't know why that ship didn't break but it didn't. But I'll tell you one thing, the gyros-I don't know how many strings of steel held up a weight in the gyro, but that broke off.

Herman: The typhoon you were talking about, I guess it was December of ' 44 , the one they ended up calling Halsey's typhoon? Or was that another typhoon?

Guedry: No, that wasn't that one, I don't think. Well, it might have been. Most of my action was in ' 44 but I had Christmas of ' 45 in Lady and then Christmas of, must've been '46, in Auckland, New Zealand.

Herman: And then you went back to the States? Back to San Francisco?

Guedry: No, I went to Long Beach.

Herman: Long Beach. I'm sorry. So was that essentially the end of your Navy career at this point?

Guedry: Yeah.

Herman: Now I understand that you signed your own discharge? Is that true?

Guedry: Yeah, I did. Wasn’t anybody else to do it.

Herman: Which technically means you're still on active duty.

Guedry: Well, they're not paying me.

Herman: So when you got back from the war of course you resumed your studies.

Guedry: Well, not right away. I went into business with my dad for a while for about 3 or 4 months.

Herman: What kind of business was your dad in?

Guedry: He was in ship-to-shore transportation business and it was booming at that time. But, unfortunately, he had some partners that were not very good people and eventually my dad lost out on that, which I felt very bad about because I had gotten out and gone back to school.

Herman: So you were at Tulane at that point? What were you studying there?

Guedry: Psychology. Fortunately, Cecil Mann got a contract with the Navy and Ash Graybiel had a rotator, so I got into vestibular work that way. 
Herman: Where was the rotator located?

Guedry: Building 625 D.

Herman: Here in [Naval Air Station] Pensacola?

Guedry: Yeah.

Herman: Was that ' 47 by then?

Guedry: Must have been.

Herman: So that was when you first got your association with Dr. Graybiel, at that point? And you got hooked I guess? You got hooked into that kind of work?

[Transcript ends here].

Other Notes Drafted by Historian Concerning Guedry's Life and Contributions

- Fred joined the V7 program, which allowed him to finish college and then join the military. He was given an enlisted rank. He graduated from Tulane, went to Northwestern to Midshipmen school, and then was commissioned to active duty. He became a Lieutenant JG, his highest rank. He became Commanding Officer of the ship as a JG at 24 years old. He left the Navy as a Lieutenant JG.

- At Fort Knox, Kentucky, while working with the Army for their aviation and helicopter community, he solved a differential equation that let him predict what would happen if you turned a tank turret 180 degrees. That was the beginning of his career. He began publishing a lot.

- The rotator that he designed was operational and he was doing other vestibular experiments with it. His experiments were being published by the Army.

- From the Army in Ft. Knox, he went to Cape Cod and had meetings there (Woods Hole). Then he was invited to Sweden to Bárány Society (met every 4 years in Sweden and every second year somewhere else). All preliminary work for putting a man in space (he is not sure of time at this point - thinks it had to be the '50s). Work connected with Swedish conference still connected with the Army.

- Fred made suggestions for an experiment in Pensacola, and he got selected to perform it. He went from New Orleans to Pensacola with Clyde Nobel. That was beginning of his career in vestibular work.

- The Navy was developing pressure suits for the space program. Guedry was still working on rotators. He worked on the rotating room with Dr. Graybiel to acclimate people to space rotation (late '50s or early '60s). 
- Fred's work and contributions to the world of centrifuges deals with cross-coupled effects and something they call it G-excess — coined/discovered by Dr. Guedry. Difficult to study because you almost need an airplane at Mach 1.

- $\quad$ One of the people that comes from Australia every year to visit Fred, Ian Curthoys, has been doing short-arm centrifuge work for the past several years and that's the reason for coming to visit Fred-for words of wisdom on some of the short-arm centrifuge related work.

- Guedry was involved in the MVI project [multi-vestibular investigations in space] in the early to mid-80s.

- He made contributions to the early testing that was done on astronauts...they all came through Pensacola. Alan Shephard is an example of an astronaut who came through Fred's testing.

- Fred made significant contributions to the understanding of reactions to cross-coupled Coriolis stimuli.

- Alain Berthoz, one of the best researchers in the world in this area, credits Dr. Guedry for getting him into vestibular research. Berthoz visited Fred and observed his work in the '60s.

- Fred's work has contributed to modeling how the vestibular system works. Fred's main contribution has probably been psychophysics, the perceptual side of what we experience. He has had "huge contributions" to this field according to Angus Rupert, cointerviewer.

- Although Fred is now retired, he is still interested in vestibular research. It's his "lifelong passion." 


\section{Appendix E.}

\section{Conference photo.}

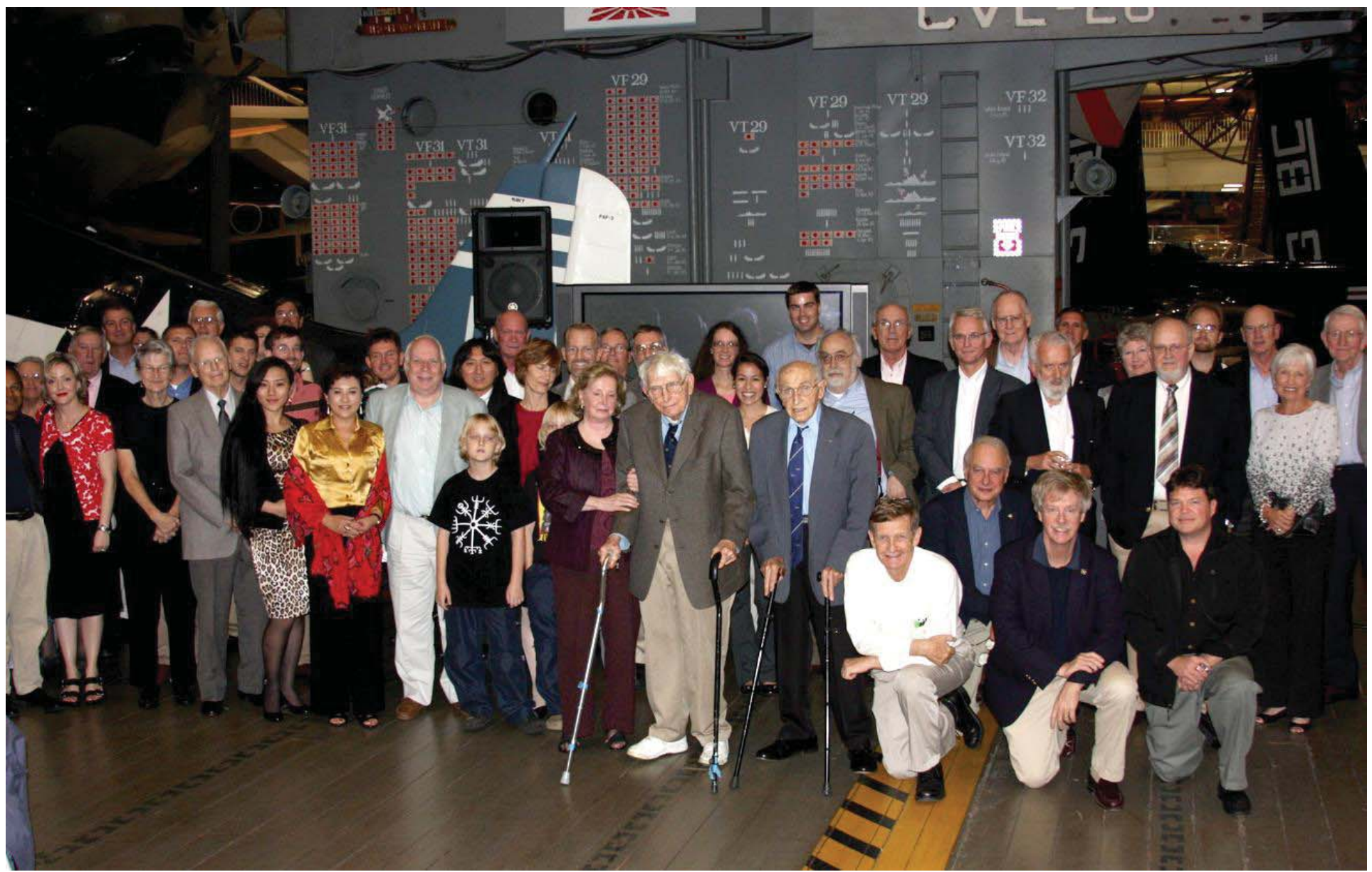

Banquet in honor of Fred Guedry, held on the deck of a World War II aircraft carrier [the USS Cabot]. Doctor Guedry is depicted front and center with his arm held by his wife, Alma Guedry. Dr. Robert Mitchell is standing to Doctor Guedry's left. Other friends and family surround him. 
Appendix F.

Scenes from the symposium.
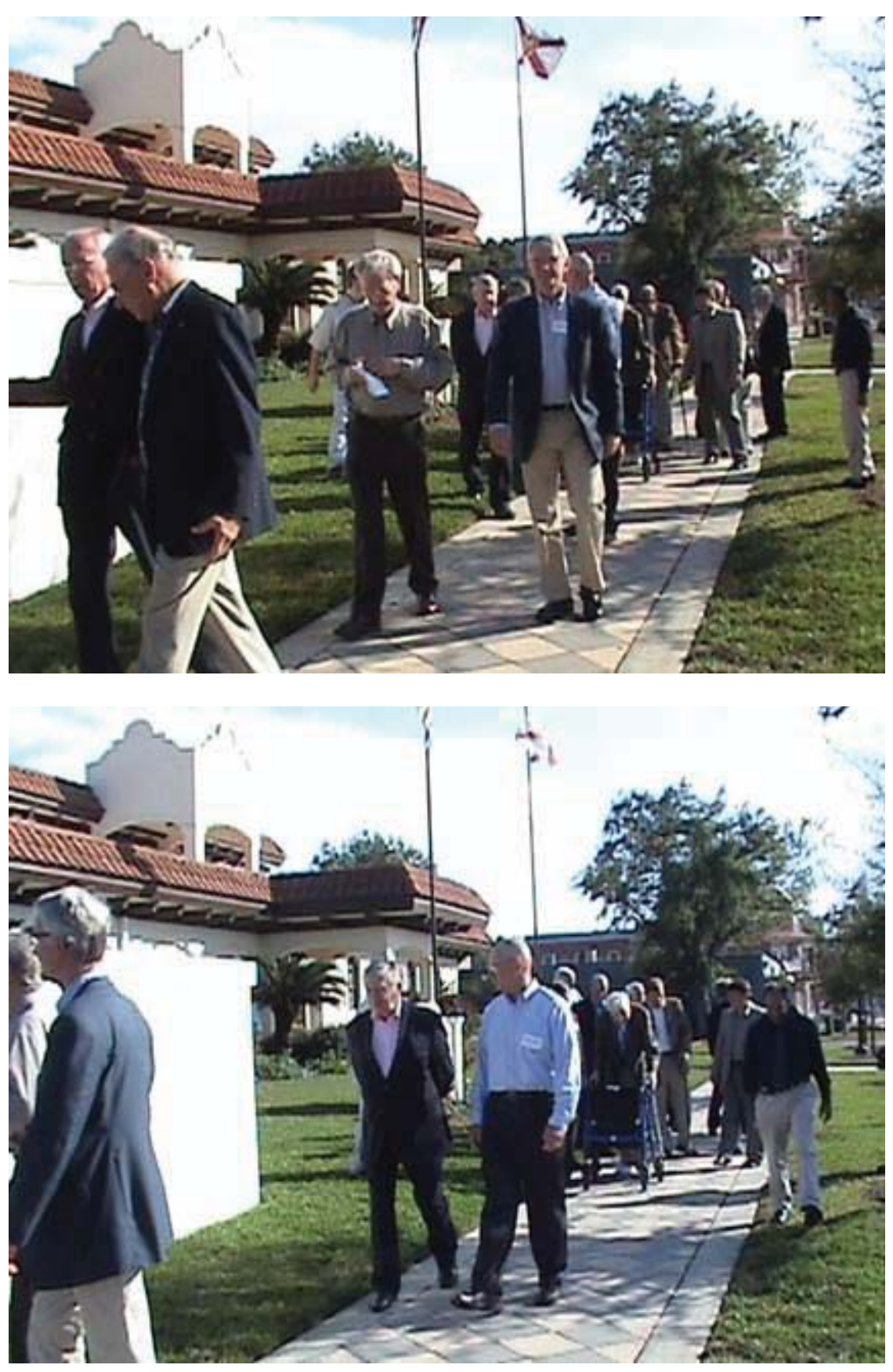

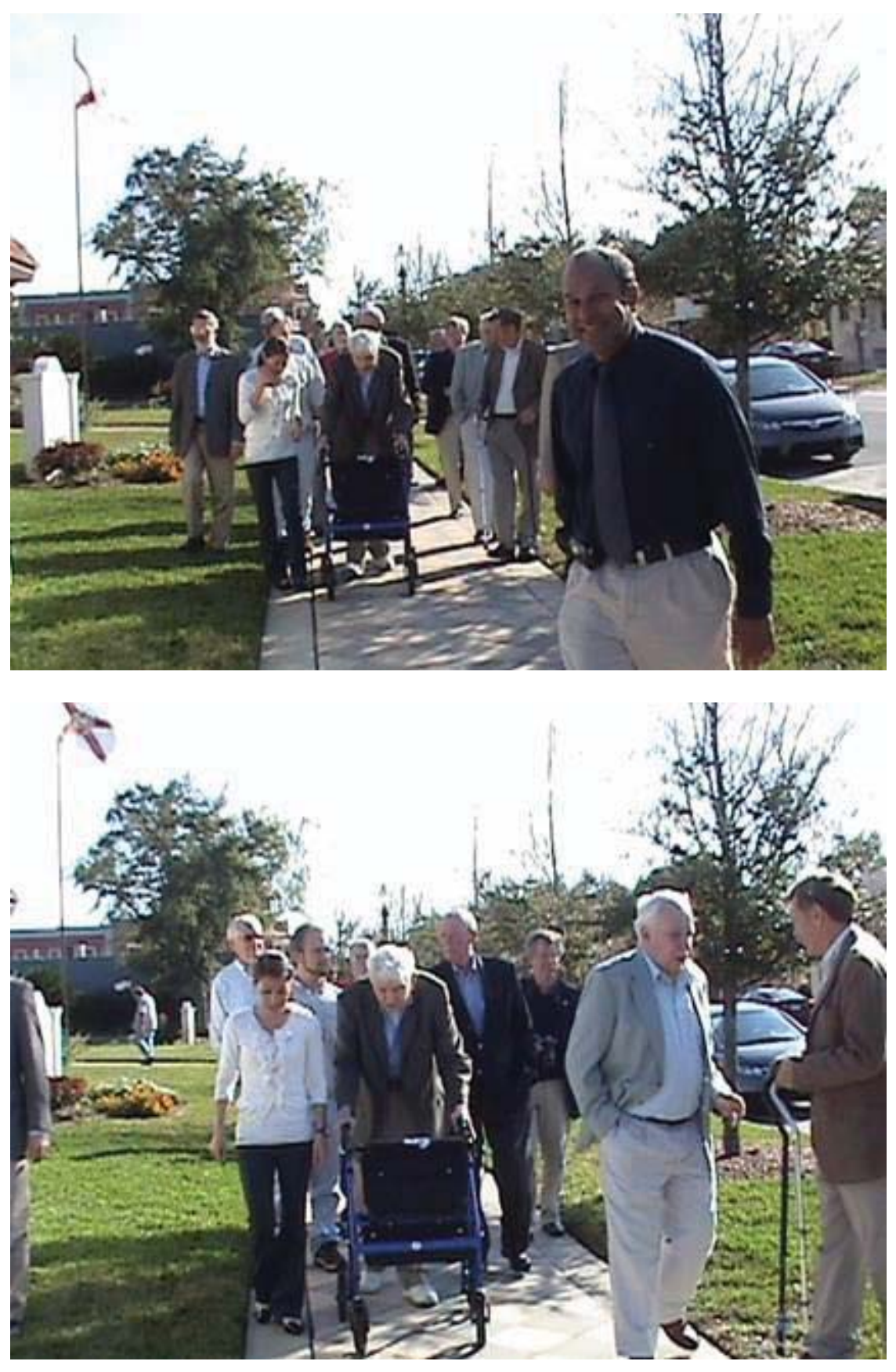

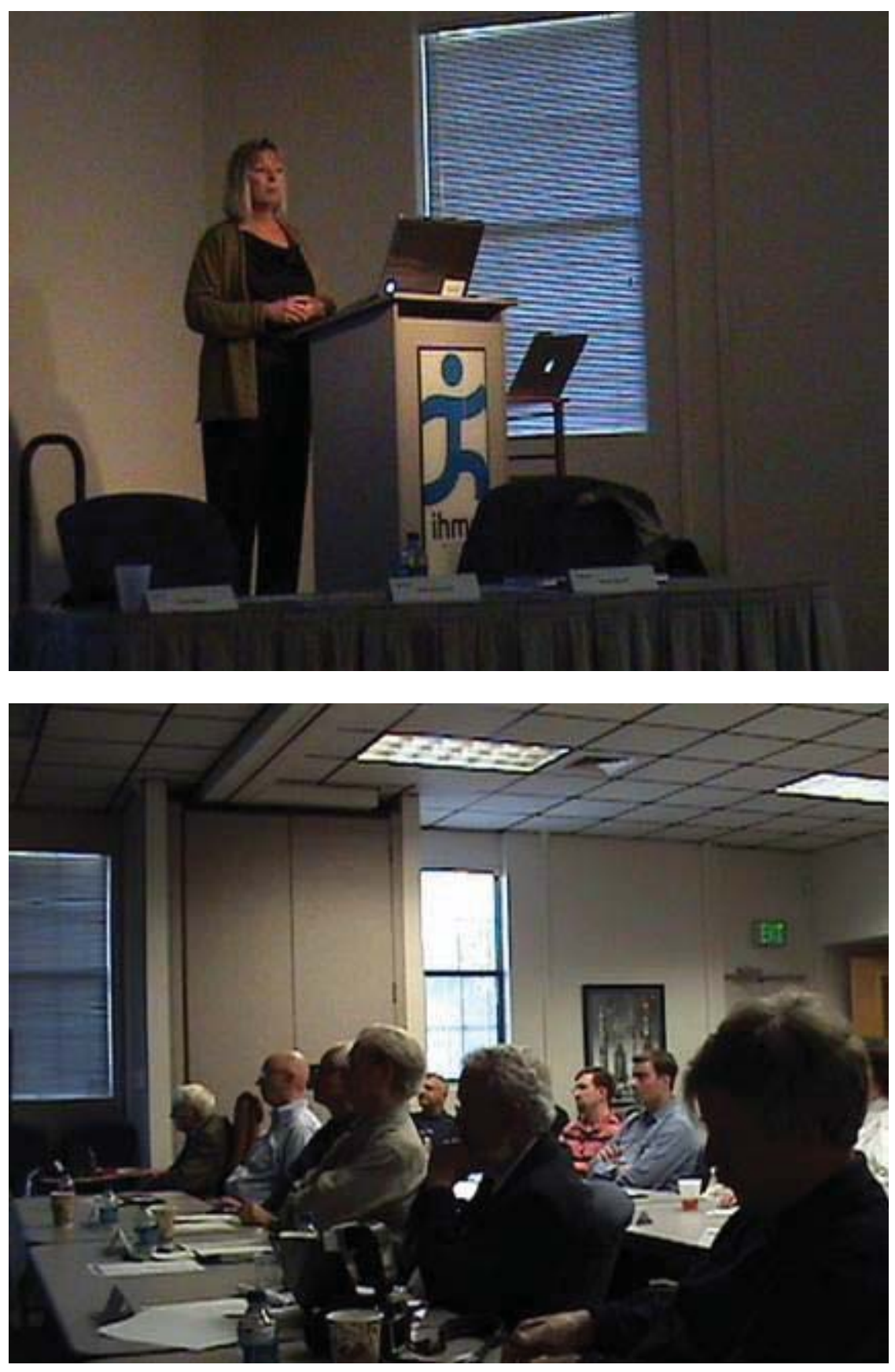

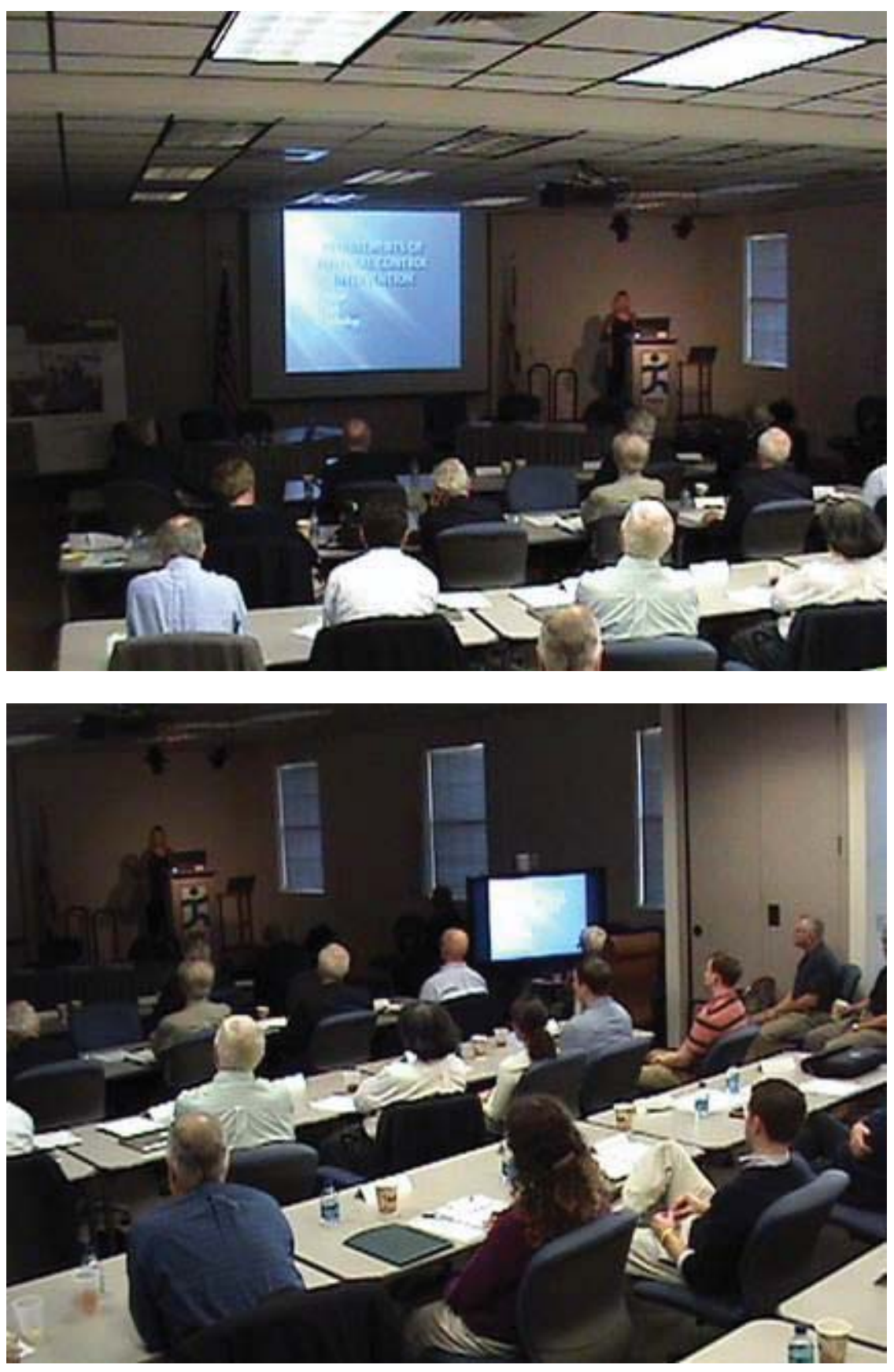

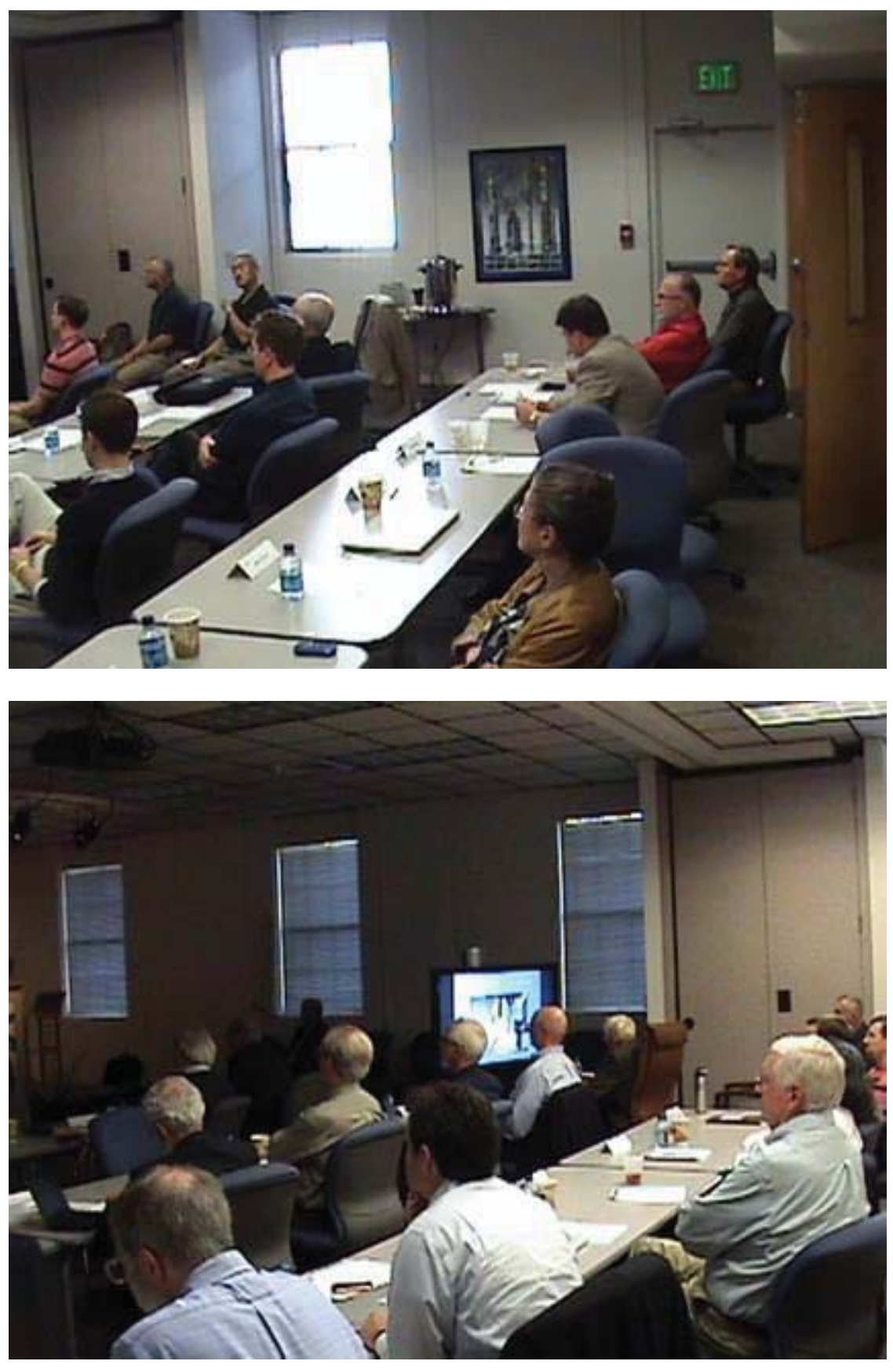

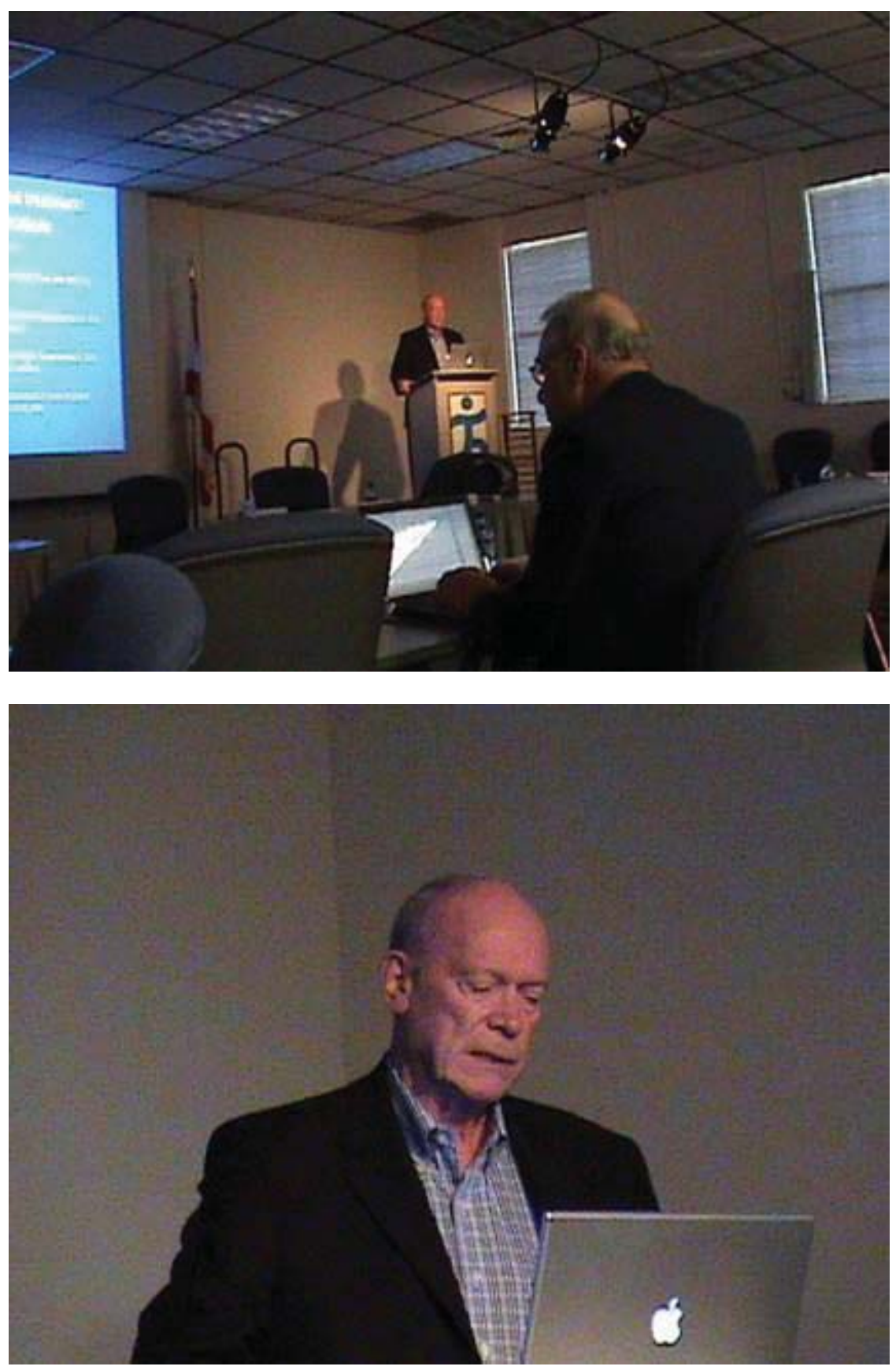

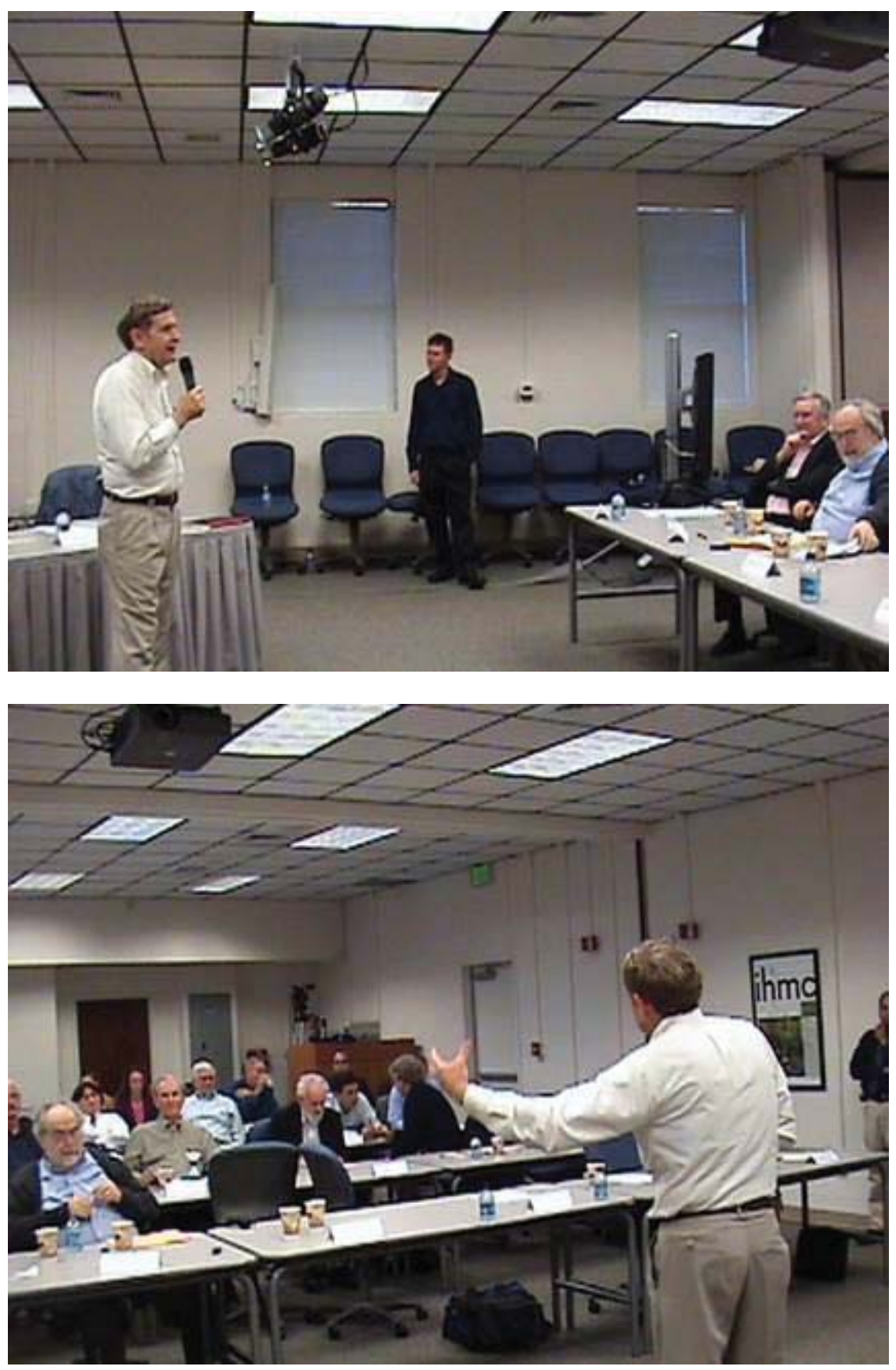

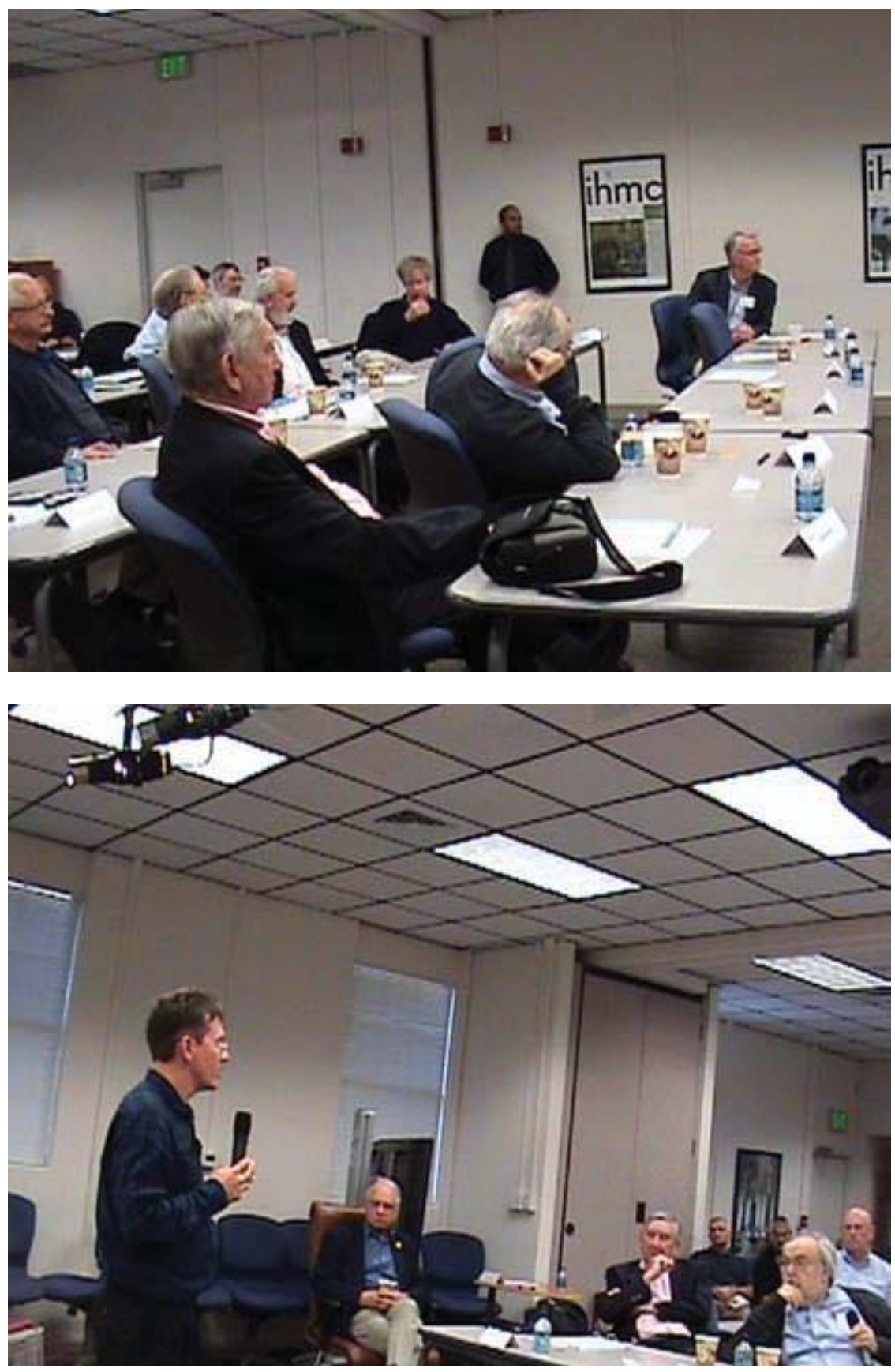


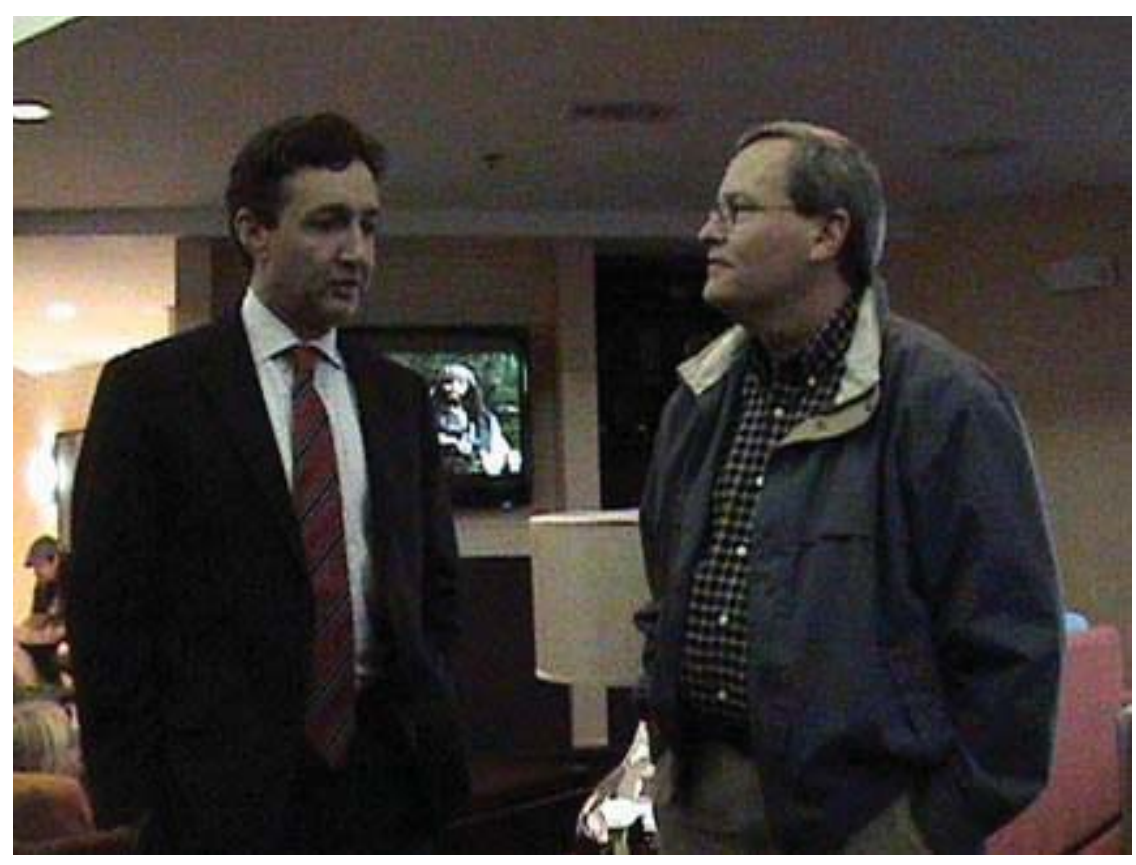



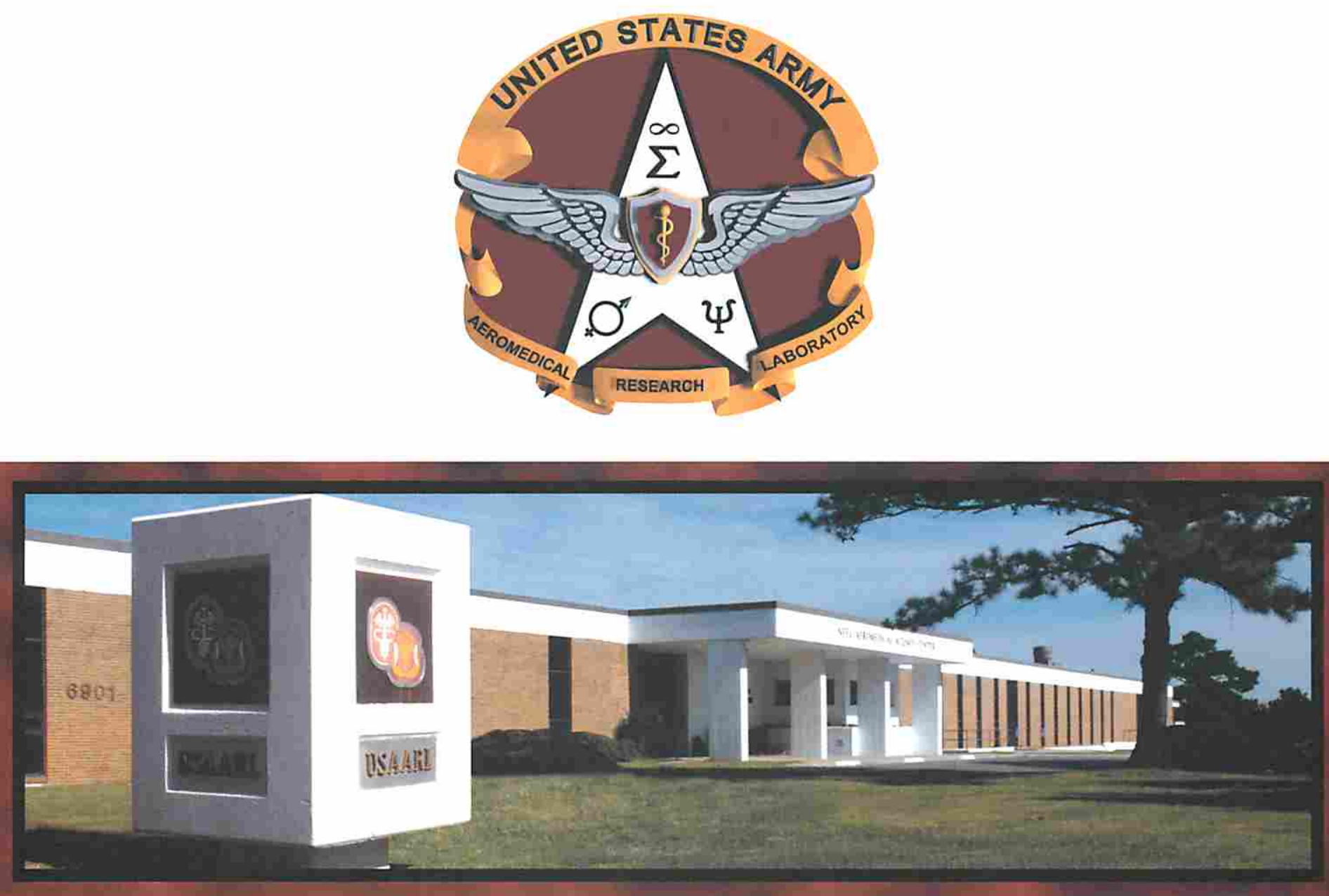

Department of the Army

U.S. Army Aeromedical Research Laboratory

Fort Rucker, Alabama, 36362-0577

www.usaarl.army.mil

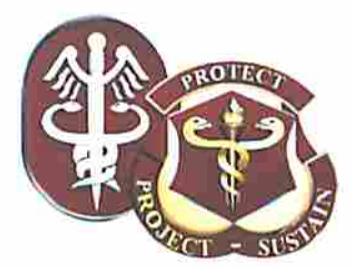

